\title{
RENAISSANCE OF SUBURBAN SHOPPING
}

BY

PAUL LIMCANGCO

A 120-point thesis submitted to the

Victoria University of Wellington in partial fulfilment of the requirements for the degree of Master of Architecture (Professional)

Victoria University of Wellington School of Architecture 2021 



\section{ACKNOWLEDGEMENTS}

I would like to thank;

My parents Rowela and Rey, for their endless support and encouragement during this research and all previous years of study;

My brother, for your wit and calmness;

My grandmother Marina, whose own thesis inspired me to pursue further studies;

My supervisor Fabricio, for your knowledge, support and patience;

My friends, 106, Drummond Boys and those at home, in Christchurch. 


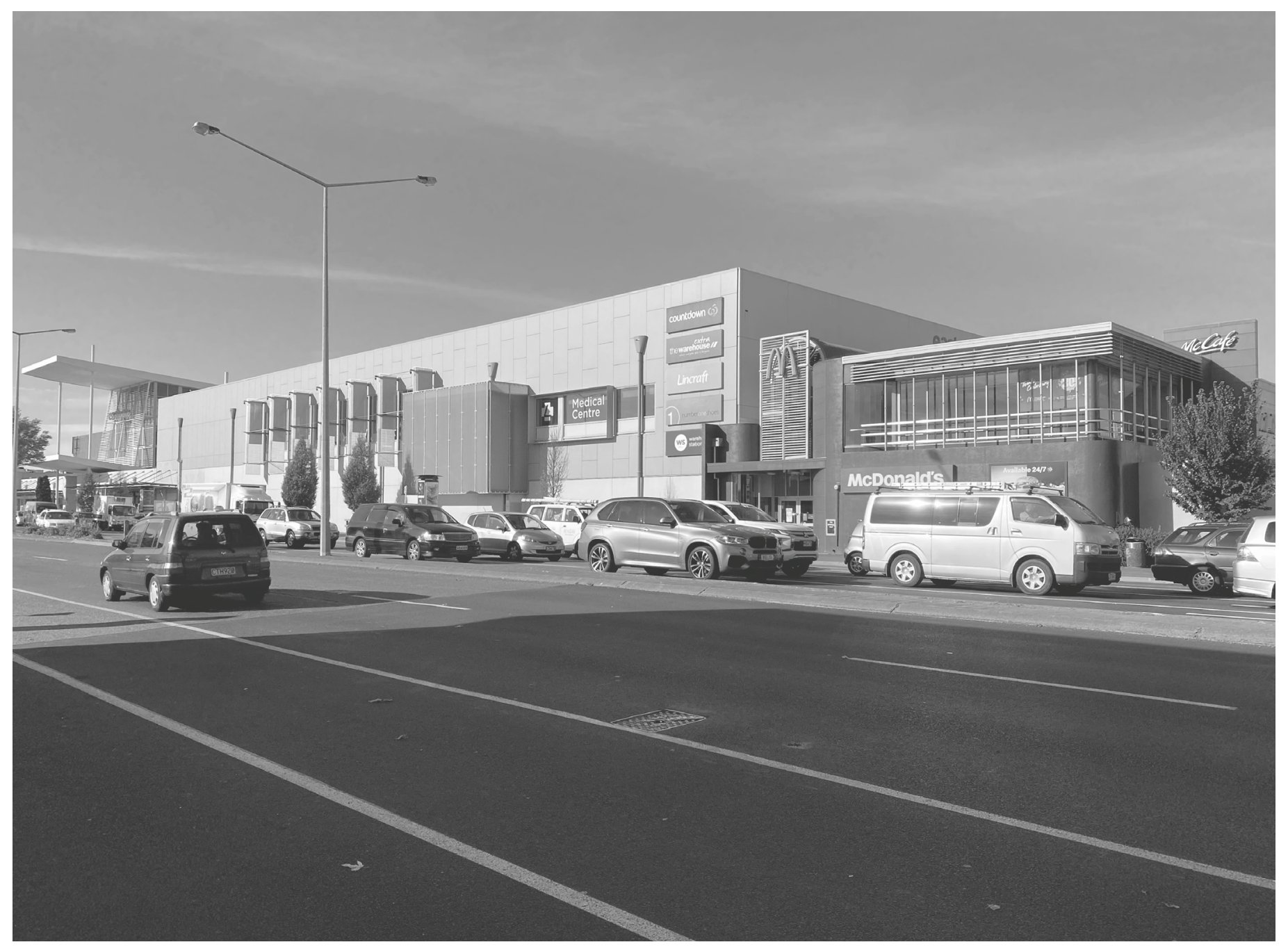

Figure 1.0. Eastgate Mall from outside. Source: Author's photograph. 


\section{ABSTRACT}

This thesis interrogates Eastgate Mall in Christchurch, to develop a revived architectural design for the neglected shopping mall. Shoppers are becoming increasingly familiar with online shopping, with many now preferring this channel over the physical (Blázquez, 2014, p. 109). While shoppers are offered convenience and often a larger range of goods, malls now appear to be spaces solely for urgent shopping (Rouz, 2014, p. 1881). This has decreased footfall and lowered people's tendency to appear in these spaces for recreational and noneconomical purposes. Shopping malls like Eastgate are declining as the "centreless centrepieces of suburbs" that deny surrounding communities their diversity, and economic and cultural prosperity (Chavan et al., 2007, p. 59).

This thesis argues that current architecture widely used in shopping malls is detrimental to retailers-particularly small local businesses. It acknowledges that retail spaces will no longer be solely for the sale of goods. Therefore, it proposes to enrich the showing and selling of experiences as a way to revive Eastgate Mall and further differentiate its physical retail spaces from those in the online channel. By enriching shoppers' experiences, the mall can embody the contemporary culture of transience and immediacy that shift its retail spaces away from the static and one-dimensional to the multi-functional and hybrid.

The proposed design aims to sever ties with traditional expectations of shopping malls, thereby conforming to the idea that,

"[I]f closed spaces [... ] truly perpetuate its society[, we must] look beyond the strictures of architectural form to understand the many attributes of what these spaces represent and what they can be" (Jewell, 2016, p. 103).

Overall, the research in response to the current stagnation of Eastgate and rising popularity of online shopping proposes an experiential mall design; it seeks to differentiate the physical from online retail spaces and contribute to fostering the sense of community that surrounding suburbs are strengthening. 
In response this thesis asks...

How can a neglected shopping mall be reconfigured to persist in a suburban Christchurch context? 


\title{
CONTENTS
}

\author{
Abstract \\ Introduction... (1) \\ Literature Review... (9) \\ Site \& Context... (43) \\ Design Explorations... (85) \\ Further Development... (131)
}

Developed Design... (203)

Conclusion... (293)

References

List of Figures 



\section{INTRODUCTION}

Context

Problem

Methodology

Aims and Objectives 


\section{CONTEXT}

Shopping malls like Eastgate bring the world to the surrounding community and suburbs, but ultimately leave the people with just one role: that of simple consumers. Consequently, the shopping mall is overwhelmingly commercial in nature and "can never be a genuinely authentic urban place" (Miles, 2010, p. 83). Environments within are inauthentic and superficial, designed with little or no awareness of, or care for local characteristics and traditions (Corroto \& Richardson, 2019, p. 1080). It is one of the many malls nationwide (and, in fact, worldwide) facing this now well-established reality in the industry. It is confronted by a predicament wherein it struggles to differentiate itself within customers' and people's minds (Allard et al., 2009, p. 40). It shares a familiar look to many other malls while offering similar products and services.

"Yet even though shopping is such an inherent part of daily life and even though it overwhelms other activities in number and in scale, it is also the most unstable, most short-lived, and most vulnerable to the threat of decline and obsolescence" (Chung et al., 2001, p. 130)

While Chung et al may be correct, retail need not be seen as dead. It simply needs a renaissance... a new vision for a new world. Retail is no longer a place in which we merely experience the act of buying and selling; retail is a combination of many things (Burrows, as cited in Insider Trends, 2019, p. 6). Small societal shifts are now driving the form of shopping that we all experience. No other aspect of society has undergone such significant and frequent change and this is key to its survival thus far. Some posit today that the growth of internet shopping has been the cause of decline in mall attendance, and while some merit may be given to such postulation, it can be more logically argued that a failure to predict and adapt to social trends is the reason (Chung et al., 2001, p. 131). This is not, however, to say that the convenience of point and click shopping can be ignored if malls and retail are to be reinvigorated. 
Mall attendance is erratic and unpredictable... it bows to the whims of the weather, economic trends, and other varied external factors. Swings in attendance numbers can be seen occurring as frequently as hourly. There are no guarantees of density of traffic (Chung et al., 2001, p. 131). On a larger scale a global decline is also apparent as the acme of mall popularity has been reached and passed; shopper boredom has arrived and with it a dire need for urgent action on the part of malls to be born-again (Chung et al., 2001, p. 133). Once glittering palaces filed with desirable goods, malls, now dusty cathedrals, and their relics of retail must be returned to their former glory (Manuelli, 2006, p. 6).

However, the big-box format that allowed malls to explode in popularity and number in the past is now anachronistic; its time has passed. It could even be argued that size ultimately came to intimidate shoppers partly causing the decline of the mall. Thanks to the internet, shoppers are now used to the intimacy of a solitary digital shopping experience. Cavernous buildings focused on pure consumption can no longer satisfy (Chung et al., 2001, p. 133).

For many, shopping is the only manner by which a public life may be enjoyed (Chung et al., 2001, p. 134). Community activities and other social condensers can be woven into a smaller and more intimate shopping experience to satisfy the needs of a diverse society and resurrect the once-thriving mall. (Harrouk, 2020). 


\section{PROBLEM}

Shopping habits have clearly changed and have significantly impacted shopping malls like Eastgate. Unable to keep up with trends and changes, the current rigid, one-dimensional configuration of Eastgate has resulted in the departure of many retailers. With more vacant units and a smaller range of shops, people are left to visit Eastgate generally for utilitarian purposes.

This thesis proposes a solution that challenges the rigidity of the shopping mall, better equipping it to fit with people's evolving lifestyles and needs today.

\section{SCOPE}

- $\quad$ Eastgate chosen for its situation.

- $\quad$ Limited to current site of Eastgate Mall in Linwood, Christchurch. This is due to it being ran by commercial operators and the thesis challenging the need to have an efficient relationship between sellable area and non-sellable area.

- Budget not considered to not restrict design exploration. 


\section{AIMS \& OBJECTIVES}

This thesis aims to revive a neglected shopping mall through architectural design.

(1) To identify revival strategies of shopping malls and contemporary physical retail spaces

(2) To examine the architectural design's impact on shopping mall revival and

(3) To develop a reconfigured shopping mall design that brings about business and social cohesion

This research establishes an alternative approach by developing a focus on the integration of experiences relating to the lifestyles and needs of customers. This is to strengthen the Eastgate Mall's identity, and further differentiate it from other shopping formats especially the online realm. Through differentiation, Eastgate can provide physical retail spaces a purpose for people to visit hence the potential for persistance.

The design iterations aim to respond to a developed criteria and principles relevant to the evolving contemporary shopping culture and environments. These iterations explore how Eastgate can be reconfigured, with the consideration and evaluation of strengths, weaknesses, as well as opportunities and complications that arise.

The design process in this thesis aims to challenge the conventional enclosed suburban shopping mall. It seeks to dismantle windowless walls and strengthen the connections between retail and functional spaces. It seeks to connect the mall to the site, to the people, and to the community. 


\section{METHODOLOGY}

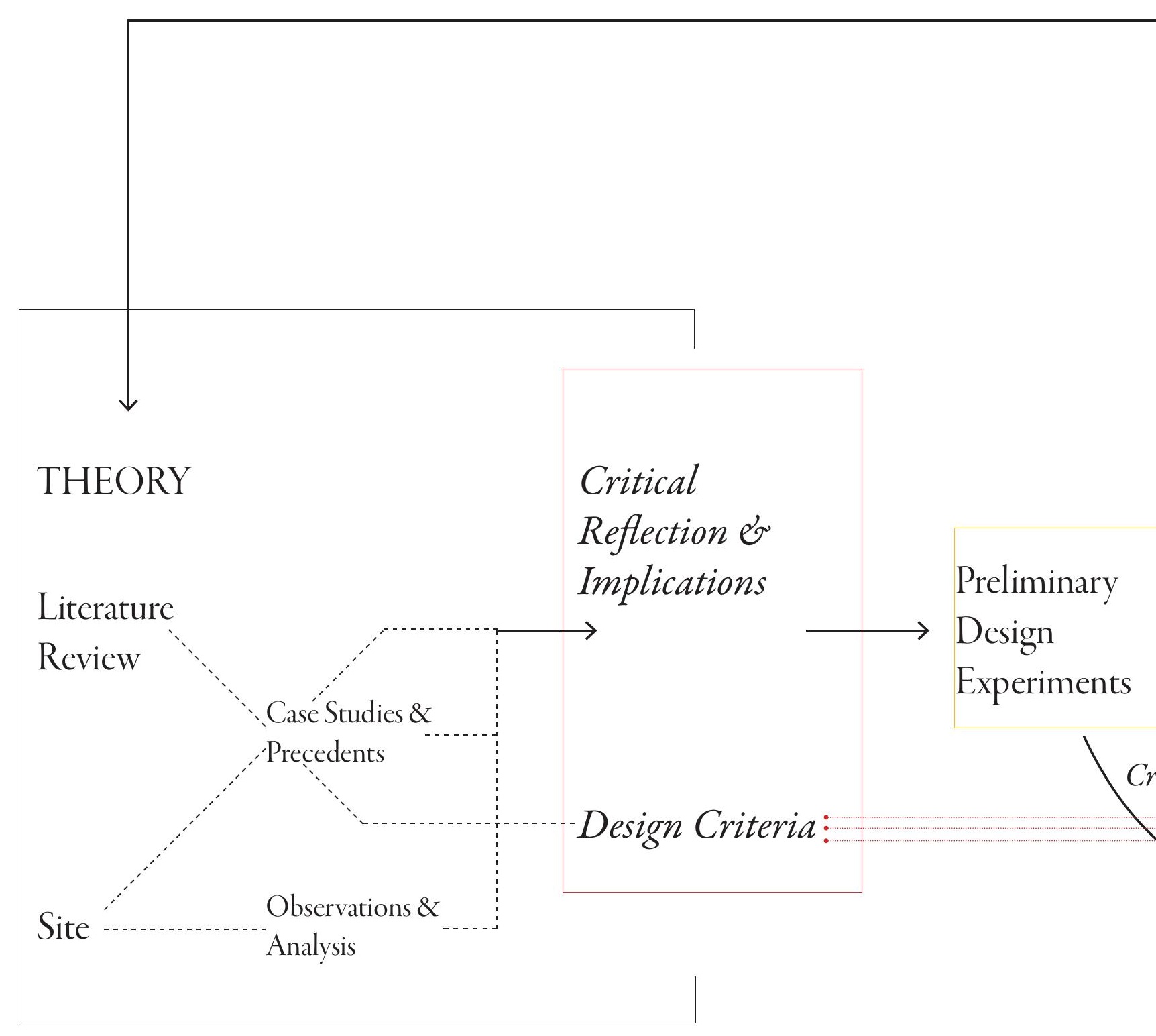





\section{LITERATURE REVIEW}

History

Development

Modern Development

The Bazaar

Strategic Manipulation

Ramifications of zoning

Expressions of lifestyle

Hegemonised?

Threatening small and local businesses

"HOPE"

Types of shoppers today

Potential Strategies

Experiences \& Theoretical Framework

Case Studies

\section{Conclusion \& Reflection}

Criteria for Evaluation of Design Explorations 
"The first markets were markets.

Not bulls, bears of invisible hands.

Not battlefields, targets or arenas.

Not demographics, eyeballs or seats.

Most of all not consumers.

The first markets were filled with people,

Not abstractions or statistical aggregates;

They were the places where supply met demand

With a firm handshake.

Buyers and sellers looked each other in the eye,

Met and connected.

The first markets were places for exchange, Where people came to buy what others had to sellAnd to talk"

Excerpt from Markets are Conversations

(Searls \& Weinberger, 2001, p. 156) 


\section{Development}

The 1950s saw the rise of nearly-universal motoring in the United States of America, leading to the development of cities' periphery (Berezko, 2014, p. 5). Despite this, suburban residents continued to be drawn to the cities' centres to immerse themselves into the public and cultural life and to consume (Berezko, 2014, p. 5). This, however, overloaded the transport systems of cities and subsequently caused environmental degradation (Berezko, 2014, p. 6). Traffic congestion and a limited number of parking spaces increasingly rendered access to public facilities more difficult in this period (Berezko, 2014, p. 6).

A solution to these problems that also satisfied the needs of contemporary life was a new building type and substitute for the central city-the shopping mall (Berezko, 2014, p. 6). Victor Gruen was a prominent figure in the development of these malls, wishing them to "redefine the contemporary city" (Chung et al., 2001, p. 381). These build on the main functions of their nineteenth century precedents— passages, galleries, and department storeswhile providing a new, effective form of retail space organisation and consumer experience (Berezko, 2014, p. 6). Consequently, they satisfy the needs of residents in different areas of a city and replicate the "complexity and vitality of urban experience without the noise, dirt and confusion" (Crawford, 2002, p. 24). With the provision of spaces for consumption, trade, recreation, and general public interactions under one roof, Gruen argues that shopping malls are actually urban environments (Berezko, 2014, p. 6). Shopping malls have since attempted to become further immersed into the unique urban environments of cities, evolving into multistorey, underground or fragmented complexes. 
This content is unavailable.

Please consult the figure

list for further details.

Figure 3.0. Modern development of shopping malls.

Source: Herzberg et al. (2020).

\section{Modern Development}

1980-Utilisation of the "Dumbell Plan": central entry points with two anchor tenants at the ends of shopping malls to activate smaller retailers between (Herzberg et al., 2020).

1995-Expansion of shopping malls: the addition of more anchors strategically placed as well as food courts at midpoints (Herzberg et al., 2020).

2010-Mini Anchors and Retail Precincting: Creation of precincts with the gathering and grouping of small stores connected by their categories. Emergence of entertainment and leisure as anchors (Herzberg et al., 2020).

The Present-Community "Hubs" and Mixed Use: creating unique community-based offerings to allow customers to gather (Herzberg et al., 2020). This encompasses programmes not limited to retail and food and beverage, to integrate amenities for health and fitness, residential, education, workspace and community.

We now see the inclusion of community needed amenities such as medical and healthcare centres, nail salons, barbers and hairdressers, and gyms; and vital services such as banking, childcare, libraries, and drycleaners. Also now to be found are affordable hospitality offerings and everyday retail provisions - groceries, affordable gifts, and fashion (Herzberg et al., 2020). 
This content is unavailable.

Please consult the figure

list for further details.

Figure 3.1. A

Moroccan bazaar.

Source: ExpatFocus

(2017).

\section{The Bazaar}

The bazaar was, and continues to be, successful in many countries, particularly in the Middle East and North African region. Bazaars function as cultural contact zones, where trade of goods occur simultaneously with interactions between traders and customers from different traditions and backgrounds that require negotiation (Grüner, 2011, p. 55). They host different social, religious, and political activities through facilities like mosques, schools, and baths, forming a "complete and uniform [social] texture" (Rouz, 2014, p. 1876). By being able to accommodate these things in parallel to commercial ventures, bazaars are able to maintain a thriving role in towns and cities. This assures a continual flow of people, as they are attracted to these centres not only for consumption but also to fulfil other vital aspects of their lives such as education and culture (Sadafi \& Sharifi, 2018, p. 152). Because it contains different functional spaces in one complex, the bazaar can be a representation of the identity of a social location (Azadarmaki, 2014, p. 87).

In comparing shopping malls to bazaars, the former appear to focus on the economic facets only. Consequently, this focus has turned malls into unimportant spaces, seemingly only for urgent shopping. Because of this "mono-functionality", there is a decreased tendency for people to appear in these centres for recreation and non-economical purposes. There is, therefore, a lack of social communication and the opportunity for the surrounding communities and people to gather and interact is lost.

If bazaars are the main passages of many cities in the world, can we set a challenge to apply this principle to Eastgate Mall within a rejuvenated design? Cannot, in some way, Eastgate Mall also consider or emulate the successes of the bazaar as a place of communication for information and news? Can it serve as a place to settle disputes and issues, or allow members of a community to gather in cases of emergency and unrest? 
Despite their differences, shopping malls base a number of their principles on the bazaar. Bazaars are often structurally organised so that each business discipline is concentrated with others of the same nature in the same physical location (Rouz, 2014, p. 1877). These areas are constructed to form covered laneways called rasteh and the modern shopping mall emulates these in their various "wings".

This system offers efficiency and cohesion in both malls and bazaars and satisfies many requirements of retailers who benefit from placement within close proximity to their competitors or other businesses selling adjunct or auxiliary products and services. This fosters greater competition and a deeper involvement in the mall "society". Additionally, consumers can easily have their requirements met (Rouz, 2014, p. 1877) without the tiresome searching of maps or walking long distances within the commercial centre.

In this way, annoyances and undesirable elements are excluded from the customer experience: so it is unlikely that a shopper will stumble upon the awkward placement of a retailer such as a hardware store next to a jewellery store. Taken to a deeper and more engaging level, stores of different but categorically linked products such as those selling carpets, drapes, light fittings, sofas, and interior decorations may be placed together in an area resembling a sitting room, whilst stores selling kitchen and related goods are placed next to stores selling dining or foodrelated products. This concept helps to orient customers and, to the benefit of the retailers, customers may be more inclined to impulse shop (Quartier, 2016, p. 33).

Sadafi and Sharifi (2018) believe that the principles of the bazaar, such as continuity, strength, beauty and centrality can be used as design ideas for modern business spaces like shopping malls (p. 155). 


\section{Strategic Manipulation}

Reimers \& Clulow (2004) argue that the success of shopping malls depends on the success of their retailers, who in turn rely on strategically manipulating an appreciable pedestrian volume (p.210). A significant way in which malls manipulate pedestrians and consumers is through their tendency to separate retailers serving different market segments and clustering together those that share customers. Accordingly, clustering compatible retailers helps consumers in their decision-making process through timesaving and the simplification of information gathering and product evaluation (Reimers \& Clulow, 2004, p. 209). "Destination" tenants less reliant on sheer volume tend to be located away from the centre of shopping activities (Reimers \& Clulow, 2004, p. 210).

Brown (2004) provides vital direction for this argument, contending that despite a good tenant mix ensuring adequate pedestrian flow, their placement within these complexes is key in defining successful pedestrian circulation (as cited in Reimers \& Clulow, p.210). With malls continually manipulating consumers through separation and clustering, the peculiarities of consumer shopping behaviours in tenant placements should be thoroughly considered. This thorough consideration would increase engagement with consumers and enable mall spaces to fit more naturally with people's habits. This, in turn, can maximise sales for the centre as a whole while reducing consumer search costs (Reimers \& Clulow, 2004, p. 210). However, tenants may potentially voice strong or arbitrary views regarding their desired locations. A desired location beneficial for one tenant, may negatively impact others nearby, altering the retail conditions with potentially undesired segments. The ability to take advantage of consumers' multipurpose shopping habits and to strategically manipulate pedestrian flow is therefore a key criterion for the success of shopping malls and their retailers' habits (Wakefield \& Baker, 1998, p. 521). For this to be achieved, directional movement encouraged by clustering should be balanced with the behavioural constancy facilitated by anchors (Jewell, 2001, p. 361). 


\section{Ramifications of zoning}

Jewell (2001) asserts that "shopping malls balance [their] culturally hybrid imagery with rigorously controlled spatial sequence" (p.340). This balance is formulated by rigorously zoning activities and retailers. Subsequently, this enables shopping malls to create diagrammatic plan forms that "transcend the unreality of the global brand imagery adorning its surfaces" (Jewell, 2001, p. 340). Jewell's critique of the Trafford Centre in Manchester, England laid the basis for this argument. He suggests that the ground plane of these complexes mediate between the control manifested in their diagrammatic plan forms and the immediacy offered by each site of consumption (Jewell, 2001, p. 344). As a result of this mediation, functional legibility and evocative imagery are combined to resolve spatial tensions (Jewell, 2001, p. 344). This enables shopping malls to effectively control consumer movement, thus exploiting their individual desires (Jewell, 2001, p. 340). By balancing "culturally hybrid imagery" with "controlled spatial sequence", it can be argued that rigorous zoning has formulated predictability. Ideals involved in the process, including store compatibility, lead consumers to feel that their needs are taken into consideration and that they may avoid conflict. There is, therefore, a greater sense of comfort, security and safety while experiencing a controlled, internalised journey of consumption (Jewell, 2001, p. 318). Subsequently, the public realm's perceptions of shopping malls' convenience are improved. This balance ensures that people can engage in multi-purpose shopping and not be preoccupied with thoughts of unanticipated encounters with undesired elements like crime. This can be attributed to the idea that the act of balancing occurring in the malls attempts to filter out these elements. 


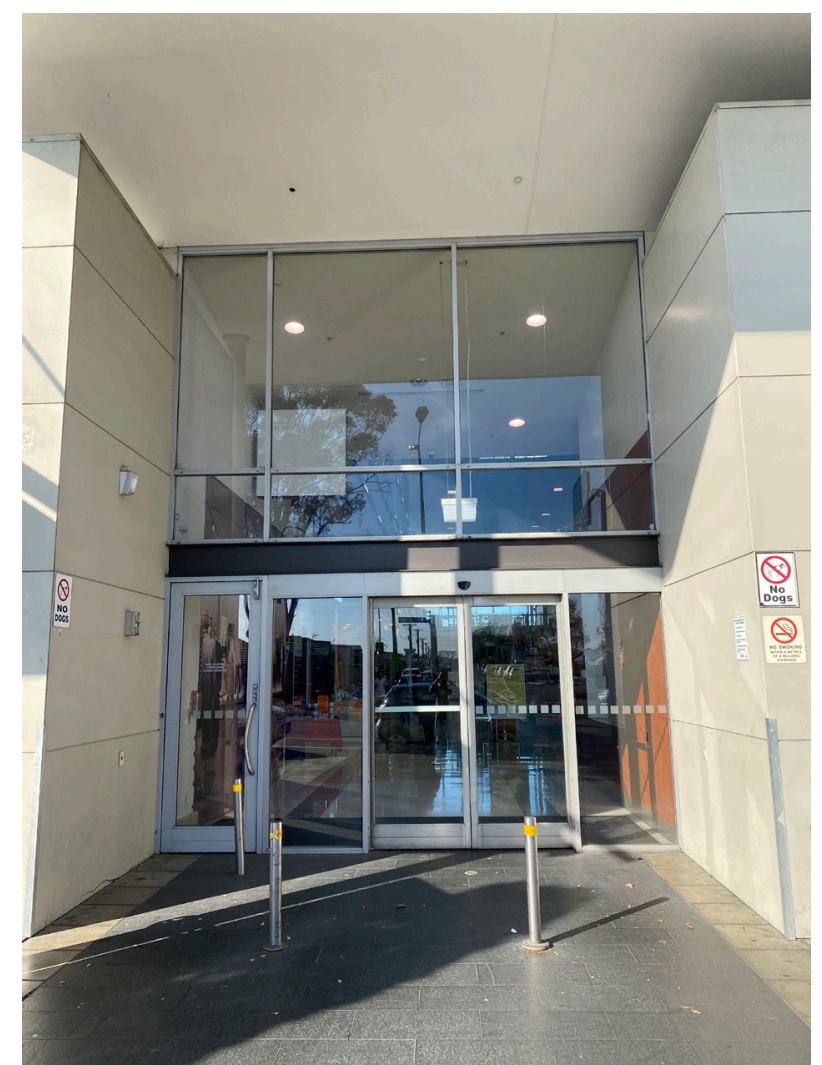

Figure 3.2. Approaching a material change in Eastgate's flooring.

Jewell further develops his critique on the ground plane, pointing out that the material palette enables the ground plane to reinforce the diagrammatic zoning and planning of shopping malls (Jewell, 2001, p. 344). Where the surfaces or materials change from grass to terrazzo paving or from concrete to marble tiles, the transition between areas is accentuated (Jewell, 2001, p. 344). Trafford Centre in Manchester, England is critiqued by Dovey (2014) who views the mall as an "inverted city" and asserts that "difficulties and tensions of public space are eased as one enters [this] protected realm of consumption and spectacle" (p.123). Through an intentional change in the material palette to accentuate transitions, malls are able to emphasise their ability to create a contrasting and "purified environment" - physically, climatically, and socially (Jewell, 2001, p. 344). Consequently, the ground plane exploits the tactic of "meaning in opposition" to reinforce the malls' status as the alternative "place" to city (Jewell, 2001, p. 345). Despite the ability of malls to create a "purified environment", transitions between material palettes suggest that they are "incapable of finding an expression of place that meaningfully reconciles form and image" (Jewell, 2001, p. 351). The architectural schemes raised seemingly impose heavy restrictions upon unplanned interactions with the outside context, preventing the mall from obtaining a sense of local identity and place. 


\section{Expressions of lifestyles}

It can be argued that shopping malls are signifiers of class, offering environments that epitomise the "lifestyle choice" of its consumers (Jewell, 2001, p. 327). Architectural elements such as brass balustrades and polished granite tiles in shopping malls are luxuries traditionally reserved for the rich and citizens of civic importance (Jewell, 2001, p. 345). By utilising these components, malls are able to manipulate people, lulling them into a "false sense of security" as they travel through an inauthentic experience of luxury (Jewell, 2001, p. 345). After all, it is the role of architecture within malls to continue and maintain the "operation of seduction" set in motion by the image of the complexes (Jewell, 2001, p. 332).

Retailers can hide behind this deceptive aura of luxury that architecture radiates over mall merchandise, thereby compensating for the actual cheapness of their goods. This illusory opulence can enable malls and their retailers to inflate the prices of certain products, presenting them with the impression of being luxurious and high-class. Considering today's social context, this can increase their appeal and thus their success, as they would be providing people with apparent (albeit false) status symbols. This would allow certain consumers to distinguish themselves from the lower classes (Laermans, 1993, p. 97). However, it may also drive out less-affluent consumers - or those not desiring conspicuous consumption—and lead to the downfall of malls and their retailers. Many buyers would be aware that they are just potentially buying for the "brand" or purchasing over-priced items. Nevertheless the aura of many shopping malls in reinforcing materialistic values continues to tempt many consumers to buy (Bloch et al., 1994, p. 39). Therefore, architecture can drive consumers (including those not having the means to purchase expensive goods) by offering them a way to distinguish themselves as being from the superior classes. 
This content is unavailable.

Please consult the figure

list for further details.

Figure 3.3. The working-

lower middle class

lifestyle image evident in

Eastgate.

Many shopping malls meticulously select tenants according to the "lifestyle image" they wish to portray with their architectural identity-thus attracting certain demographic groups (Jewell, 2001, p. 333). Malls have a need to create a warm atmosphere for shopping (Harris \& O'Brien, 2012, p. 95). It is therefore important that they manage to create the best image possible, to encourage consumers to return (Harris \& O'Brien, 2012, p. 95). With a focus on a particular demographic group, malls give an identity to that lifestyle, but also segregate it into a particular spatial "cluster" (Jewell, 2001, p. 328).

Rather than suggesting tolerance towards different groups, mall architecture is frequently engineered to promote familiarity and reduce risks of encounters with the "other". Subsequently, it segregates or excludes people to create safety and appeal based on the perception of being with your own kind (Jewell, 2001, p. 328). A good mix of tenants would ensure an adequate influx of people penetrating into malls. But, engineering a particular "lifestyle image" would see a more meticulous selection that asserts the notion of an "ideal". It may strengthen the marketability and value image of stores, the customers' shopping intentions, and manage the diversity within shopping malls (Zielke \& Toporowski, 2009, p. 95). However, this would reinforce the homogenisation of physical spaces, implying that "control-led diversity is more profitable than unconstrained social differences" (Voyce, 2007, p. 2057). Senett (2014) believes this could instil a fear of the "other", where certain identities are restricted, to retreat back to the ideal of a "purified community" (as cited in Dovey, p.136). This retreat would ultimately dispossess people from growing tolerant to "difference" and "otherness" that would characterise a truly "civil" urban life (Dovey, 2014, p. 136). Despite several benefits, it can be argued that meticulous selecting tenants according to a particular "lifestyle image" are detrimental to the mall and surrounding communities. The market reach of malls could be restricted, thus threatening their lifespans and viability, including their retailers. 


\section{Hegemonised?}

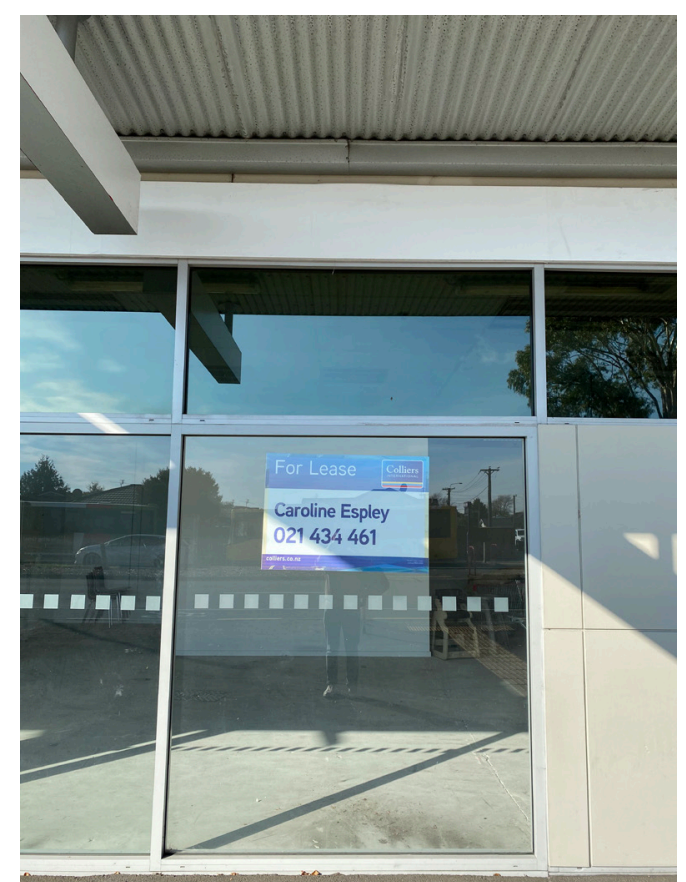

Figure 3.4. Indication of Eastgate's operators.

Despite shopping malls bringing the world to communities and cities, they continue to struggle due to the controls and restrictions their operators and managers impose (McGreevy, 2017, p. 427). Operators sometimes heavily rely on "experts" (for example market researchers) to formulate the allocation of space, juxtaposition of retailers, business mix and aesthetics in accordance to standards, and command and control processes (McGreevy, 2017, p. 427). Mall management with consultation from these so-called experts can intervene and impose control over the creativity and innovation that should be left to the truly-expert knowledge of each retailer. Voyce (2017) substantiates this argument, pointing out that retailers are constantly restricted when orchestrating their layouts, décor, window displays, signage and atmospherics (as cited in McGreevy, p.427). Consequently, mall managers regulate their tenants and potentially their ability to portray a genuine image of their brand and identity. Flexibility and fluidity is key for retailer success in aligning with the zeitgeist of today's diversified society. 
With "experts" relying on command and control processes, and standardisation, there is no room for spontaneity within these complexes (Miles, 2010, p. 83). Some argue for a more planned environment due to time-deprived lifestyles wherein the lack of spontaneity essentially gives customers the opportunity to solely consume without distraction (Jackson et al., 1998, p. 113). "Experts" also tend to repeat the "successful" elements of their preceding works when tackling new shopping mall issues, including architecture but this can lead to a profound stagnation in the creative process and hinder advances that are in dire need today (McGreevy, 2017, p. 427). Malls can suffer immensely from this sluggish approach to design since, for instance, what works in suburban Auckland may not work in suburban Christchurch. With shopping malls imposing control over their tenants, these complexes become overwhelmingly commercial and corporate in nature (Miles, 2010, p. 83). They come to solely represent 'structuration of space to facilitate consumption and thus the realization of retail profits' (Rosenbaum et al., 2016, p. 159). Consequently, these complexes fail to fuse naturally into people's everyday lives and can never be genuinely authentic urban places (Goss, 1993, p. 40). This would undermine the operation of malls and their tenants, therefore exacerbating their struggles and consequent decline. It must again be reiterated that a vibrant and fresh approach with "out of the box thinking" is imperative for the continuation (and, indeed, restoration) of the mall as a central component of a thriving community. Designers can not rest on their laurels relying on trite models; that manner of thinking is as passé as the societies into which the original basic dumbbell theory was born. 


\section{Threatening small and local businesses}

In many cases, shopping malls are detrimental to small and local businesses. Malls integrate retail trade into the world of large corporations (Goodman \& Coiacetto, 2012, p. 253). Large brands and retailers that malls attract have a stronger preference for, and often offer, lower prices and more promotions (McGreevy, 2017, p. 427). However, "big-box retailers [...] do not refresh local economies. They can take up to a billion dollars in sales out of a local economy over 20 years, but what do they put back?" (Blundell, 2006). Although big-box retailers serve as key anchor tenants that attract people to malls, they can economically saturate the community and kill the competition (Blundell, 2006). While these retailers gain considerable market penetration, it is at the expense of small retailers who are confronted with declining sales and profits (Arnold \& Narang Luthra, 2000, p. 144). These big-box retailers may replace up to fifty stores with one big store to potentially strip out a community of a considerable amount of social interaction (Blundell, 2006). Malls consequently become outlets for branded goods instead of promoting goods sold by small, local retailers (Chhabra, 2012, p. 89). While malls and agencies mostly driven by commercial interests promote branded goods as fashionable trends, threats of potential unemployment emerge. Malls and their well-known retailers with greater financial capabilities take a large share of the market and snatch the livelihood of local craftsmen and traders. Many small and local businesses refusing to integrate themselves into these complexes (due to controls imposed by shopping mall operators and architecture,) have experienced significantly decreased footfall (On Buy, 2017). Because of the restrictive nature of shopping malls, tenants may struggle to keep up with contemporary and newer business models. This can lead them to surrender to competitors who may consume their business. 


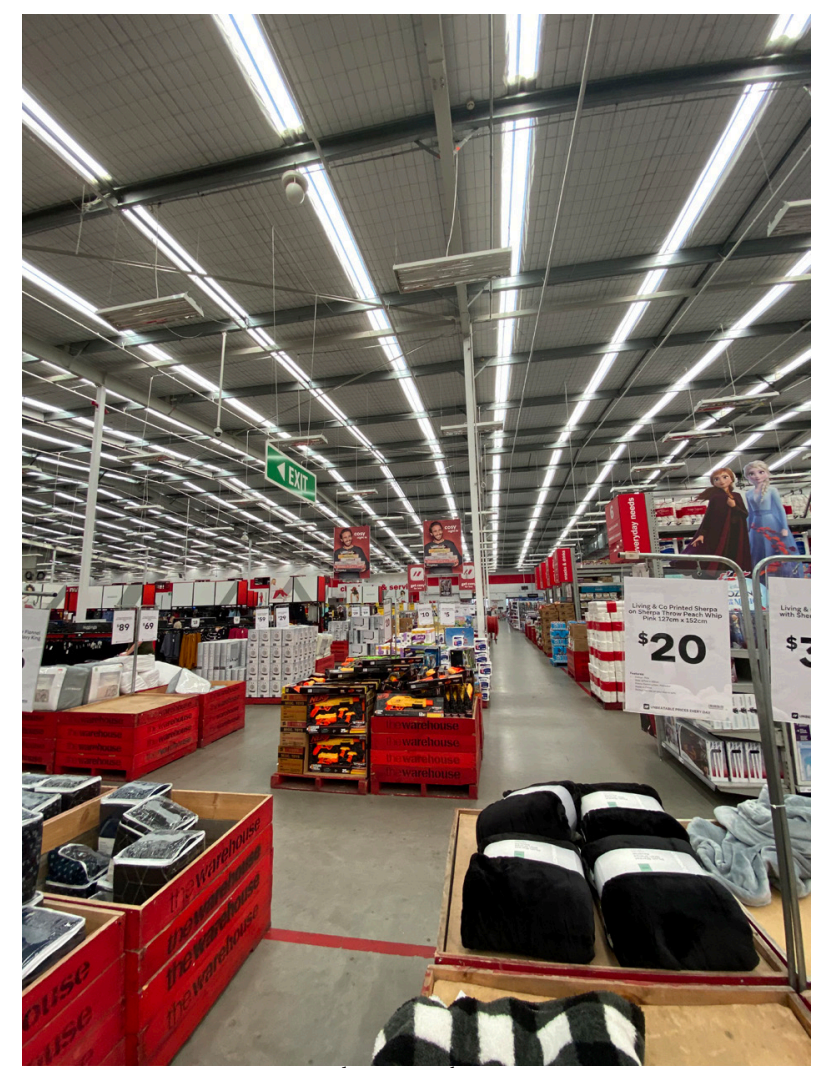

Figure 3.5. Big-box retailer in Eastgate.

By neglecting the integration of small and local retailers to a greater extent, malls deprive themselves of opportunities to attain a more complete sense of place (Chhabra, 2012, p. 91). Small and local retailers contribute to that sense of place with their provision of flexible and specific or exclusive catering for consumer needs despite their limited range of products and services (Ibrahim \& Galven, 2007, p. 243). The loss of small and local retailers denies shopping malls the ability to foster a unique, local ambience that trumps the desire for the "global" and "commercialised". With a desire for the "global" and the "commercialised", it can be argued that cheap consumerism and materialism would be promoted to consumers; this would tarnish the image of small and local businesses as well as the identities of local communities (Blundell, 2006). However, if the revitalisation of shopping malls thoroughly takes into account their social contexts, stabilisation of the surrounding community can be attained (Musil, 2011, p. 112). This would encourage new development and investment, and boost the competitiveness, confidence and resilience of small, local retailers in particular (Robertson \& Fennell, 2007, p. 168). 


\section{"Hope"}

"[The role of the store] hasn't really [changed much]. Before, you had a space that was well designed and created an environment that was engaging and enticing and attractive to consumers. That hasn't changed. It's just the means by which you do it that has changed." (Wilkinson, as cited in Insider Trends, 2019, p. 11).

"Nothing can replace the feeling of holding a product in your own hands... Other factors that customers search for during shopping are distraction, change and entertainment. These feelings cannot be replaced, either" (Manuelli, 2006, p. 117).

This thesis argues that shopping malls, including Eastgate, will have hope for the future. People still want to find everything they need in one place, but for this to remain true, shopping malls must change and adapt. It is argued that retail design heavily involved in the architecture of shopping malls, is "situated as part of a larger whole, taking shape in a wider context of demographic, social and cultural changes; economic development; and technological advances" (Petermans et al., 2016, p. 13). Because of this, shopping malls have the potential to positively contribute to communities as a stimulator in the regeneration of physically, socially and economically neglected areas.

Some say that retailers tend to be stronger on tactics than on strategy, being more concerned with reacting quickly and positively in order to meet the day-to-day problems of running their businesses in a fast-moving and highly competitive environment (Wilcox \& O'Callaghan, 2001, p. 217). While these reactive strategies may suffice when the external environment is changing slowly, "in a turbulent environment [such as the one we have today], reactionary responses may be fatal" (Wilcox \& O'Callaghan, 2001, p. 217). 
As susceptible shopping malls begin to decline, they seem to always anticipate the next crisis (Chung et al., 2001, p. 134). This renders them dynamic physical spaces that are "inevitably subject to continued redefinition by the contexts wherein they exist" (Petermans et al., 2016, p. 13). Subsequently, they look to evolve into different forms to renew the way they present themselves to consumers and increase their lifespans. Physical retail locations like shopping malls are places where brands and businesses can make genuine connections with consumers who are, today, more engaged and informed than ever before (Insider Trends, 2019, p. 2). Consumers still want and need physical stores, and they still want genuine connections (Insider Trends, 2019, p. 2). In the United States, despite the strong presence of online retailing, close to 90 percent of retail sales still happen in stores (McKinnon, 2020). Shoppers still feel that stores where they are able to see, touch and feel products first hand, are important (Insider Trends, 2019, p. 5). However, they have become increasingly "channel agnostic", expecting consistent experiences across every possible touchpoint (Insider Trends, 2019, p. 2). Thus, retailers must look at their online and in-store operations as one, rather than separately (Insider Trends, 2019, p. 2).

If shopping malls wish to have a future, they must re-invent themselves in an increasingly visionoriented world encompassing a more challenging and discerning shopping public (Miles, 2010, p. 79). Malls and their stores should be more intuitive and personalised for customers (Alexander \& Blazquez Cano, 2020, p. 5). Shops should be more than just points of sale, but also points of contact. People today want more than a product and the act of consumption (Manuelli, 2006, p. 117). This thesis argues that Eastgate still has a future. However, for that to be true, it must re-invent itself by presenting immersive experiences to increase engagement between people and the mall's retailers. 
Types of shoppers today (Blázquez, 2014, p. 103):

Adventure shoppers (searching for stimulation)

Idea shoppers (gaining awareness of the latest trends and new products)

Value shoppers (bargain hunting)

Social shoppers (socialising and interacting with others)

Utilitarian shoppers (convenience and cost saving)

Potential Strategies (Alexander \& Blazquez Cano, 2020, p. 5)

showrooms-for convenience or experience;

try-before-you-buy (click and collect outlets);

pop-ups

smaller 'brandship' bespoke stores - replacing the large format and 'cookie cutter' approach to retail store rollout and the growth of third places within retails paces

flagship stores- create, reinforce, and represent a retailer's brand; not necessarily focus on generating economic or sales results (Costa \& And, 2016, p. 53).

shop-sharing (rent space to others),

media-based stores (change like a magazine),

co-collaborations (brands conjoin to share space)

community-centres (socialization and experience). 


\section{Potential Strategy: Pop-up Stores}

Pop-up stores are an experiential form of retailing strategically located in areas with high flows of people. Typically, they have a simplified set-up and reduced product assortment (Costa \& And, 2016, p. 54). This form of retail has been touted as a viable alternative to standard stores for individual brands to protect against the complex retail environmental problems linked to the regeneration of urban centres (Alexander et al., 2016, p. 78). Where a challenging economic climate exists for shopping malls (with unpredictable and often low store occupancy rates), pop-up stores can provide a commercial solution for both landlords and businesses or retailers (Alexander et al., 2016, p. 78). This form of selling is particularly beneficial for smaller businesses that have been, or continue to be, financially or legally limited (Alexander et al., 2016, p. 78).

These stores use various forms of guerrilla marketing to generate buzz around retailers and they play on the notion of limited time and, often, exclusivity. (Alexander \& Bain, 2016, p. 168). At the same time, pop-up stores provide convenience and a simplified experience of consumption (Alexander \& Bain, 2016, p. 168). Nevertheless, they still aim to provide an exciting experience engaging to all of the customers' senses. Through this, pop up stores create a sense of personal discovery and being in the "now", while implanting in consumers a fear of missing out on the unrepeatable (Alexander \& Bain, 2016, p. 169). Consequently, retailers can increase awareness of their own brands despite seemingly making sales a secondary function (Alexander \& Bain, 2016, p. 168) 


\section{Experiences \& Theoretical Framework}

With the rise of online shopping and increased competition, it has been argued that the power structure between retailers and consumers has tilted in favour of the latter (Helm et al., 2020, p. 1). Consumers possess greater ability to shape and possibly dictate retail change (Helm et al., 2020, p. 1). The rise of online shopping, competition, and changes in power structure have led to a more fragmented approach to shopping in terms of what, where, when, how and why people buy (Christiaans, 2016, p. 212). Many consumers today take their online shopping preferences with them to physical stores, which in some ways defines the amount of exploration they do (Christiaans, 2016, p. 213). Physical stores now also have to compete with the convenience that the online realm provides, further contributing to the stagnation many are experiencing (Alexander \& Blazquez Cano, 2020, p. 5).

Despite the circumstances aforementioned, many retailers and shopping malls worldwide remain optimistic, seeking ways to get people back to stores. In response, methodologies to handle Fluid Retail (shopping with no clear delineation between format, location, and category) can be adopted to revive shopping malls like Eastgate. Fluid Retail suggests that “[retailers] don't need to stock everything” (Alexander \& Blazquez Cano, 2020, p. 5). This framework encompasses a change in retail space, advocating for flexibility and agility regarding location, store scale as well as their continuous renewal (Alexander \& Blazquez Cano, 2020, p. 5). By making physical retail spaces flexible and agile, malls can persist in being responsive to the evolving needs of contemporary consumers. These would be compatible with the concept of Complexity Theory which reiterates the need for built forms that can incrementally adapt, grow and evolve (McGreevy, 2017, p. 427). The concept looks into defining the life of great places by “...routinely [attracting] large numbers of people to a single compact and connected location for a diversity of reasons" (McGreevy, 2017, p. 427). To bring life to places and achieve complexity, the theory calls for: 
- density, diversity and a mix of uses

- $\quad$ the harmonious fitting together of diverse autonomous parts to create a whole

- $\quad$ connected, permeable, compact and easily traversable spaces

- diverse autonomous ownership of businesses and uses intermingled with temporal availability and serendipity (McGreevy, 2017, p. 427).

"[T]here is so much innovation, traditional mindsets must change to keep up with new models of doing retail... Why can't stores function like media? moving, living, breathing" (Alexander \& Blazquez Cano, 2020, p. 5).

In consideration of Fluid Retail and Complexity Theory, a way for malls to be flexible, agile and responsive could be achieved by looking at the act of shopping, with a different perspective. Malls should not view shopping solely as being for consumption, but instead as providing consumers opportunities to discover new things and inspiration as well as interact with people. However, they must be conscious that omnichannel may become the "new normal", blurring the line between a variety of channels to the point where one may no longer distinguish between them (von Briel, 2018, p. 221).

In response, the revived architectural design of Eastgate Mall should consider the following as strategies to persist and remain relevant:

- $\quad$ entertainment-to amplify consumers' sensory experiences

- $\quad$ integrating and celebrating experiences

- $\quad$ storytelling - to provide knowledge of brands or products

- $\quad$ ability for consumers to edit choices to ensure their fulfilment (Alexander \& Blazquez Cano, 2020, p. 6) 
These strategies can help Eastgate transform into a zone of experience and lifestyle, to seemingly take the mall and its stores to the consumers. Because of the pleasure they may gain from these strategies, people can be led to buy things they were not even aware they wanted. Ultimately, it is the experiences from these physical spaces that will follow consumers home and on social media.

"Consumers are now more than ever looking for the experience. They want to feel special, be doted on and entertained or go to a new unique place and have fun"- (Sarkissian, as cited in Insider Trends, 2019, p. 10).

"[Malls must create] an opportunity where retail is not just the act of buying, but a way to create memory. [They must] focus on adding value, rather than trying to be the whole purpose" -(Galperin, as cited in Insider Trends, 2019, p. 13).

Many consumers in contemporary societies are spending more time on recreation (Baghaee et al., 2019, p. 1). In response, a number of shopping malls have integrated leisure activities into their function and design as leisure interests are changing with users, time, culture and social environment (Baghaee et al., 2019, p. 1). Therefore, it can be said that if retailers and shopping malls want to remain competitive and relevant in the market, they must adapt and focus on providing a holistic consumer experience rather than simply selling the right products (von Briel, 2018, p. 221). Shopping malls should create an experience that people are drawn to before they are enticed to shop-with the experiences being memorable to the extent that they cannot be replicated online but can, instead, be represented in social media posts, thus attracting additional physical traffic from the online market segment (Berman, 2019, p. 78). This approach would instil in Eastgate Mall an innovative and more inclusive attitude that could allow it to play a greater role in the surrounding community and, most importantly, people's lives. 
Shopping malls have been criticised as monolithic, largely windowless, concrete-laden structures that encourage boredom and deny shoppers meaningful experiences (Rosenbaum et al., 2018, p. 66). Enclosed malls like Eastgate, have "passionless" consumption landscapes, often lacking green and natural elements people desire (Miles, 2010, p. 79). Consequently, they possess little or no interest to consumers apart from fulfilling immediate needs.

In response, Eastgate can explore biophilic design approaches, looking into incorporating natural forms, elements and conditions into the built environment. Studies in biophilic design contend that natural elements visible for instance as greenery and water features, inherently contain complexity, mystery and coherence (Rosenbaum et al., 2018, p. 67). These dimensions suppress boredom and can evoke positive emotional responses from employees and consumers (Rosenbaum et al., 2018, p. 66). By utilising natural elements to evoke positive emotional responses, there is a potential domino effect where contact between people and retail are fostered (Rosenbaum et al., 2018, p. 66). This would be beneficial for the mall, as a way to encourage consumers to further engage, explore and spend more of their money (Joye et al., 2010, p. 60). Because natural elements and environments can transform, yet are easy to understand and also appeal to the senses, they can transcend the basic architectural form and function of the shopping mall (Ortegón-Cortázar \& Royo-Vela, 2019, p. 170). Being able to transcend its form and function can invite people to view the mall as an escape from their daily lives. This may encourage consumers to spend more time and money in the shopping mall, thus contributing to retailers experiencing greater prosperity (Rosenbaum et al., 2019, p. 1035). 


\section{Case Studies}

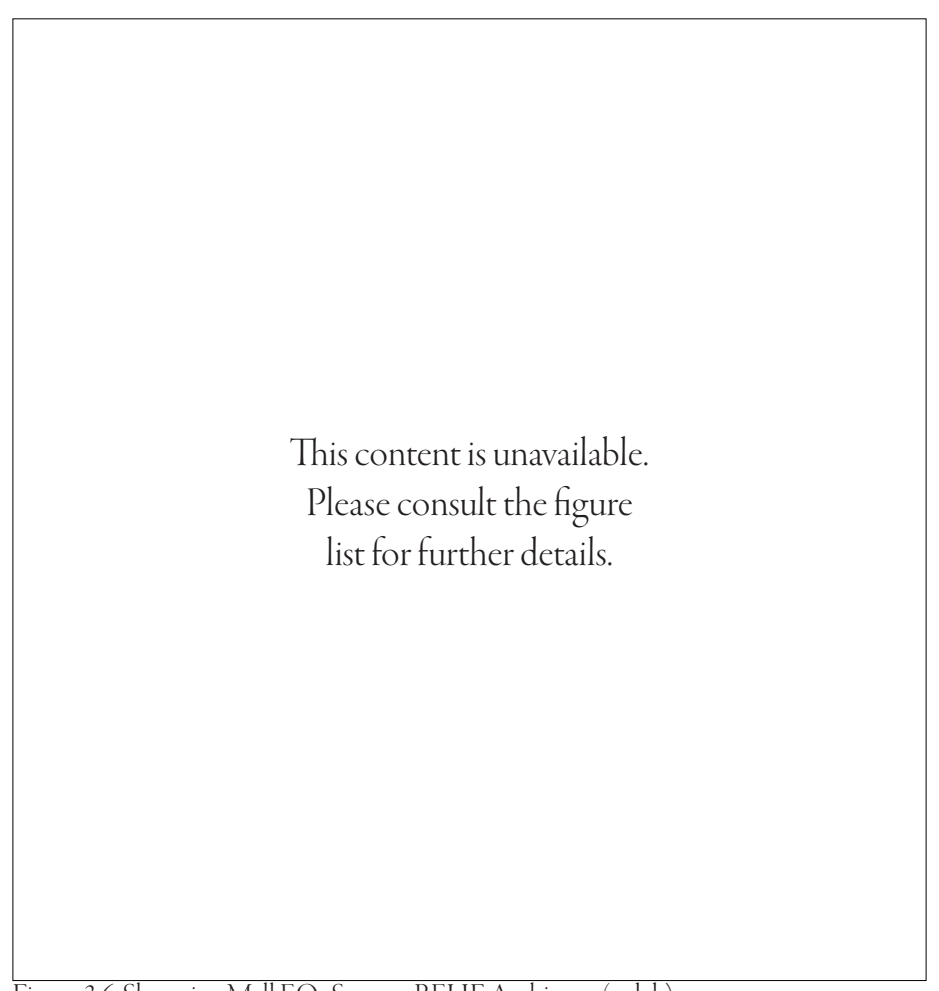

Figure 3.6. Shopping Mall EO. Source: BEHF Architects (n.d.-b)

\section{Shopping Mall EO}

This aims to provide both the classic shopping mall and marketplace-inspired atmospheres (BEHF Architects, n.d.-b). The two atmospheres are provided in two separate structures, which customers can wander between to highlight the complex being both an indoor and outdoor mall.

The complex widely arches around its parking lot, enhancing access to shops and ensuring each is within short reach. This arching creates a round and smooth shape that enhances its ability to harmonise into the surrounding context (BEHF Architects, n.d.-b). Through the complex's arching form, corners, edges and junctions are softened to assist in customers' ability to orient themselves. 
This content is unavailable.

Please consult the figure

list for further details.

Figure 3.7. Retail Centre Neukauf Villach. Source: BEHF Architects (n.d.-a)

\section{Retail Centre Neukauf Villach}

This centre features an all-glass façade complemented by an elaborate canopy, clad with shiny, organic-shaped stainless sheets. The cladding enables the canopy to reflect people's activities and movement along the mall's circulation. This is intensified with lighting during the night. Holding the canopy in place are pillars wrapped with climbing plants, to give people the feeling of walking along a green oasis (BEHF Architects, n.d.-a).

The pillars wrapped with climbing plants are complemented by poetic flooring. The flooring utilised for the path underneath the canopy features a unique pattern resembling a nearby river evoking an association with movement (BEHF Architects, n.d.-a). This effect enhances the overall social atmosphere within the space where shop entries and dining areas are located. 
This content is unavailable.

Please consult the figure

list for further details.

Figure 3.8. Westfield Mall. Source: MVSA Architects (n.d.)

\section{Westfield Mall of the Netherlands}

Expected to be completed by 2021, this shopping mall looks into "redefining shopping for the age of the internet [by] transforming a functional activity into a thrilling experience" (MVSA Architects, n.d.). The design focuses on unifying aspects like dining, entertainment and relaxation to meet the evolving needs of consumers. Consequently, it focuses on creating a landscape rather than a single building.

Westfield utilises a draped façade, inspired by a silk shawl to create a bold architectural statement and gesture. This allows it to stand out from its surrounding urban environment, while unifying formerly scattered buildings in the complex (MVSA Architects, n.d.).

With a complex circulation network, the design implements several social spaces as a way to create nodes. By creating nodes, this complex network is given clarity and cohesion. 


\section{Reflection}

"Experience sells because if we enjoy ourselves, if we are entertained, if we are entertained, if we are inspired, then we want to capture that feeling. We're willing to buy into a brand, or product, that makes us feel that way" (Insider Trends, 2019, p. 15).

In summary it is clear that malls and retail spaces are no longer solely for shopping and consumption. Miles (2010) suggests the notion the shopping is less a functional activity and more an experience (p. 79). People wish for immersive shopping and tangible experiences (Herzberg et al., 2020). Creating these experiences is a tool that can be used to differentiate the shopping mall from competitors like online shopping and media which is typified by homogenisation (Petermans et al., 2016, p. 24). Society has moved on from an era of objectivity and rationality, to that of desire and feelings where there is now an emphasis on subjectivity and experience (Petermans et al., 2016, p. 15). Contemporary society is immersed in a culture of transience and immediacy, which demands a shift from static and one-dimensional spaces to multi-functional hybrid retail spaces (Alexander $\&$ Bain, 2016, p. 70). Recent trends suggest that members of the so-called millennial generation are increasingly likely to spend their money on events and activities and not than physical things, as was the manner of their antecedents (Kreutzer, 2017, p. 3). People demand something unique, authentic, original-something 'real' (Petermans et al., 2016, p. 27). Different store typologies can be further developed and implemented, to strengthen the ability for shopping malls to differentiate themselves from online retail (Petermans et al., 2016, p. 24). Shops in shopping malls don't just have to be shops. They should morph into being a "part" shop, while at the same time diversifying their spaces by becoming part cafés, galleries, and event spaces. By fusing art and culture into retail and consumption, shopping malls can further set themselves apart from retail spaces and, most importantly, enrich consumers' shopping experiences (Alexander \& Bain, 2016, p. 72). 


$$
\text { IMMERSIVE? HYNTERTAINING.? }
$$
COLLABORATINE?
CURATION? FLEXIBILITY? EMOTIONAL?

CONTEXMALLY FLUID? COMMUUNAL. CuLtural? RELEVANT? EPTEMERAL? EMCATHONAL?

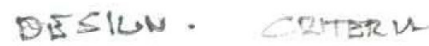

Figure 3.9. Reflective brainstorm. Author's illustration. 
An evaluation criteria is outlined below. This aims to develop a framework of principles that will enable architectural form to respond to the objectives of this thesis. This criteria would be key in developing the reconfigured shopping mall design, striving to enrich the showing and selling of experiences. This would revive Eastgate Mall and further differentiate its physical spaces from those in the online channel—as exciting, multi-functional and hybrid spaces, that help business and social cohesion in the Linwood community.

\section{Criteria for Evaluation of Design Explorations}

\section{Connectedness}

The design should promote active community engagement...

Engagement with community

Enable social interaction while providing safe and comfortable environments for retailersparticularly small ones

Challenge the social impact of the shopping mall on the nearby communities it serves

\section{Exposure and openness}

The design should exude a welcoming aura...

Spaces should be readily accessible to customers, and be welcoming to the public Maximise the opportunities for retailers and their connections to compatible retailers

\section{Flexibility}

The design should provide retailers flexible and adaptable spaces...

Ability to be used for other programmes, combine different programmes

Flexibility can present benefits and opportunities for Eastgate and its retailers

Flexibility can allow the design to change over time and persist

Not necessarily about directly or explicitly selling products, but raising awareness of the products and the processes related to them 


\section{Identity}

The design must respect scale and density of area, while standing out to become a representation of surrounding communities and its willingness to help them grow and develop.

The design must incorporate a high level of diversity in its architectural qualities (spatial, functional, program).

This is to differentiate itself from its contemporaries and competitors, which includes the digital and online realm.

Help physical retail spaces differentiate themselves from the online; provide purpose to still utilise physical retail and shopping spaces.

Showcase local businesses and chains; help them thrive

\section{Balance}

The design must create balance between convenience and experience

The design should strive to create memorable experiences that make the mall and its retailers destinations. This should be executed in a manner respectful of the needs of consumers who still wish for convenience to be maintained, in fulfilment of the mall's offering as a one-stop establishment.

Enhance the immersive sensory experience that architecture can help to construct, which could be educational, enjoyable and entertaining. 


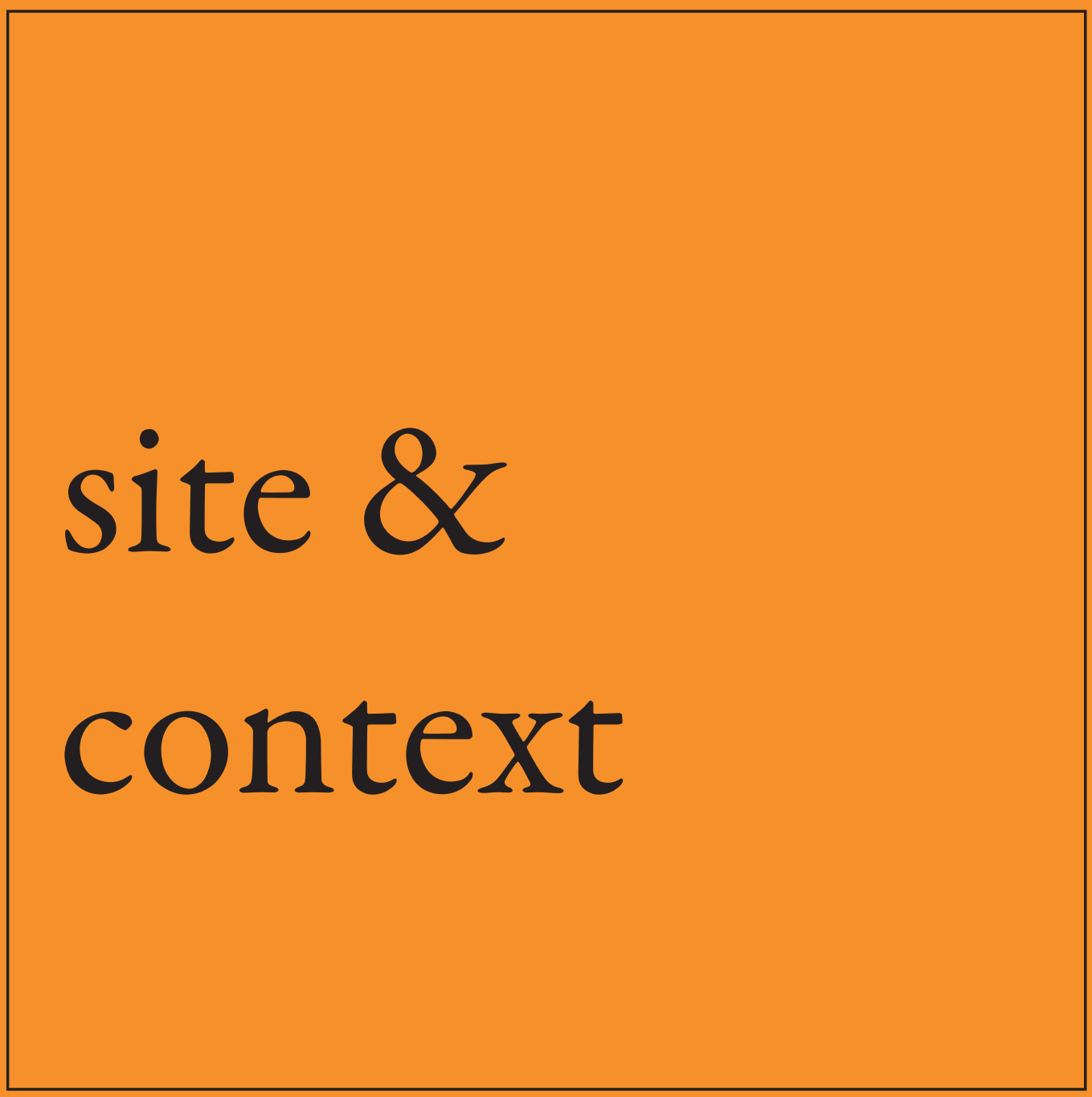

SWOT

Linwood

Present Eastgate Mall

Impulse vs. Destination

Pre-colonial History

Conclusion \& Reflection

Contemporaries

Potential Strategies for Eastgate 


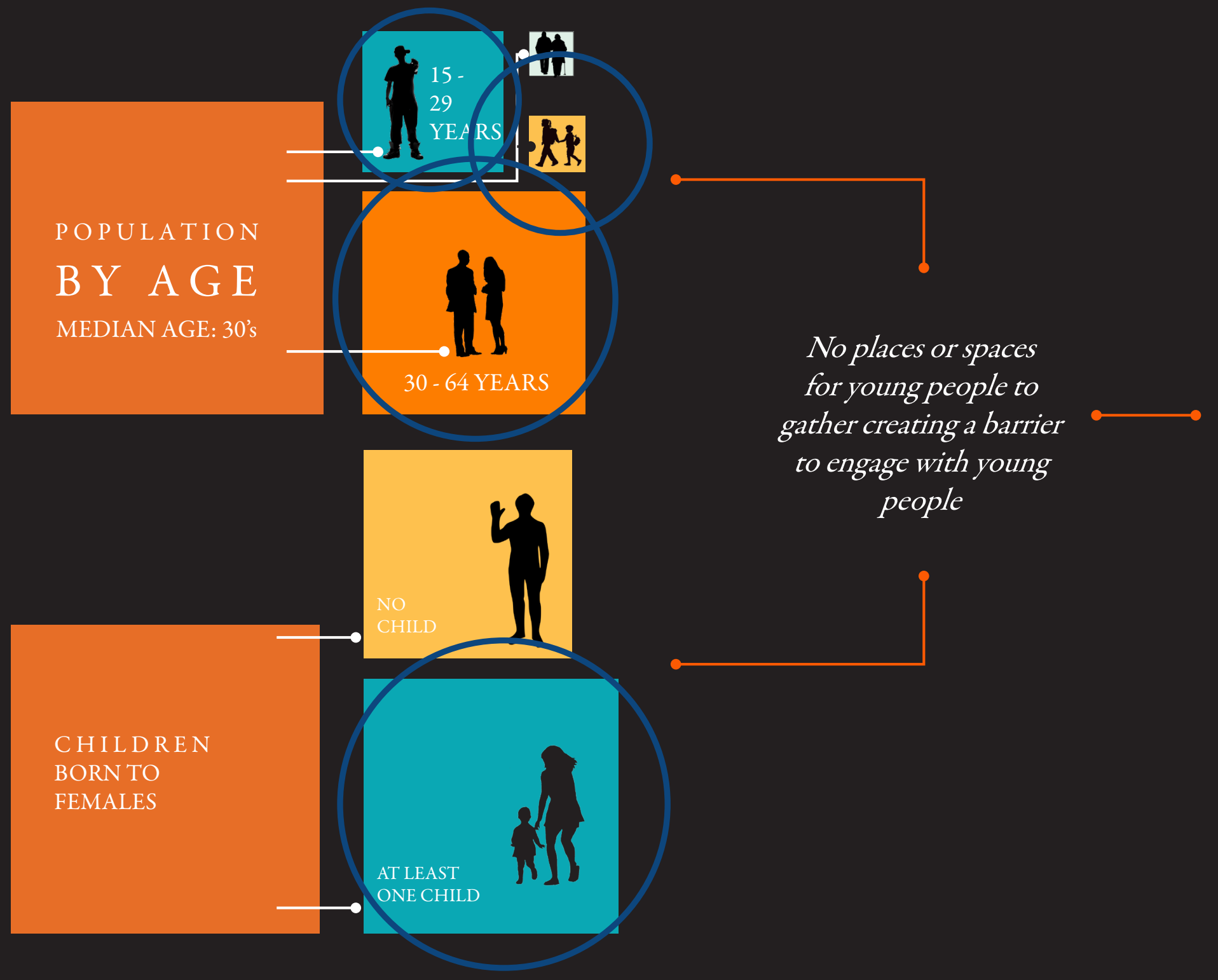



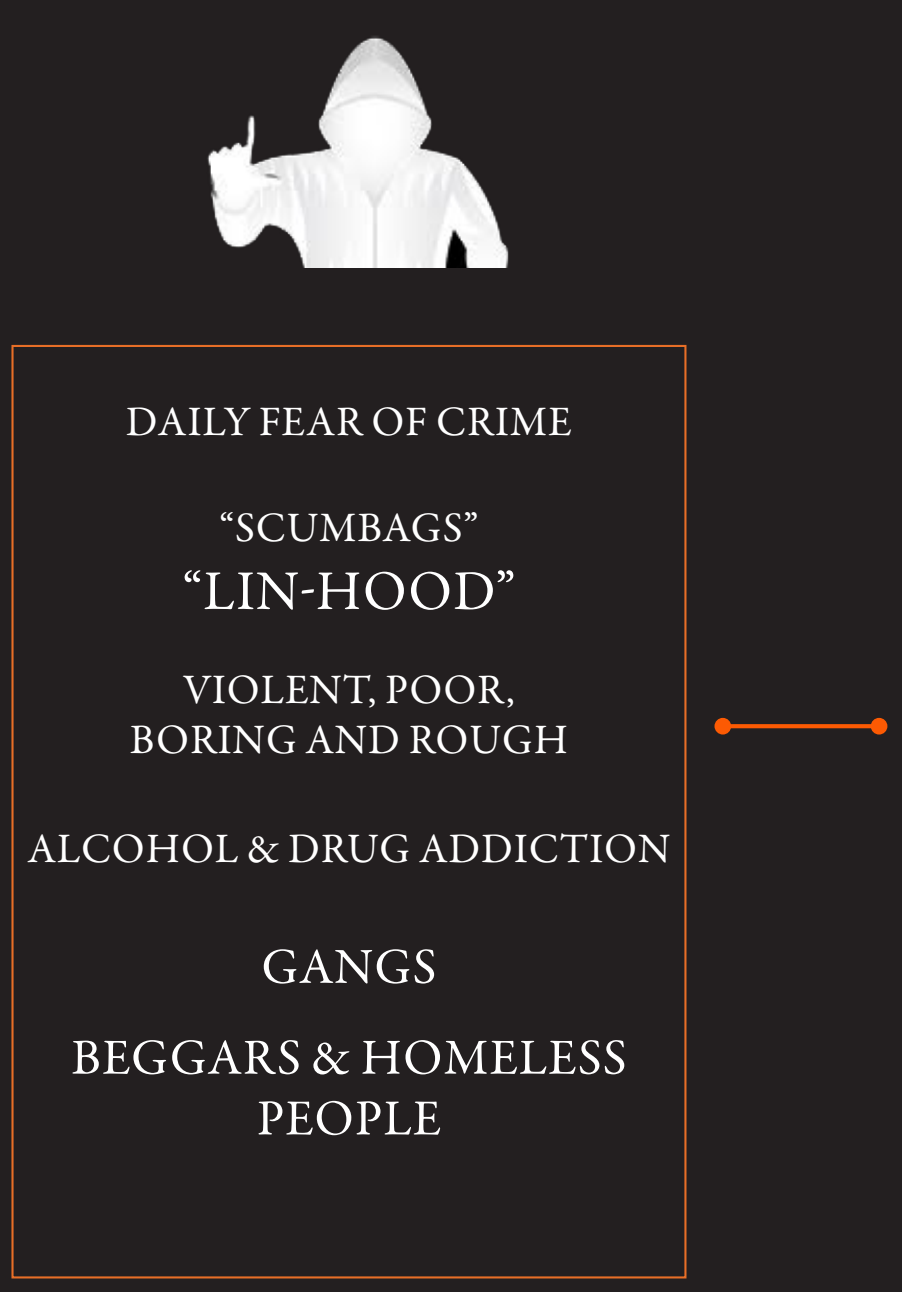

\section{(d)}

INTIMIDATED TO ROAM

TARNISH

COMMUNITY

IDENTITY

NO AUTHENTICITY

DIVERSITY

\section{WEAKEN \\ BUSINESS VIABILITY, \\ VITALITY AND \\ SYNERGY}



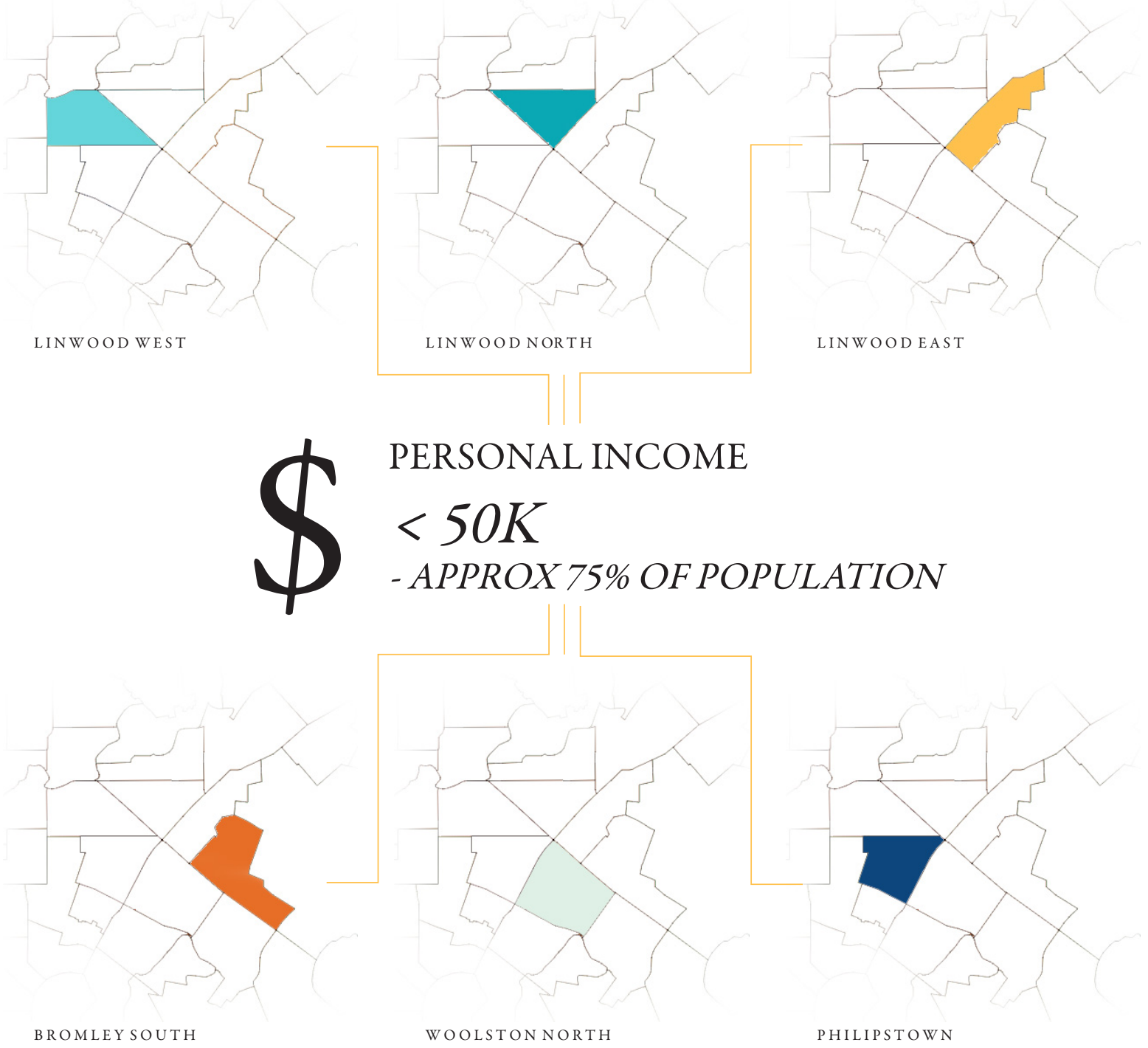

Figure 4.1 Suburbs surrounding Eastgate. Author's illustration. 


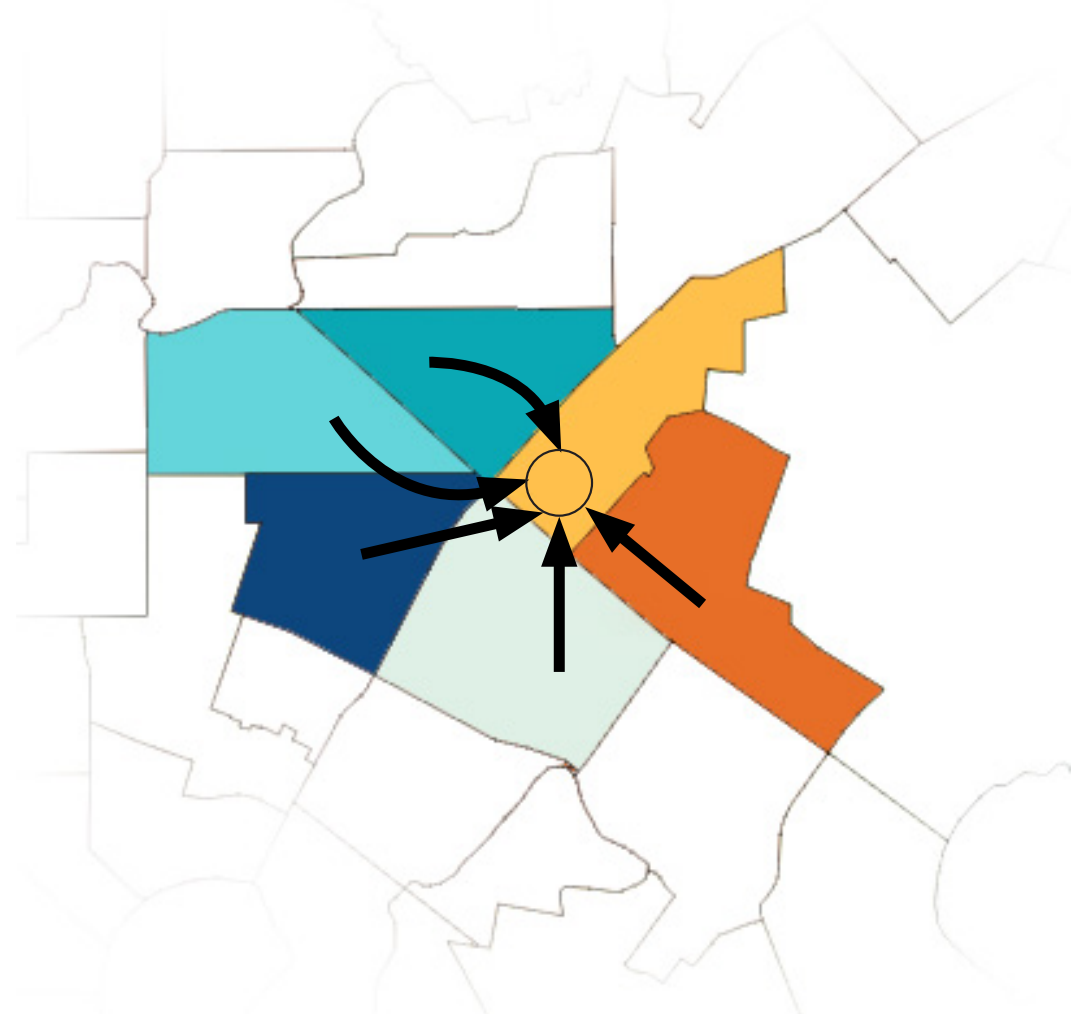

Figure 4.2. Eastgate and surrounding suburbs. Author's illustration

"Christchurch shoppers sticking to the suburbs"

"Suburb has family like atmosphere, strong sense of belonging and acceptance"

"Appreciate ...location in city"

"[We] want new shops and businesses, fewer bottle stores" 
This content is unavailable.

Please consult the figure

list for further details.

Figure 4.3. Linwood population by age.

Note. Adapted from Linwood West, by Stats NZ, 2018 (https://

www.stats.govt.nz/tools/2018-census-place-summaries/linwood-west).

Copyright 2018 by Stats NZ.

This content is unavailable.

Please consult the figure

list for further details.

Figure 4.4. Statistics into children in Linwood.

Note. Adapted from Linwood West, by Stats NZ, 2018 (https://

www.stats.govt.nz/tools/2018-census-place-summaries/linwood-west).

Copyright 2018 by Stats NZ. 
This content is unavailable.

Please consult the figure

list for further details.

Figure 4.5. Ethnicity and employment Statistics in Linwood compared to Christchurch average.

Note. Adapted from Linwood West, by Stats NZ, 2018 (https://www.stats.govt.nz/tools/2018-census-place-summaries/linwood-west) Copyright 2018 by Stats NZ. 
This content is unavailable.

Please consult the figure

list for further details.

Figure 4.6. Land use zones in Linwood.

Note. Adapted from Commercial centre factsheets, by Christchurch

City Council, 2017 (https://ccc.govt.nz/culture-and-community/

statistics-and-facts/facts-stats-and-figures/commercialcentrefactsheets).

Copyright 2017 by Christchurch City Council

Land use zones:

Commercial Core Zone

Open Space Community Parks Zone

Residential Medium Density Zone

Residential Suburban Zone

Residential Suburban Density Transition Zone

(SPS) Specific Purpose School Zone 
This content is unavailable.

Please consult the figure

list for further details.

Figure 4.7. Social and community facilities in Linwood.

Note. Adapted from Commercial centre factsheets, by Christchurch City Council, 2017 (https://ccc.govt.nz/culture-and-community/ statistics-and-facts/facts-stats-and-figures/commercialcentrefactsheets). Copyright 2017 by Christchurch City Council

Since the 2011 earthquakes, Linwood has...

- $\quad$ lost approximately $1500 \mathrm{~m} 2$ of retail space

- $\quad$ approx. $4800 \mathrm{~m} 2$ increase in vacant land

- $\quad$ approx. $2900 \mathrm{~m} 2$ increase in vacant floor space

- $\quad 19$ more vacant units

- Less businesses operating, a decrease of 24 (125 to 105)

- $\quad$ Less employees working in the vicinity

(ู) Community operated facilities

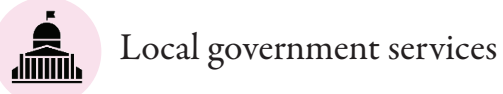
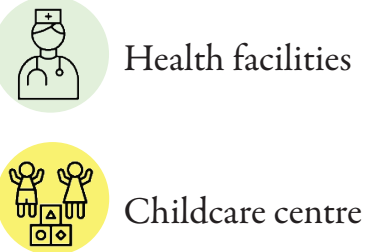

Linwood...

- Has many community run facilities

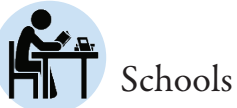

- Has many local government agencies

- Is Deprived of indoor recreation

- Is deprived of public open space

Christchurch City Council (2017). 


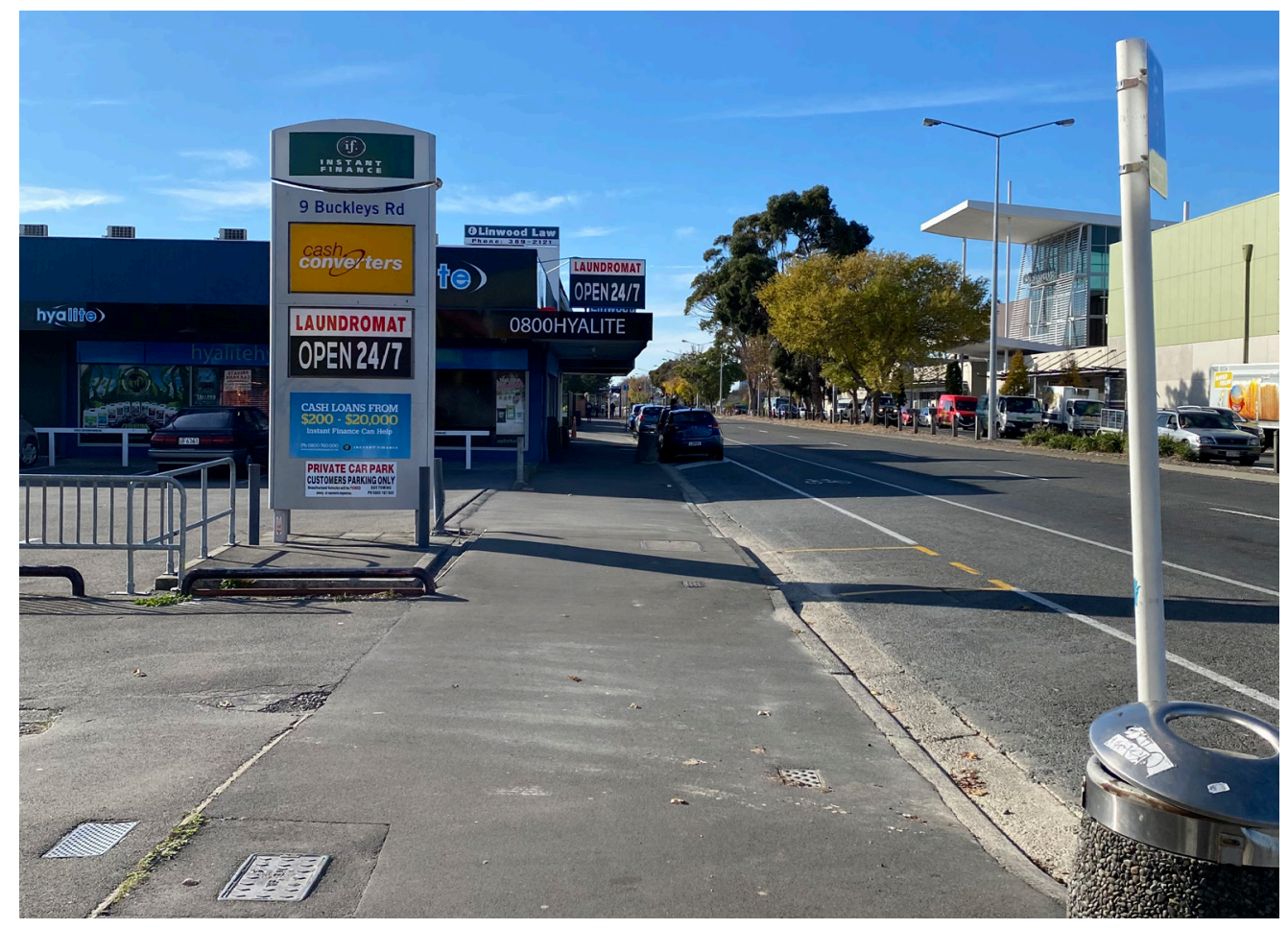

Figure 4.8. Shops outside Eastgate. Source: Author's photograph.

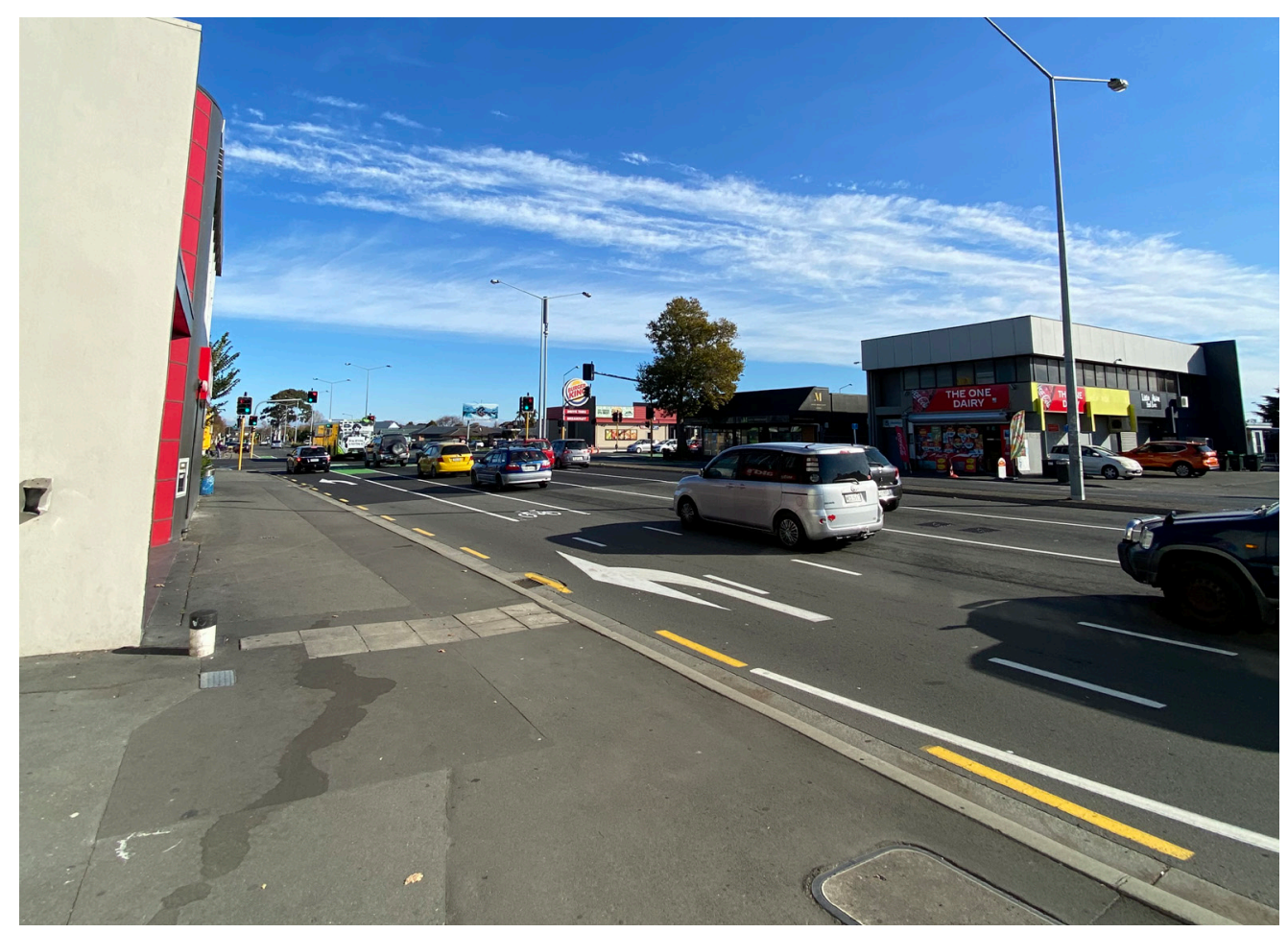

Figure 4.9. Shops outside Eastgate, Source: Author's photograph. 


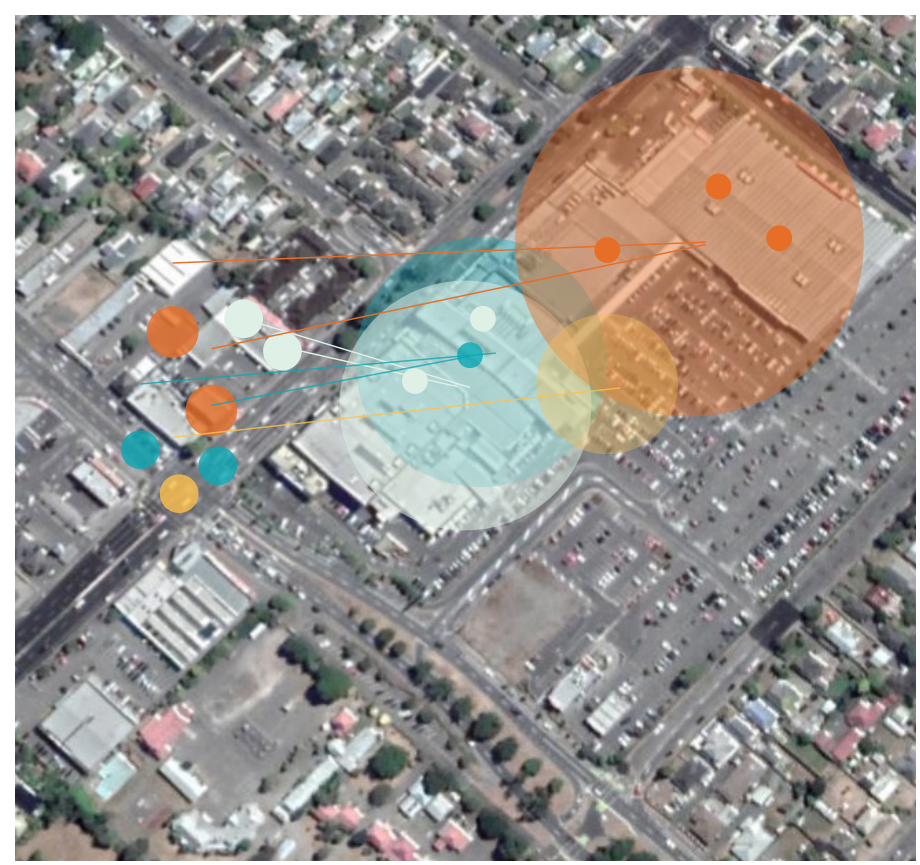

Figure 4.10. Mapping out the businesses near Eastgate. Author's illustration.
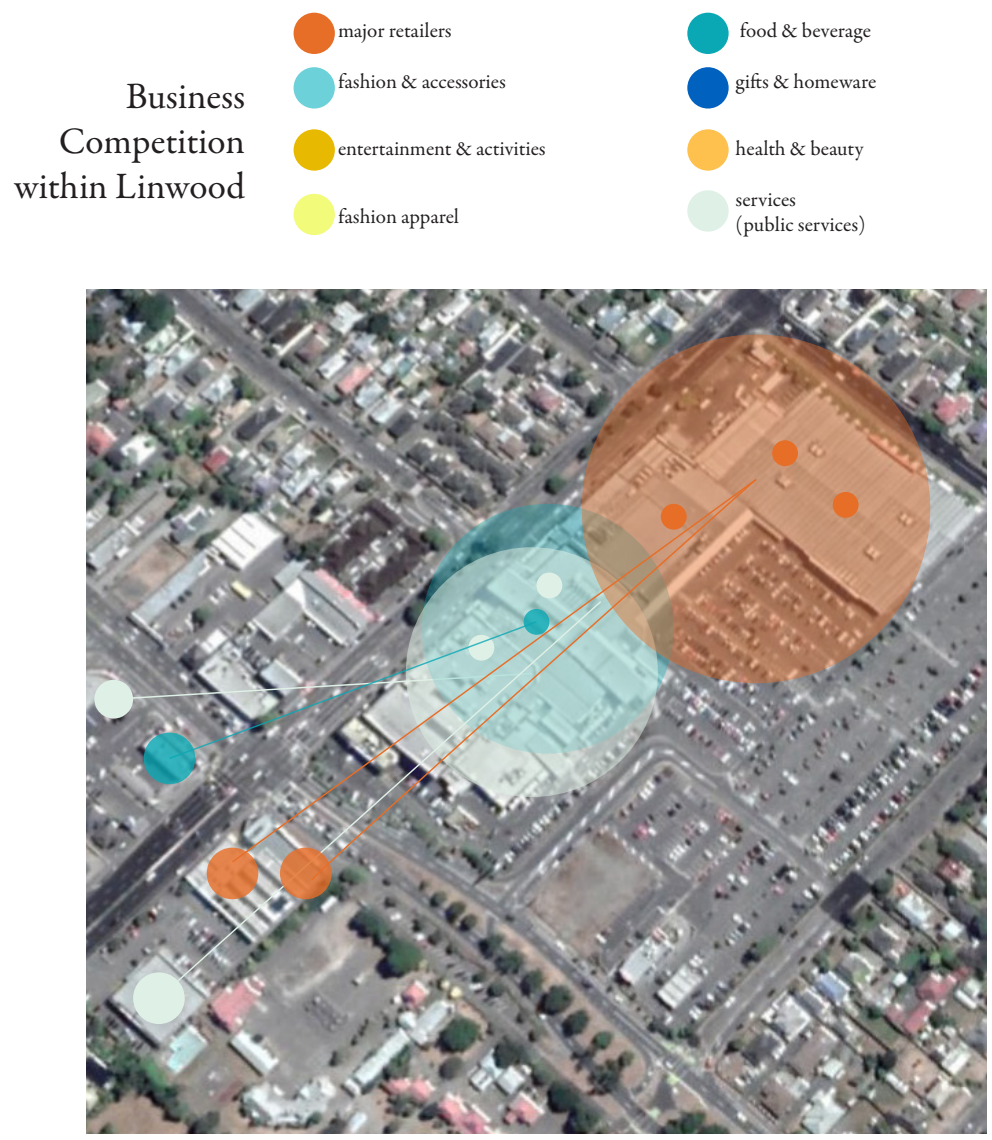

Figure 4.11. Mapping out the businesses near Eastgate. Author's illustration. 

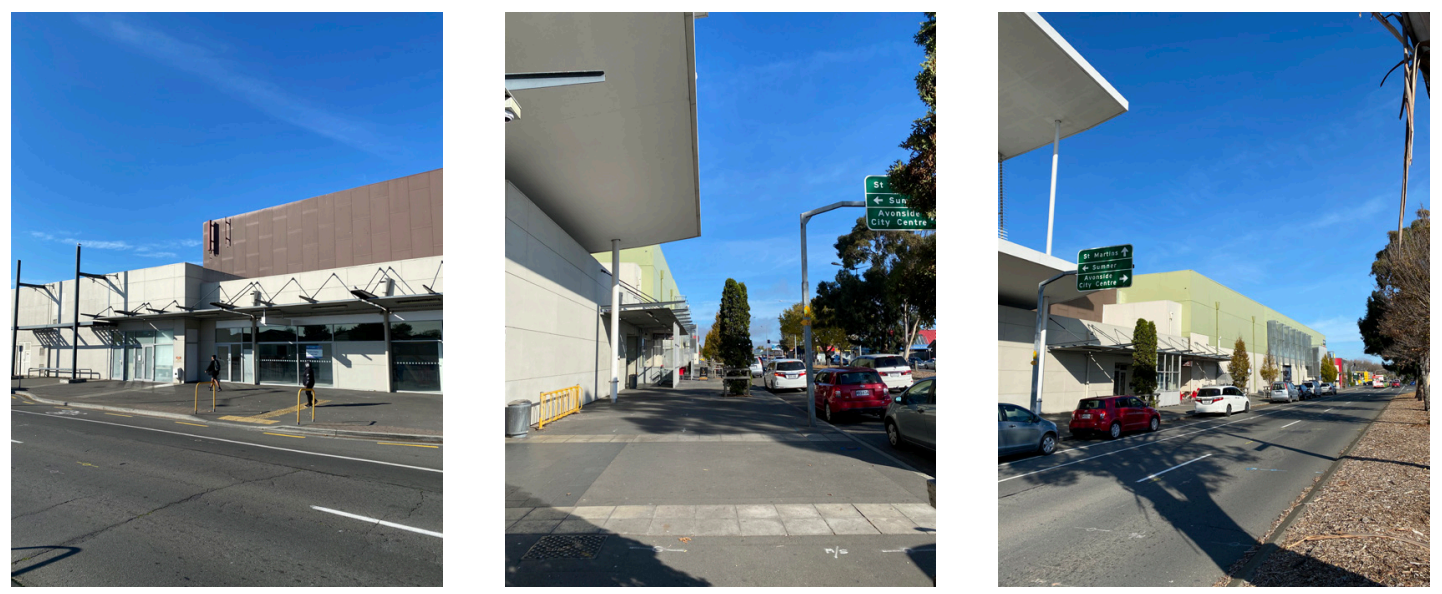

Figures 4.12-4.14. Eastgate Mall exterior. Source: Author's photograph.

Strengths:

- Well known anchor tenants

- Strong community function-community and healthcare facilities present

Weaknesses:

- $\quad$ Many inactive frontages, conveying a poor image

- Highly accessible by car, sufficient link provision of public transport (buses). However, high traffic volumes contribute to poor pedestrian experiences

Opportunities:

- Strengthen the mall's function as a community hub

- Undertake a redevelopment to create a more appealing focus away from the prominent road intersection

- $\quad$ Better links to public infrastructure

Threats:

- Competition from other centres—draws tenants away from Eastgate

- Continuing westward growth of Christchurch—moving away from the East

- Malls can either rejuvenate or tarnish a community's identity—Eastgate is tarnishing Linwood's identity and not changing perceptions of it. This discourages new development and investment 


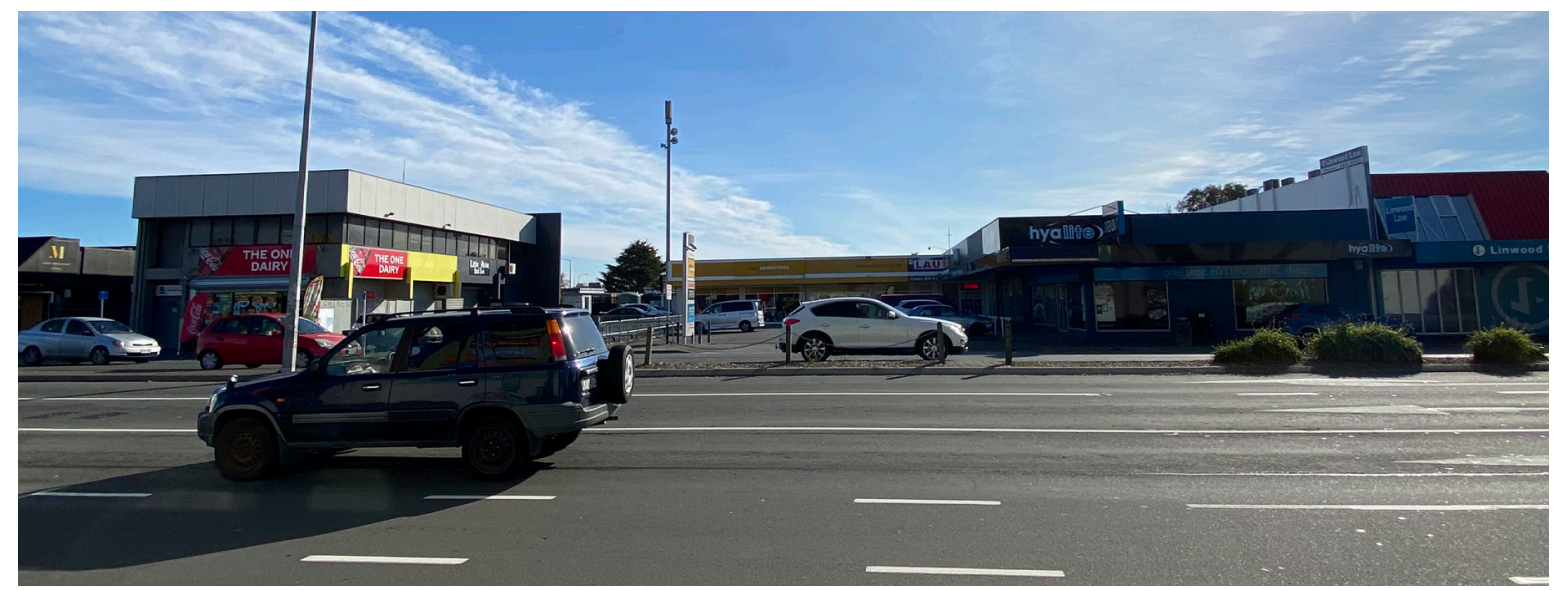

Figure 4.15. Shops outside Eastgate, Source: Author's photograph.

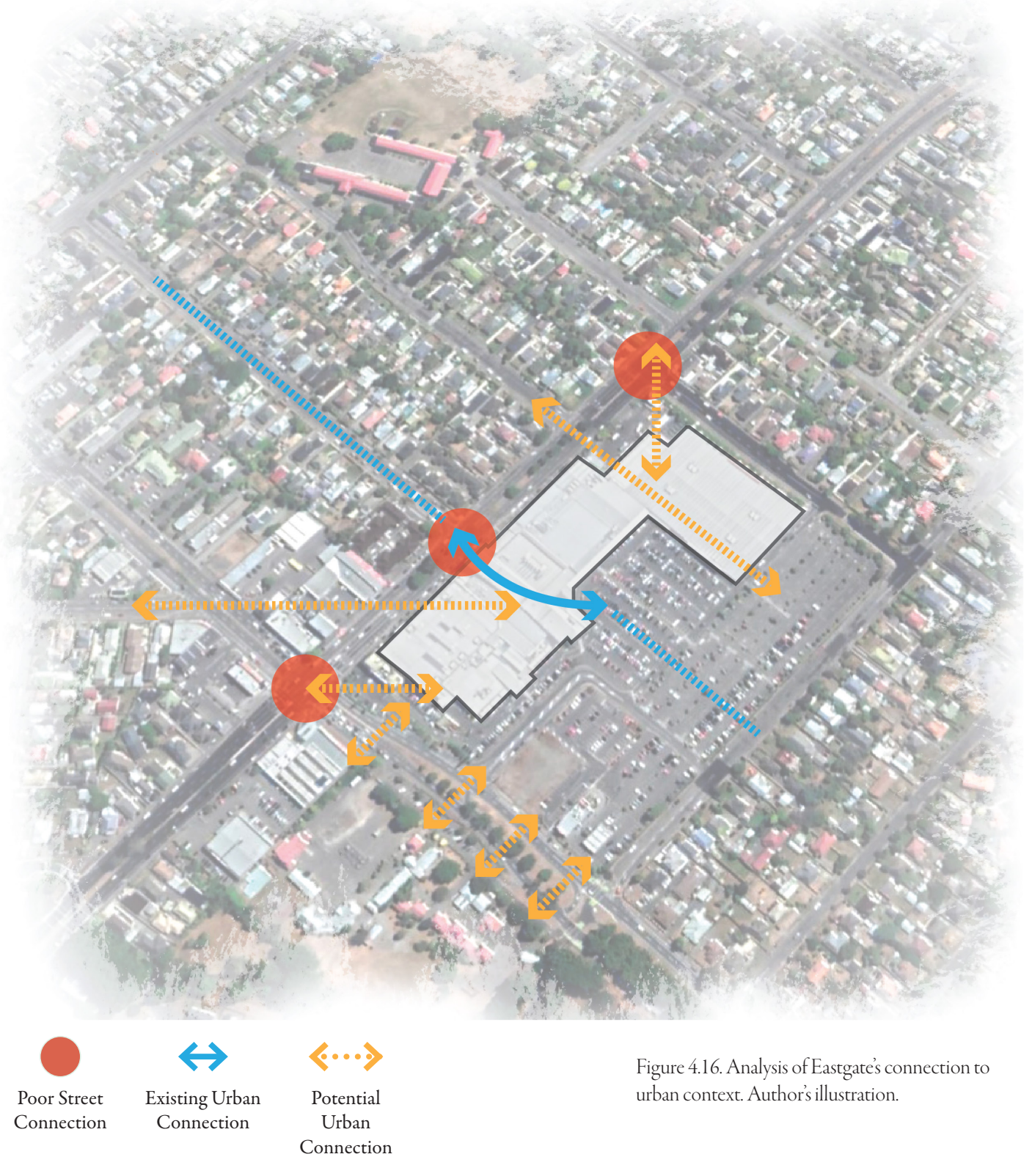




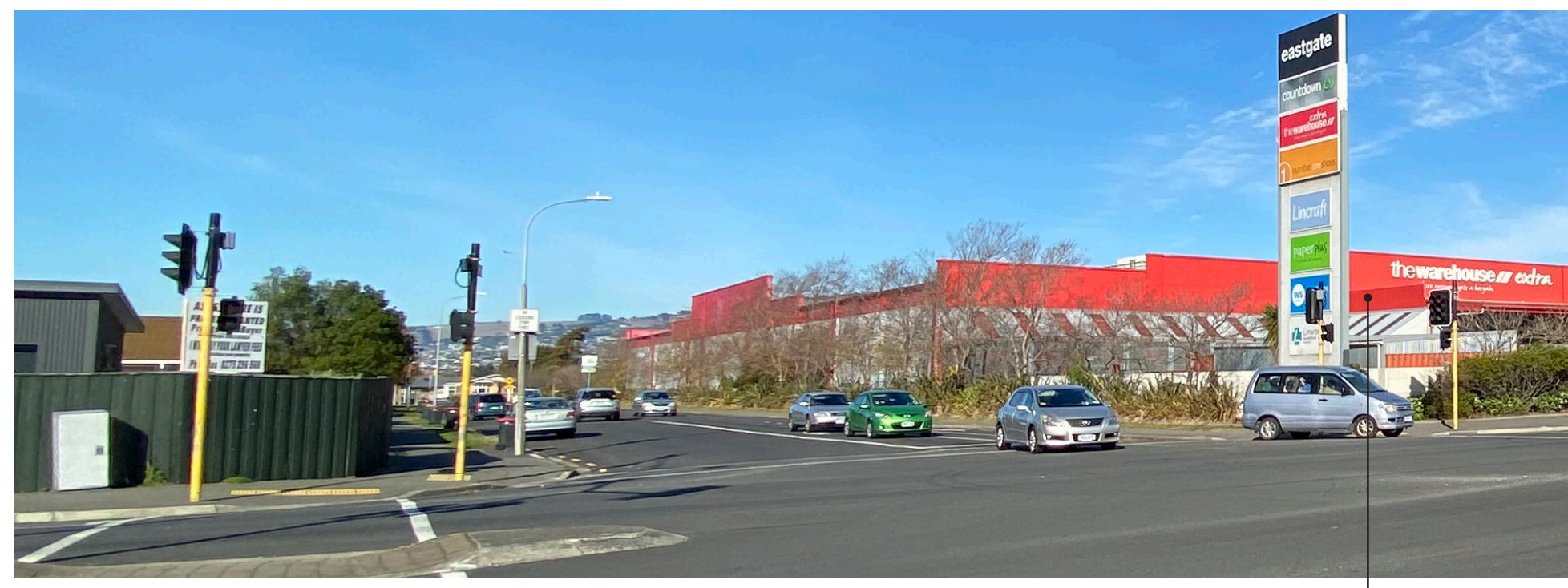

Figure 4.17. Eastgate Mall exterior. Source: Author's photograph.

INACTIVE Facade
poor facade design

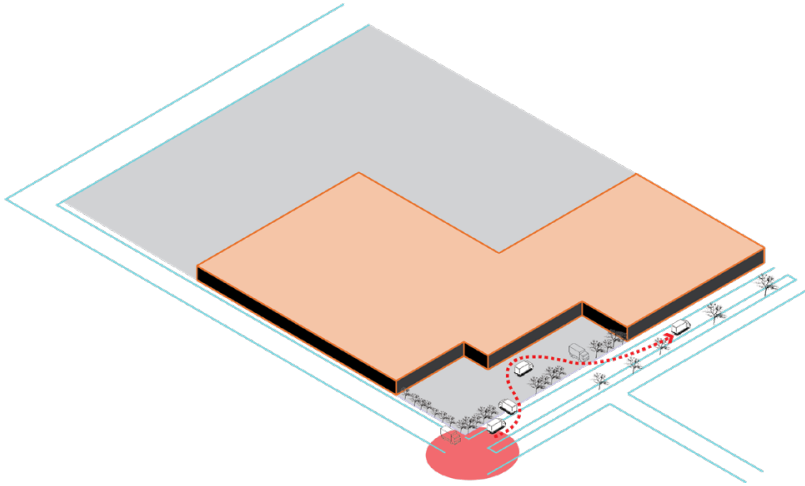

Figure 4.18. Poor urban connection and mapping out inactive facades in Eastgate. Author's illustration.
Facades requriring
REACTIVATION

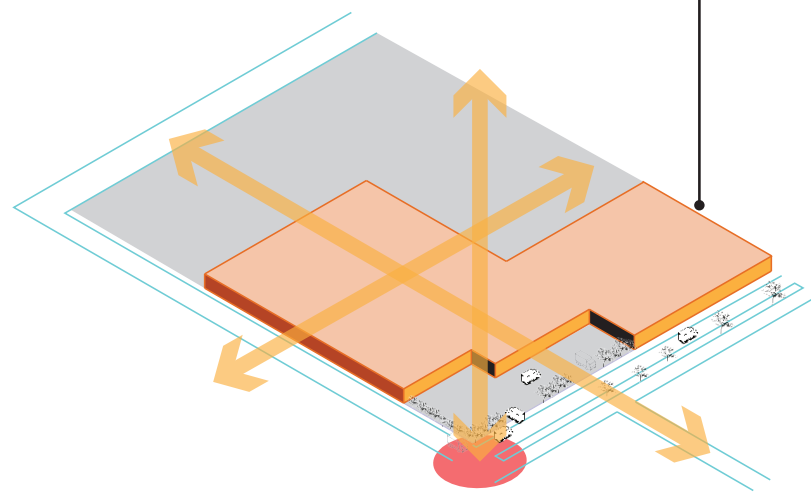

Figure 4.19. Potential new urban connections to activate and enhance Eastgate. Author's illustration.

Figure 4.22. Eastgate exterior from key road

intersection. Source: Author's photograph.

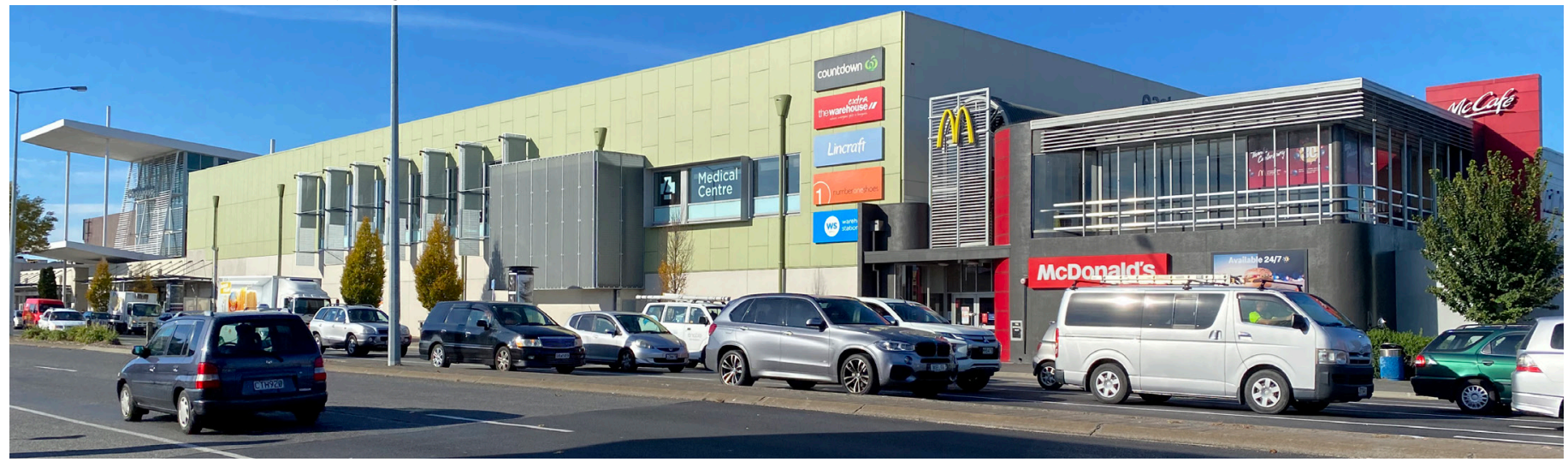




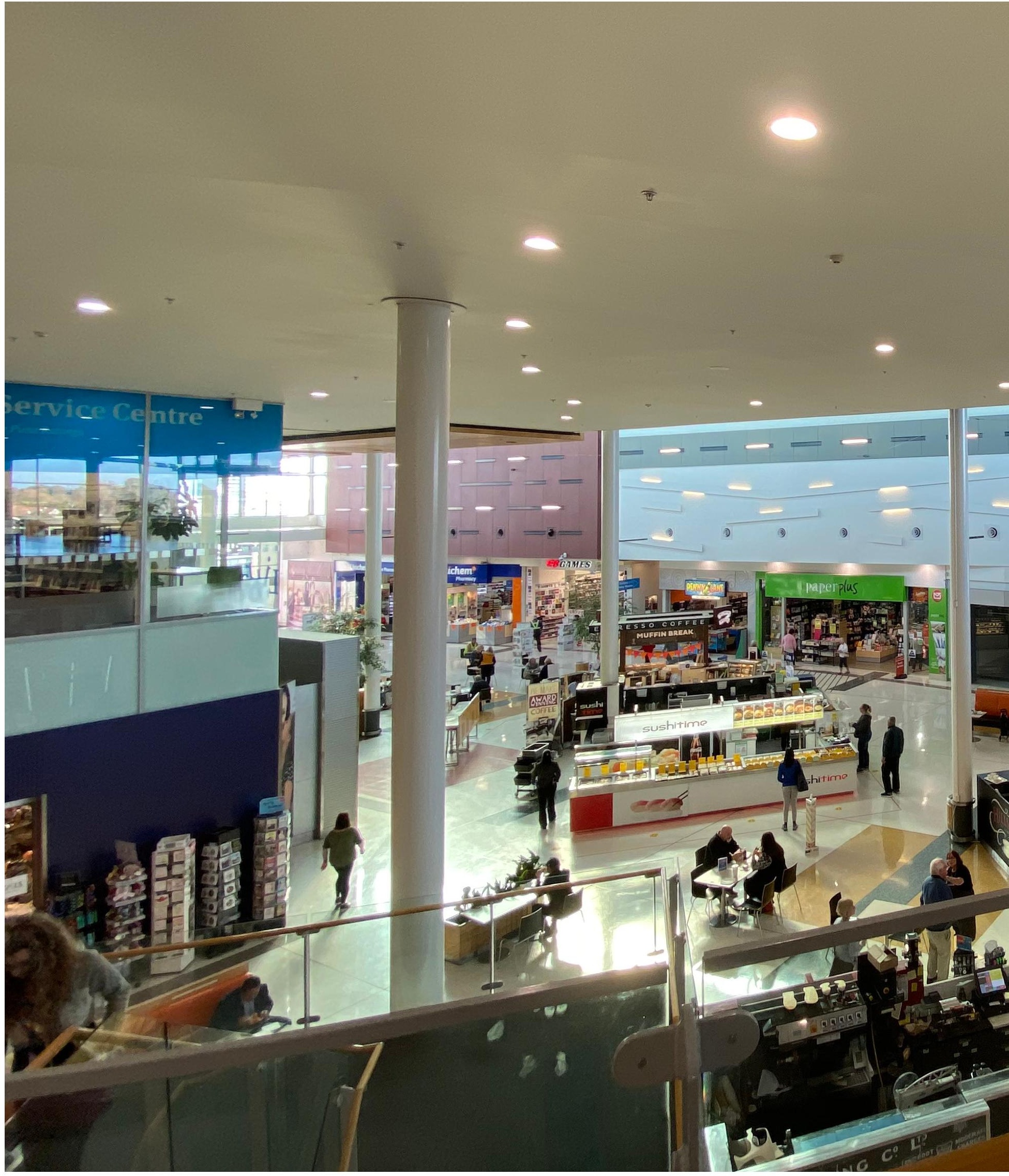




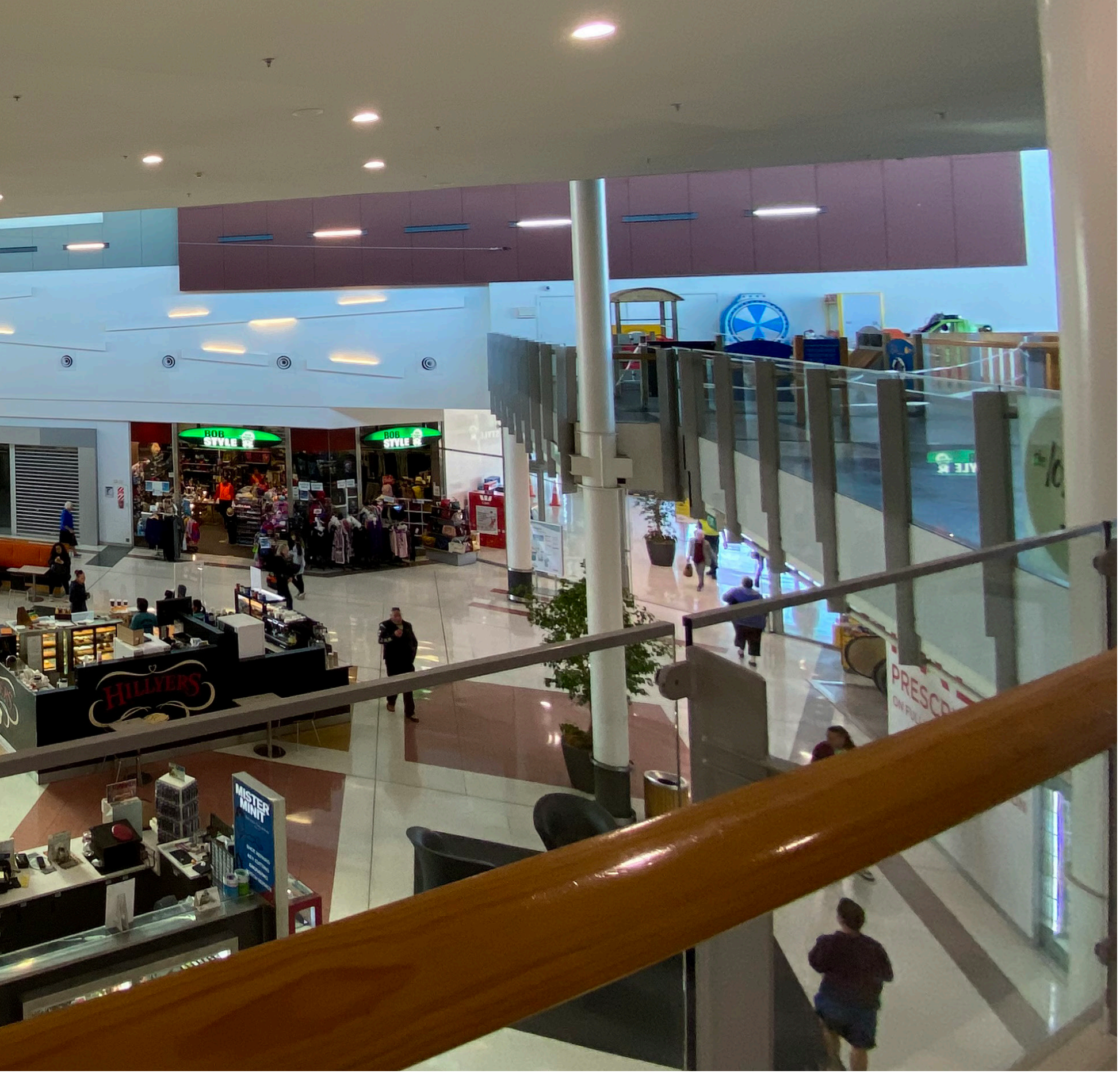

Figure 4.24. A view of Eastgate's existing food court.

Source: Author's photograph. 


\section{PRESENT}

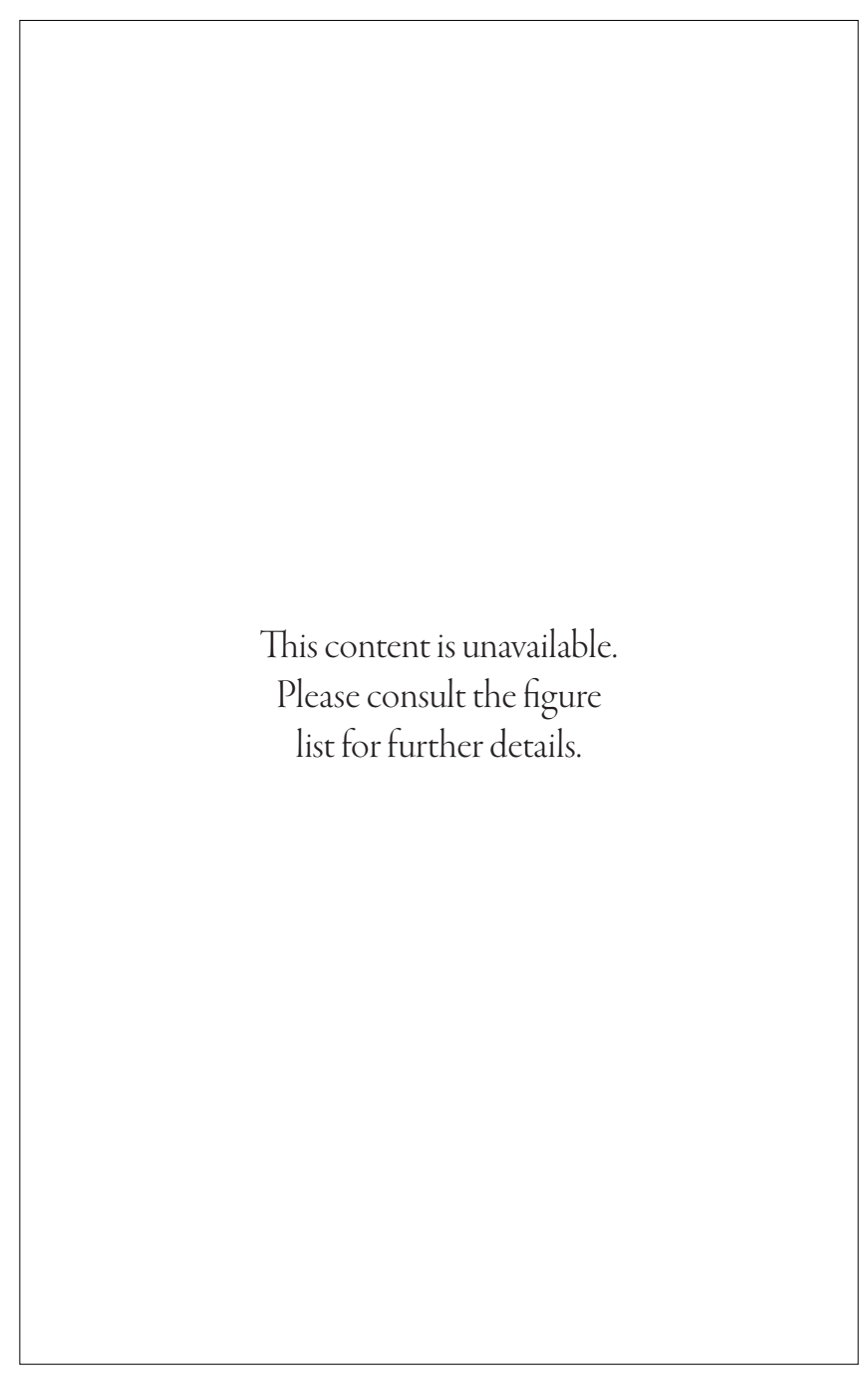

Major Retailers
The Warehouse

Warehouse Stationery

Countdown

Fashion \& Accessorie

Shoes \& Jewellery

Entertainment \& Activities

Book shop, Video Game Store Gaming Are

Fashion \& Apparel

Minor offtering only; from Postie \& Bob's Style
Figure 4.25. Existing Eastgate floor plan.

Note. Adapted from Our Shops, by Eastgate Mall (https://eastgate.co.nz/ shops/?map=map). Copyright by Eastgate Mall.

This content is unavailable. Please consult the figure list for further details.

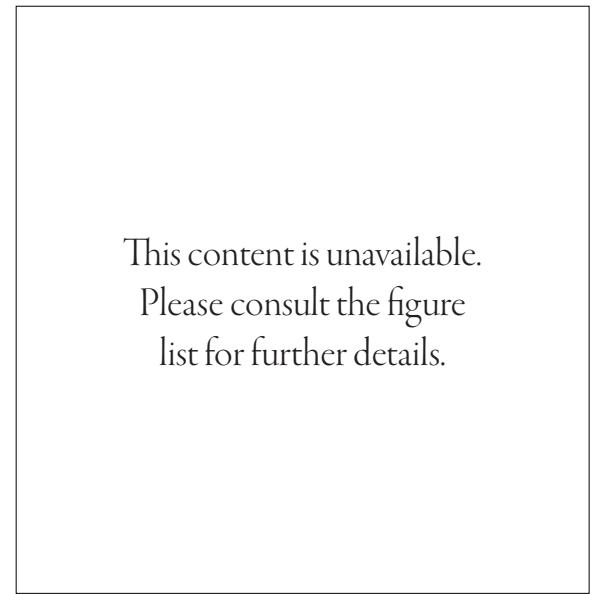

Food \& Beverage

seat foodcourt

Gifts \& Homeware

Considerable offering \& occupatio

Health \& Beauty

A pharmacy \& salons

Services

Centre Management

Christchurch City Libraries Linwood Branch

Linwood Medical Centre 

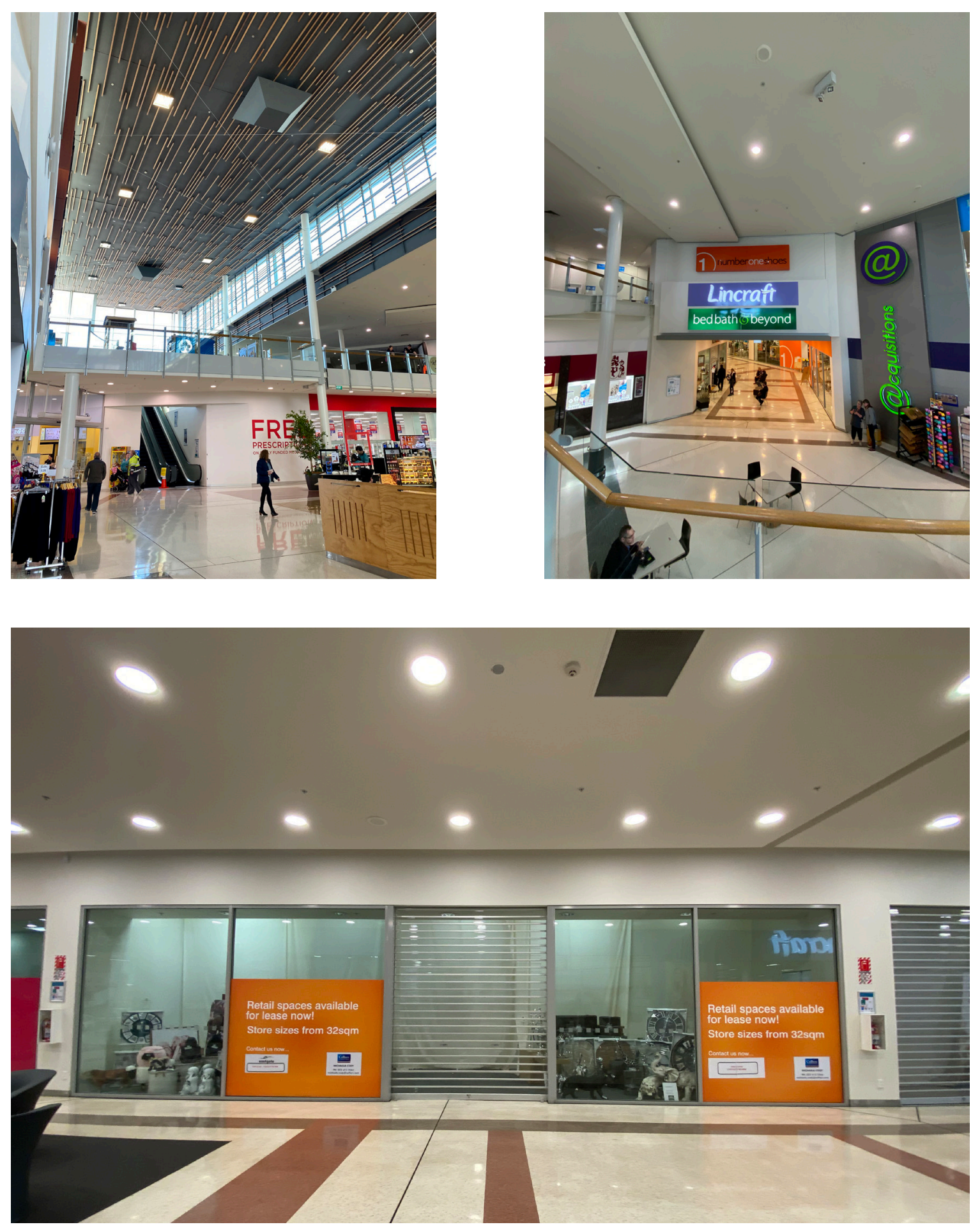

Figures 4.26-4.28. Existing Eastgate Mall interior with evidence of vacant units. Source: Author's photograph. 


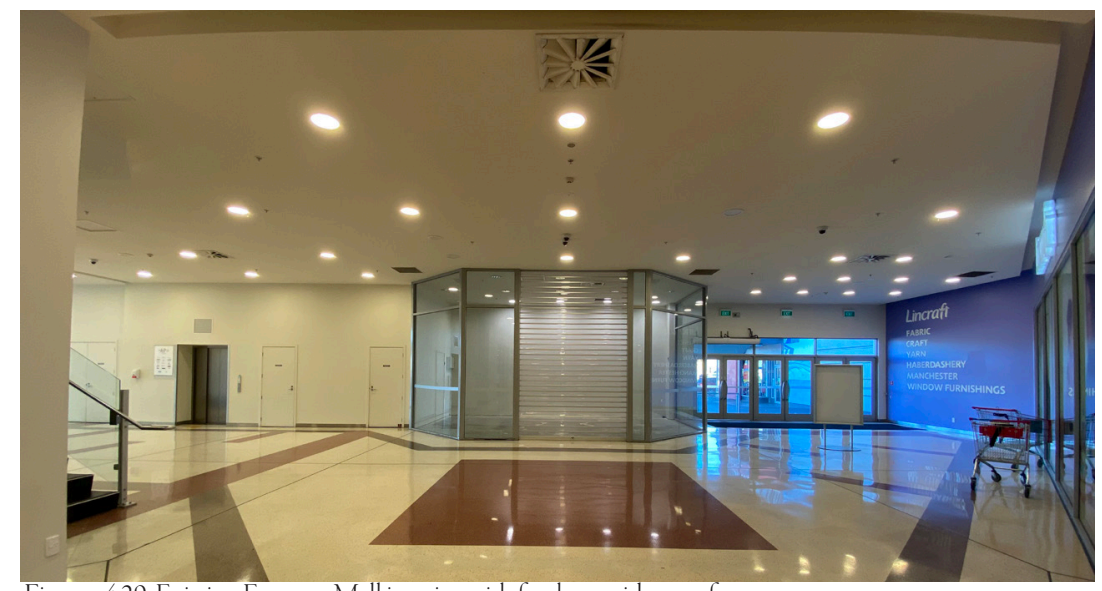

Figures 4.29. Existing Eastgate Mall interior with further evidence of vacant units. Source: Author's photograph.

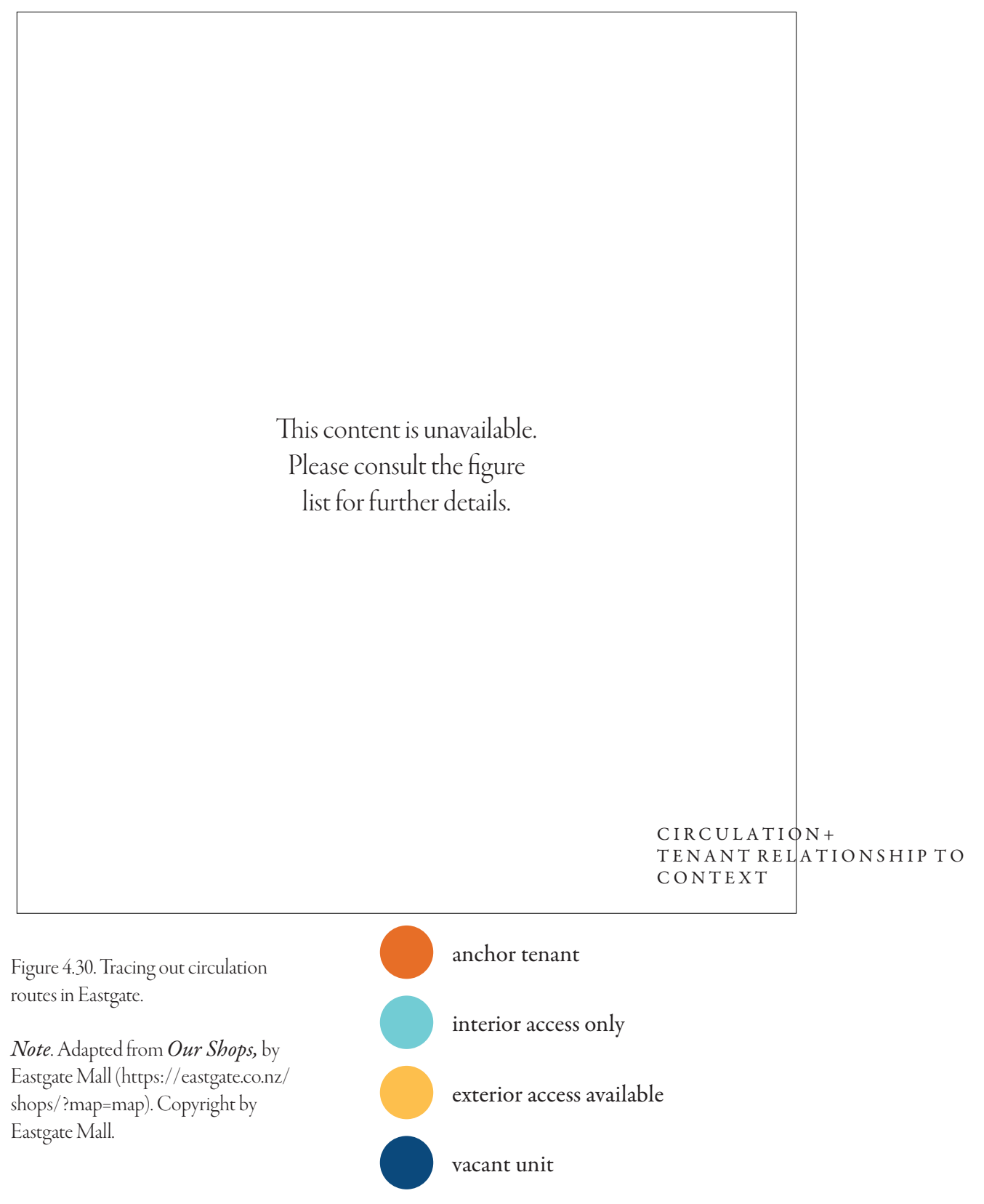




\section{Impulse vs. Destination}

With the notion of destination, shoppers (Yu \& Bastin, 2017, p. 318):

- Immerse in rational and task/goal-oriented consumer behaviour

- $\quad$ Aim to complete purchases efficiently

- derive shopping value from the outcome of the shopping activity itself; not necessarily by buying a product or service

- benefit whether tasks are completed efficiently or not

Meanwhile, with impulse, consumers buy with little planning and/or intention before performing purchases, which may mean more revenue for retailers as research suggests (Gwee \& Chang, 2014, p. 3).

- This generally occurs because an external or internal motivators or stimulus catches the shopper's attention. (Zhuang et al., 2006, p. 31).

Many relevant architectural elements stem from the external motivators linked to the physical and social environment. Therefore, the rejuvenated design for Eastgate should:

- look into enabling architecture to enhance key factors including visual stimuli, ambience, perceived crowding. Architecture must be carefully considered to enhance store layouts which strongly impact impulse purchase behaviour (Dash \& Akshaya, 2016, p. 38)

- $\quad$ remain aware that the success of malls also depends on balance between directional movement and the behavioural constancy facilitated by the anchor stores (Jewell, 2001, p. 361). Key/anchor tenants must be located at strategic points so they can maximise pedestrian flows between them

- increase the mall attractiveness considerably dependent on the design and appearance of the building and types of shops.

- $\quad$ remember consumers need efficiency... but efficiency alone will no longer suffice. 


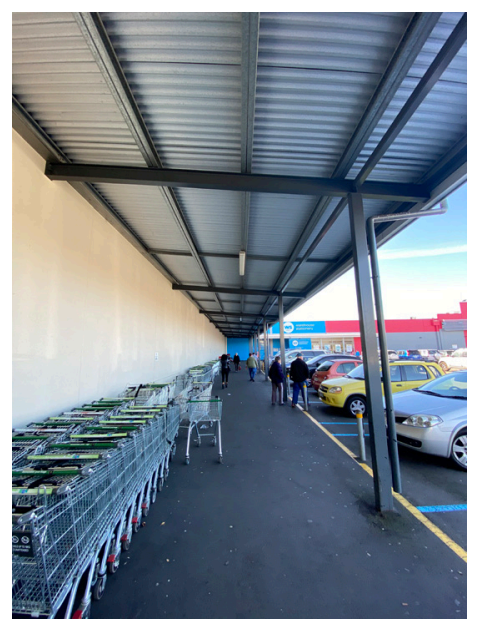

Figure 4.31. Poor existing link between stores. Source: Author's photograph.

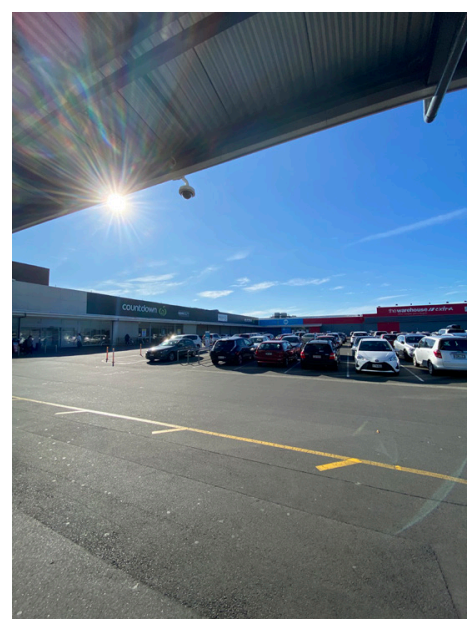

Figure 4.32 Existing carpark provision. Source: Author's photograph.

This content is unavailable.

Please consult the figure

list for further details.

Figure 4.33. Tracing out circulation routes in Eastgate, including entry points and dead ends in relation to $\mathrm{key} \mathrm{focal/gathering} \mathrm{points.} \mathrm{A} \mathrm{key} \mathrm{gathering} \mathrm{point} \mathrm{by} \mathrm{the} \mathrm{anchors} \mathrm{is} \mathrm{dragged} \mathrm{outside} \mathrm{to} \mathrm{the} \mathrm{carpark} \mathrm{due} \mathrm{to}$ the mall's poor architectural design and configuration. It is evident that Eastgate has a poor connection to its urban context, to the main street, seemingly reachable only via private vehicles.

Note. Adapted from Our Shops, by Eastgate Mall (https://eastgate.co.nz/shops/?map=map). Copyright by Eastgate Mall. 


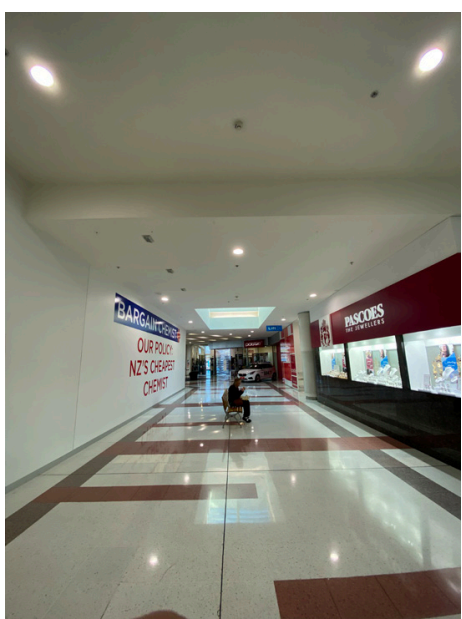

Figure 4.34. Dull interior spaces. Source: Author's photograph.

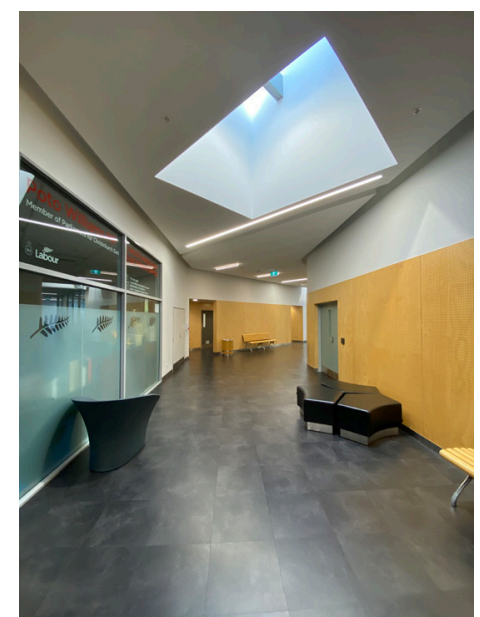

Figure 4.35. Dull interior spaces on level one where community facilities are located. Source: Author's photograph.

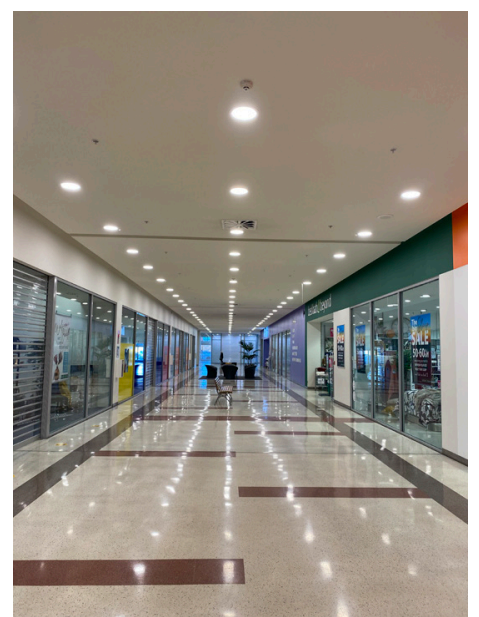

Figure 4.36. A long, dull aisle in Eastgate. Source: Author's photograph.

Eastgate Mall is a quintessential suburban shopping mall that introduces a world "free from bad weather, life, crime, dirt and troubles" (Feinberg \& Meoli, 1991, p. 426). The measure of Eastgate's success is determined by the success of its retailers (Reimers \& Clulow, 2004, p. 210).

Eastgate has several large anchor tenants. They are, however, not strategically placed and are too close to each other. It can be said that this stops the mall from being successful. With this poor placement, the mall is unable to draw a greater amount of shopper traffic to its nonanchor tenants, many of which are small retailers. These retailers suffer from poor pedestrian circulation and volumes. Outside, the mall building contains few architectural amenities and is surrounded by paved free surface parking.

More specifically the mall's side aisles that experience lower footfall are occupied by small tenants selling lower-priced goods with lower margins. These tenants should be located nearer to anchors, allowing these aisles to be occupied by service tenants like banks, and travel agencies. Service tenants are destination stores and do not largely rely on passing traffic (Carter $\&$ Vandell, 2005, p. 242).

Anchors should be at opposite ends of the mall's linear axis to draw footfall past or into the smaller retailers between them. This would fundamentally utilise the dumbbell plan. With this scheme, anchors can “...claim to cater [to] consumers' needs at [the] extremities... [to force the individual] along a path made appealing by the promise, at its end, of reaching one's destination" (Jewell, 2016, p. 23). Consequently, the mall can trigger temptations and curiosity within customers to heighten their desire to consume (Jewell, 2016, p. 123). 


\section{" [Mall] environments are inauthentic and superficial, designed without awareness of, or care for, \\ local characteristics or traditions ฯ \\ (Corroto \& Richardson, 2019, p. 1080)}




\section{Pre-colonial History}

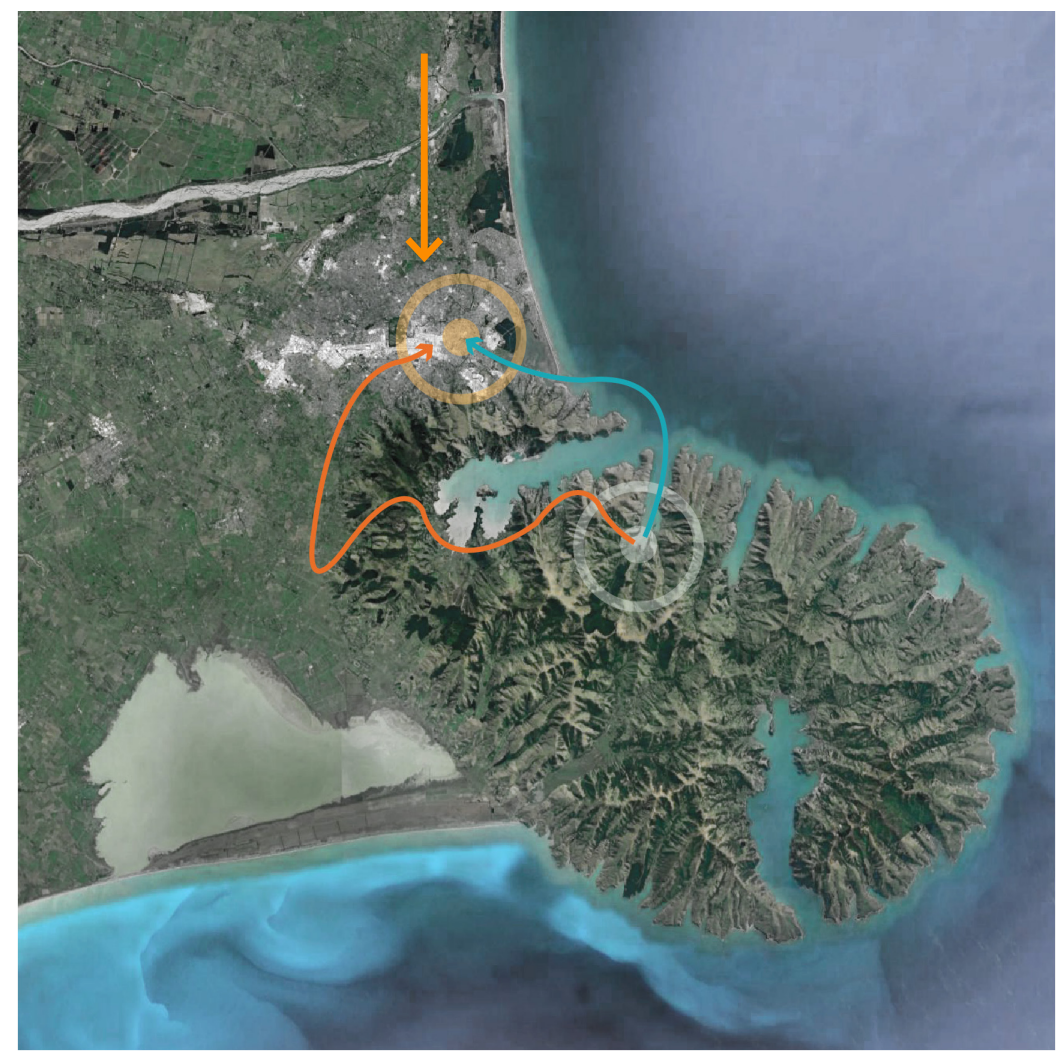

Figure 4.36. Tracing out historic Maori journeys in the Christchurch region. 
This content is unavailable.

Please consult the figure

list for further details.

Figure 4.37. Map of waterways, swamps and vegetation cover in nineteenth century Christchurch. Source: Canterbury Earthquakes Royal Commission (2011)

This content is unavailable.

Please consult the figure

list for further details.

Figure 4.38. Existing current Eastgate complex in relation to historic swamps.

Note. Adapted from Christchurch area showing waterways, swamps \& vegetation cover in 1856 map, by Canterbury Earthquakes Royal Commission (https://canterbury. royalcommission.govt.nz/documents-bykey/2011-09-2348). Copyright 2011 by Crown. 
Today, Eastgate sits upon a system of swamps that once existed throughout Christchurch (W. Taylor, 1952, p. 46). This historic system, drained by the Avon and Heathcote Rivers, was surrounded by vast swathes of raupo and flax vital for the livelihoods of Maori people (Tikao, n.d., p. 5). Consequently, this caused the area to be significant for gathering food and resources. While said food and resources were gathered, it provided access and areas for trade, resting and temporary shelter (Tikao, n.d., p. 5). The significance of these practices were manifested by constant food exchanges that occurred in this area between Maori people from Kaiapoi Pa and Banks Peninsula (Tikao, n.d., p. 13). With these customs, it can be concluded that the general historic area surrounding Eastgate was a vital and dynamic passage. The vitality and dynamism was defined by the engagement and communication between people and different family groups to create a connection among them.

To traverse the rivers and streams encountered in these exchanges, temporary rafts needed to be constructed from the resources at hand. The swamps and wetlands provided the ideal material for such tasks. The leaves of raupō contain tubular air pockets, which create a spongy buoyancy (Tikao, n.d., p. 11).

Some architectural substance can be extracted from these exchanges and traditional customs and practices. These exchanges involve the exhibition of food on tall structures depicting an inverted V-framework with a platform (kaho) or stage (whata or tīrewa) running across, to provide tiers for holding baskets of food (Tikao, n.d., p. 13). Following a simple interpretation of these exchanges and customs, it can be said that there is a subtle suggestion of verticality as an underlying architectural theme. The crossing of rivers and streams using natural materials adds further substance by suggesting the notion of lightness. The themes of verticality and lightness can be employed to strengthen Eastgate's identity in the rejuvenated architectural design proposed by this thesis. 
This content is unavailable.

Please consult the figure

list for further details.

Figure 4.39. Image depicting nineteenth century landscapes reminiscent of Eastgate's past with the swamps, vegetation and spaces where traditional exchanges occurred. Source: Eagle Vision Times (2019). 


\section{Conclusion}

Eastgate Mall find itself in a volatile position where the growth of Christchurch continues to move westwards. This has left the surrounding area neglected, decreasing its attractiveness for development.

However, the site still has potential. There is a community to serve and it can be strengthened and expanded with the services and unique experiences the mall can provide.

A rejuvenated design of Eastgate Mall can revitalise the greater Linwood area. This has the potential of bringing economic prosperity vital for businesses in the area struggling from slowing growth and development. This renaissance can alter people's perspective of the area and its own people, to attract others from a diverse range of backgrounds and social statuses. 


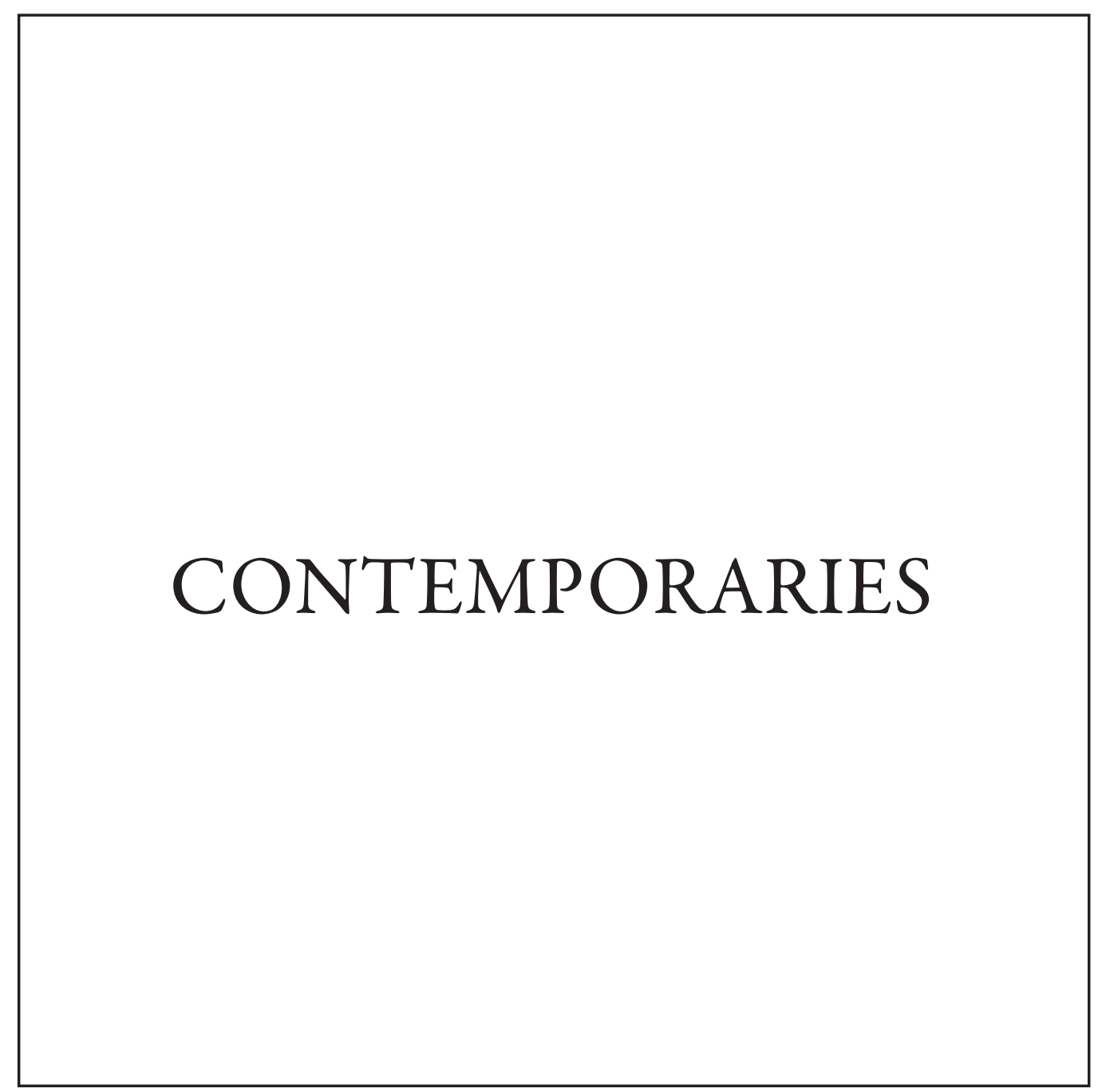




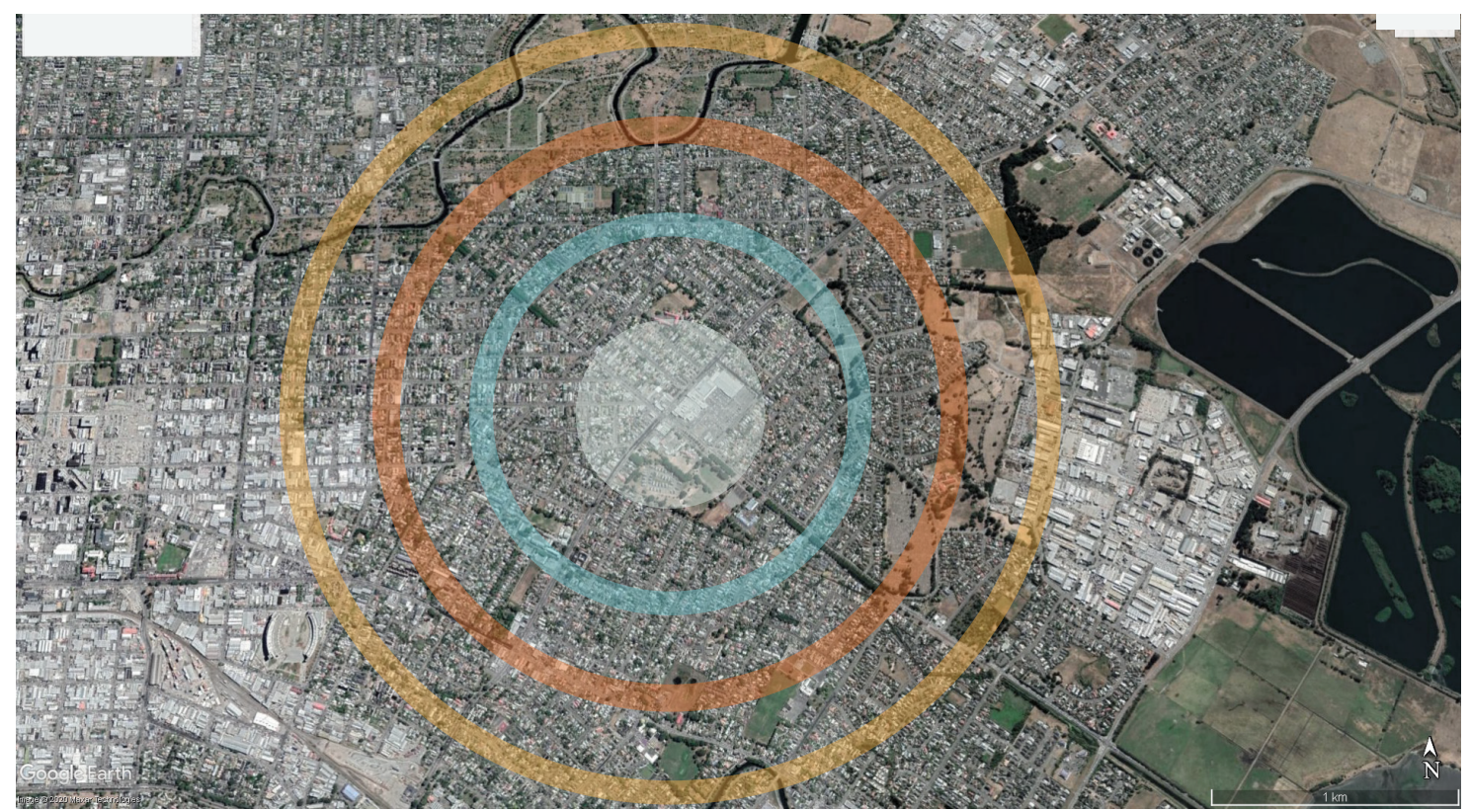

$0.5 \mathrm{KMS} \quad 1 \mathrm{KM} 2 \mathrm{KMS} \quad 3 \mathrm{KMS}$

Figure 4.40. Areas surrounding Eastgate and their distances to the mall. Author's illustration.

Figure 4.41. Proximity of Eastgate to competing shopping malls, centres or precincts, with consideration of market segments being catered for. Author's illustration.
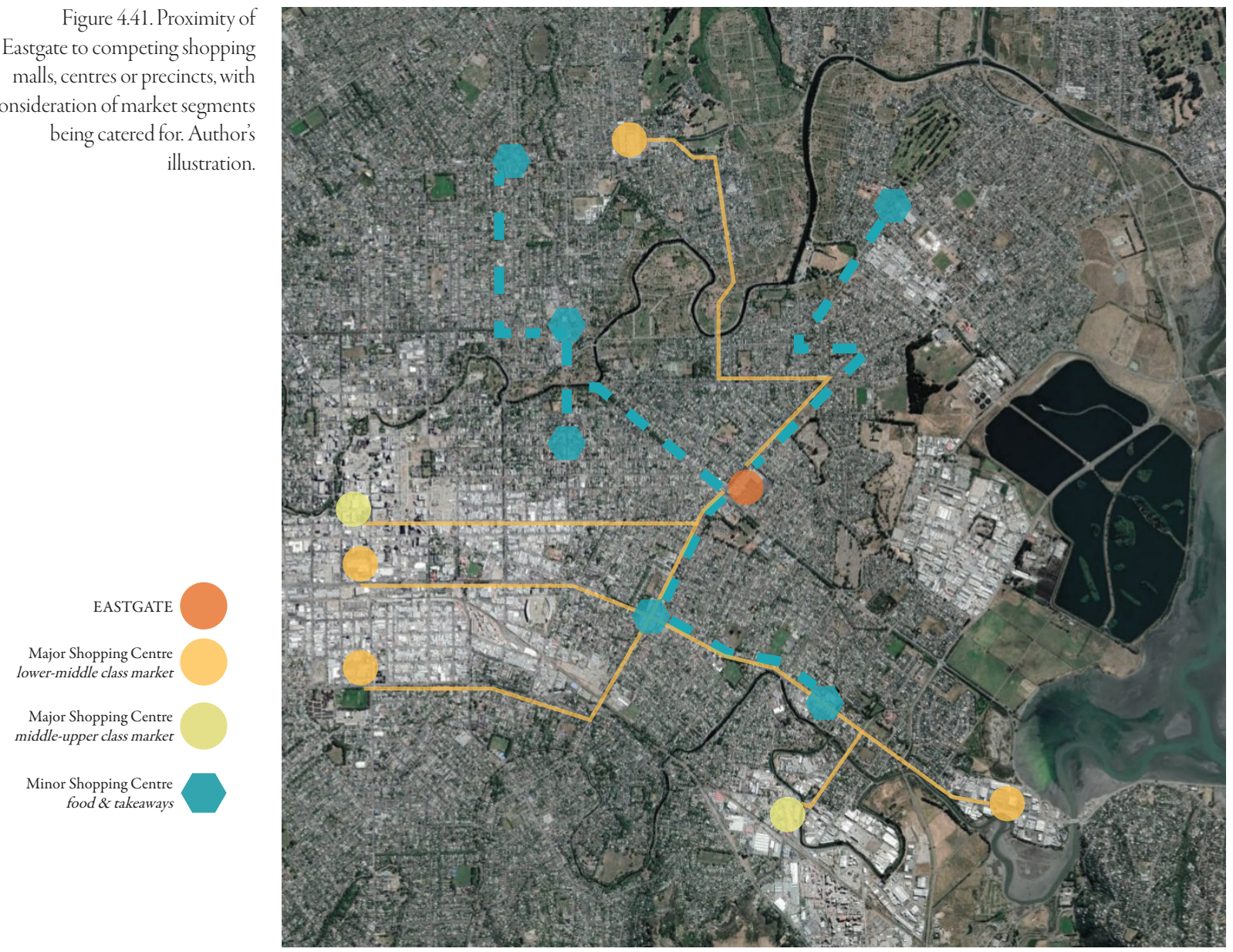

BUSINESS COMPETITION 
This content is unavailable.

Please consult the figure list for further details.

\section{SOUTH CITY}

MAJOR SHOPPING

CENTRE

lower-middle class market

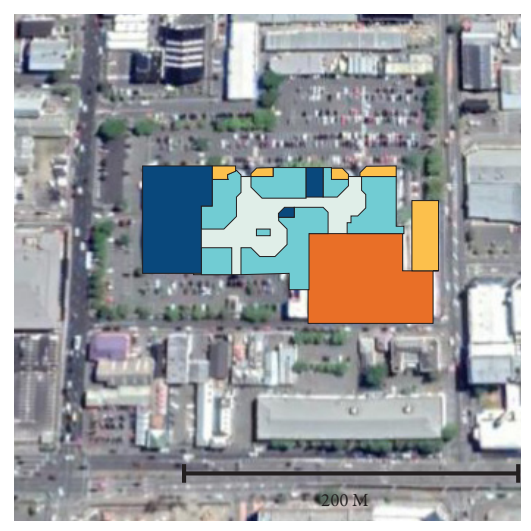

Figure 4.43. South City Mall in context.

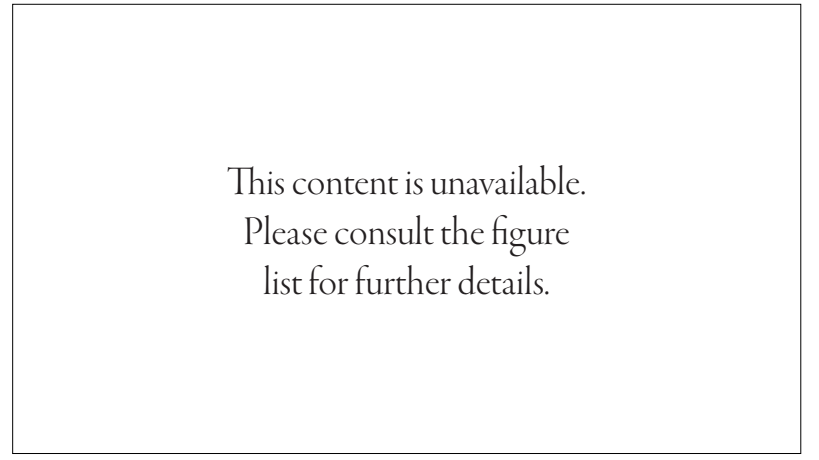

\section{THE PALMS}

MAJOR SHOPPING

CENTRE

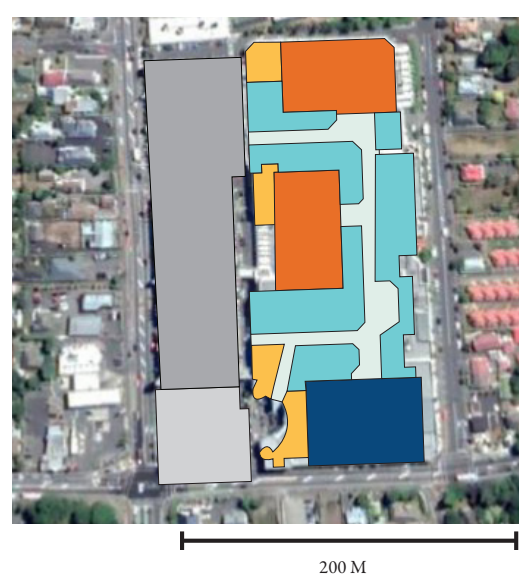

Figure 4.45. The Palms.

Source: McDonald, Liz (2020).

Figure 4.46. The Palms in context.
Figure 4.44. South City Mall floor plan.

This content is unavailable.

Please consult the figure

list for further details.

Note. Adapted from Directory, by South City Shopping Centre

(https://southcity.co.nz/wp-content/uploads/2020/03/South-

City-Map.pdf). Copyright 2020 by South City Shopping Centre.

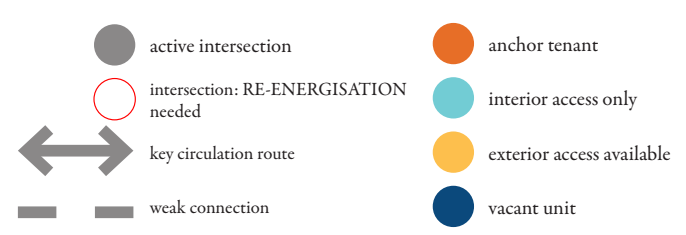

open carpark covered multi-storey
carpark

Figure 4.47. The Palms floor plan.

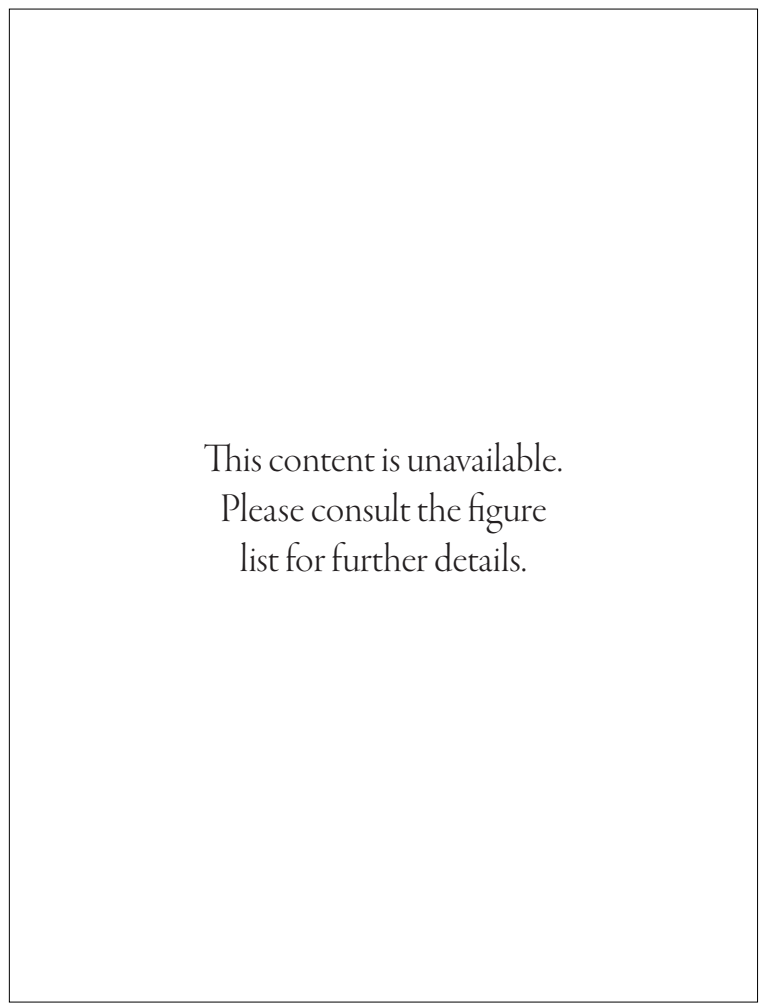

Note. Adapted from Centre Map, by AMP Capital Shopping

Centres (https:// canterbury.royalcommission.govt.nz/documents-bykey/2011-09-2348). Copyright by AMP Capital Shopping Centres. 
This content is unavailable.

Please consult the figure list for further details.

MAJOR SHOPPING

middle-upper class market

Figure 4.48. The Tannery

Source: Fulton, Tim (2015)

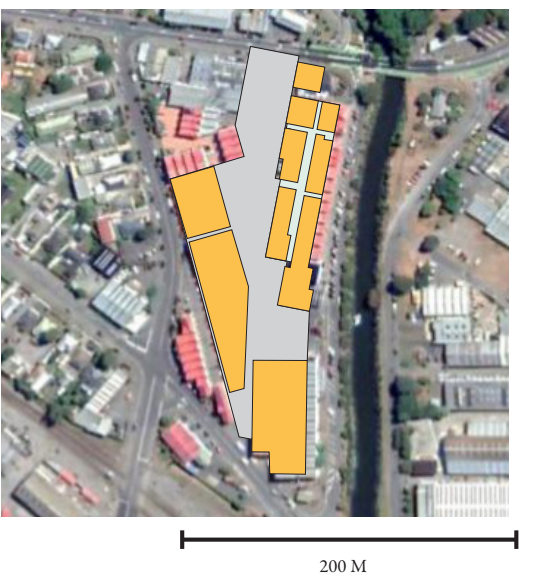

Figure 4.49. The Tannery in context.
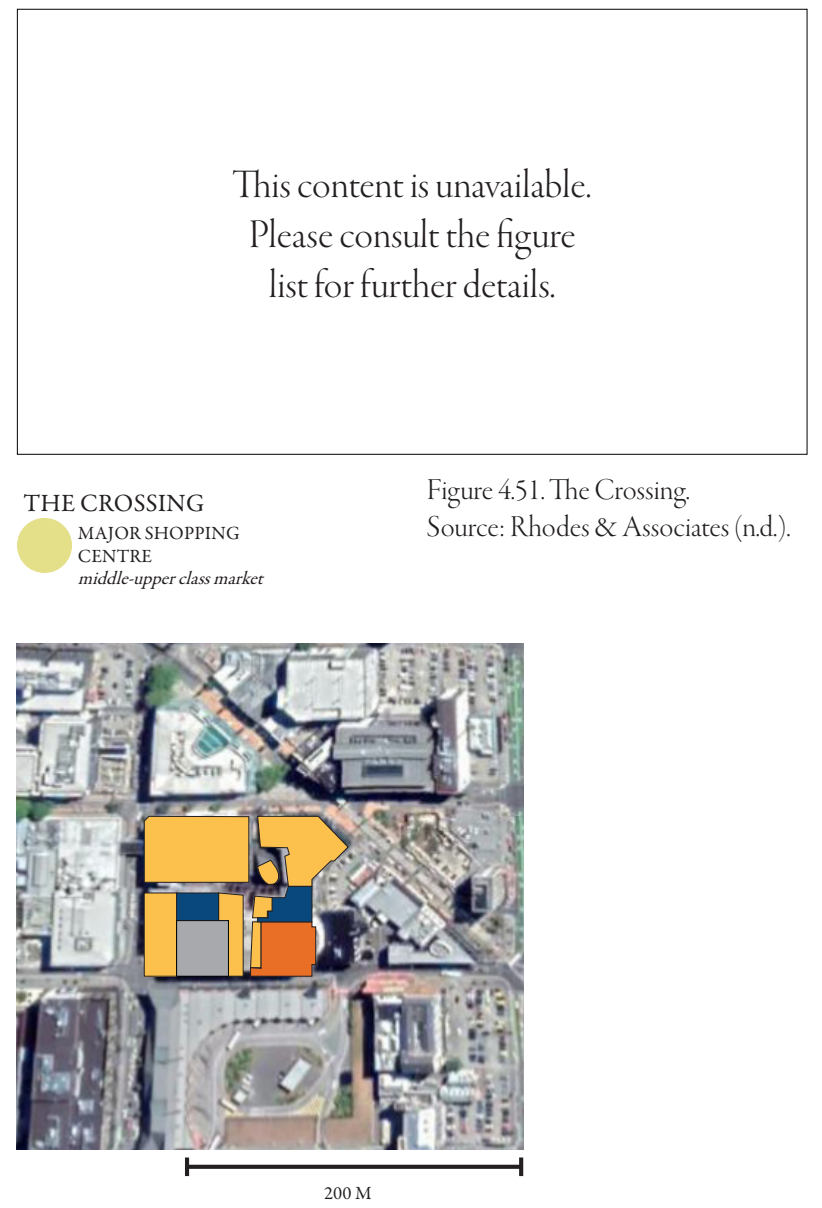

Figure 4.52. The Crossing in context.

This content is unavailable.

Please consult the figure list for further details.
Figure 4.50. The Tannery floor plan.

Note. Adapted from Store Directory \& Parking Information, by The Tannery (https://thetannery.co.nz/contact/parking-information/). Copyright by The Tannery.
This content is unavailable. Please consult the figure list for further details.
Figure 4.53. The Crossing floor plan.

Note. Adapted from Store Directory, by The Crossing (https:// thecrossing.co.nz/directory/). Copyright by The Crossing. 


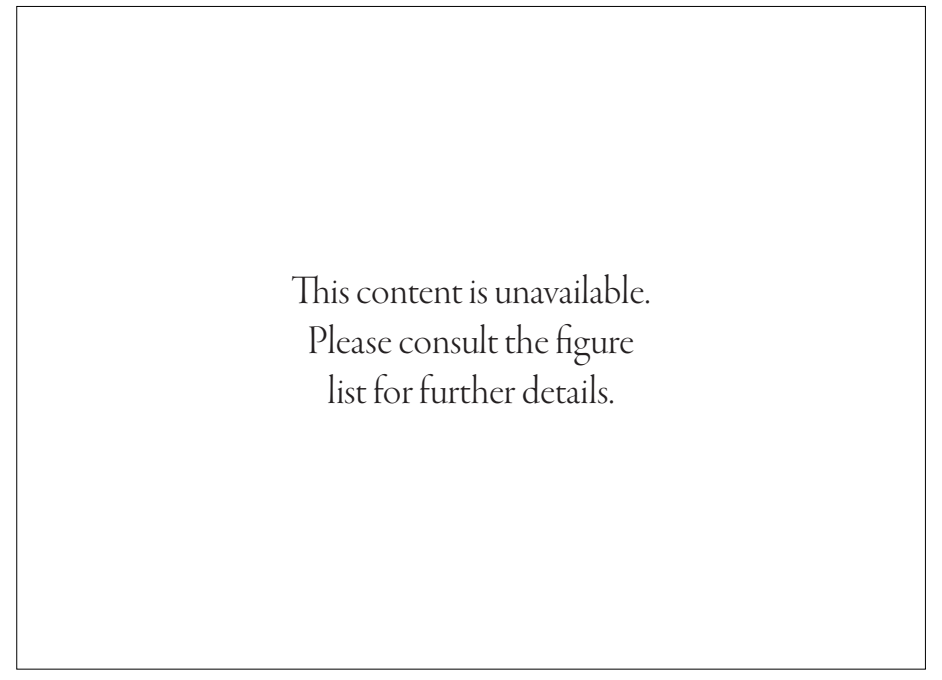

Figure 4.54. The Hub. Source: MRM (n.d.).
THE HUB

MAJOR

lower-middle class market

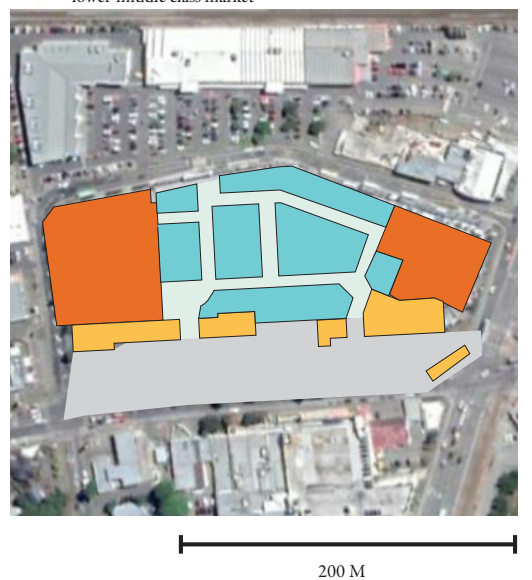

Figure 4.55. The Hub in context.
Figure 4.56. The Hub Floor Plan.

Note. Adapted from The Hub Hornby, by The Hub Hornby (hetps://thehubhornby.co.nz/ location/). Copyright by The Hub Hornby.

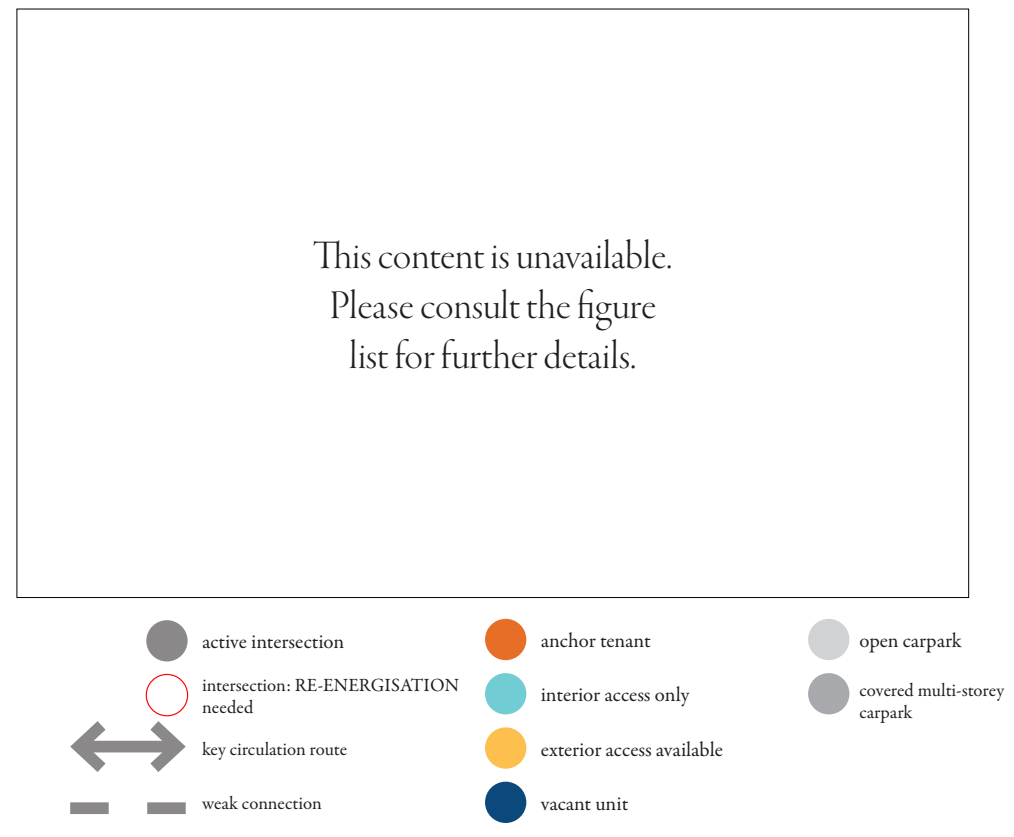


This content is unavailable.

Please consult the figure

list for further details.

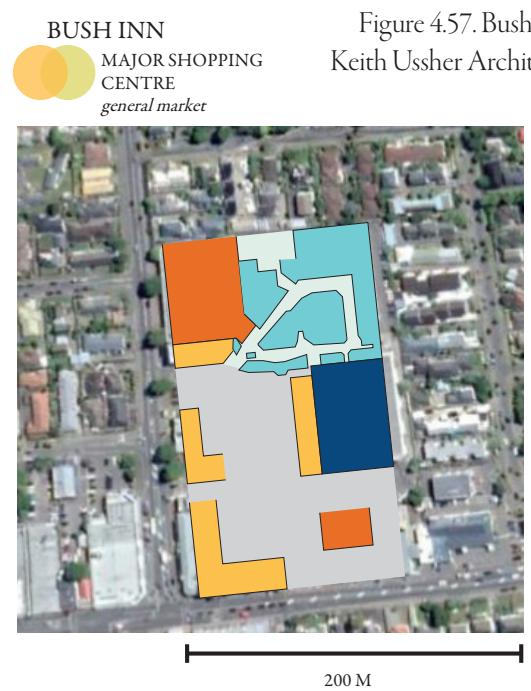

Figure 4.58. Bush Inn in context.

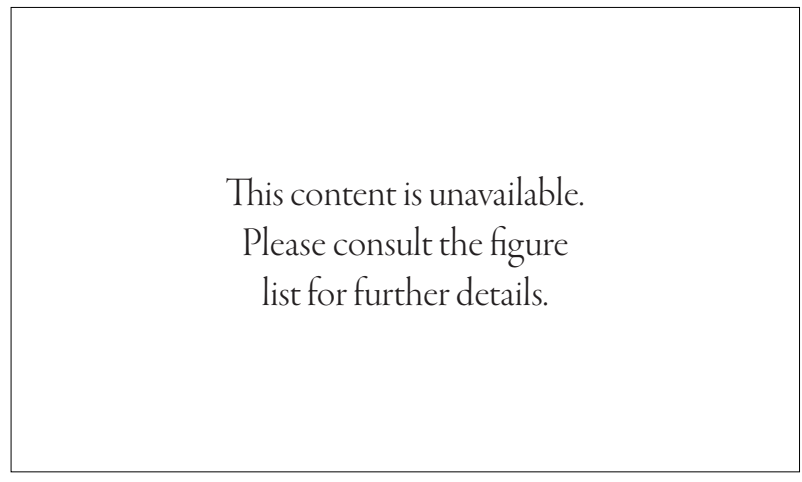

\section{DRESS MART}

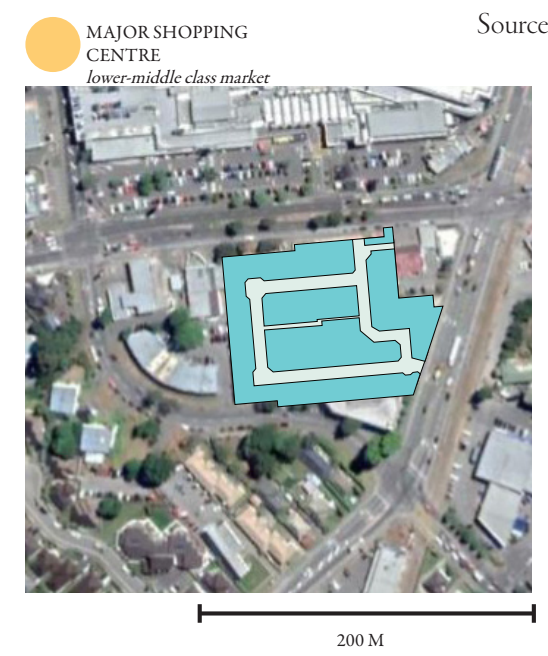

Figure 4.61. Dress Mart in context.
Figure 4.60. Dress Mart urce: Steeman, Marta (2019).

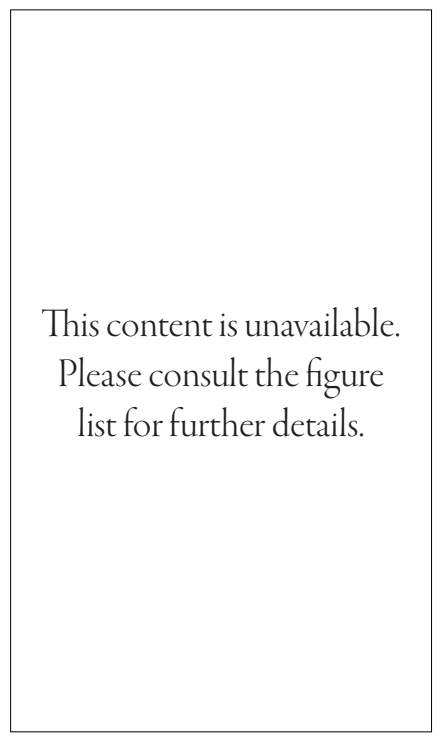

Figure 4.59. Bush Inn floor plan.

Note. Adapted from Bush Inn Centre, by Bush Inn Centre (https:/ bushinncentre.conz/?da_image=24). Copyright by Bush Inn Centre.

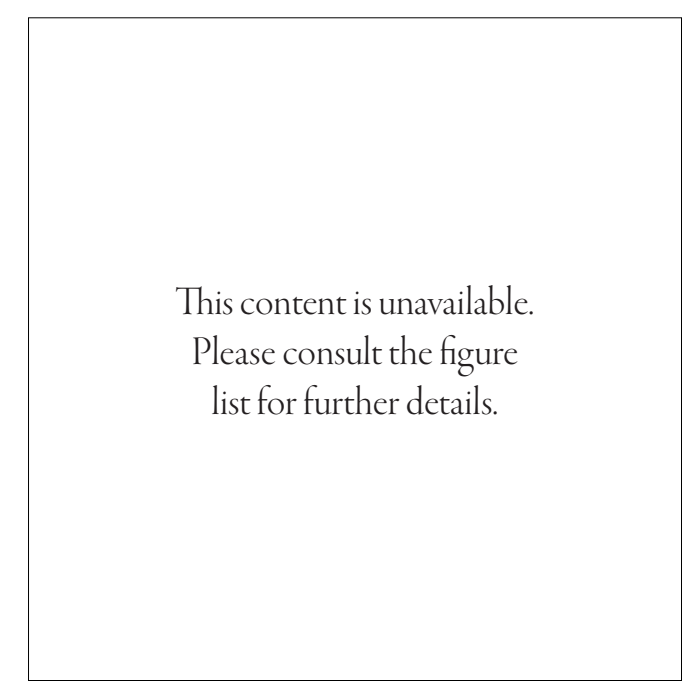

Figure 4.62. Dress Mart floor plan.

Note. Adapted from Stores - Dress Smart, by DressSmart (https://www. dress-smart.co.nz/stores). Copyright by DressSmart. 
This content is unavailable.

Please consult the figure

list for further details.

WESTFIELD RICCARTON (G)

MAJOR SHOPPING

CENTRE
general market
Figure 4.63.Westfield Riccarton. Source: Scentre Group (n.d.).

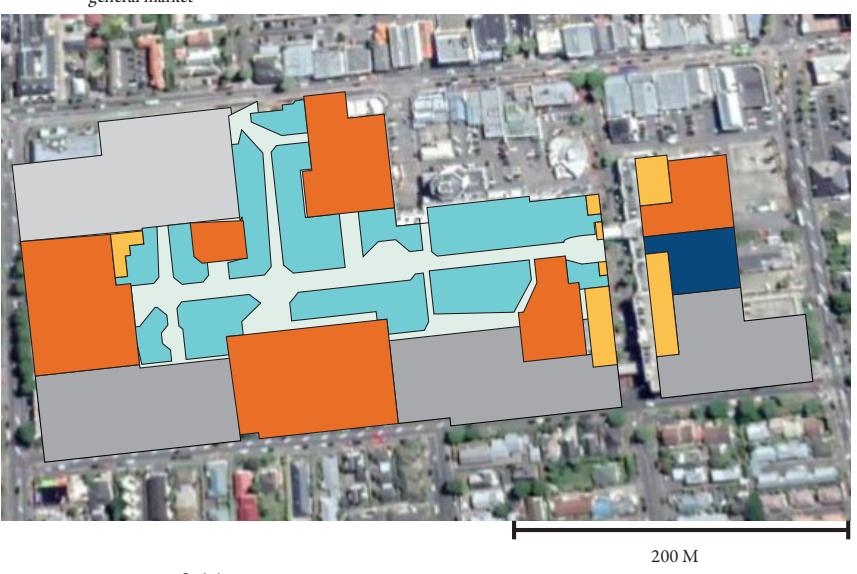

Figure 4.64. Westfield Riccarton in

$200 \mathrm{~N}$

context.

This content is unavailable.

Please consult the figure

list for further details.

Figure 4.65. Westfield Riccarton floor plan.

Note. Adapted from Westfield Riccarton Centre Map | Map of Stores in Centre, by Westfield (https://www.westfield.co.nz/

active intersection

intersection: RE-ENERGISATION needed

key circulation route

weak connection

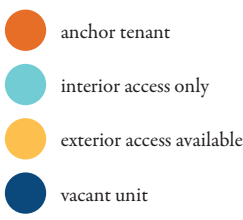

open carpark

covered multi-storey riccarton/centre-map). Copyright by Westfield. 
This content is unavailable.

Please consult the figure

list for further details.

BARRINGTON

MAJOR SHOPPING

CENTRE

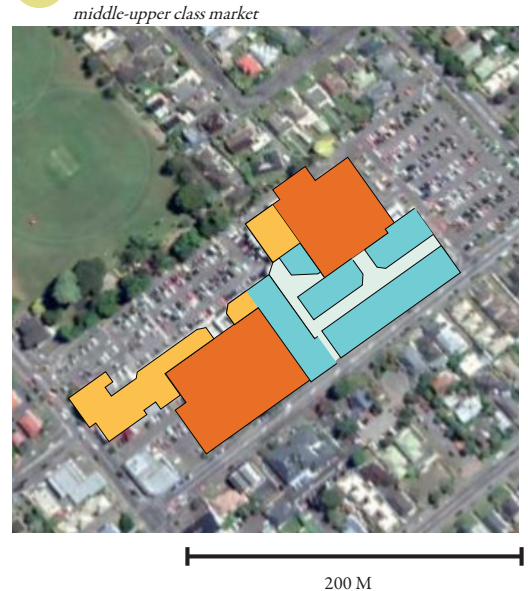

Figure 4.67. Barrington Mall in context.
Figure 4.66. Barrington Mall.

Source: Tinline Property (n.d.).
This content is unavailable.

Please consult the figure

list for further details.
Figure 4.68. Barrington Mall floor plan. Note. Adapted from About Barrington, by Tinline Property (https://www.tinline. co.nz/our-places/barrington/the-place/). Copyright by Tinline Property. 


\section{Christchurch Malls}

These existing shopping malls lack in urban design principles and possess bland architecture defined by long, relentless corridors and windowless walls. Consequently, these malls have created a "fantasy urbanism", devoid of weather, traffic and often featuring people from undesired social classes. They share excessive sameness in architecture (exterior and interior) and appear to be solely for satisfying utilitarian needs. Consequently, their architectural forms seem to just follow function and are essentially rendered as isolated objects. For these malls to better contribute to the prosperity and social and economic growth of surrounding contexts, further integration is needed to the communities and people.

\section{Potential Strategies}

Malls could...

- $\quad$ reconnect to natural features- creeks, swamps

- $\quad$ Enhance connections to urban contexts- links to streets, public facilities, green spaces, parks; i.e. sports retailers could be oriented towards sporting facilities, bring along schools into mall?

- Introduce new functions/amenities to contrast surrounding urban context? I.e. in an industrial area, malls could bring large swathes of greenery, surrounded by cafes? Outdoor cinemas for areas with considerable vehicular traffic?

- $\quad$ Explore structured/underground parking to maximise space for advertising and selling 


\section{Potential Strategies}

Eastgate can explore...

- $\quad$ Defining and intensifying its edges, includes street edge

- Framing linear routes with diversion and intrigue- in this way the mall can attempt to transcend the monotony of its physical structure (Jewell, 2016, p. 23)

- $\quad$ Dynamic grid- not just squares; overlaying different grids

- Introduce natural features- i.e. green spaces or paths to break up and energise grid

- utilisation of natural elements to help define the built form

- $\quad$ observe natural elements from various perspectives and points within mall; moving through the greenery

- Transitional thresholds- indoor and outdoor environments; variation

- $\quad$ Experiencing natural elements- indoors and outdoors

- Tie in the selling of products, with non-retail functions for social and cultural enrichment and relaxation. This is to prevent it from being a cul-de-sac rather than thoroughfare in the urban fabric. 

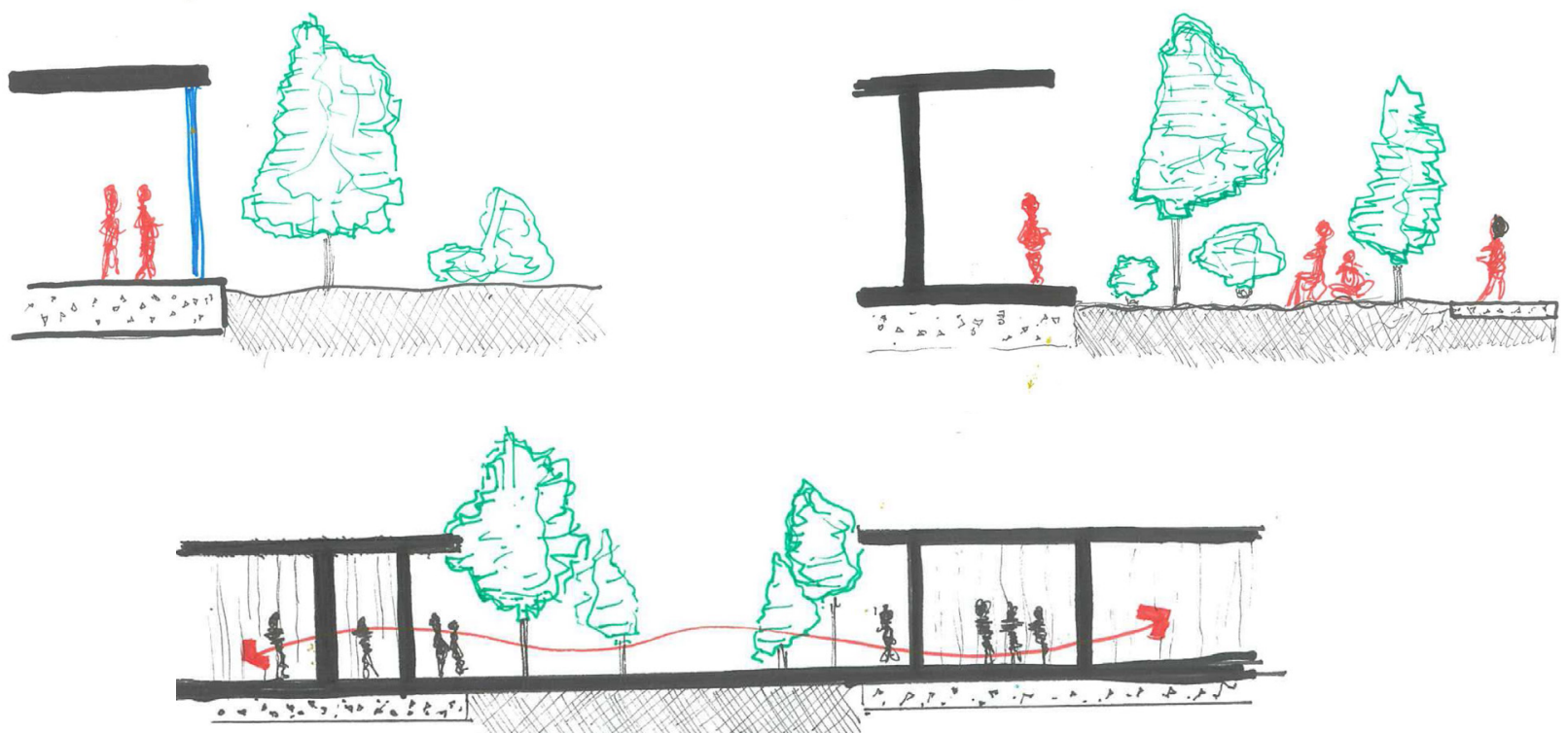

TRANSTIONAL THRESHOLS
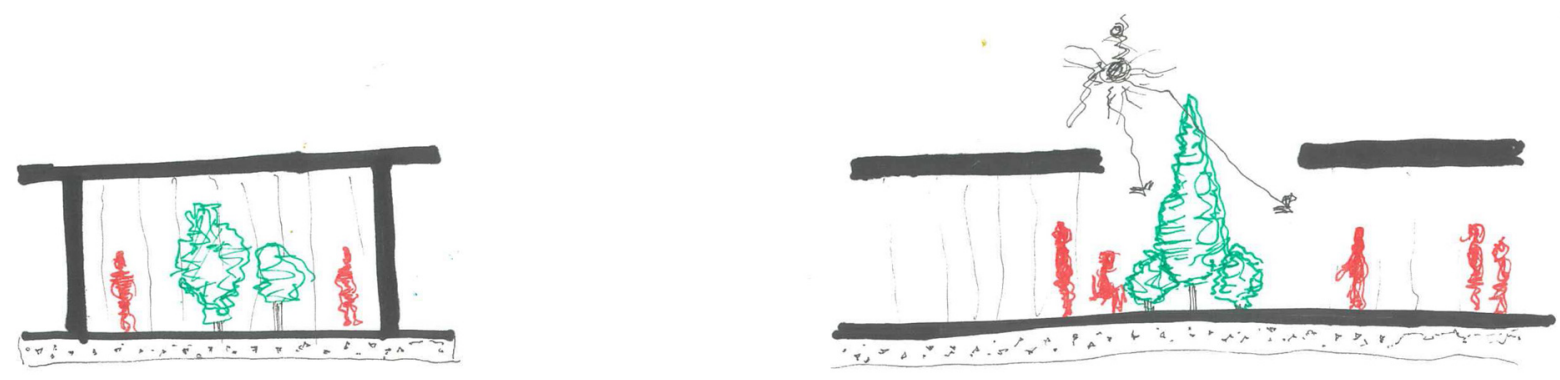

Figure 4.69. Thresholds of green spaces. Author's illustration 


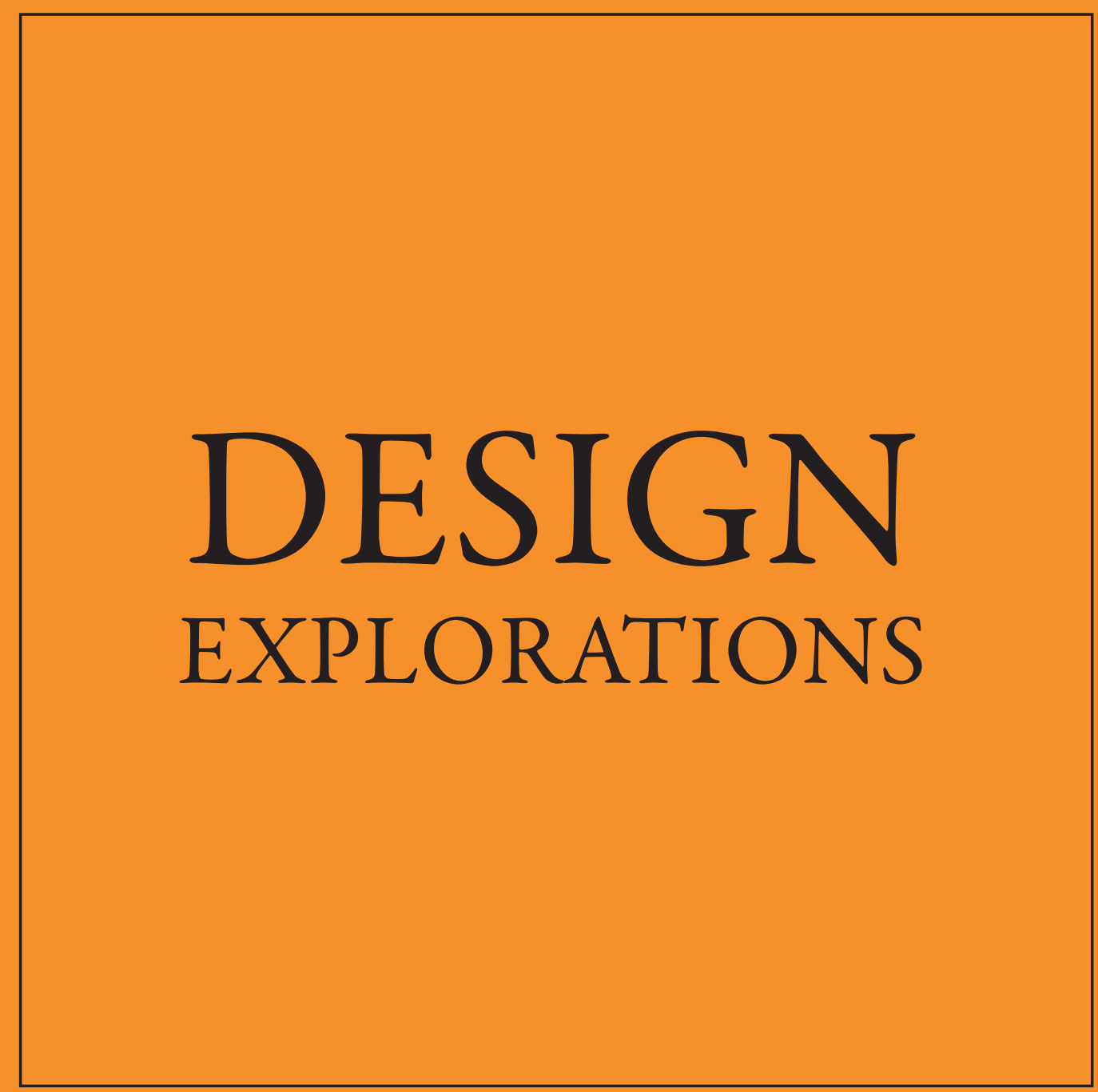

Strategies

Phase One-

Phase Two-

Gesture 


\section{Strategies}

Strategies to help fulfil or meet design criteria

\section{Fluidity}

Promote and enhance the interrelationship between the different retail sites rather than polarising them further (Kärrholm et al., 2014, p. 128). This can be achieved by finding a balance in the variety of retail and non-retail activities (but ensuring retail is strong enough not to decline and disappear) (Kärrholm et al., 2014, p. 128). For Eastgate to persist and counter the current trend of retail mono-functionality and homogenisation it should not look into stabilising itself. Instead, it should look into increasing fluidity in shopping mall spaces and embrace concepts from fluid retail (Kärrholm et al., 2014, p. 128).

This can be achieved by looking to:

- allow for new associations and hybrids - hybridisation of retail planning and areas by embracing new relations on different scales, and associations to spaces that cross the scales and types

- introduce elements that are not usually found at a mall

- $\quad$ include non-retail spaces

\section{Ramifications:}

- $\quad$ help make spaces flexible and challenge its identity without necessarily breaking it

- $\quad$ widen the connotations of 'mall' as a concept

- and/or be part of the production of a new building type-redesigning Eastgate to not just a "mall". 


\section{Compatibility}

Clustering or grouping compatible stores together to allow two or more businesses to interchange customers and increase convenience for consumers in their decision-making (Reimers \& Clulow, 2004, p. 209). This would save them time and effort in gathering information and evaluating products

Additional:

- $\quad$ Separate retailers serving different market segments

- Locate retailers according to the peculiarities of consumer shopping behaviour

(Reimers \& Clulow, 2004, p. 210)

- Locate retailers in a way that would maximise sales for the centre as a whole

\section{Shelter}

Find a balance between exposing people to interior and exterior environments. People appreciate being sheltered from the elements in a controlled environment, but also desire to see a depiction of external environments. For instance, people still do not want to walk around the mall in the rain.

Continue providing:

- warmth in the cold weather conditions and coolness in warm weather

- $\quad$ shelter throughout the year from the elements 


\section{Increasing Eastgate's liveliness and attractiveness}

Today consumers are making fewer trips to the mall because they are time-pressed (Nicholls et al., 2002, p. 149). However, if Eastgate creates an impression of being exciting, pleasant and worth one's time, this issue can be counteracted.

It is imperative to increase the appeal of Eastgate's spaces as comfortable, entertaining, diverse and convenient (Rajagopal, 2009, p. 100). Studies suggest these characteristics lead to the formation of people crowding (Mokgabudi, 2012, p. 12). In low-income communities like Linwood/Eastgate, crowding is positively perceived and enables retailers to present a rich environment with large quantities of products and people (Mokgabudi, 2012, p. 12).

External motivators including visual stimuli, layout and ambience should be enhanced and thoroughly considered in the rejuvenated thesis design. These are essential to increasing Eastgate's liveliness and attractiveness and are vital to evoking positive emotions towards certain products-potentially leading to good evaluations of them and sudden purchases (Lukito \& Tulipa, 2016, p. 8072). These would boost impulse purchases as well as positively influence hedonic shoppers to consume (Zhuang et al., 2006, p. 34). 


\section{Green Spaces}

It is important to use green space as a tool to further increase Eastgate's liveliness and attractiveness. It has been widely suggested that people like to be outdoors and the design outcome must not just be a long covered pedestrian street (M. J. Taylor, 2002, p. 50). With shopping malls involving many large swathes of indoor spaces, green spaces can increase liveliness and attractiveness by:

- $\quad$ creating fascination

- $\quad$ creating a sense of being away from everyday locales

- $\quad$ fostering consumer experiences, making them more memorable to incorporate a greater sense of place

- $\quad$ providing an escape from daily life, stress and boredom while simultaneously enhancing opportunities to socialise (Rosenbaum et al., 2016, p. 158).

\section{Ramifications:}

- $\quad$ response against creating increasingly homogenous urban landscapes (Miles, 2010, p. 93).

- may further increase customer satisfaction and contribute to sales and better performance for Eastgate

- $\quad$ can manipulate pedestrian flow while simultaneously ensuring non-retail functions do not disrupt it (Reimers \& Clulow, 2004, p. 211)

- In potential events of anchor/large tenants leaving and consequent vacancies, the inclusion of green spaces can equip the mall with the ability to remain resilient and $s$ till continue to attract people. 


\section{Balance, Convenience, Efficiency}

The design process in this thesis must show an awareness that sheer size and scale can be overwhelming and make it difficult for people to find particular stores and or products. This may mean fewer sales and increase the likelihood of customers leaving if unable to locate a desired product or products.

Food \& Beverage/Restaurants:

- $\quad$ place in intermediate areas off Eastgate- provide focal points for socialisation and breaks for shopper convenience; and allow these tenants to remain open outside Eastgate's trading hours.

- Cafes- strategically place in positions to intercept shoppers and perform equivalent role of the proposed food court, creating a mood congenial to purchasing (Reimers \& Clulow, 2004, p. 213).

- $\quad$ Restaurants- incompatible with fashion, therefore best suited to the periphery (Reimers \& Clulow, 2004, p. 213)

Fashion Retailers:

- $\quad$ place at core location since they serve as key/major attractors;

- concentrate these retailers in the core to facilitate store compatibility and comparisonshopping;

- maximise flow of traffic past retailers along limited access points of the mall (Reimers \& Clulow, 2004, pp. 211, 216). 
Professional, consumer and community services:

- $\quad$ place at periphery due to irregular consumption

- $\quad$ planned rather than impulsive; reliant on regular clientele

- $\quad$ dead retail frontage discourages window shopping; loose association with shopping and usually the least patronised tenants (Reimers \& Clulow, 2004, p. 213).

\section{General}

- Strategically position anchor tenants in the shopping mall, visible from key decision points

- Ensure accessibility through various modes of transportation: carparks for private vehicles, buses and integration to public transport.

- Mix shopping with living, working, and other activities at the human scale to foster a more urban experience of shopping (Rao, 2019, p. 16). 


\section{PHASE ONE- DESIGN EXPLORATIONS}

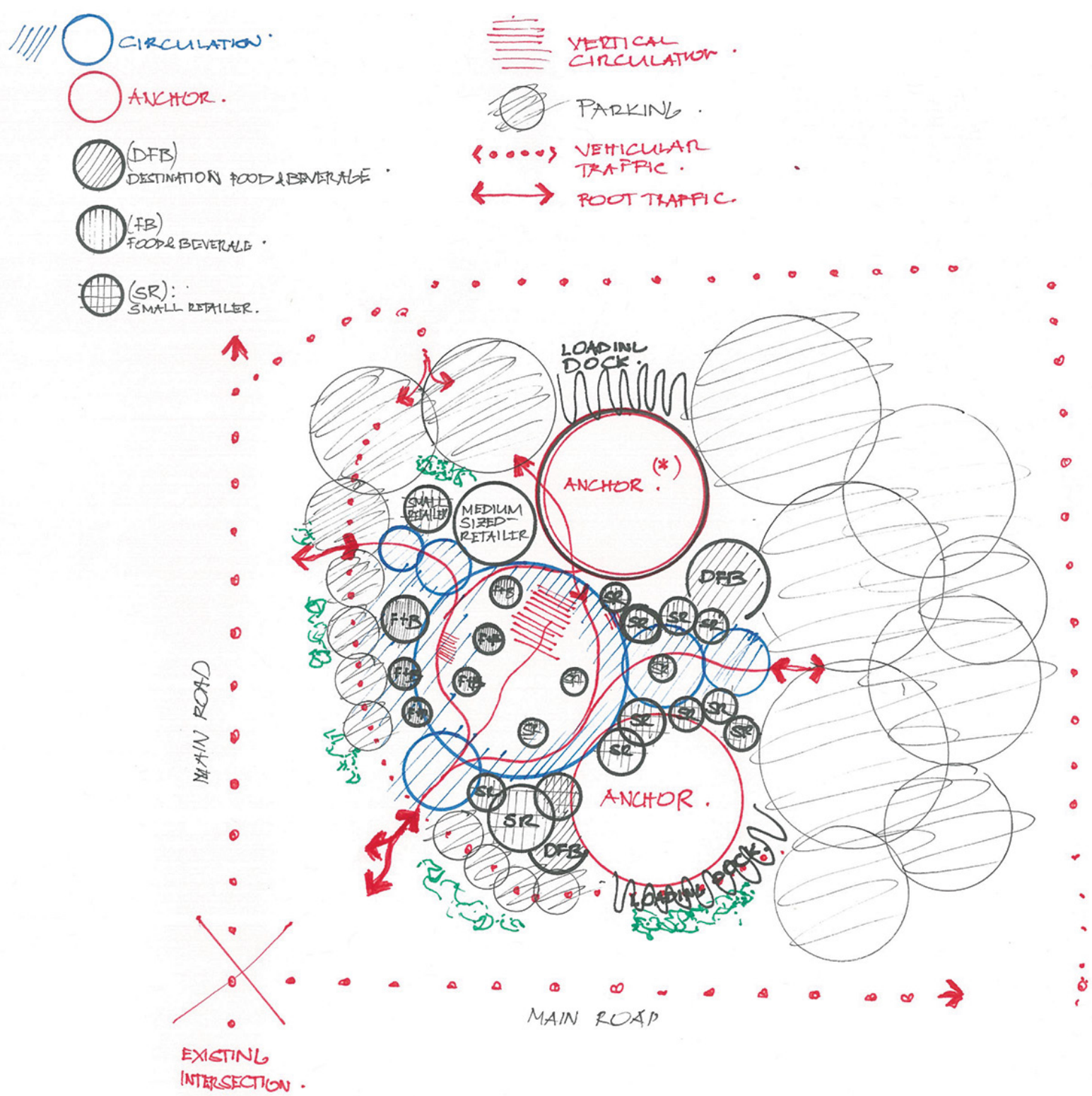

Figure 5.0. Bubble diagram attempting to reconfigure Eastgate's ground level. 


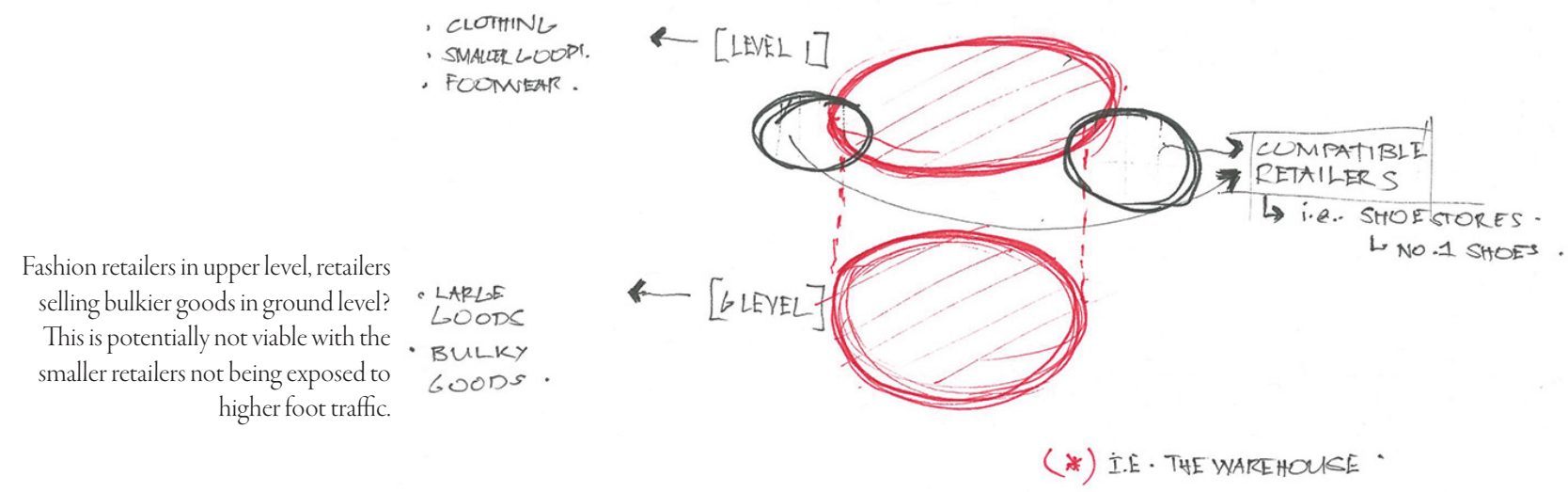

Figure 5.1. Exploring use of atrium to ensure visibility of retailers in upper level.

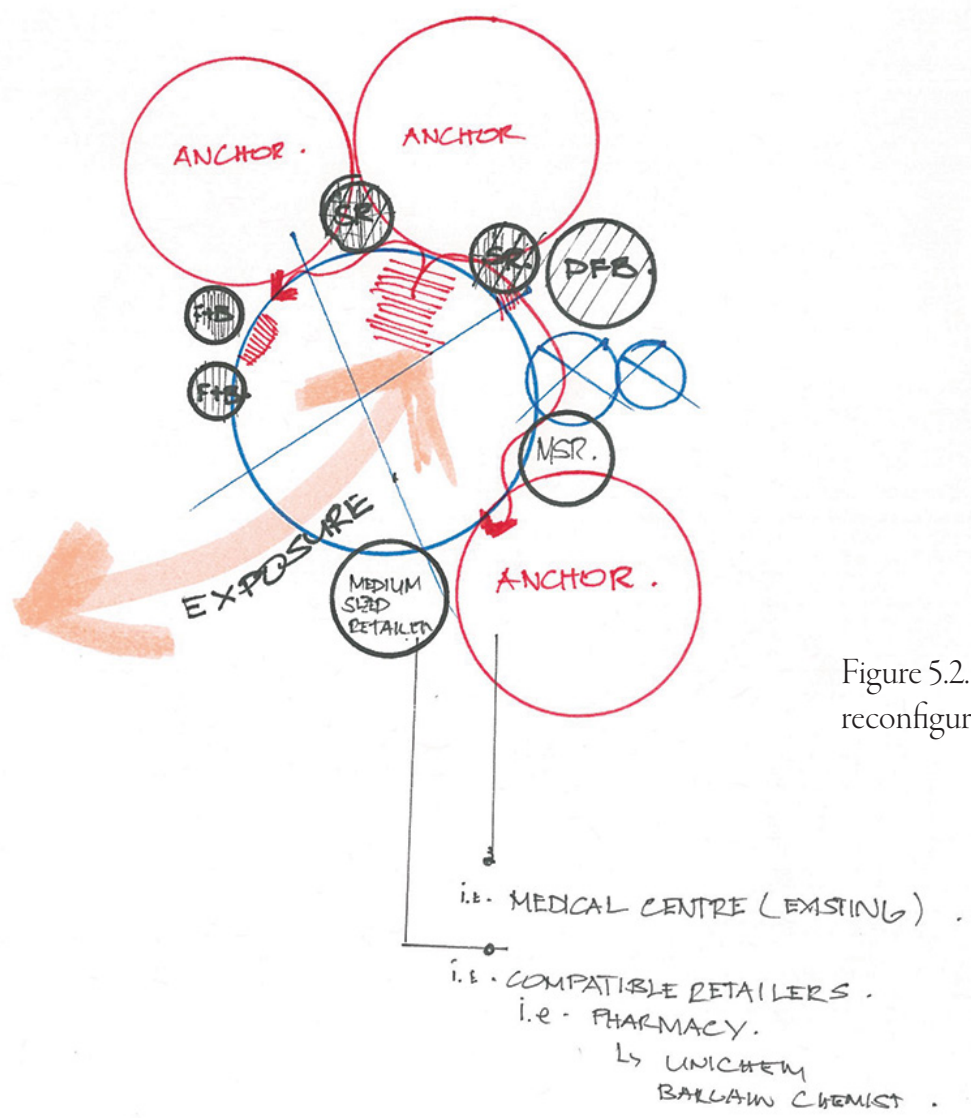

Exploring potential implementation of having two-level anchors to increase attraction to the less trafficked upper level. Destination retailers are proposed to be placed in this level, with food and beverage tenants included to add interest and amenity. 


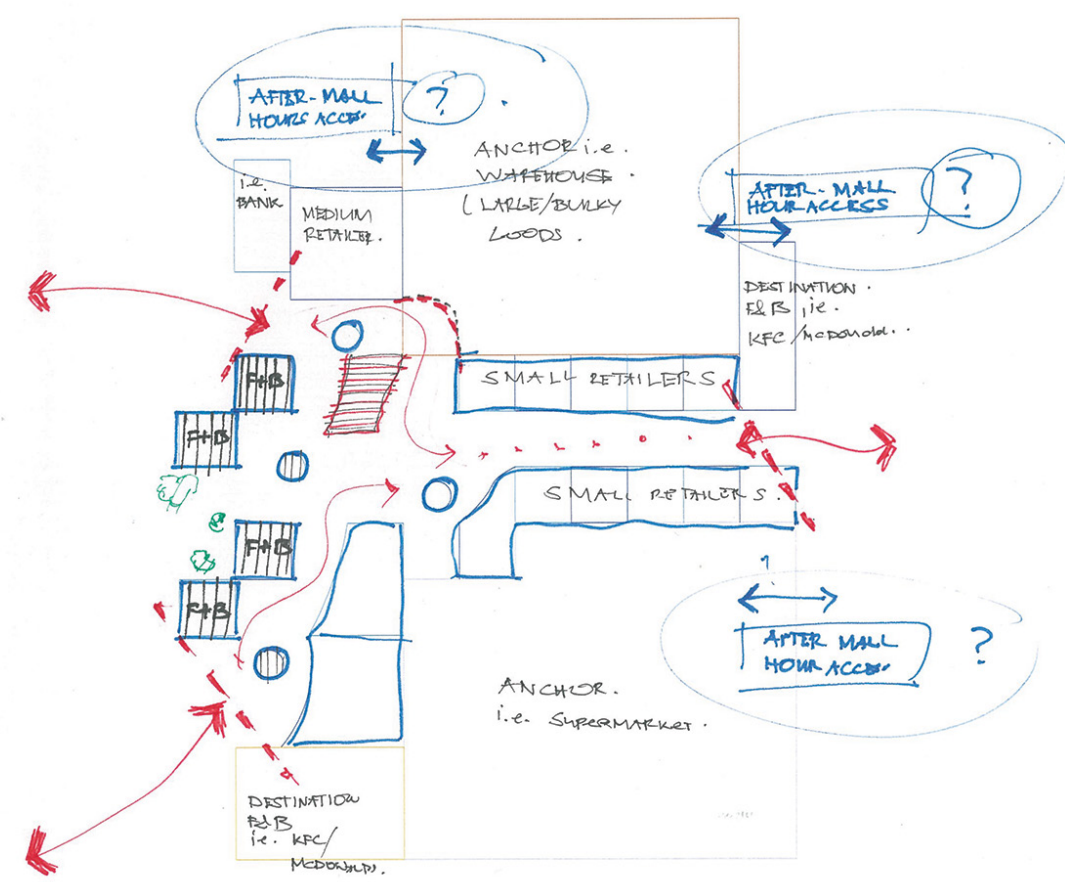

Figure 5.3. Iteration 1.1 ground level.
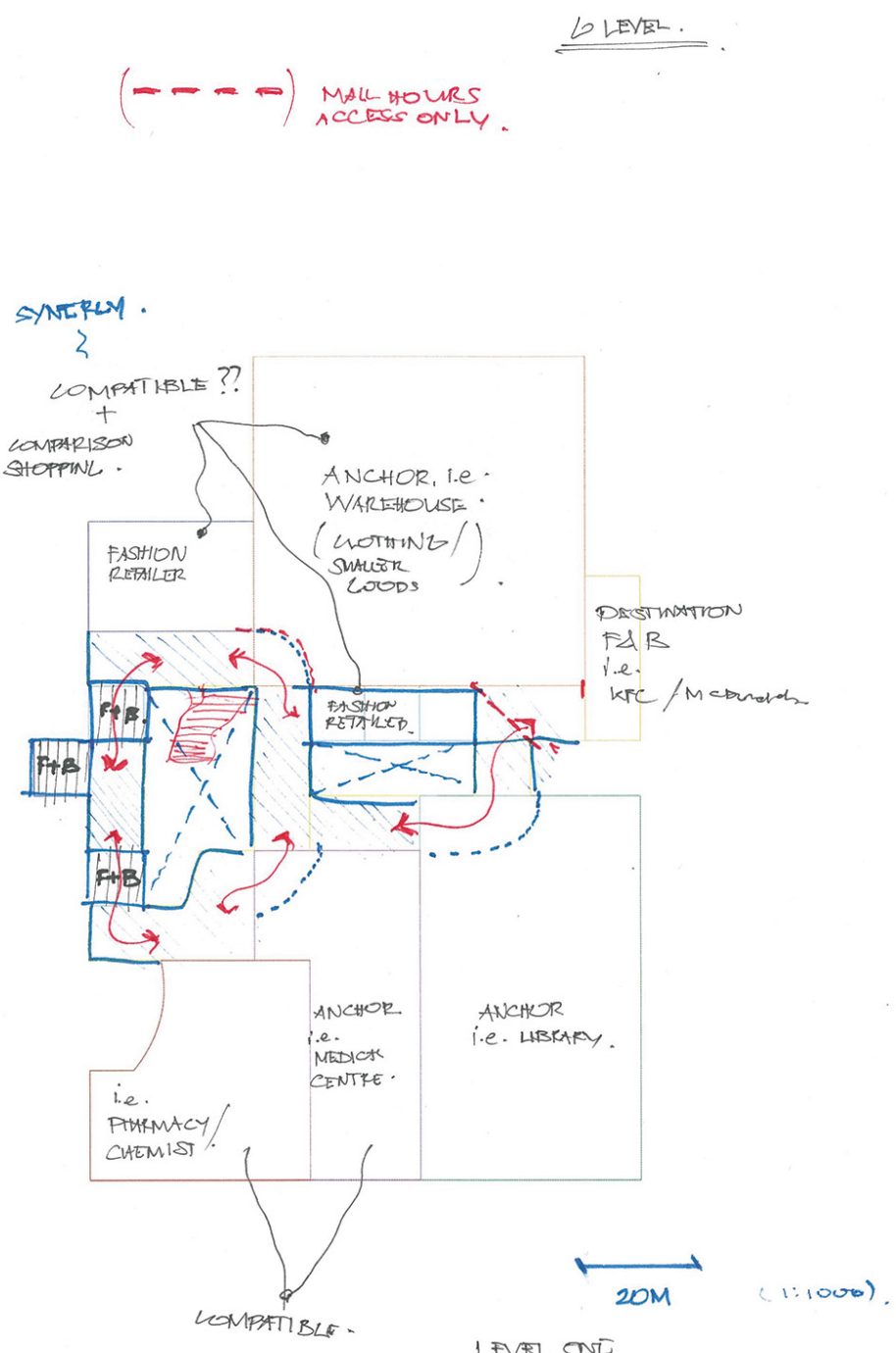

Figure 5.4. Iteration 1.1 upper level.
Small retailers placed in this level to maximise their exposure to foot traffic. Food court placed at the west end to serve as a magnet to attract people deeper into the mall, considering that parking is provided on the east end.
Idea consists of atriums to ensure visibility of retailers in upper level. Food and beverage tenants may struggle in this level with tenants being mostly destination. 


\section{Iteration 1.1}

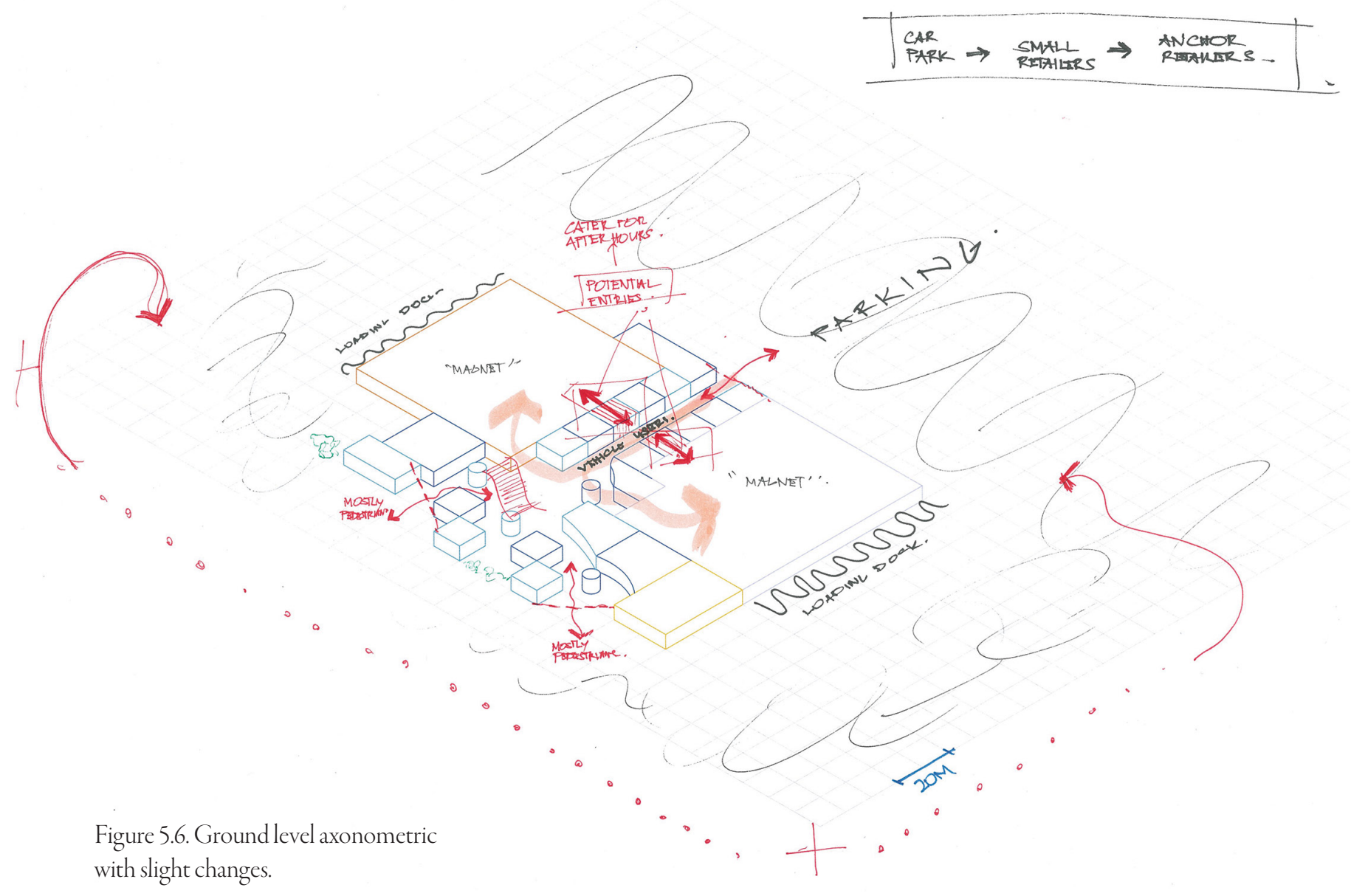


Spreading out food and beverage

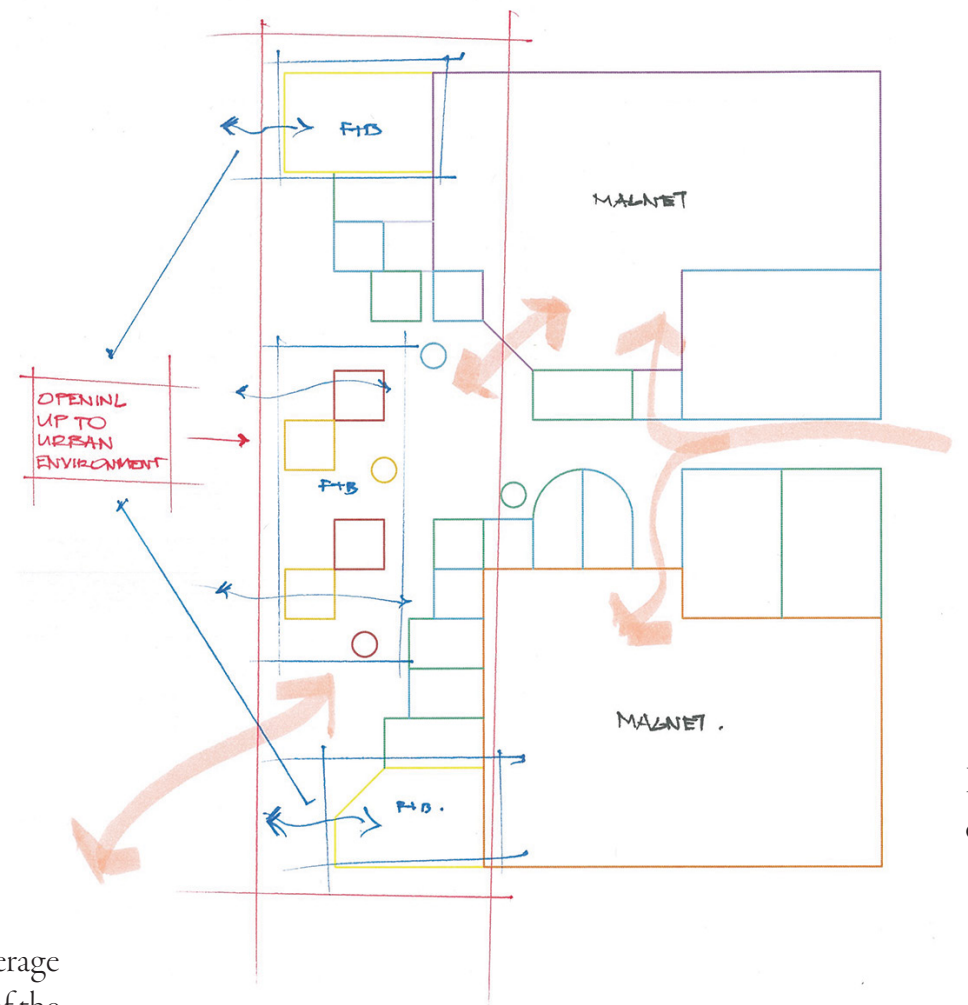

Figure 5.7. Iteration 1.2 ground level, developing earlier iteration.

tenants on the west side of the mall to open up Eastgate to the surrounding urban environment,

further increase attraction of people into that side, considering most will get to the mall via private transportation.

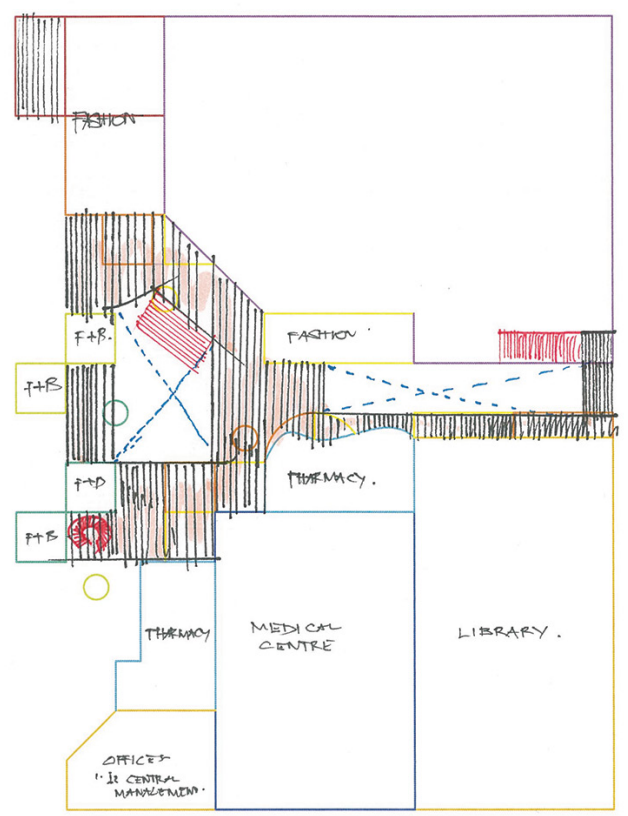

Figure 5.8. Iteration 1.2 upper level.

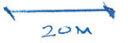

$1: 1000$ 


\section{Iteration 1.2}

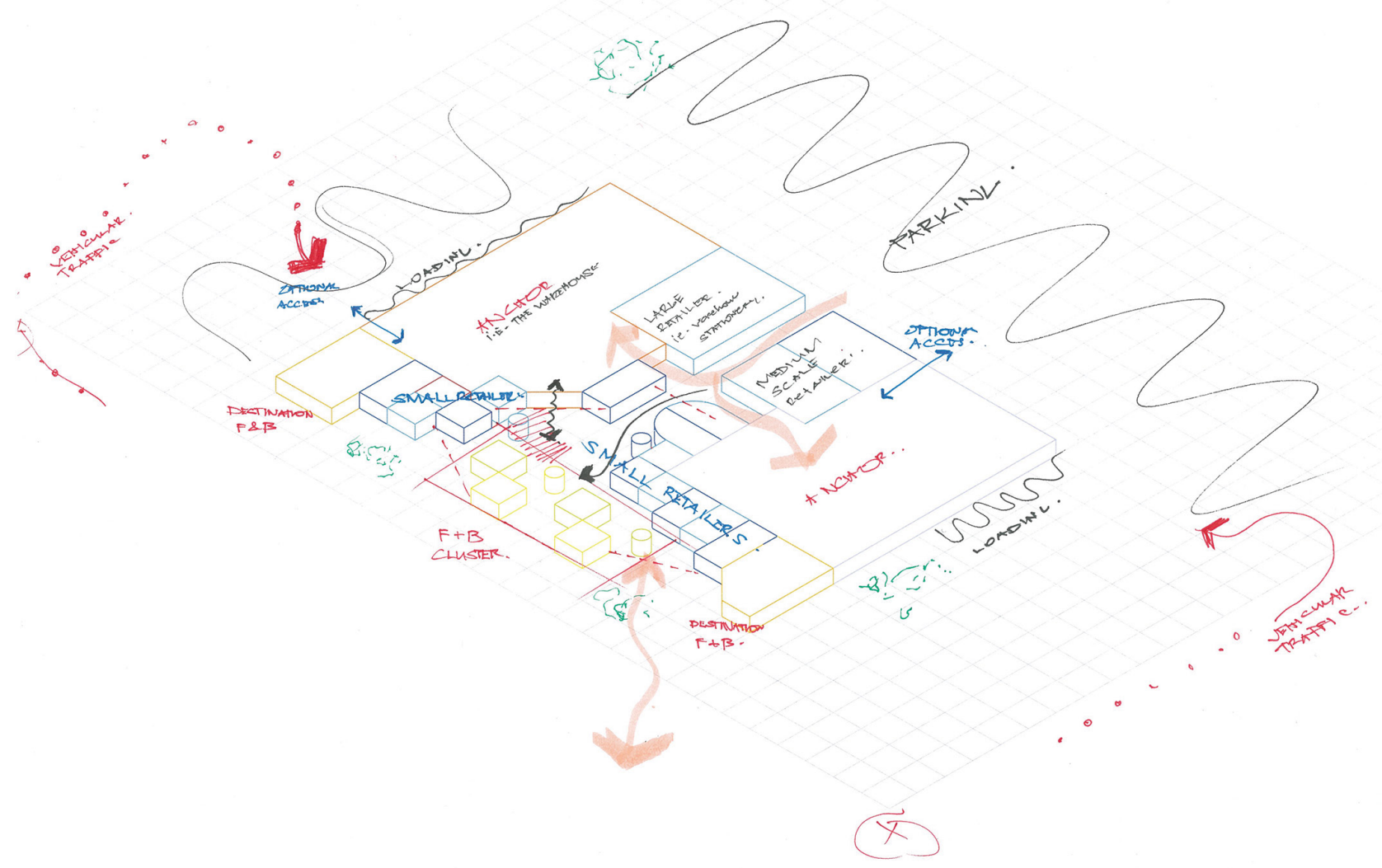

Figure 5.9. Iteration 1.2 ground level axonometric. 


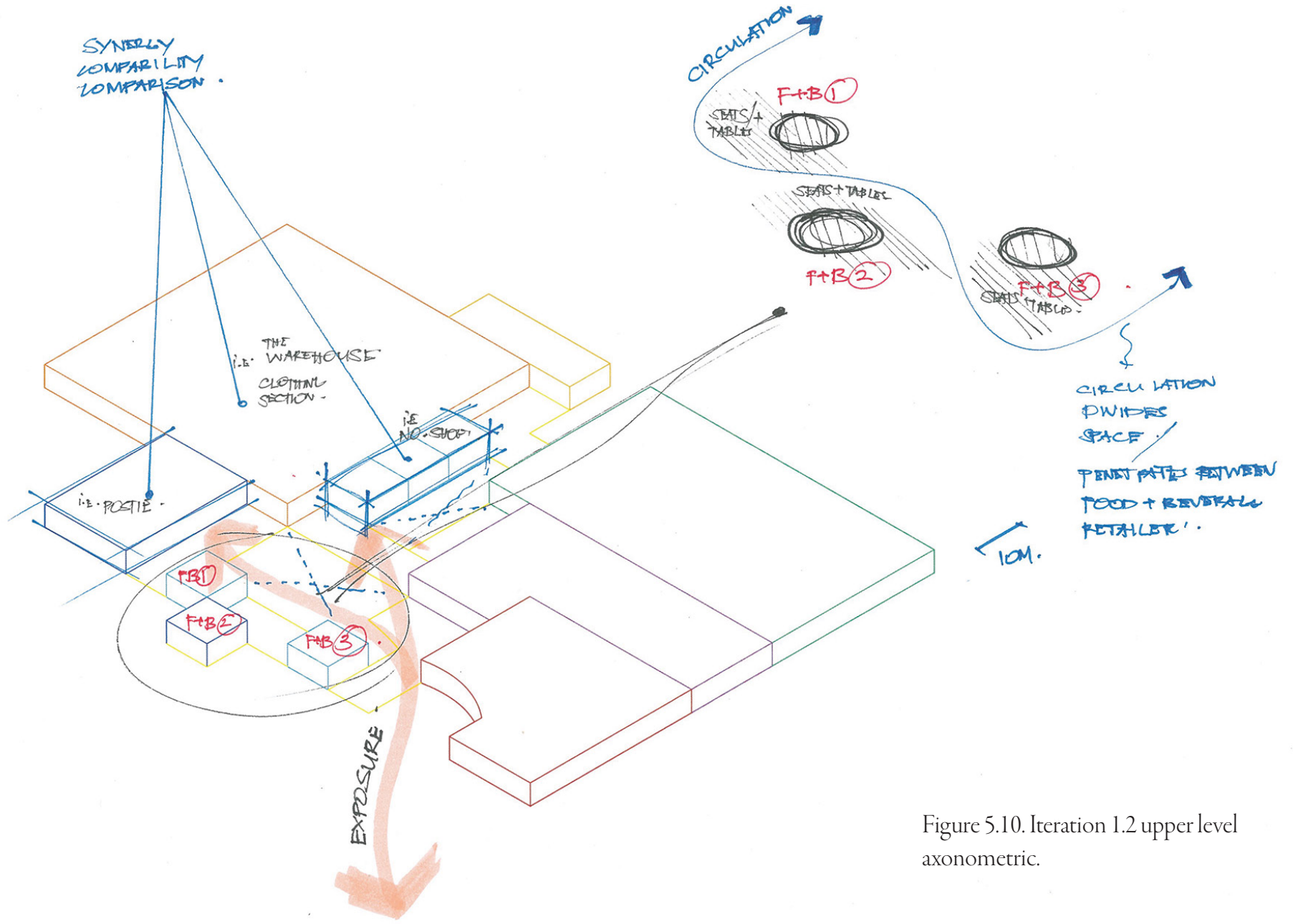




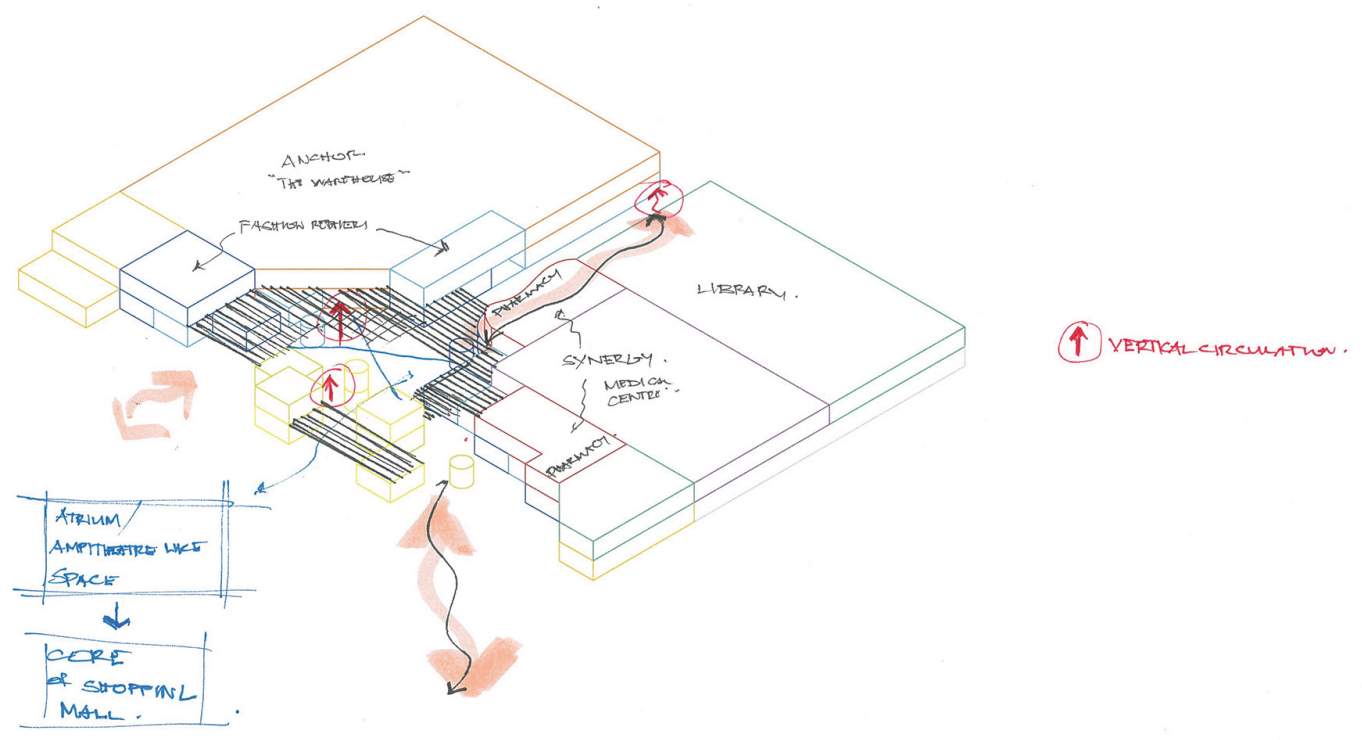

Figure 5.11. Iteration 1.2 axonometric. 


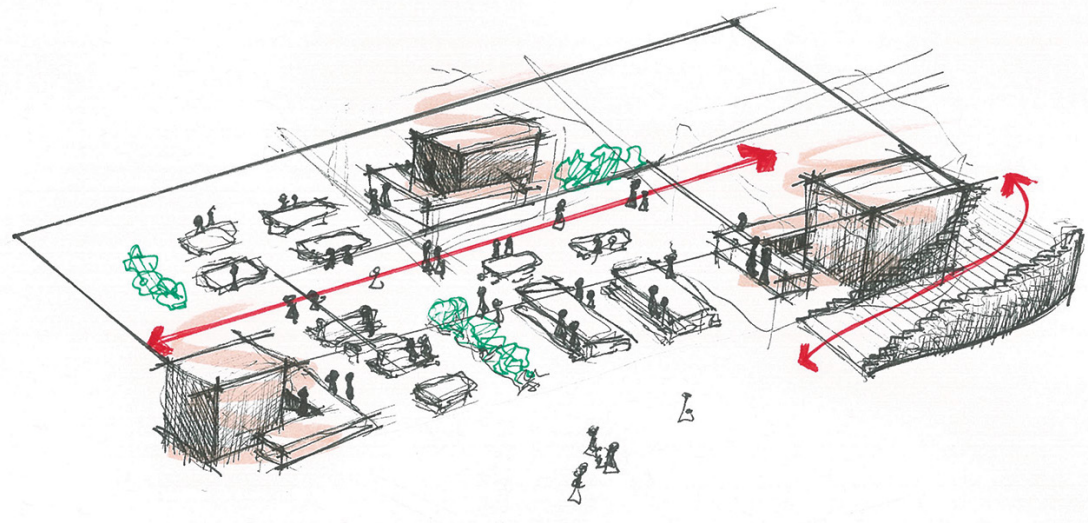

Figure 5.12. Conceptual food court.

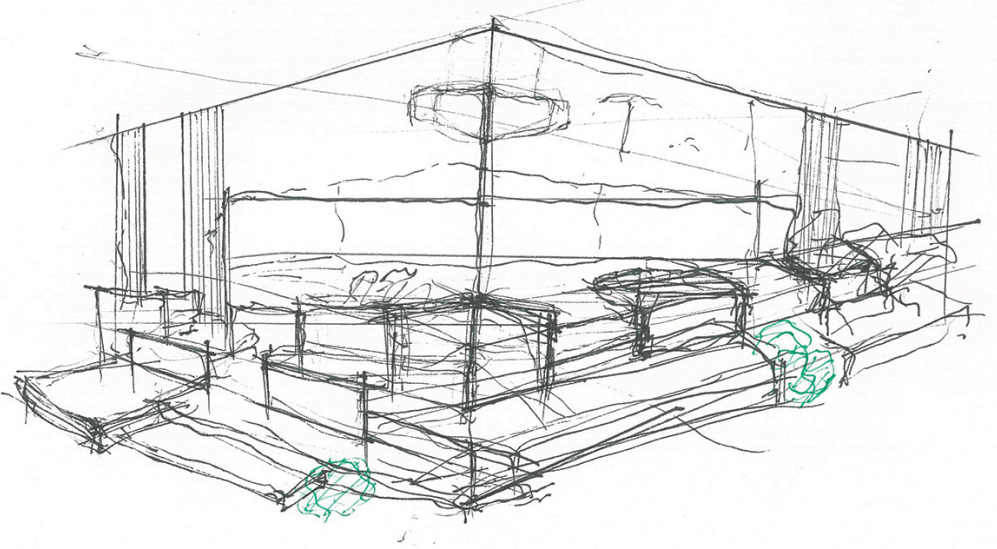

Figure 5.13. Staging landscape potentially for food court. 


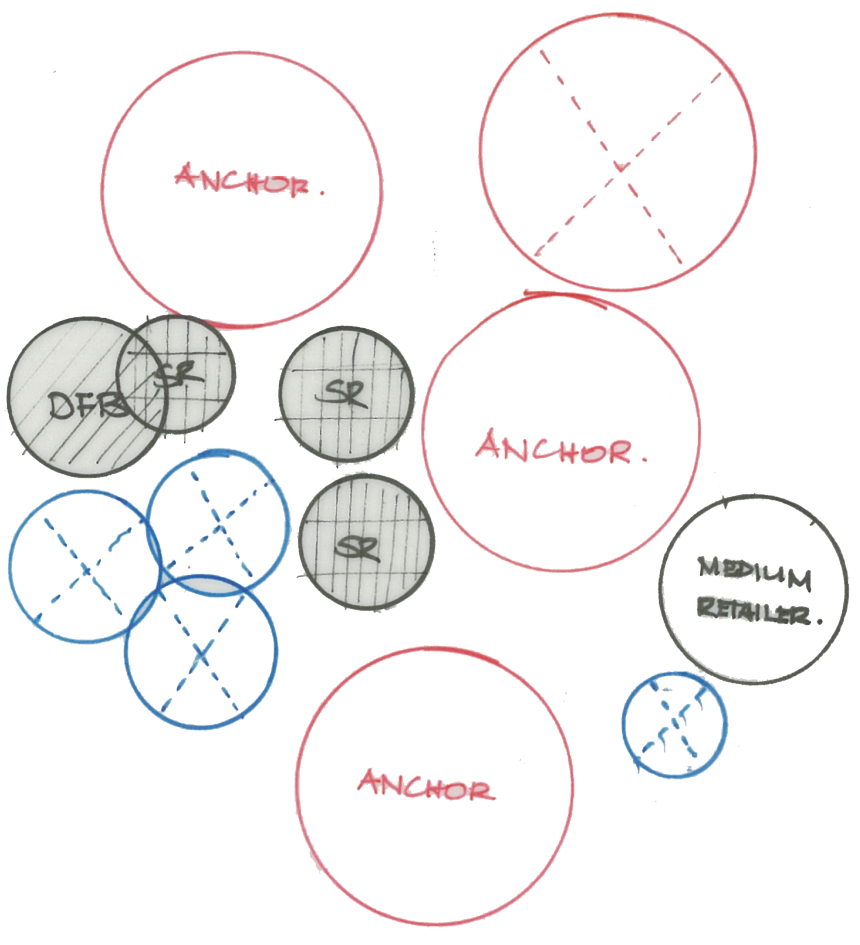

Two-storey anchors, mixed with small retailers and food and beverage tenants to add mix of tenants to the level and ensure it is not solely destination.

Figure 5.14. Bubble diagram for upper level.

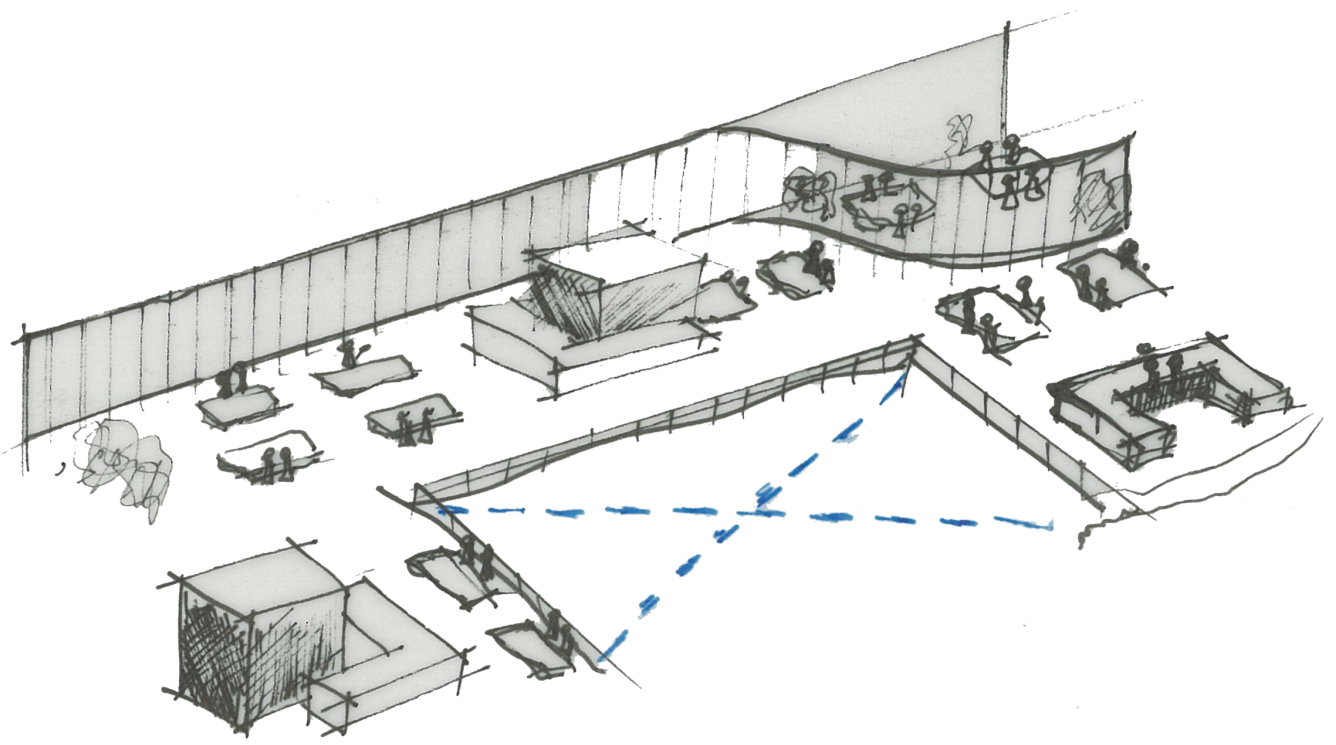

Figure 5.15. Conceptual food court on upper level, with an atrium to overlook ground level. Tenants appear similar in nature to pop-ups, with some outdoor dining spaces to add excitement to the experience. 
May leave the back of storage spaces of anchors to face parking area, leaving the parking area to be confronted with very inactive facades. On the other hand, anchors may be tempted to place entries by the carpark consuming all foot traffic and leaving small retailers inside with little.
VEHCULAR

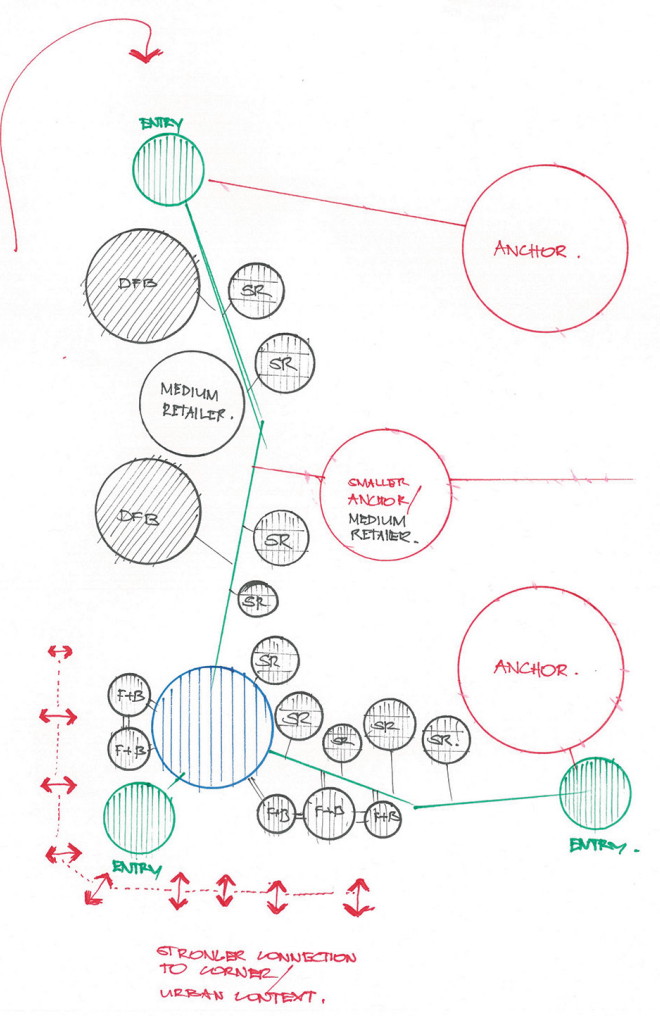

Figure 5.16. Bubble diagram for further reconfiguration.

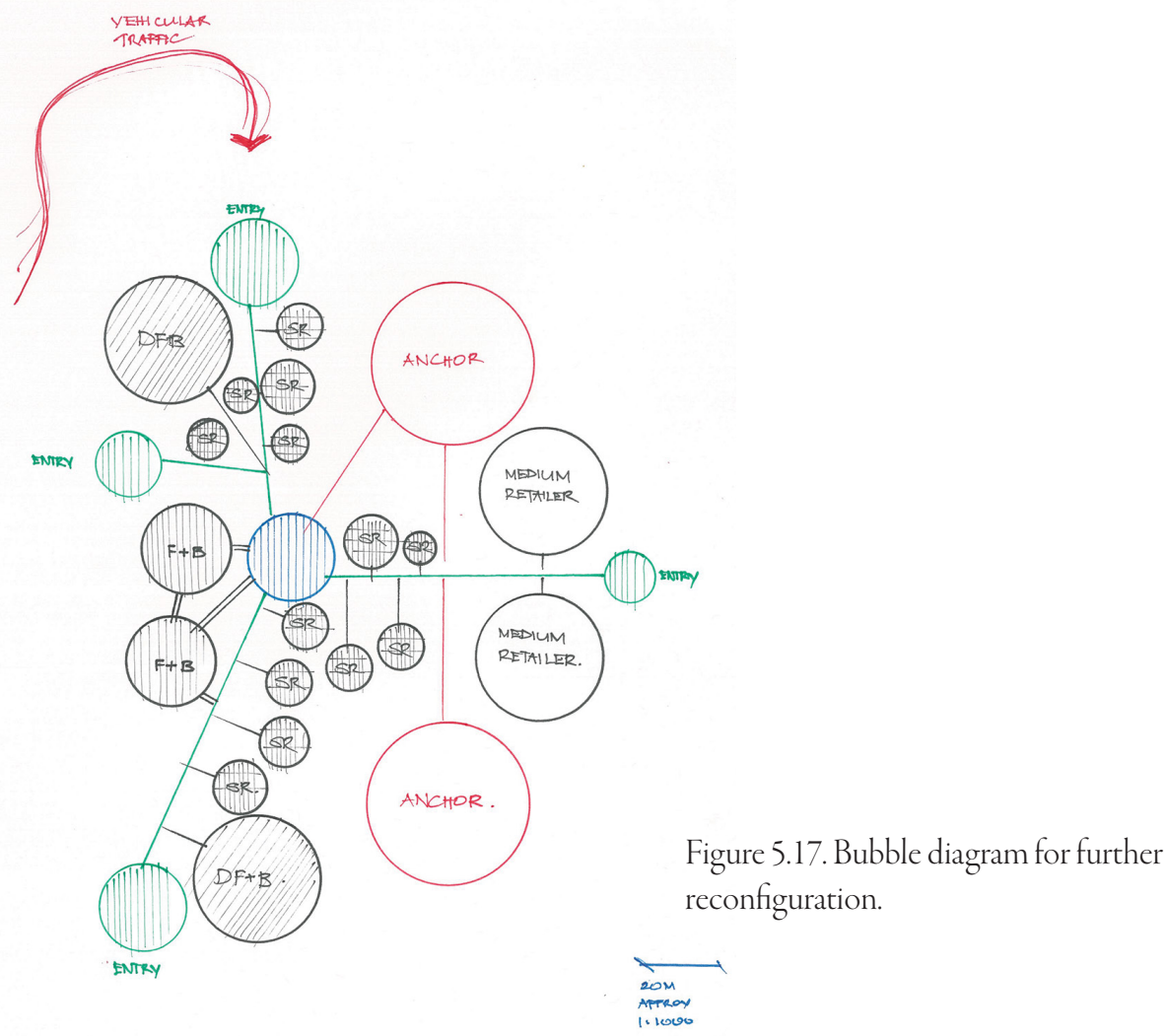




\section{Towards Iteration 1.3}

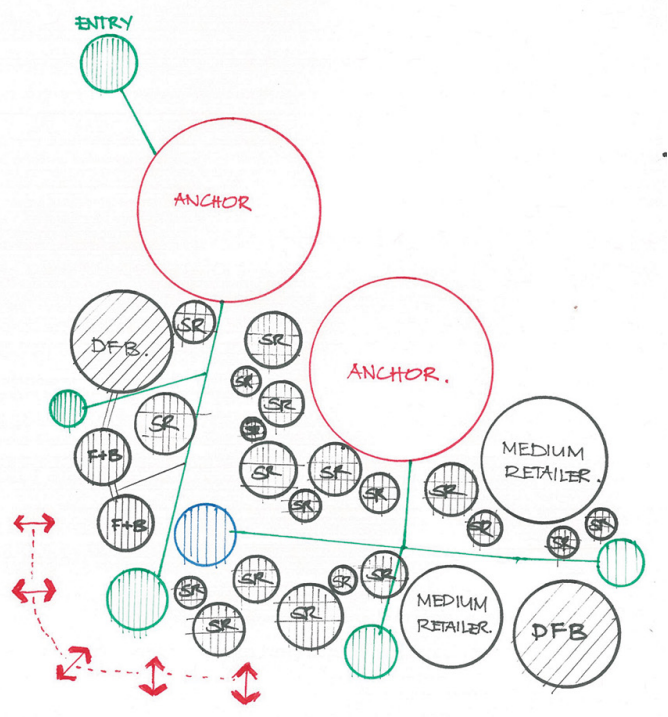

Figure 5.18. Bubble diagram for further reconfiguration. 


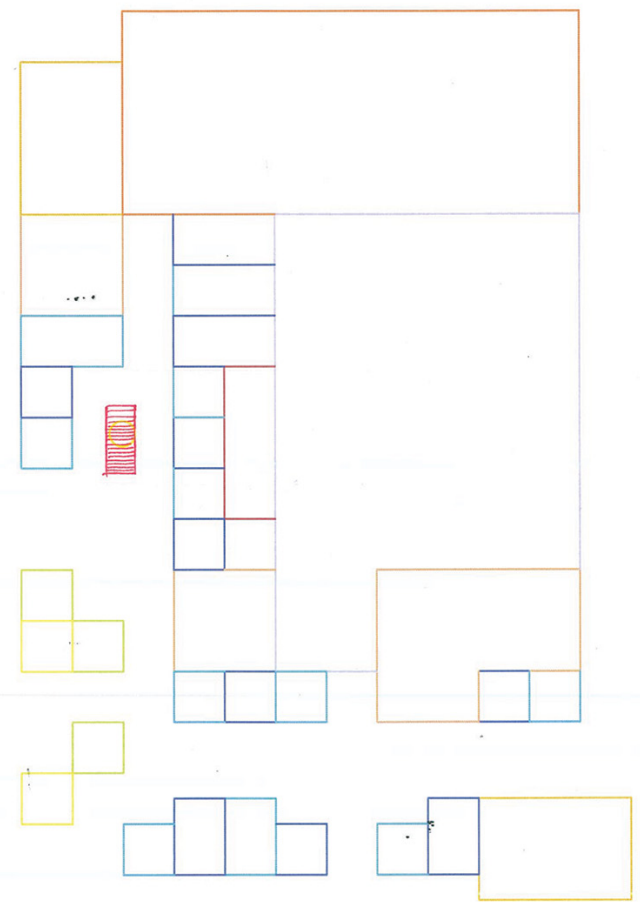

Figure 5.19. Iteration 1.3 ground level.

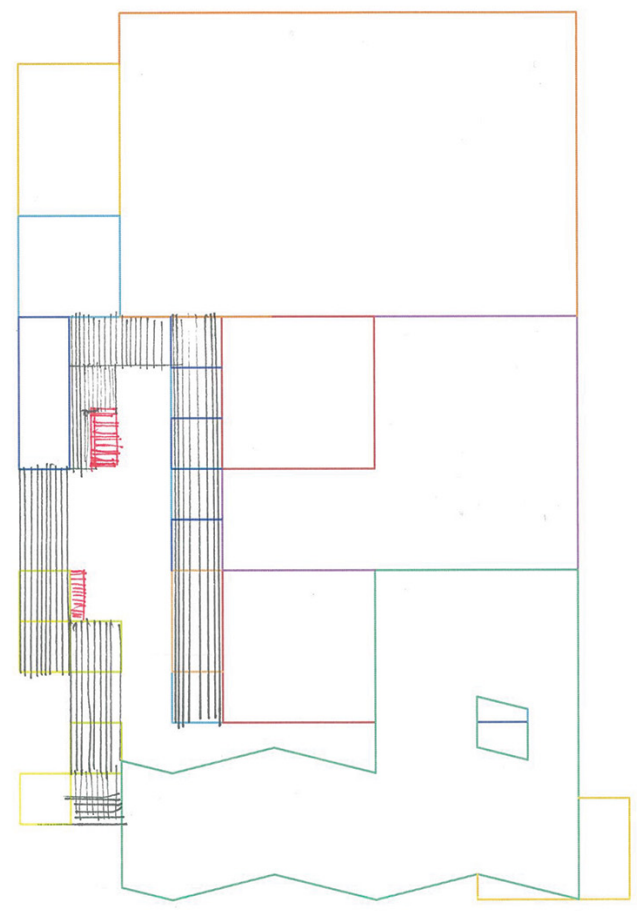

Figure 5.20. Iteration 1.3 upper level. 


\section{Iteration 1.3}
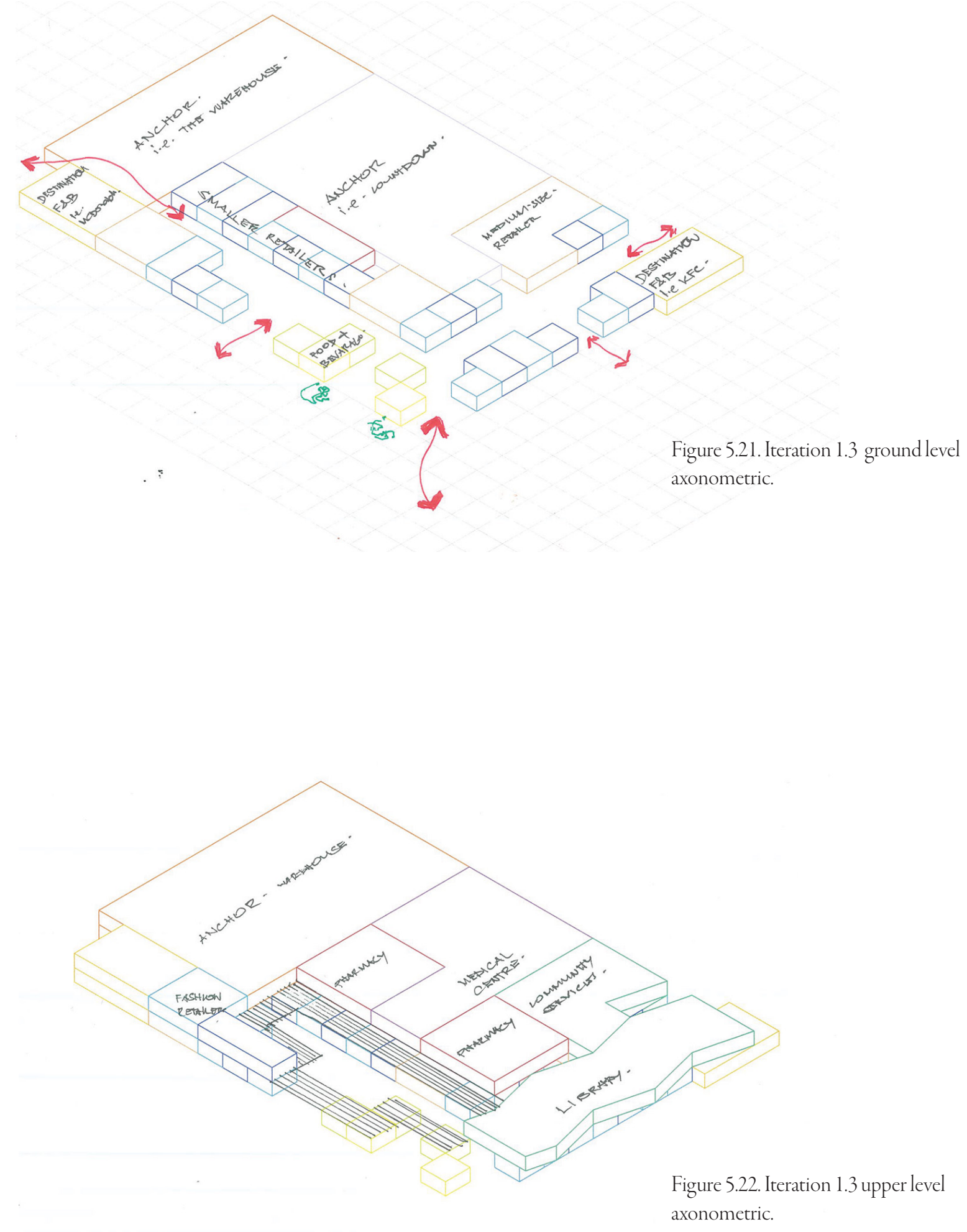
Evaluation on first series of iterations:

Strategies:

X Fluidity

Iterations do not showcase variety of non-retail activities- entirely mono-functional and purely for retail.

Compatibility

Iterations efficiently arrange retailers. Anchors are spread throughout the mall with small retailers placed between them.

X Shelter

Iterations are largely focused on interior spaces and do not showcase exploration of integrating retail and mall spaces outdoor

X Increasing Eastgate's liveliness and attractiveness

Iterations are still largely similar to current mall architecture with no clear points of differentiation.

X Green Spaces

Iterations do not feature green spaces.

Balance, Convenience, Efficiency

Iterations appear to make it easier for people to find stores.

Criteria for Evaluation of Design Explorations:

X Connectedness

Iterations appear to make gestures of opening up to the surrounding environment, but it still largely has a strong internal orientation or focus

X Exposure \& openness

Iterations still appear to be hesitant in opening up to the public

X Flexibility

Iterations still observe rigid boundaries and hesitant on exploring knocking down walls for easier interaction and collaboration between retail spaces

X Identity

Iterations do not showcase sufficient level of uniqueness- they continue to appear like every other mall

Balance

Iterations do not have balance between convenience and experience. There are no unique experiences, with the current iterations being solely looking into increasing convenience and efficiency. 


\section{PHASE TWO- DESIGN DEVELOPMENT}

Next series of iterations look into introducing green spaces into the mall to meet principles established in criteria. These

iterations also look into breaking down the mall, to provide it with greater flexibility to lead the design process into creating unique experiences.

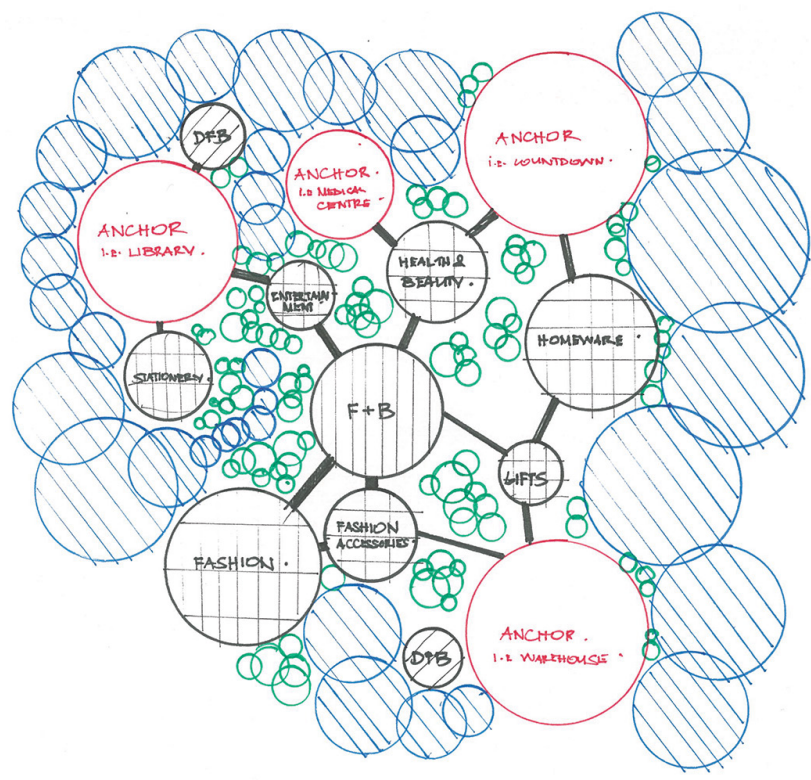

Figure 5.23. Bubble diagram further developing earlier configurations.

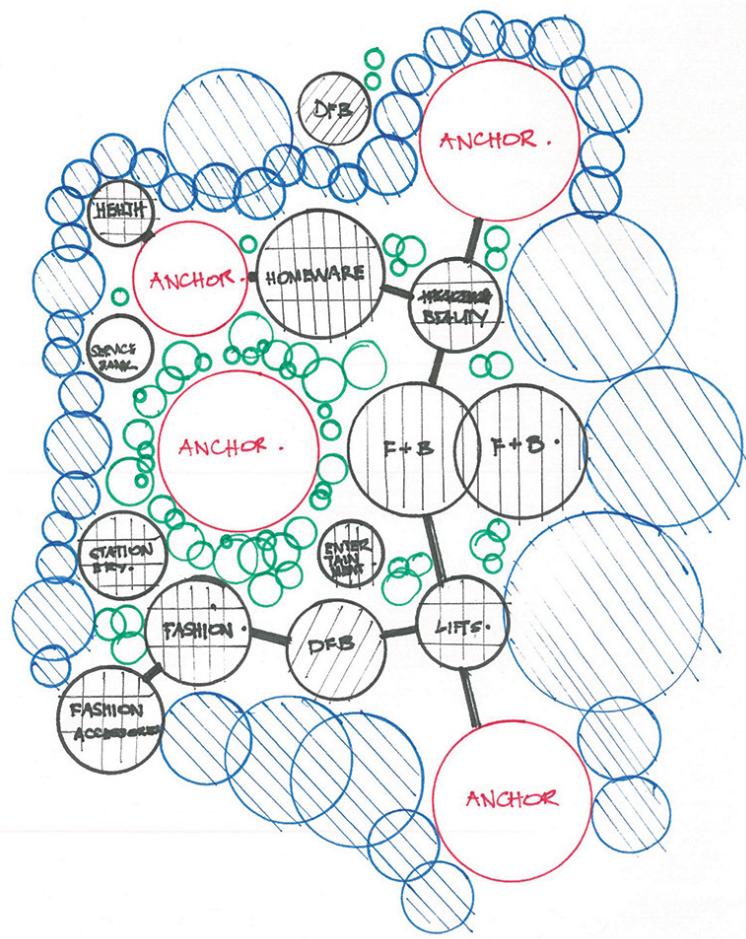

Figure 5.24. Bubble diagram iteration,

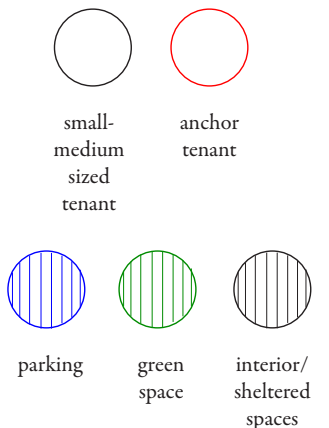




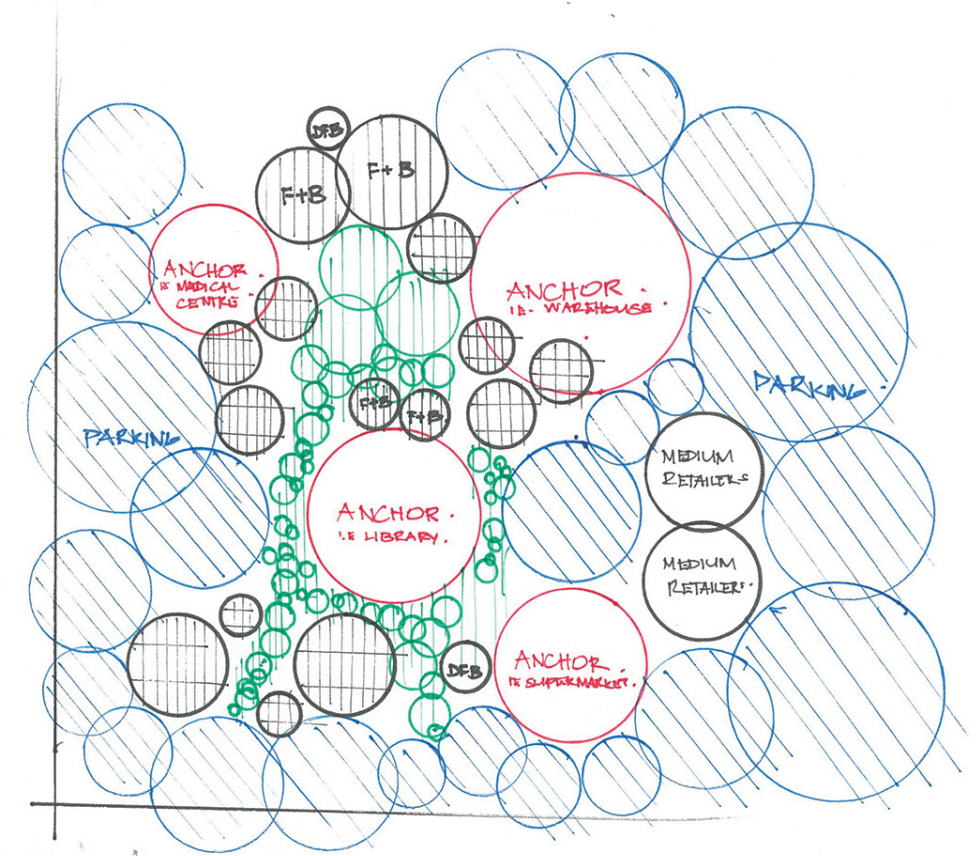

Figure 5.25. Bubble diagram iteration,

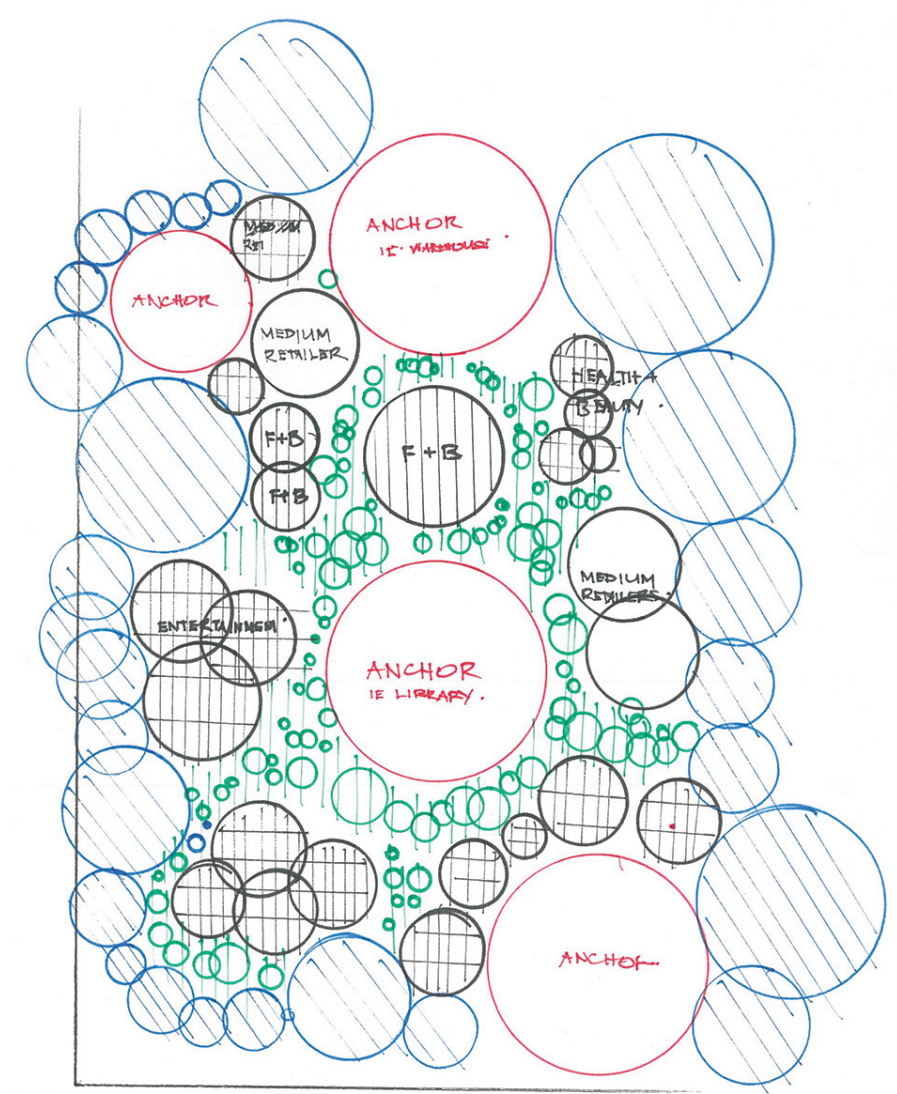

Figure 5.26. Bubble diagram iteration, 


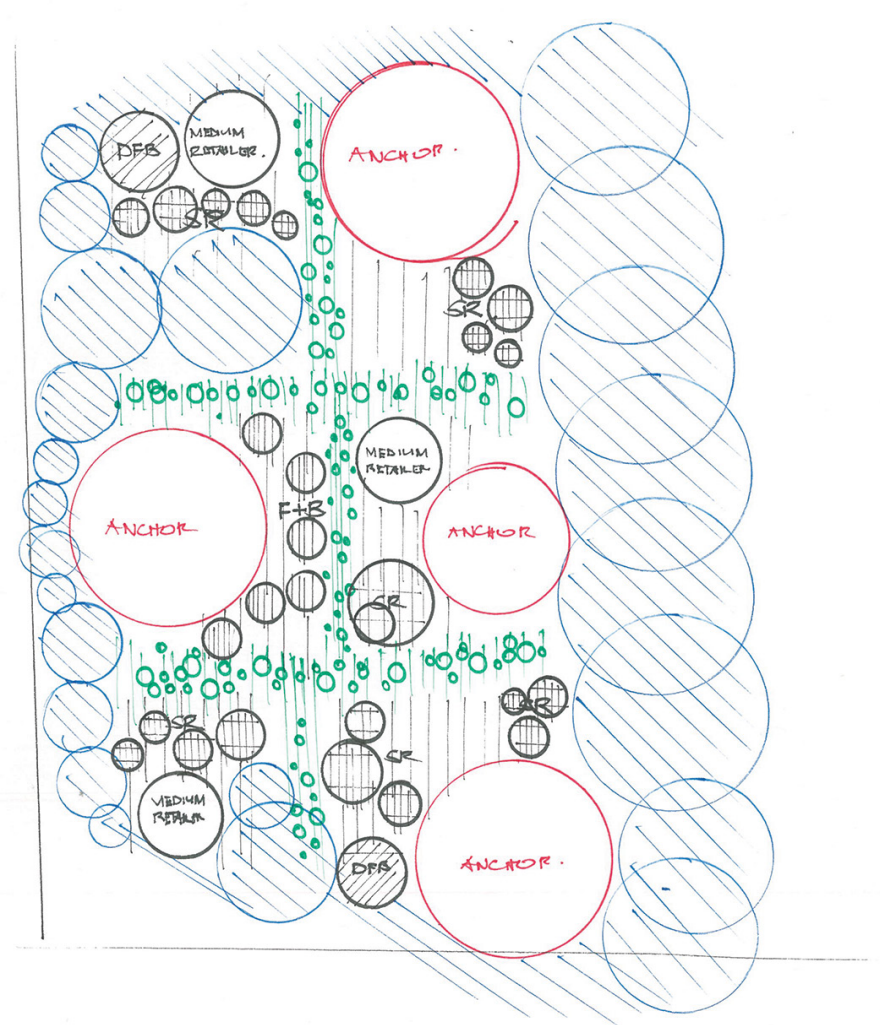

Figure 5.27. Bubble diagram iteration,

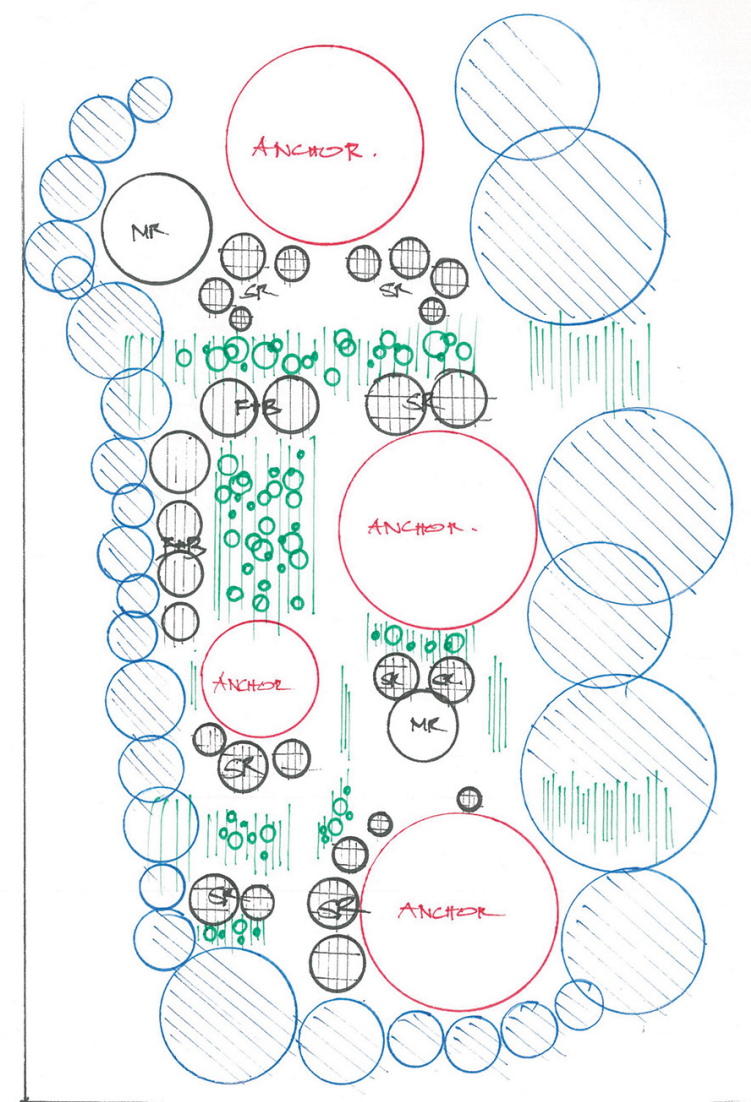

Figure 5.28. Bubble diagram iteration,

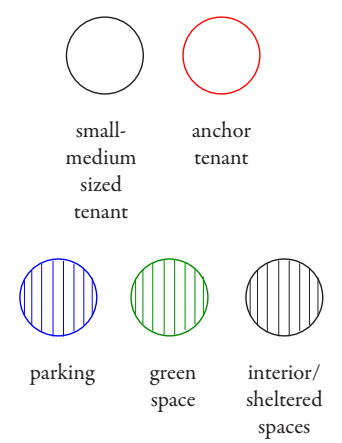




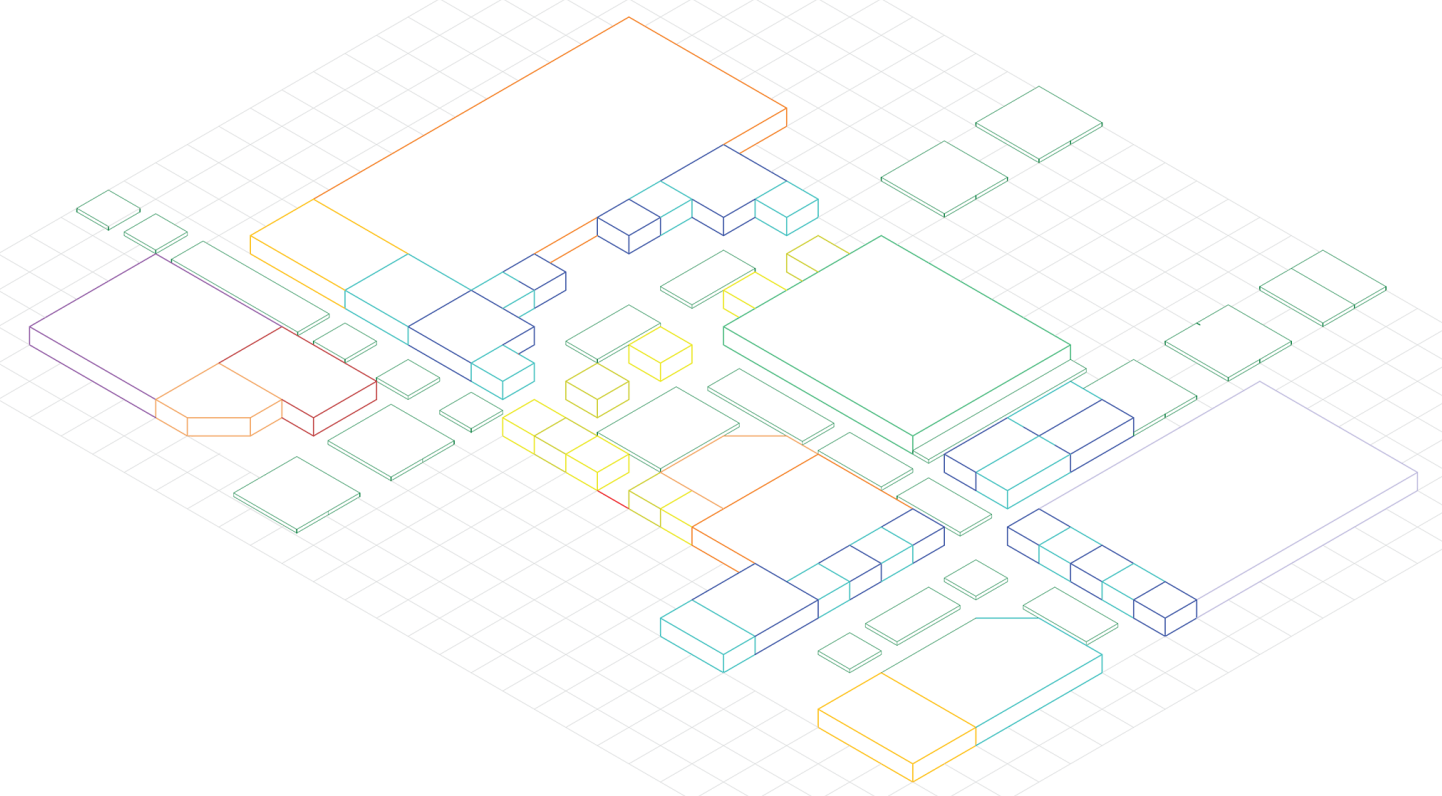

Figure 5.29. Iteration in axonometric.

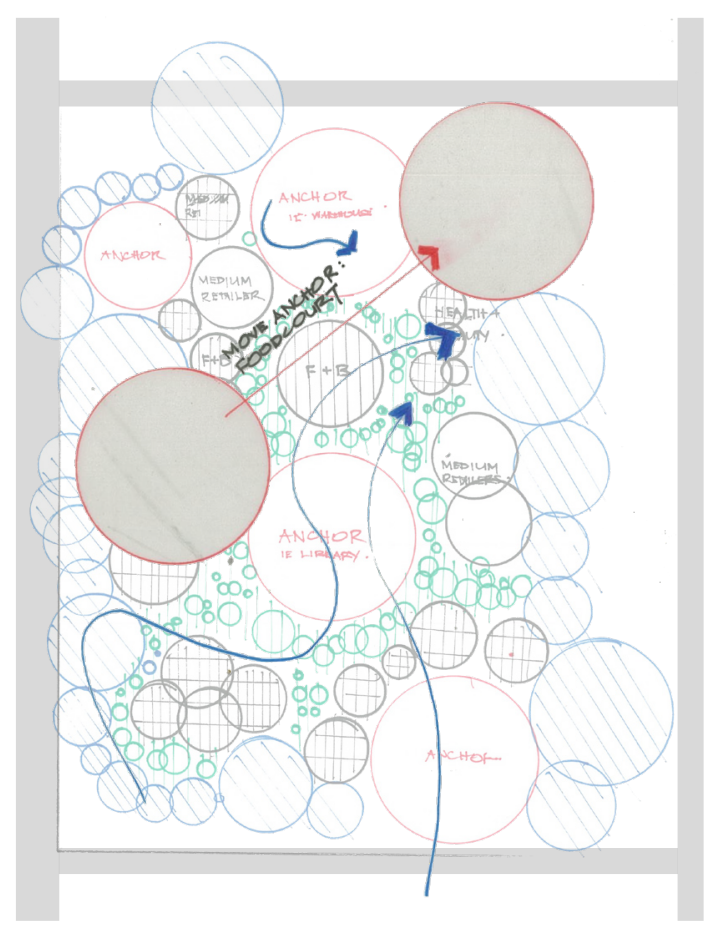

Figure 5.30. Key move- moving food court and replacing it with green spaces to attract people from main street.

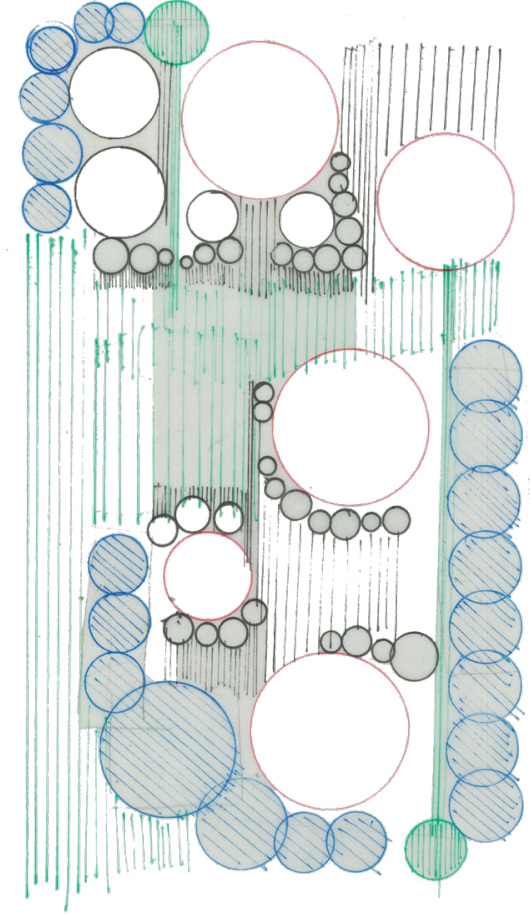

Figure 5.31. Bubble diagram iteration. 


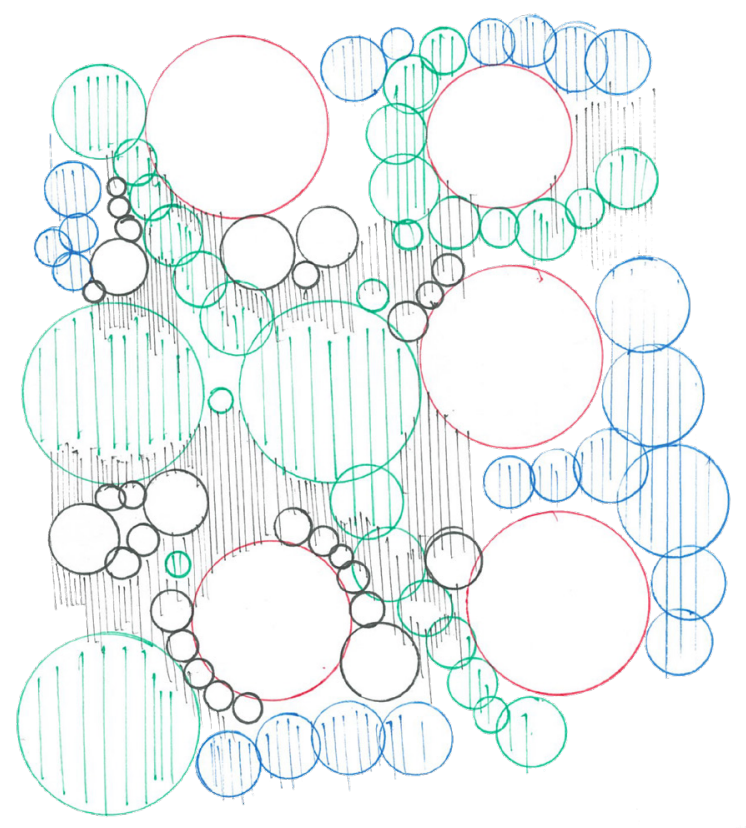

Figure 5.32. Bubble diagram iteration.

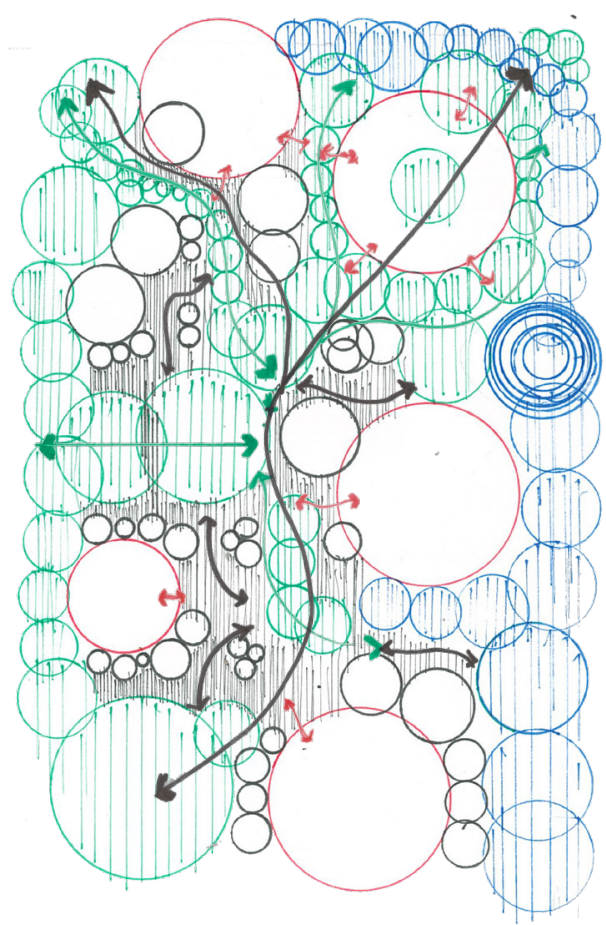

Figure 5.33. Detailed bubble diagram iteration labelled with circulation and entry points to anchors and clusters.

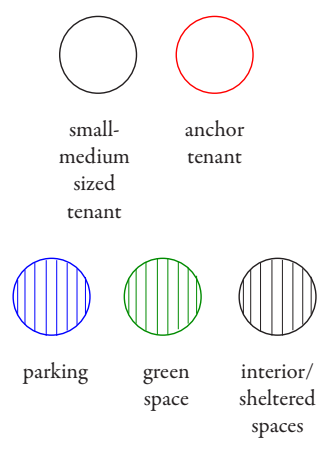




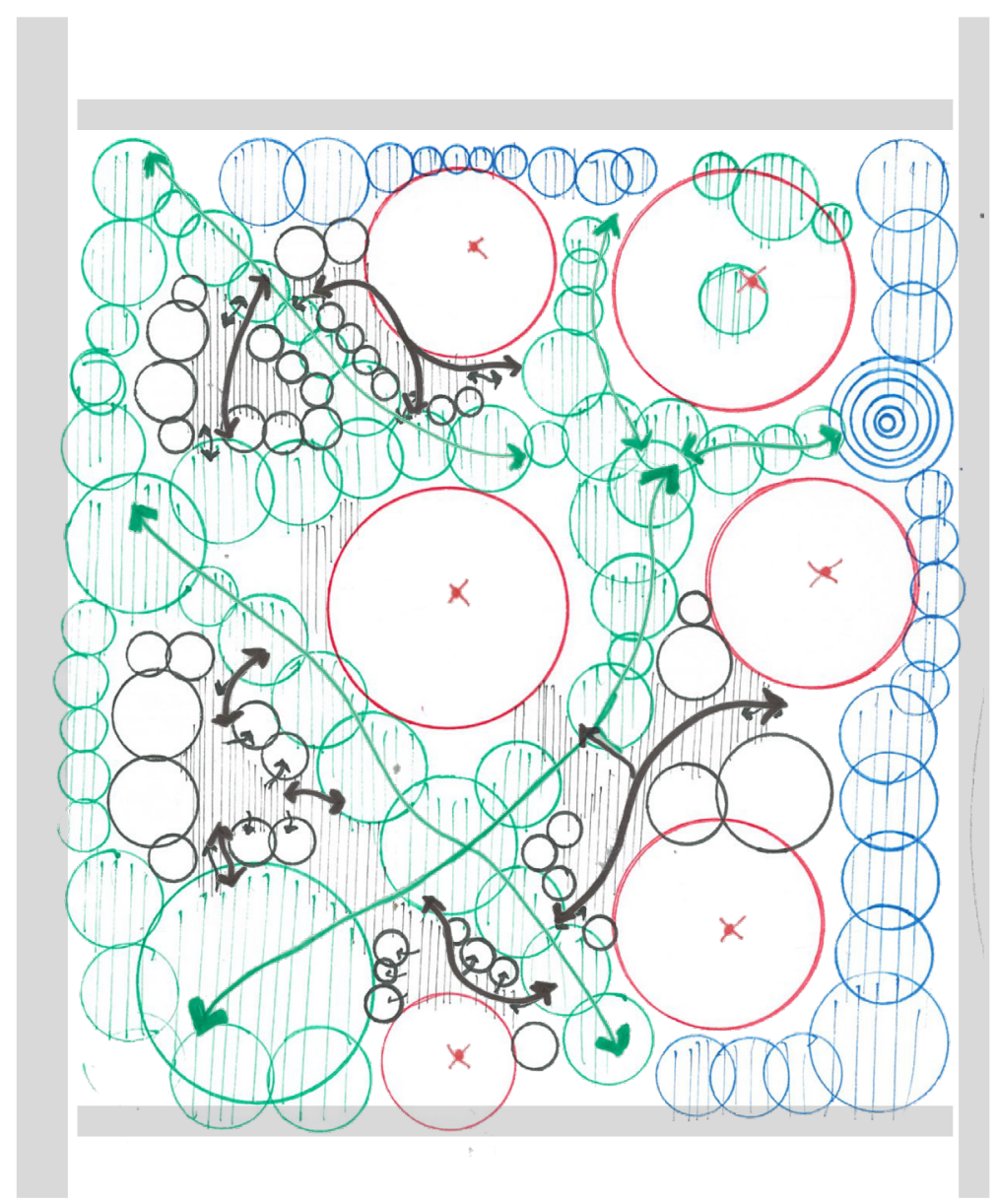

Figure 5.34. Detailed bubble diagram iteration labelled with circulation and entry points to clusters.

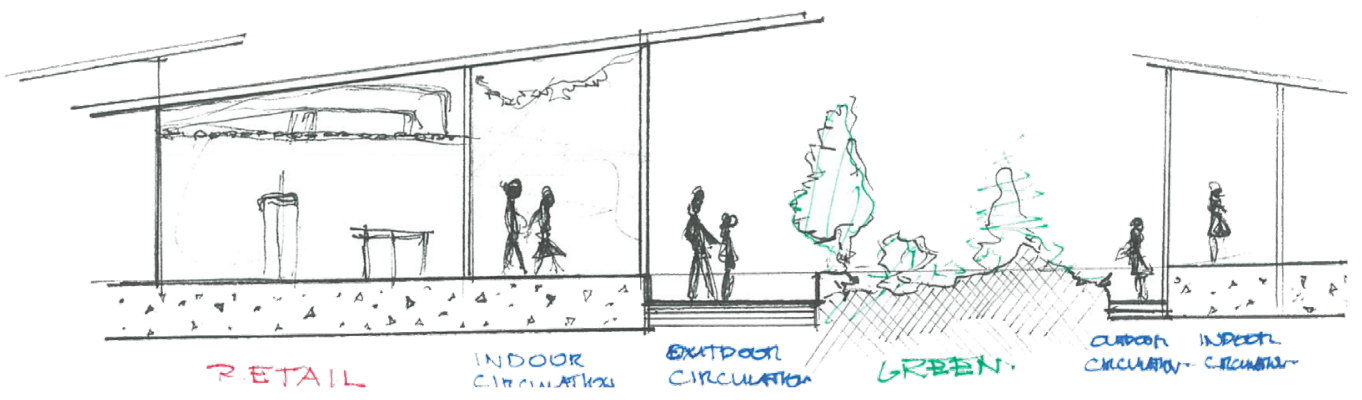

Figure 5.35. Sectional illustration of conceptual mall experience. 


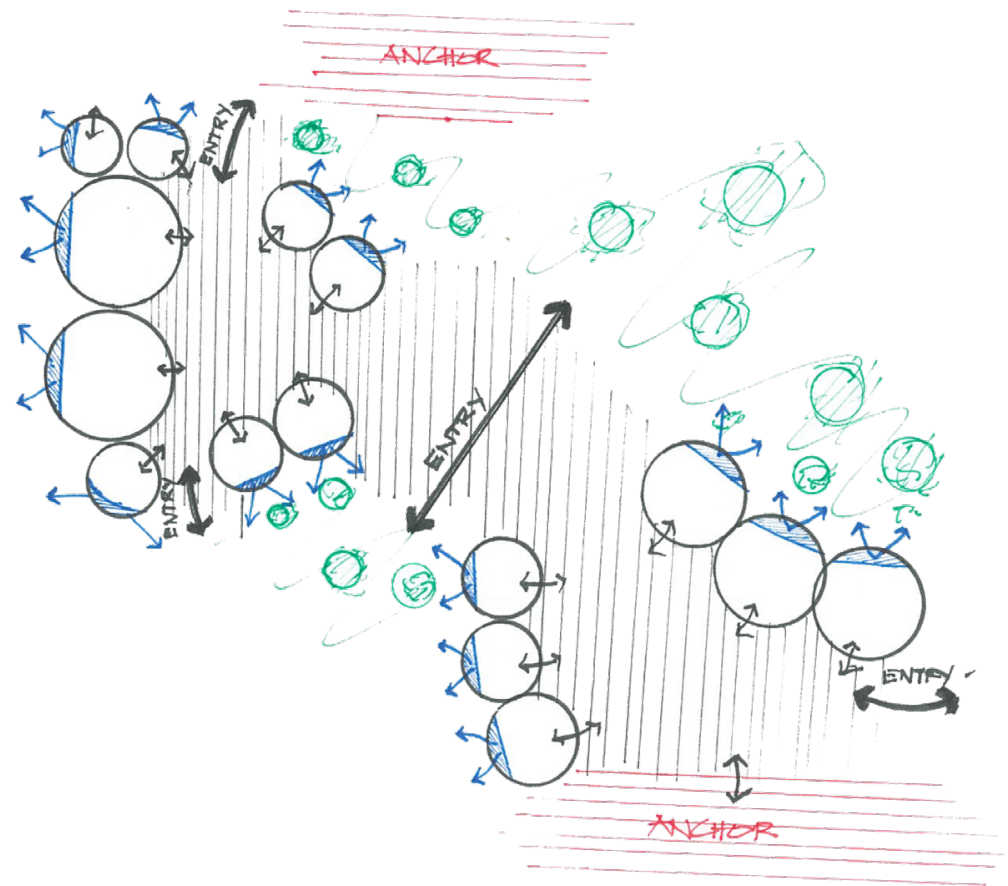

Figure 5.36. Diagram of clustering in the mall, with entries and relationships between shop frontages to green spaces indicated.

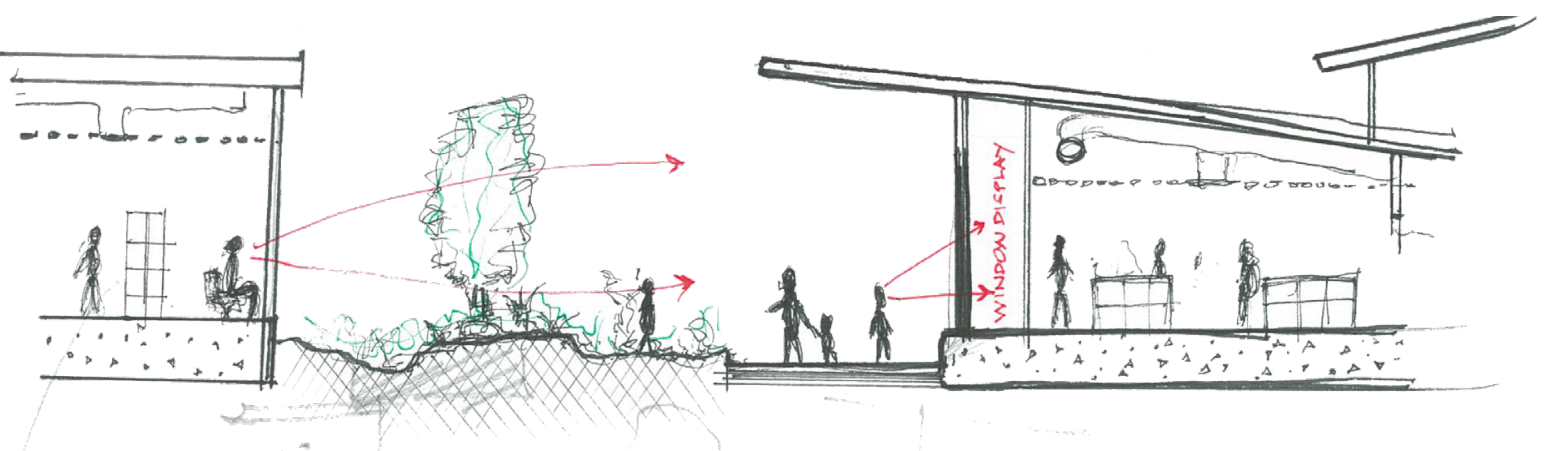

Figure 5.37. Sectional illustration of conceptual mall experience. 


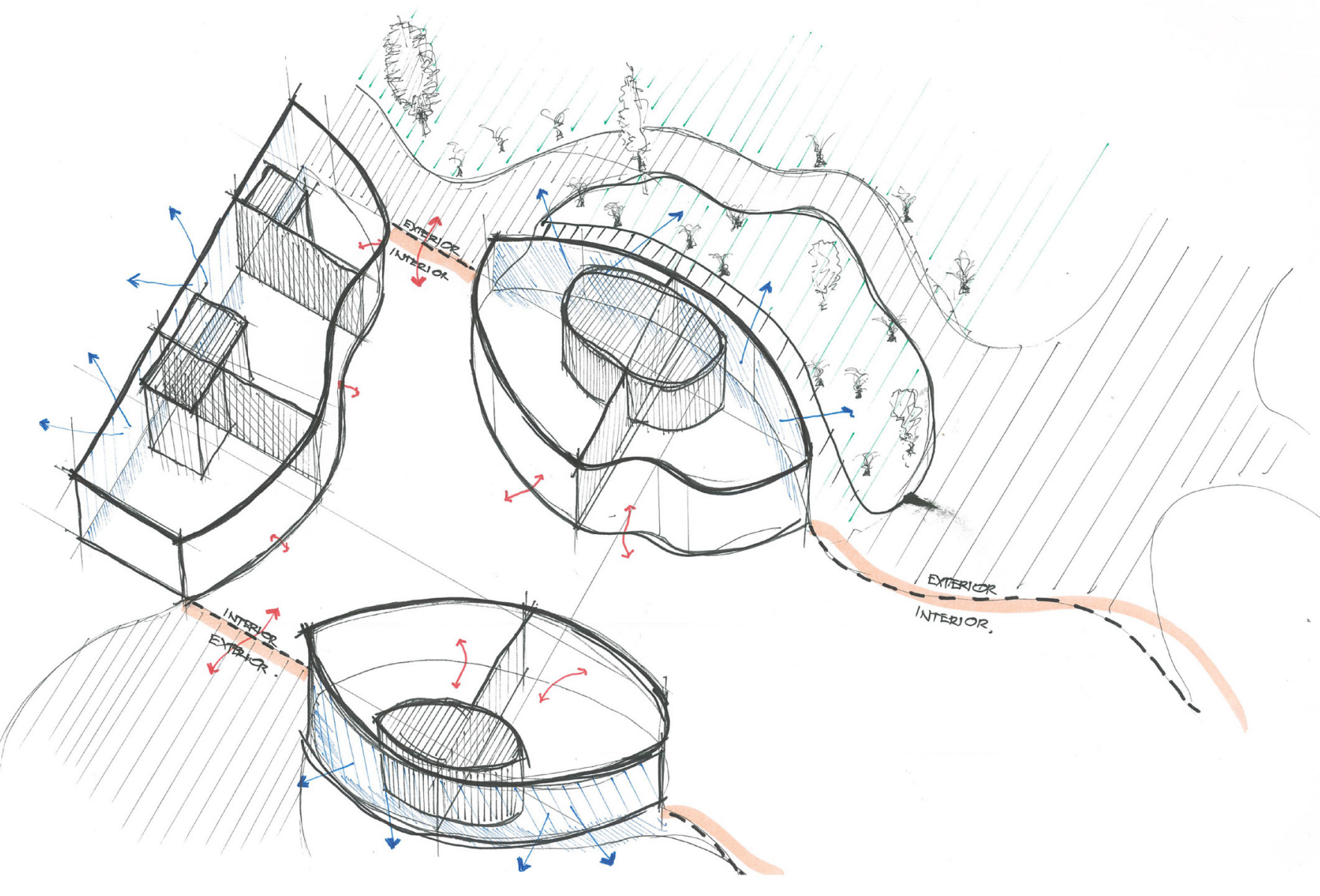

Figure 5.38. Axonometric illustration of clusters in mall, with entries and relationships between shop frontages to green spaces indicated.

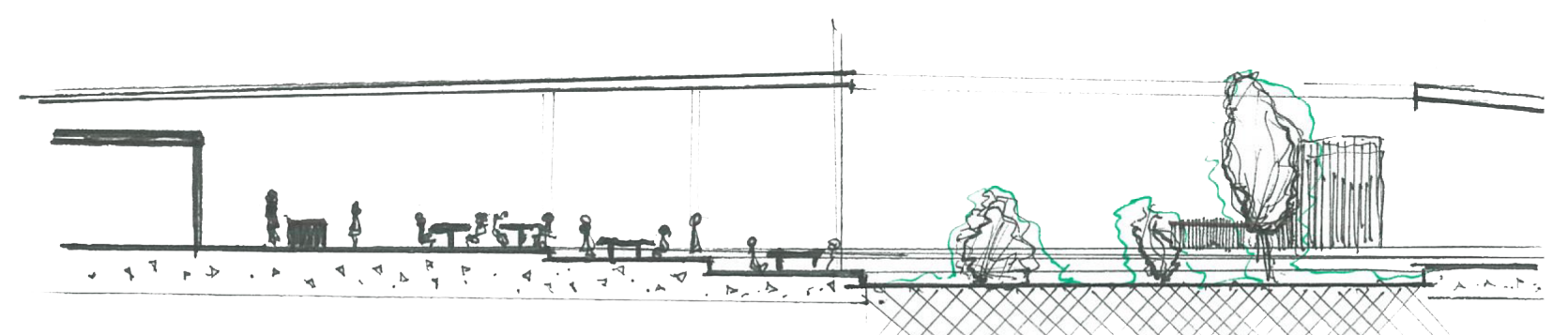

Figure 5.39. Sectional illustration of conceptual food court experience. 


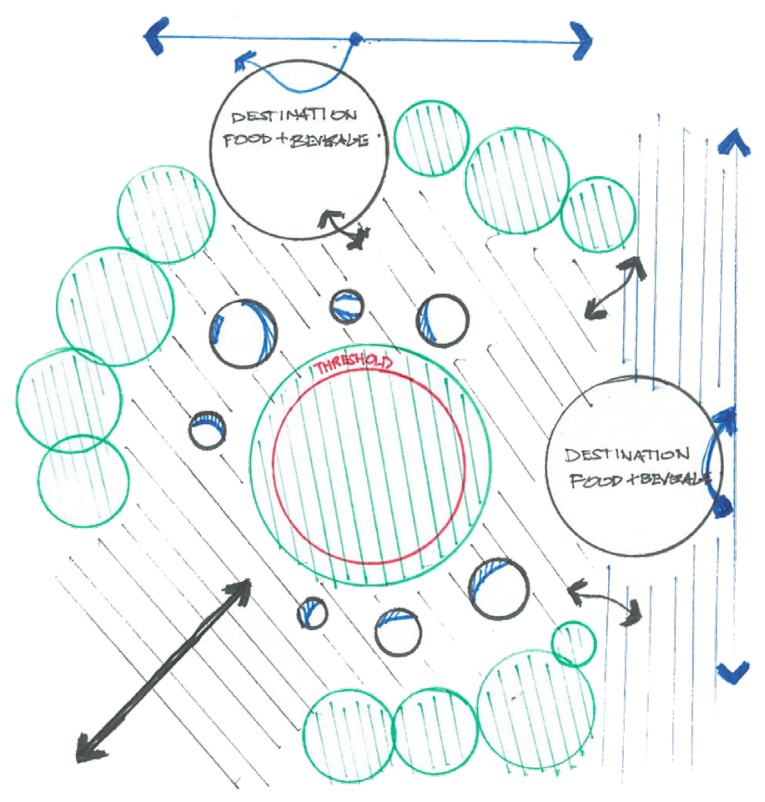

Figure 5.40. Bubble diagram for food court and green spaces within.

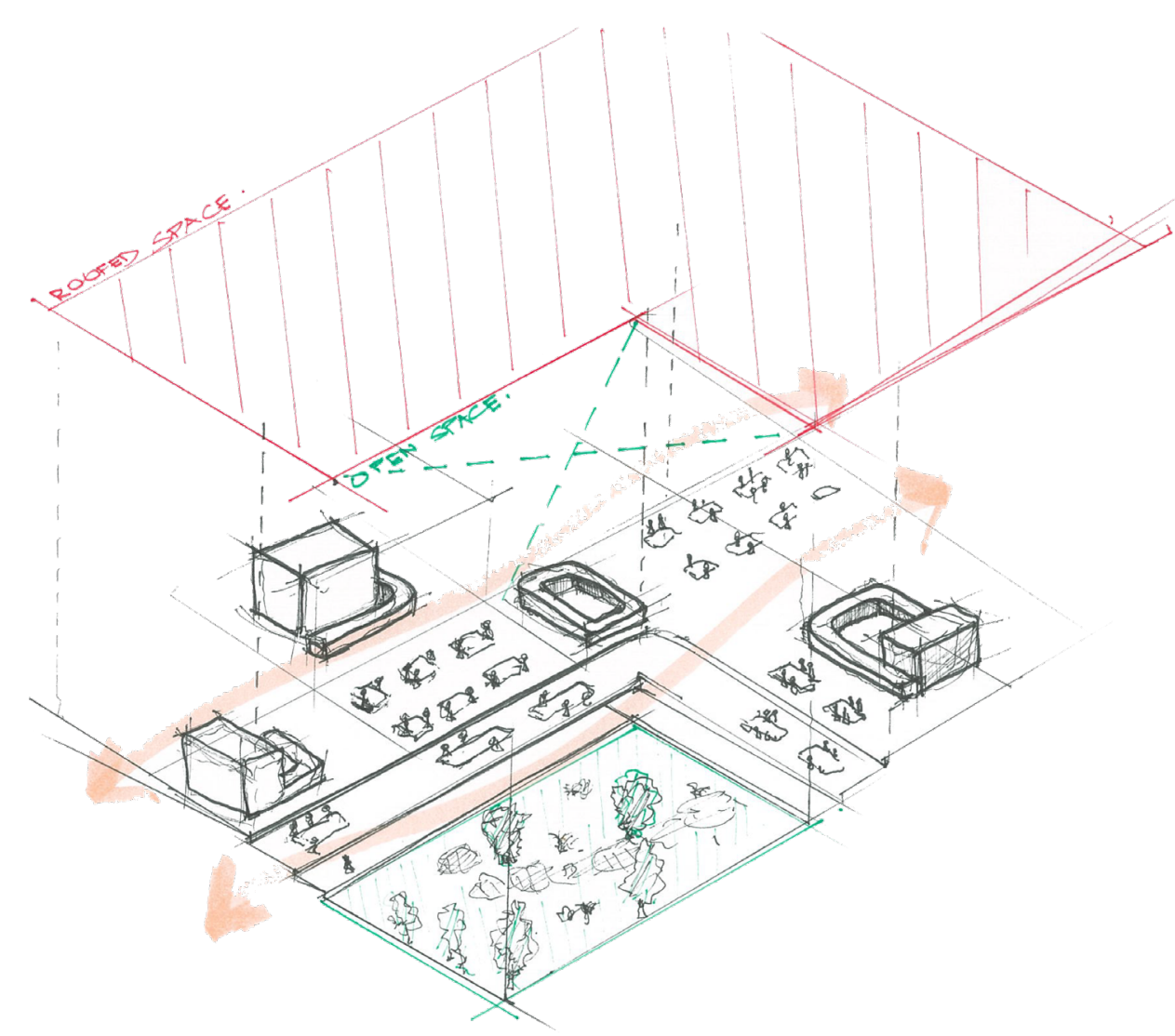

Figure 5.41. Axonometric illustration of food court experience with outdoor spaces and al-fresco dining. 


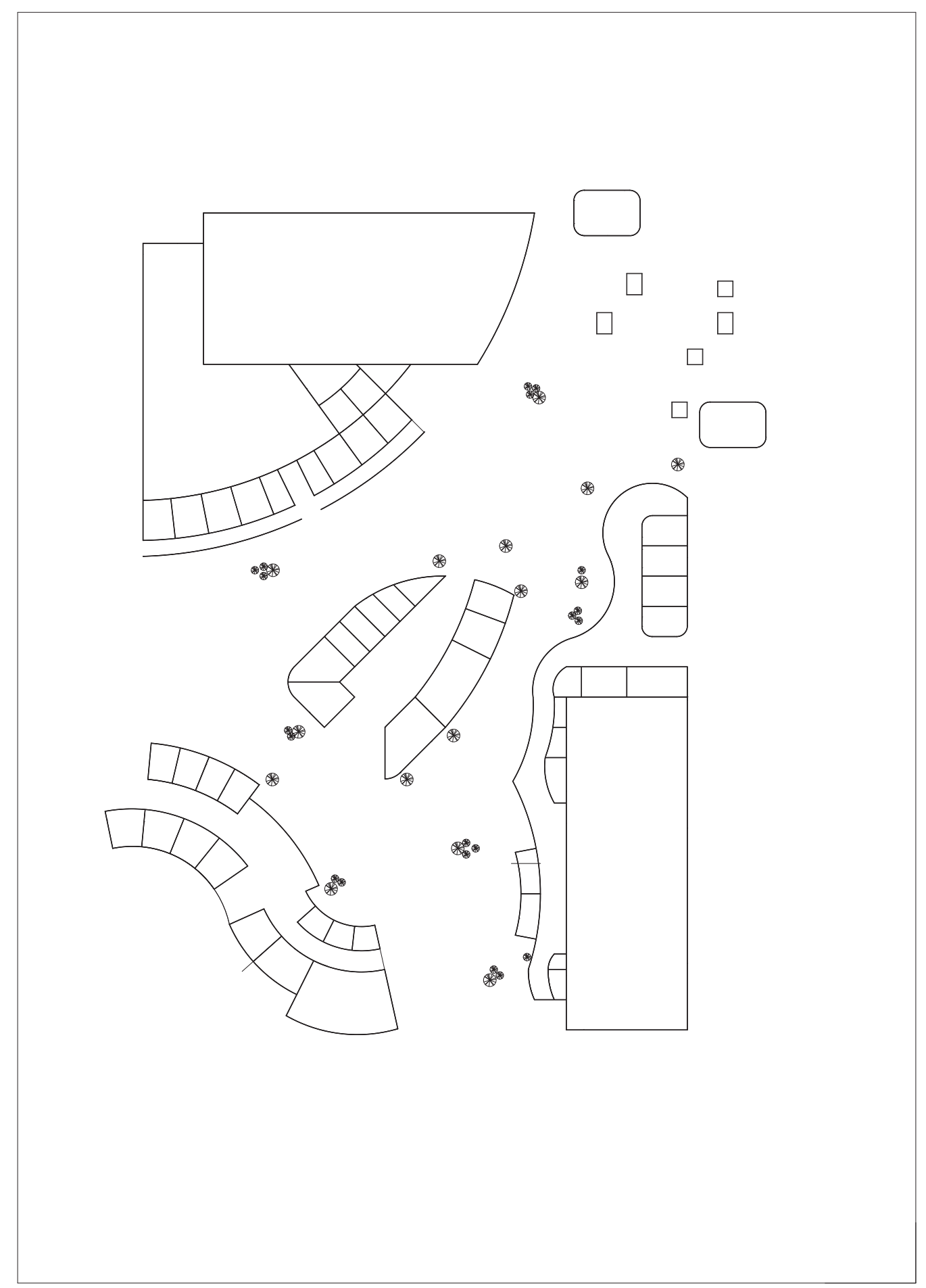

Figure 5.42. Plan of iteration 2.1.

1:2000@A4 


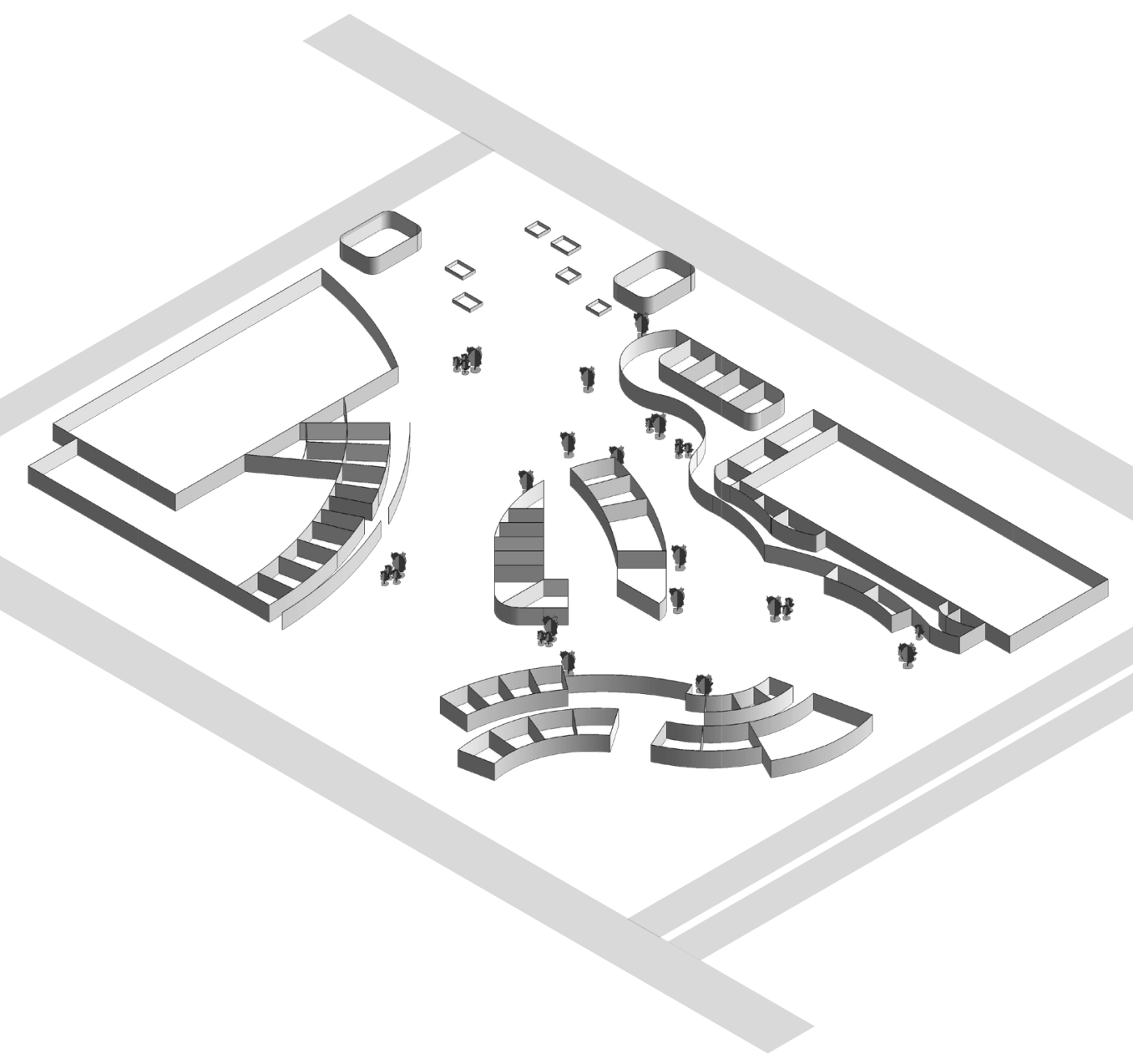

Figure 5.43. Iteration 2.1 axonometric plan. 


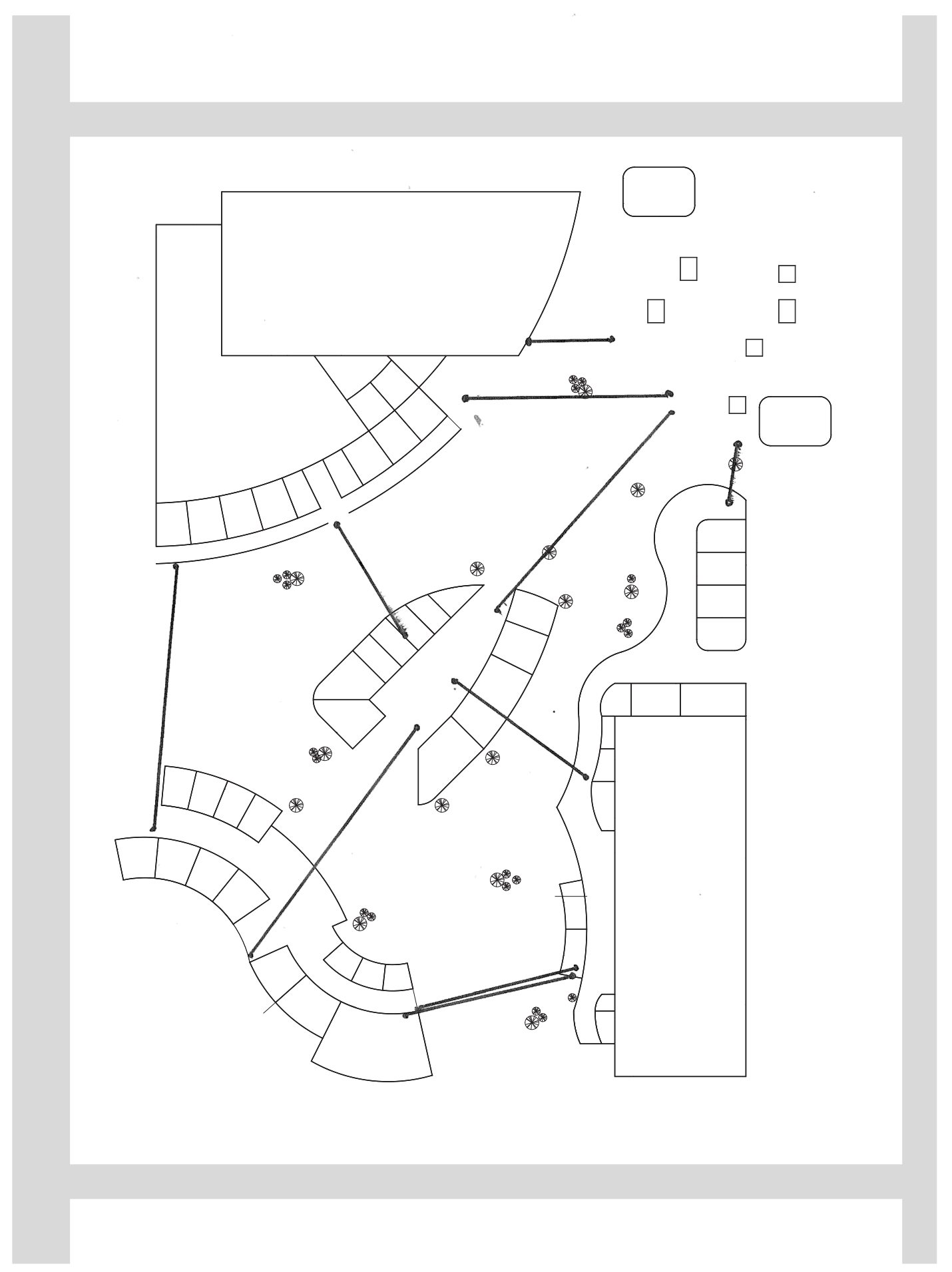

Figure 5.44. Mapping out potential architectural links to connect different segments in iteration 2.2 . 


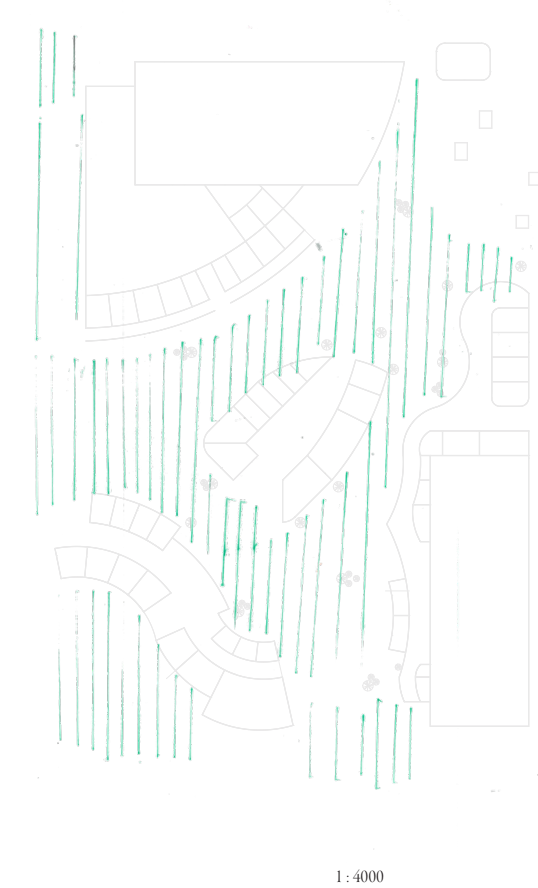

Figure 5.45. Iteration 2.1 green spaces.

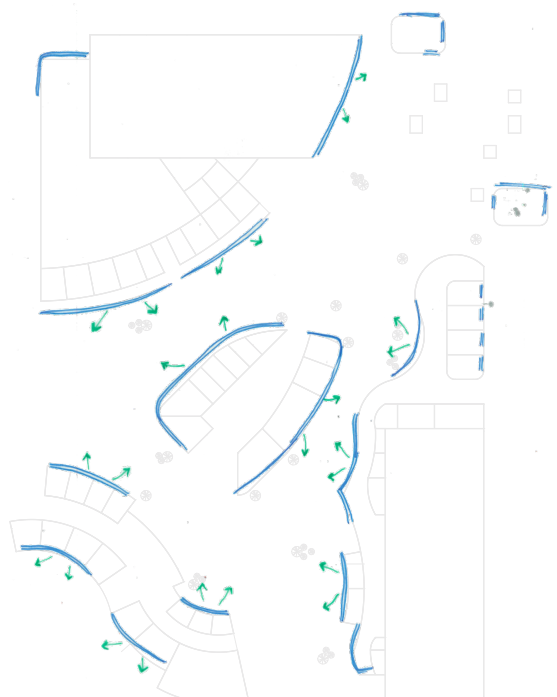

Figure 5.47. Iteration 2.1 key frontages.

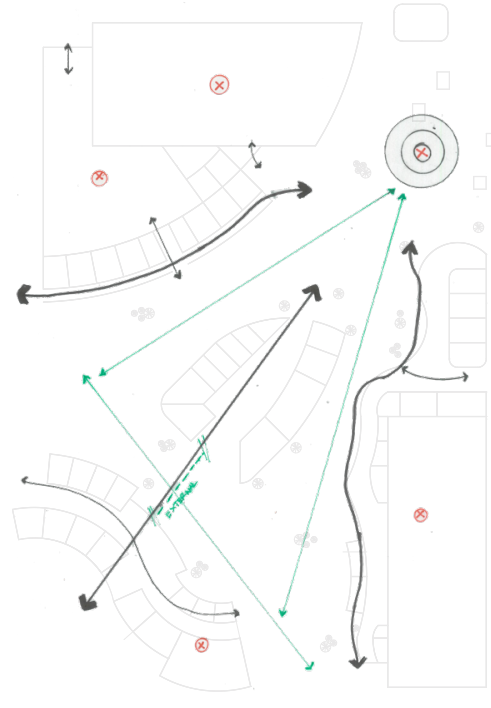

Figure 5.46. Iteration 2.1 Circulation routes and anchor stores.

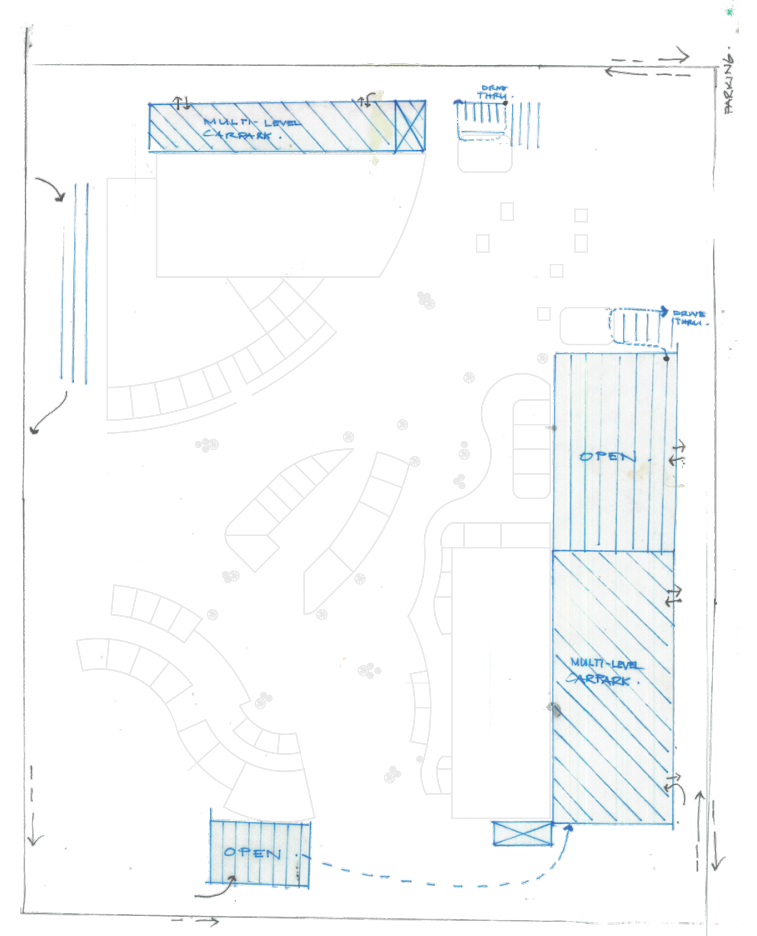

Figure 5.48. Iteration 2.1 carparking. 


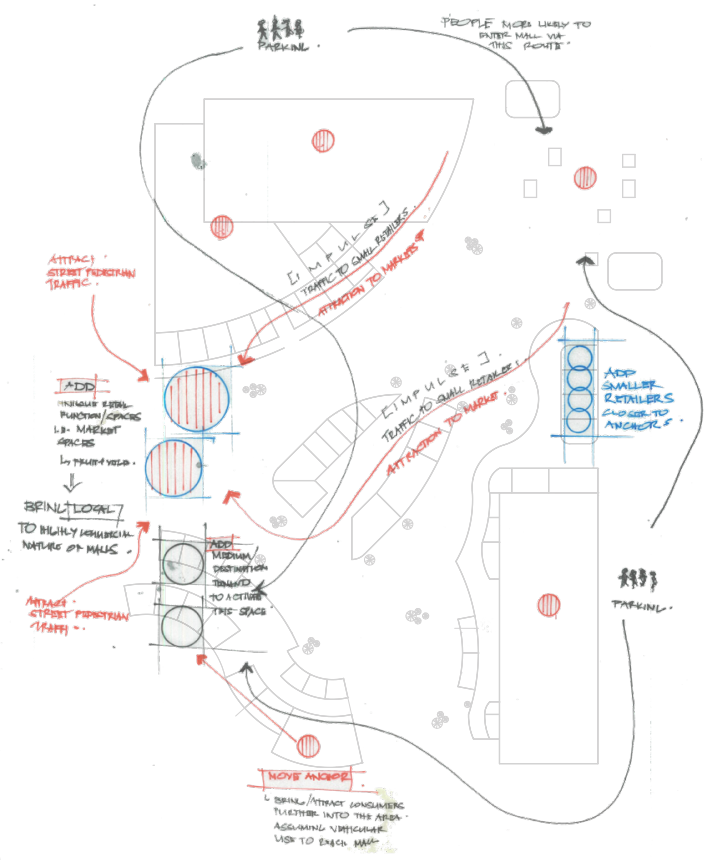

Figure 5.49. Potential strategies to develop iteration 2.1.

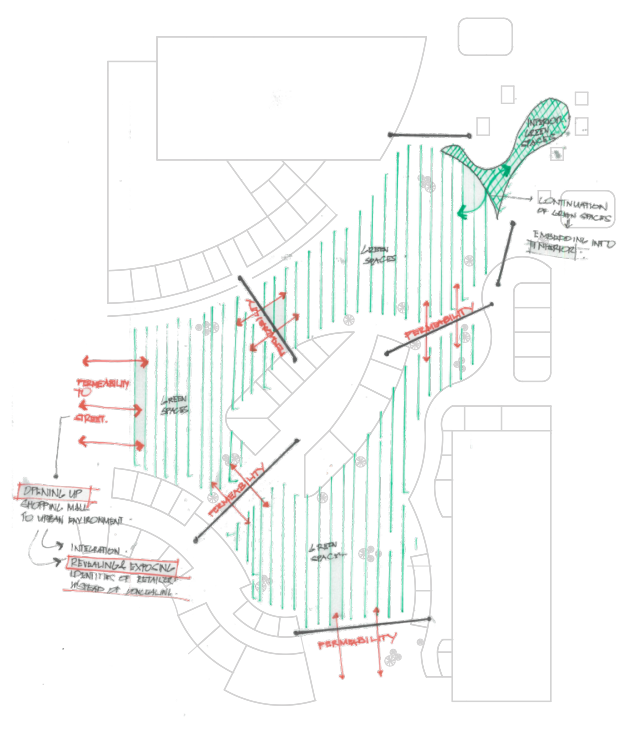

Figure 5.50. Key strategies to maintain and develop in iteration 2.1. 


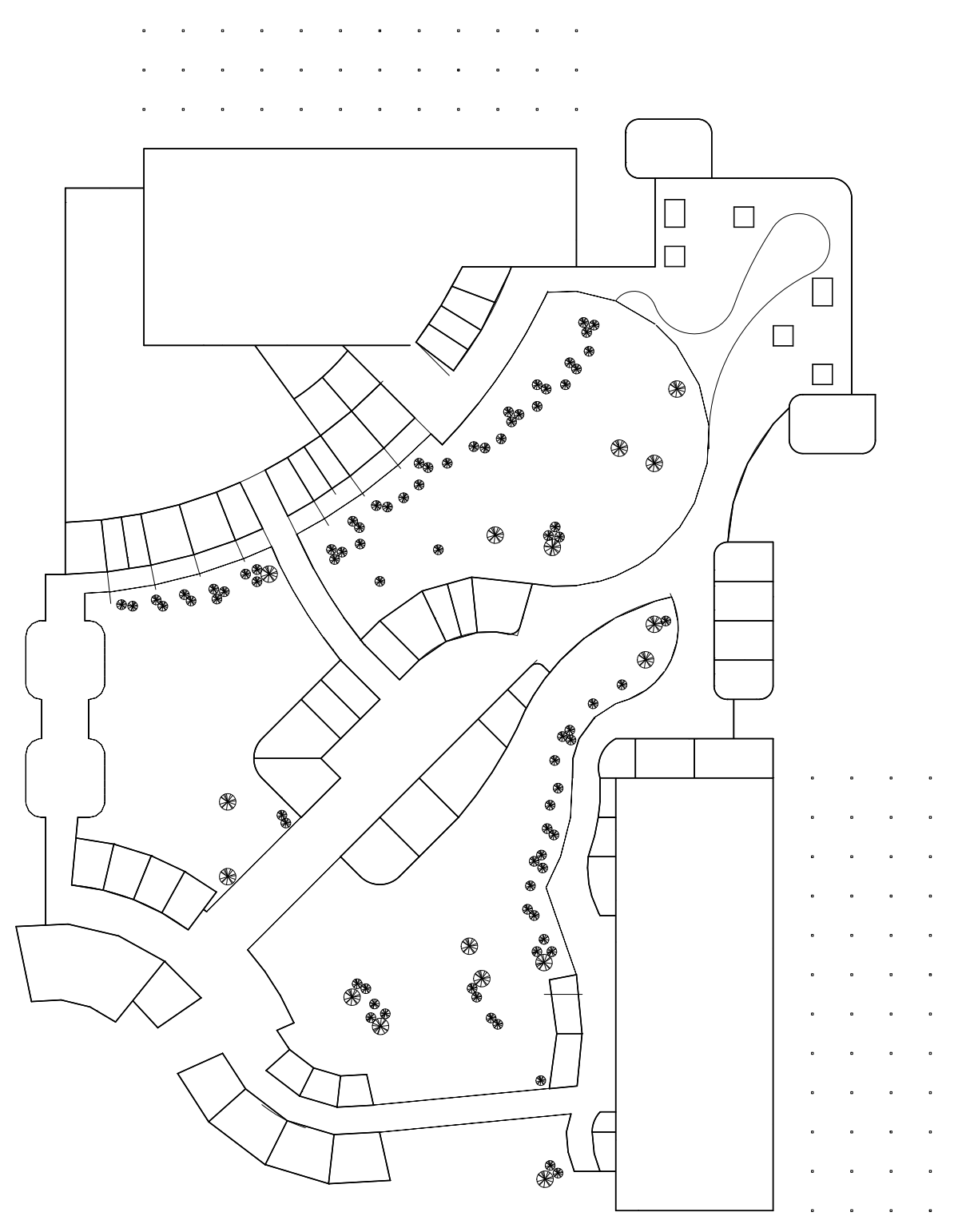

Figure 5.51. Iteration 2.2.

1:2000@A4 


\section{Design Development}

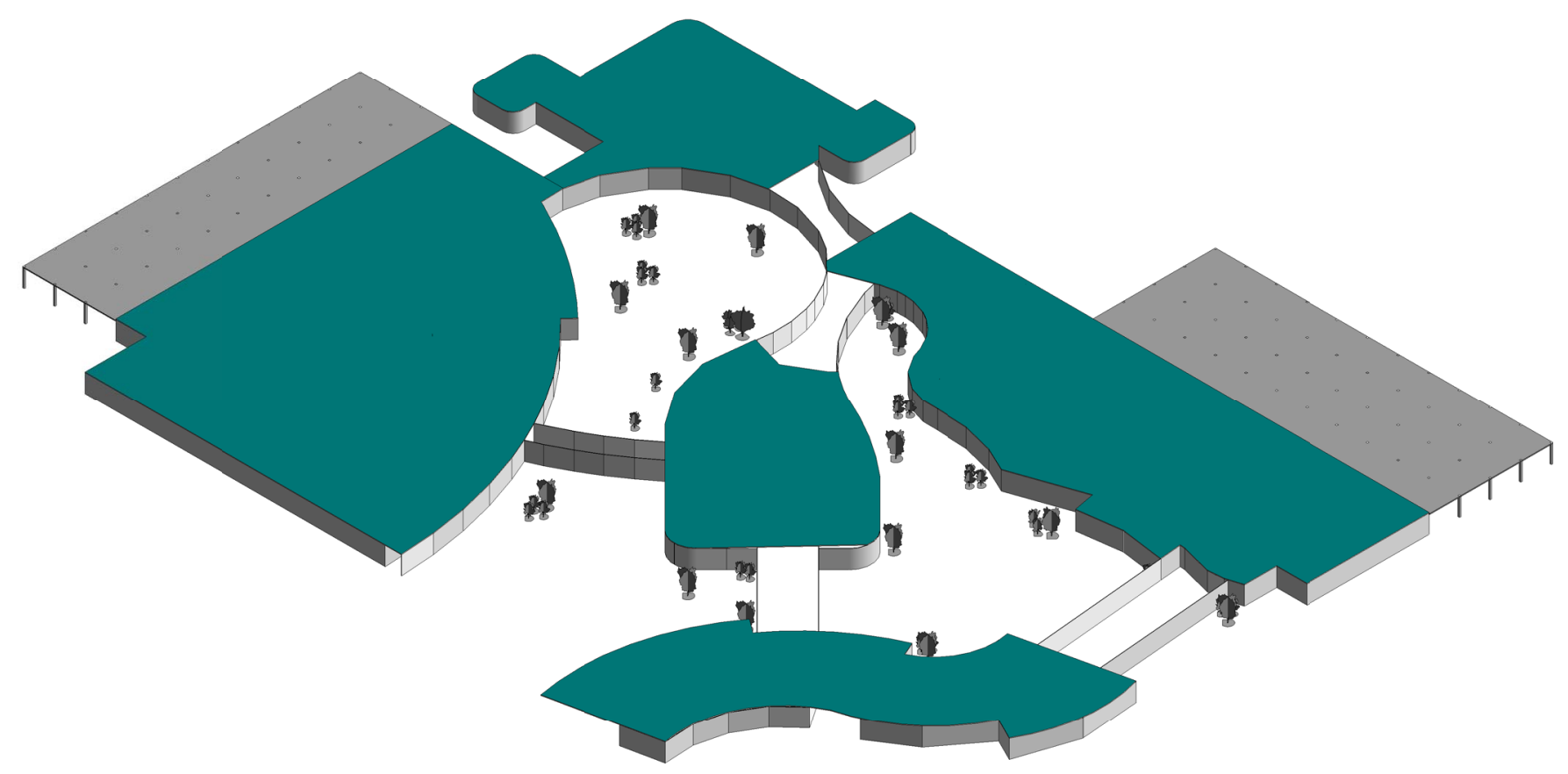

Key to this iteration are a series of sheltered linkages to ensure people and shoppers are sheltered from the elements while in the mall, but still have access to green spaces.

Figure 5.52. Iteration 2.2 axonometric. 


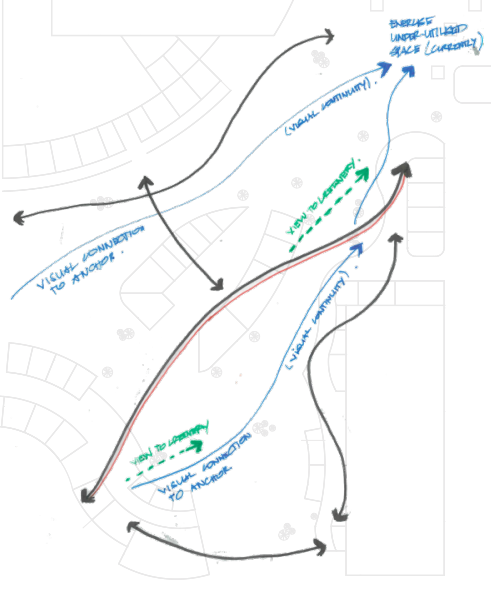

Figure 5.53. Development of visual continuity leading to iteration 2.2
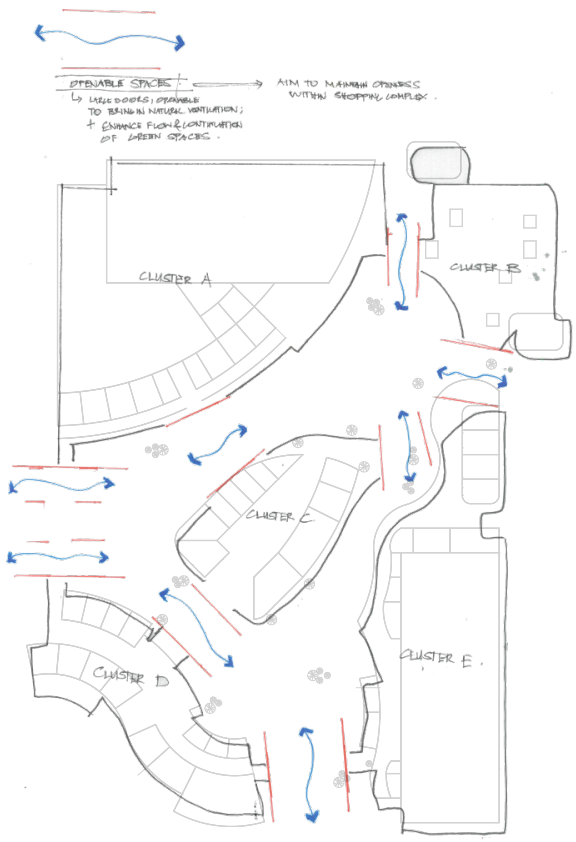

Figure 5.55. Development of flexibility with spaces (utilising especially designed commercial doors) that can be opened to allow for a feel of the elements and weather inside.

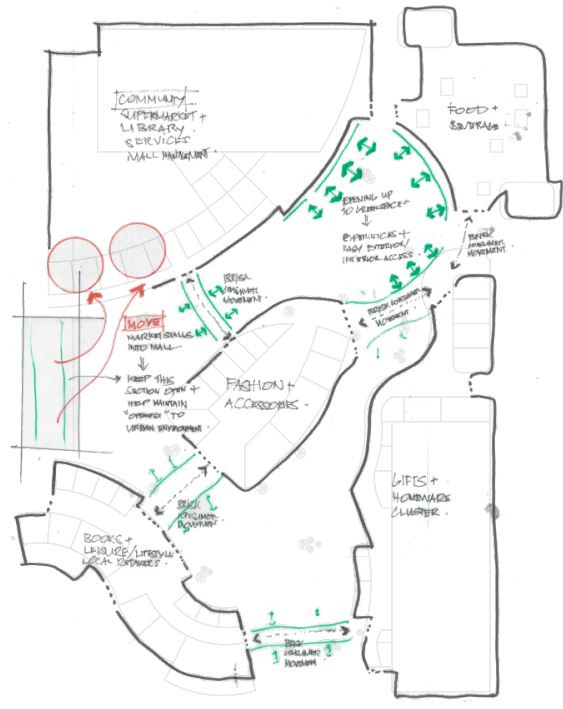

Figure 5.54. Development of linkages leading to iteration 2.2 with consideration of tenant placements.

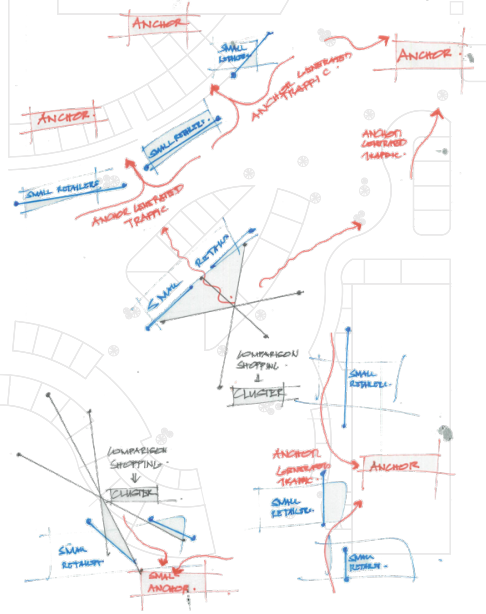

Figure 5.56. Consideration of the relationship between anchor and small retailers for the development of iteration 2.2 . 


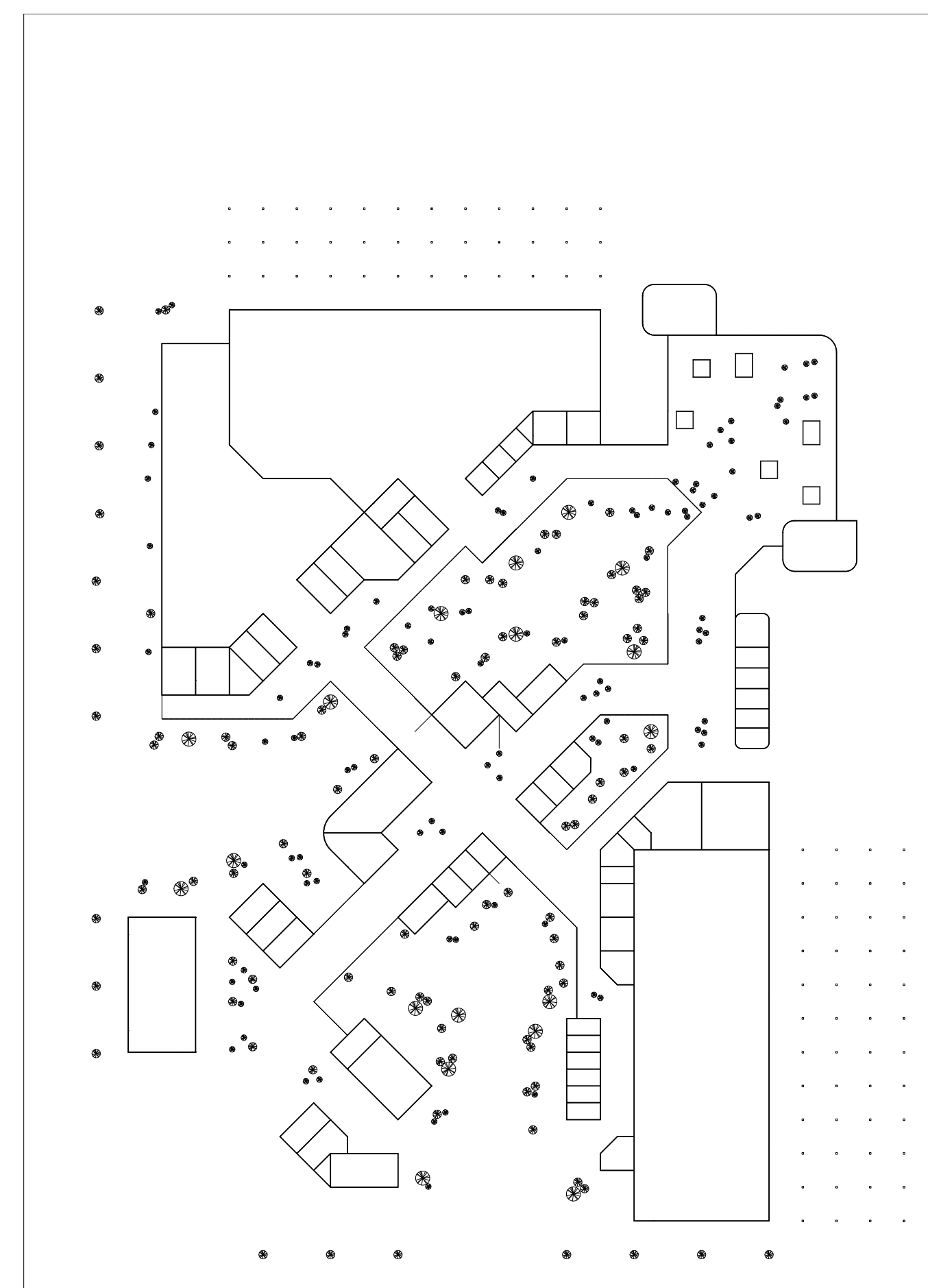

Figure 5.57. Floor plan of iteration 2.3.

1:2000@A4 
Design Development

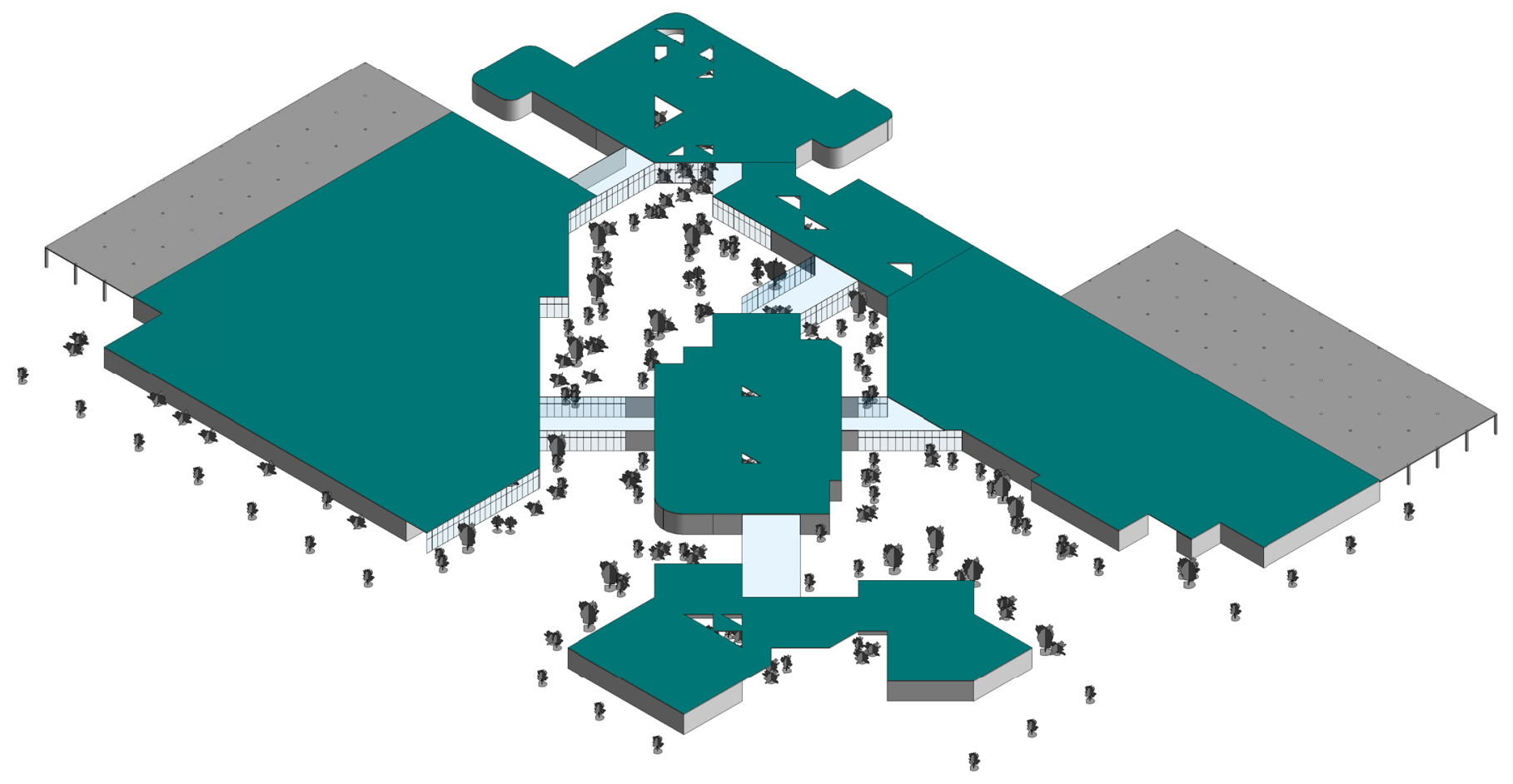

Figure 5.58. Axonometric of iteration 2.3. 

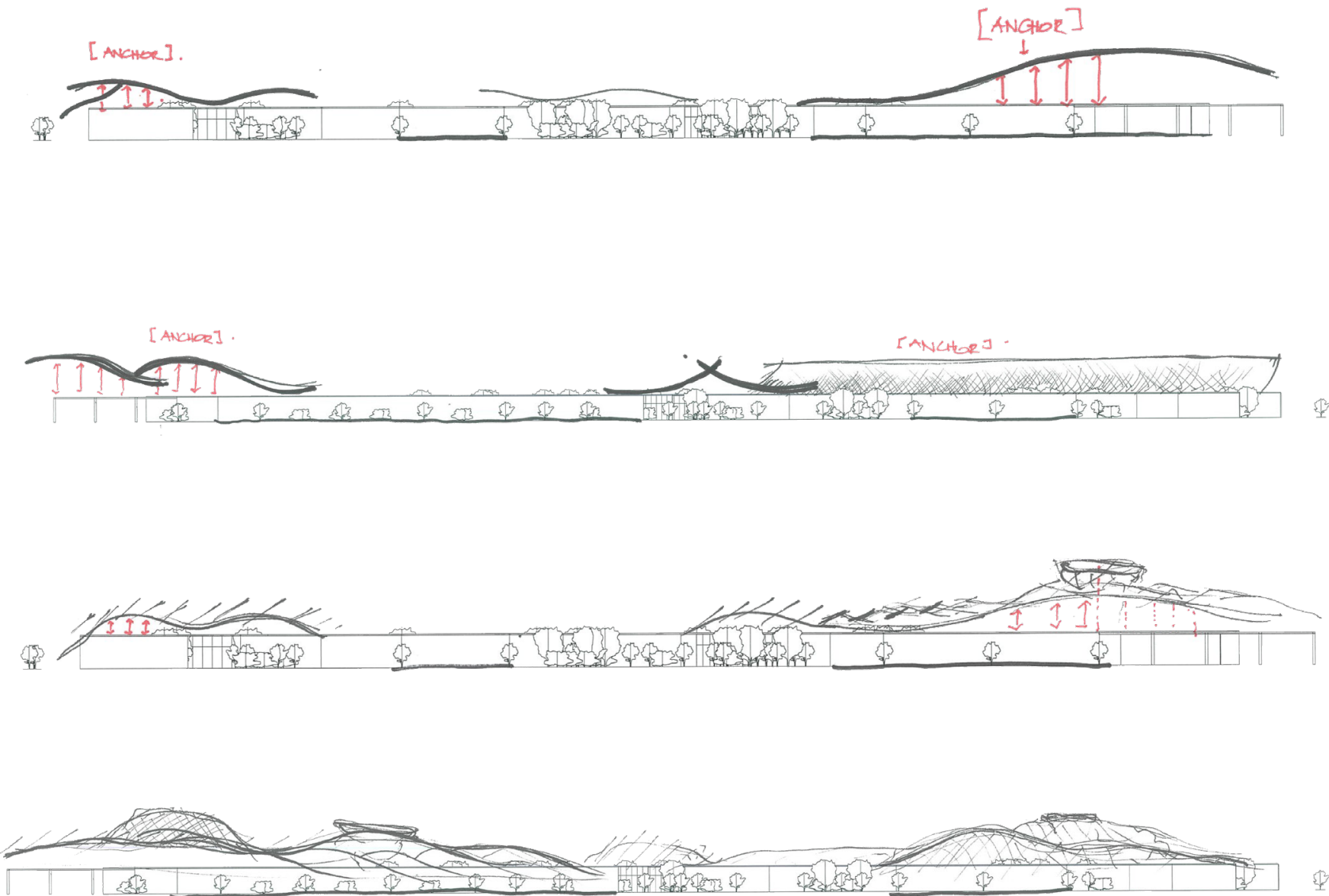

Figure 5.59-5.62. Sketches depicting the utilisation of bold architectural gestures especially through the roofing to create a "wow" factor for the mall that would become its reference to people. I.e. the mall with the "undulating" or "wavy" roof. 


\section{“GESTURE”}

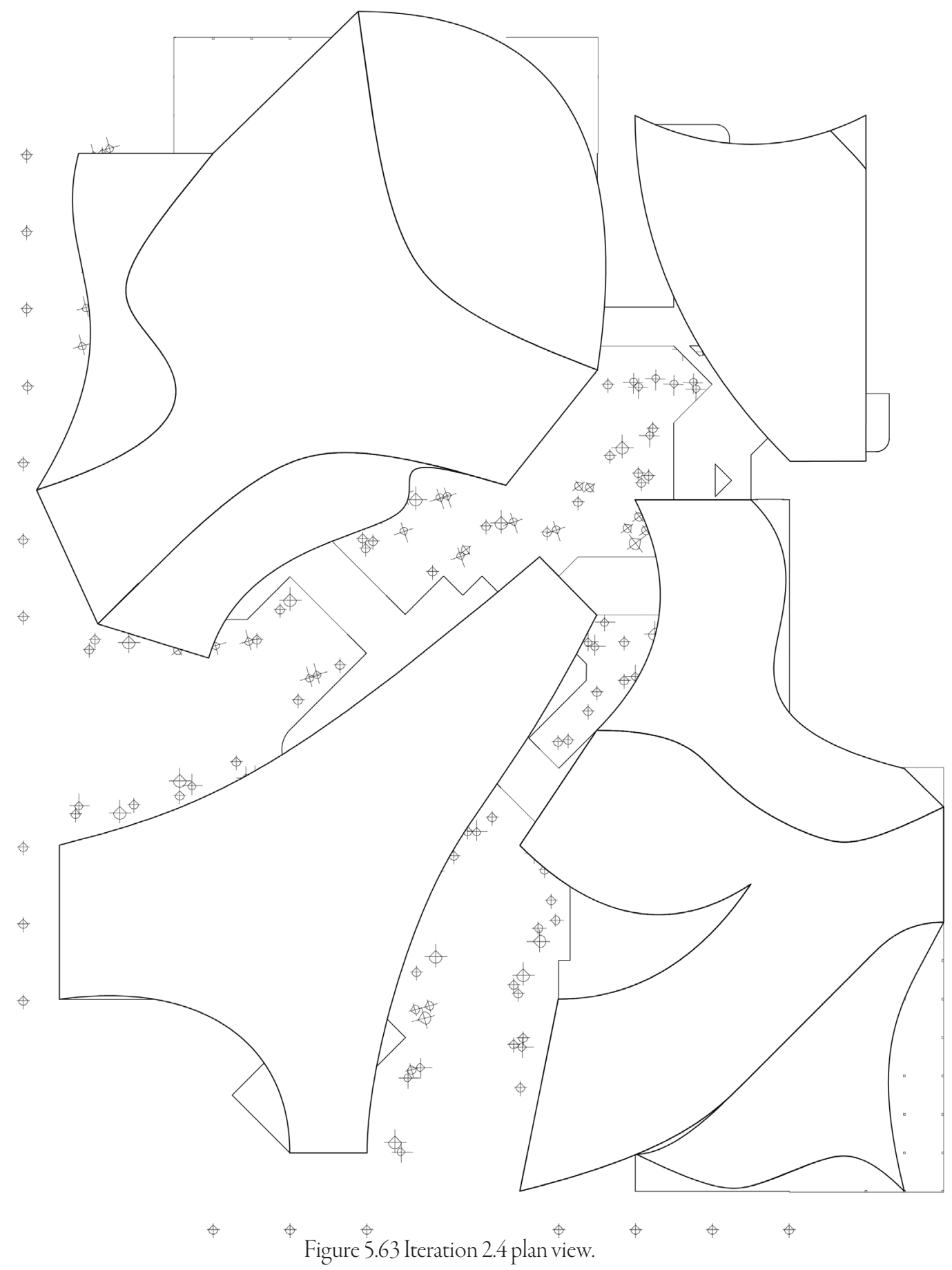



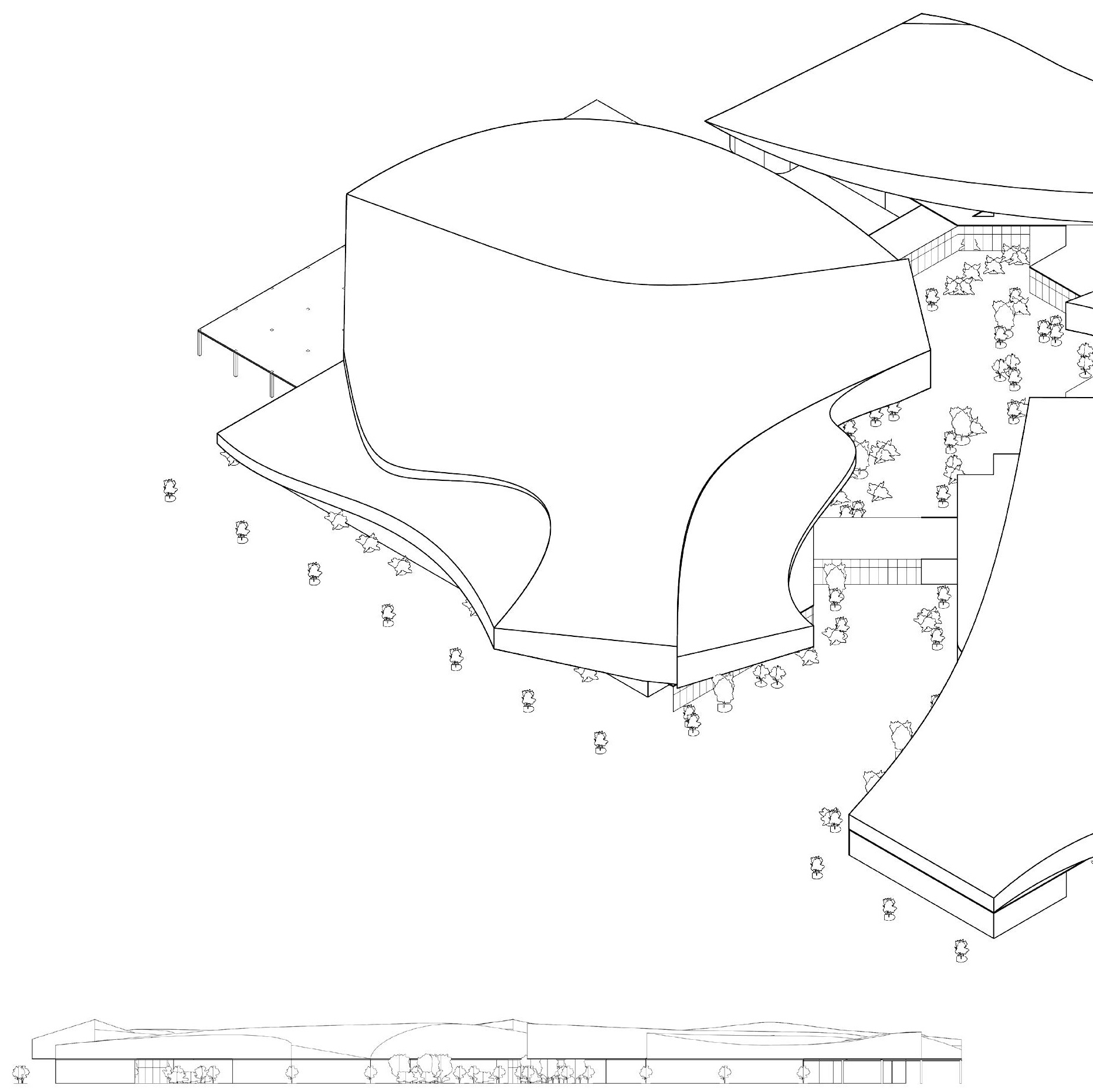

Figure 5.65. Iteration 2.4 South elevation.

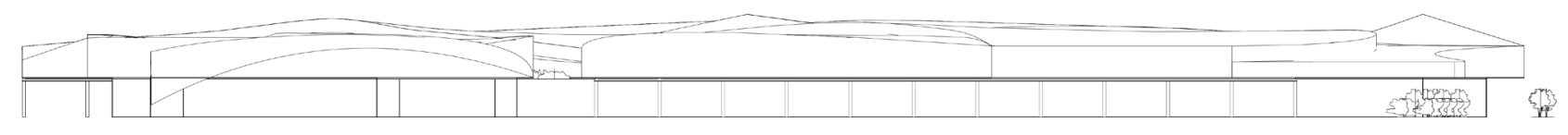

Figure 5.66. Iteration 2.4. north elevation. 


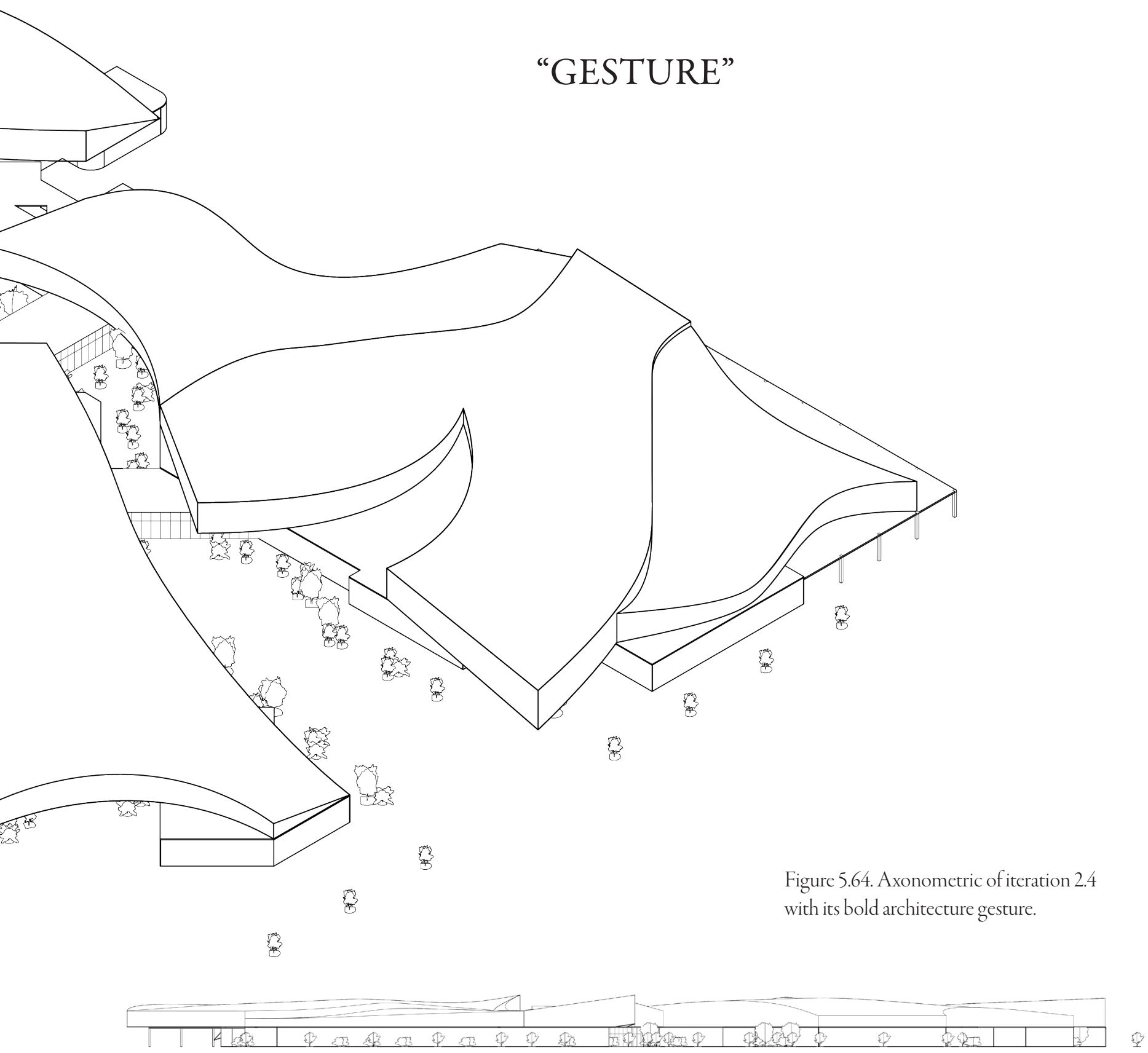

Figure 5.67. Iteration 2.4 west elevation.

3

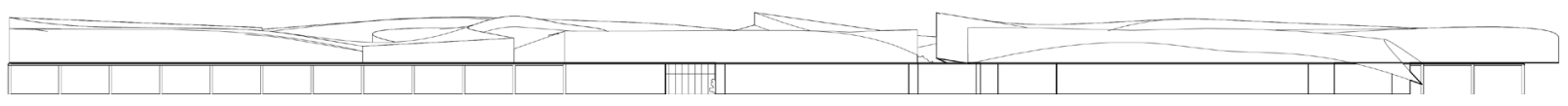

Figure 5.68. Iteration 2.4 east elevation. 


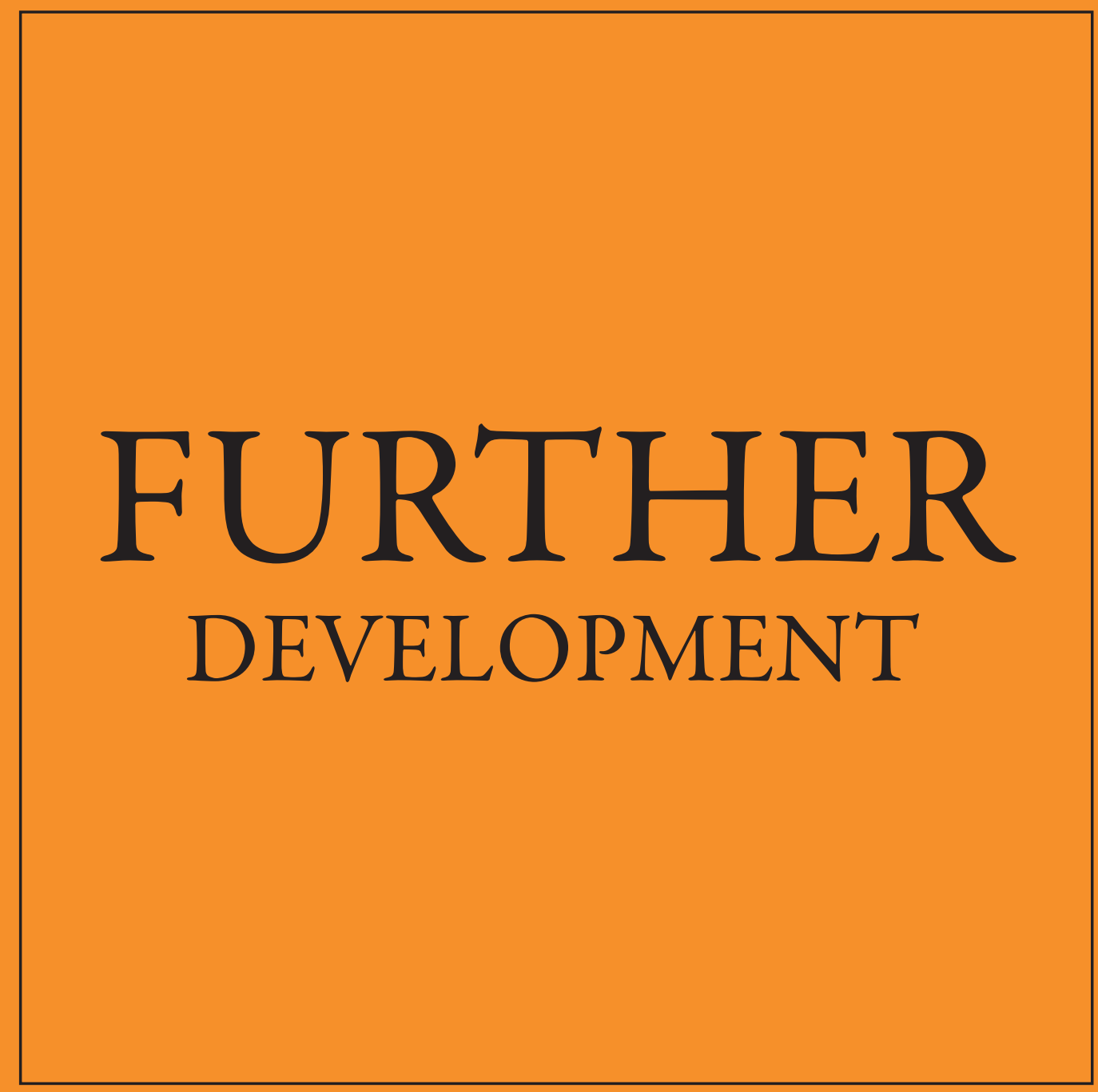




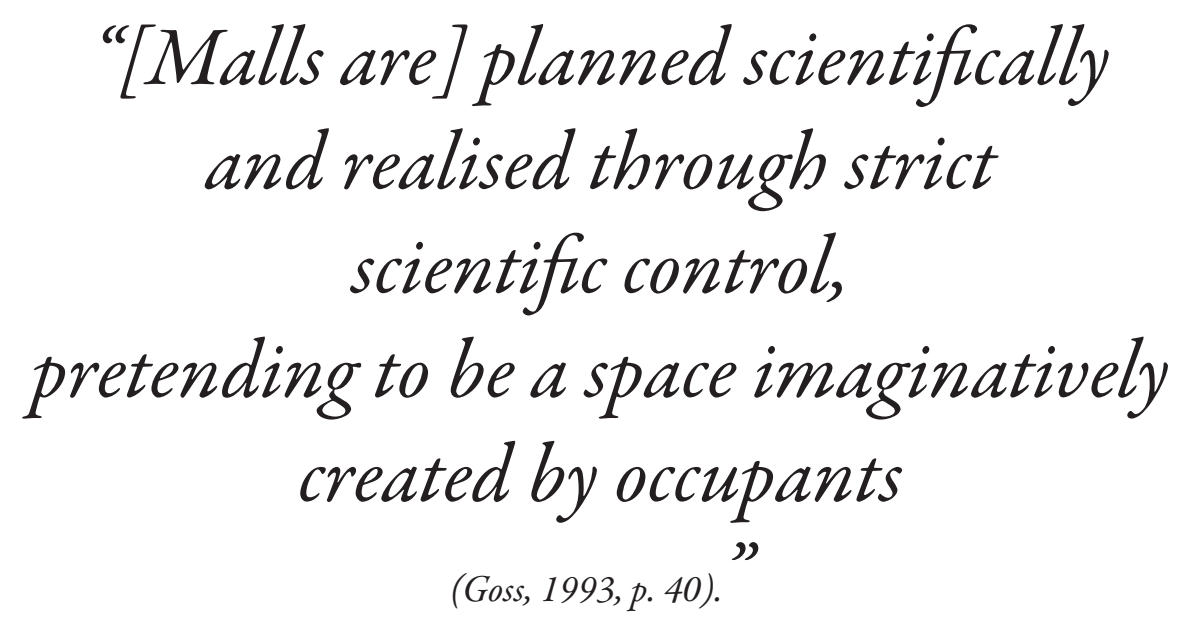

Malls therefore struggle to become a natural part of people's everyday lives. 


\section{Step back and Re-evaluate}

The design process so far, has seemingly taken a "cookie-cutter" approach. This approach to revitalise and enable Eastgate to persist is unfeasible. It would unable to adapt to constantly changing demographics and different spatial demands for space. It has been suggested that there is a reduction in required retail spaces and increasing preference for "non-retail" space geared toward the touch-and-feel experience (Rao, 2019, p. 15). In response, perhaps Eastgate can mix shopping with living, working, and other activities at the human scale to foster a more urban experience of shopping (Rao, 2019, p. 15).

- Design needs to be more critical in terms of strategy towards retail- think and approach it not so much retail and even spatial?

- Could rethink alliance with buildings around the mall?

- Reconsider and analyse the definition of to persist:

What has worked with the current mall?

Why for instance have precedents like the bazaar worked? And continue to persist today?

Consider how person to person trade has persisted? And ways the built environment has aided it?

Focus on small shops and retailers, rely less on anchors

However, making the optimum use of spaces is essential to retail store designs. 


\section{Step back and Re-evaluate}

- Think smaller- work at a smaller scale- could look at the small, intimate experiences, collate and add them together to create one big experience that will define the rejuvenated Eastgate Mall design

- $\quad$ Many people do not buy products; they buy the brand. Products and experiences provided are the extension of brands.

- People want to shop in a number of different ways and count on brands to offer them services that reflect the way they live

- $\quad$ Provide something that can't be found online

Additional questions to guide design development:

- $\quad$ By thinking and working at a smaller scale, perhaps we can contribute to persistence by asking "how do we reinvent the store to enrich customer experiences?"

- How can Eastgate provide an escape from daily life, boredom and stress?

- Malls were envisioned to be alternatives to the city, to house a city within a building. A basic element of cities are nodes- and nodes of human activity (Berezko, 2014, p. 6). How can we reinterpret nodes as spatial elements to help shape and revitalise Eastgate Mall? As experiences?

What could this look like?

- $\quad$ Creating a place conducive to a leisurely stroll

- Go skating, ride a ferris-wheel and swim all in one day and at the same place?

- $\quad$ Efficient shopping is not the primary goal; lead people to embark on a journey of discovery, to find inspiration and almost only incidentally become aware of products 
LESILN IN REVIEN

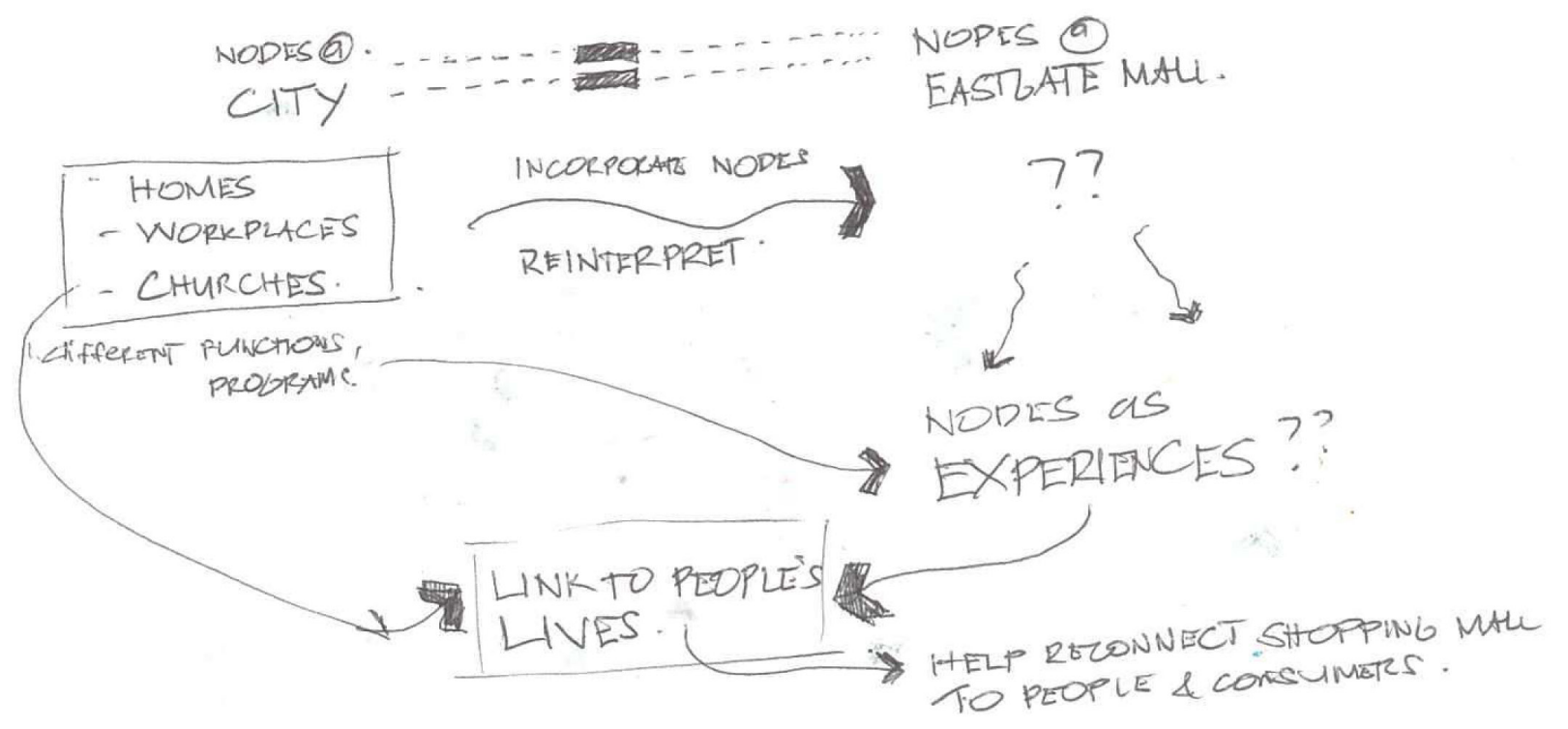

Figure 6.0. Rethinking Eastgate in terms of nodes. 


\section{RE-DIRECTION}

The architectural design proposed by this thesis aims to enhance shopping and social environments within the complex to encourage patronage and the growth of local (and particularly small) retailers.

It will be fundamental to create a balance between experience and convenience. To counteract the globalised one-size-fits-all, "cookie-cutter" strategy, the design proposed by this thesis focuses on experiences. The spaces in this rejuvenated architectural design for Eastgate, aim to make experiences meaningful and memorable by activating social interactions-whether they be encounters, exchanges and relationships. This approach can transform stores into destinations that customers want to visit. It would also divert attention from explicitly selling to a focus on raising awareness of products and related processes such as their manufacture or crafting. This would add an educational and entertaining dimension. Although these experiences may be "free giveaways", they can encourage people to return, and boost customer loyalty and sales.

General overview of design:

- $\quad$ Focus on making shopping mall spaces engaging and interactive

- Utilise striking and unique elements that can go "viral"- utilised in stores/general mall spaces to embed stronger and more enduring means of evoking context and culture.

- $\quad$ Focus on creating "stages" for people, to allow retailers and customers to switch roles and thus communicate, enjoy and consume in a different way.

- $\quad$ Enable spaces to be flexibly arranged to provide customers with free-flowing experiences

- Enable spaces to be configured recreationally to entice internet shoppers, justifying a physical presence for retailers with online presence whilst attracting new customers through mall footfall.

- $\quad$ Aim to enhance existing paths around Eastgate and extending these inside the mall. This is to integrate the building to the urban context, and connect activities and programs to it 


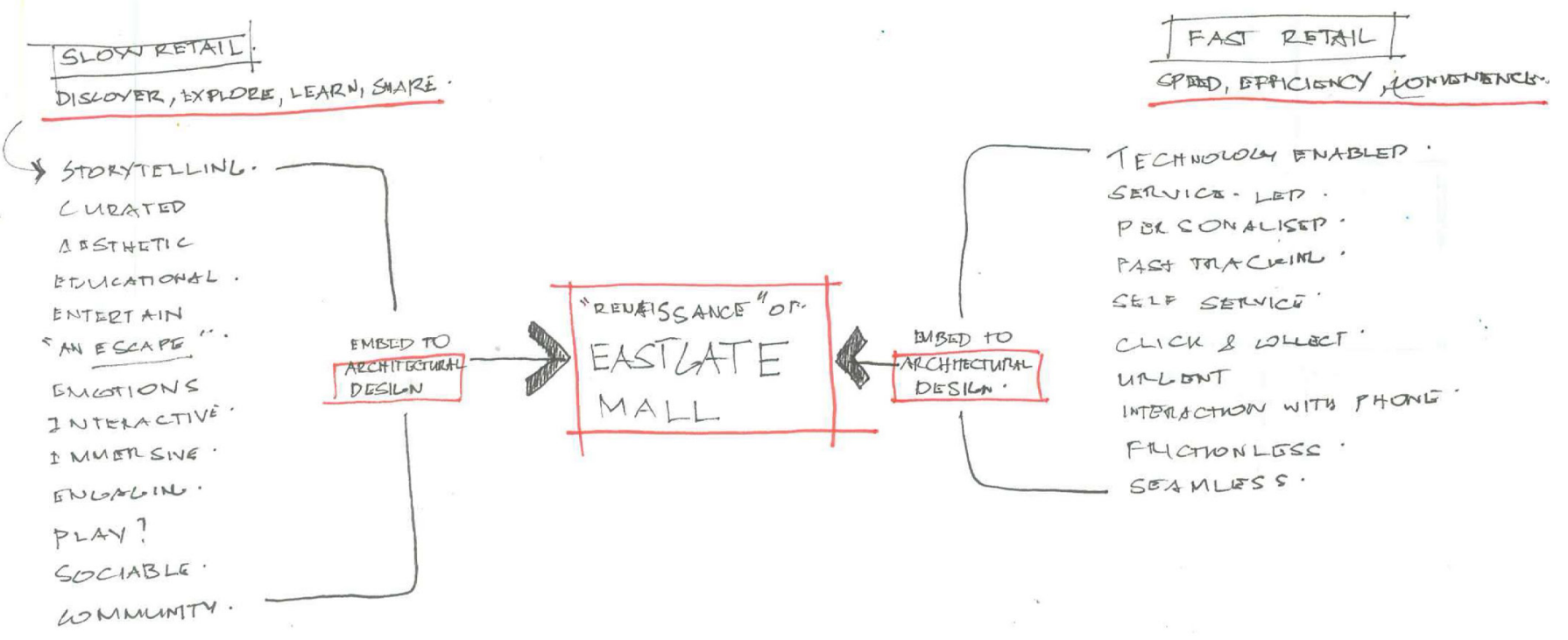

Figure 6.1. Balancing between slow and fast retail to offer both experience and convenience.

FLUID RETAIL

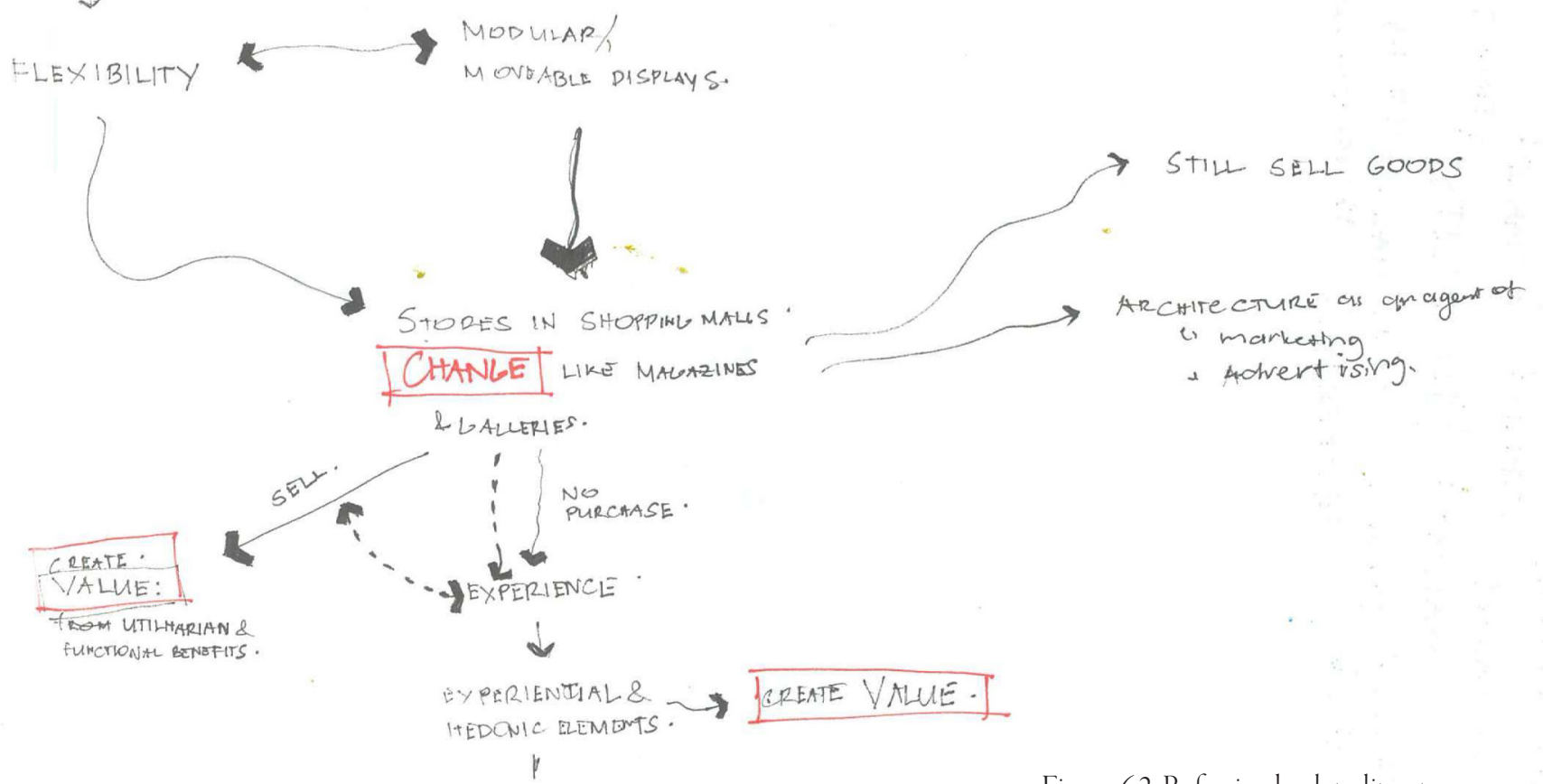

Figure 6.2. Referring back to literature review and the framework of Fluid Retail. 


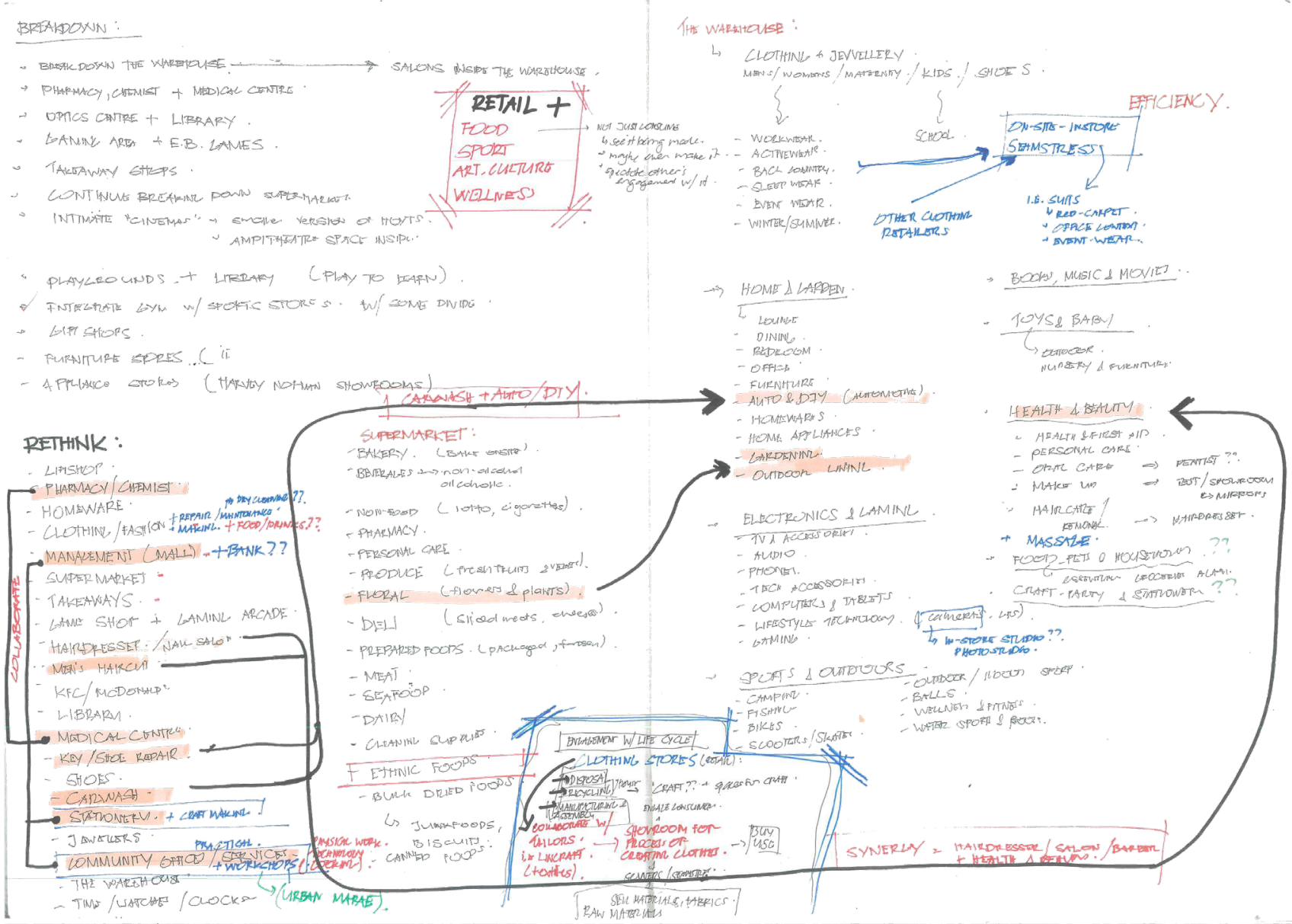

\section{BREAKDONN:}

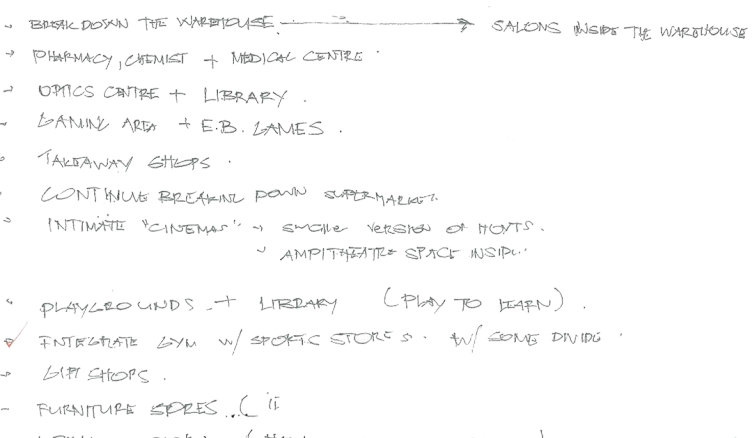

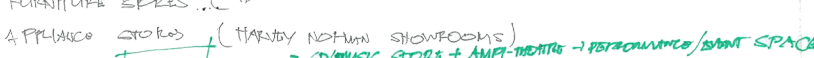

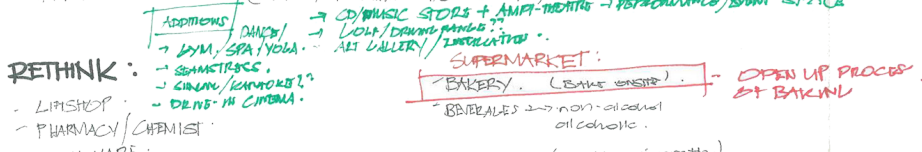

- Pharmacy / CatMISI

HOMEWARE.

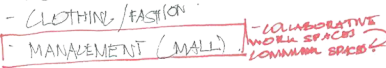

- SUPERMALKET, CONAE T TO

GAME SHIOT I LAMINL ARCADES

- MAIRDRESSER. NAMU SAlon-

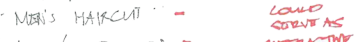

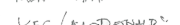

KFC/MCDONAL: - JNTERTM

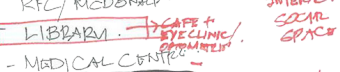

- KEY STOE REPART, SHUTE W

DSHOES. TARANA CAFE?

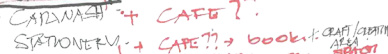

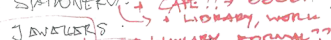

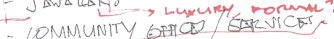

- the warencus

- Tho/hatches / clocks

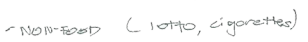

- Praemacy

- persenar care.

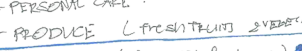

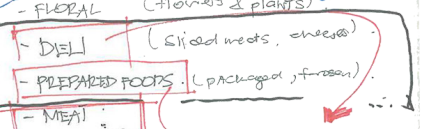

- SEAFOOO I.

DAIR

- cheaniar supplás.

- Bunk DRED iOODS

is JuRMPOODS,

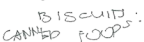

i. T2. Theos

IN STOON STMPLES

TBAROON'

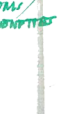

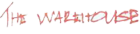

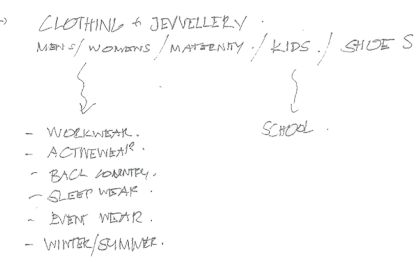

EFFCIENCY
BOoks, MUSIC \& MONIt]

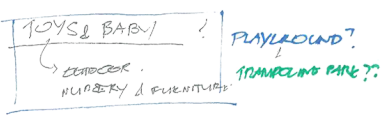

HEALTH \& BEATM

- HOME APPLIANCES .

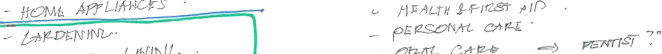

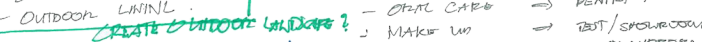

Haircitiel

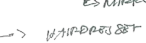

$\rightarrow$ ELECTRONICS \& LAMINL

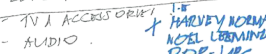

PHONE:

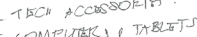

COMPUTAR \& TABLETS

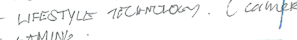

GTMINE

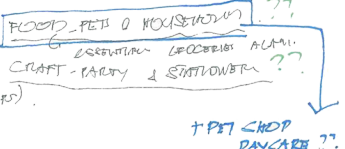

$+P 7<$ CAOP

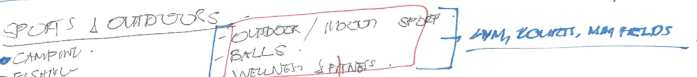

\section{Thisince}

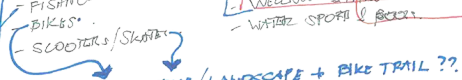

LI LREEW SHOWROOMS/LAWOSCAPE + BIKE TRAIL ??

$\rightarrow$ POND, MNI LAKE

IADDitions /

L Laund foryars.

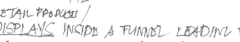

A FOOJBHC PRID (MIN)

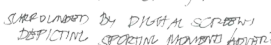

Figure 6.3 \& 6.4. Rethinking relationships between different current shop types in Eastgate to create hybrids. 


\section{FXPERIENTINL FORMATS:}

FlaLSHIP STORES.

- CONCEAT STORES.

$$
\Longrightarrow \quad \begin{aligned}
& \text { MULTI-SENGORY } \\
& \text { STORT SETTINLS }
\end{aligned} \Rightarrow
$$

- POP UP STORES.

SHOWROOMS.

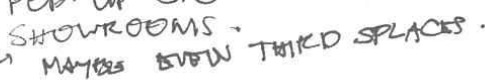

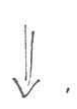

- AR, VR,

- INTRLLILAT FUTML ROONS.

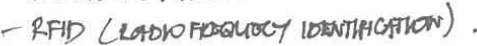

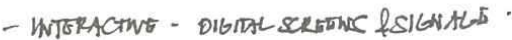

- IPADS/WIF

- seff-seonce checuouis

- Mosile apos.

- Click \& collorg/torivi.

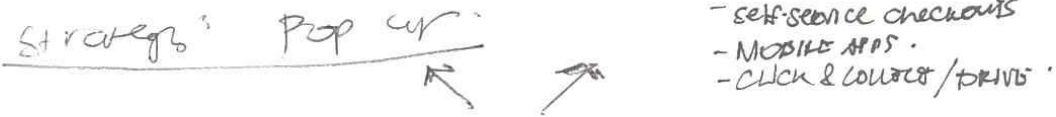
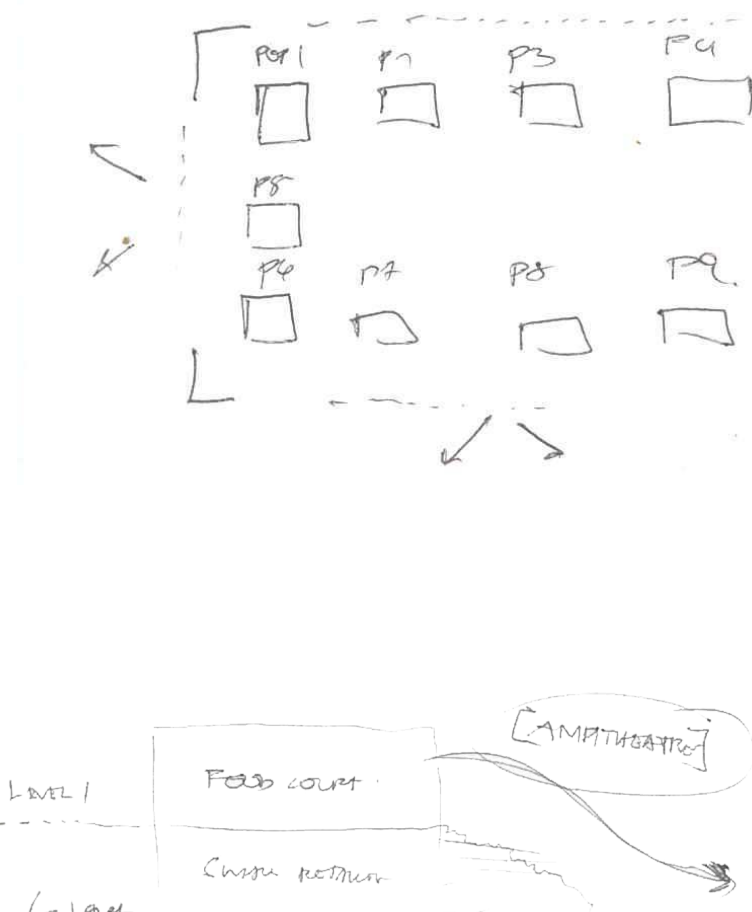

Coner

oumooor binil spaces.
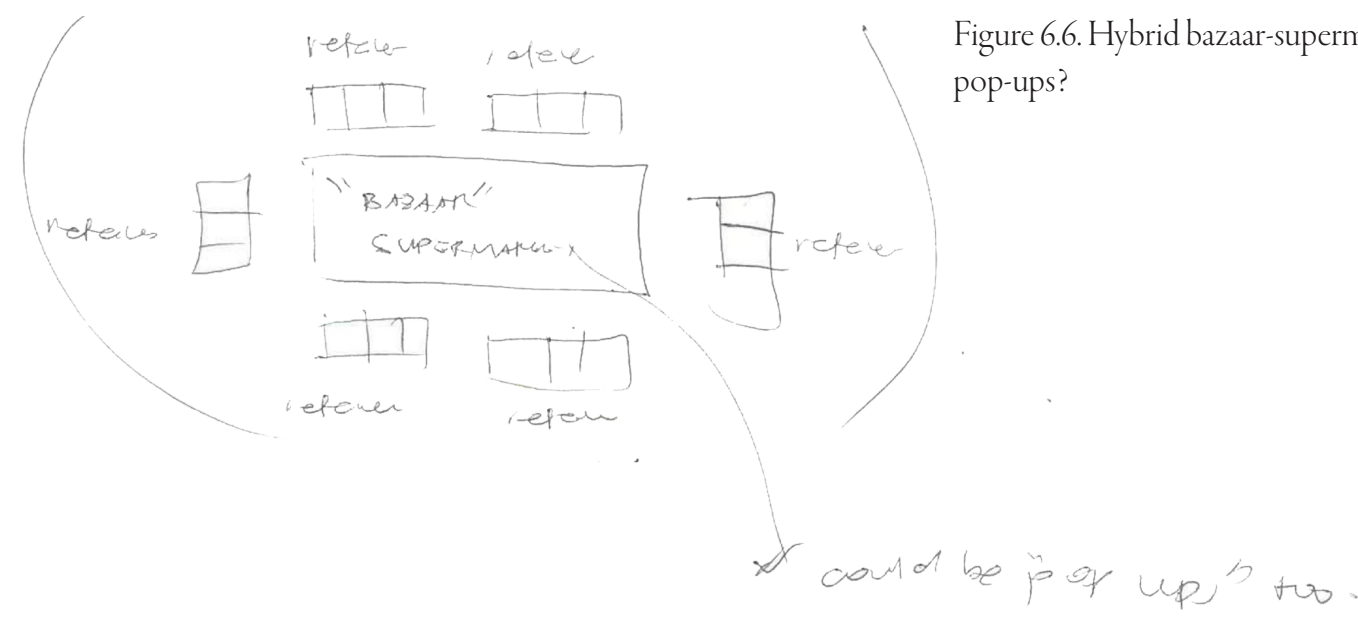


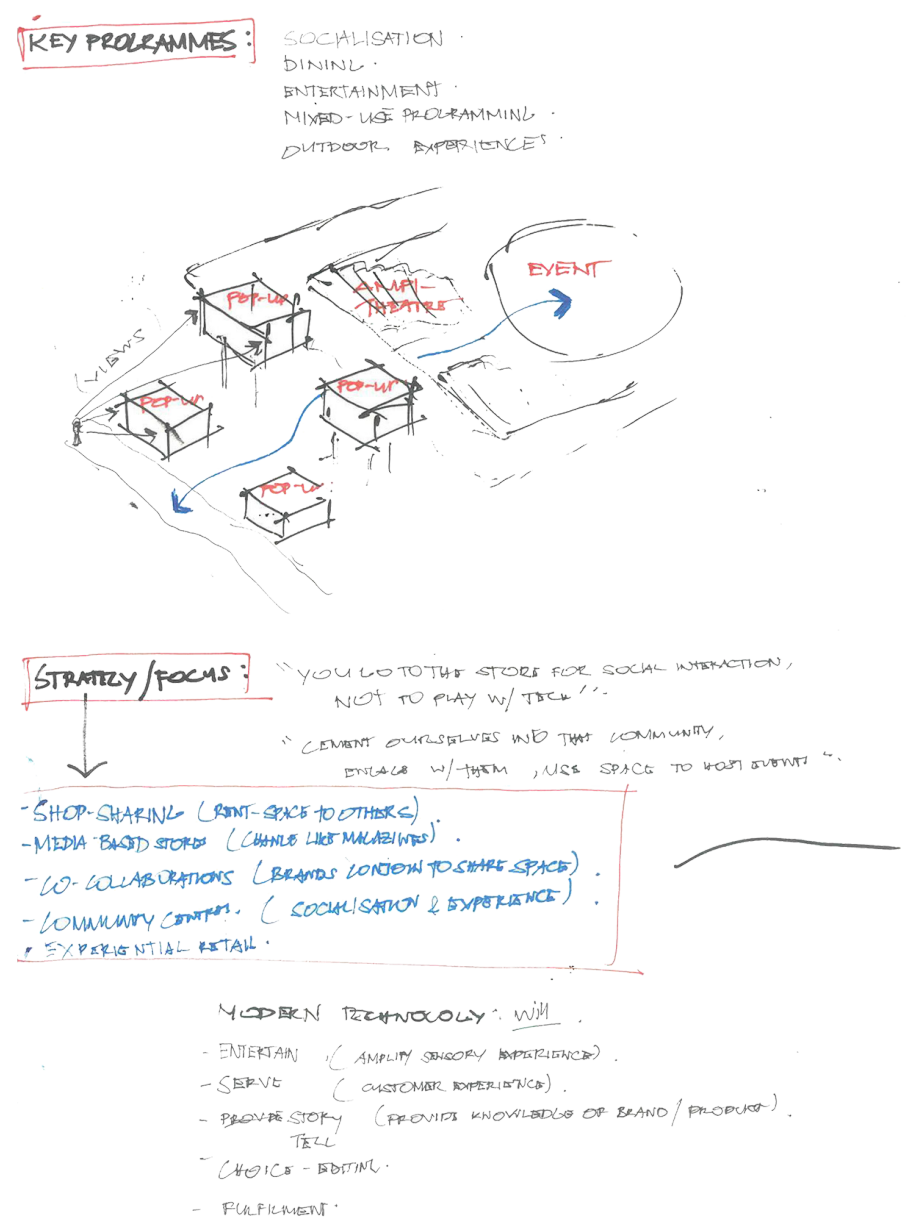

Figure 6.7. Illustration of potential shopping experiences.

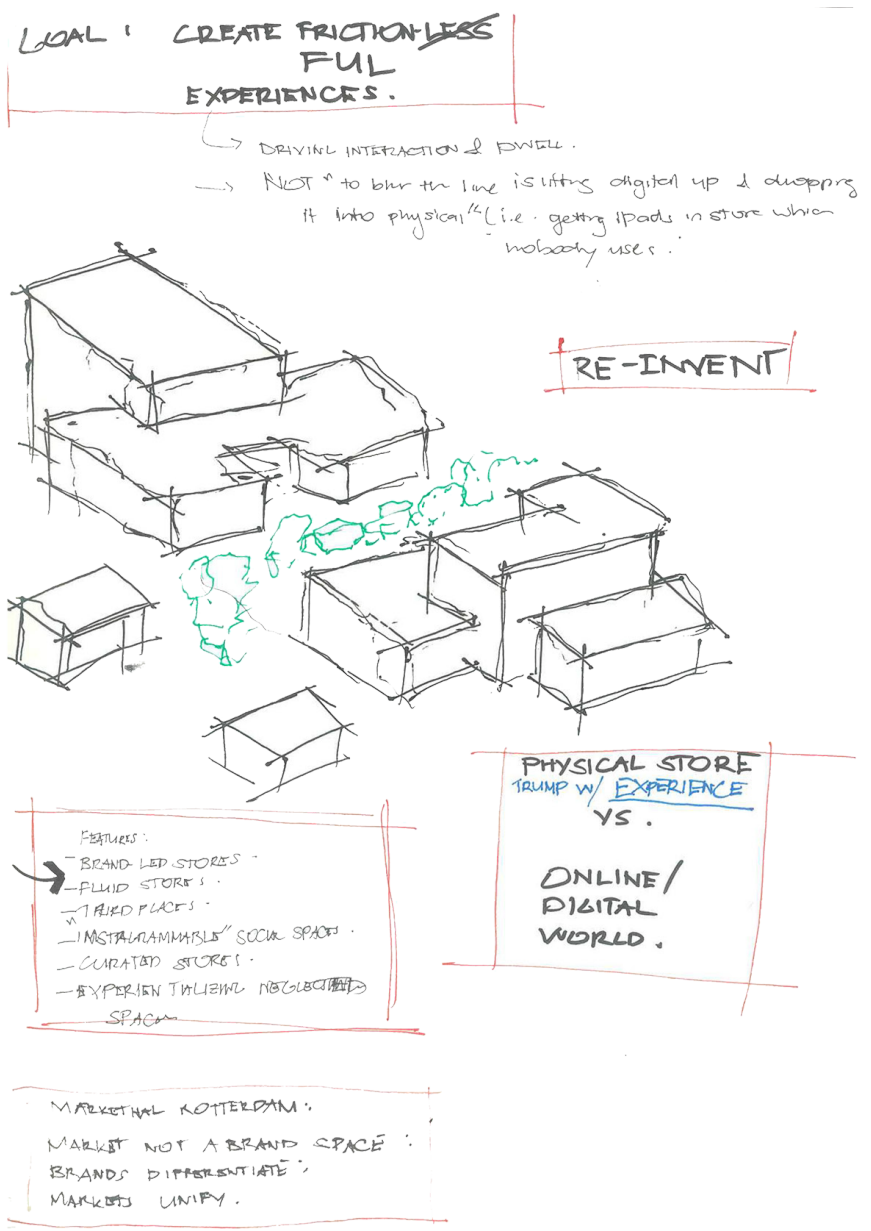

Figure 6.8. Illustration of building volumes in relation to greenery. 


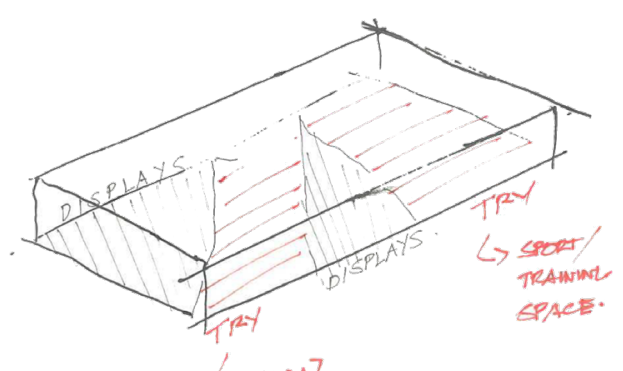

1. E. CONCERTIL

SPUा SHDP.

GPON SHOP

+ LYM/TRACK?

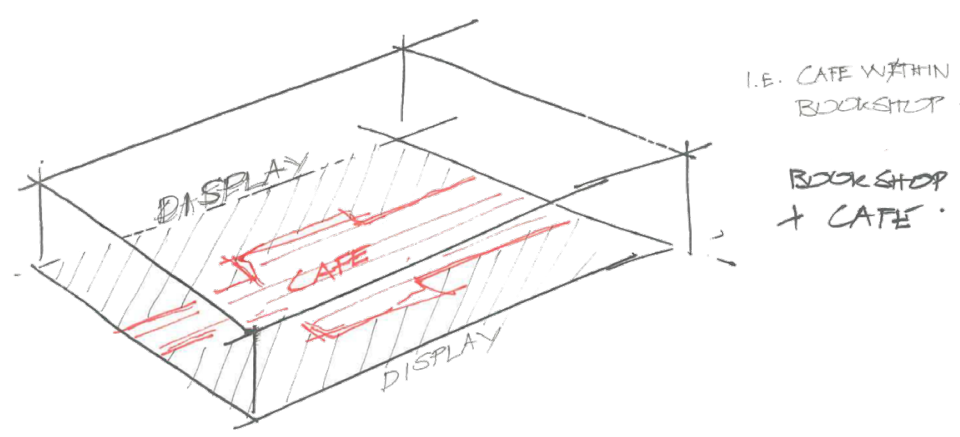

Figure 6.9. Illustration of potential clothing shop experiences.

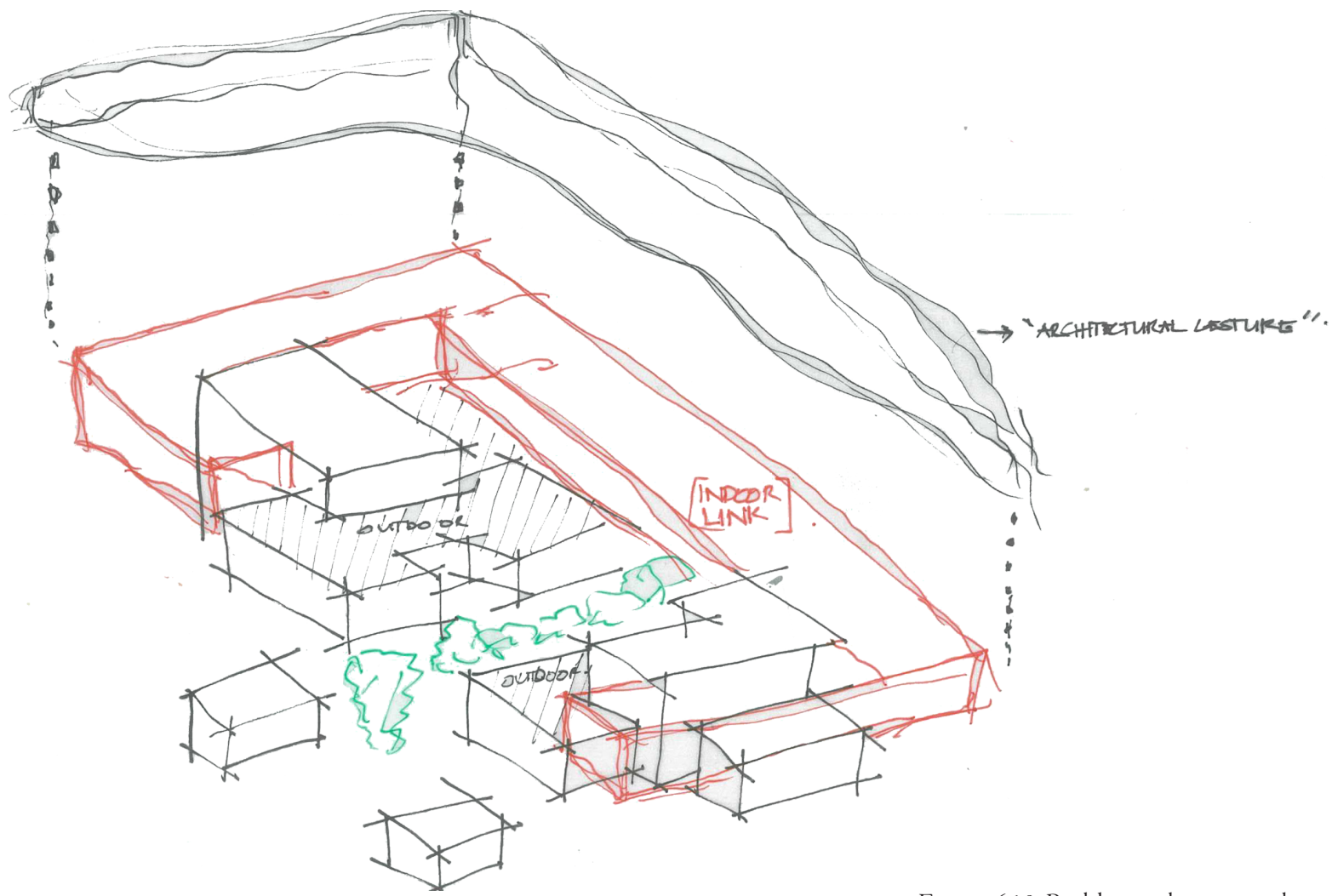

Figure 6.10. Building volumes in relation to a bold architectural gesture. 


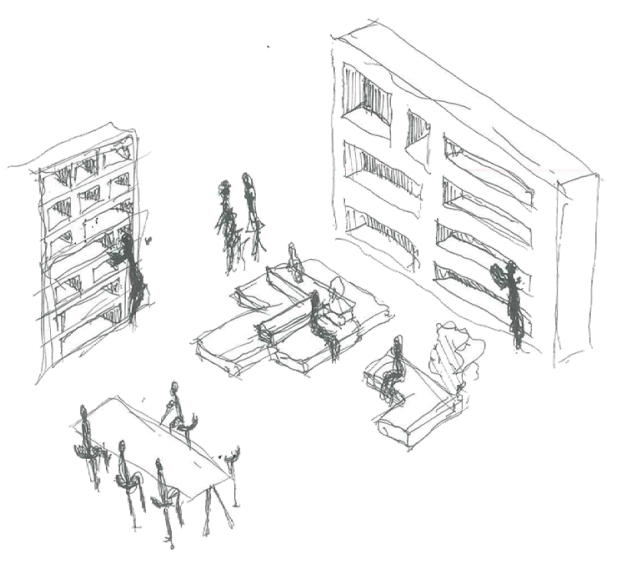

Figure 6.11. Café and bookshop combined.

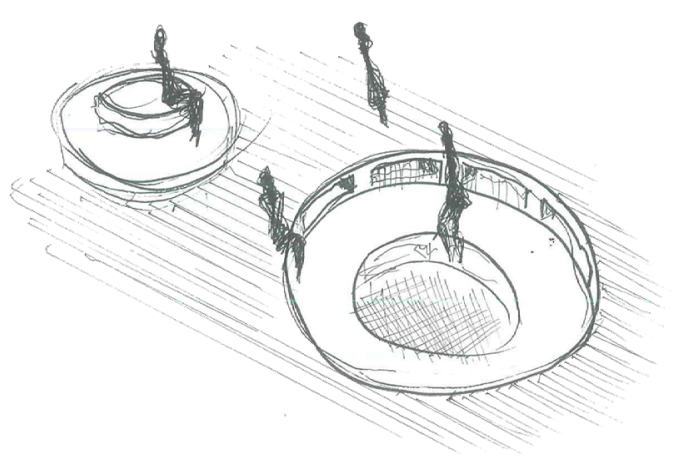

Figure 6.13. Bookshop, green and social spaces. .

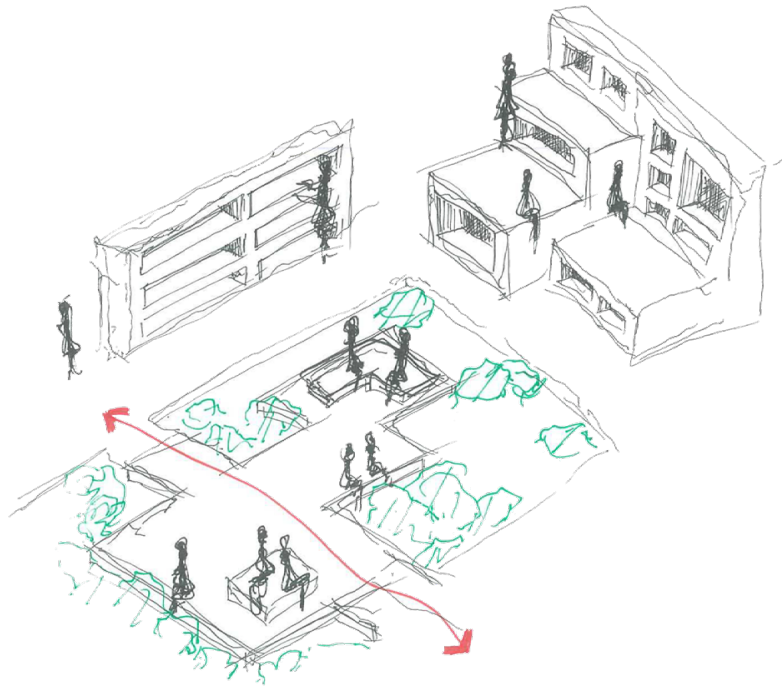

Figure 6.12. Bookshop and social spaces.

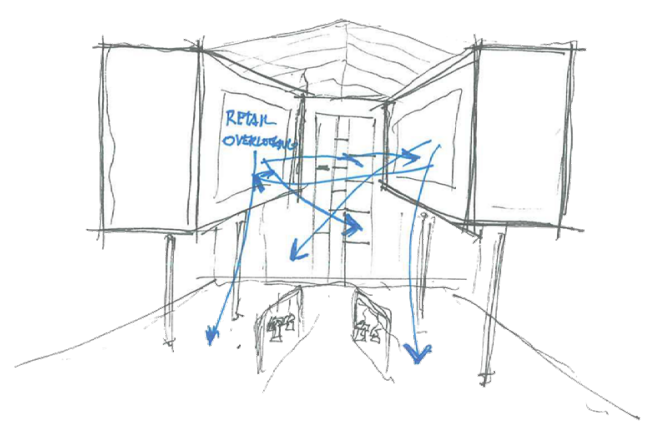
OVERLOKNNG.

Figure 6.14. Retailers overlooking each other to maintain visual continuity and connection throughout the mall. 


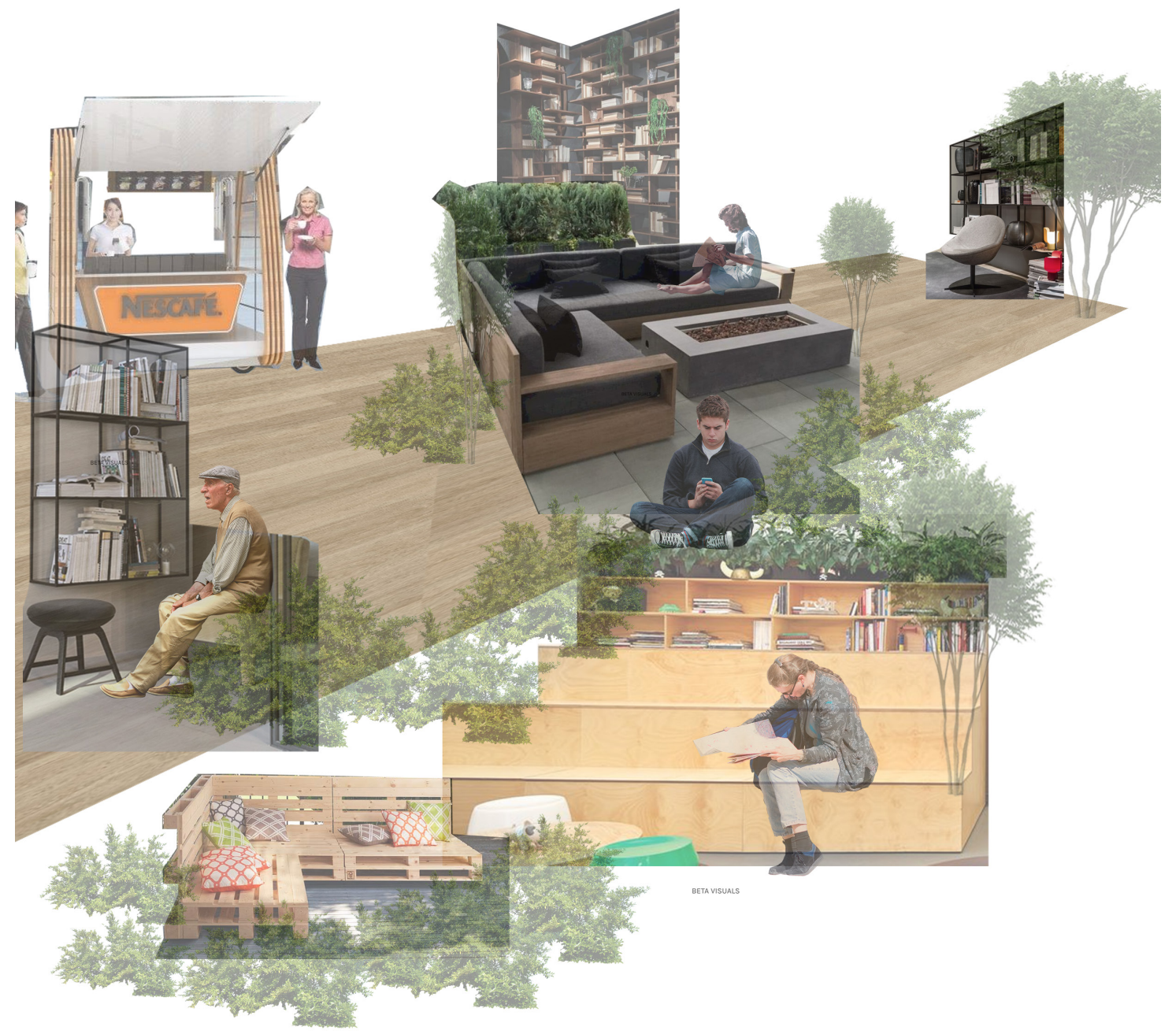

Figure 6.15. Atmosphere of social spaces combined with shops. Author's illustration. 


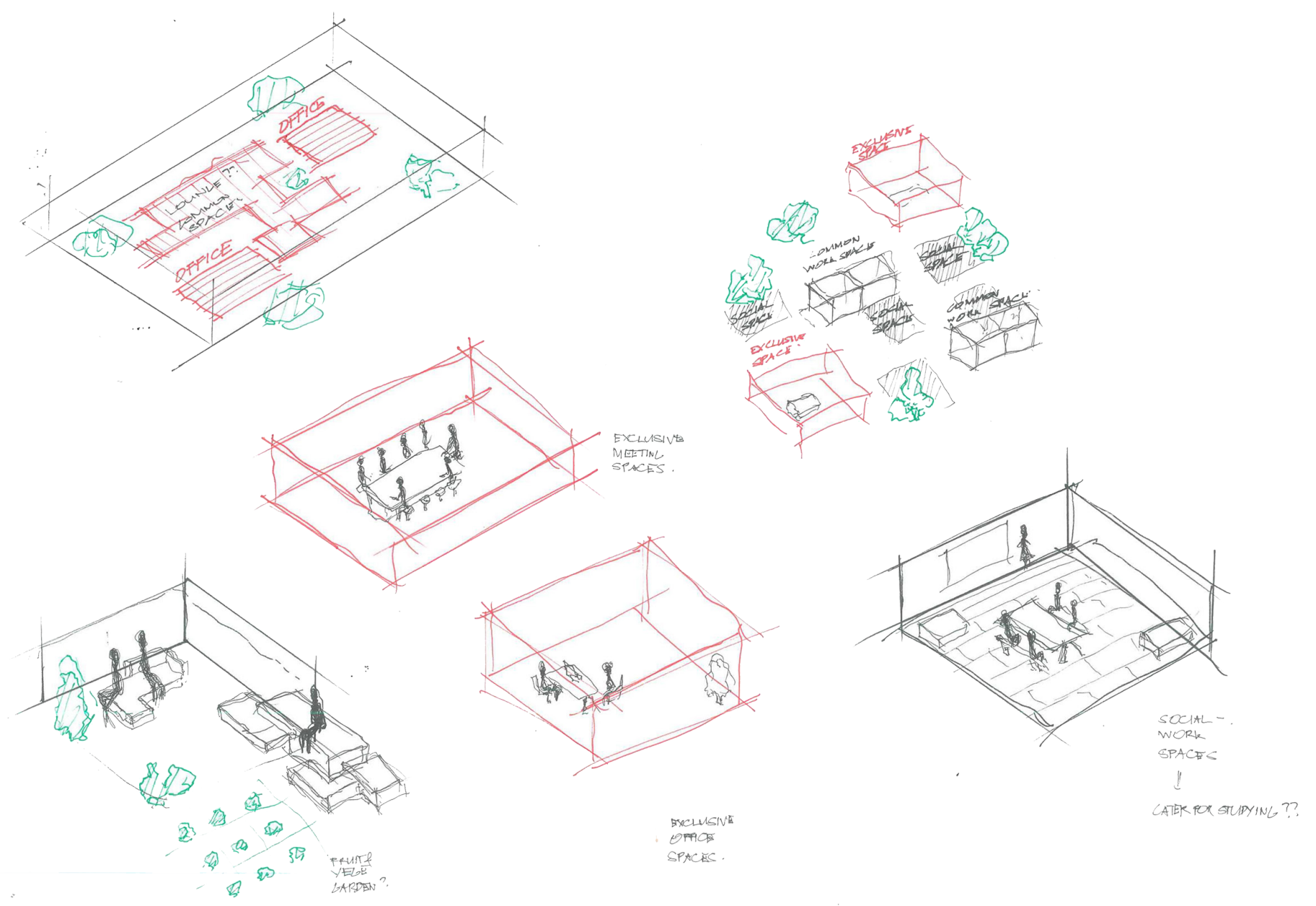

Figure 6.16. Offices spaces within the mall with greenery. 


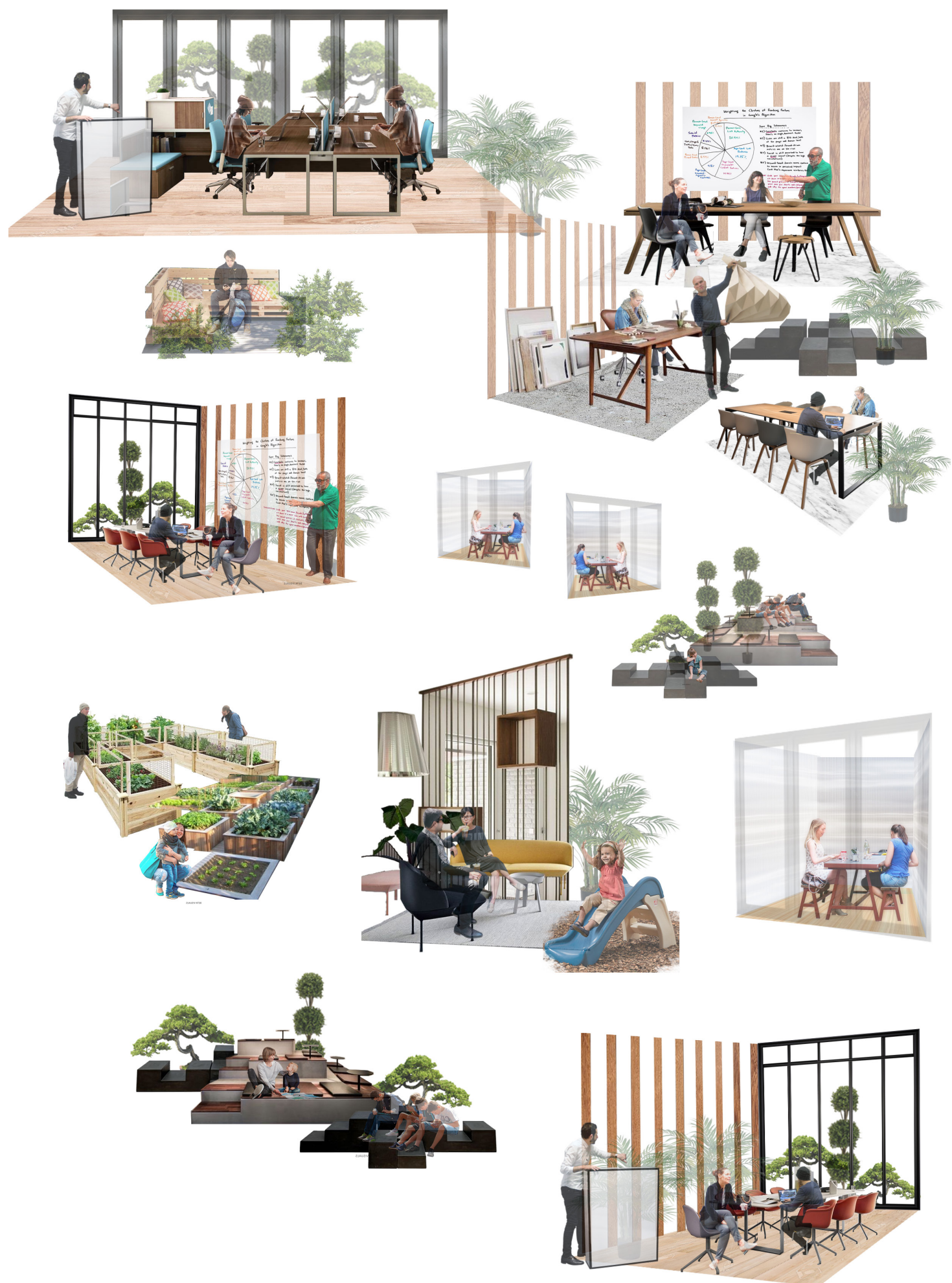

Figure 6.17. Atmosphere of offices spaces within the mall with greenery. Author's illustration. 


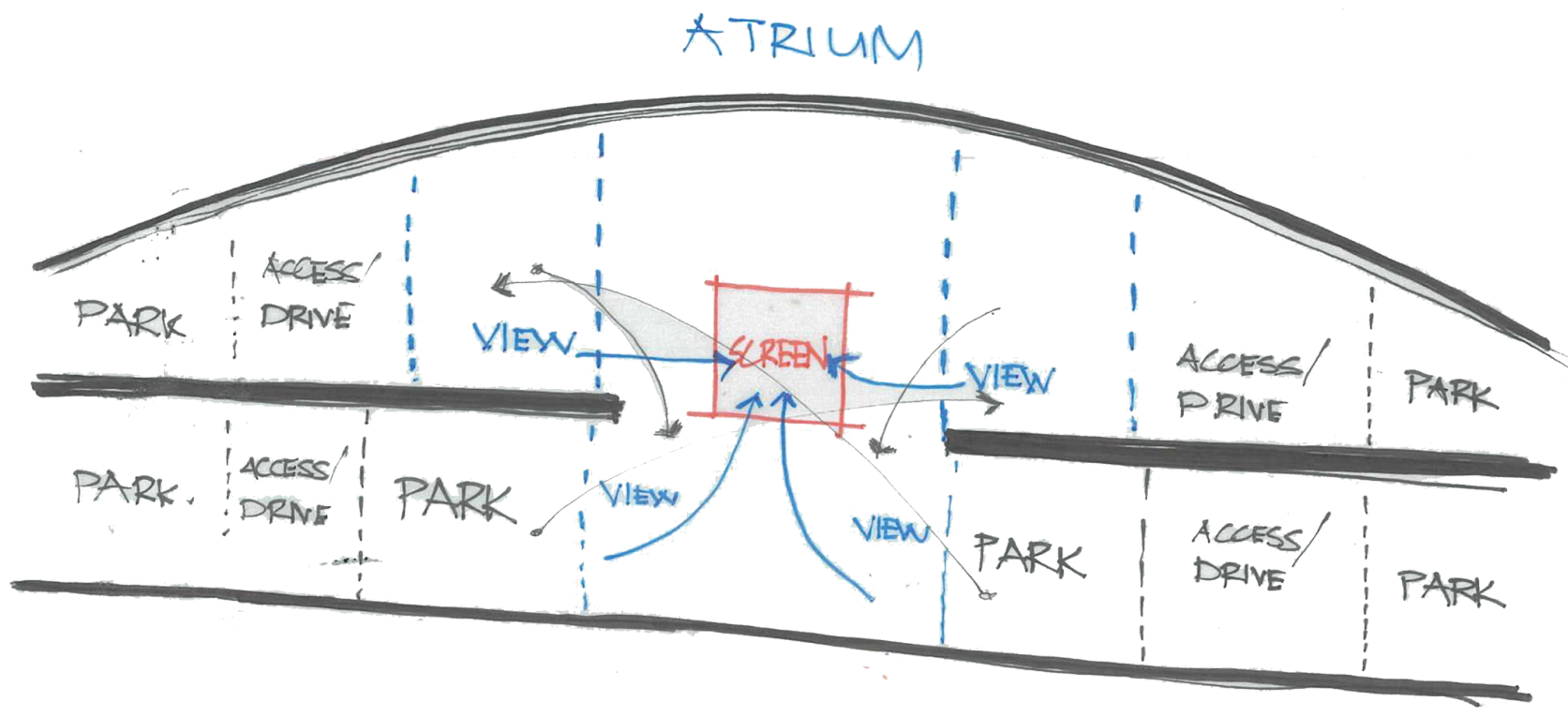

Figure 6.17. Sectional illustration of a potential drive-in cinema in carpark.

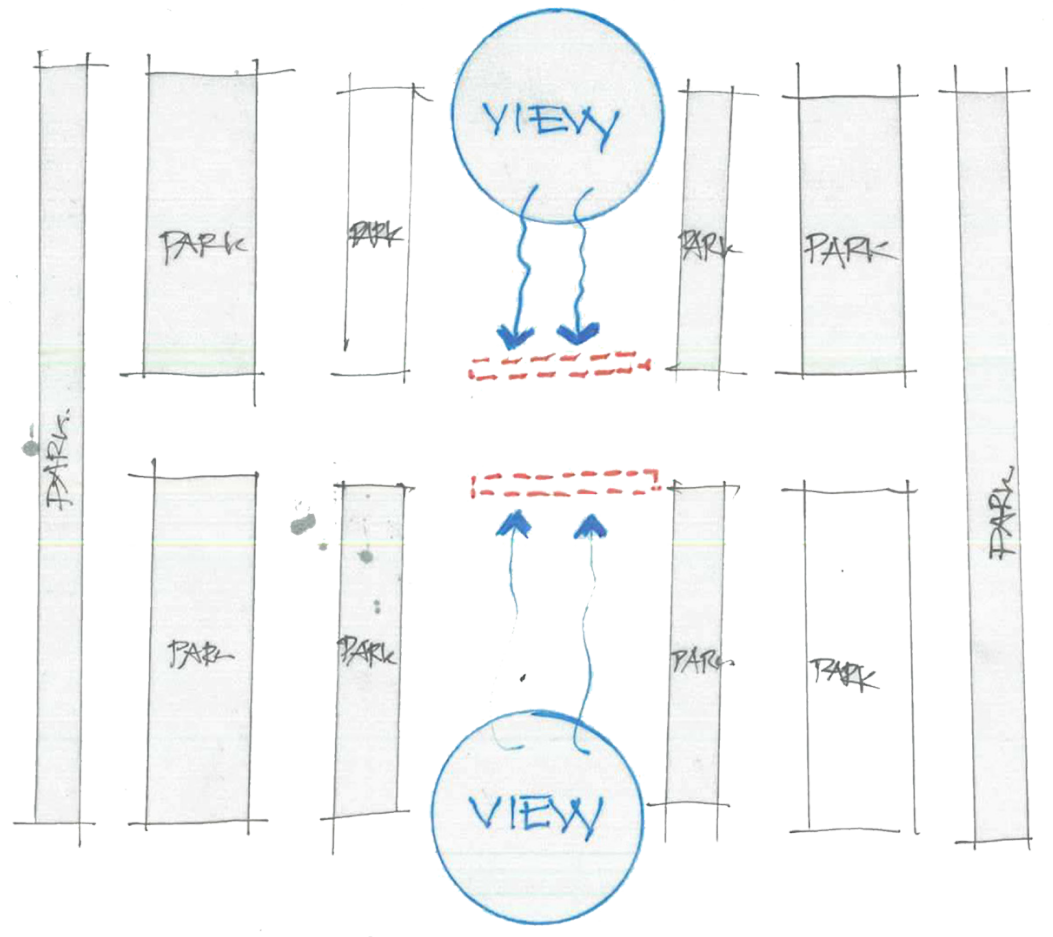

Figure 6.18. Plan of drive-in cinema. 


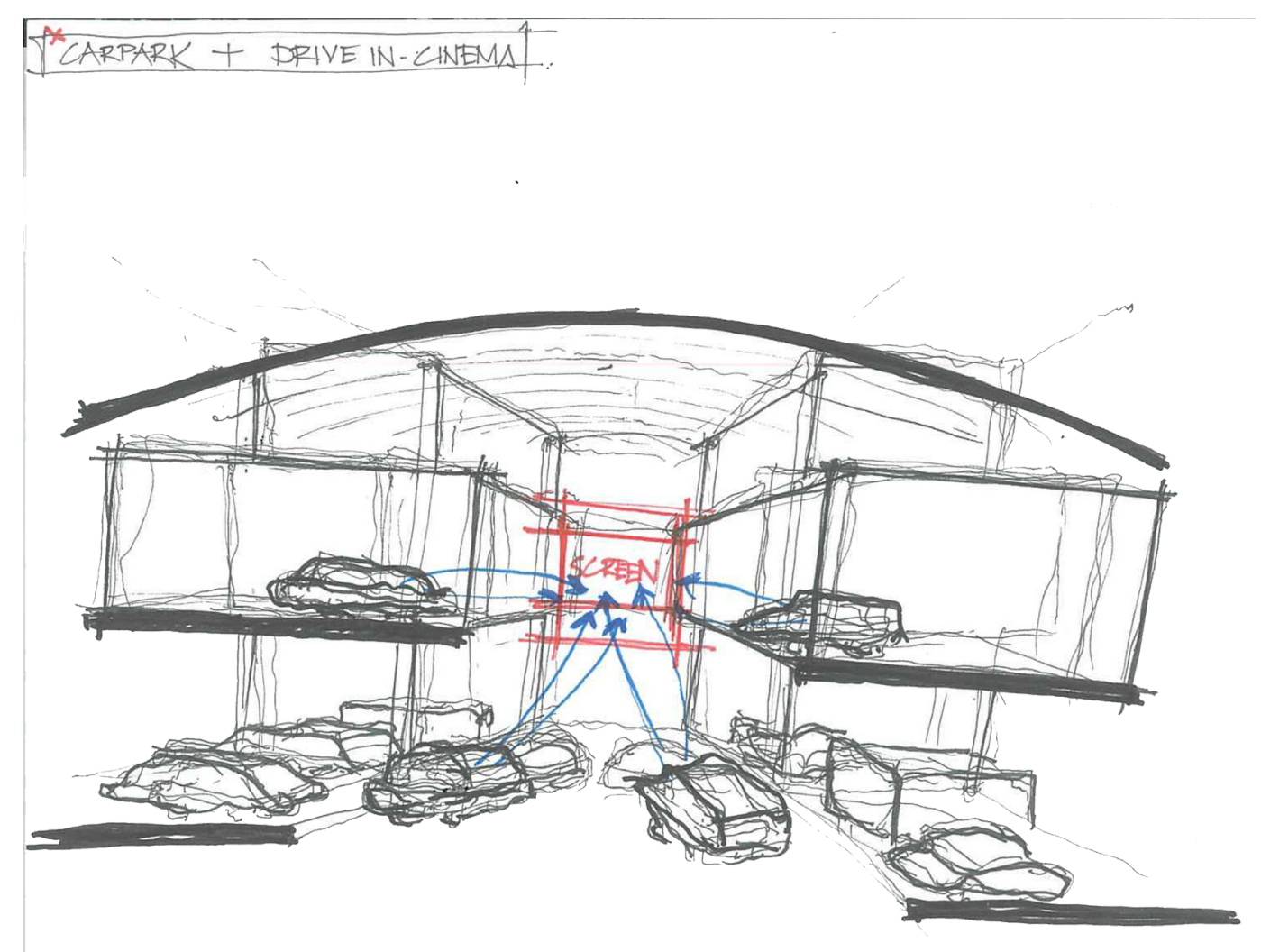

Figure 6.19. Atmospheric sectional illustration of drive-in cinema.

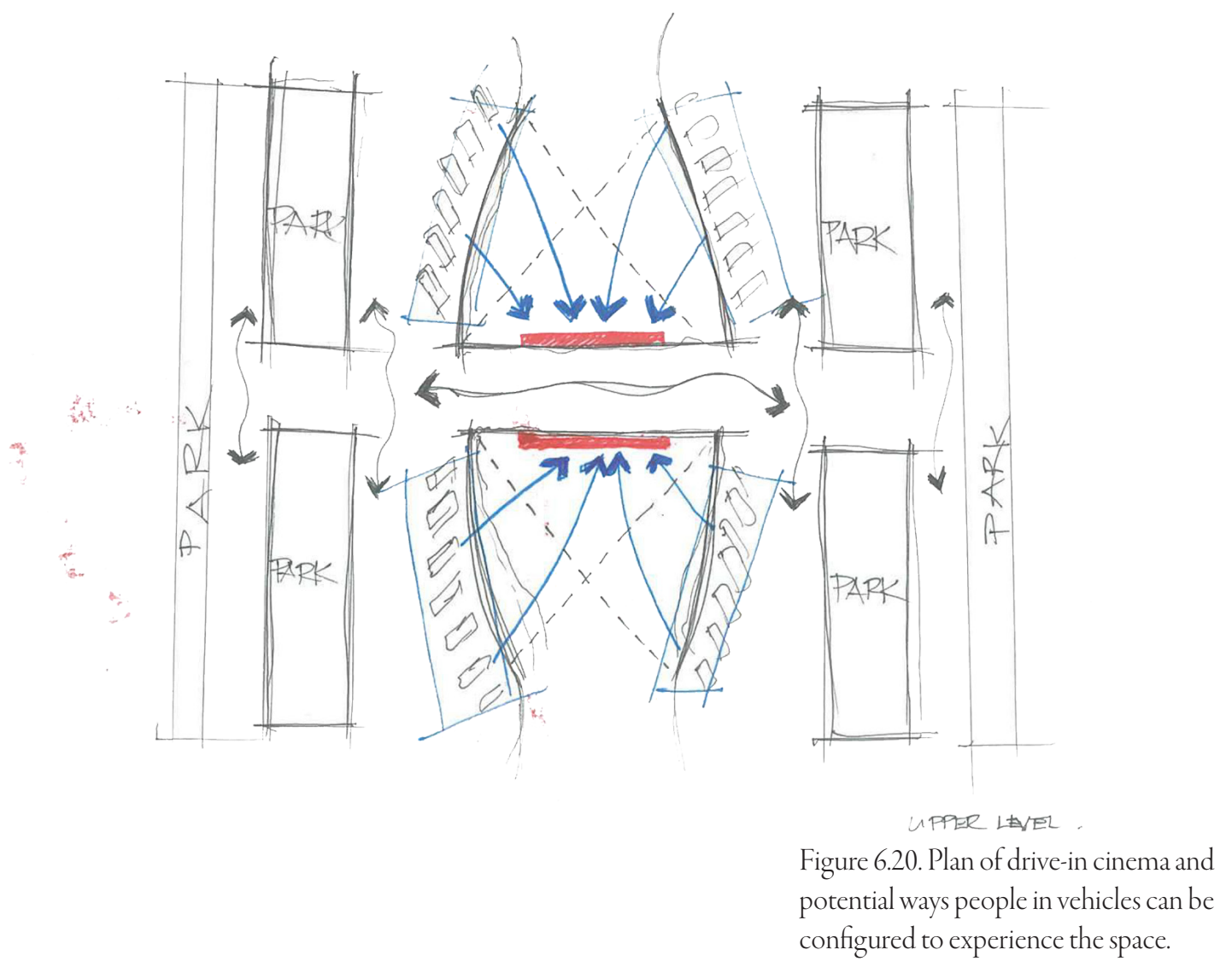




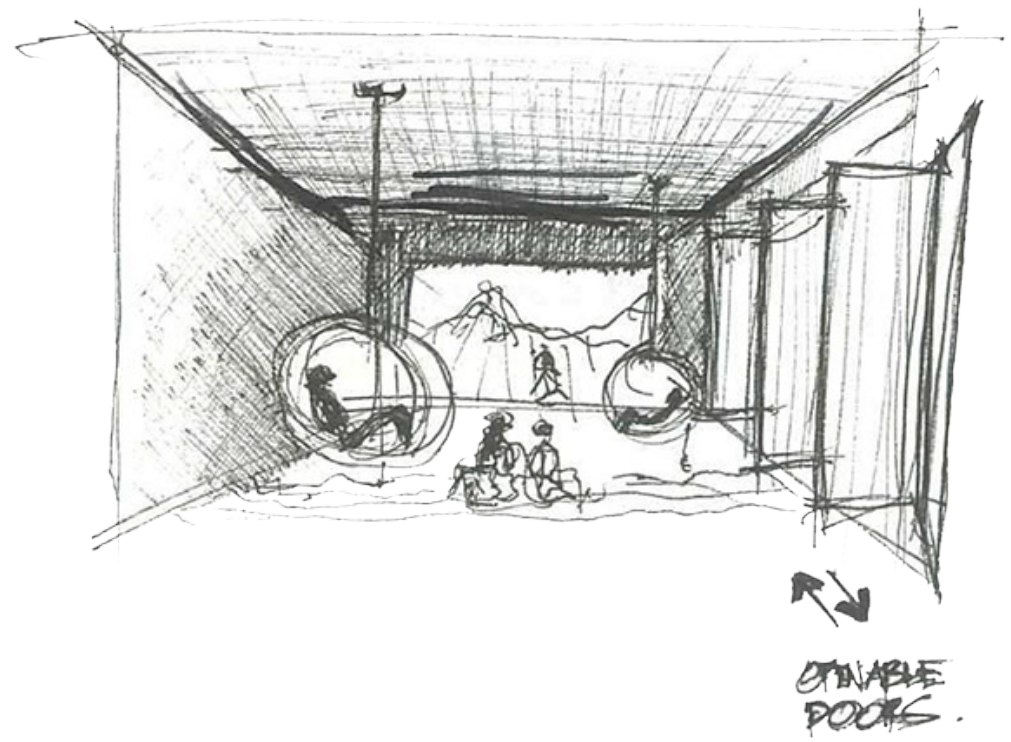

Figure 6.21. An experiential boutique cinema could be integrated into the mall.

Figure 6.22. Experiential boutique

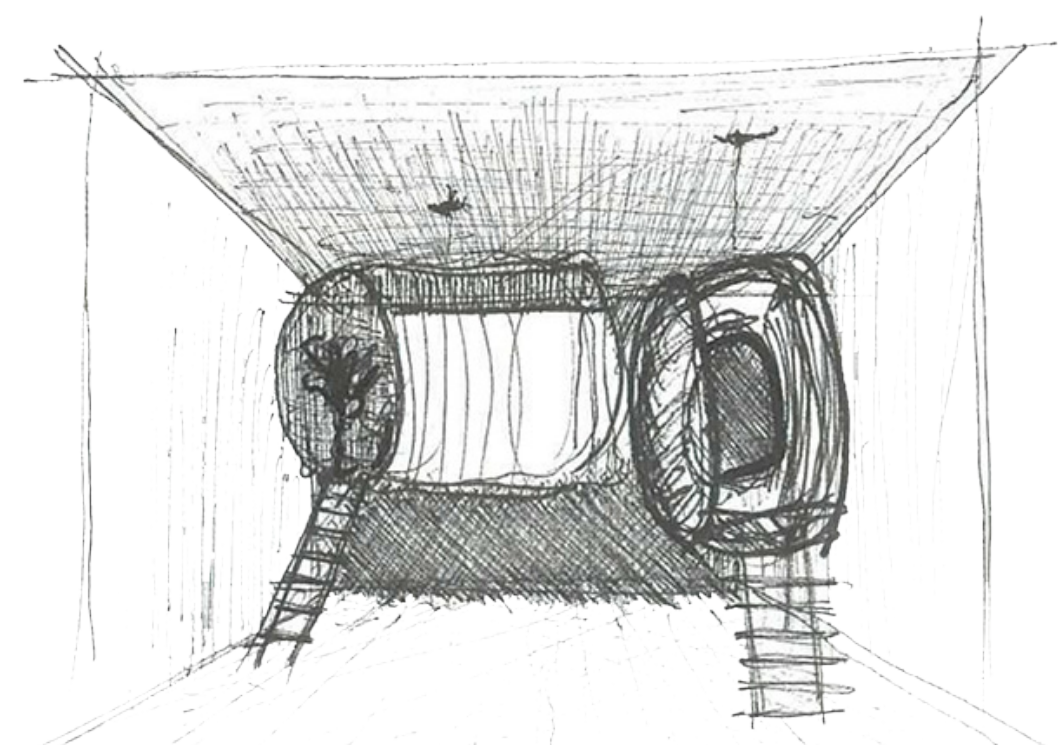

cinema. 

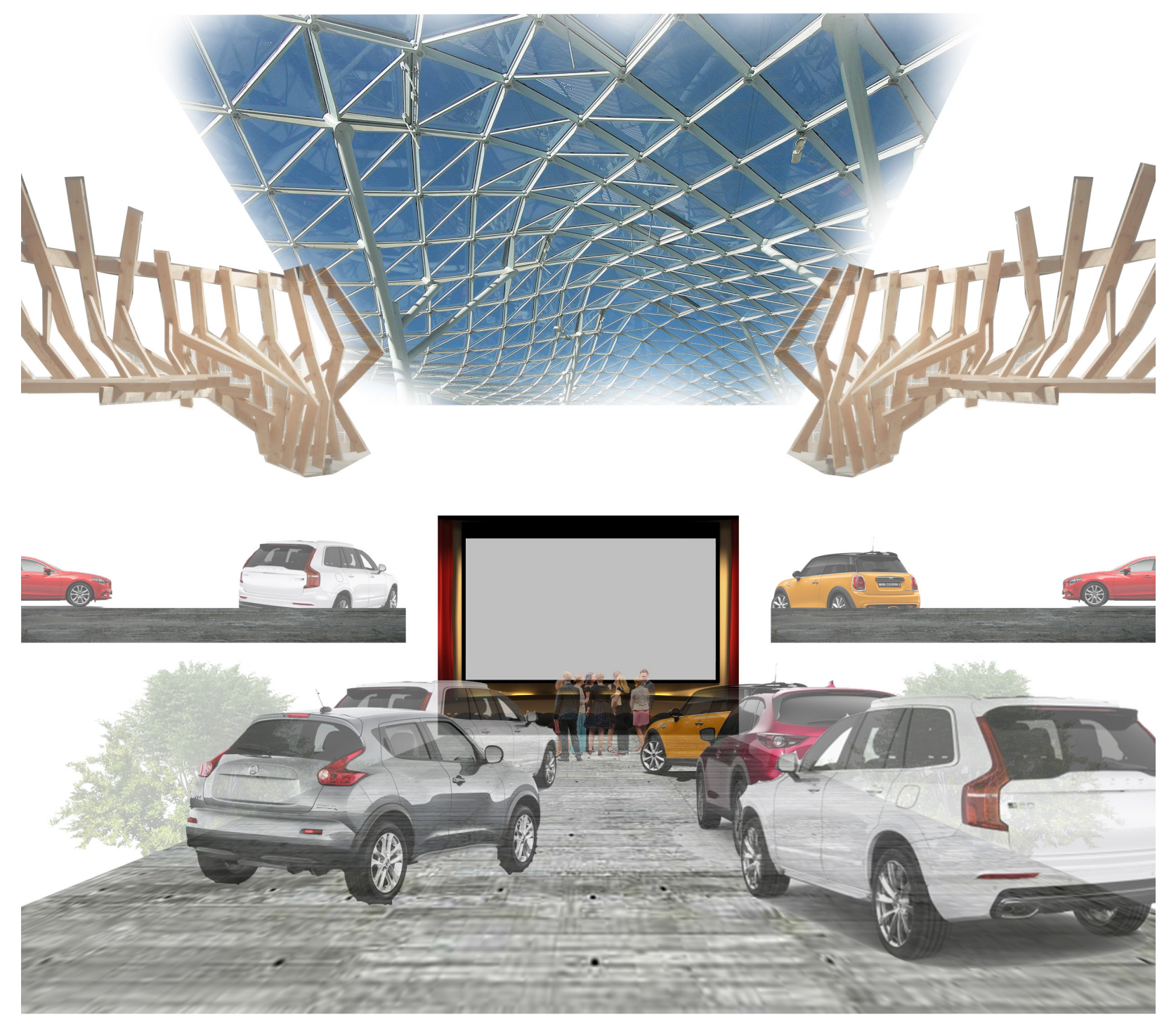

Figure 6.23. Atmospheric illustration of drive-in cinema. Author's illustration. 


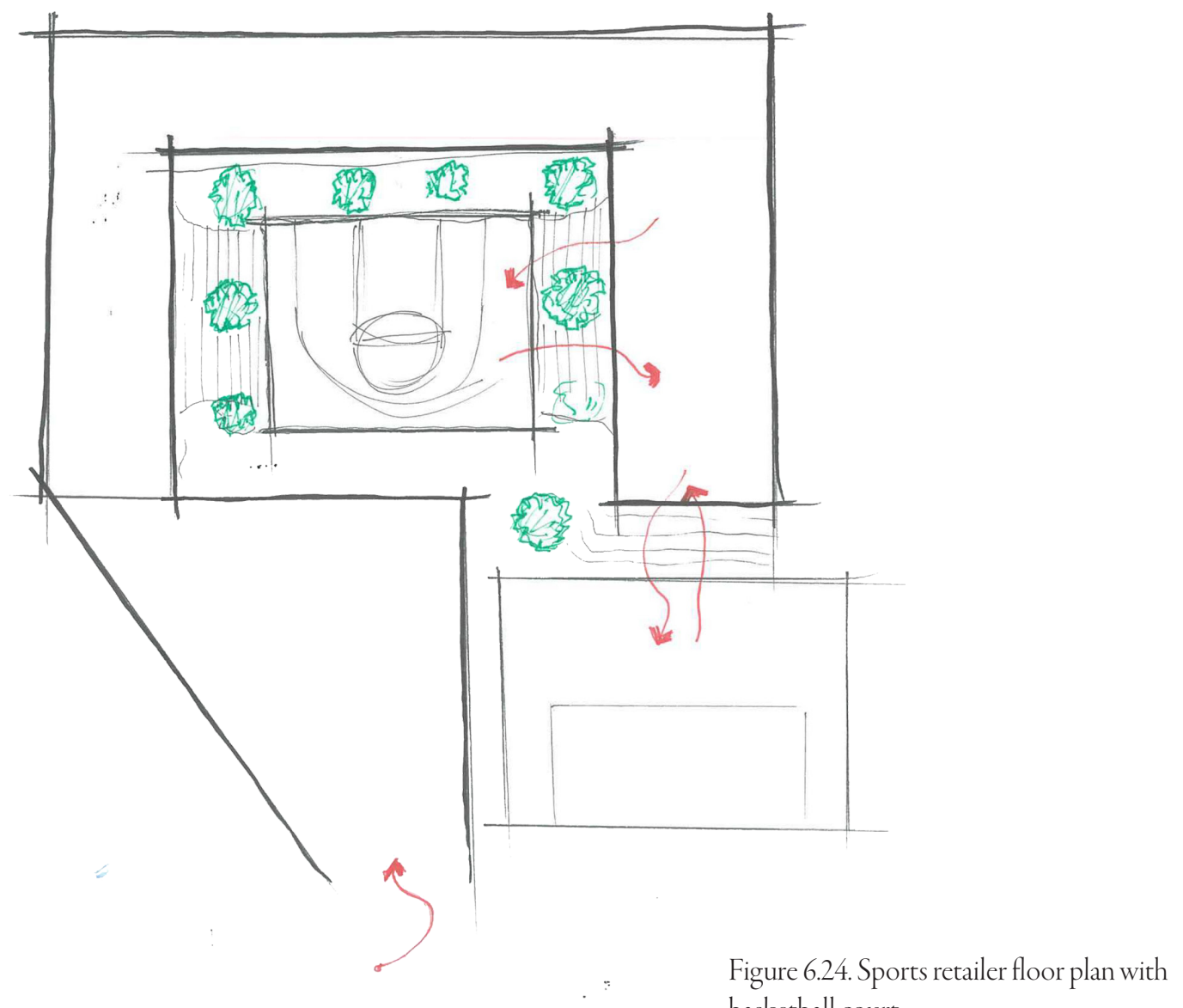
basketball court.

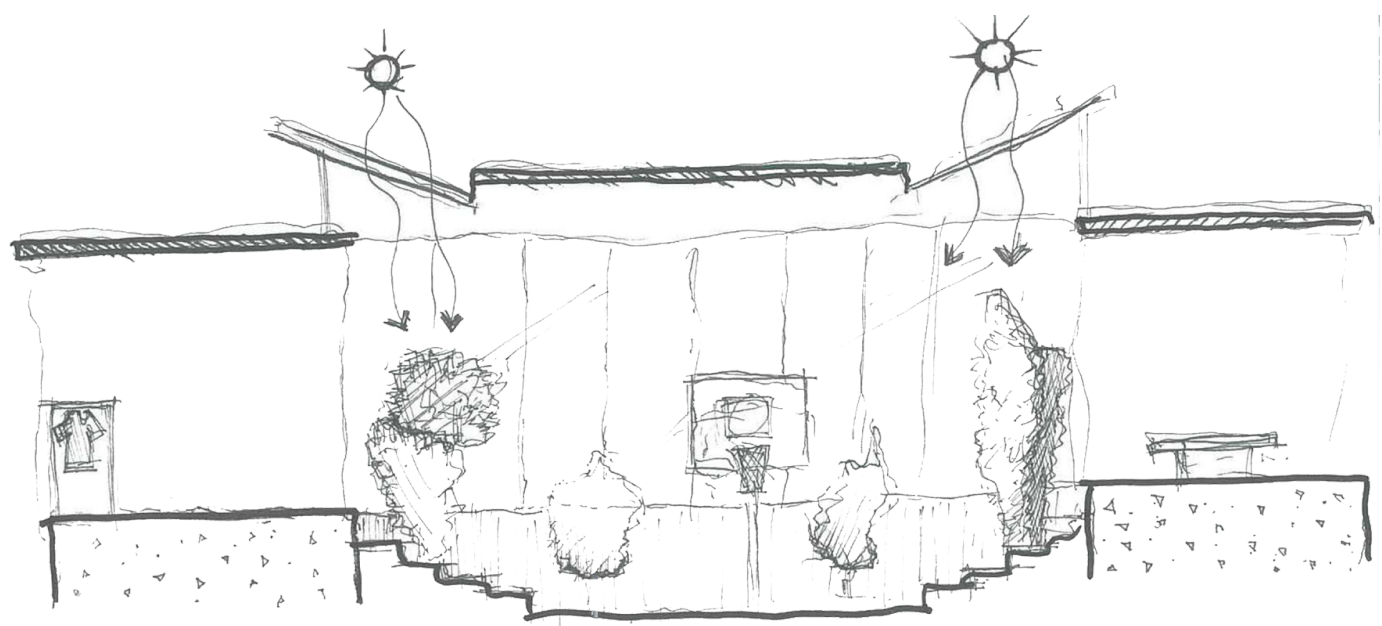

Figure 6.25. Sports retailers in section with basketball court. 

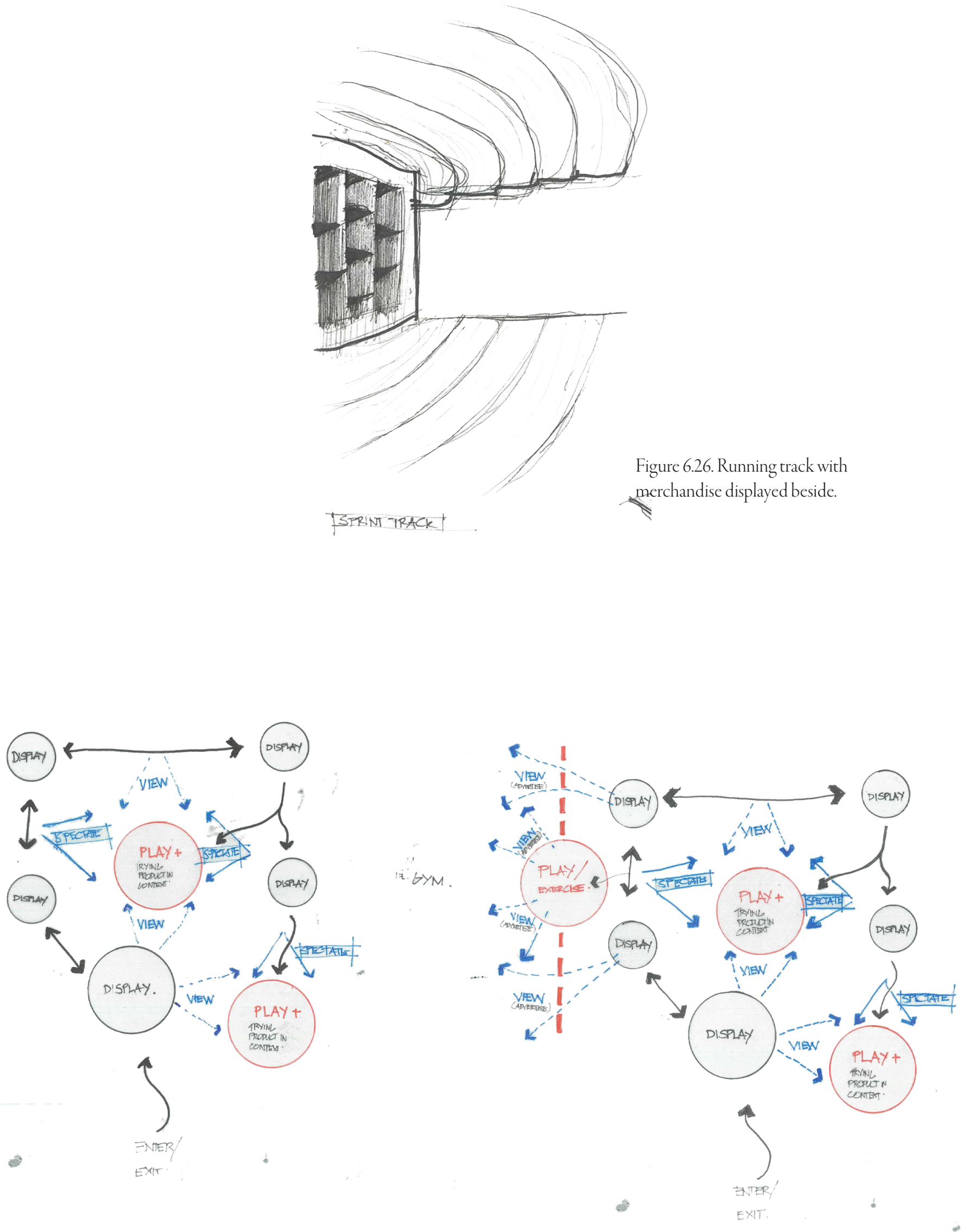

Figure 6.27-6.28. Bubble diagram of experience in sports retailers. 

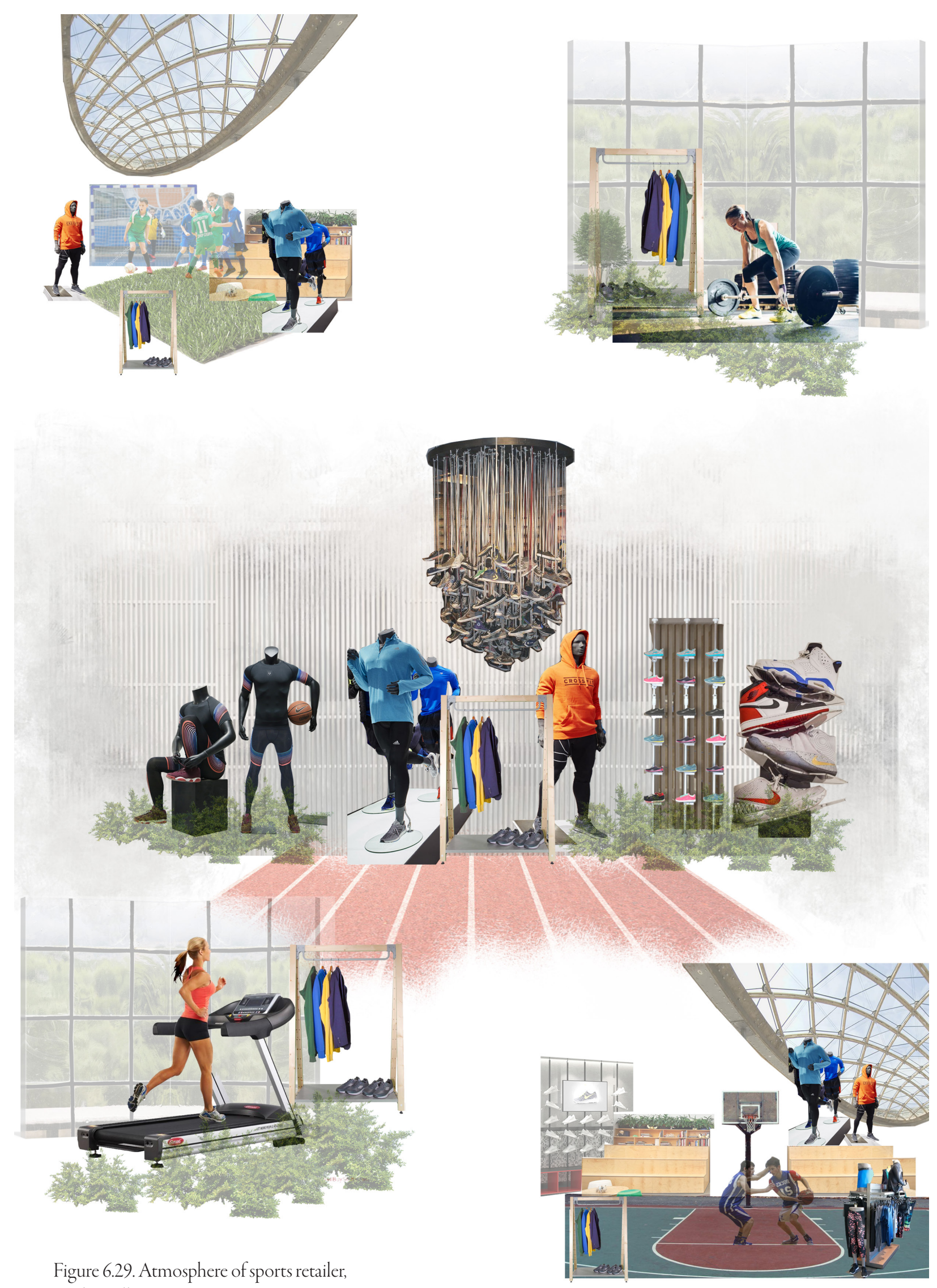

Author's illustration. 


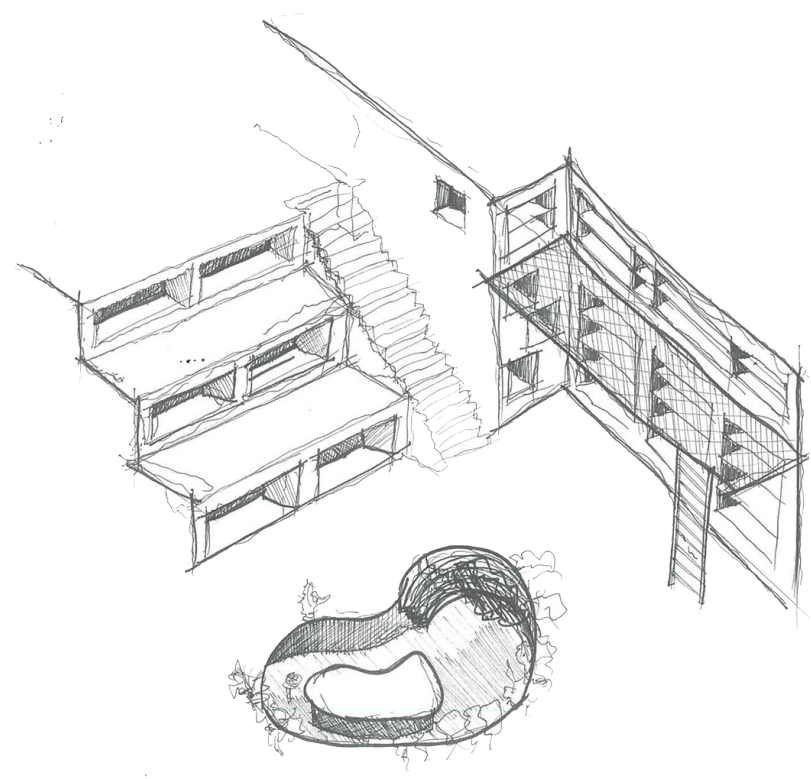

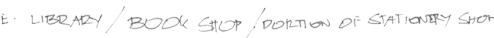

Figure 6.30. Shop displays with social spaces.

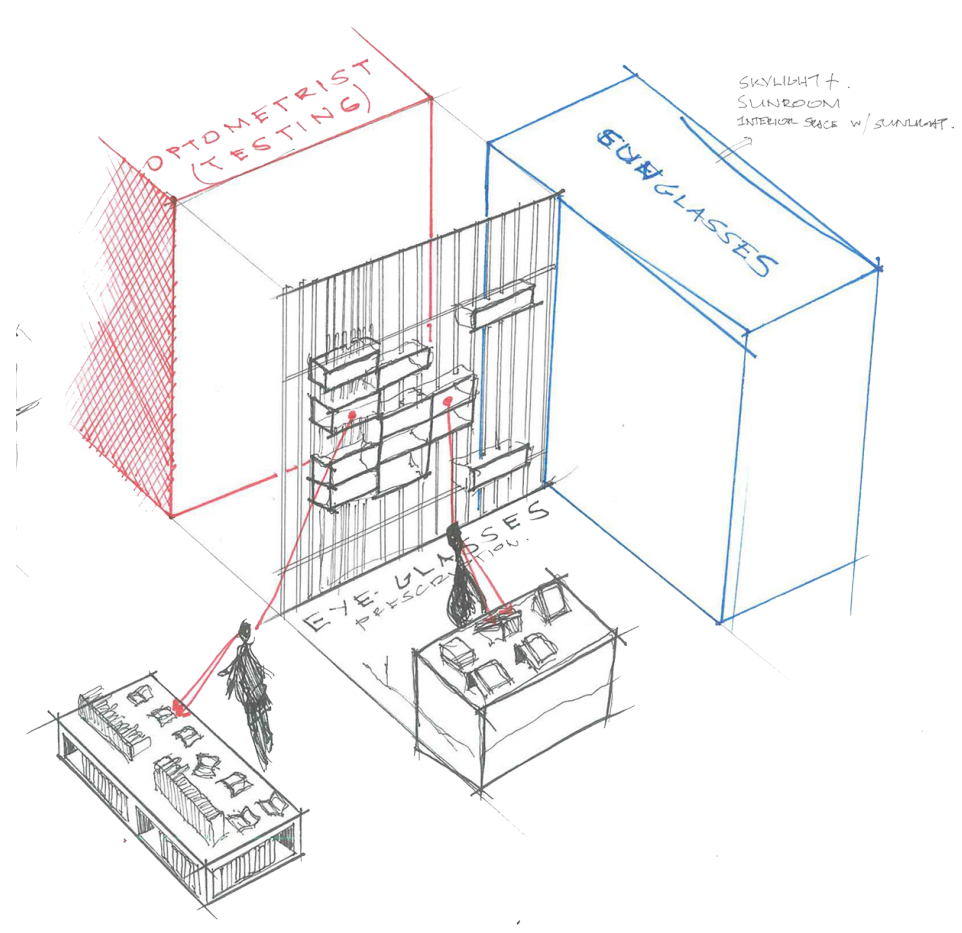

Figure 6.31. Shop with testing areas for products.

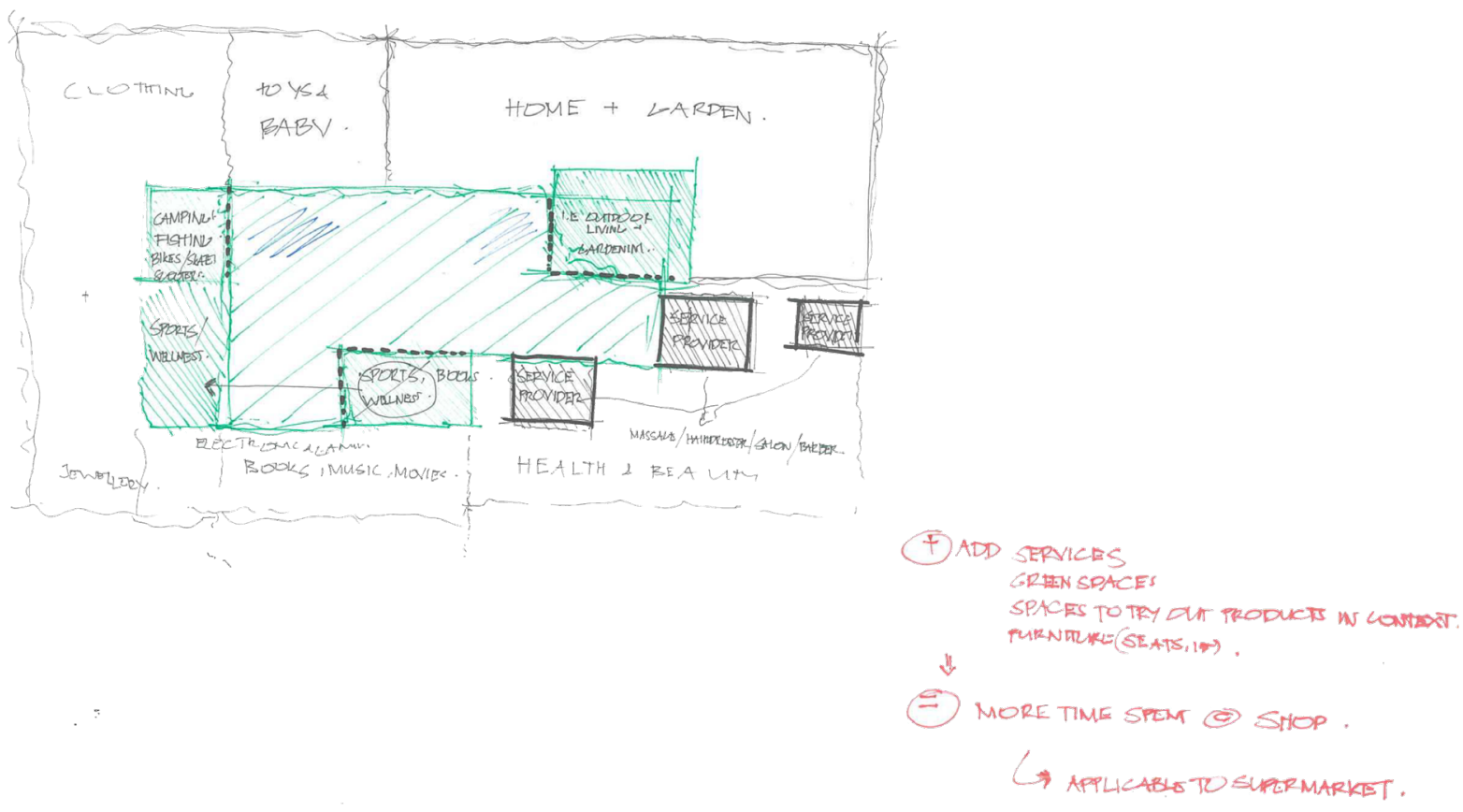

Figure 6.32. Breaking down anchor retailers (The Warehouse used as an example) to provide retailers with real environments to try products. 


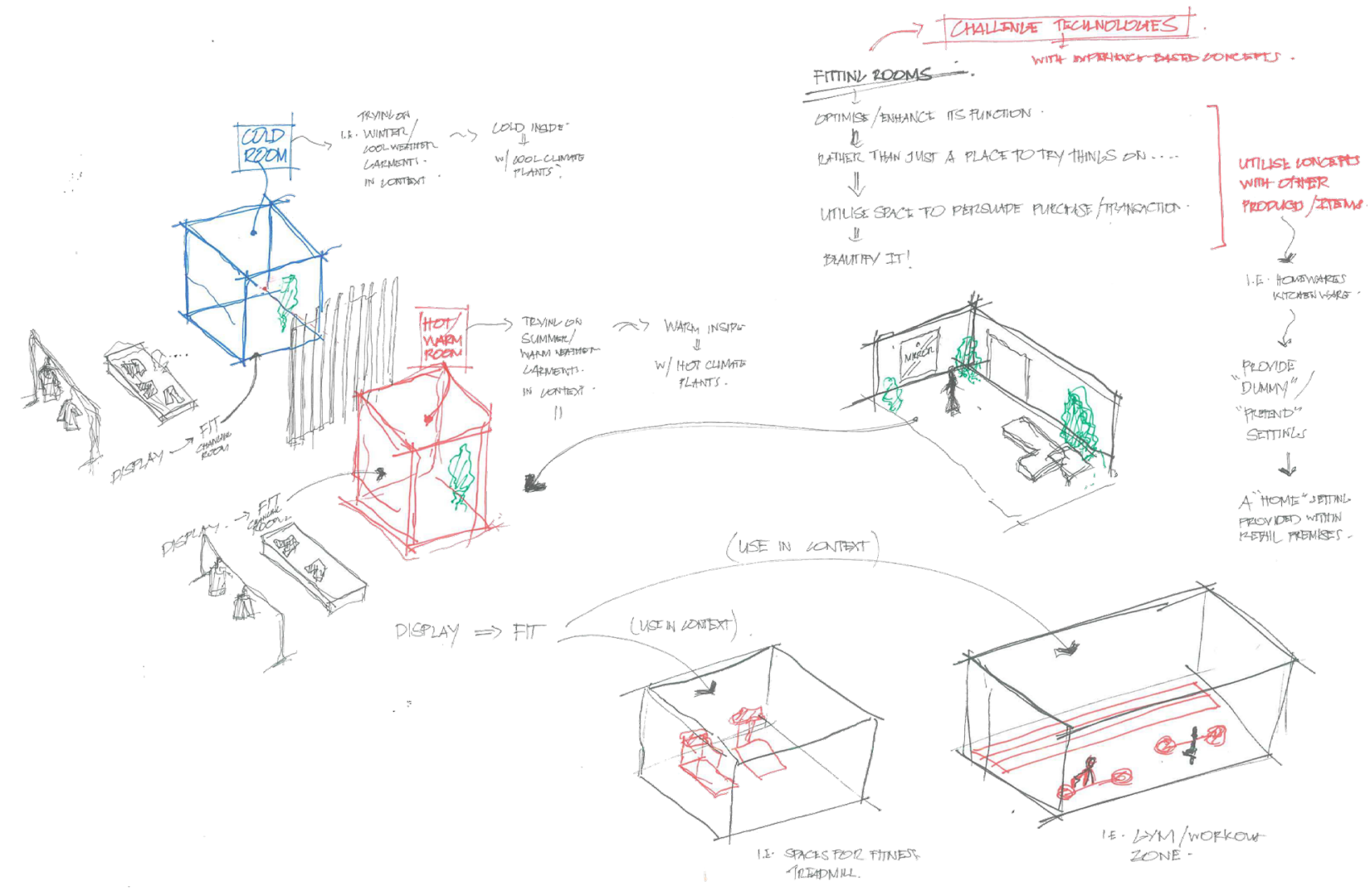

Figure 6.33. Providing customers spaces within retailers to try products in environments that mimic real-life conditions to test out products. 


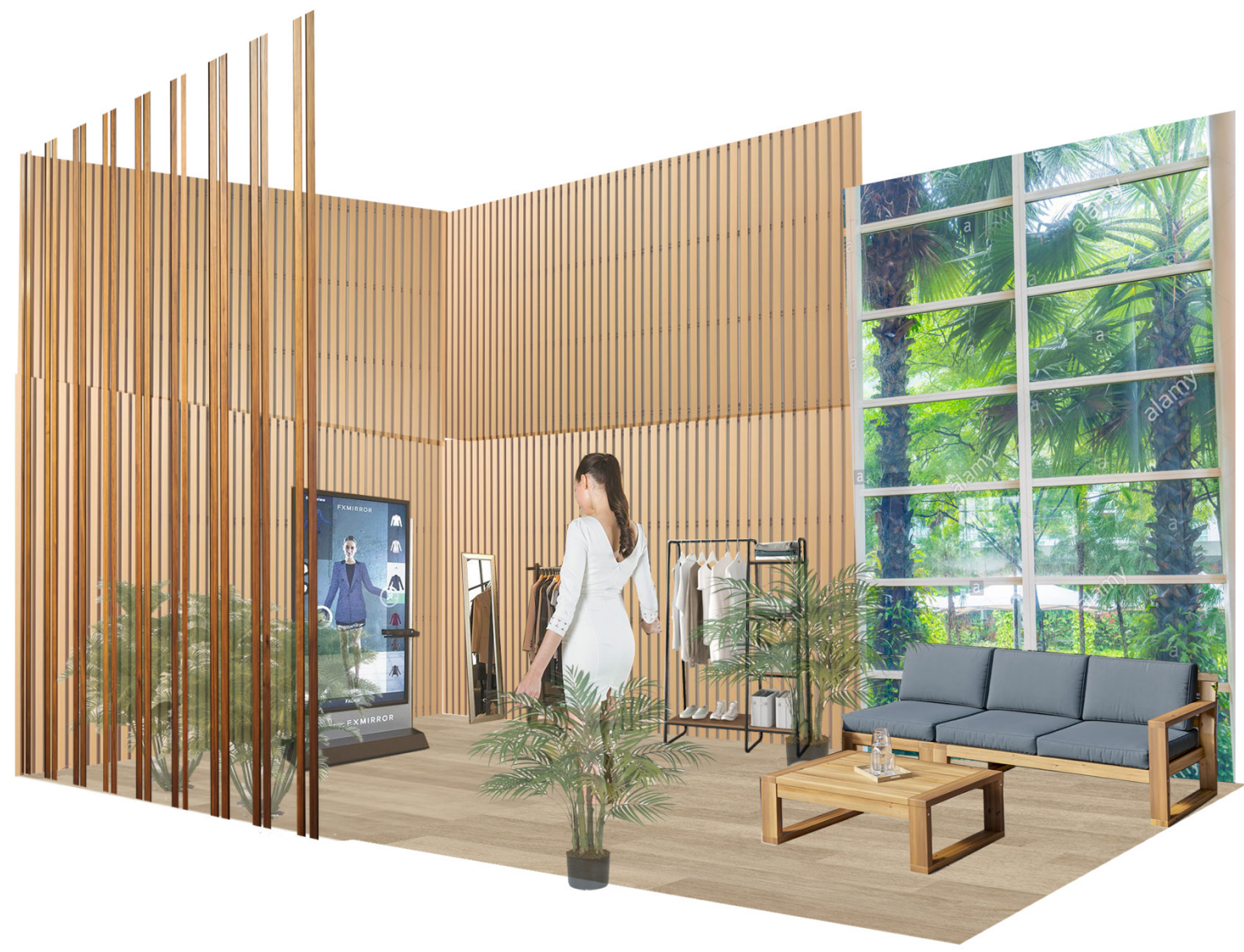

Figure 6.35. An exclusive space for womenswear. Author's illustration. 


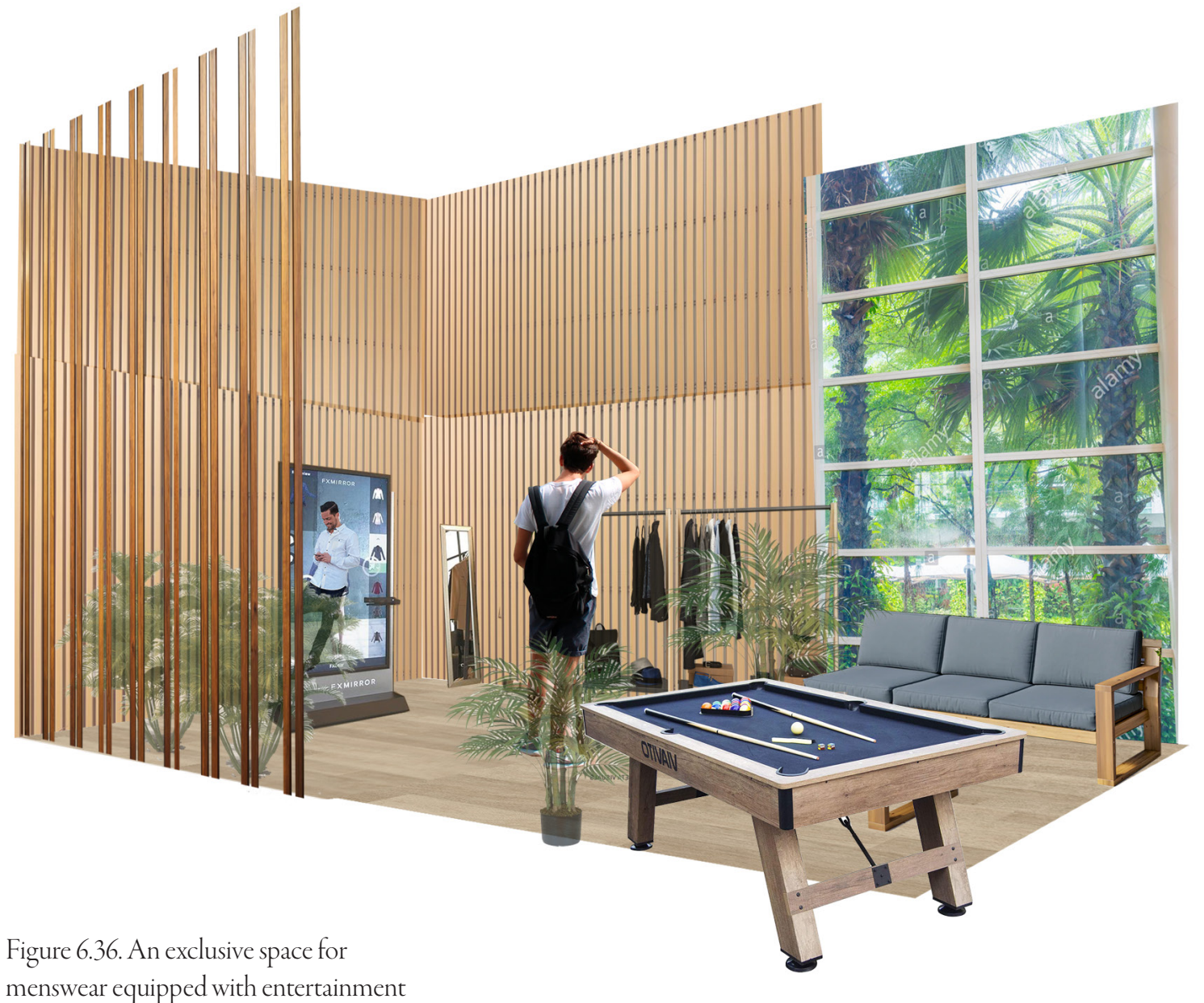
amenities. Author's illustration. 


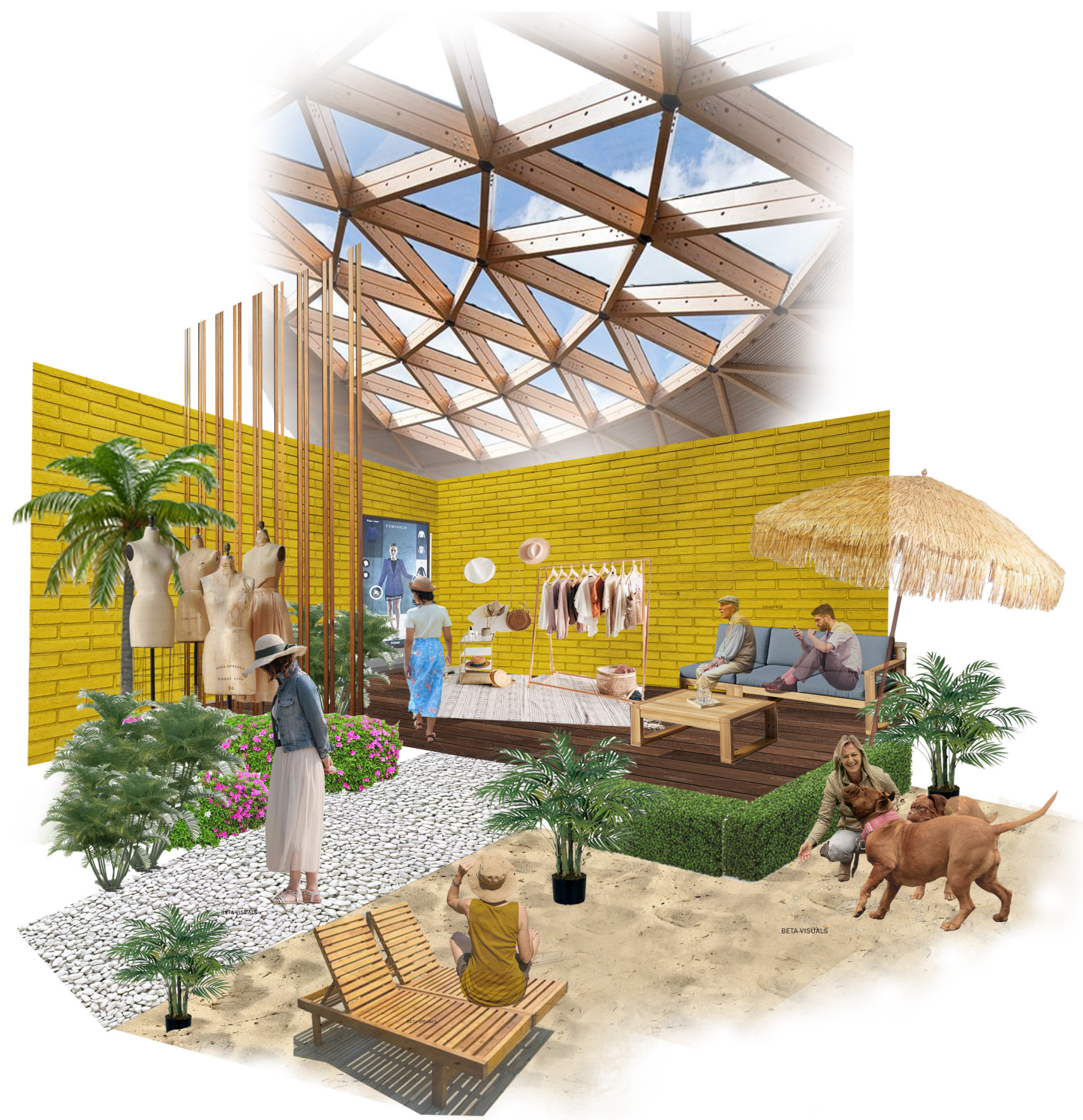

Figure 6.37. Room with summer conditions for trying out products. Author's illustration. 


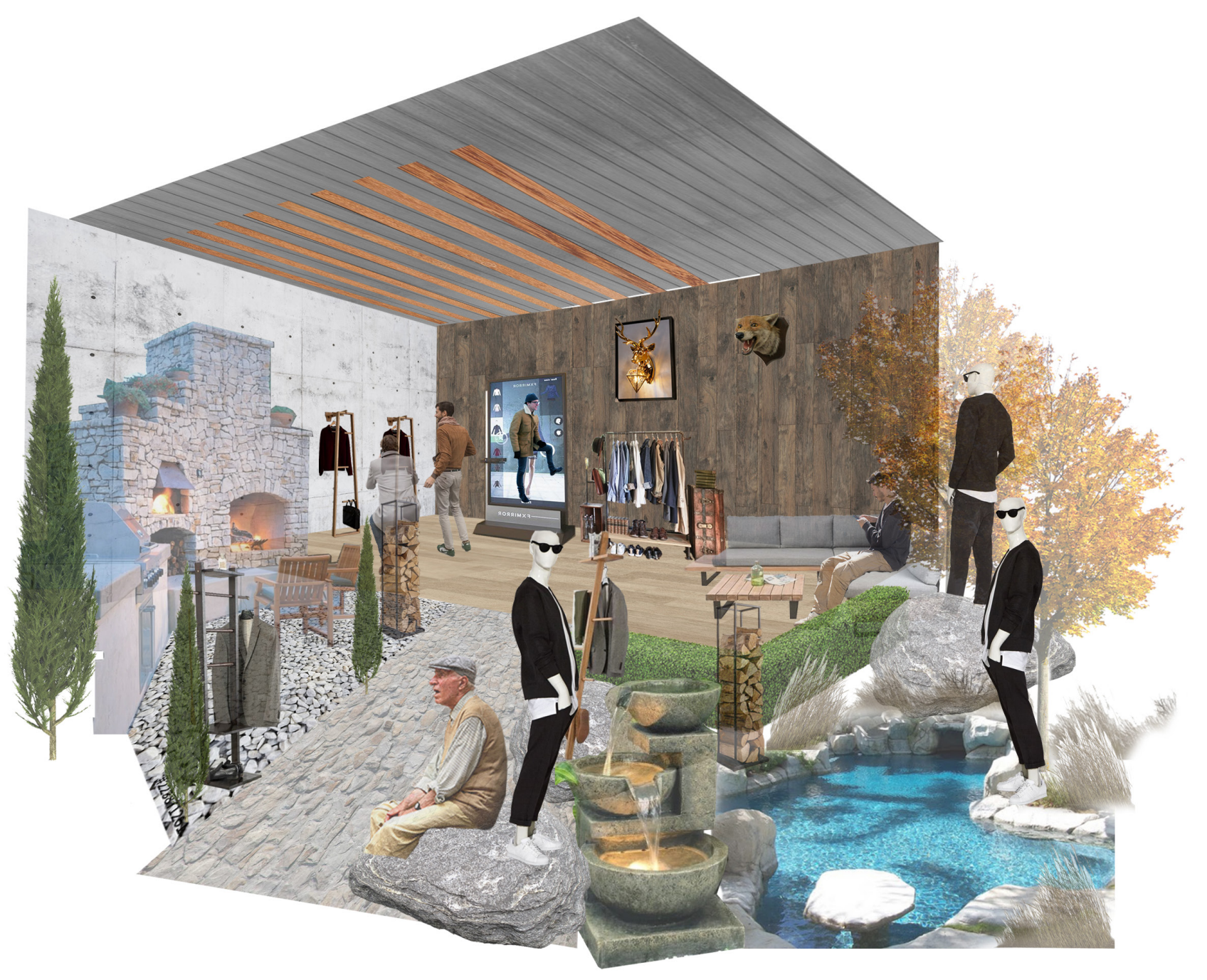

Figure 6.38. Room with winter conditions for trying out products. Author's illustration. 


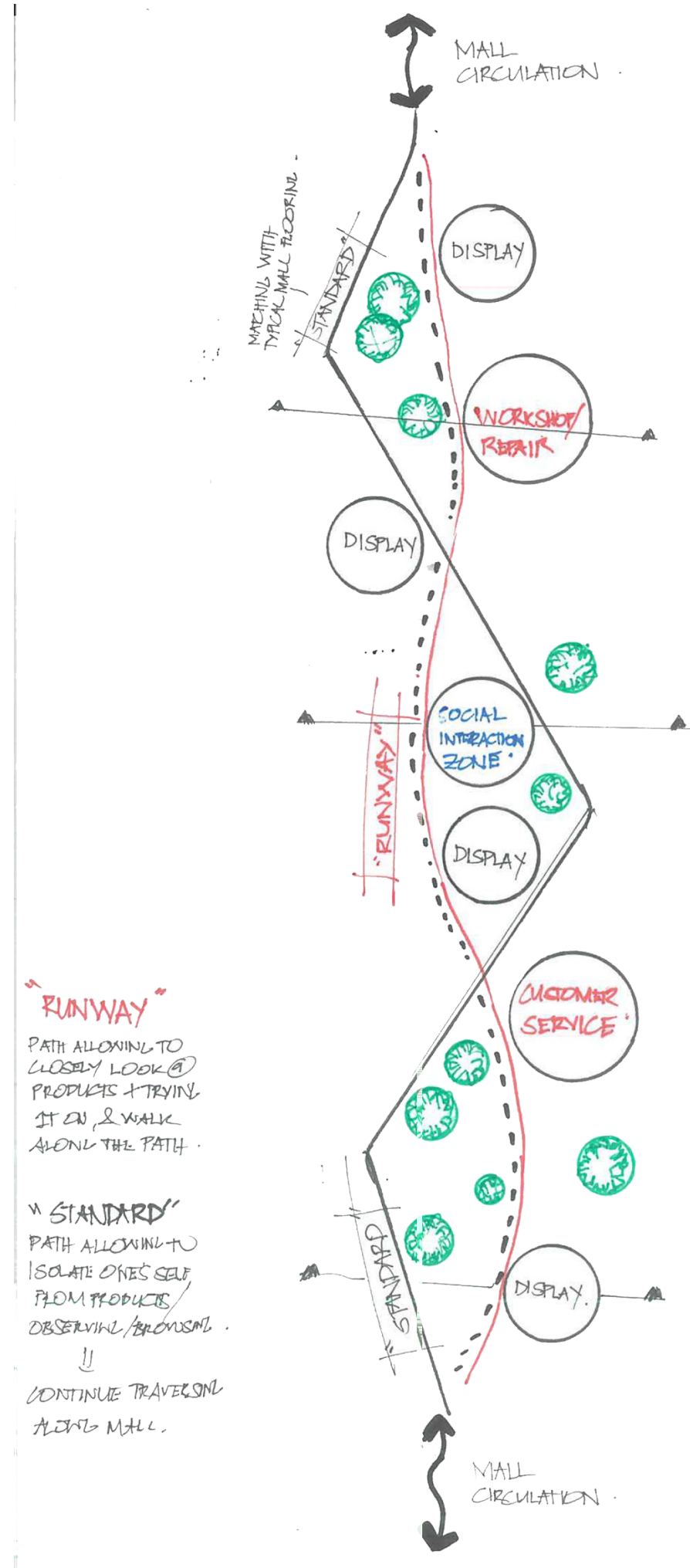

STRATEL:

EMEED SHOPS/REAHLERS INTO MALL CHCULATION.

it

DISPLAYS THEN RENDERED AS

TPOP-UPS

II

WORKSHOP / REPAIR PRISENT

Fo ENHANCE CUSTUMER

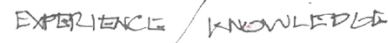

II

ALLOWHARCHITECMRE TO

WNK CONGUMER wint

Propuct \& PFODUKEn

CRAPTSMEN

$\Downarrow$

INTIMAE EXPERTENCE

Figure 6.39. A runway themed shoe store to display shoes and try them on. 

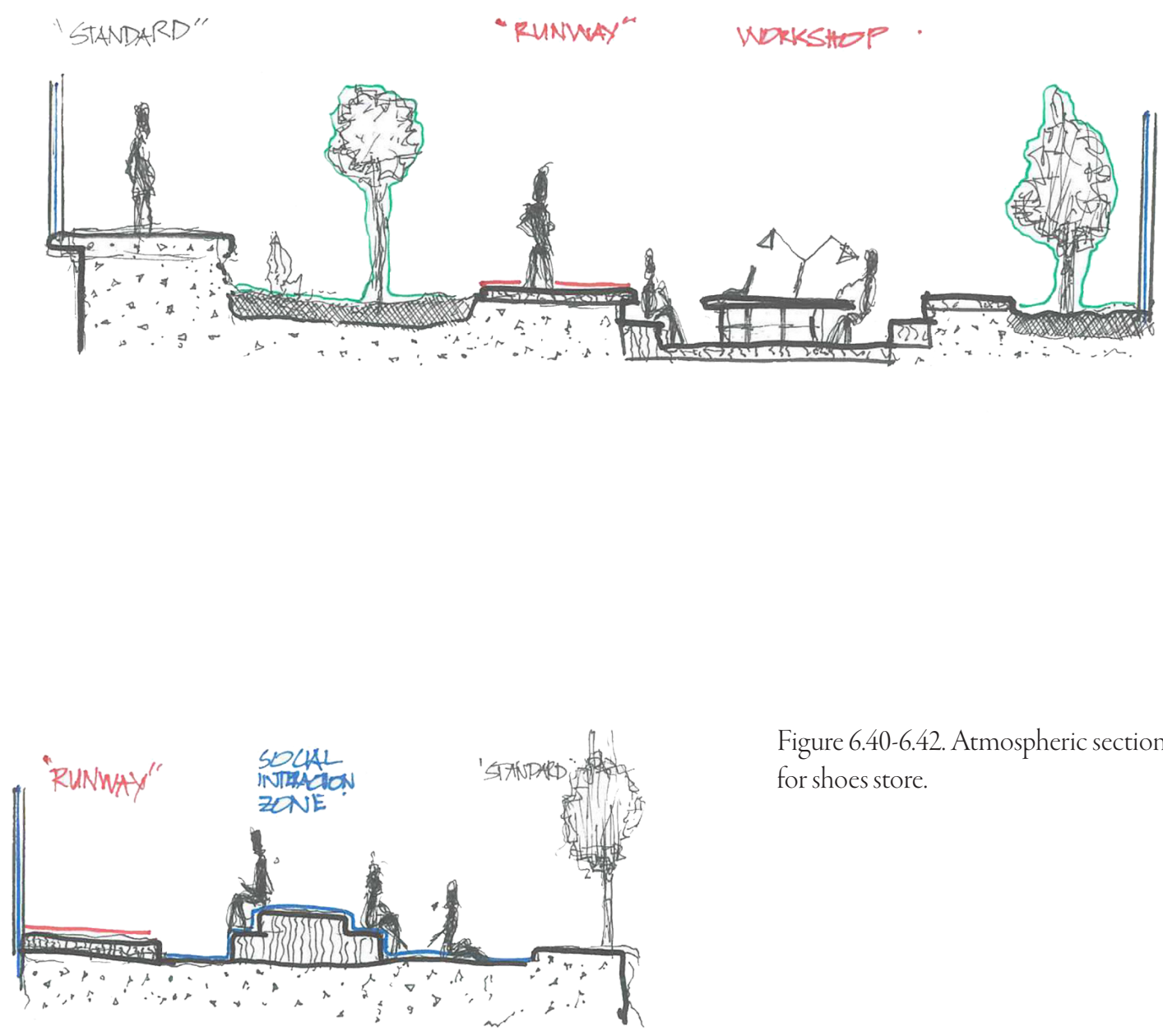

Figure 6.40-6.42. Atmospheric sections for shoes store.

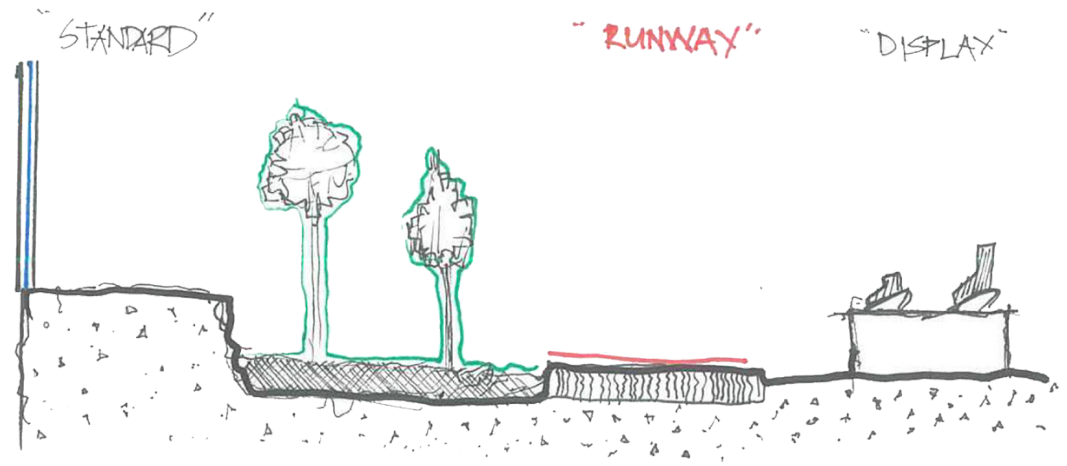

159 


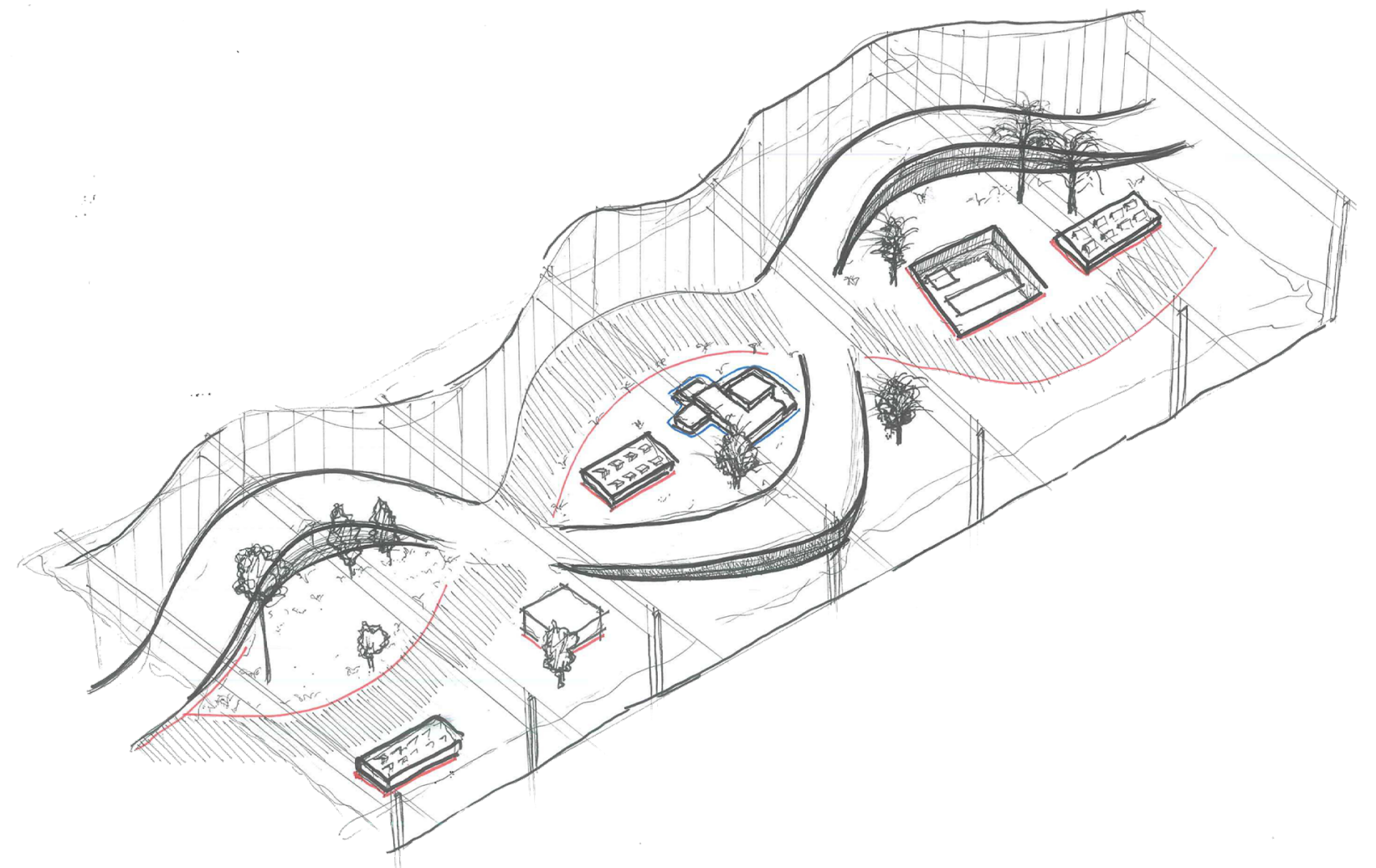

Figure 6.43. Atmospheric axonometric for shoe store. 


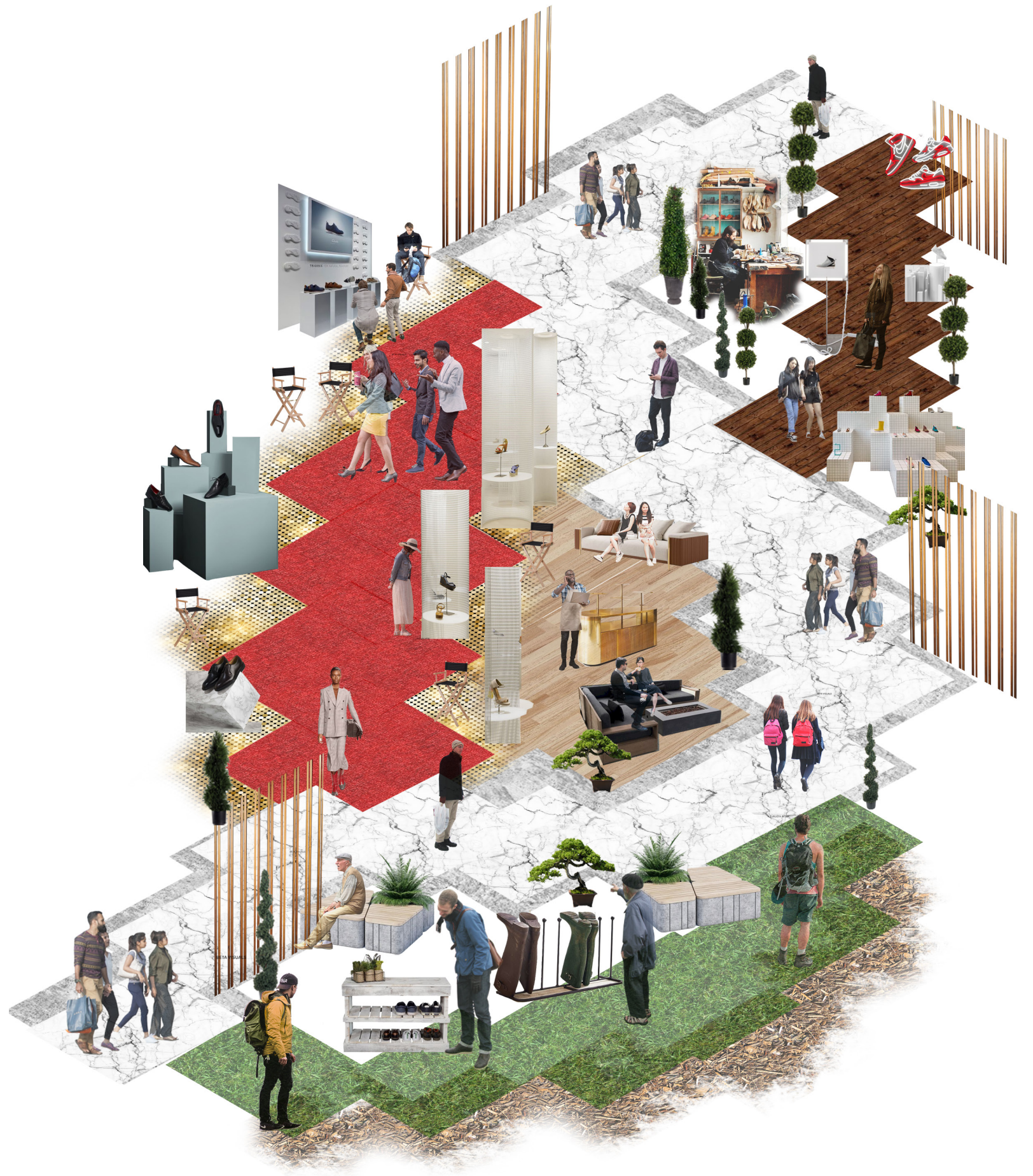

Figure 6.44. Atmospheric illustration of conceptual shoe store. 


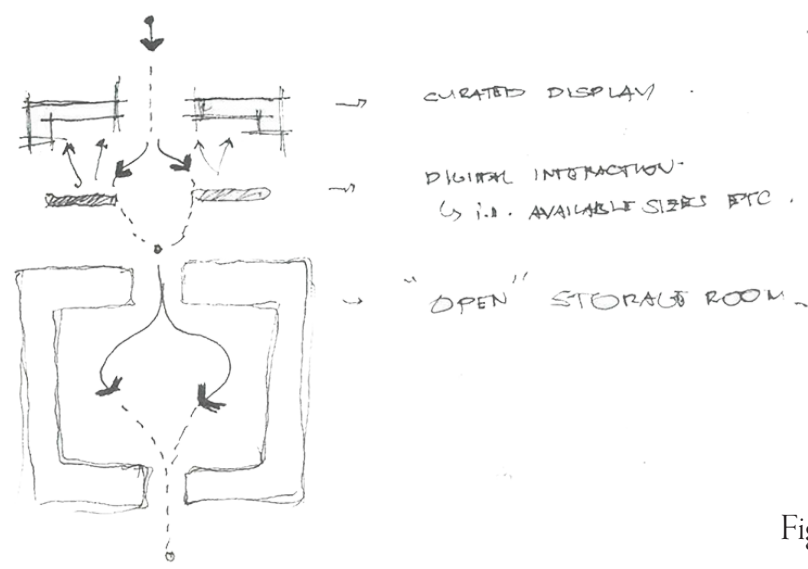

Figure 6.45. A new storage system.

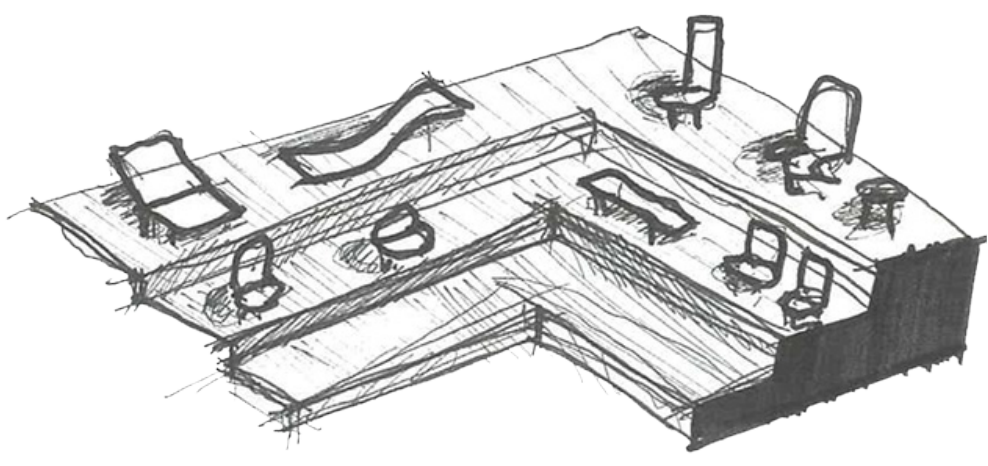

\section{tChAIR DSTLAY}

Figure 6.46. Stages to display store products.

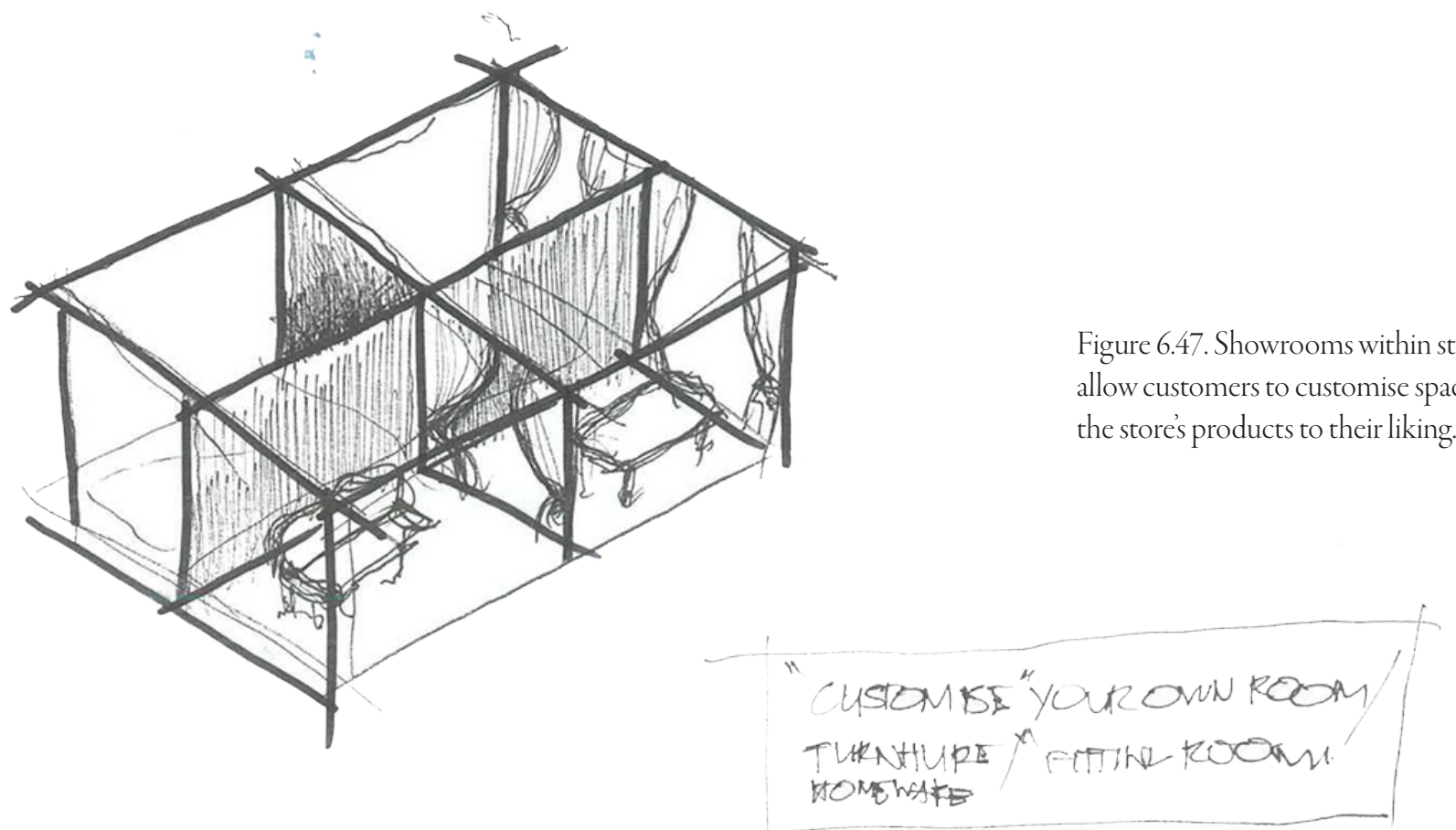



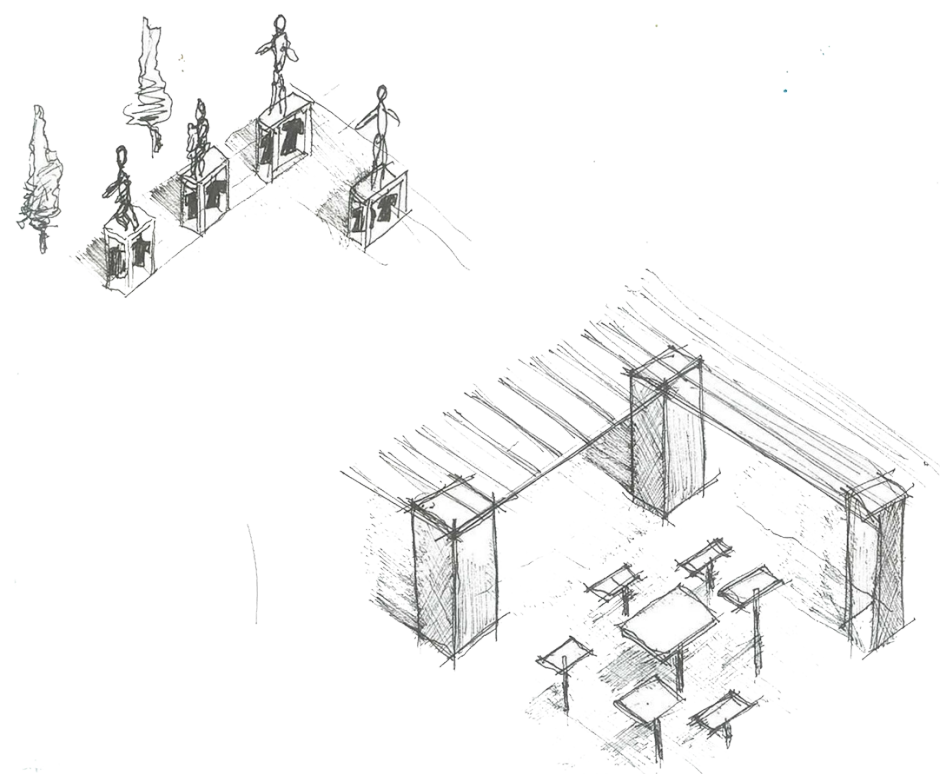

Figure 6.48 Atmospheric illustration of shops.

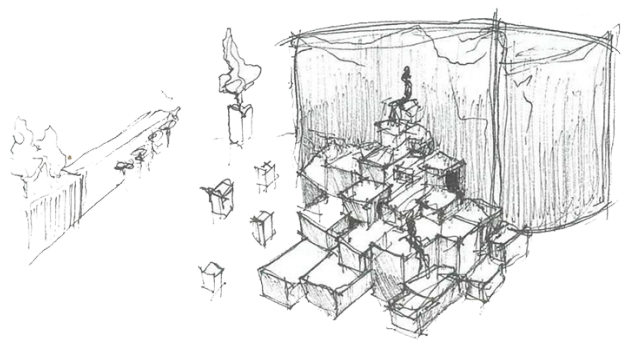

Figure 6.49. Creating an engaging landscape within shops.
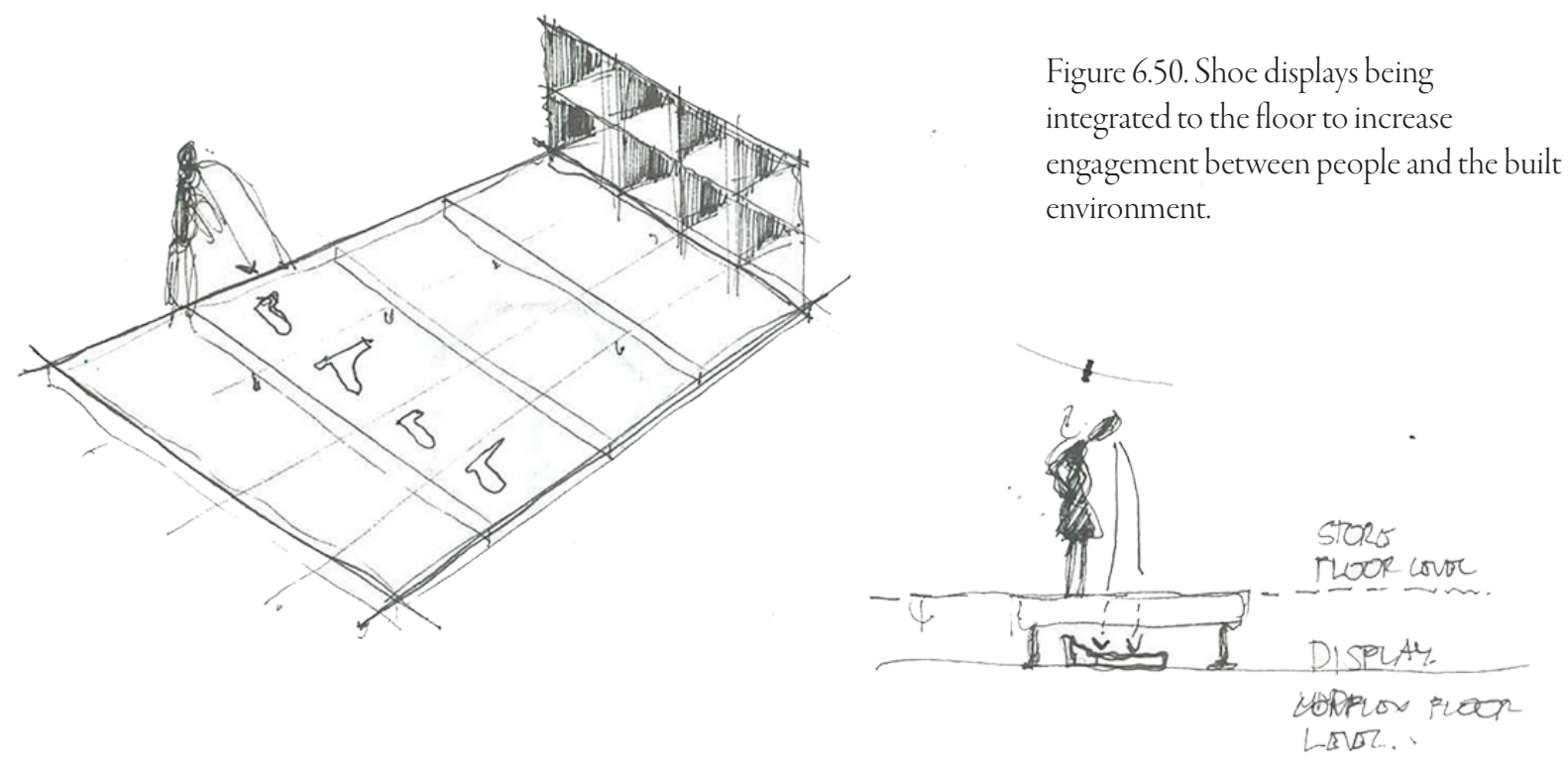

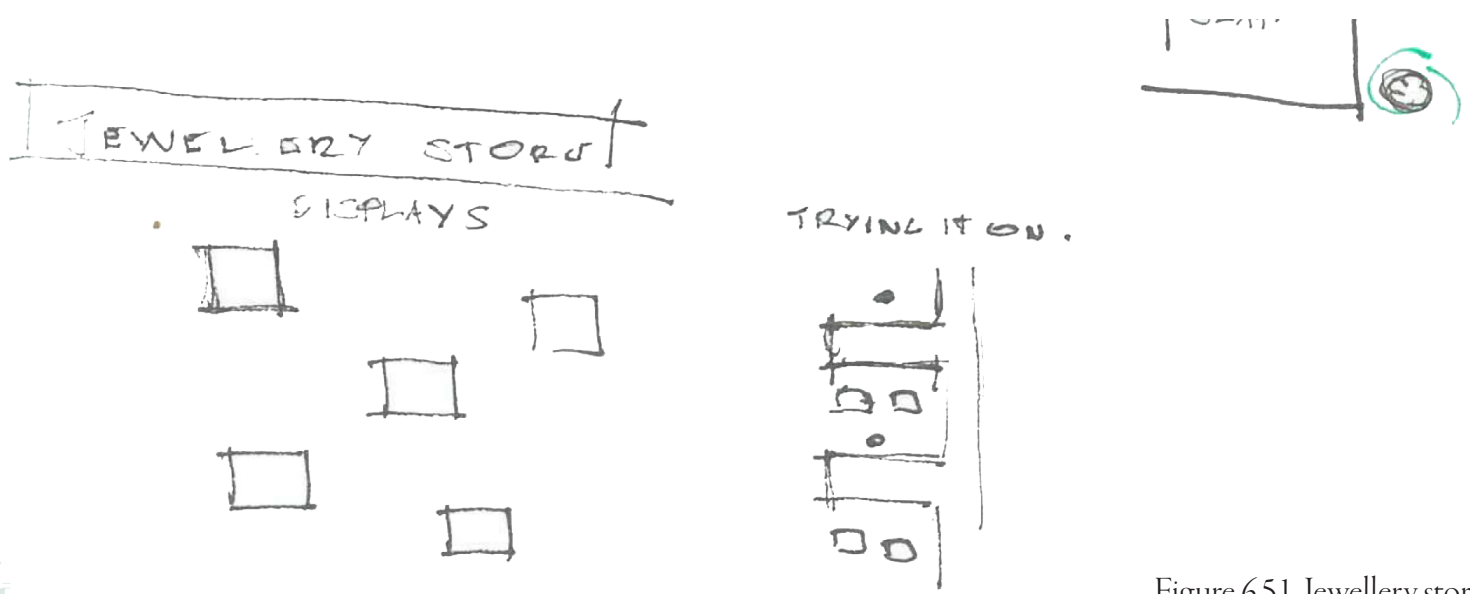

Figure 6.51. Jewellery store concept with exclusive spaces to try products.
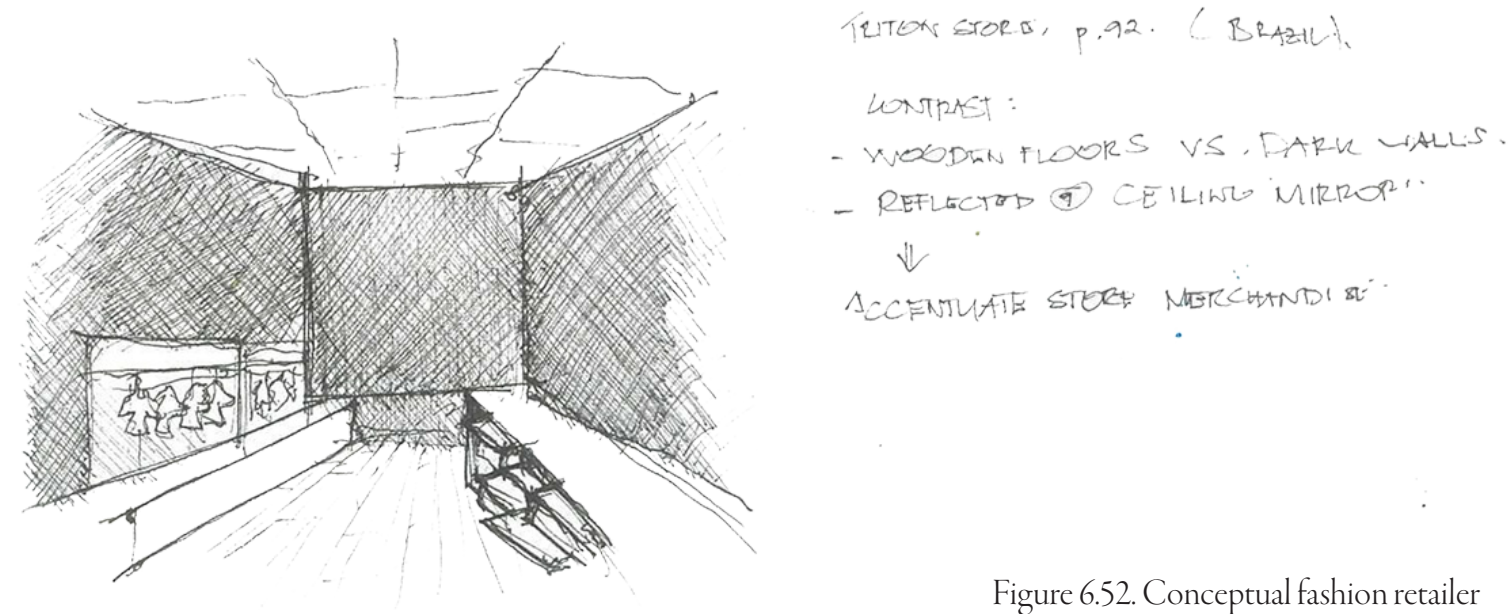

Figure 6.52. Conceptual fashion retailer atmosphere. 

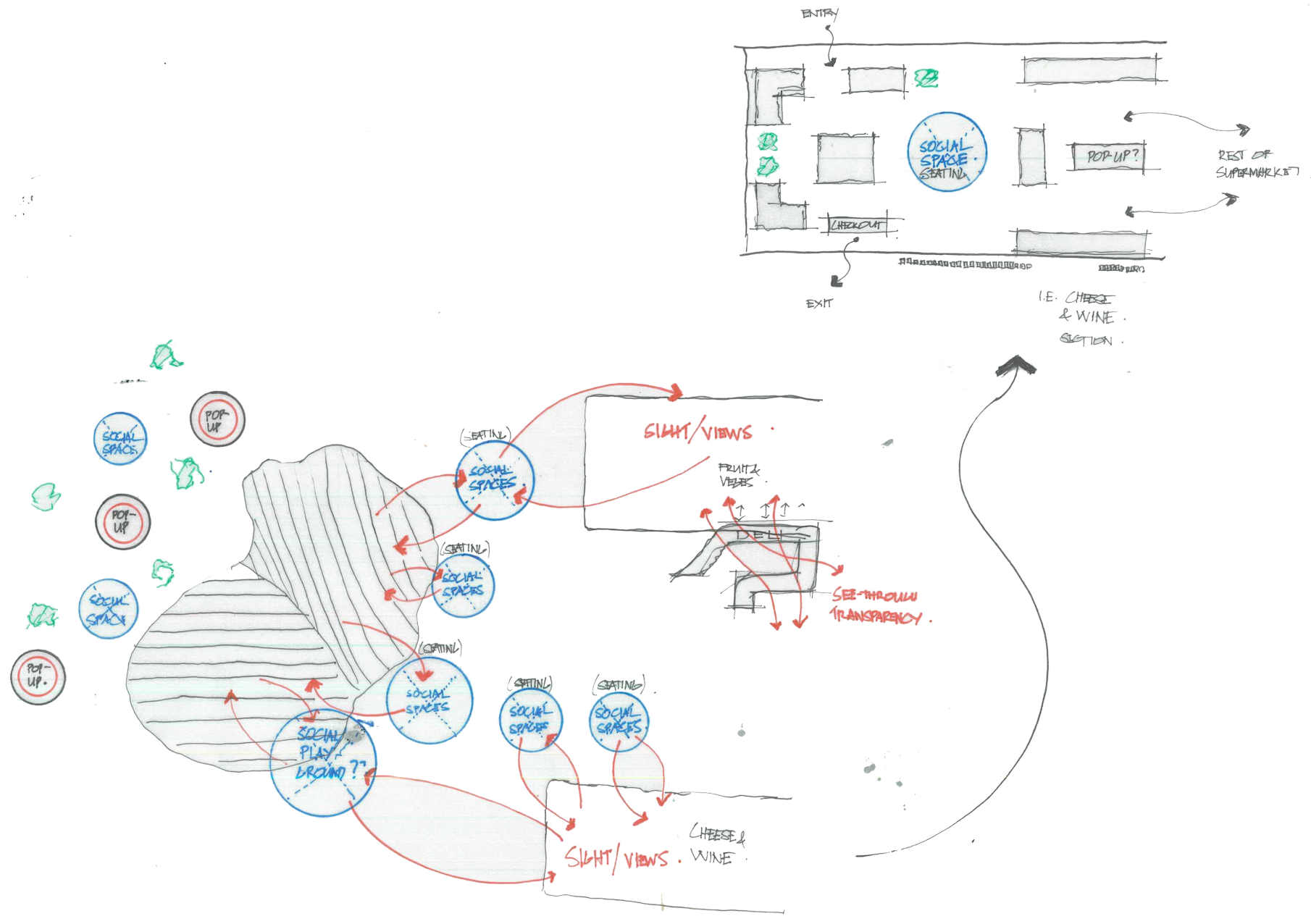

Figures 6.53-6.54. Reconfiguration of a supermarket to increase engagement while still maintaining convenience.

J.E. DAKSRY \& SUPERMARKET.

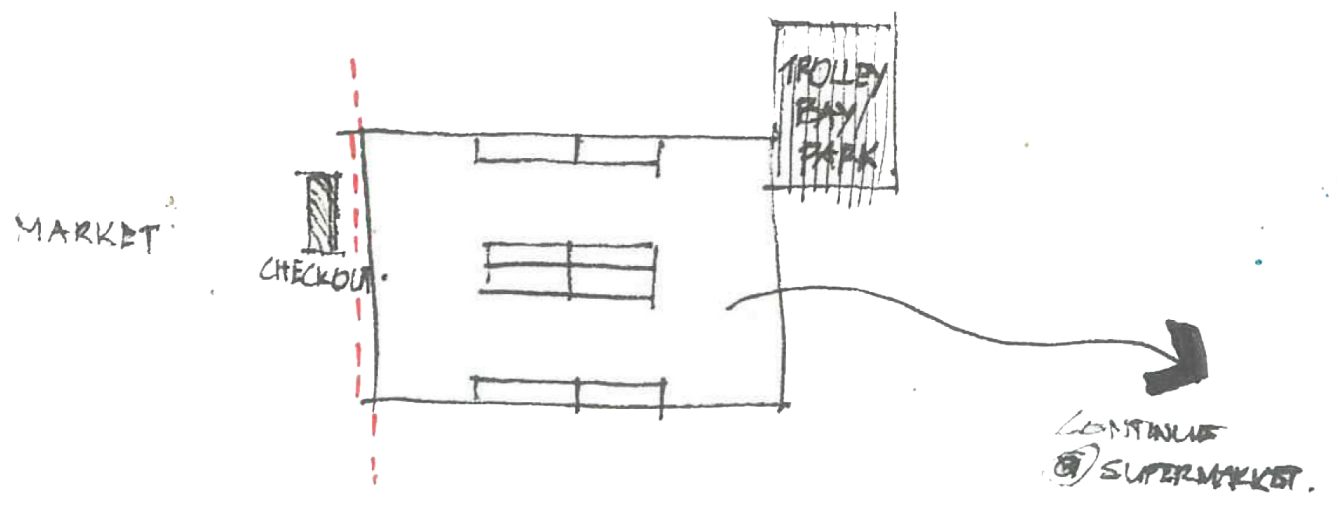




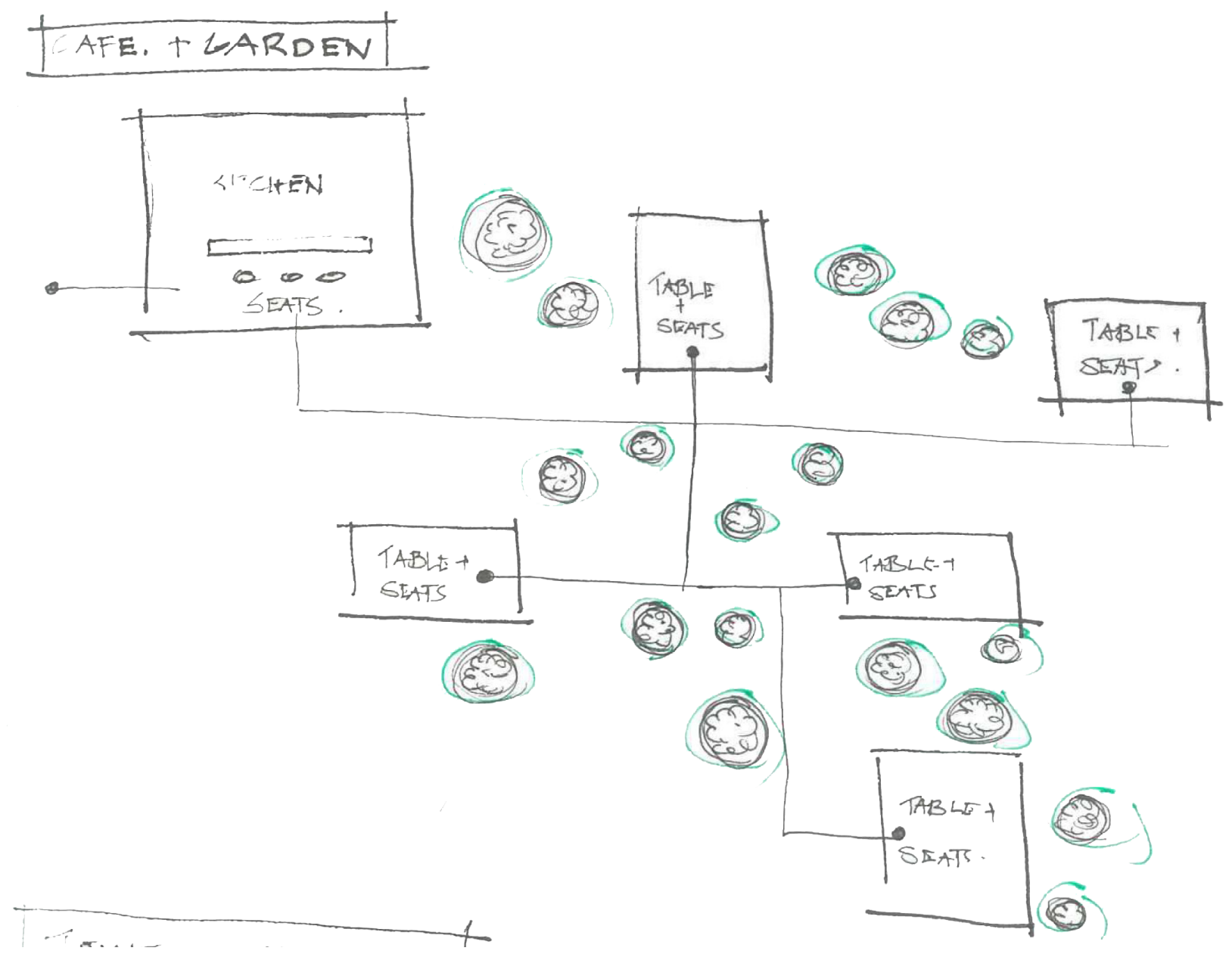

Figure 6.55. Café with green spaces integrated.

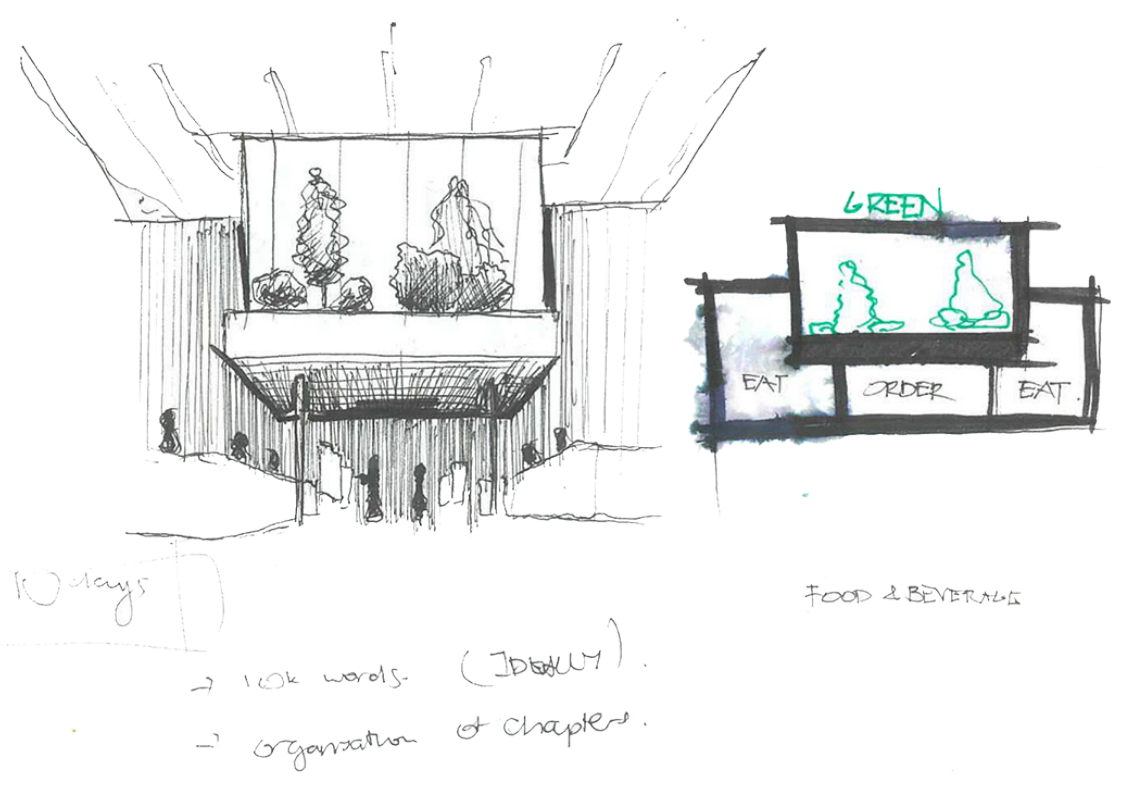

Figure 6.56. Food and beverage tenant with green spaces integrated. 


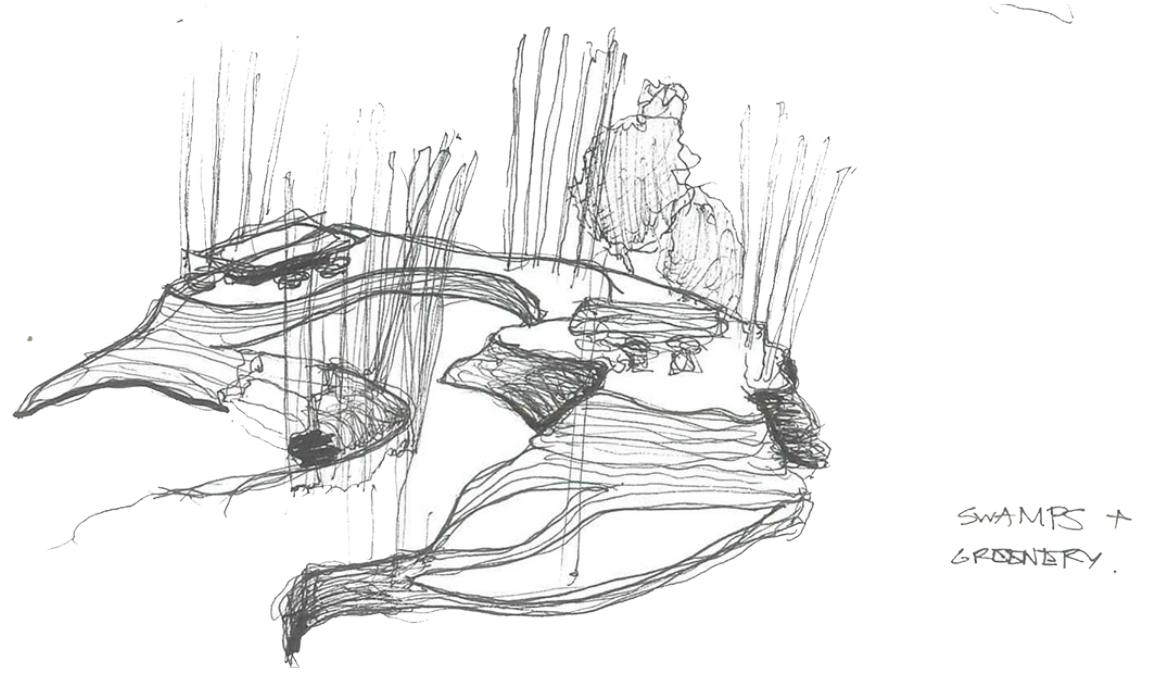

Figure 6.57. Social/ food and beverage space with green spaces integrated.

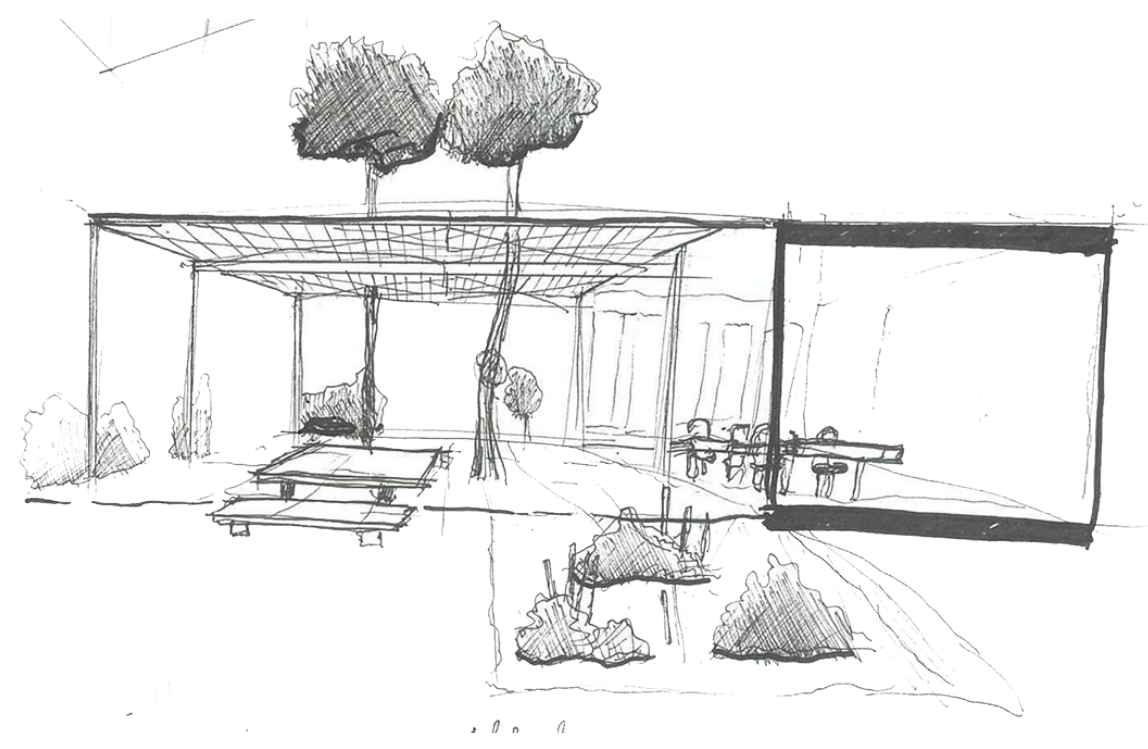

Figure 6.58. Social/ food and beverage space with green spaces integrated. 


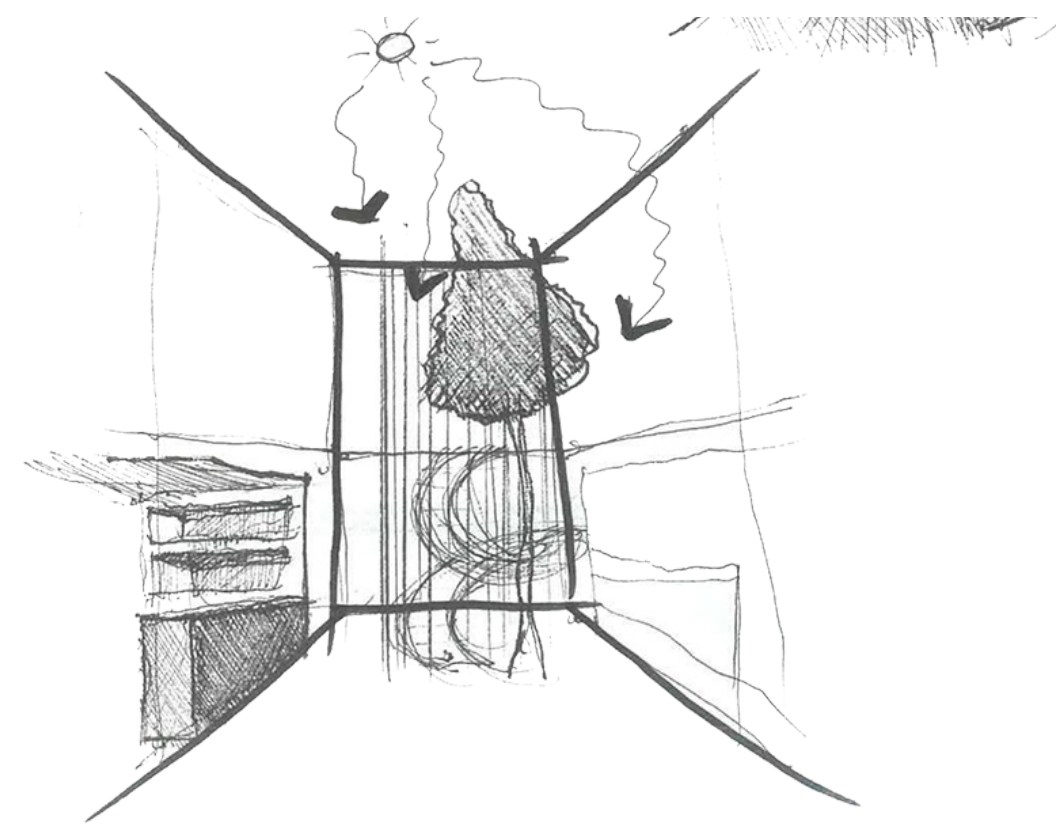

Figure 6.59. Social/ food and beverage space with green spaces integrated.

ATRIUM /

DUUBLE HEVLI QUTEOON SPACE

(9) rooncout

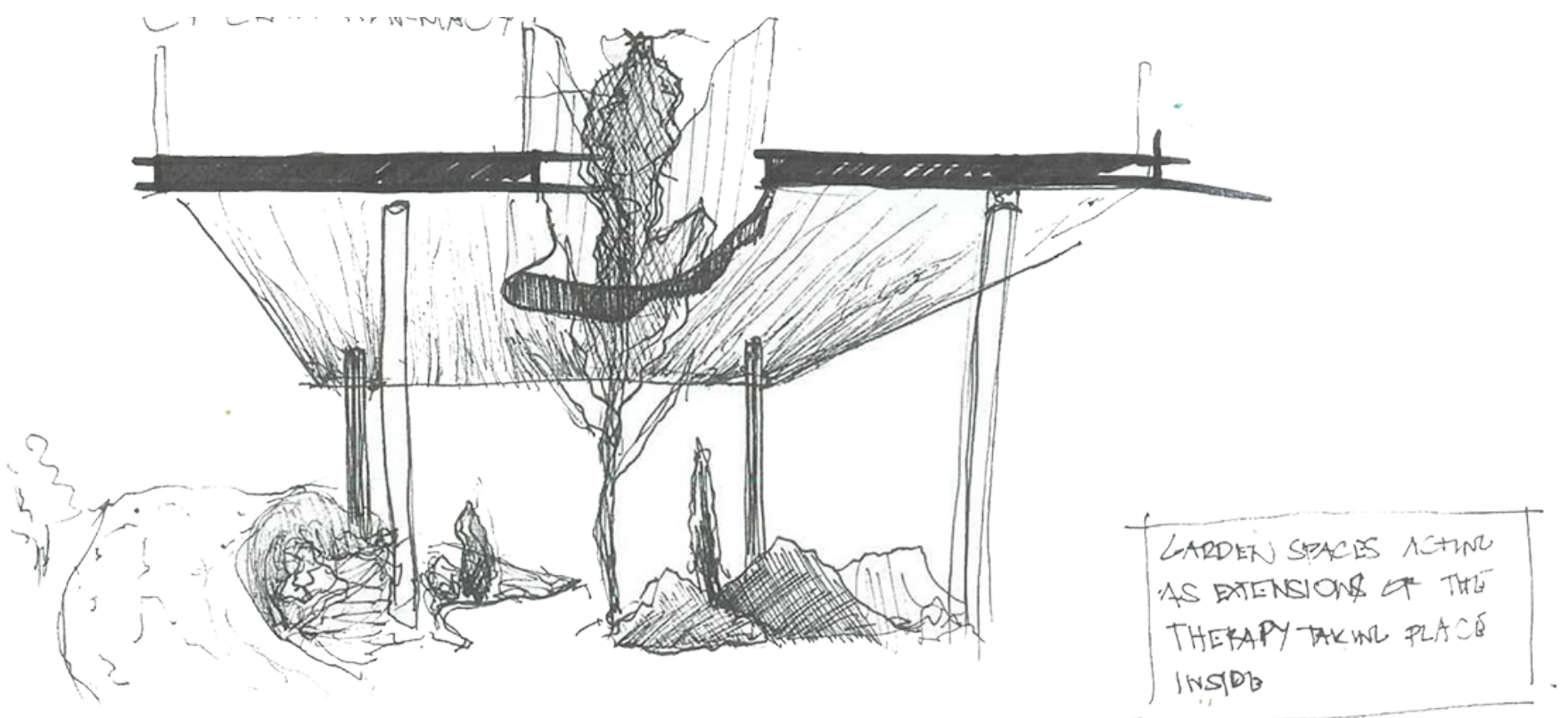

Figure 6.60. Social/ food and beverage space with green spaces integrated. 

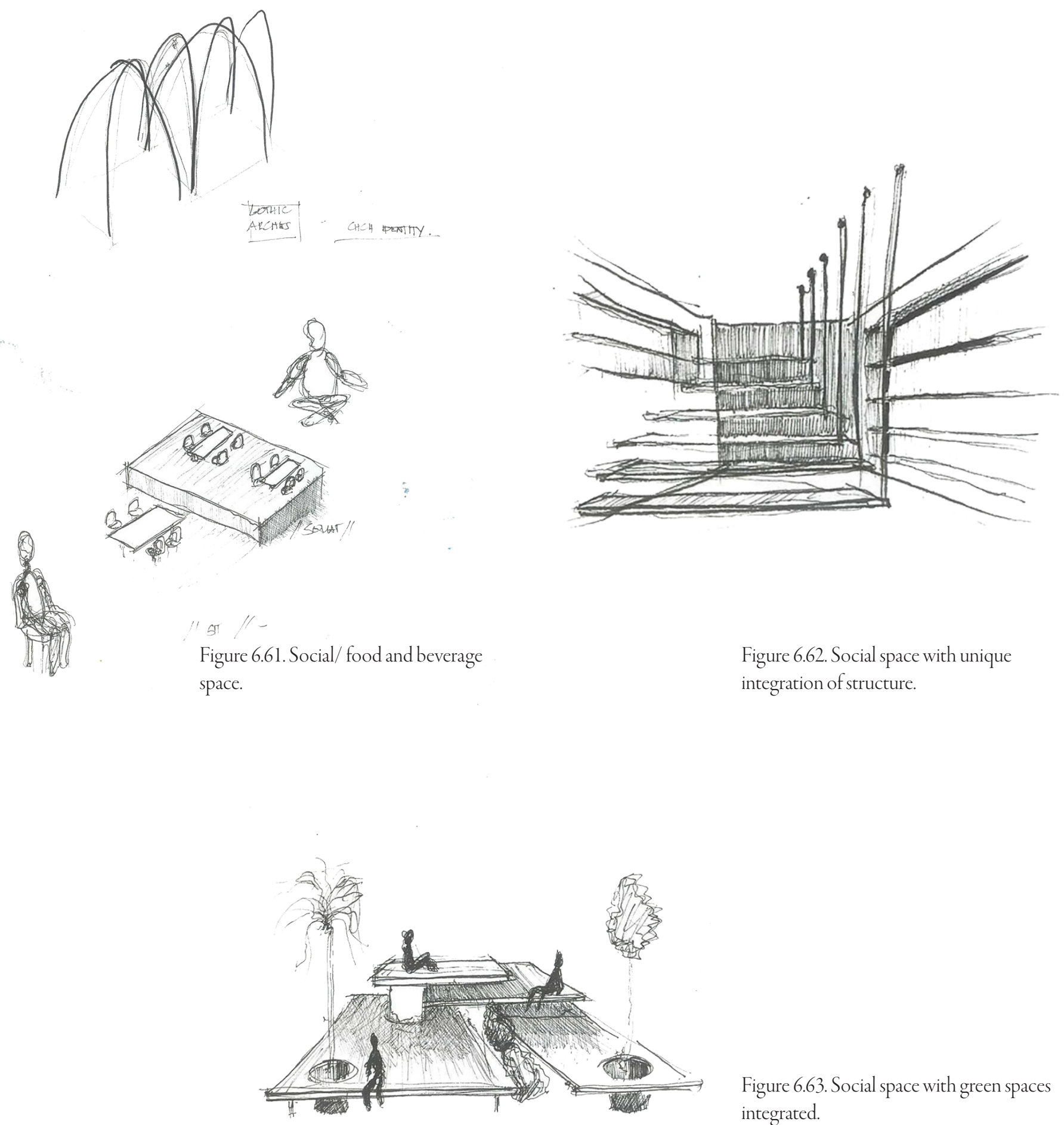

Figure 6.62. Social space with unique integration of structure.

Figure 6.63. Social space with green spaces integrated.
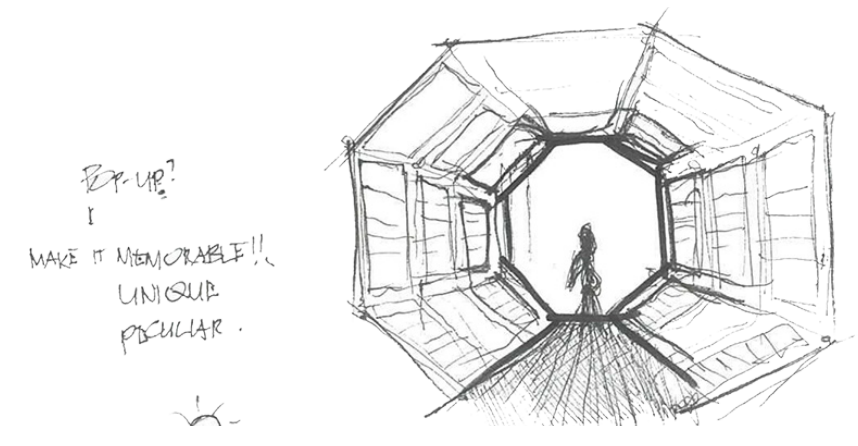

Figure 6.64. Social space that can serve as pop-up retail space. 


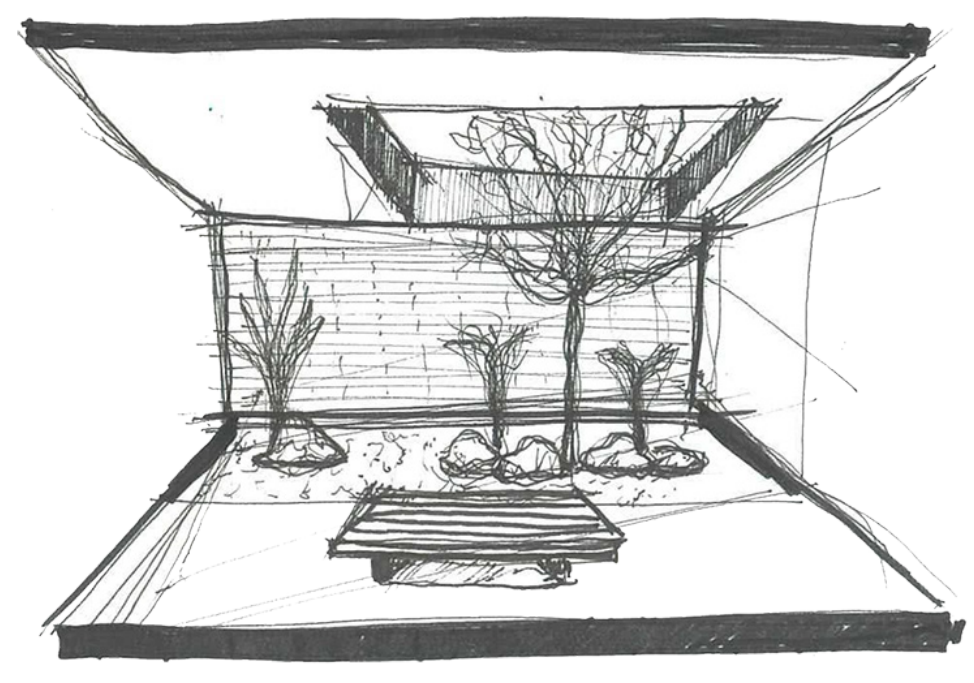

Figure 6.65. Social space that can be integrated with the mall's circulation and green spaces.

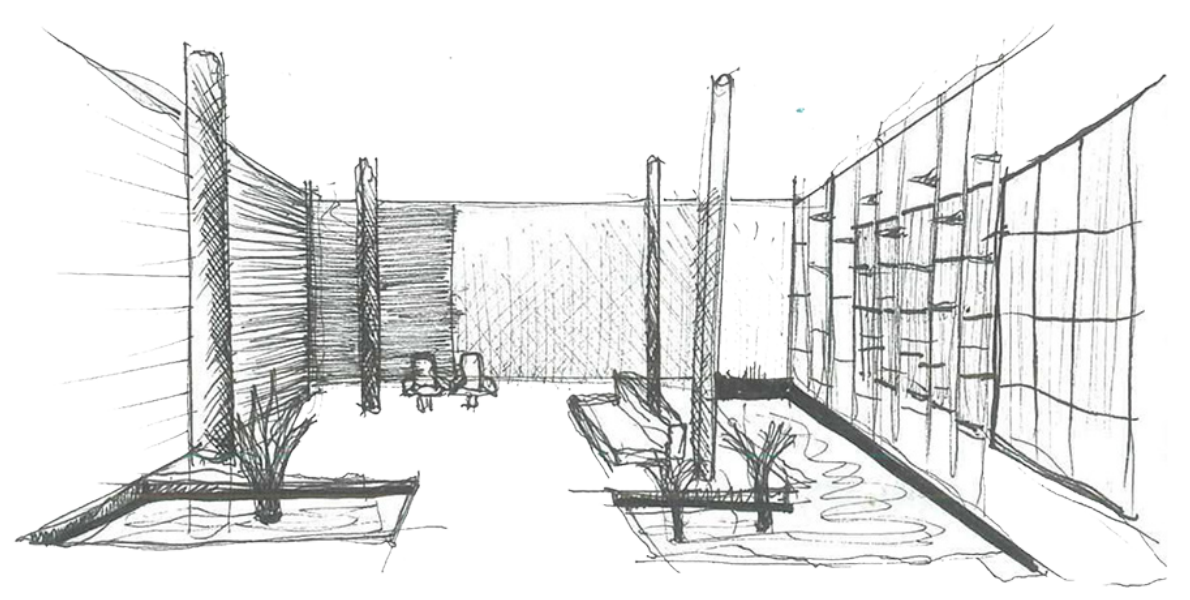

Figure 6.66. Social and/or retail space that can be integrated with the mall's circulation and green spaces. 


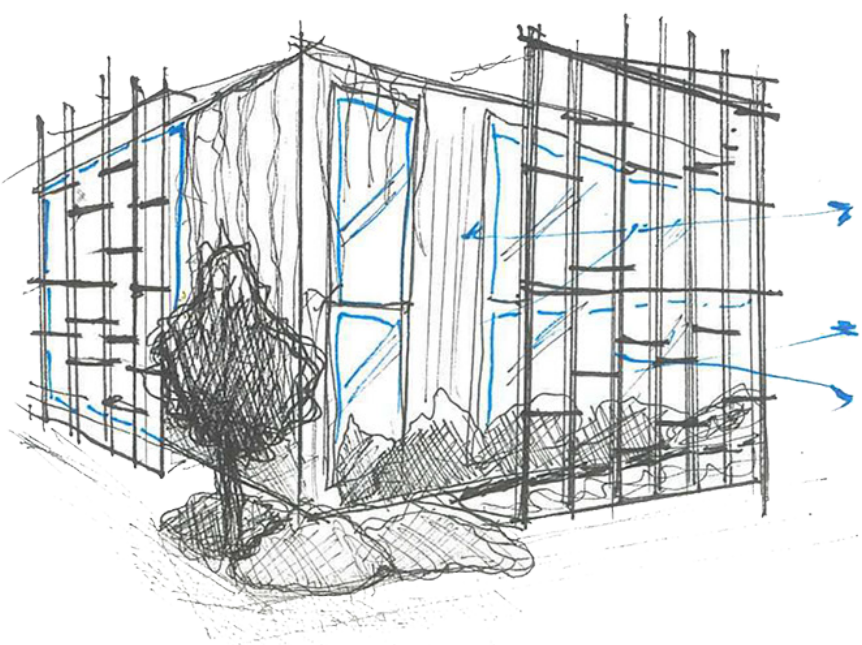

Figure 6.67. Fenestration dependent on arrangement of social and/or retail space integrated with the mall's circulation and green spaces.

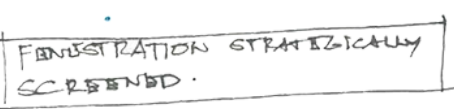

Figure 6.68. Therapeutic retail space that can be integrated with the mall's circulation and green spaces.
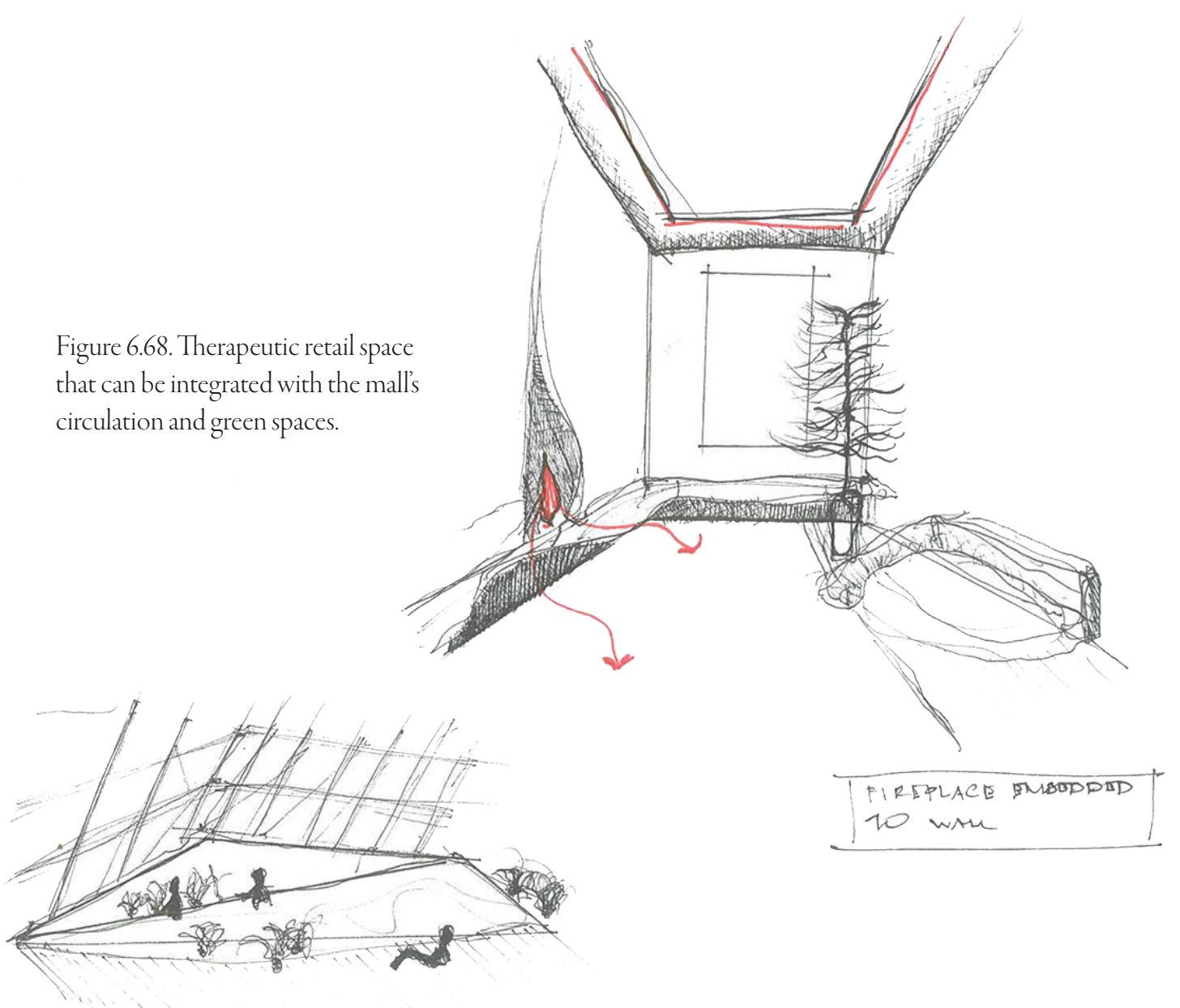

Figure 6.69. Therapeutic retail space that can be integrated with the mall's circulation and green spaces. 

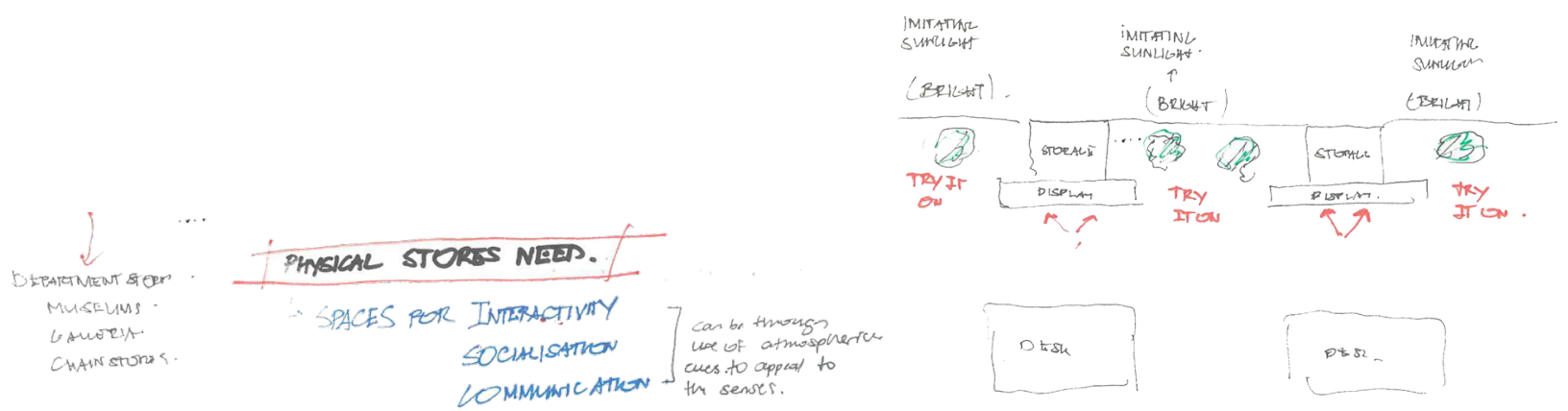

STRELIED.

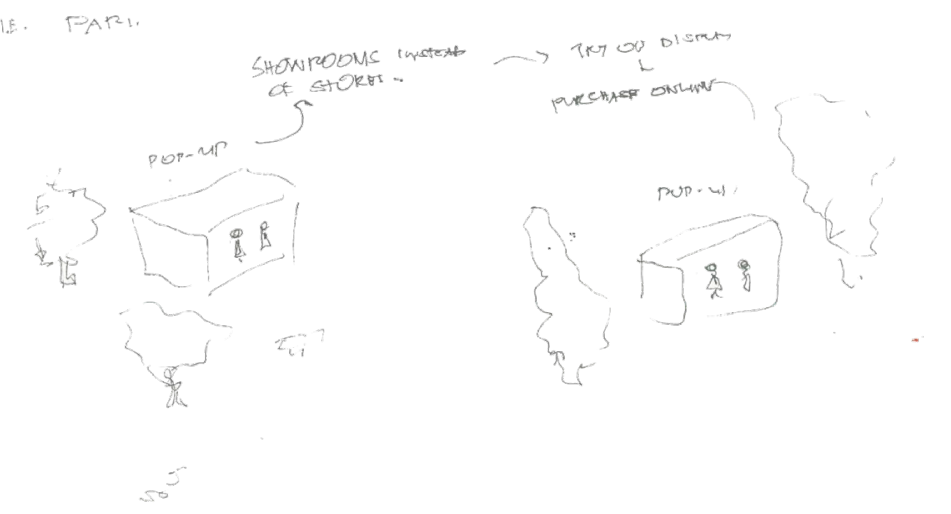

H. MARESTS

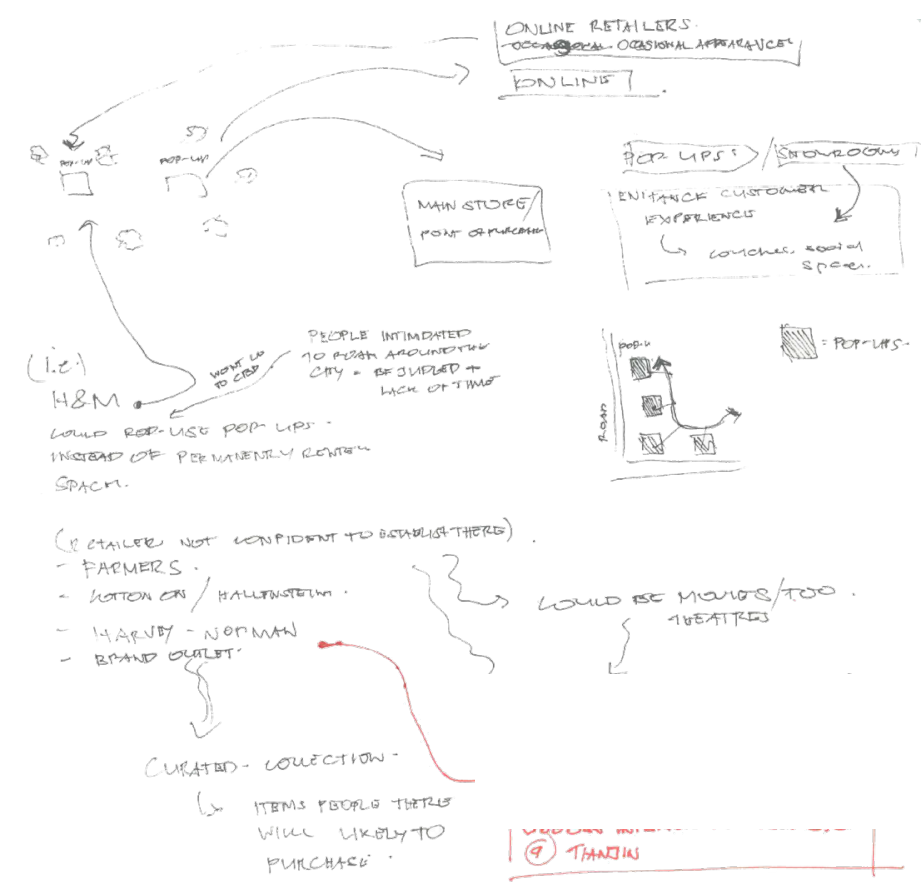
roD-uPS. $\Rightarrow$ ENHANCE IMPULE.

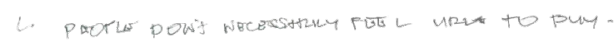

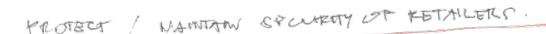

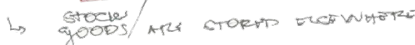

MUET RADICALLY RECLNSIDER The $f \rightarrow$ potentialy whin

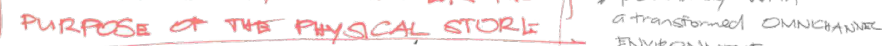

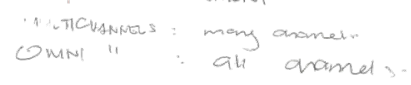



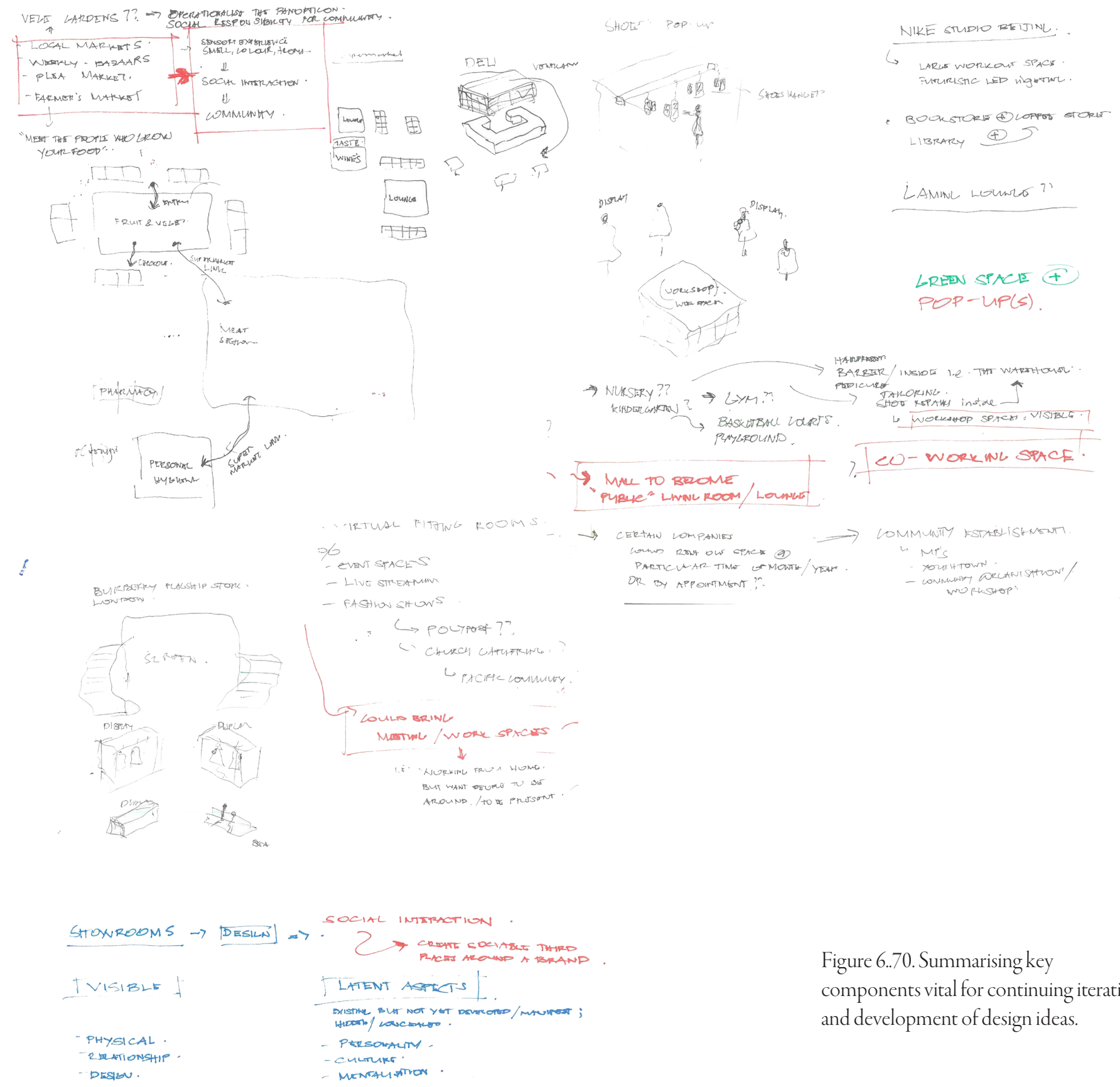

Figure 6..70. Summarising key components vital for continuing iteration and development of design ideas.
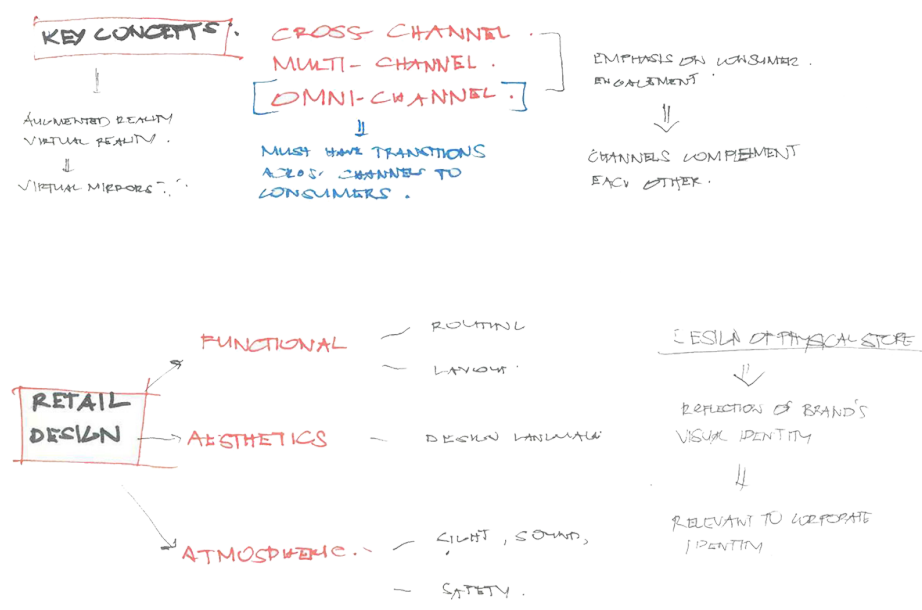


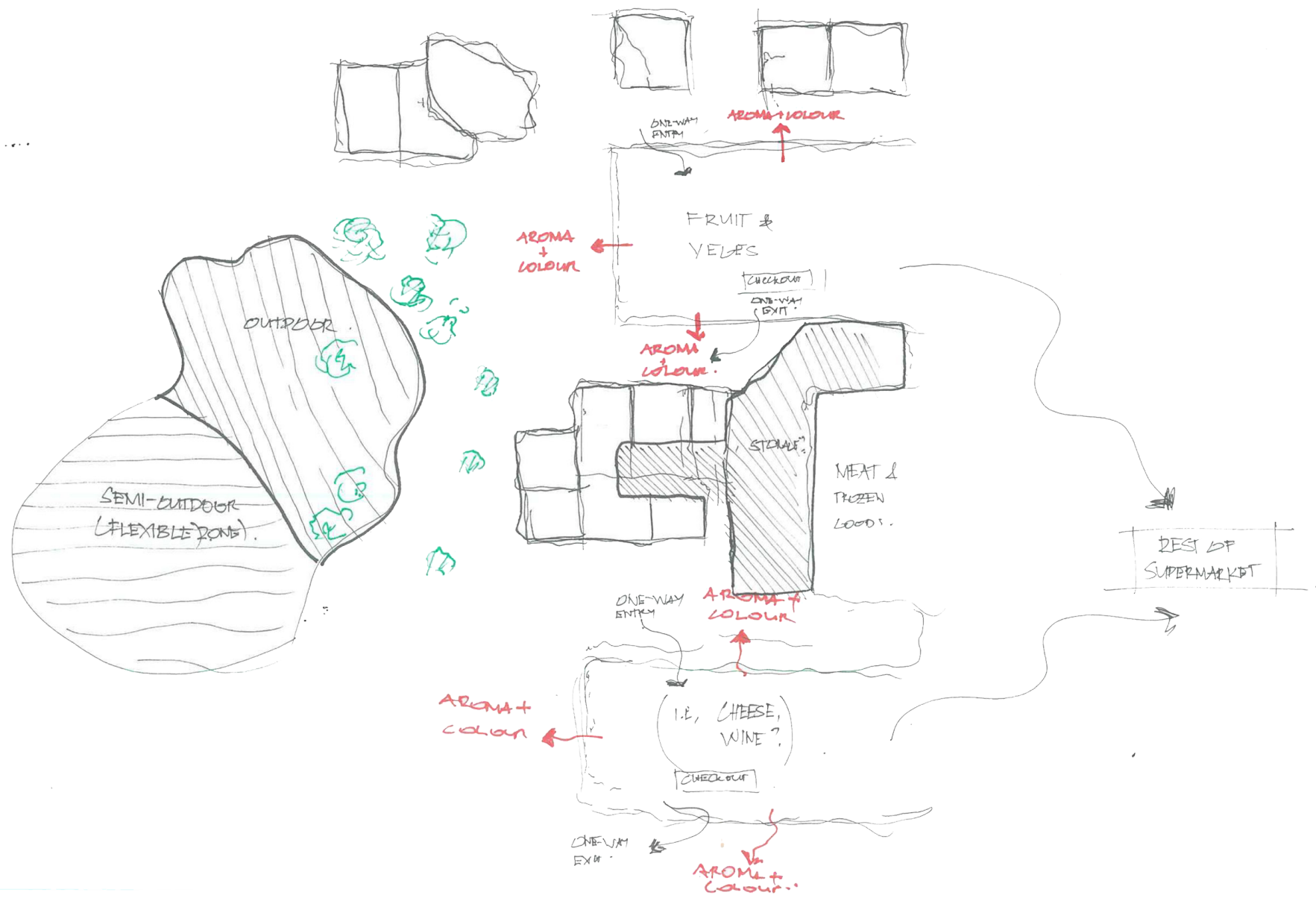

Figure 6.71. Reconfiguration of a supermarket and link to food court to enhance engagement between retailers and people. 


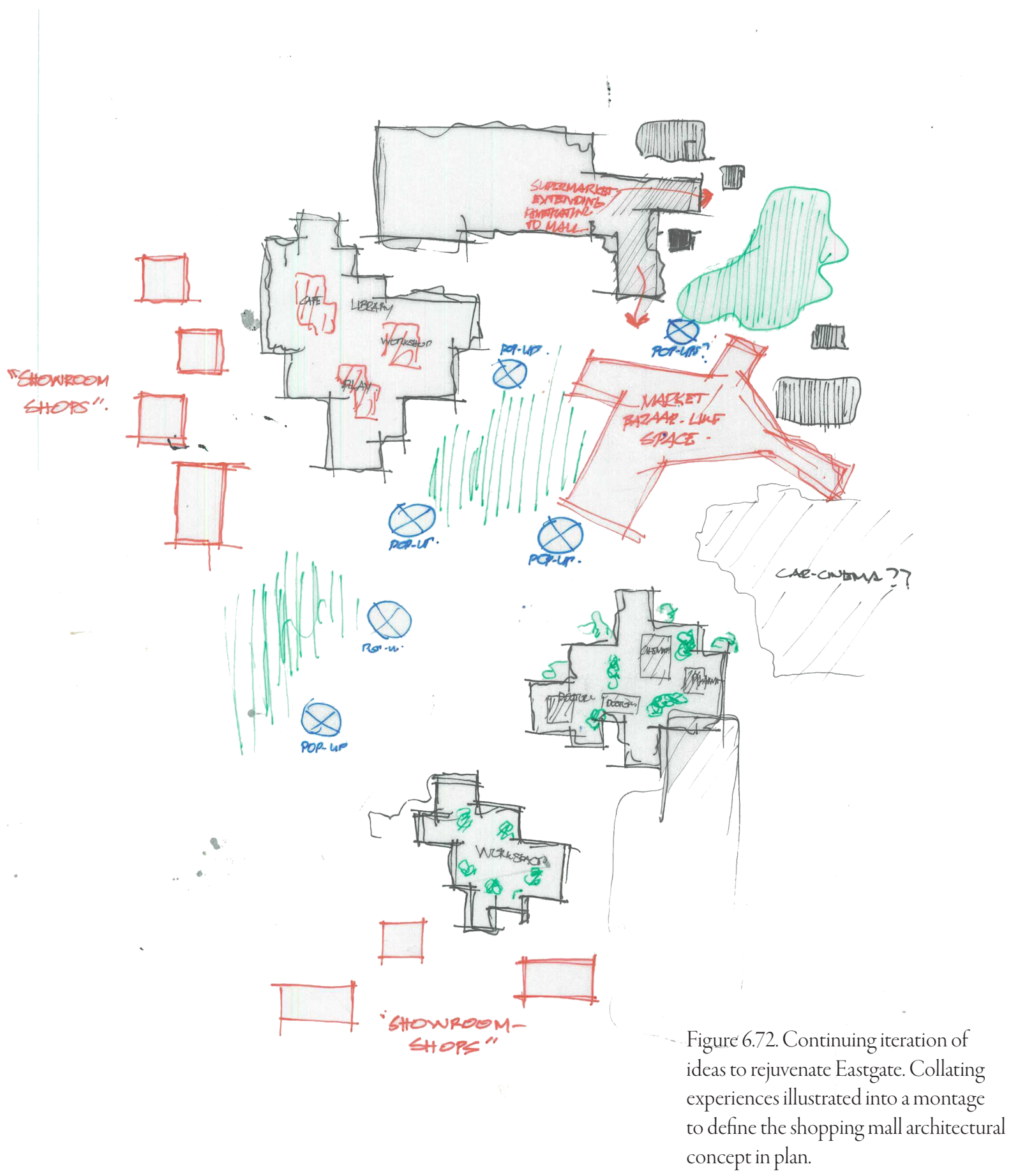




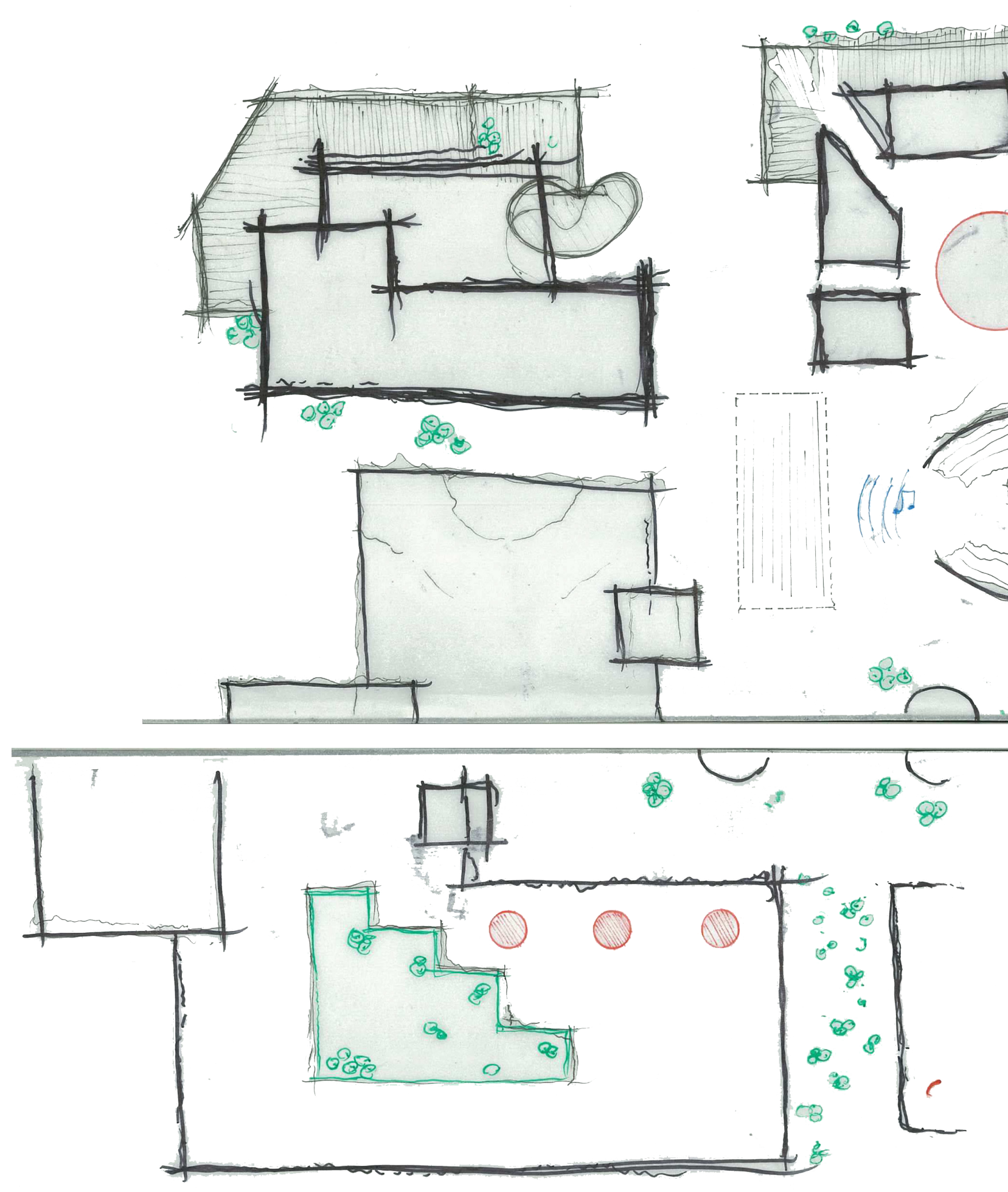




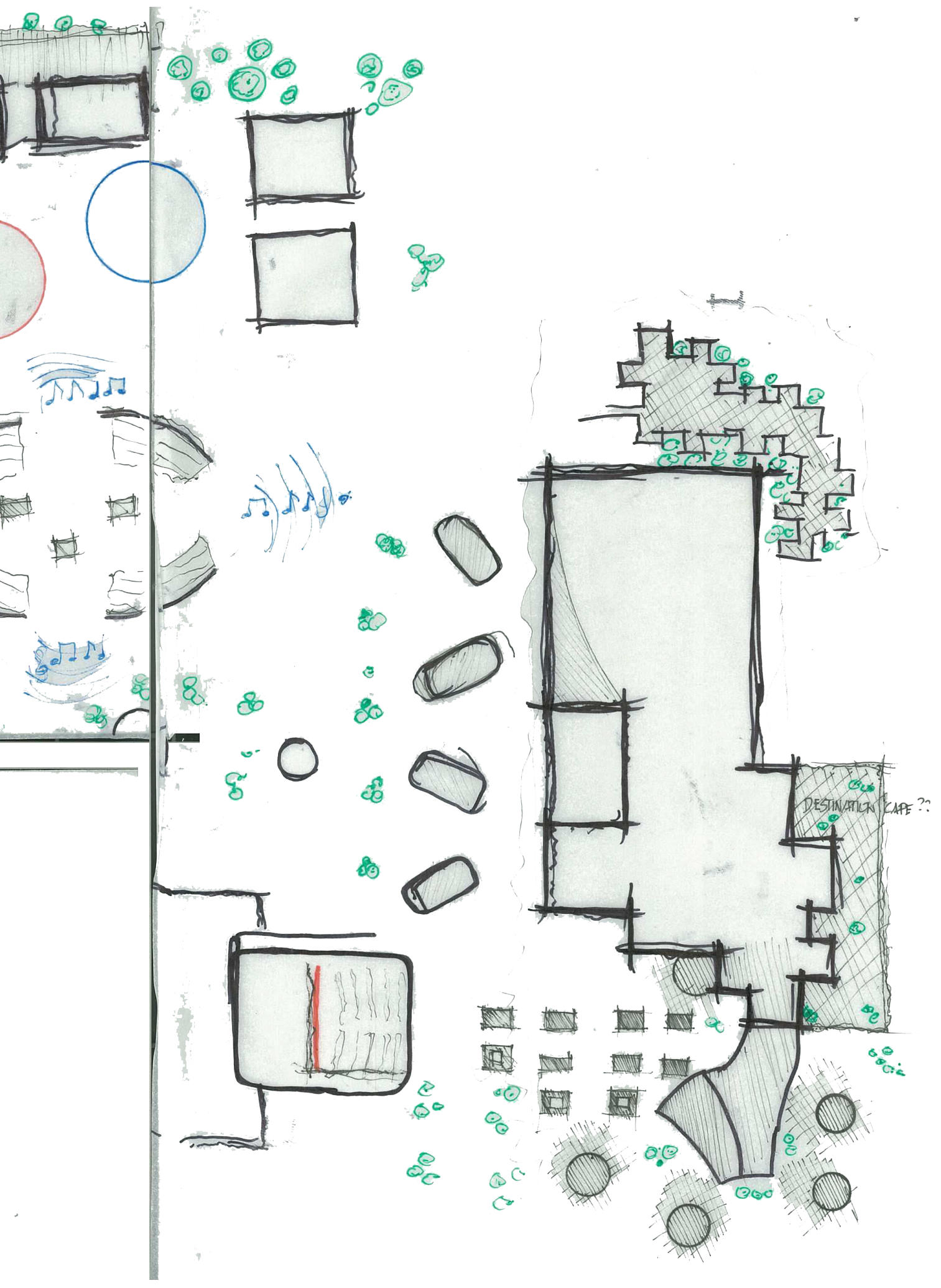

Figure 6.73. Iteration 3.1. 


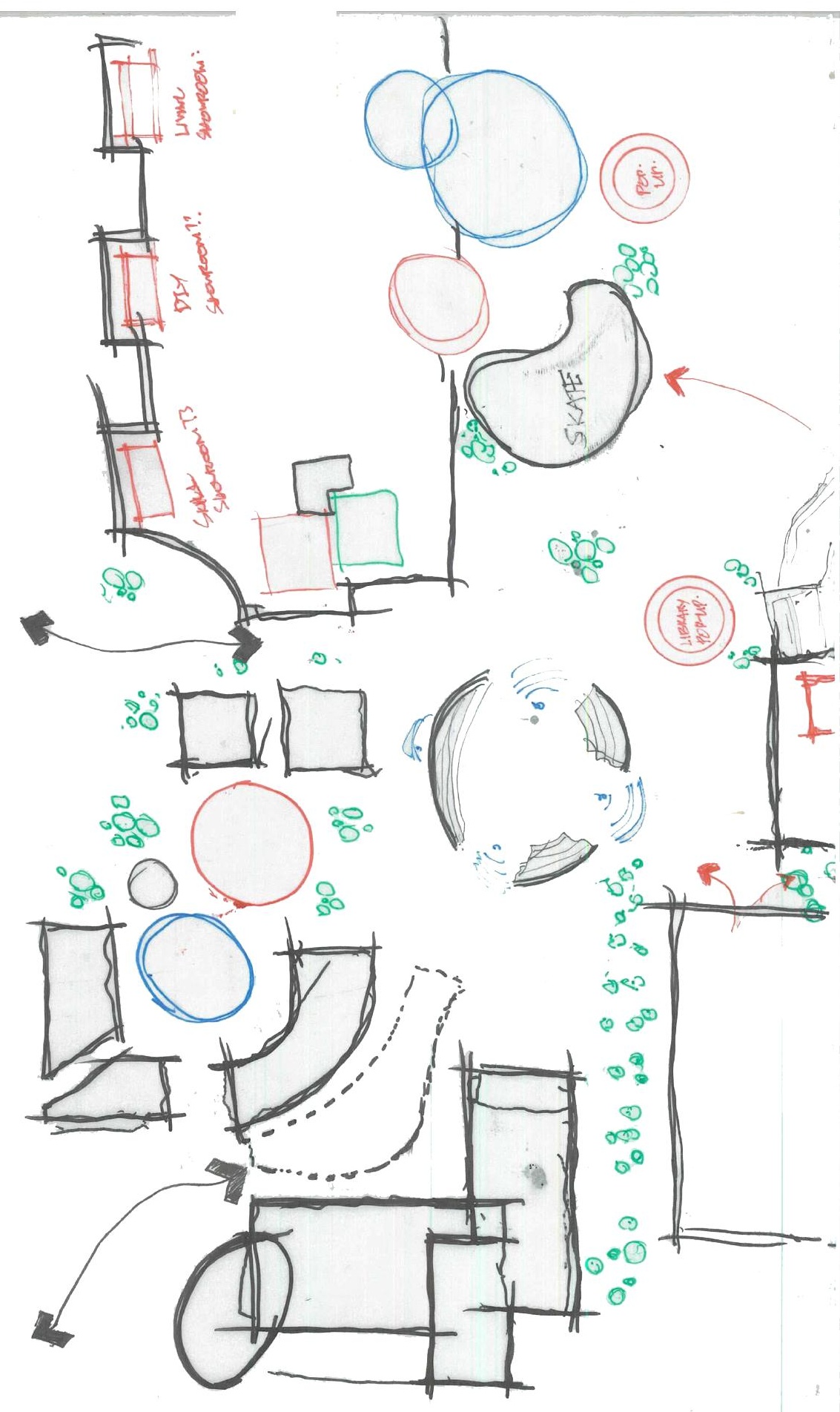




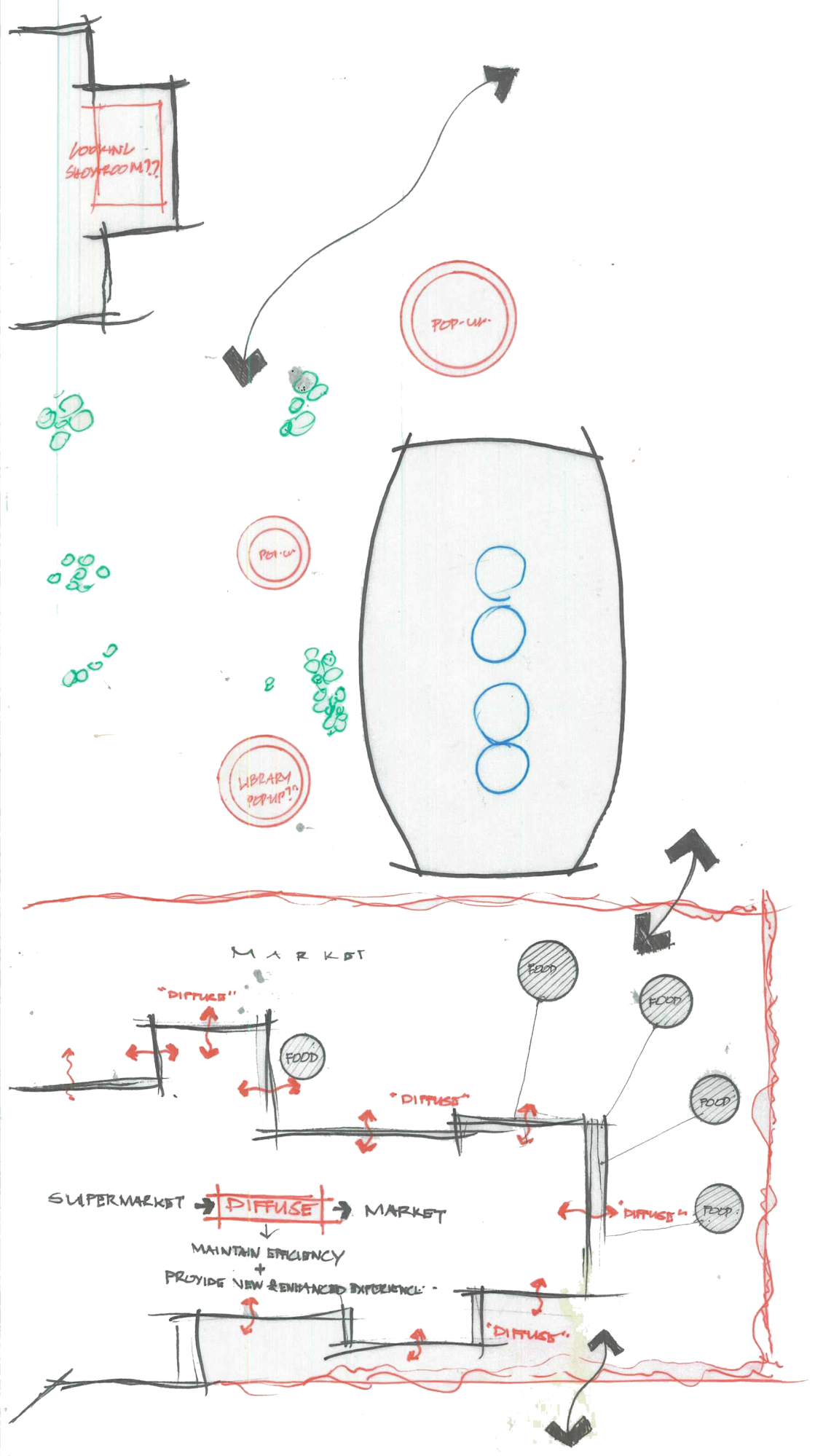

Figure 6.74. Iteration 3.2 


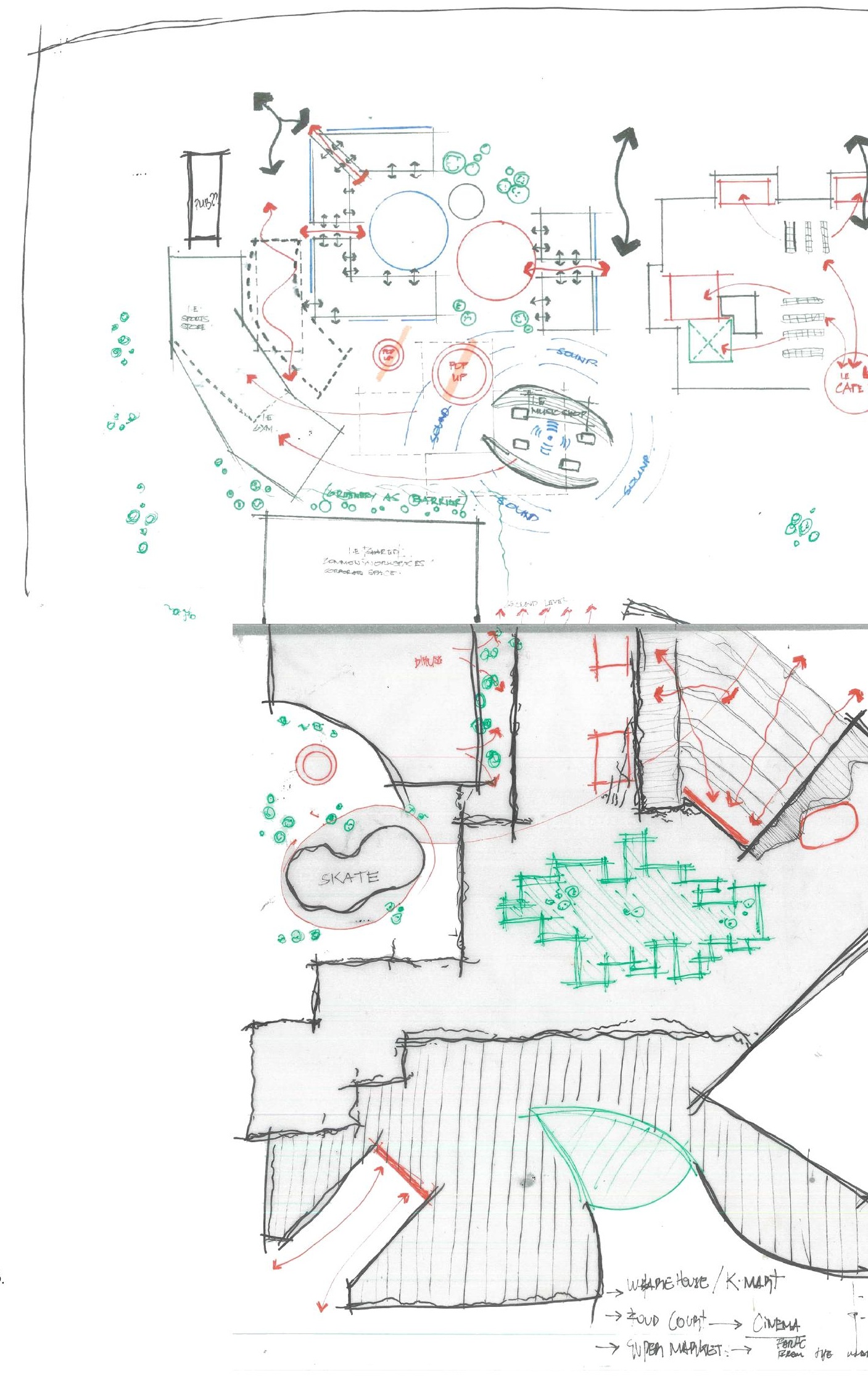




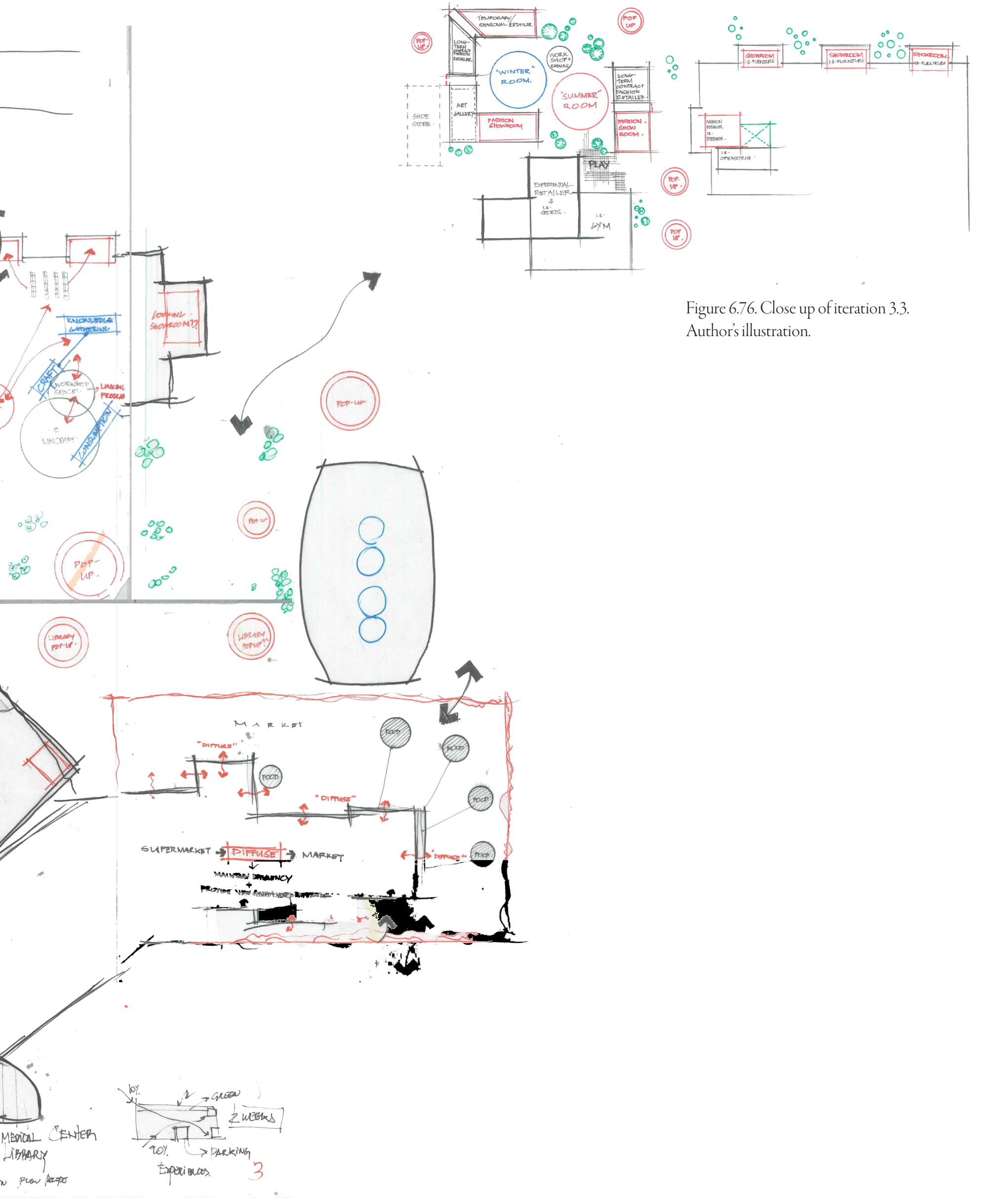




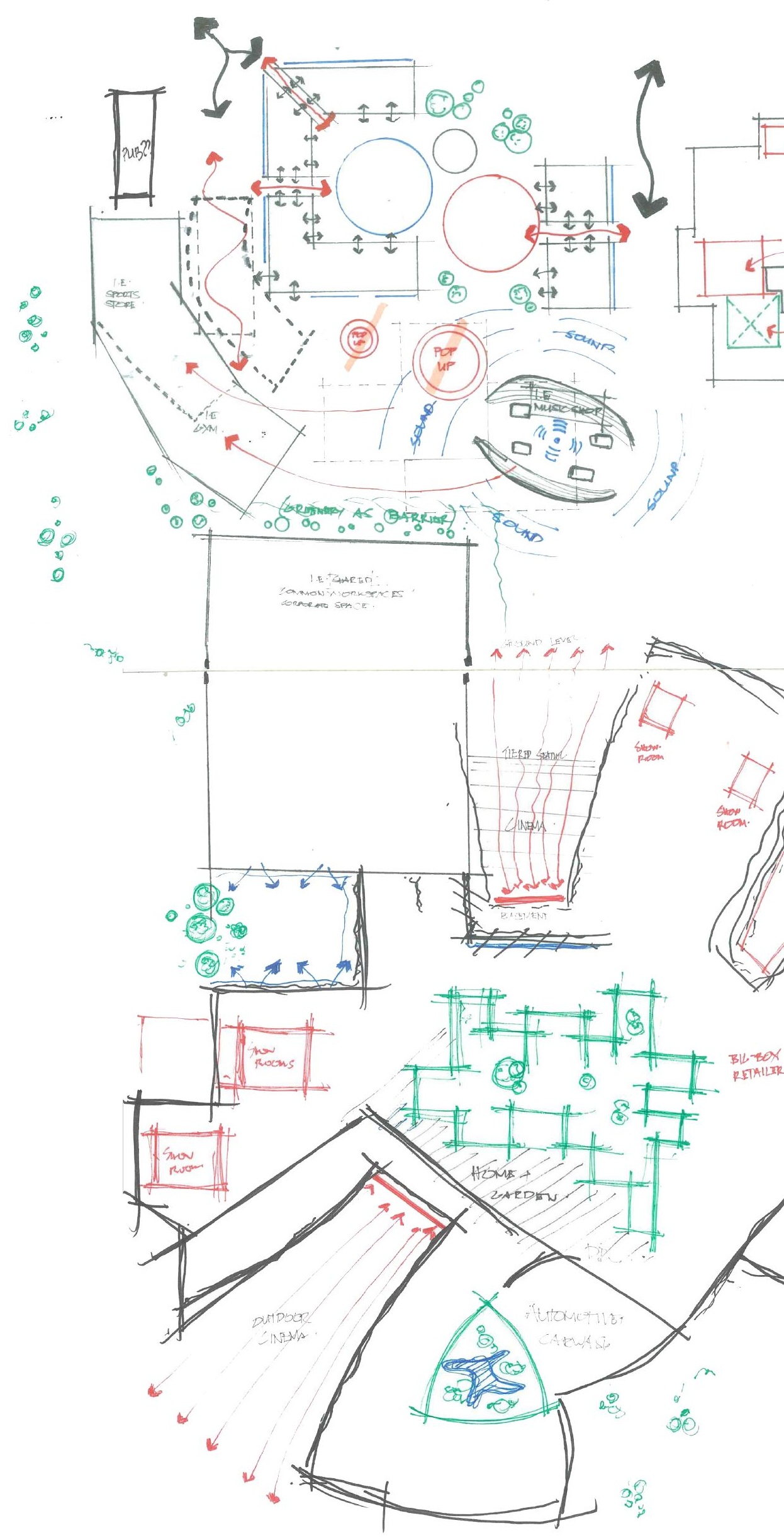




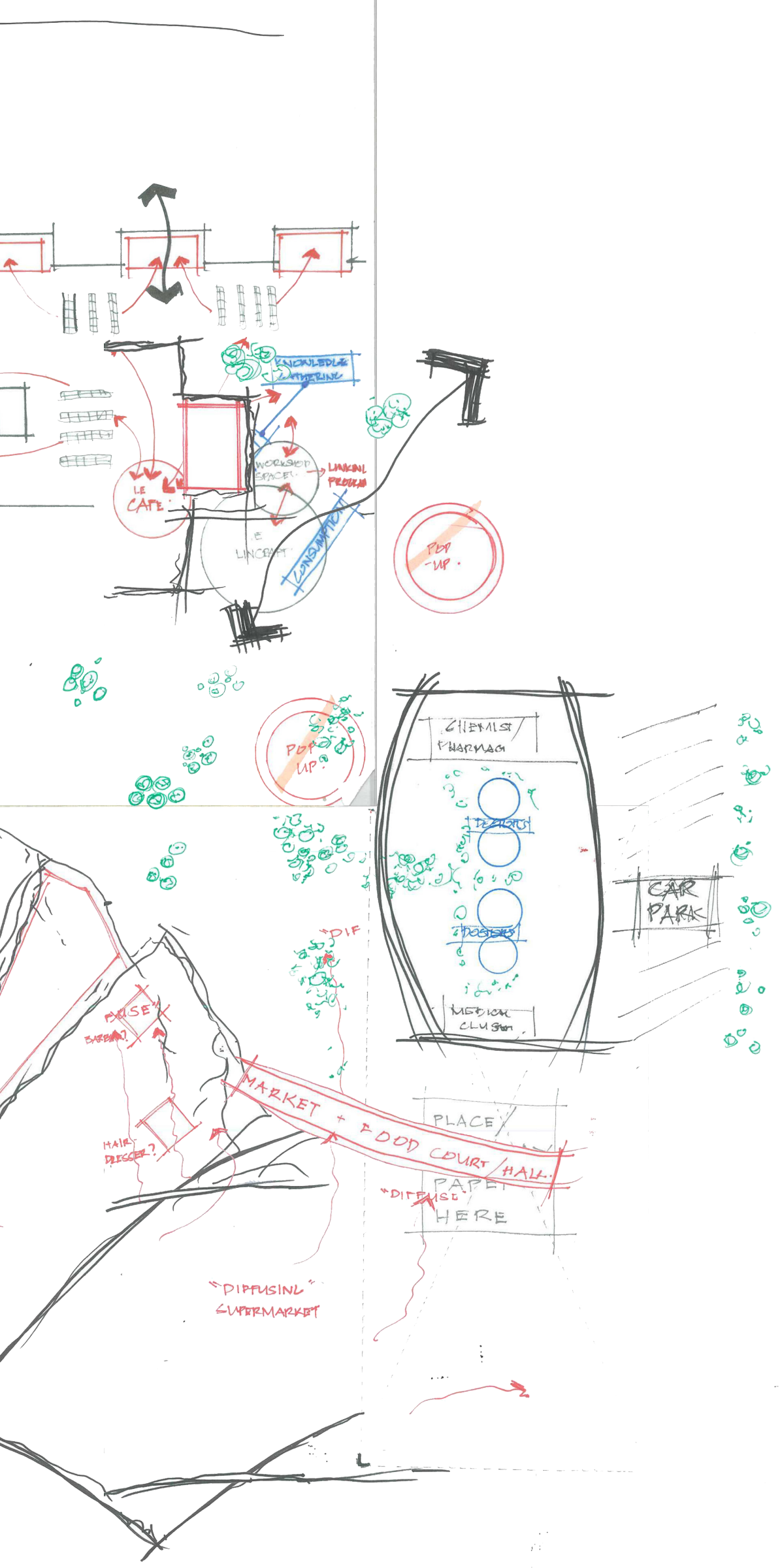

Figure 6.77. Iteration 3.4- further developing ideas in previous iteration. 


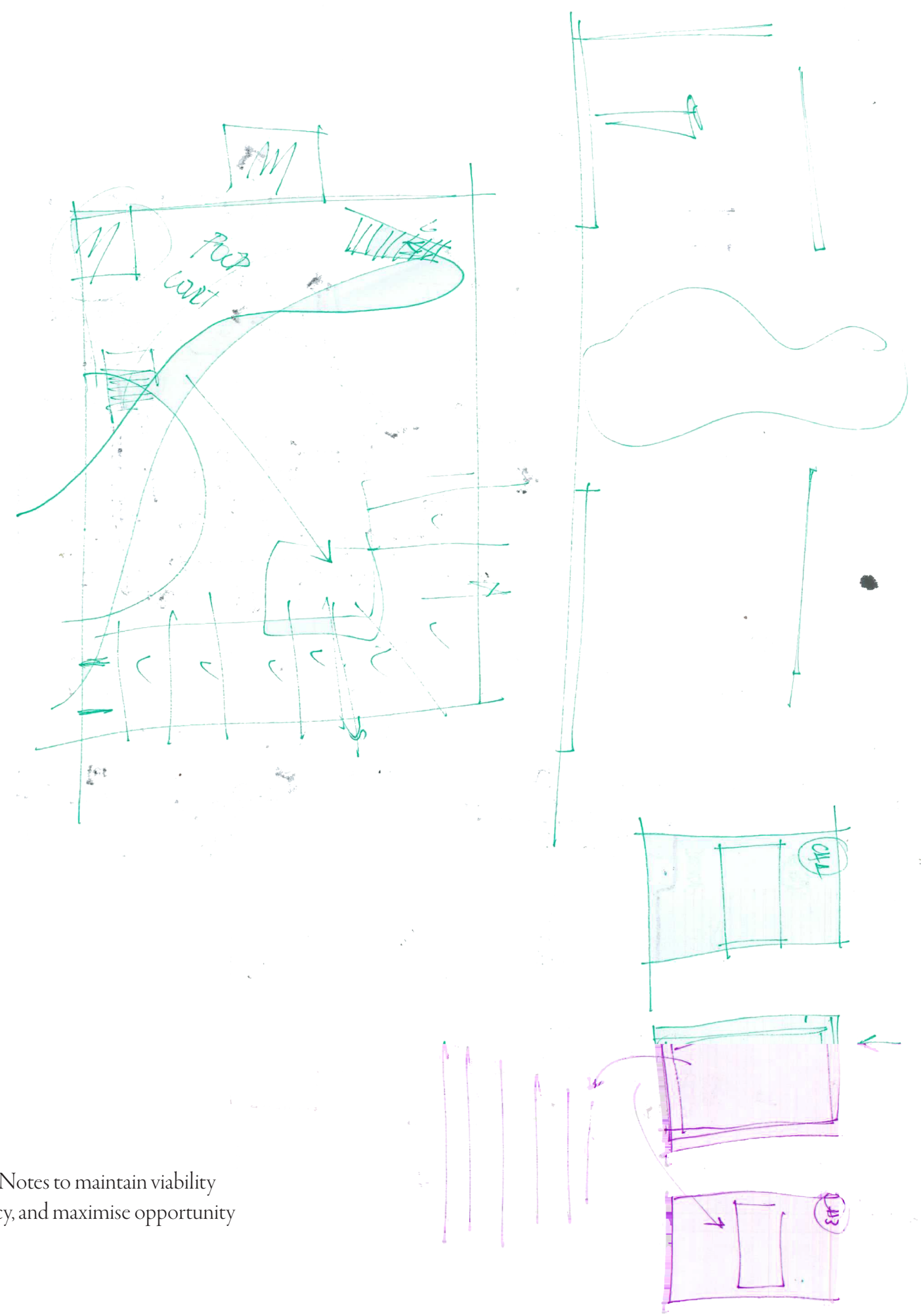

and efficiency, and maximise opportunity for retailers.

184 


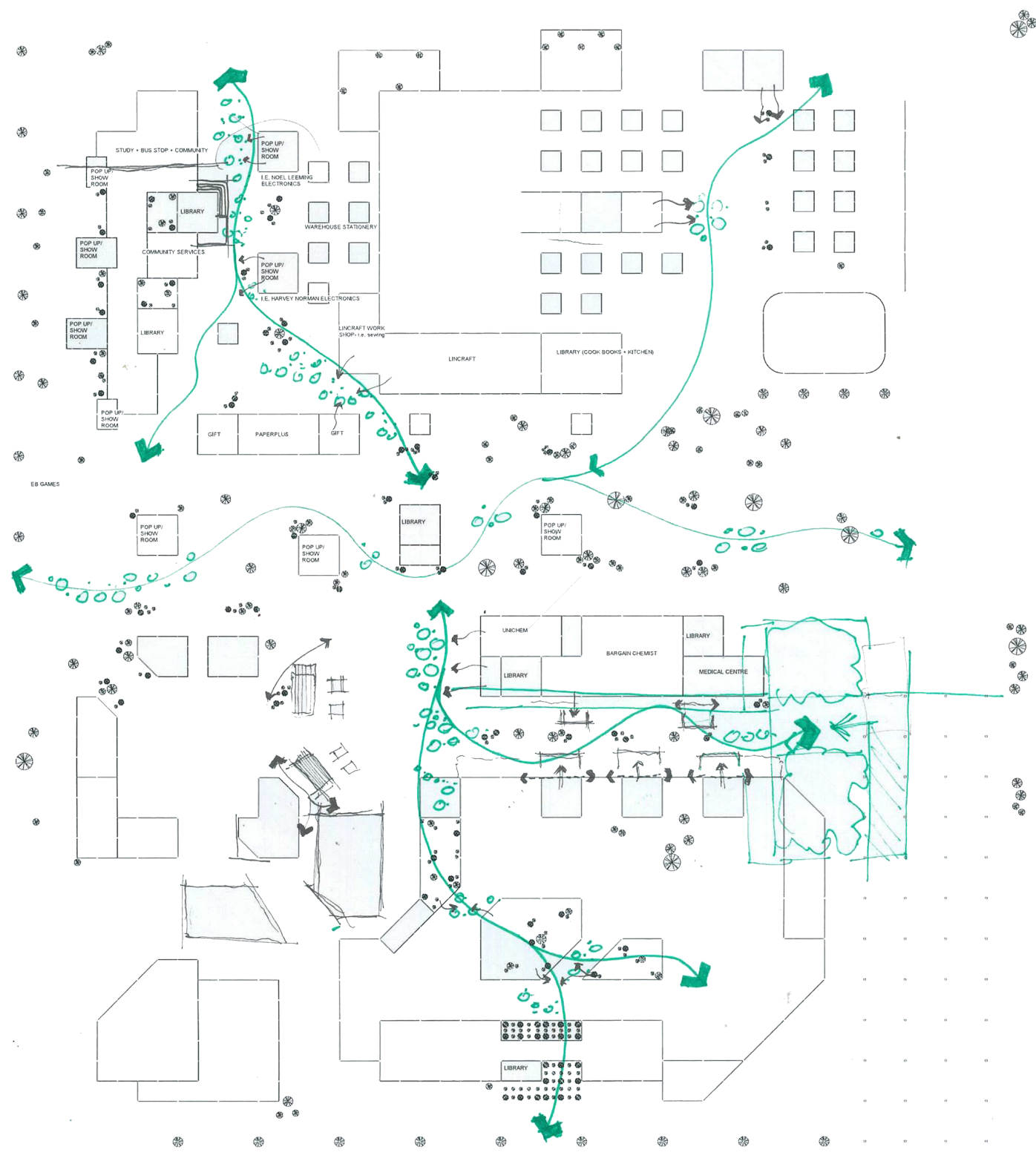

Figure 6.79. Iteration 3.5 and green paths as the mall's new architectural gesture. A realisation that the gesture to make the mall unique does not have to be a grand architectural statement. 


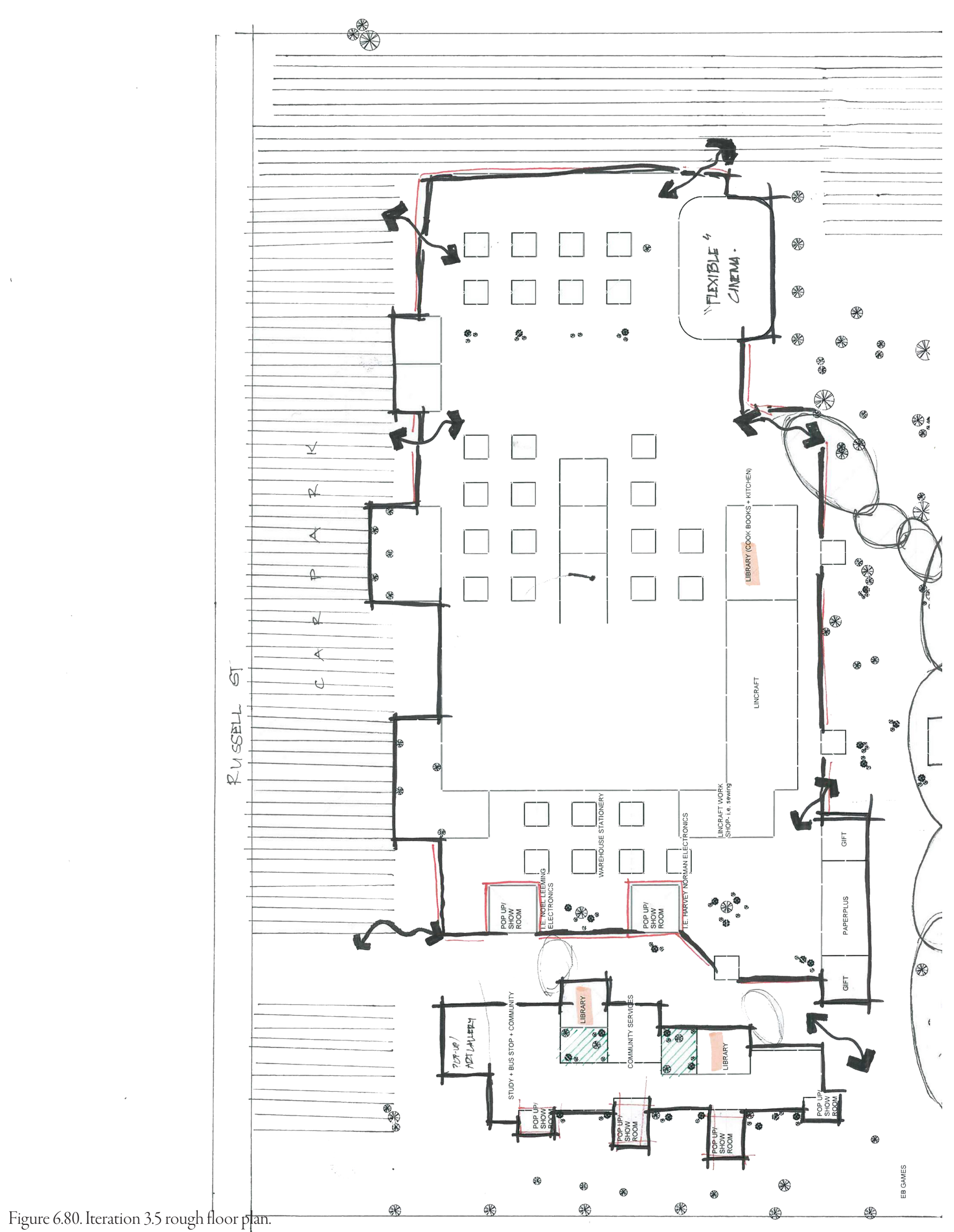




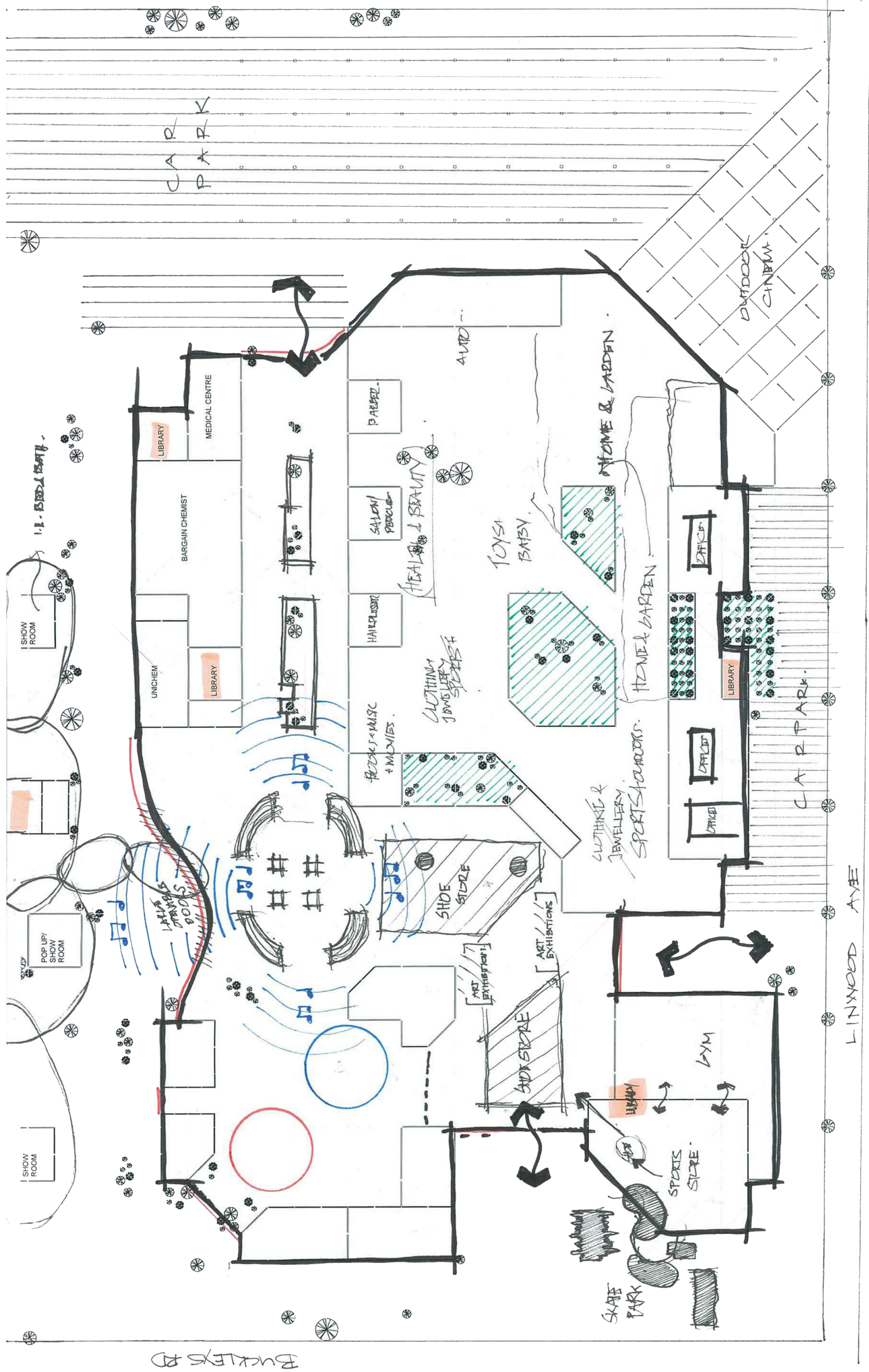




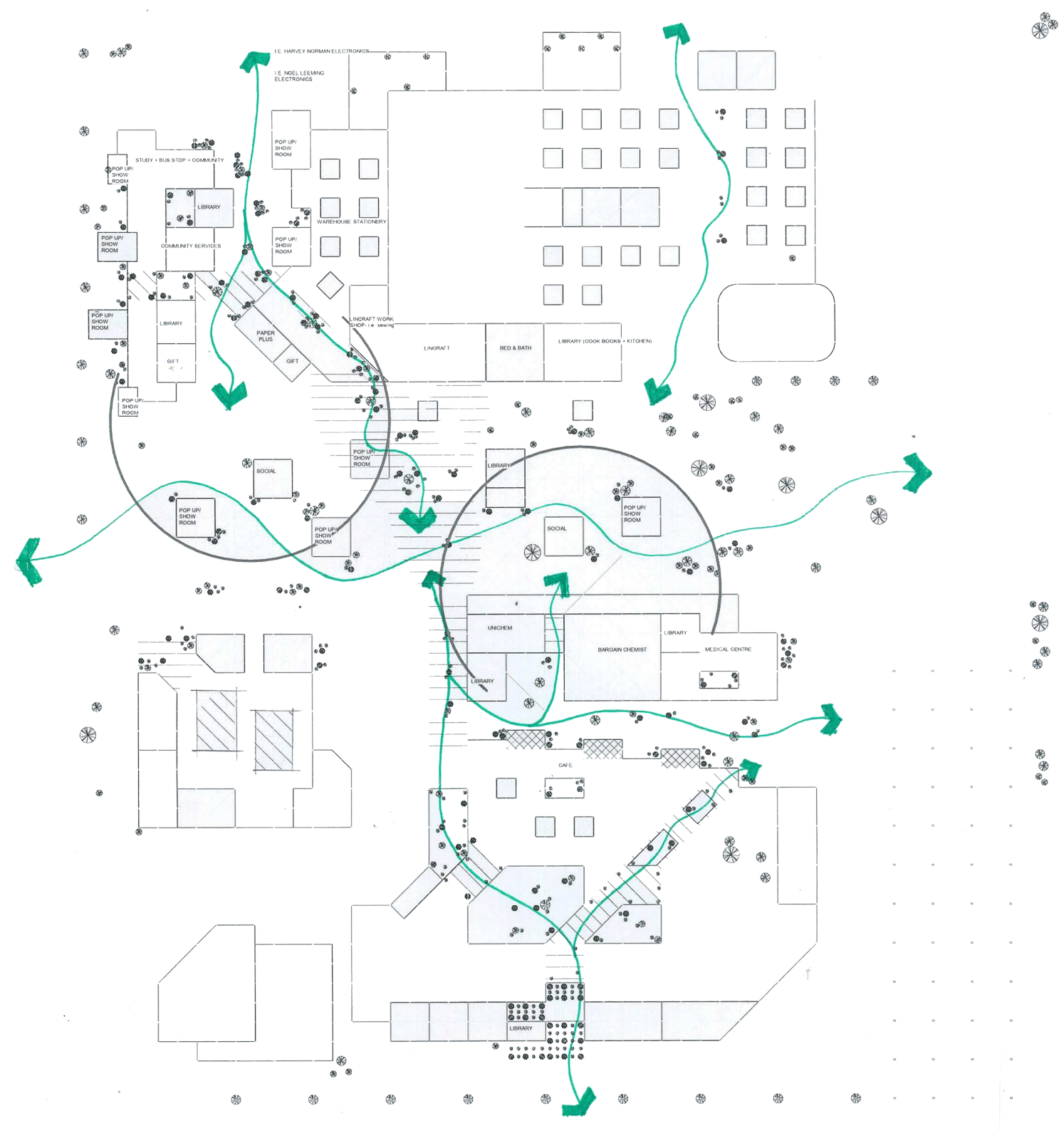

Figure 6.81. Linking up the mall's fragmented segments. 

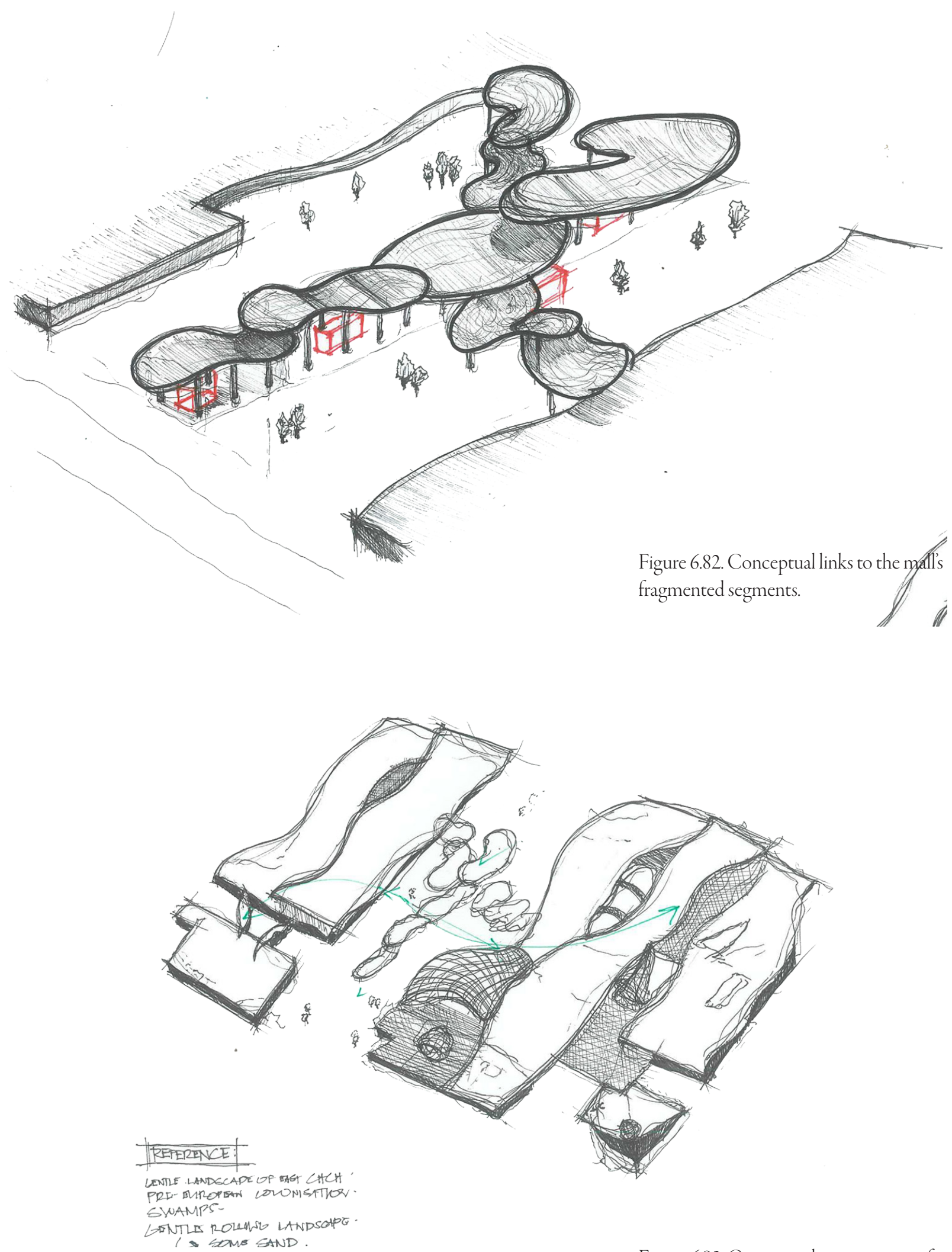

Figure 6.83. Conceptual axonometric of a rejuvenated Eastgate based on iteration 3.5. 


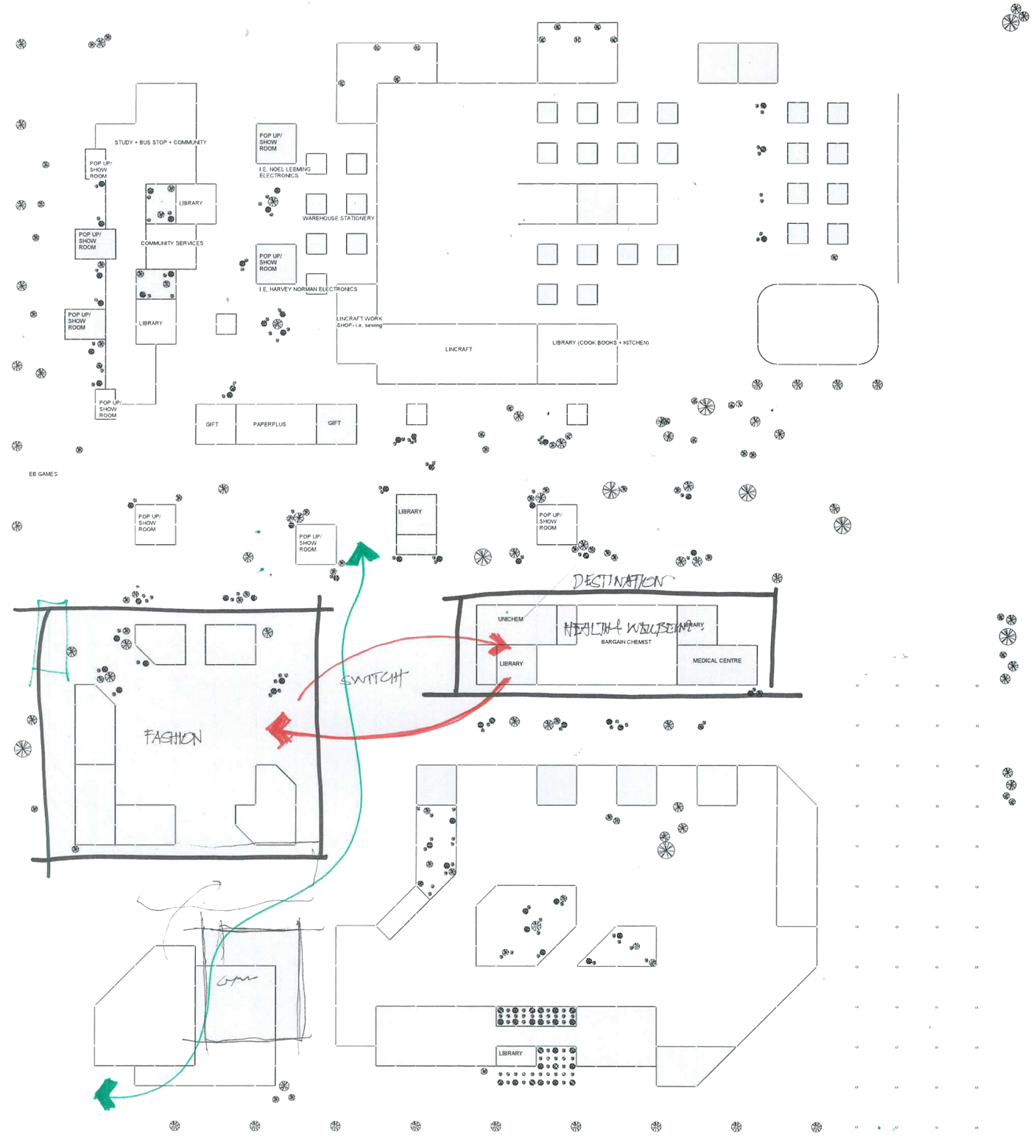

Figure 6.84. Swapping the placements of fashion and destination wellbeing/ medical tenants to maximise opportunity for fashion retailers. 


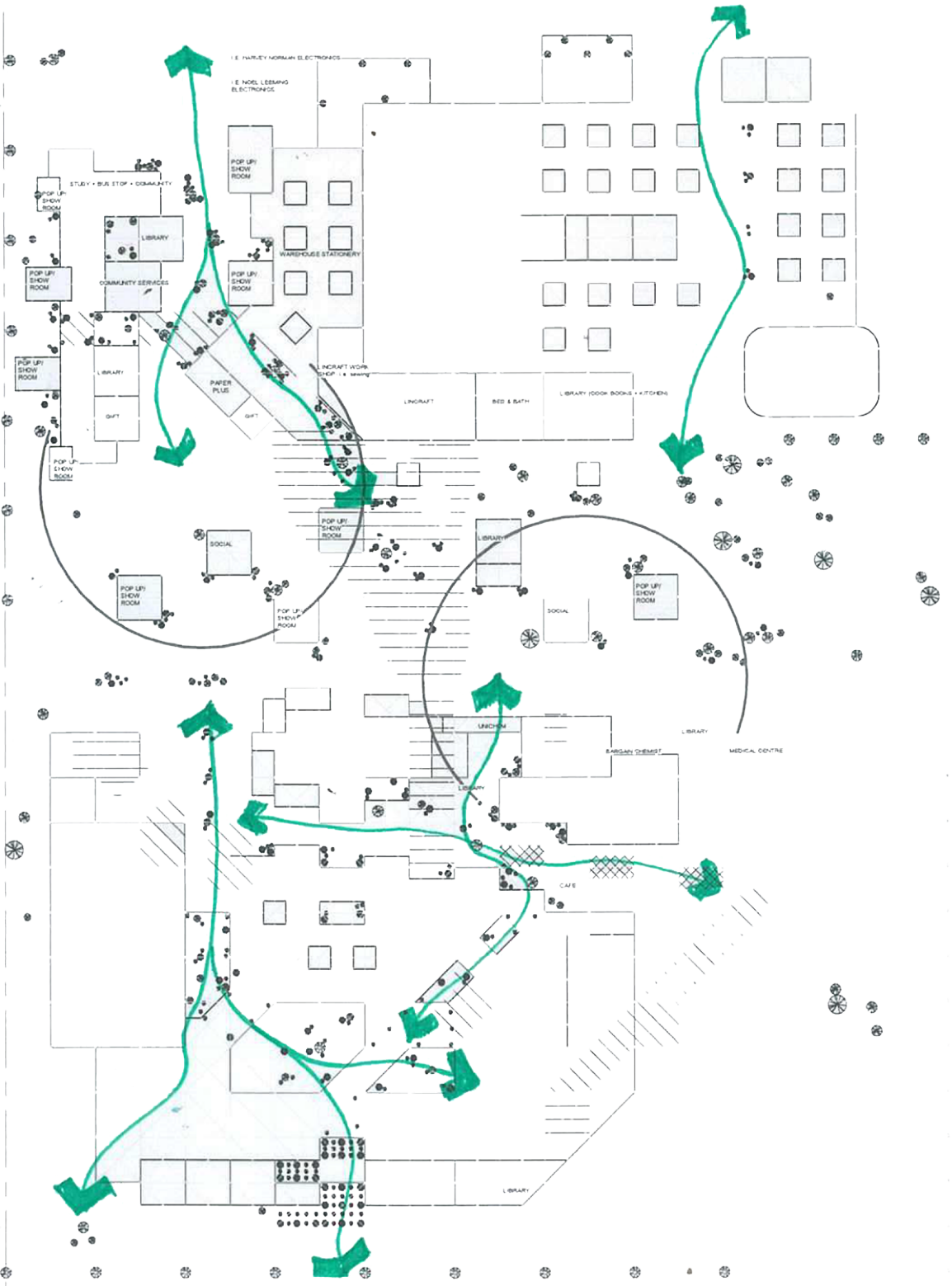

*

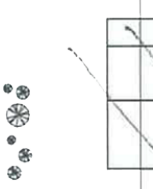

:

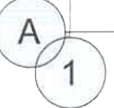

Figure 6.85. Conceptual links to the mall's fragmented segments. 


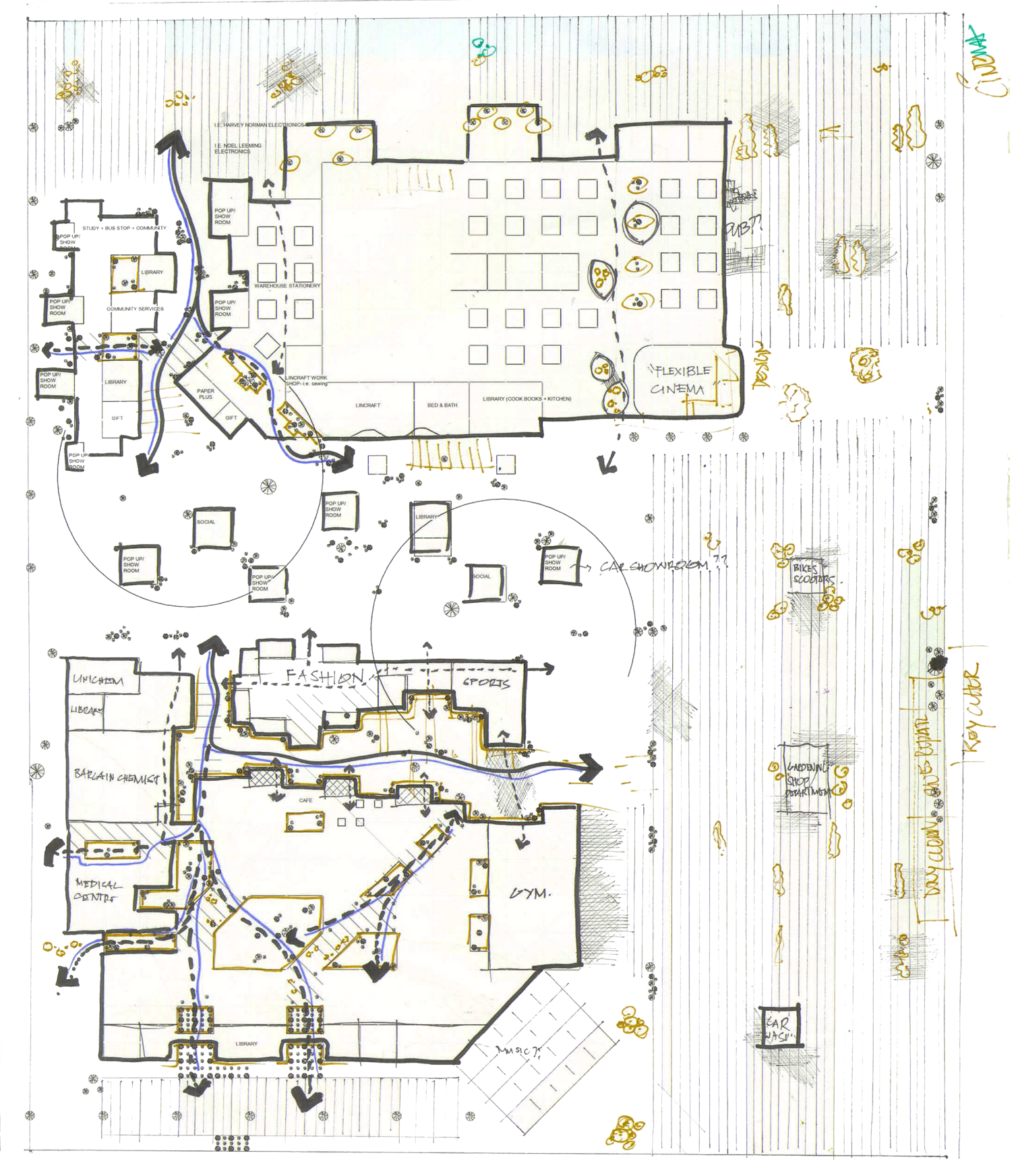

Figure 6.86. Iteration 3.6 rough floor plan and circulation. 


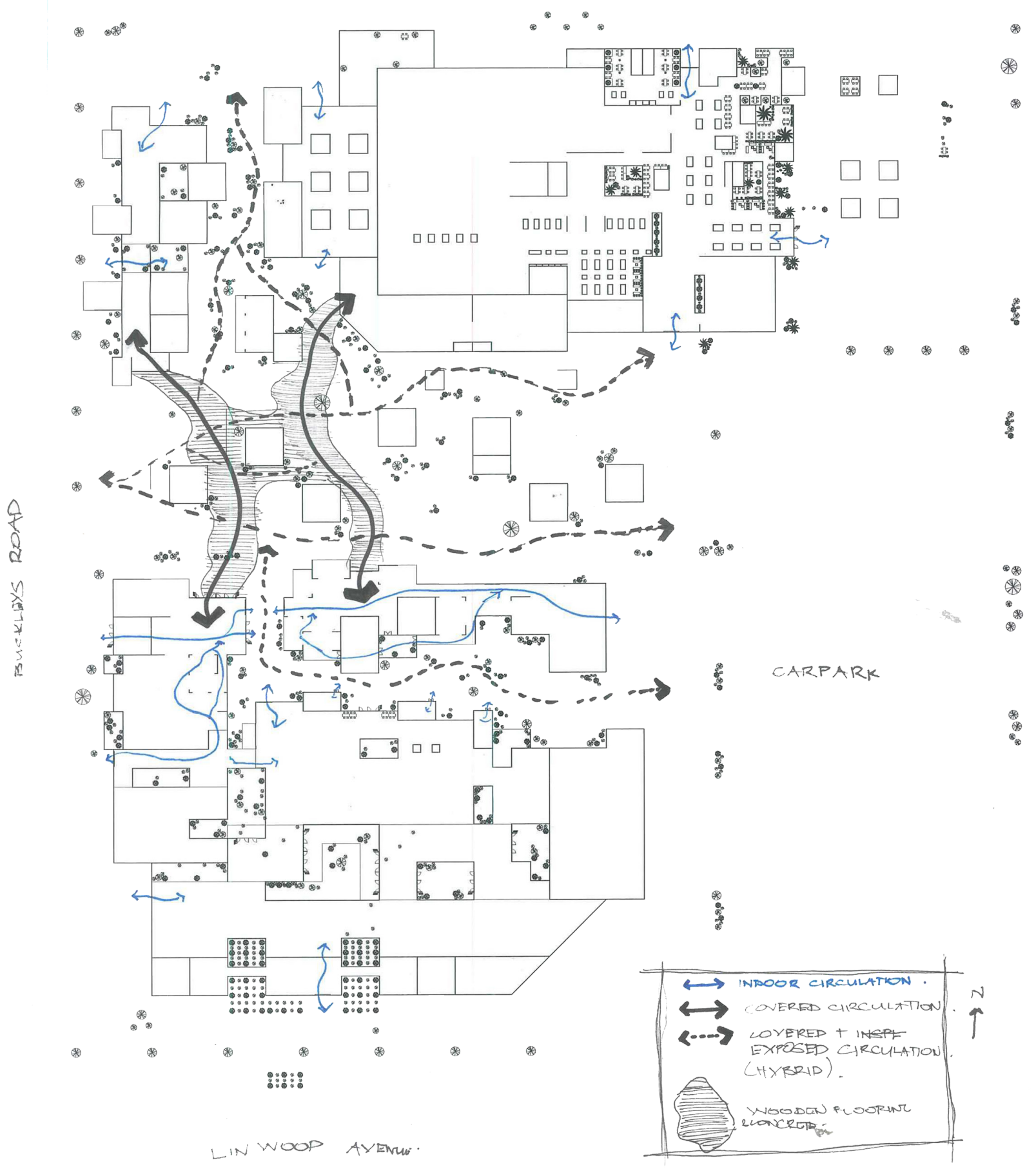

Figure 6.87. Development of iteration 3.6 mapping out potential links and further integrating green spaces within the mall to enhance architectural and shopping experiences. 
A substantial amount of design development has been in two-dimension and plan. These models have been created to assist the three-dimensional development of design ideas, giving them clearer form and substance. Experiences with greenery and efficiency are abstracted into physical models, with consideration of the themes lightness and verticality which arise from the site's historical significance. These themes are important to Eastgates rejuvenated identity.

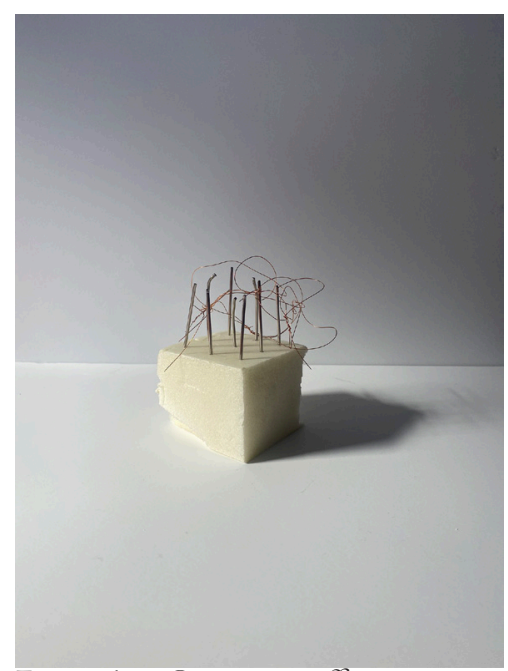

Figure 6.89. Greenery + efficiency.

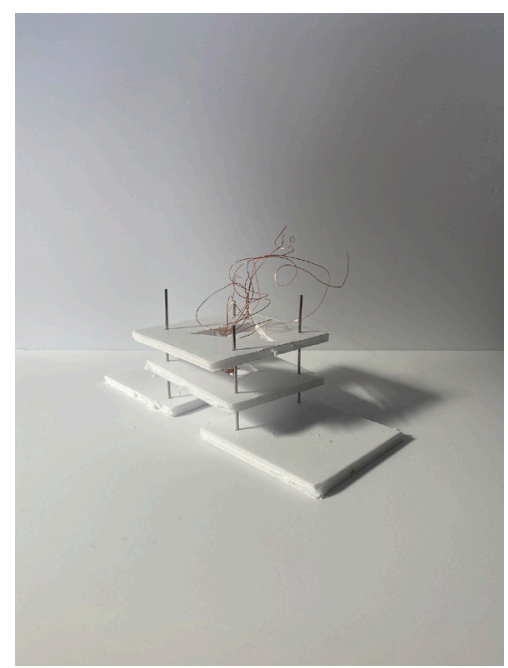

Figure 6.91. Greenery penetrating.

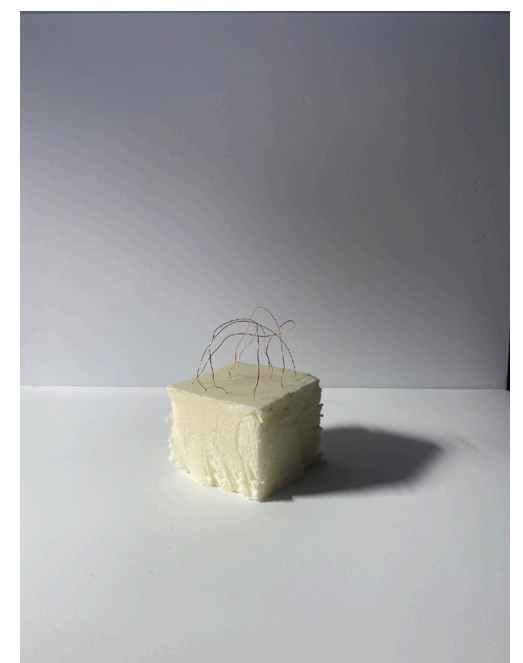

Figure 6.88. An experience with greenery abstracted.

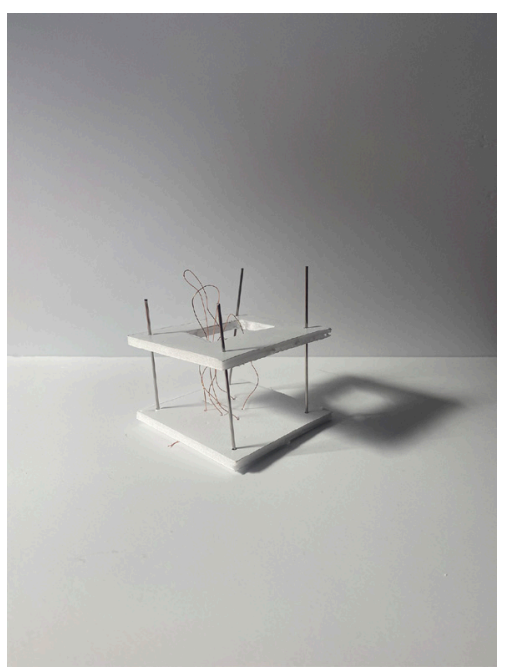

Figure 6.90. Greenery penetrating.

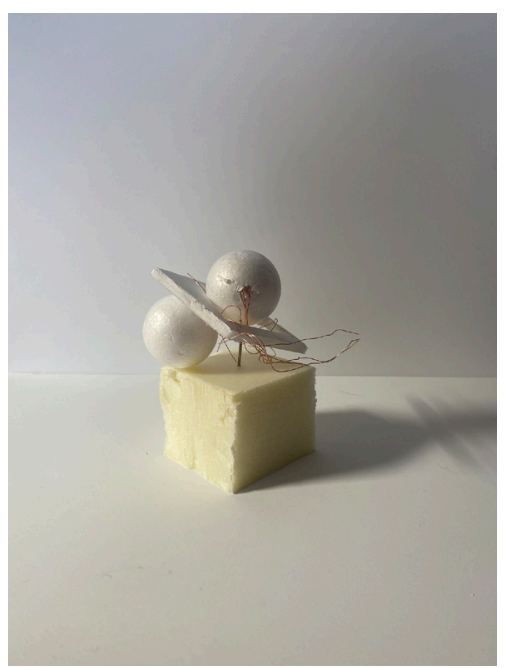

Figure 6.92. Fragmentation. 


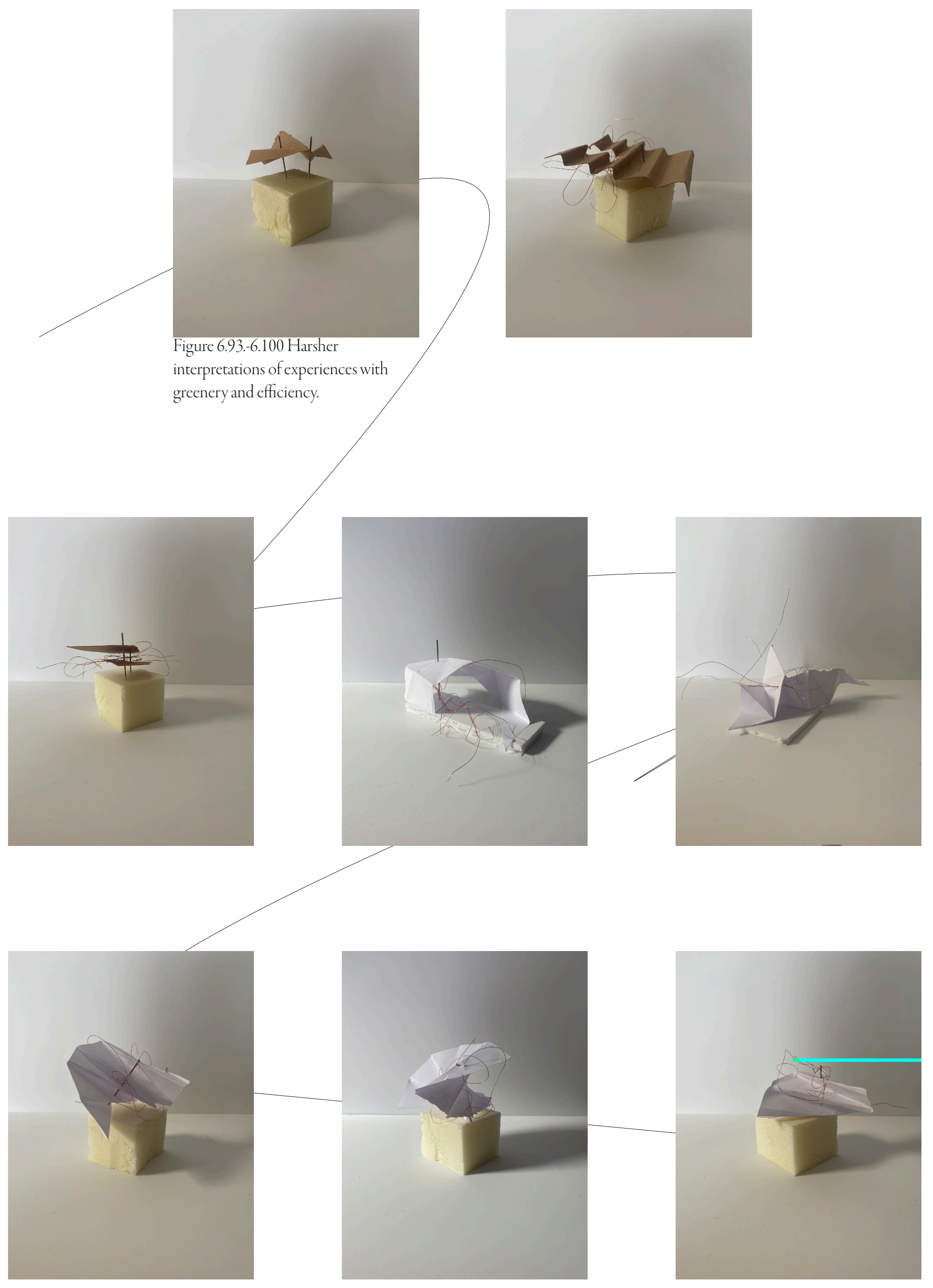



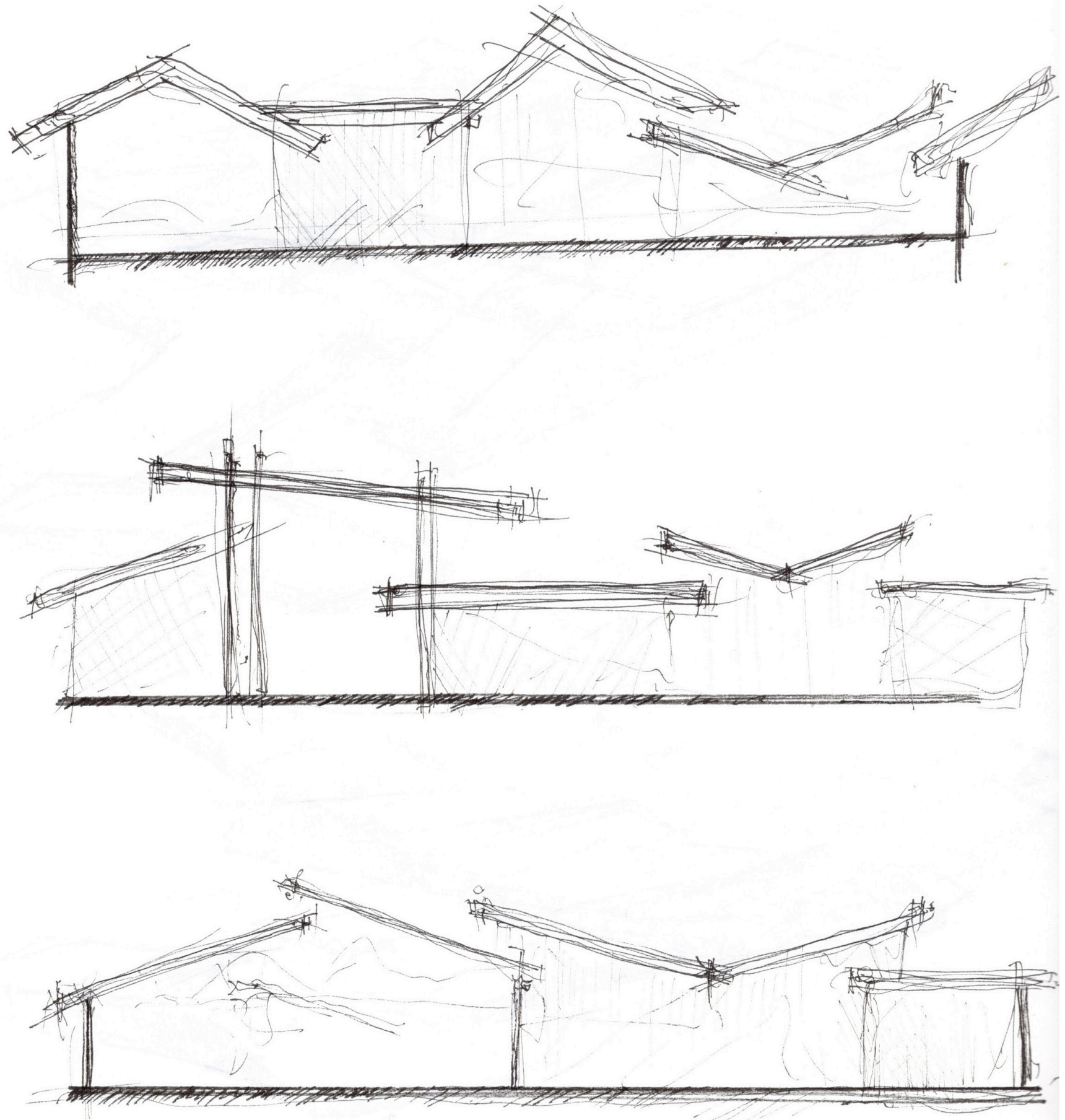

Figure 6.101. Sectional sketches. 

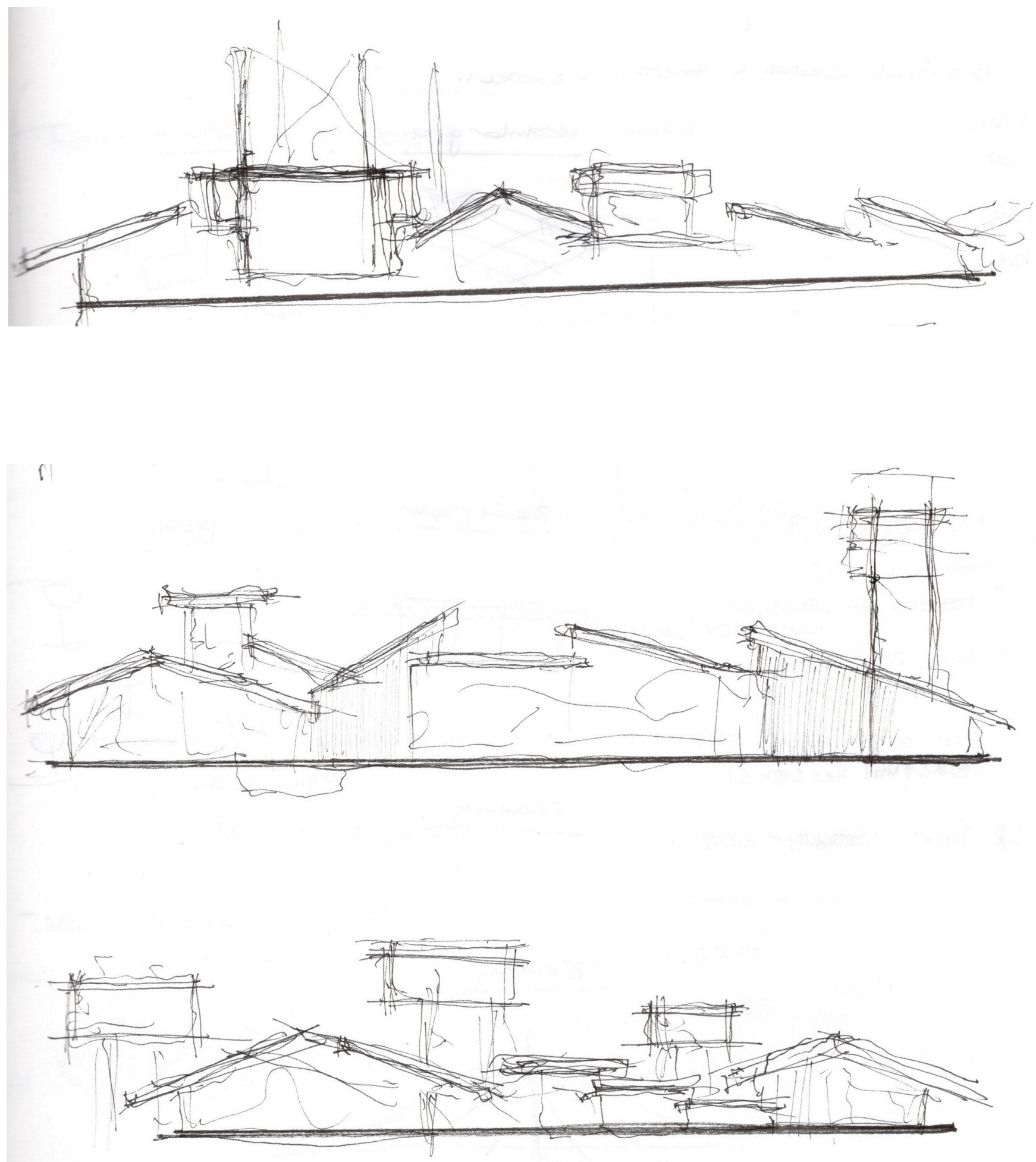

Figure 6.102. Sectional sketches.

Sectional interpretations of models towards development of form 

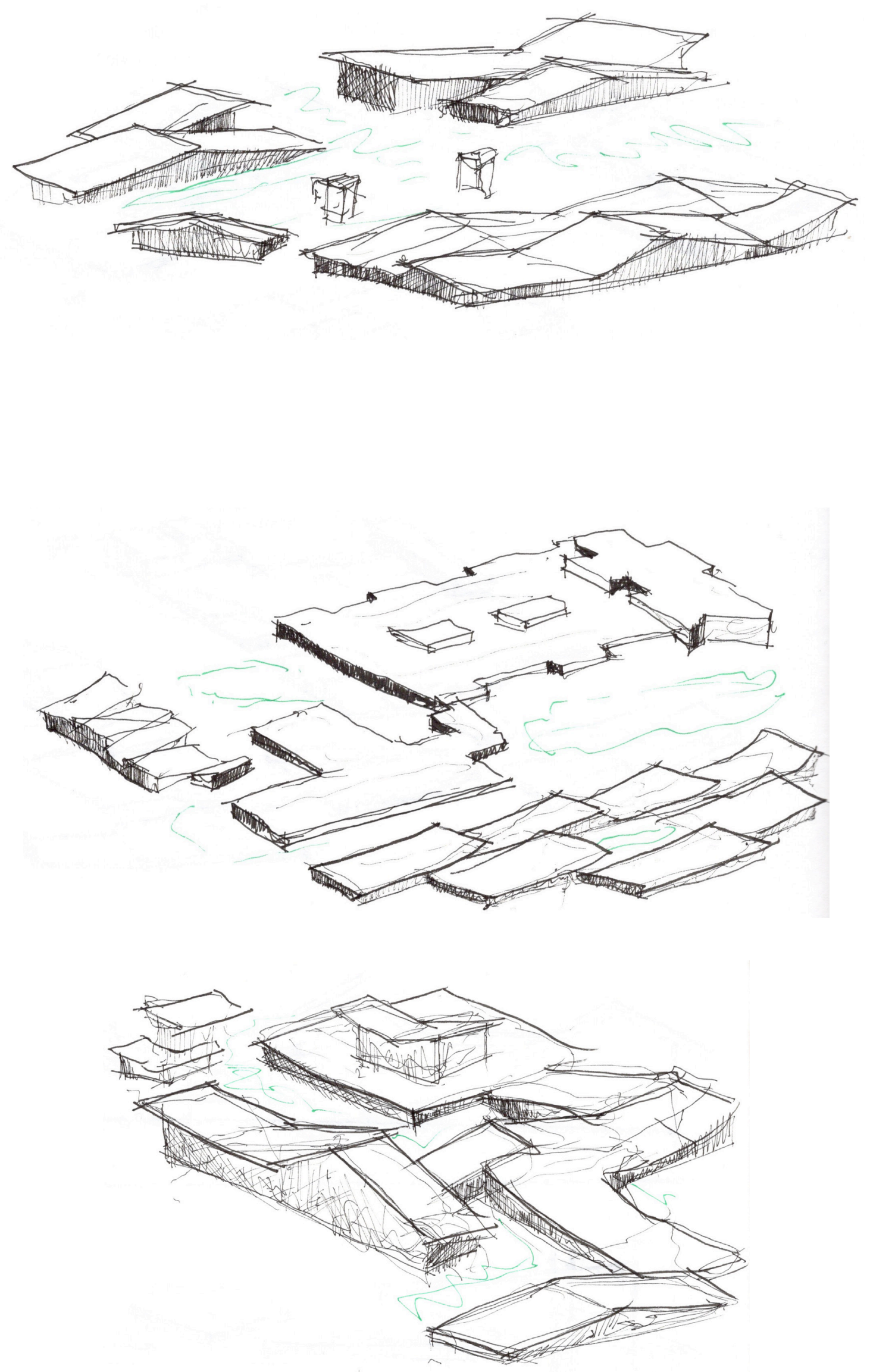

Figure 6.103.3D sketches 

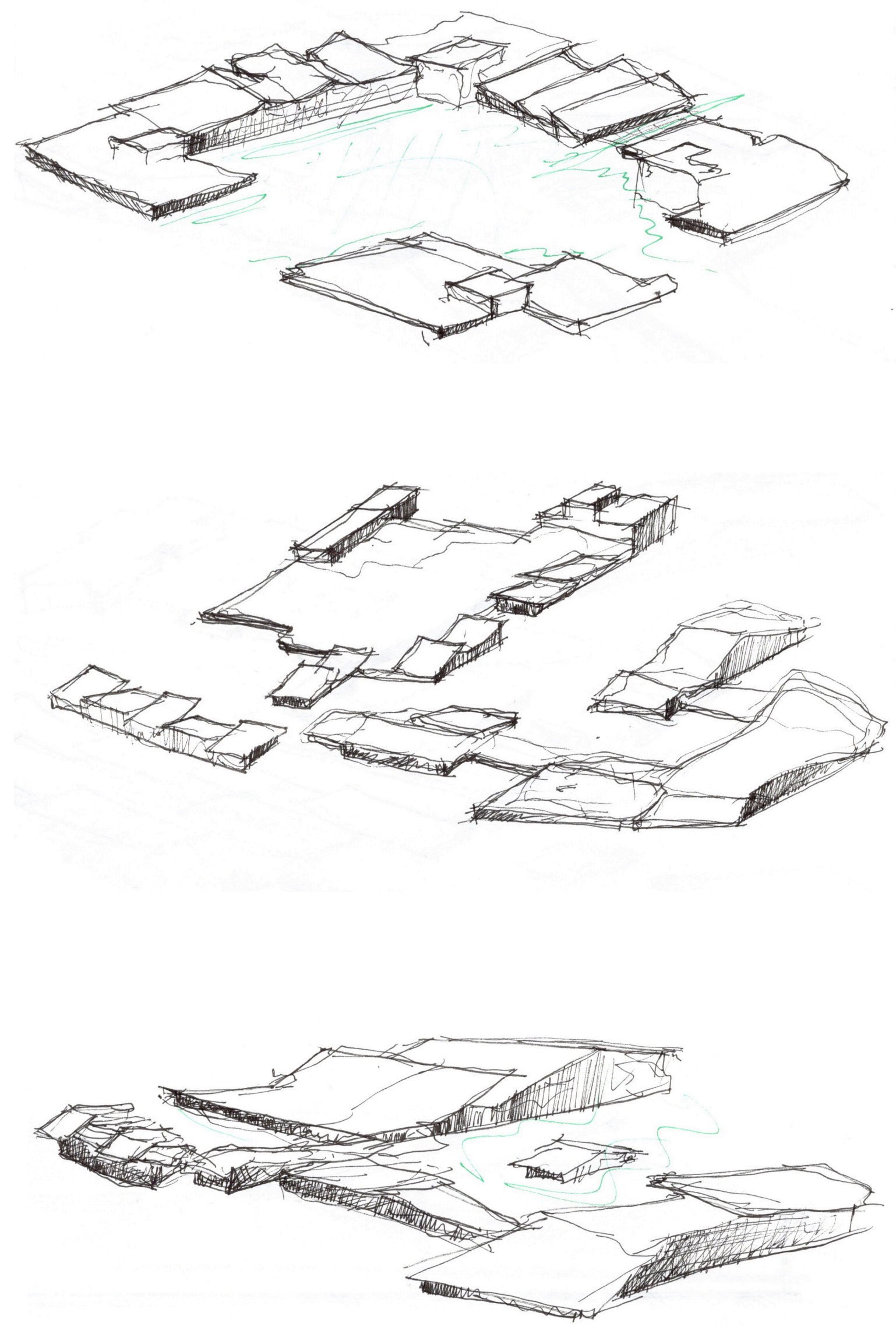

Figure 6.104.3D sketches

Three-dimension interpretations of models and subsequent sectional sketches towards development of form. 

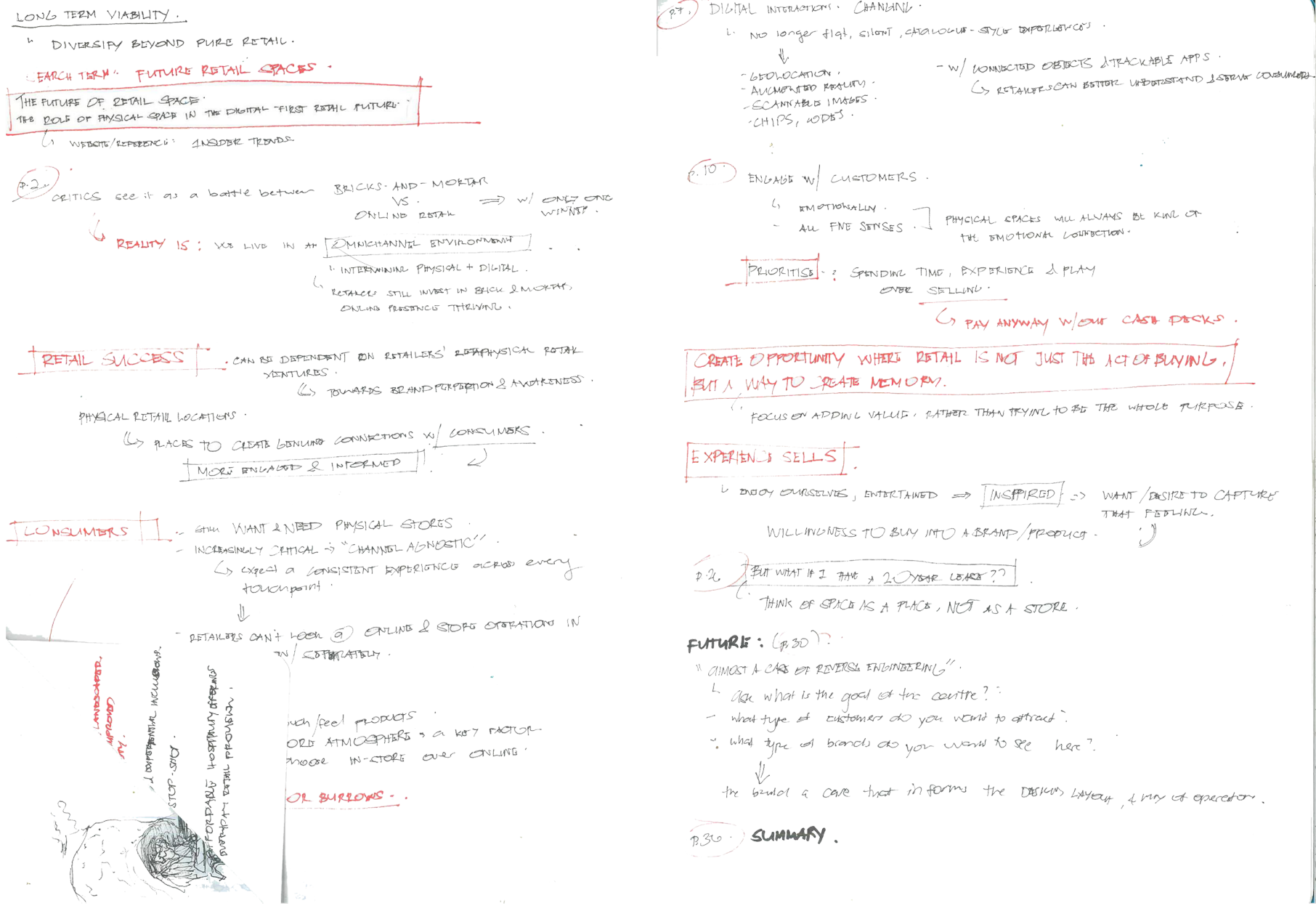

Figure 6.105. Key points in this design phase relevant to meeting design criteria. 


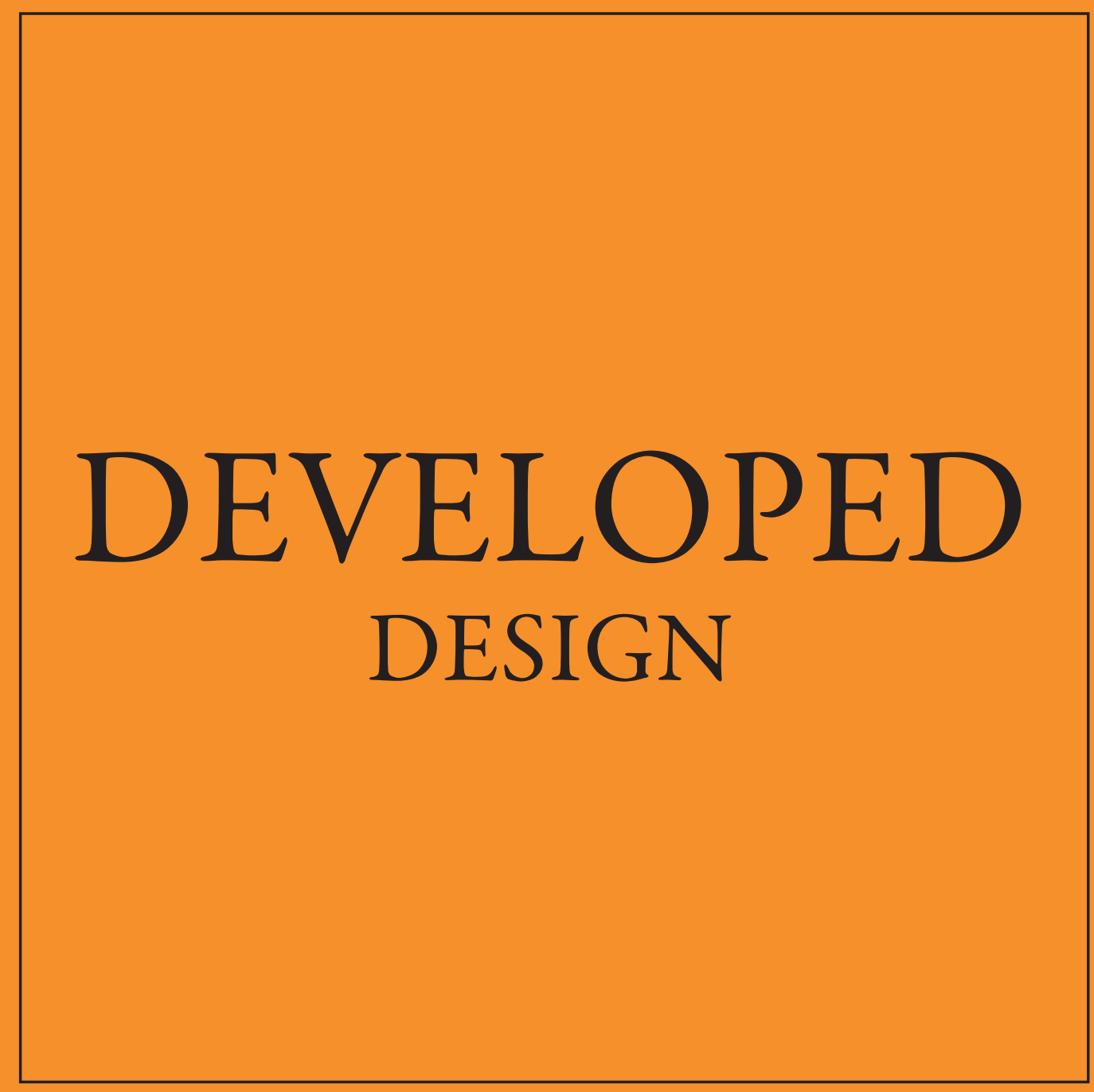




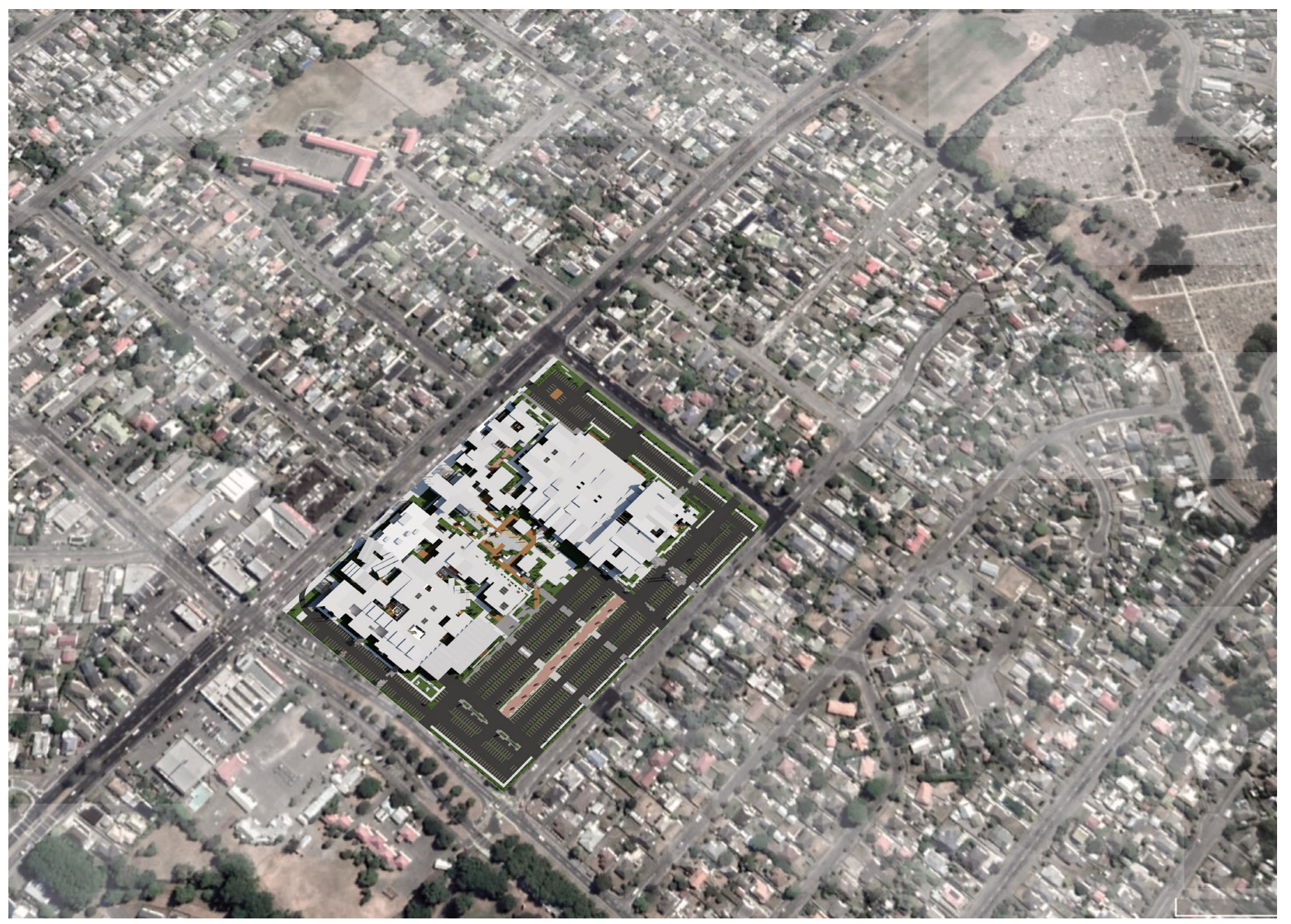

Figure 7.0. Final contextual plan. Author's illustration. 


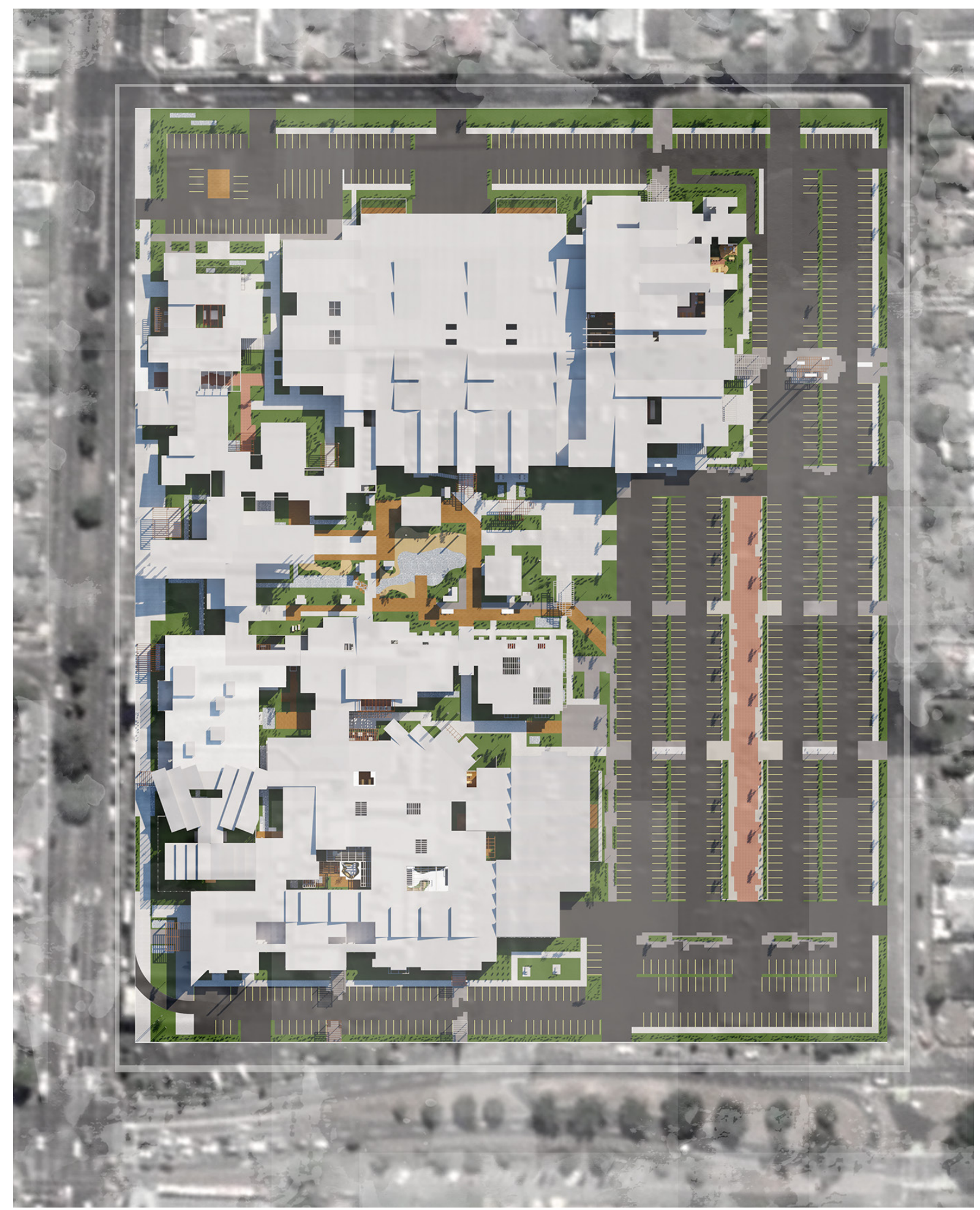

$1: 2000$

Figure 7.1. Final site plan. Author's illustration. 


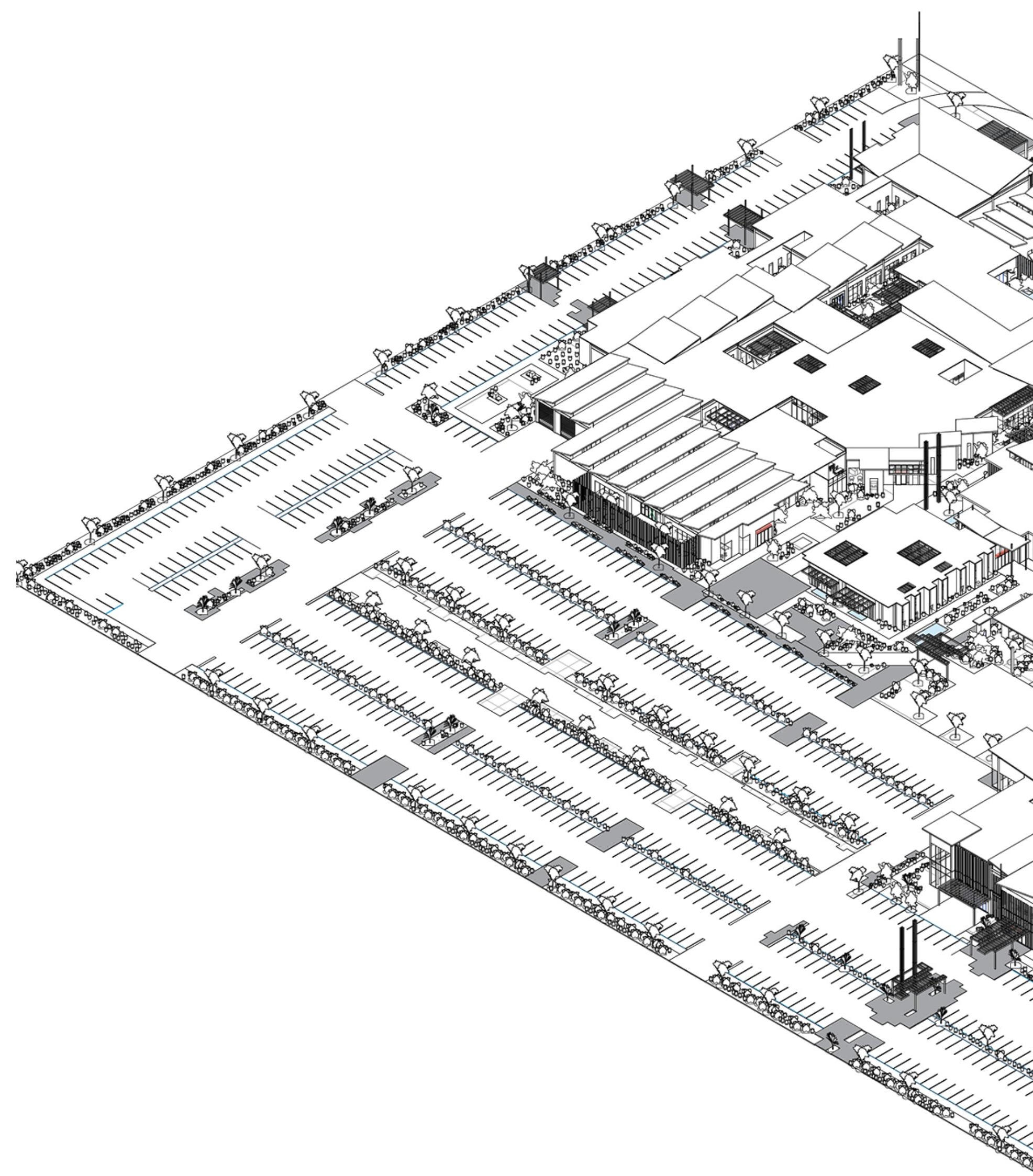




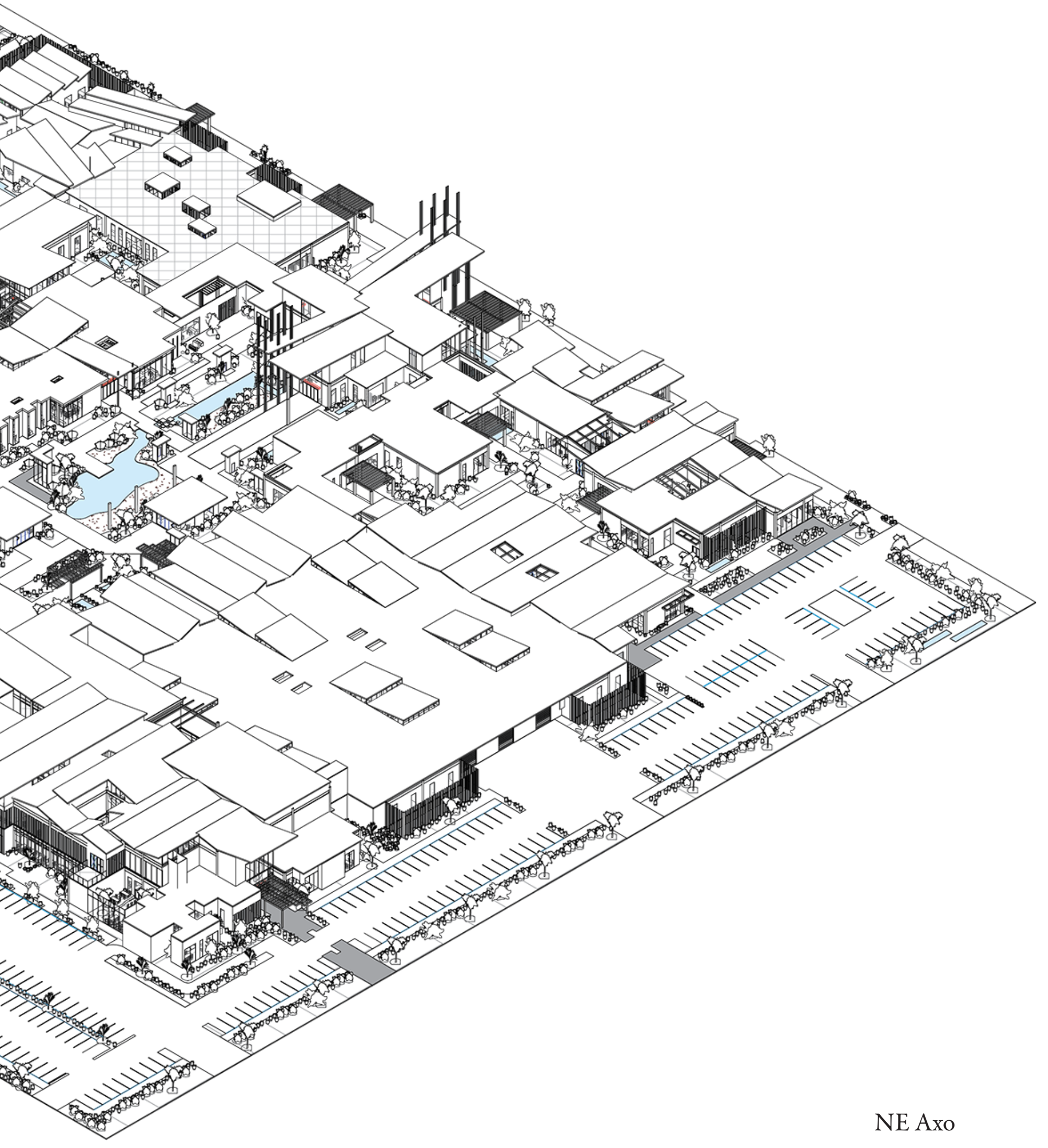




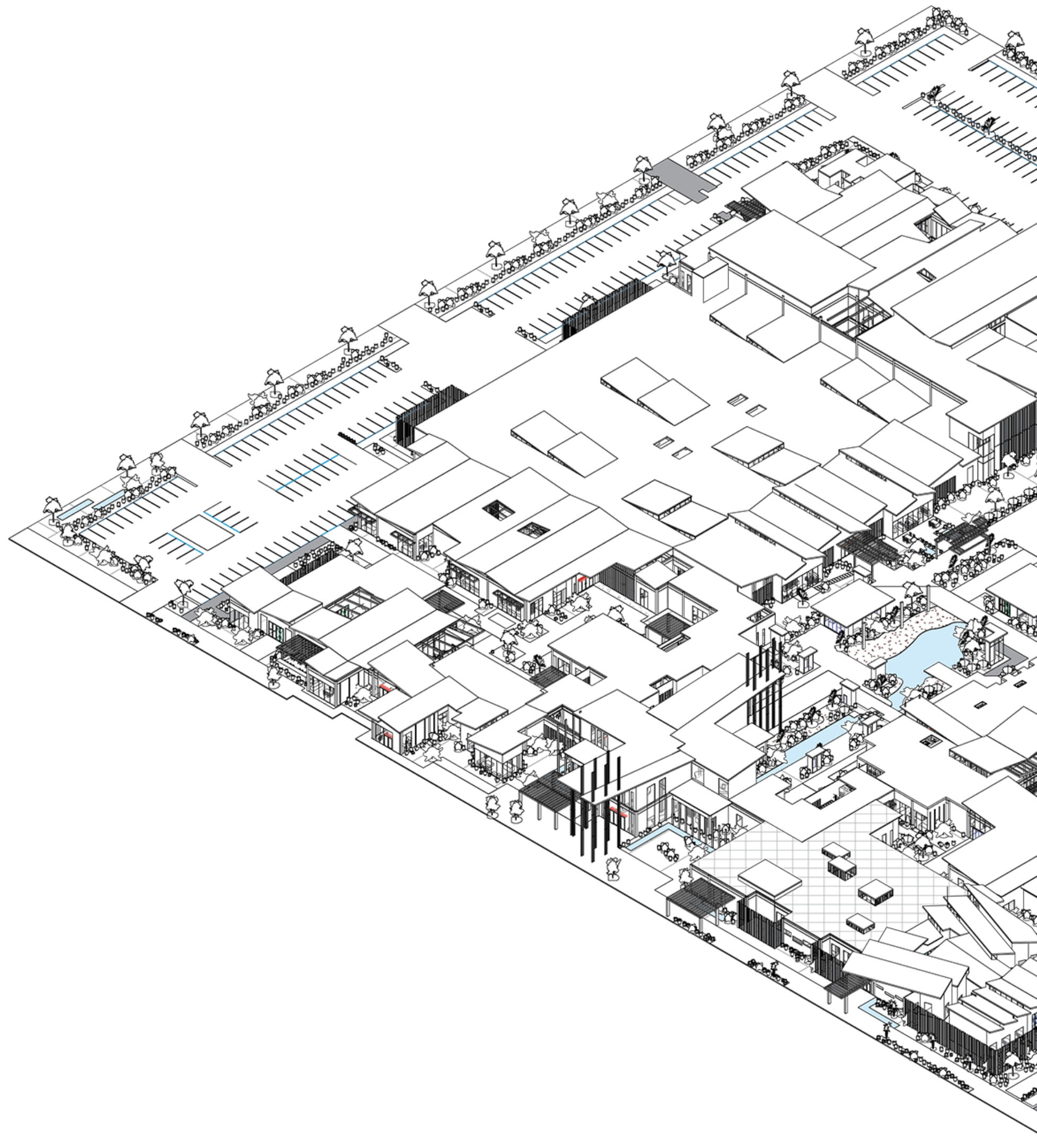




\section{Skylights}

Louvred skylights echo the effect of dappled light to further develop a sense of verticality being used as an architectural theme to rejuvenate Eastgate and its identity. By attempting to echo the effect of dappled light, aspects of outdoor experiences can be brought in to enhance atmospheric qualities and related components like ambient lighting. This enables the space and overall mall building to still feel connected to the outdoors.

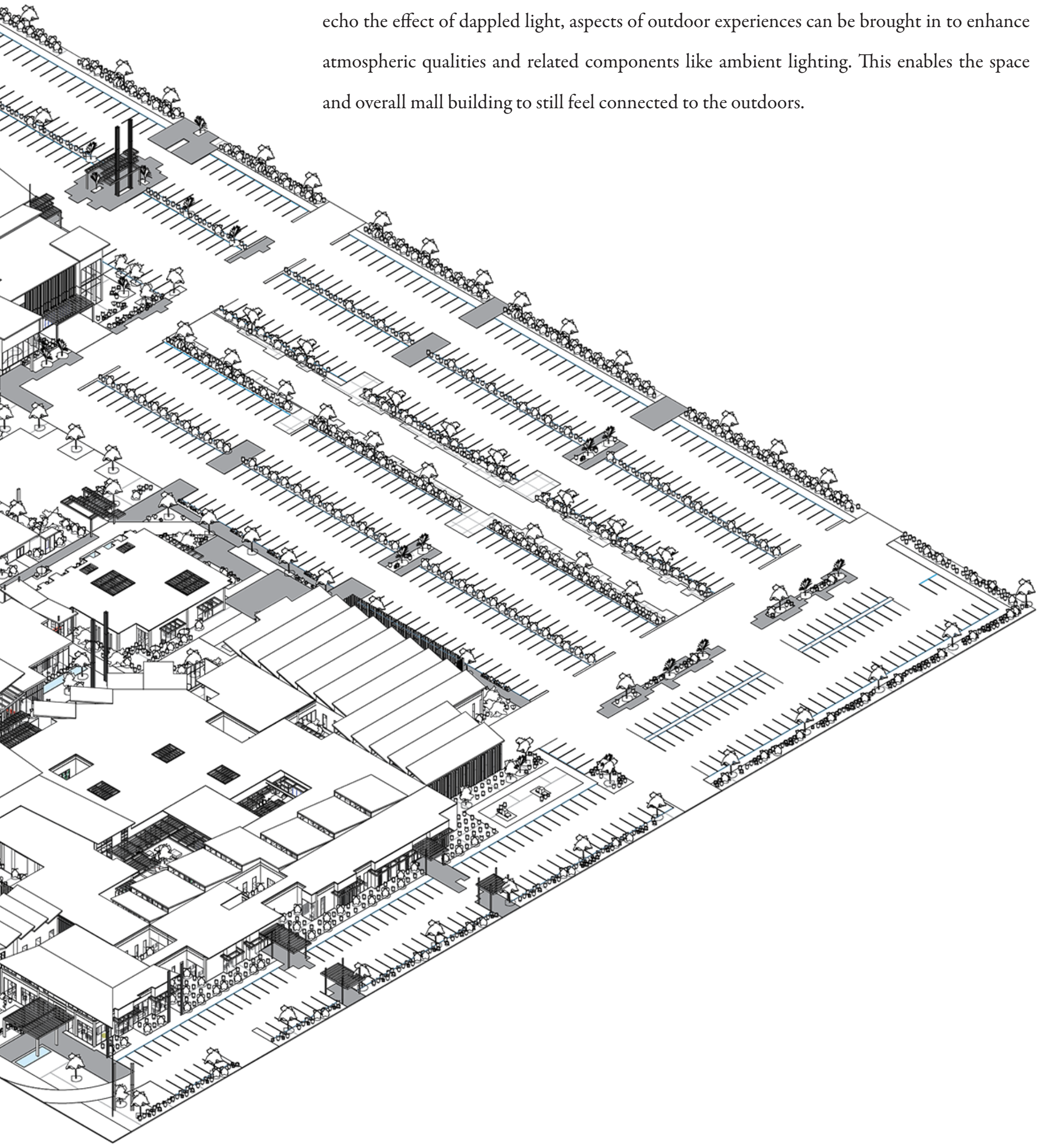

SW Axo 


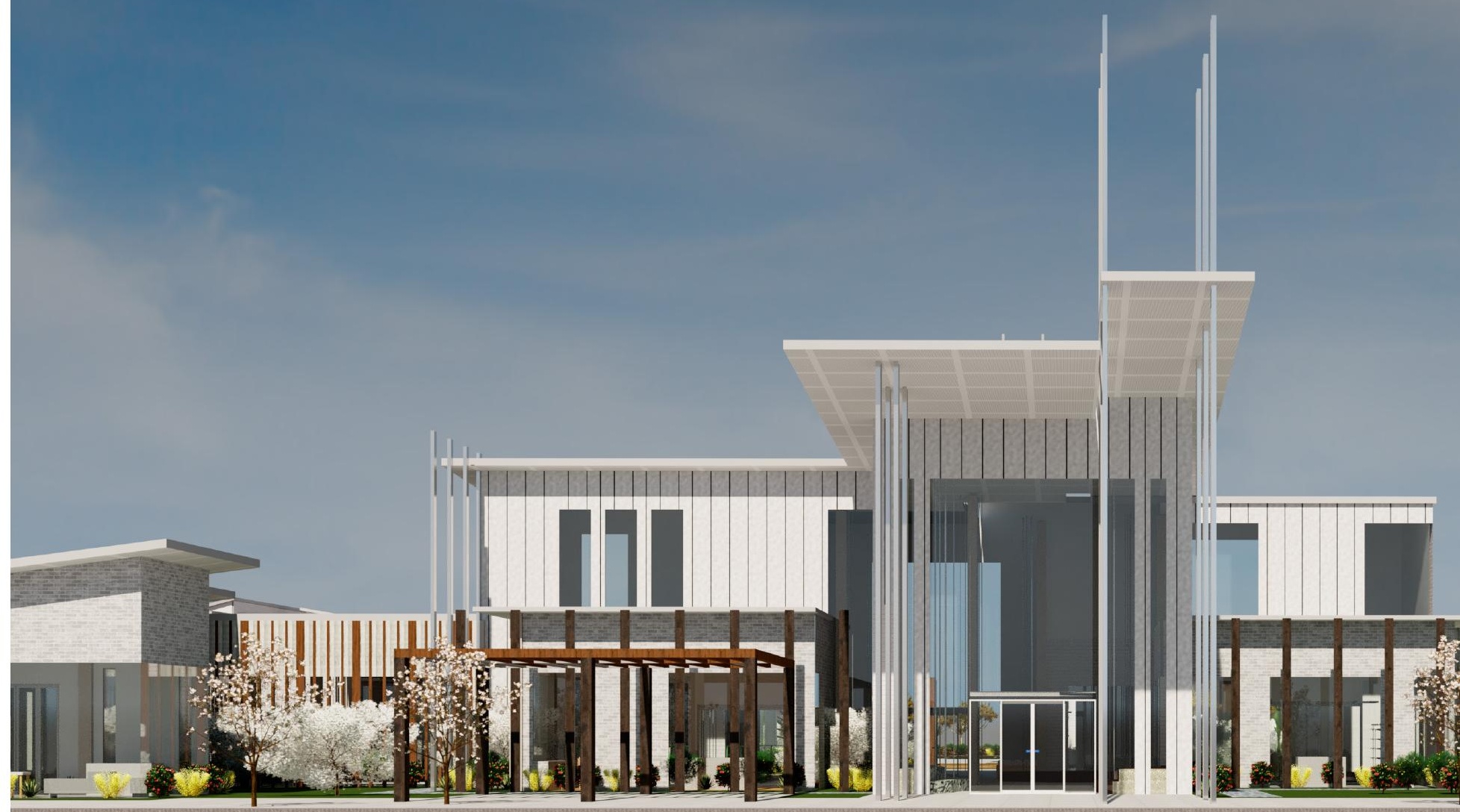

\section{Roofing}

A diverse landscape of evocative pitched roofs. Sloping roofscape to:

- Counteract the feeling of being in one monumental building; as one may feel in a large building complex with flat roofing

- highlight the dynamism and fluidity of the shopping mall and the different areas; give each area its own identity and reference for people

- create a small scale, natural and spontaneous feeling;

Glazing integrated into clerestory to provide a continuous experience of light and air.

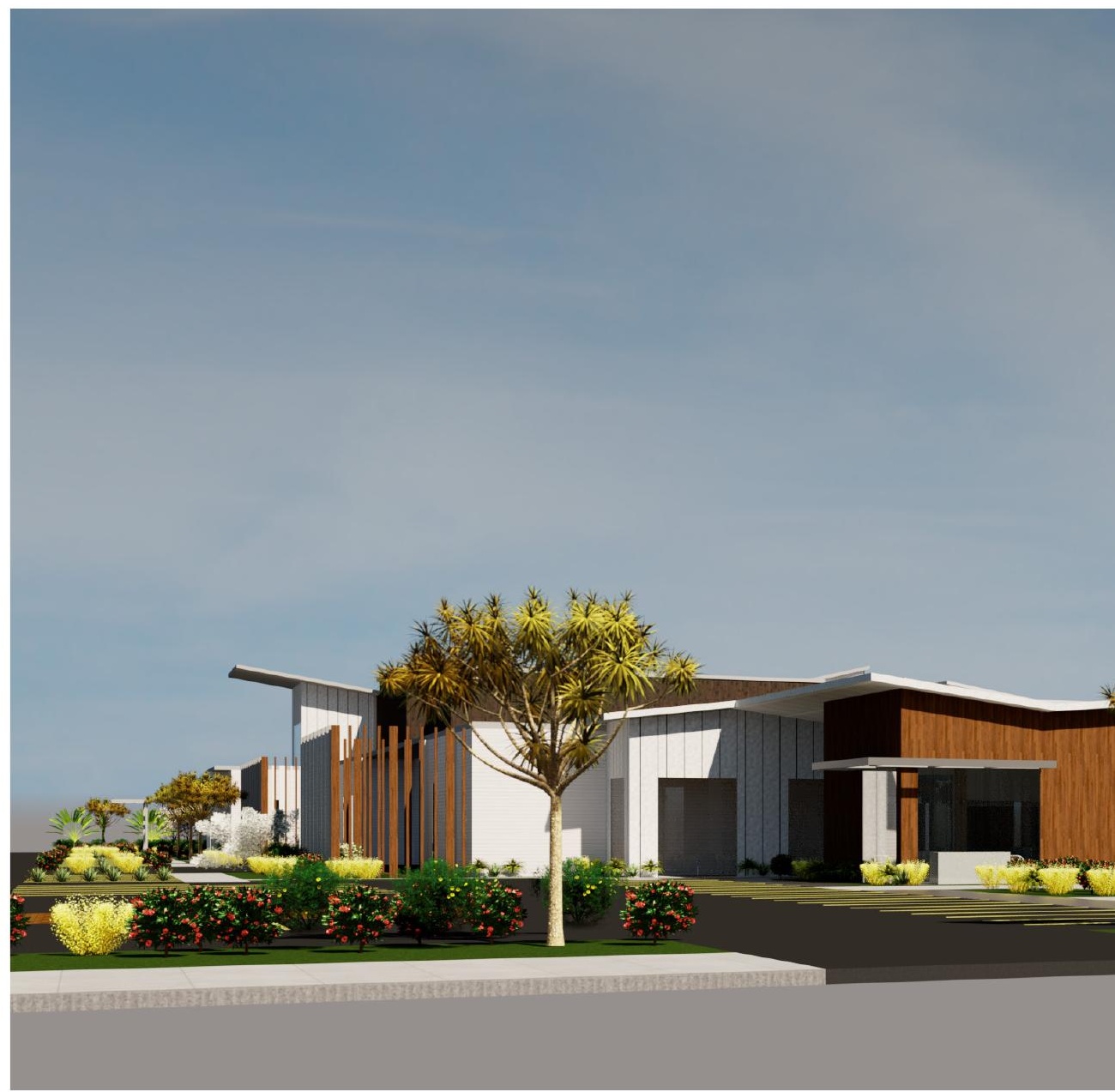


Figure 7.2. Key mall entrance overlooking

Baldwin Road.

Figure 7.3. Northwest perspective. 


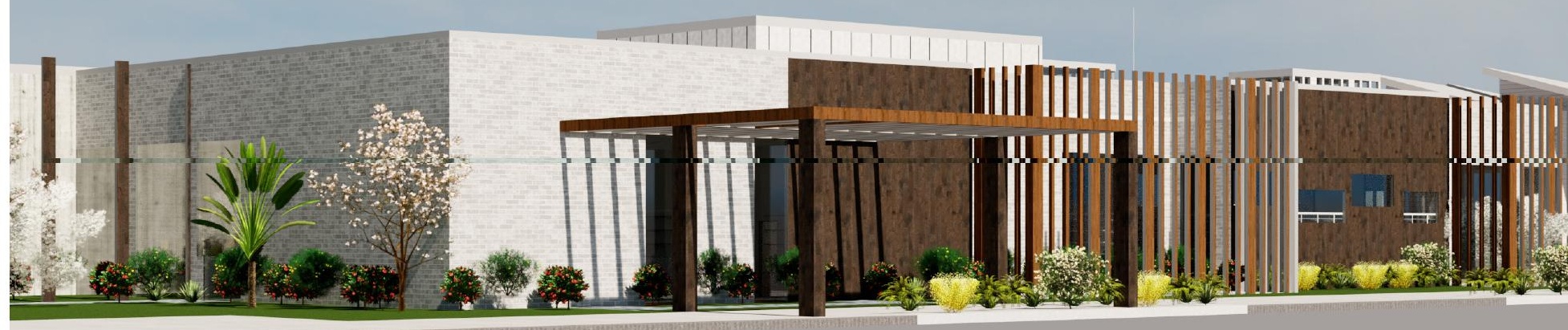

Figure 7.5. Perspective outside food court from carpark.

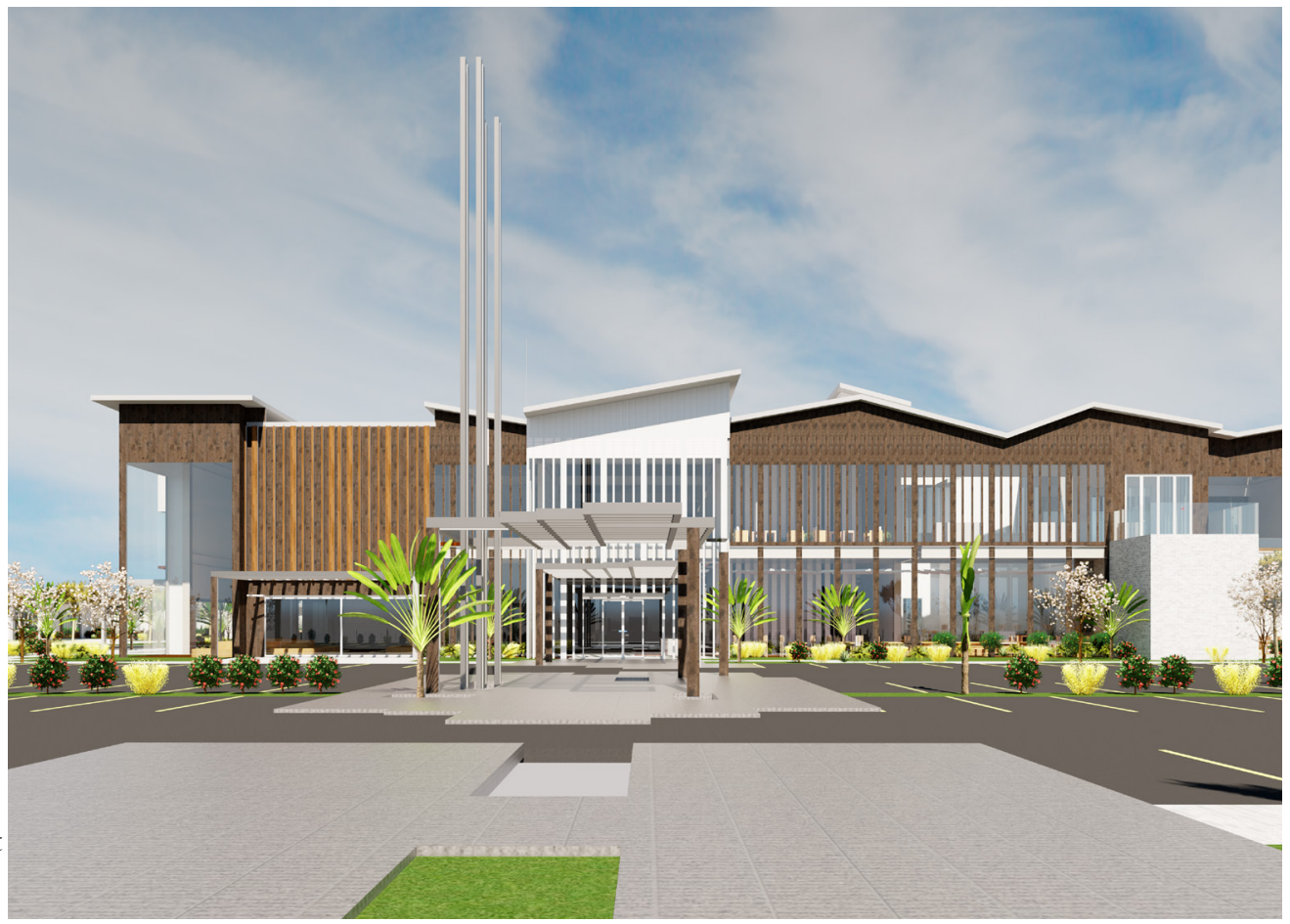


Figure 7.4. Medical centre and pharmacy from Baldwin Road.

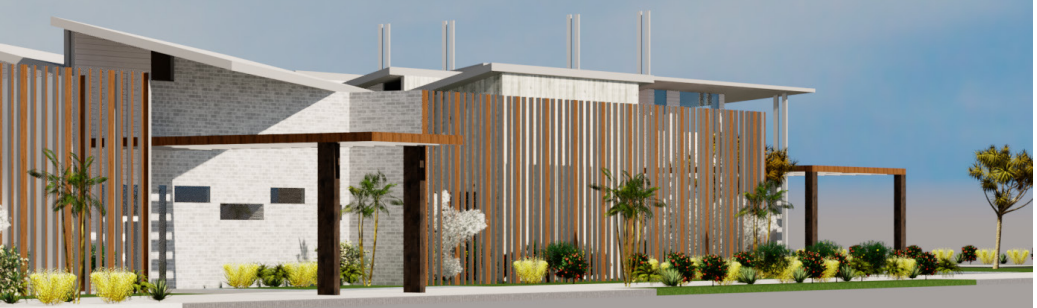




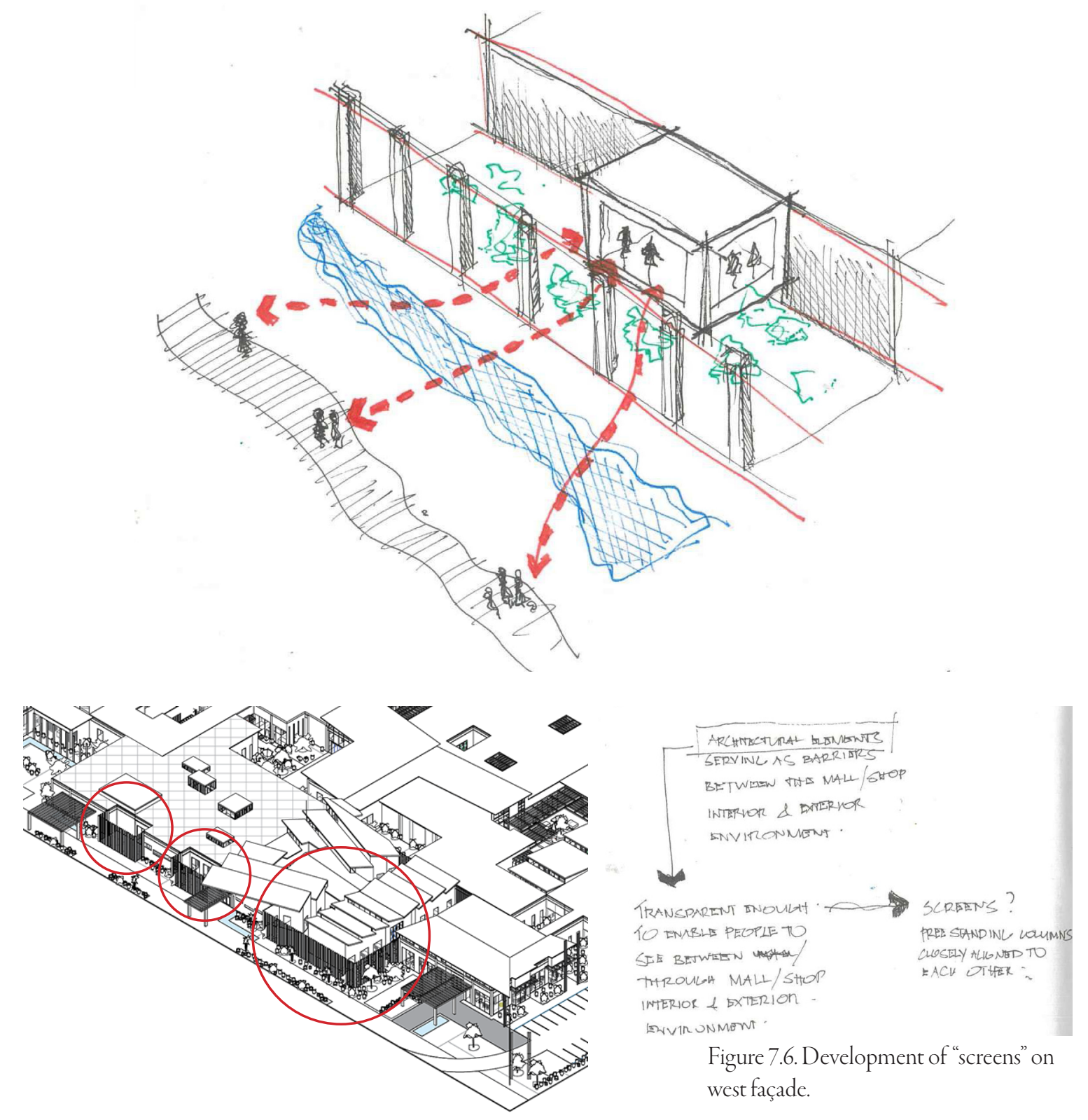

\section{Lattice pattern Screens/Louvres}

These are heavily utilised in this proposed architectural design. This is to filter sunlight into a play of light and shadow, to contribute to enhancing the interior atmosphere of Eastgate. 

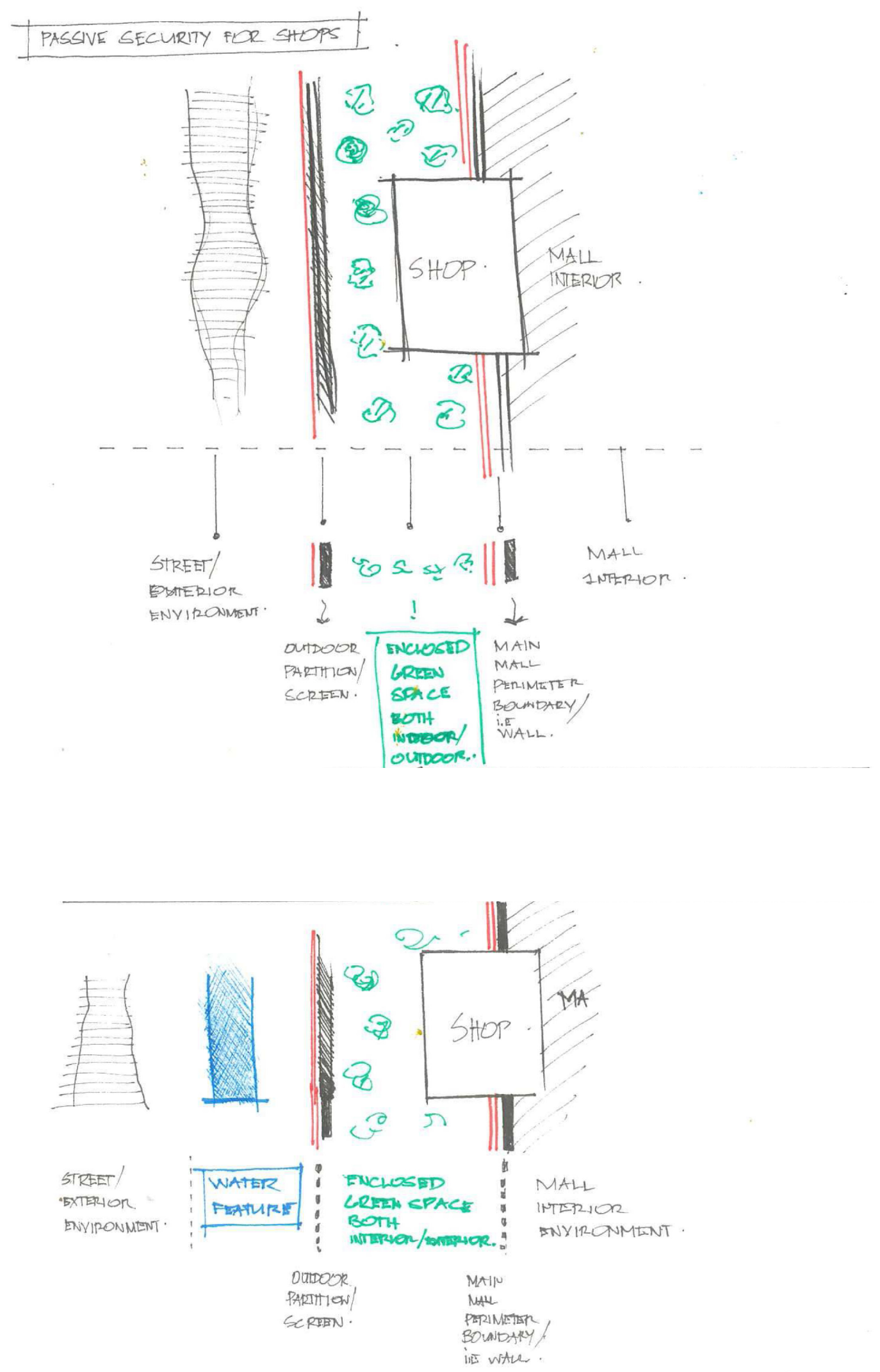

Figure 7.7. Passive security utilising "screens" on west façade. 

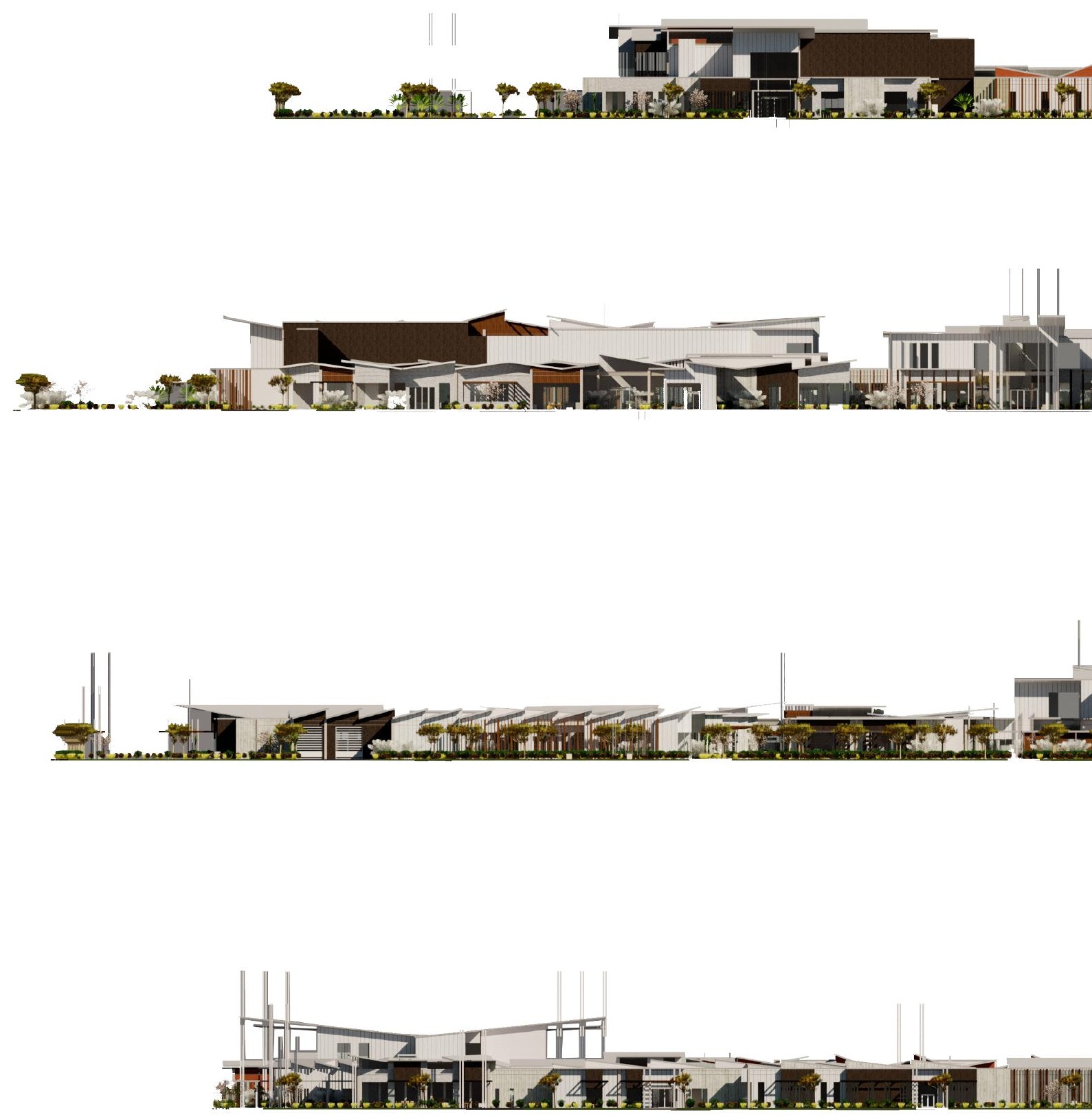
Floor Plan

$1: 1000$ osere.
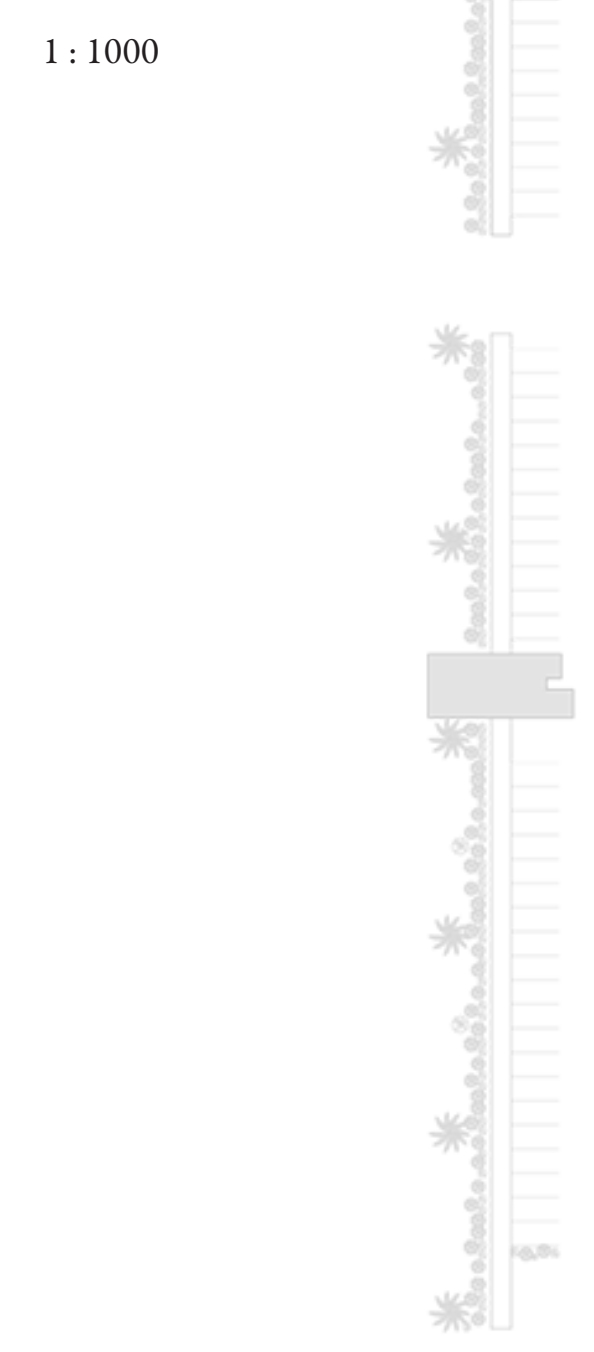

Figure 7.12. Final Design Ground Floor Plan.
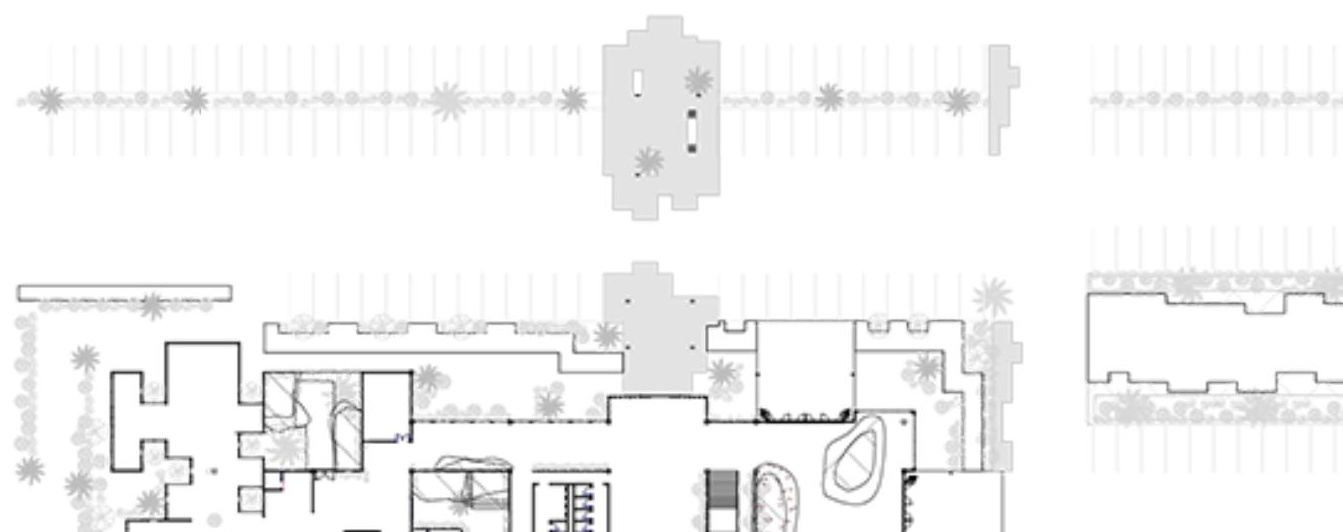

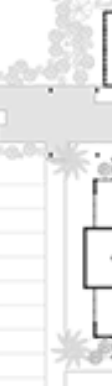
进四

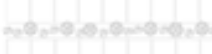

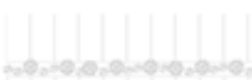

$-$

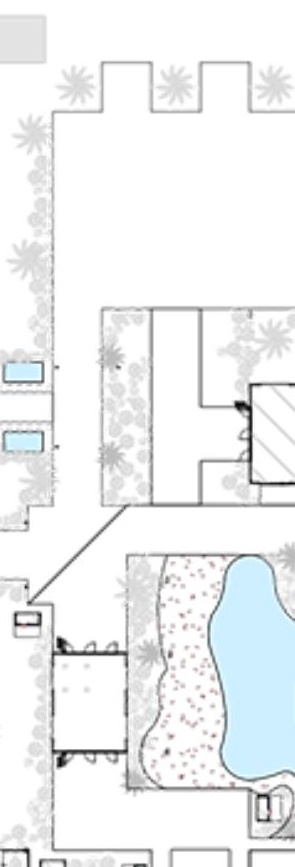


Figure 7.13. Site section and Final design atmospheric ground floor plan.

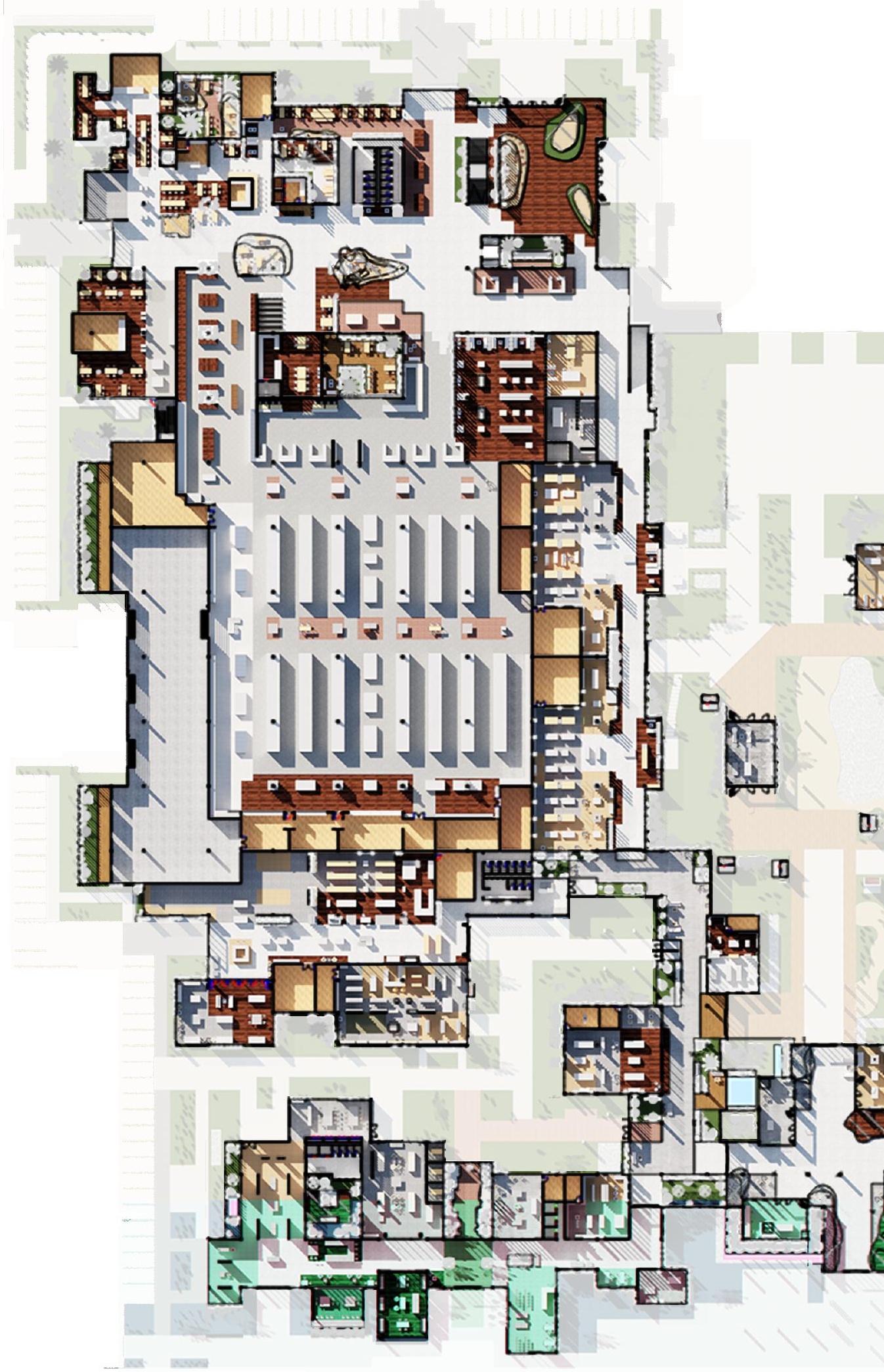



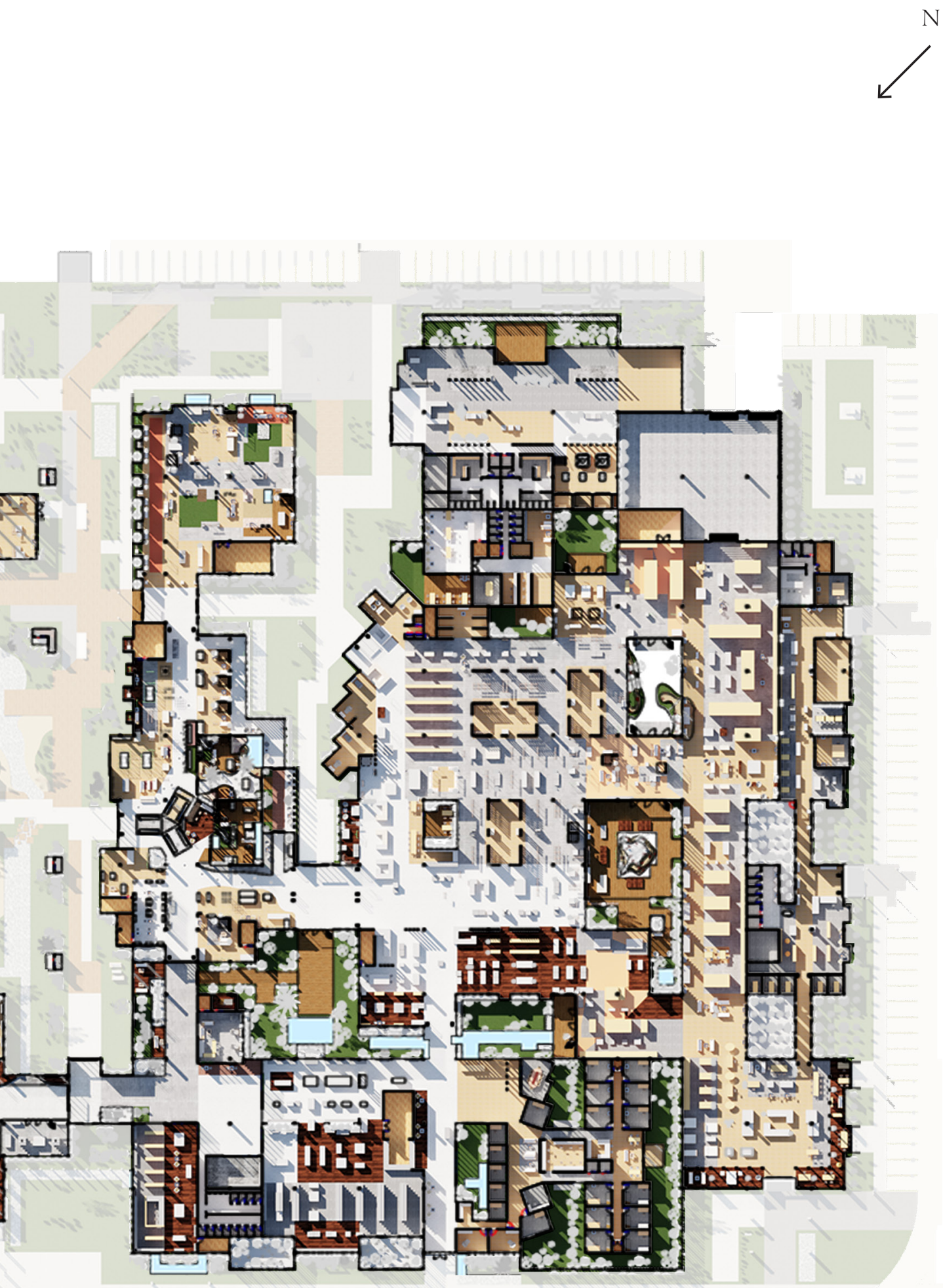


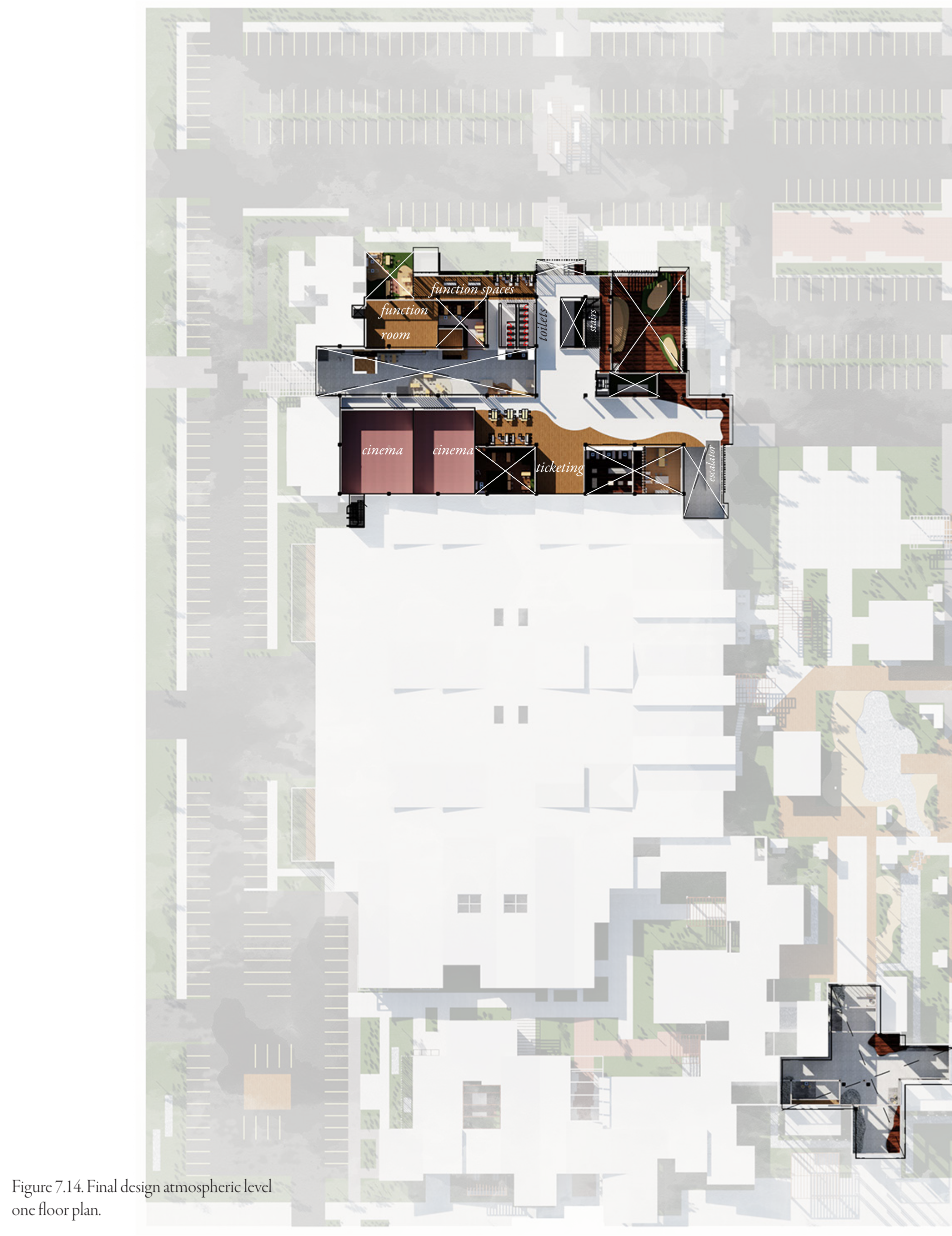




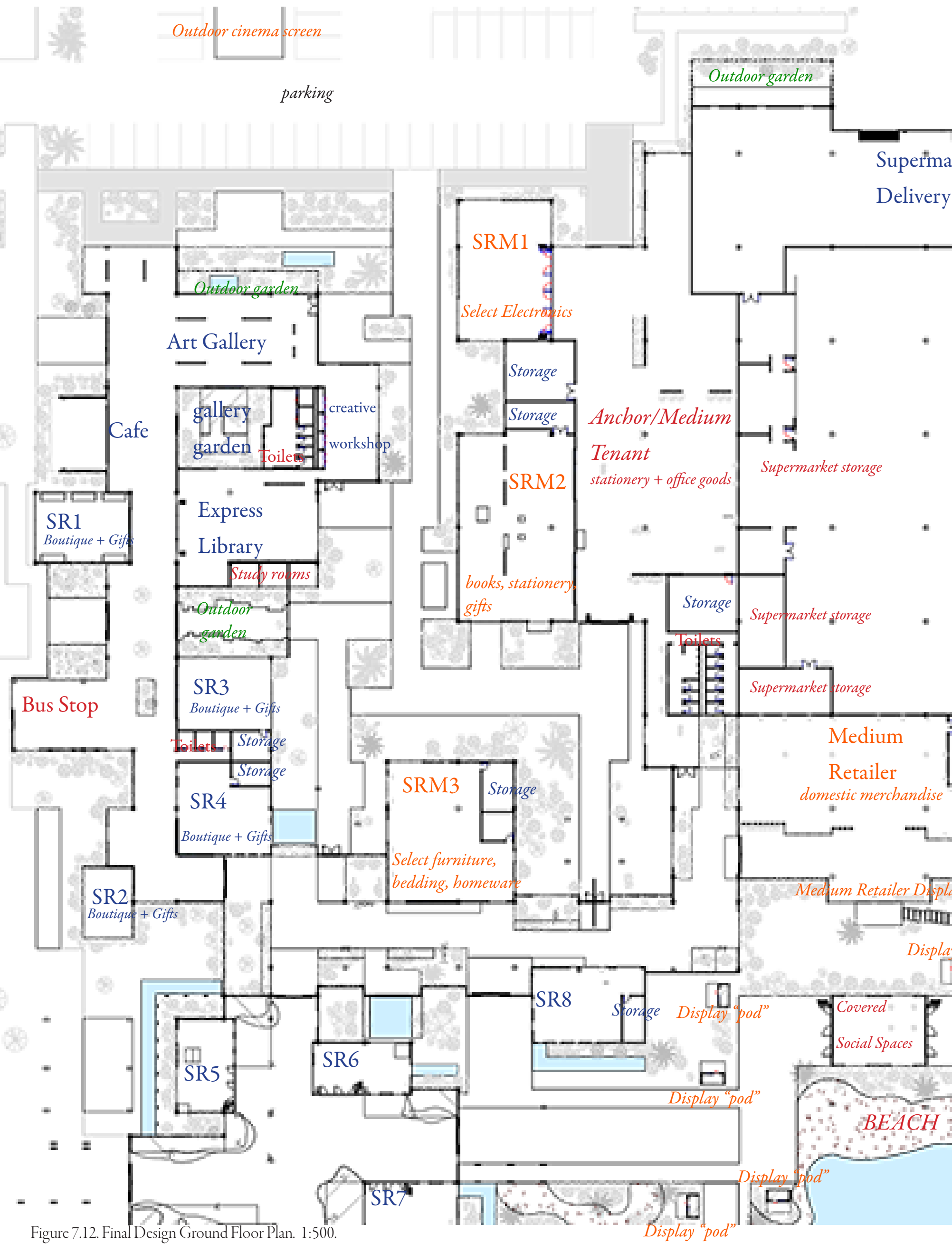




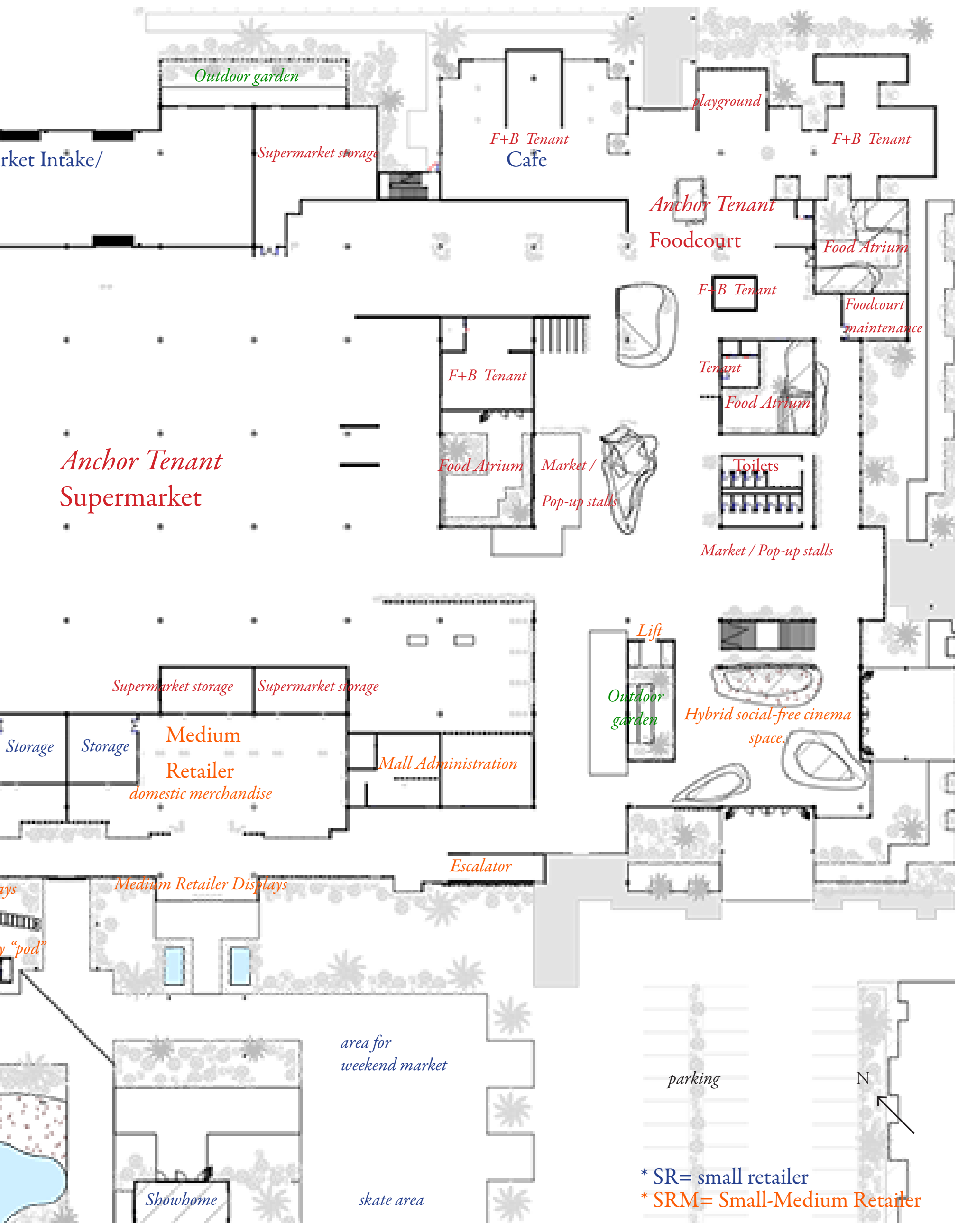




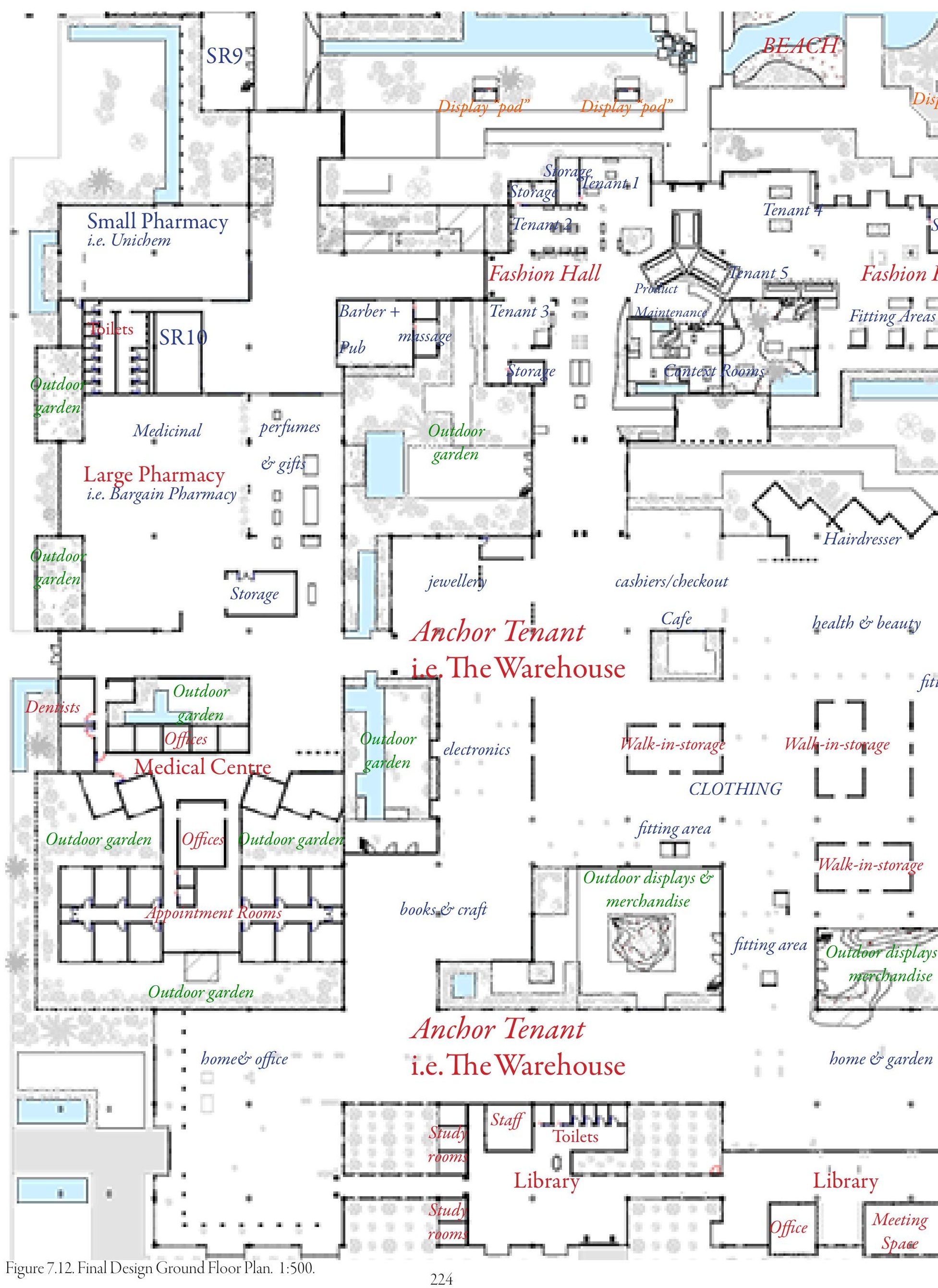




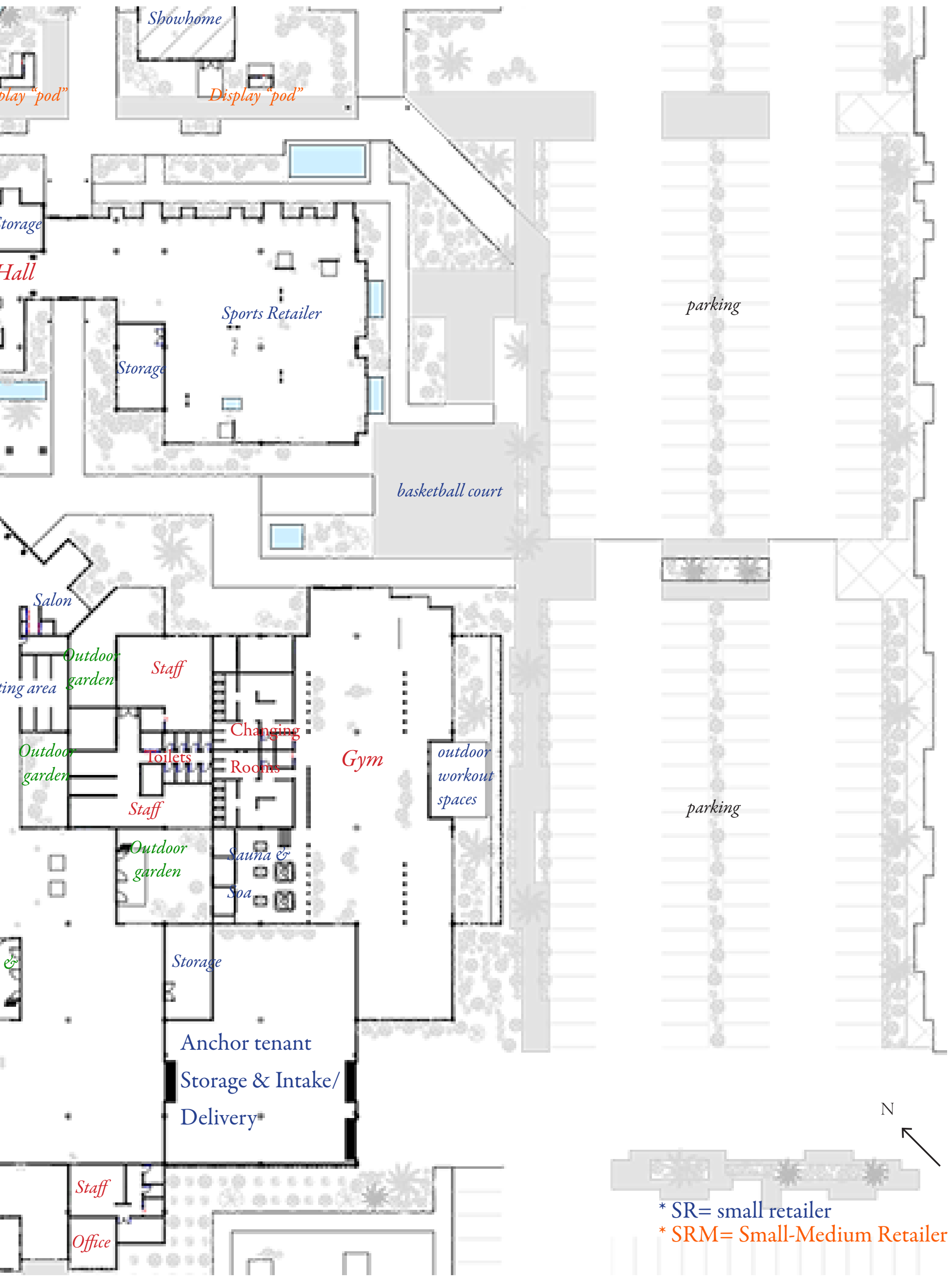




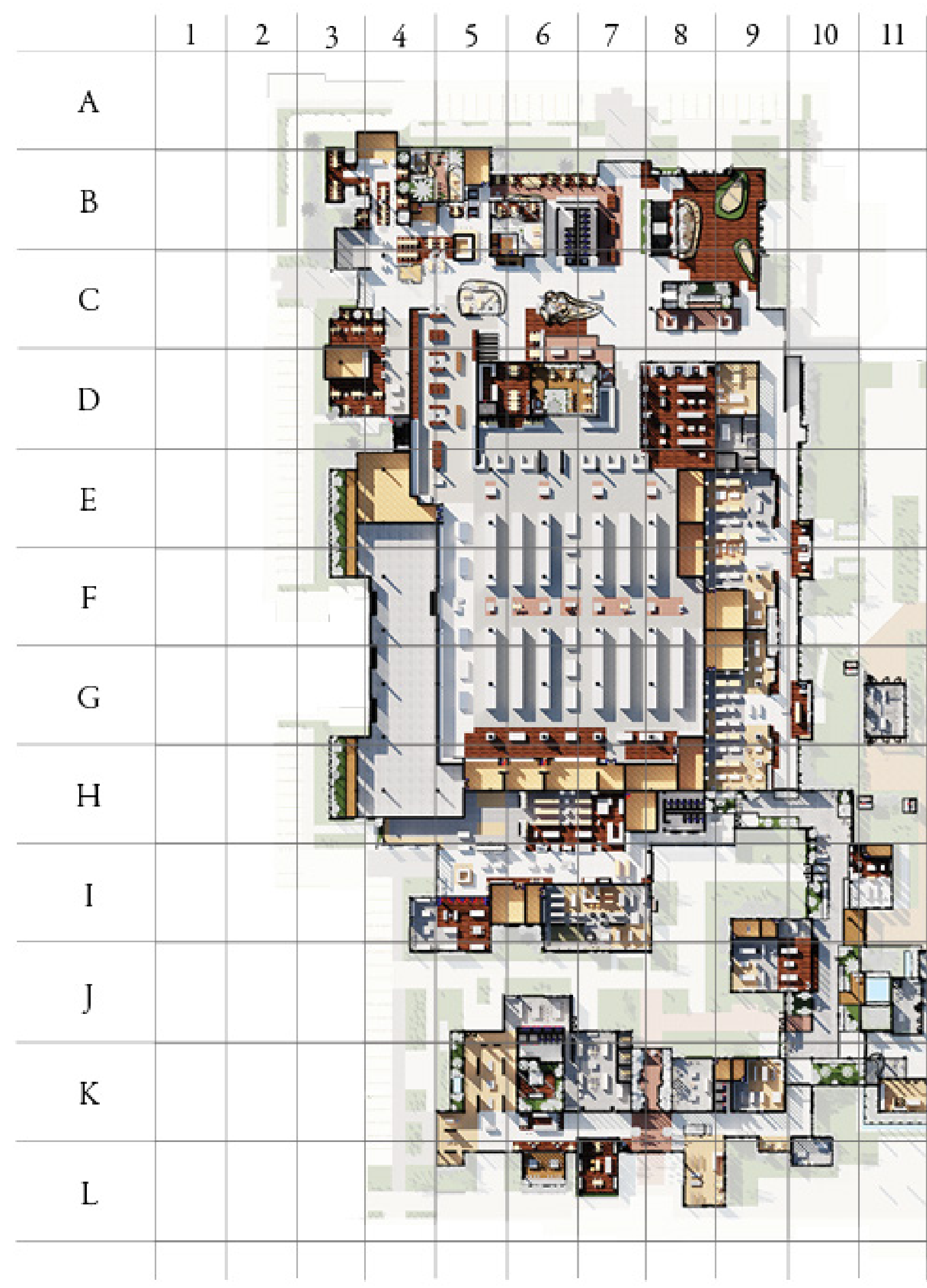


- Reference Map for renders

\begin{tabular}{l|l|l|l|l|l|l|l|l|l|l|l|}
12 & 13 & 14 & 15 & 16 & 17 & 18 & 19 & 20 & 21 & 22 \\
\hline & & & & & & & & & & \\
\hline & & & & & & & & & \\
\hline & & & & & & & & &
\end{tabular}

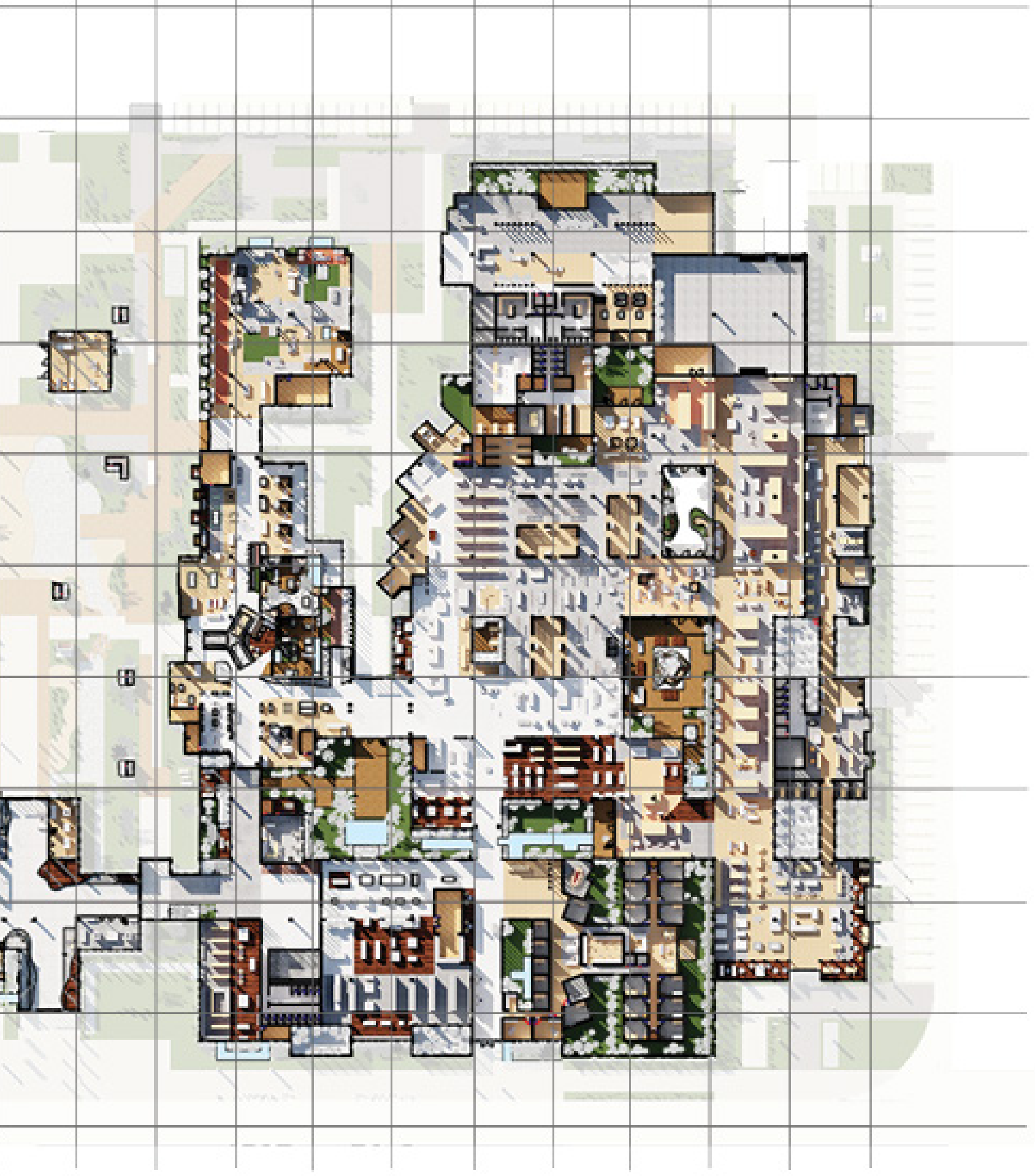




\section{- $\mathrm{B} 16$}

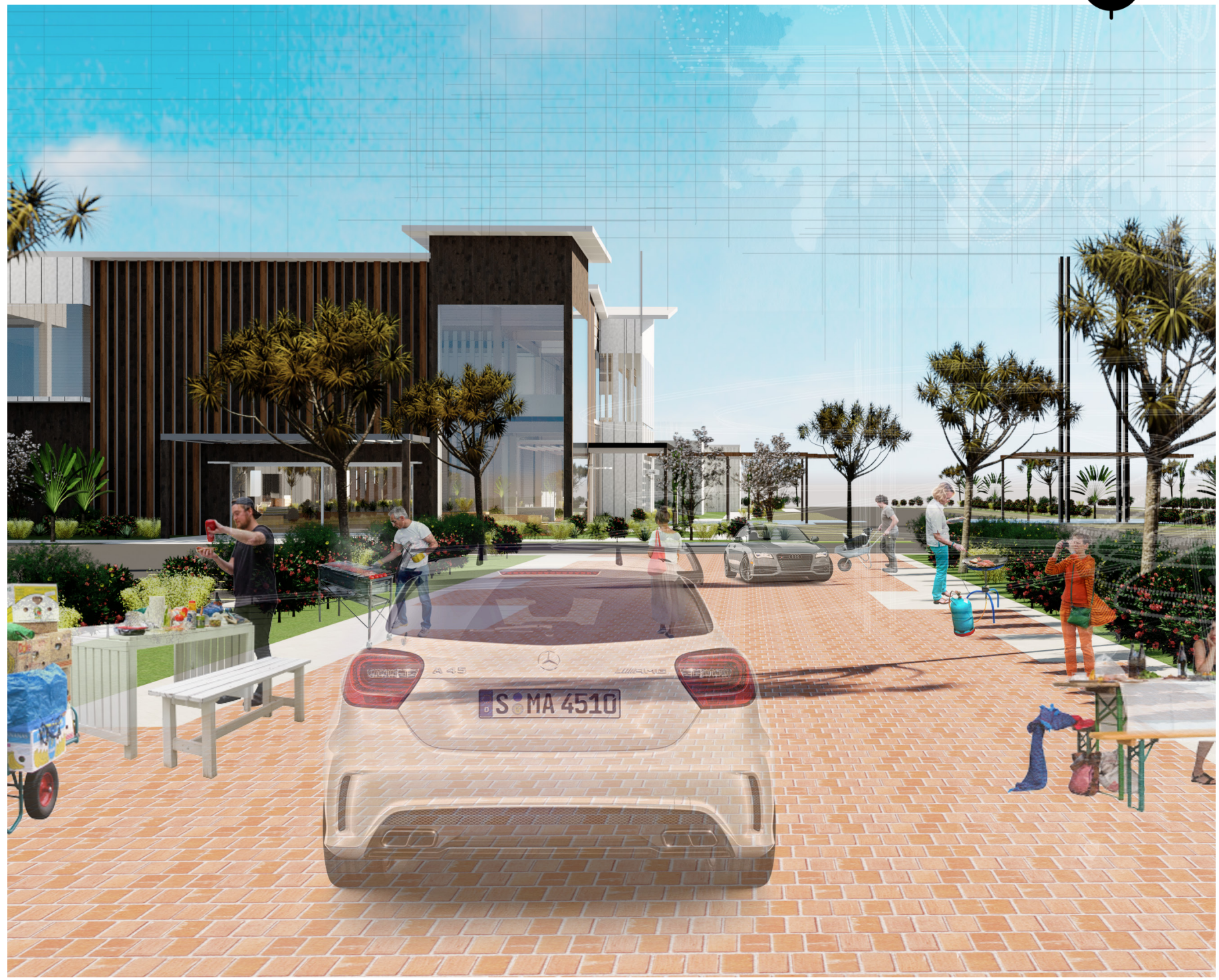

Figure 7.15. Carpark lane with spaces for outdoor community gatherings. 

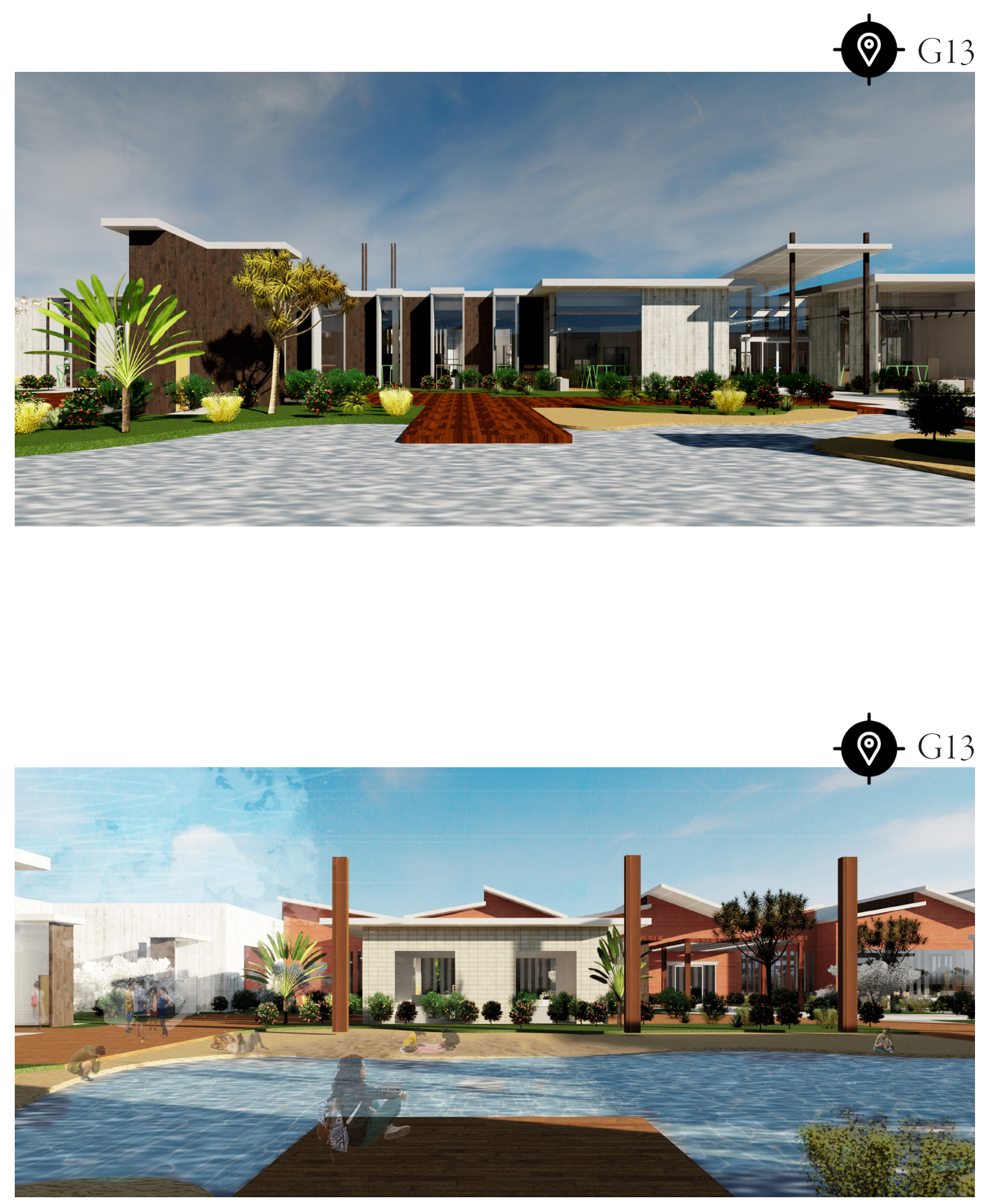

Figures 7.16 \& 7.17. Mall “beach”. 


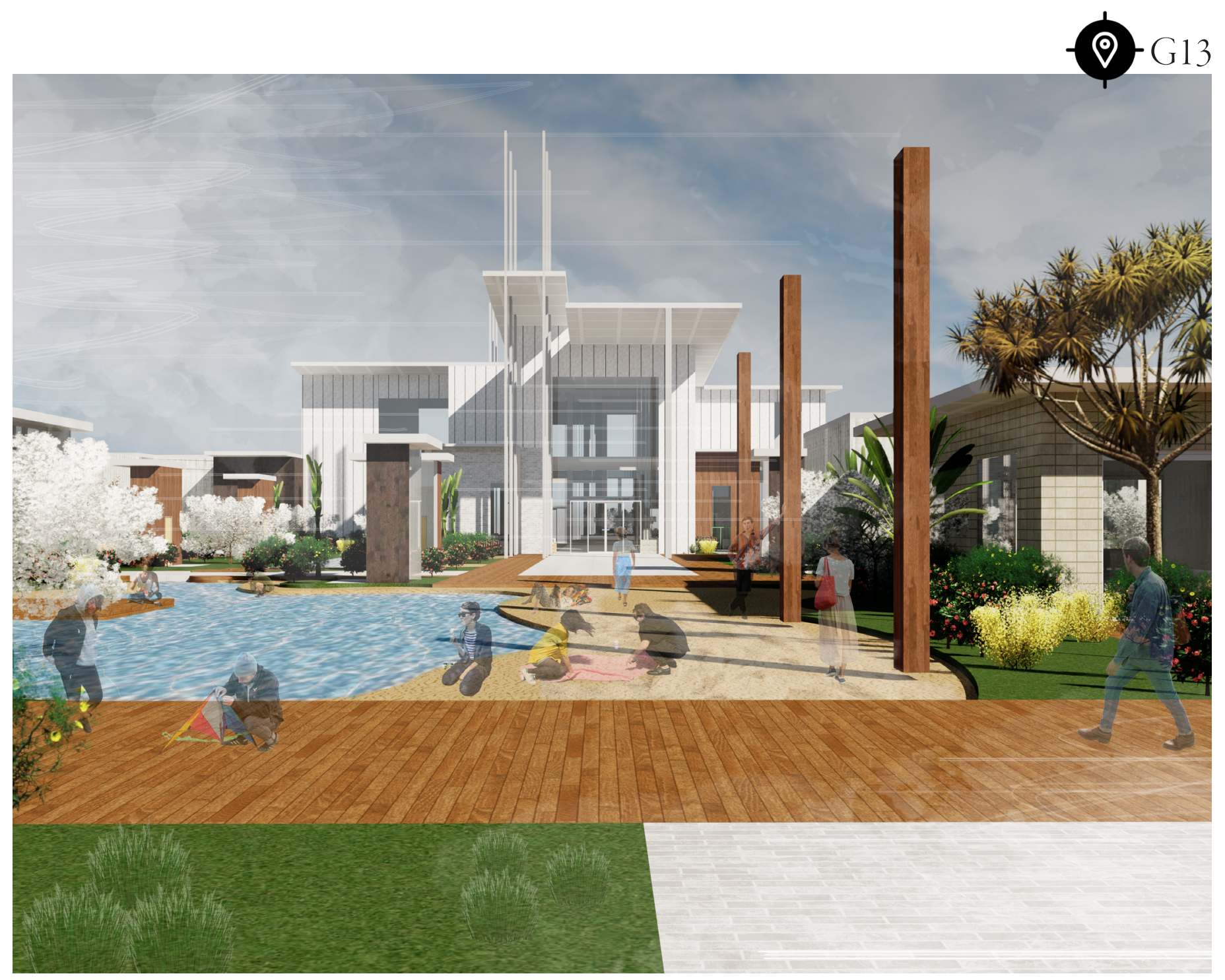

Figure 7.18. Mall "beach".

\section{"Beach"}

Addition to the proposed design of Eastgate, in response for the need to integrate spaces programmed to drive community, socialisation, and dwelling. It is proposed to:

- Serve as a node - a key space for the public and the associated social encounters and interactions;

- $\quad$ Serve as a tool in increasing engagement with mall spaces

- $\quad$ Redefine leftover spaces for activities- designing for many people's desire to be outdoor

- $\quad$ Elevate overall experiences of being in the mall

- $\quad$ Provide space for enjoying public life 
(9) 16

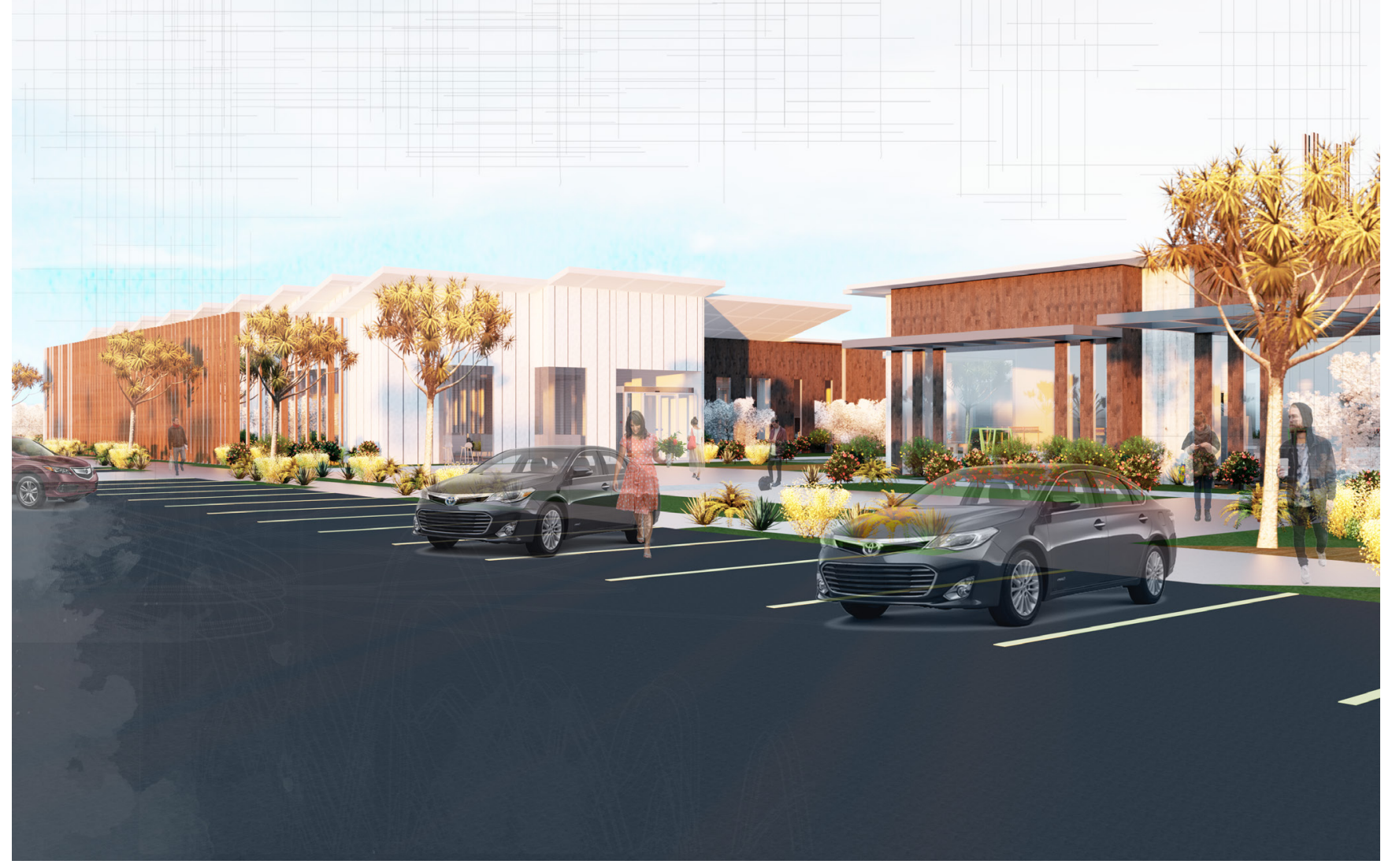

Figure 7.19. Outside sports retailer and

gym.

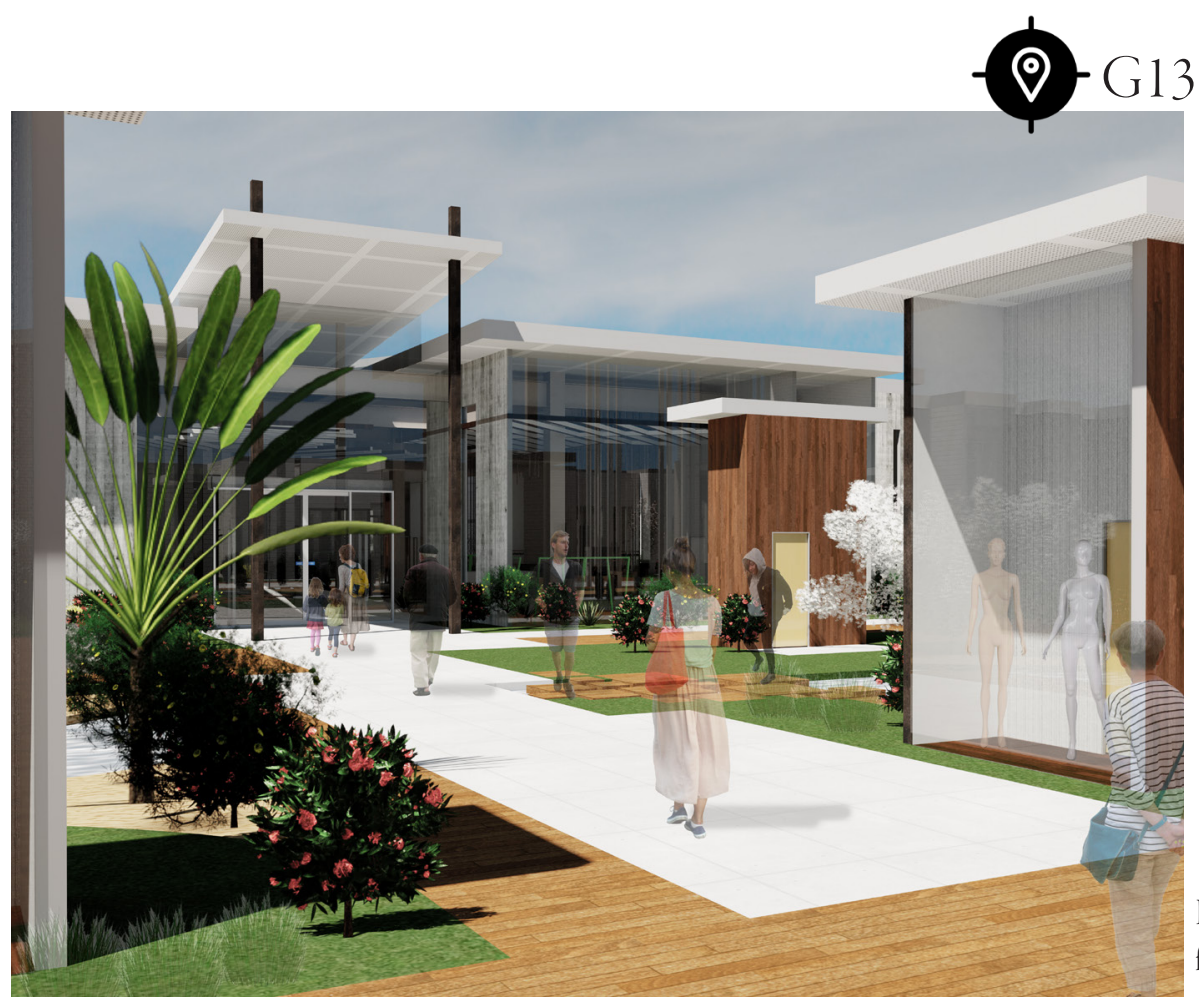

Figure 7.20. Approaching entrance to fashion hall. 

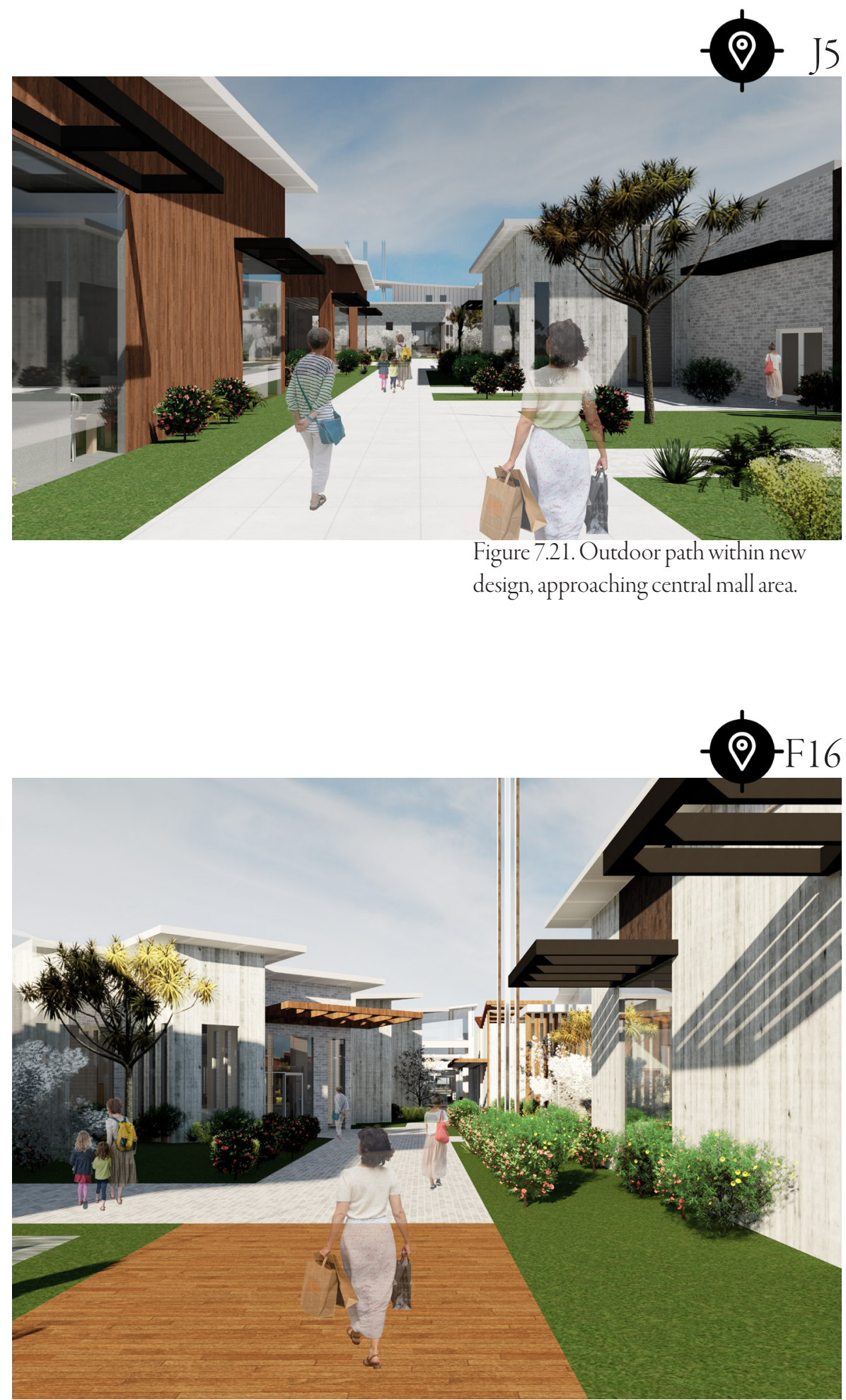

Figure 7.22. Outdoor path within new design, between fashion hall and anchor tenant. 


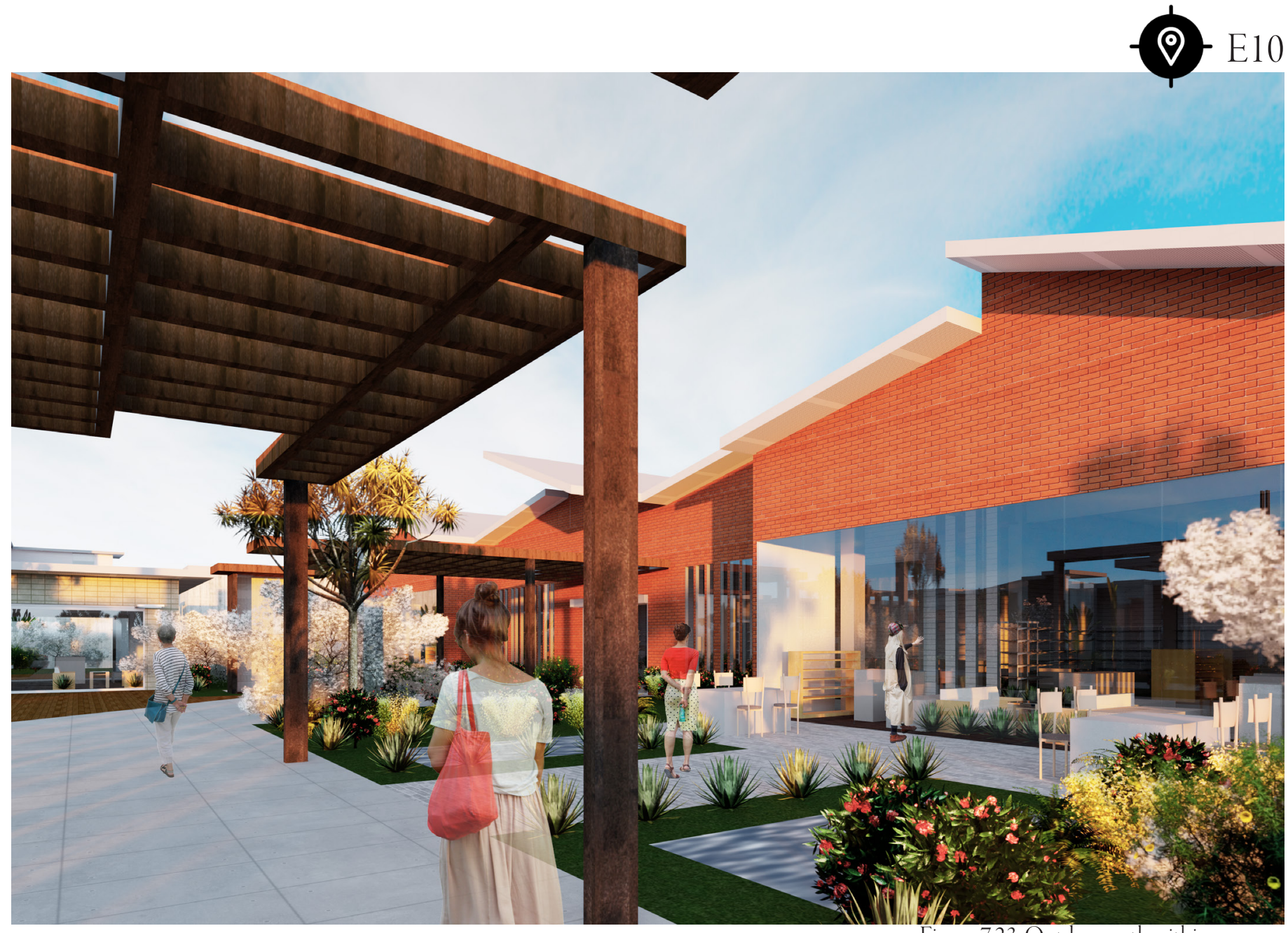

Figure 7.23. Outdoor path within new design, in the mall's central area. 


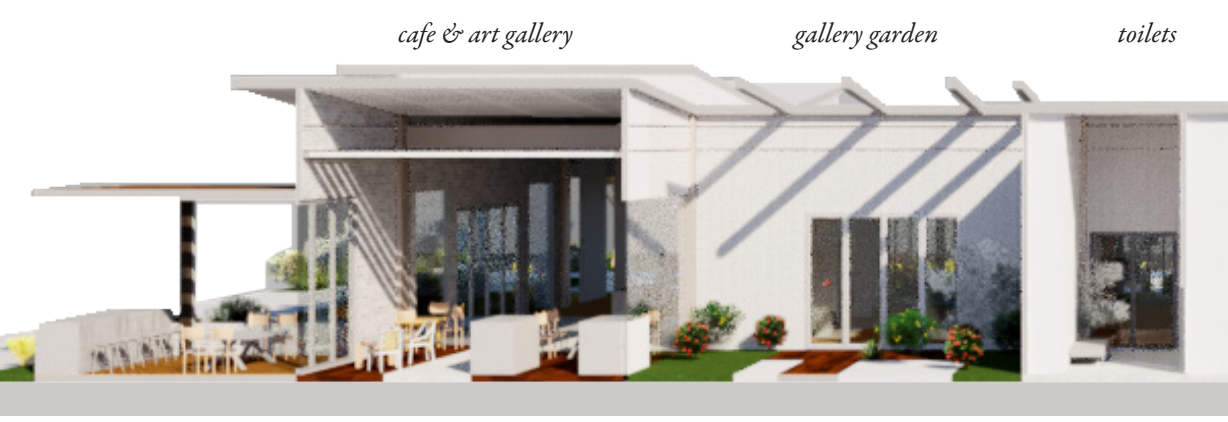

$1: 200$

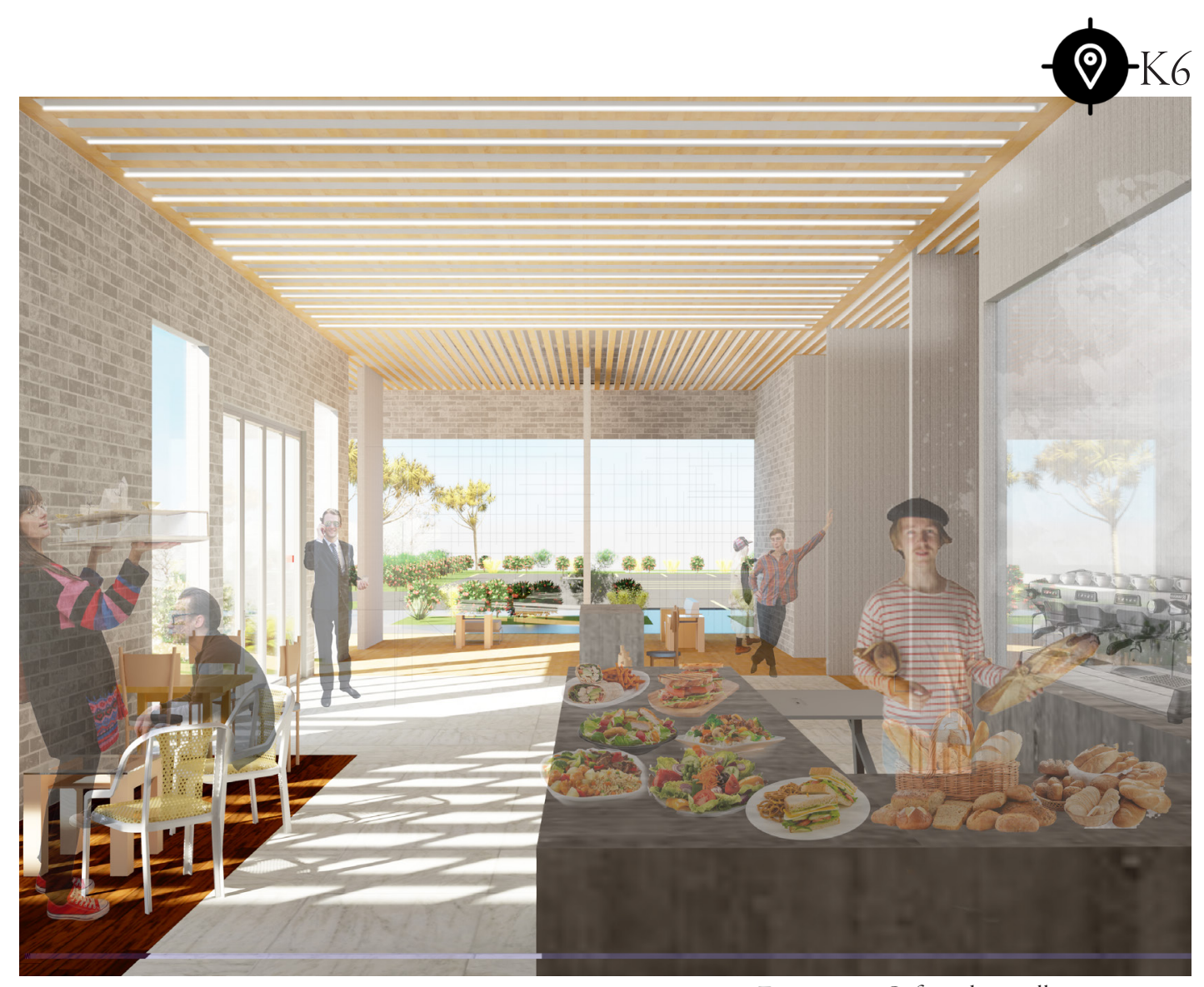

Figure 7.25. Café and art gallery. 


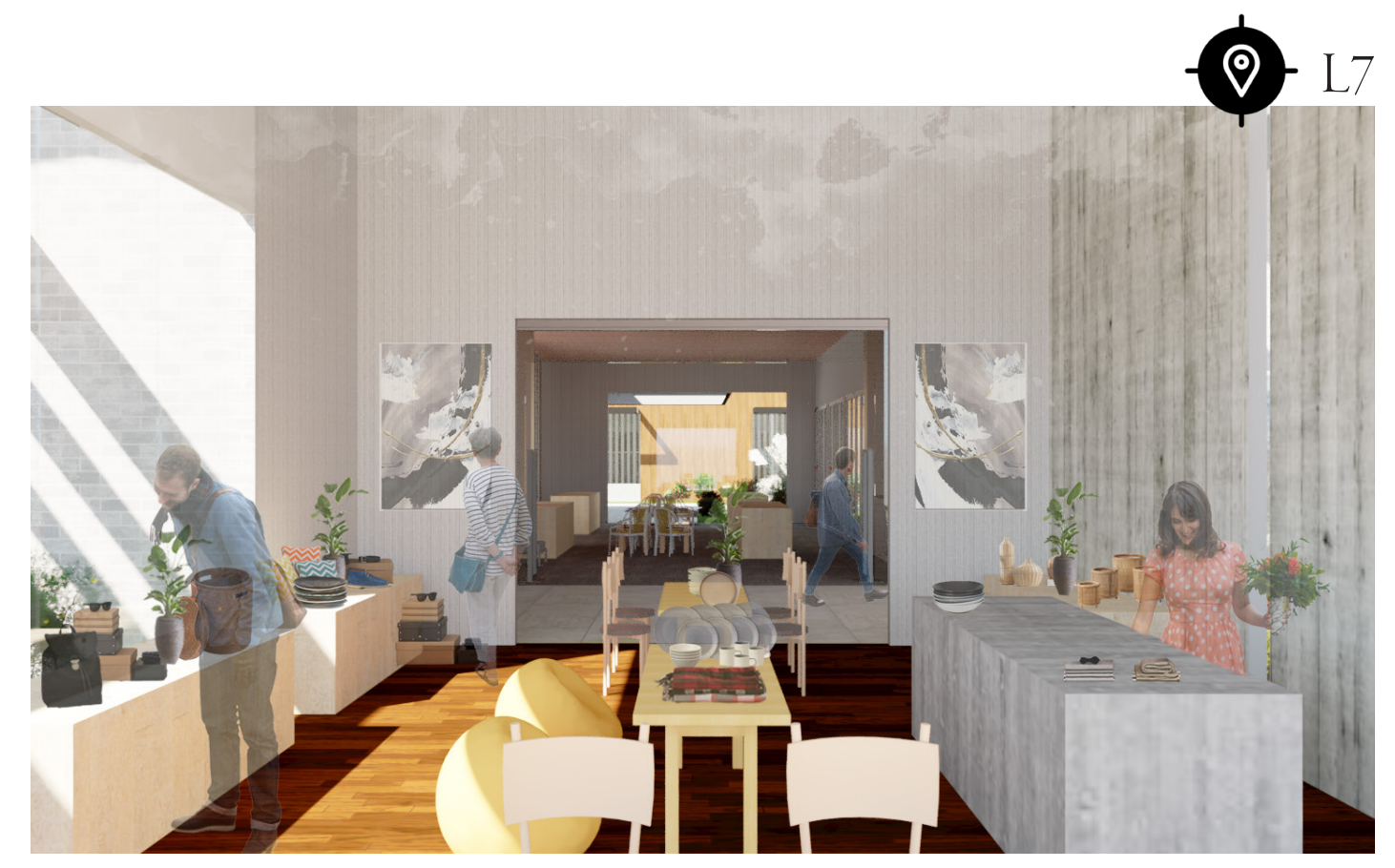

Figure 7.27. Small retailer opposite popup library.

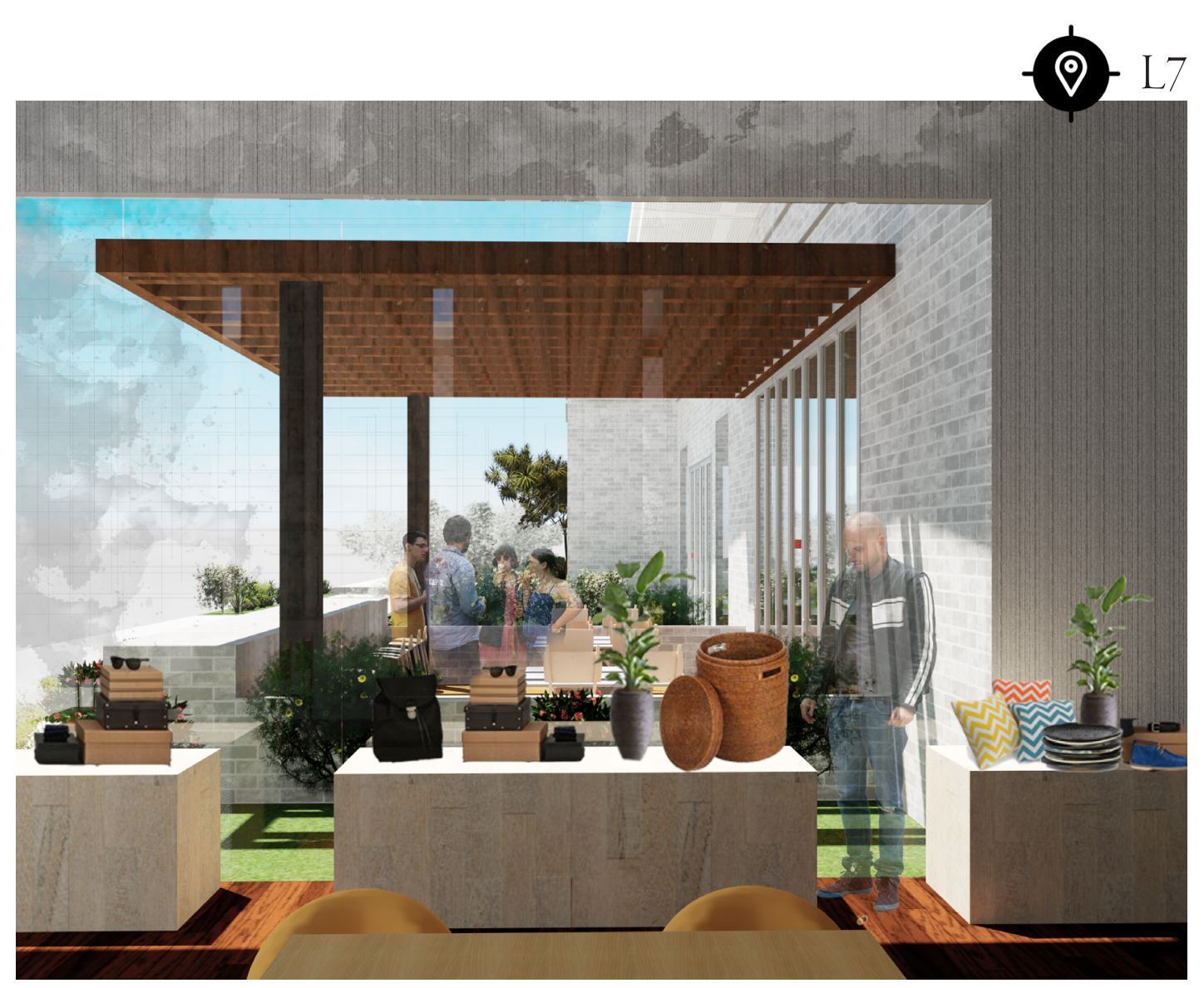

Figure 7.28. Small retailer overlooking café. 


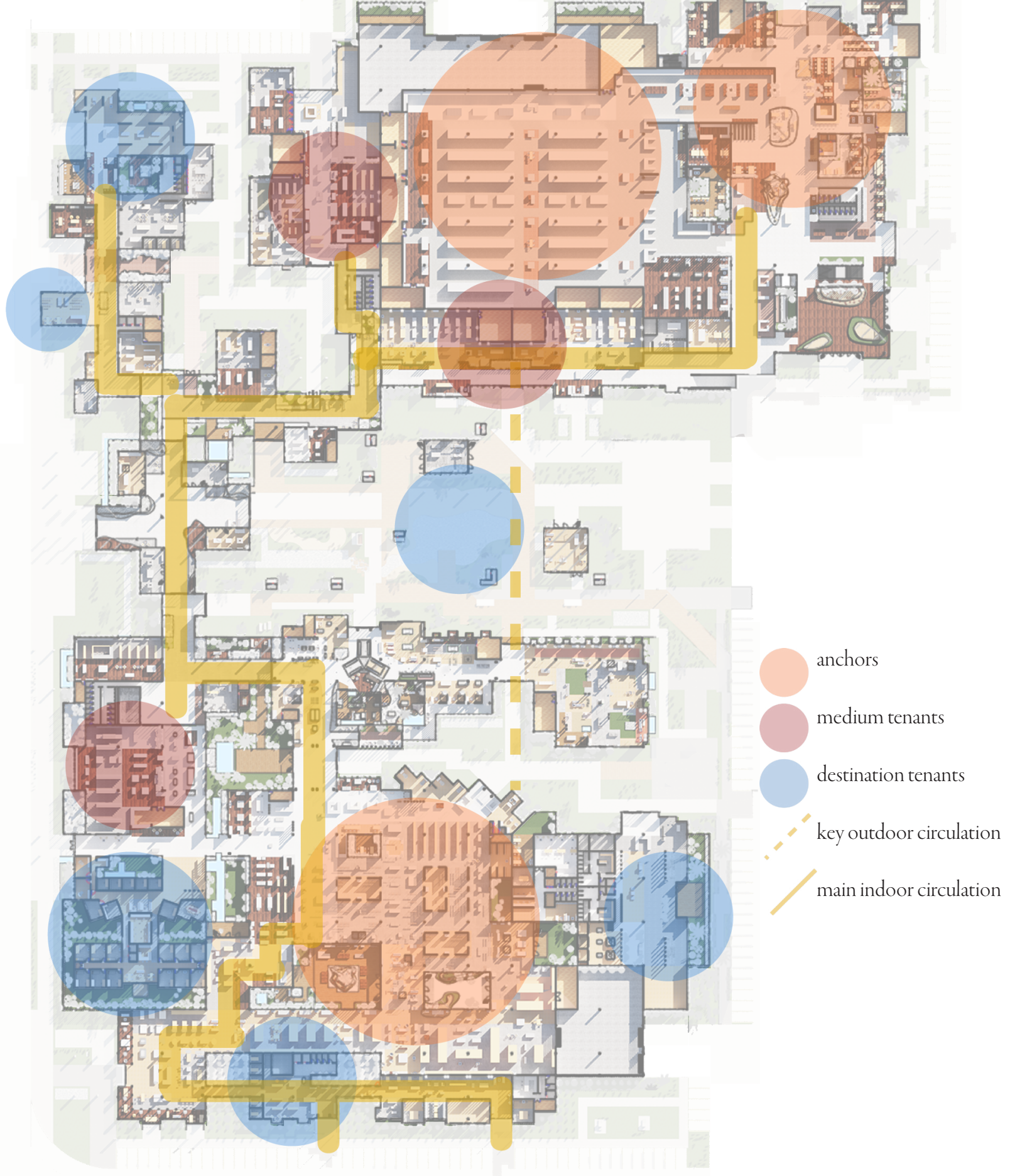

Figure 7.29. Anchor, destination and medium tenants locations. 


\section{Main Entrance Space}

Acts as key reference point for rejuvenated Eastgate design.

- $\quad$ Provide spaces for pop-up shops

- Can provide retail spaces for shorter leases which can appeal to digitally native brands; they could then use these spaces to test brick and mortar/physical retail.

Provide continuity for social spaces through the mall's circulation:

- $\quad$ Reference to the movement of pre-colonial Maori throughout greater Christchurchmove, pause and gather, move, pause and gather, and vice versa; space to gather

- $\quad$ Space possesses monumental scale to emphasise Eastgate's gesture of welcome and openness

- Monumental scale and verticality stems from an abstract development of the large, historical food gatherings and exchanges of Maori in the area- including their atmosphere

Interior landscape consisting of raised platforms:

- Provide different experiences: people can choose to either sitting or standing, grouping or being alone

- Aims to capture elements of amphitheatres, to promote interaction between people and enable this space to hold a variety of events and pop-ups; platform for creating relations with people and the surrounding community 

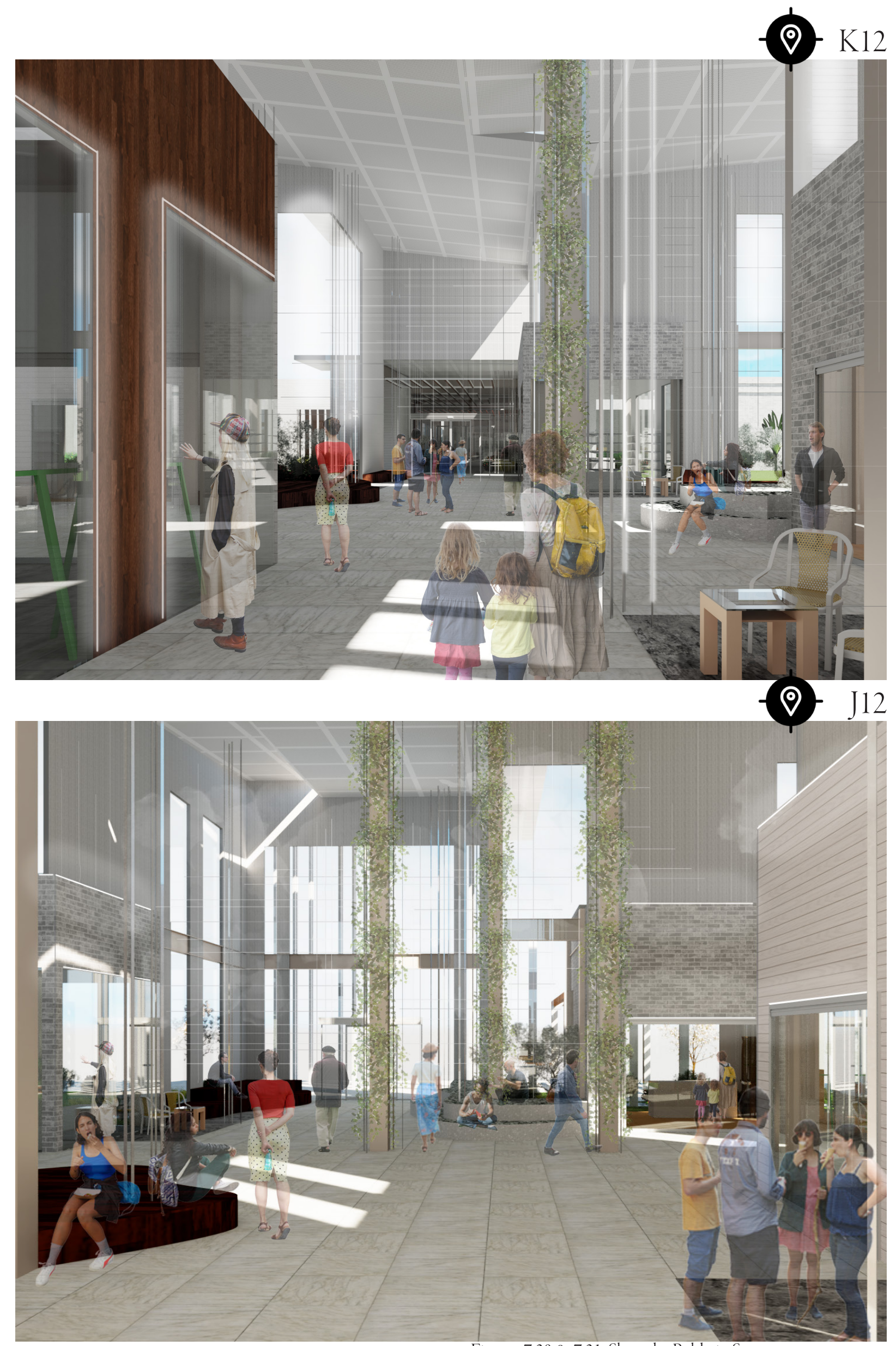

Figures 7.30 \& 7.31. Shops by Baldwin Street entrance. 


\section{Circulation}

Eastgate's circulation system is intentionally complex, to increase people's curiosity and lessen its predictably, to assist in making it an exciting space. It intentionally draws inspiration from the historical Maori associations with the greater Christchurch area. This is a way to rebel against the current inauthenticity and superficiality of Eastgate that speaks of its ignorance for local characteristics and traditions which are arguably vital for the built environment.

The complexity draws upon the movement of historical Maori tribes, who moved throughout the South Island. They hunted and gathered from low-lying plains to mountains, sandy bays to braided rivers (Tikao, n.d., p. 6). Cognitive maps were essential to these activities, allowing them to navigate vast and often hostile environments. These are integrated and developed as the verticality in the design, which serve as references when moving through the rejuvenated Eastgate—high/tall elements, skylights.

\section{Different materials for circulation}

A range of materials are utilised to enable the changes or transitions between them to clearly mark circulation. Multiple materials are used to echo different terrains and landscapes the Maori encountered in their historical journeys and activities-from the swamps to the rough mountainous terrain.

The material palette consisting of concrete, steel and timber which aims to support the notion of intertwining the man-made with the natural. This intertwining exhibits a level of industrial refinement colliding with the ambiguity and mystery arising from the area's rich indigenous history. 
indoor paths hybrid paths(indoor + outdoor) $\uparrow \downarrow$ vehicular entries

outdoor paths indoor paths embedded into anchor $\uparrow \downarrow$ delivery, logistics access

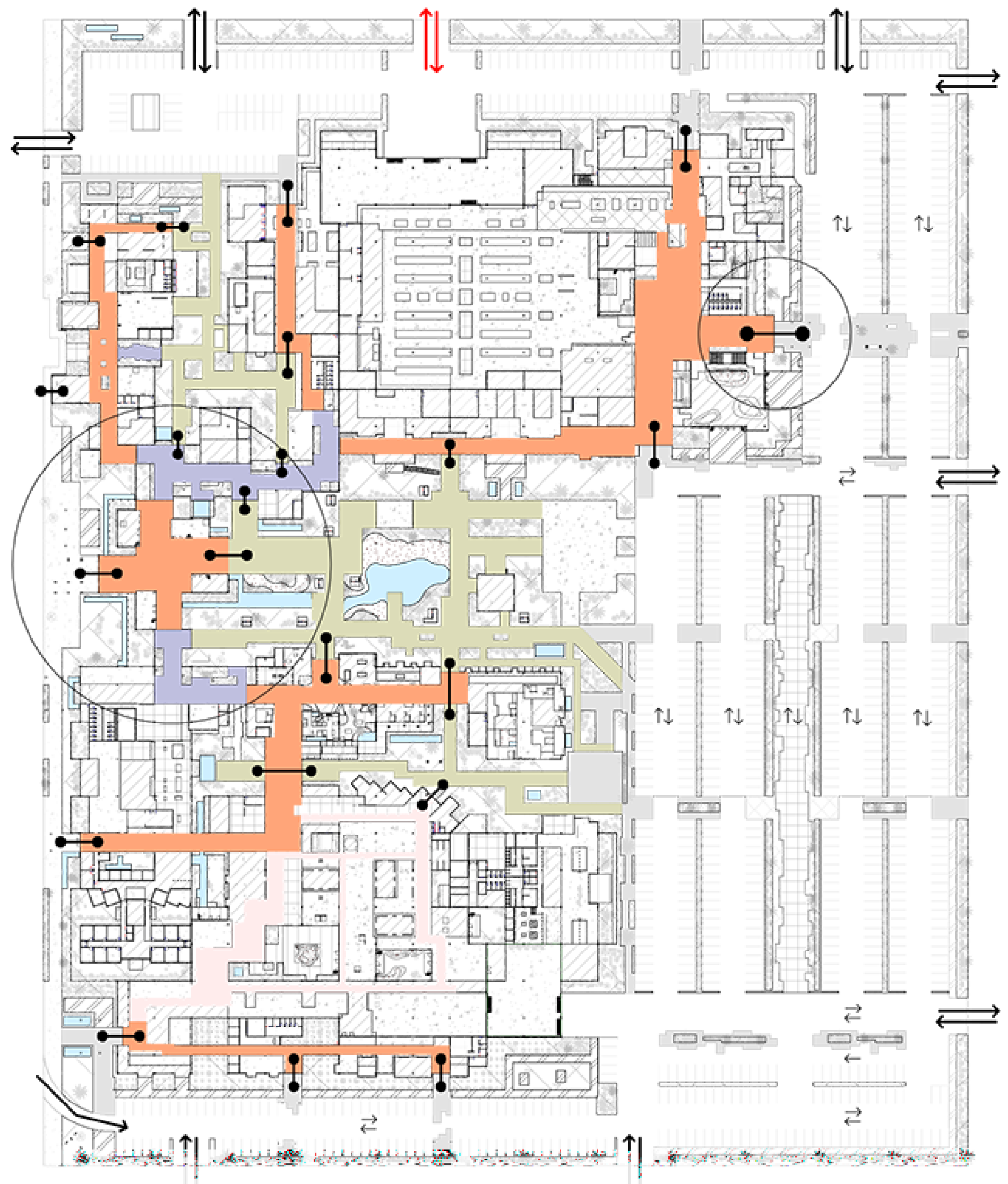

Figure 7.32. Eastgate circulation system. 


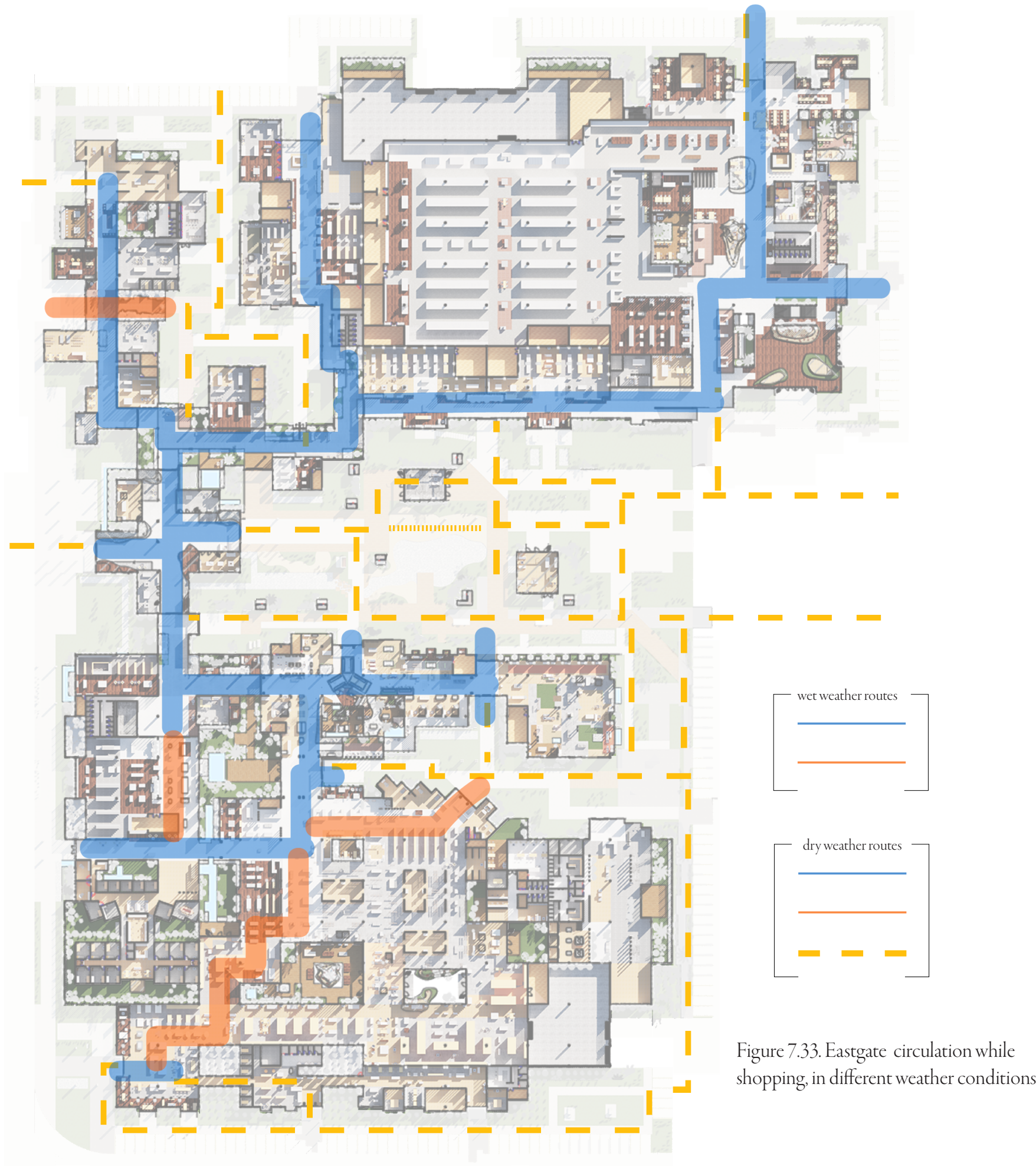



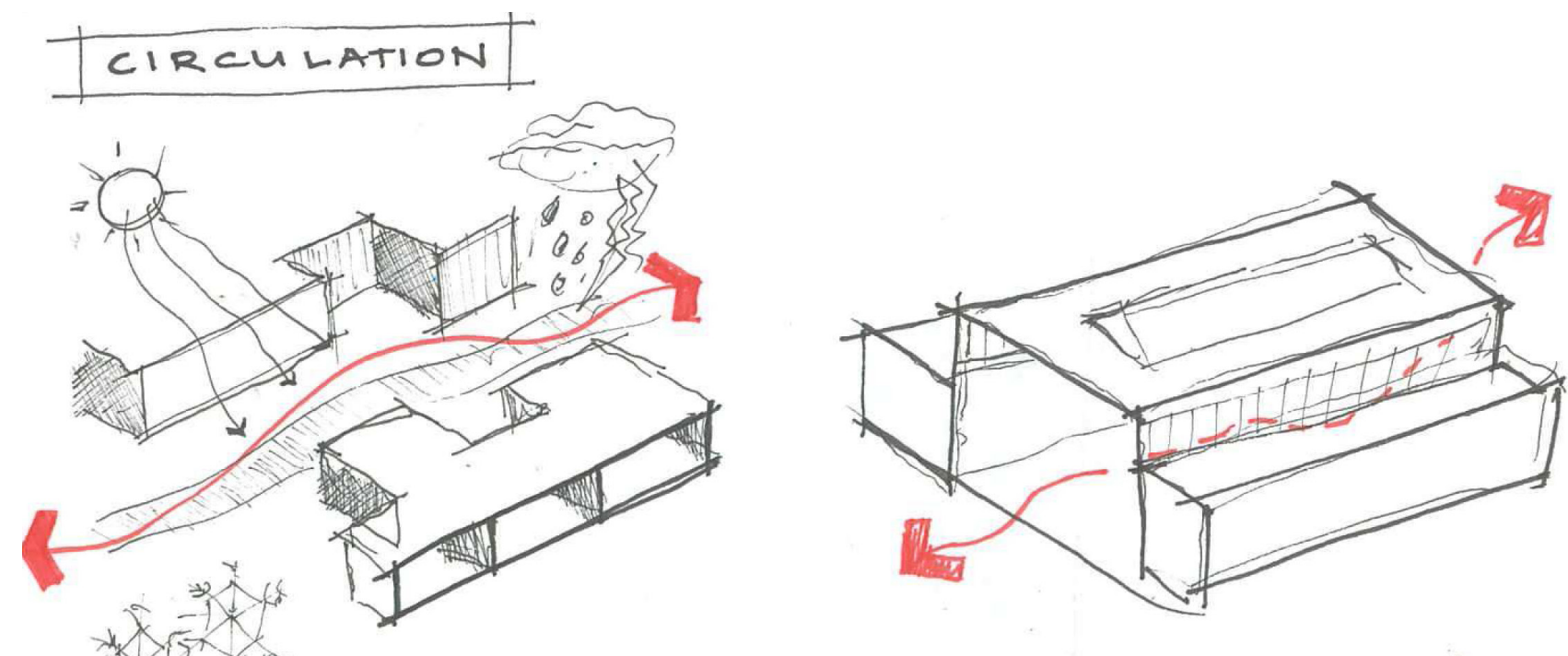

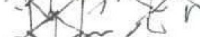

$x+2$

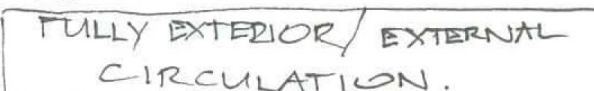

circulaticon.

$\rightarrow$ EXPOSEIR' TO ELEMENTS -

$\hookrightarrow$ DECREAST RODTFALL.
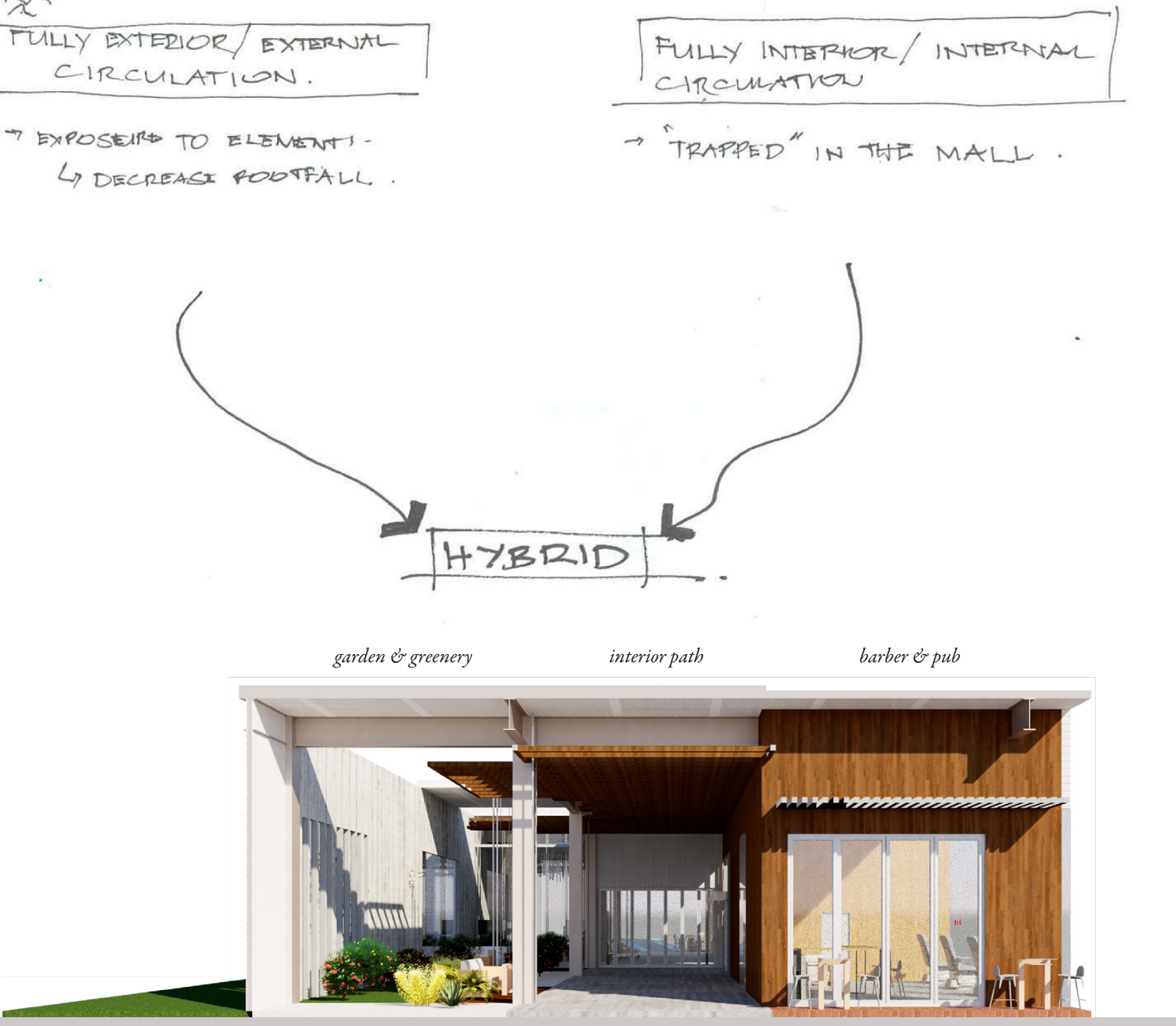

Partial section 1:200

Figure 7.34. Development of circulation. 


\section{Hybrid Circulation Spaces}

These branches in Eastgate's circulation system further develop ideas obtained from cognitive maps. These maps were known to weave together spiritual, genealogical, historical and physical information that bound people to place (Tikao, n.d., p. 6). The thesis design develops this concept, by introducing a notion of intertwining in these spaces. The man-made elements in the designed environment are exposed to meet and intertwine with the natural.

- Strategically placed to maintain an overall sense of openness in the mall, while providing continuity in circulation and protection from the elements to still draw people in different weather conditions.

- People for instance are manipulated to follow the sheltered paths to draw them into shops despite rain.

- These blend indoor and outdoor spaces and elements to reduce monotony experienced in long and dull indoor paths.

- These spaces are designed to provide shelter while still enabling people to experience some outdoor conditions.

- Concrete utilised to complement light penetrating through roof openings to enhance the feeling of serenity and calmness; add a contrasting experience and mood while people shop or walk through Eastgate

- It provides a unique experience that people may want to stop for, likely transforming it into a social space.

- With the presence of greenery, temperatures within these spaces can be somewhat maintained at comfortable temperatures. 


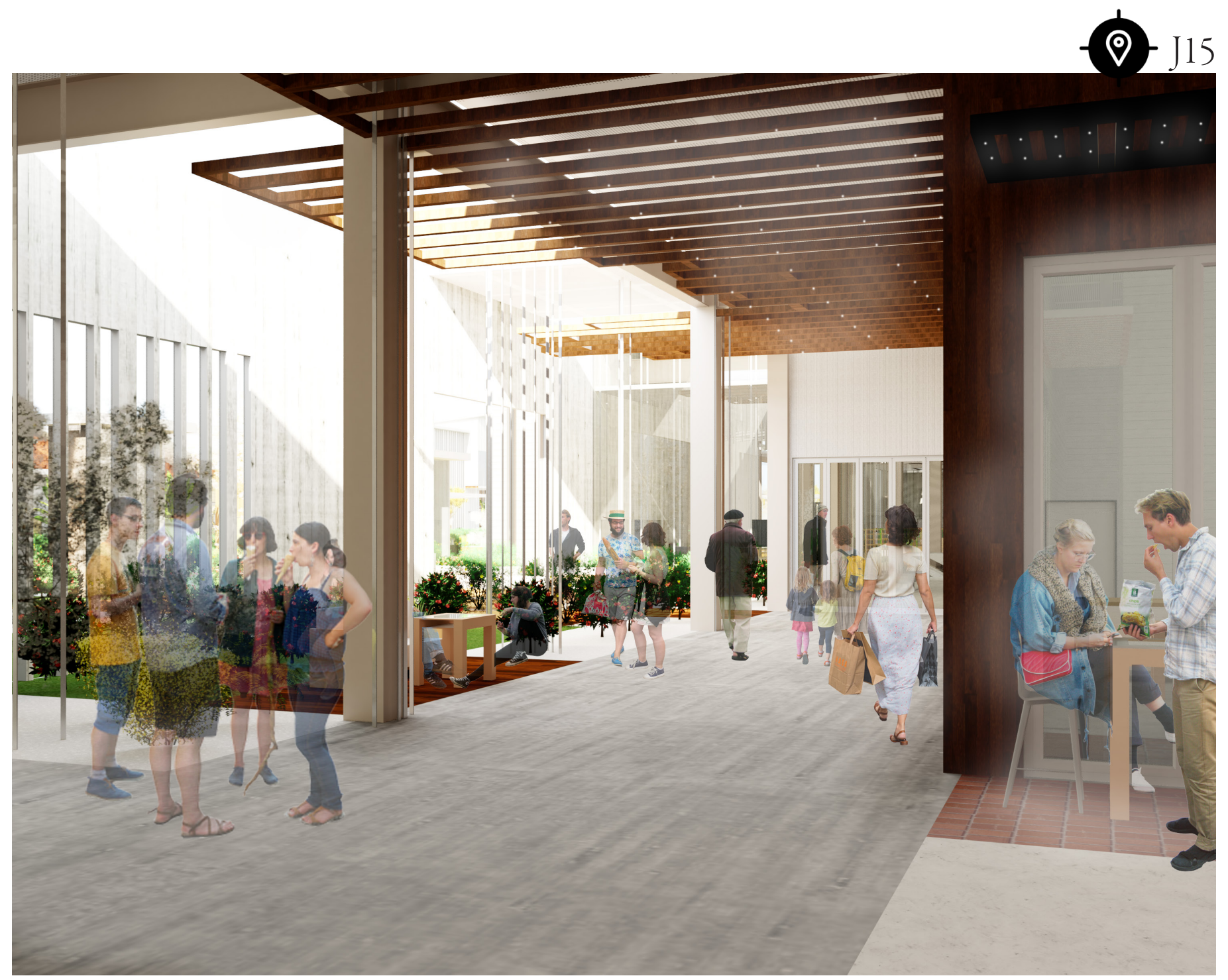

Figure 7.35. Hybrid circulation space approaching anchor tenant. 


\section{Natural Elements}

Greenery and green elements (including trees, shrubs and bushes) are heavily integrated to turn Eastgate Mall into an oasis, aiming to achieve harmony between the built and natural environments. Greenery helps render the proposed design as a hybrid of a market place and a public park, where the atmosphere achieved from the harmony between the built and natural environments encourages social interactions.

A diverse background of customers and people would use and experience the proposed mall design. However, nature and greenery can be a common link and "voice" between them. This would unite the different customers and people, enabling the proposed mall design to enhance the area's sense of community. Greenery and natural elements are also integrated in the mall's interior to further realise the potential of this common link and voice. This is evident through the use of internal gardens, canopies, paving and outdoor materials inside the mall.

Natural elements and greenery are tools to help regulate indoor temperature and ensure comfort. More importantly these are strategies aimed towards neutralising the level of complexity and fragmentation in the proposed design. They are used to compensate for the disconnection in architectural design and assure that the proposed plan is unified and coherent as a whole. 


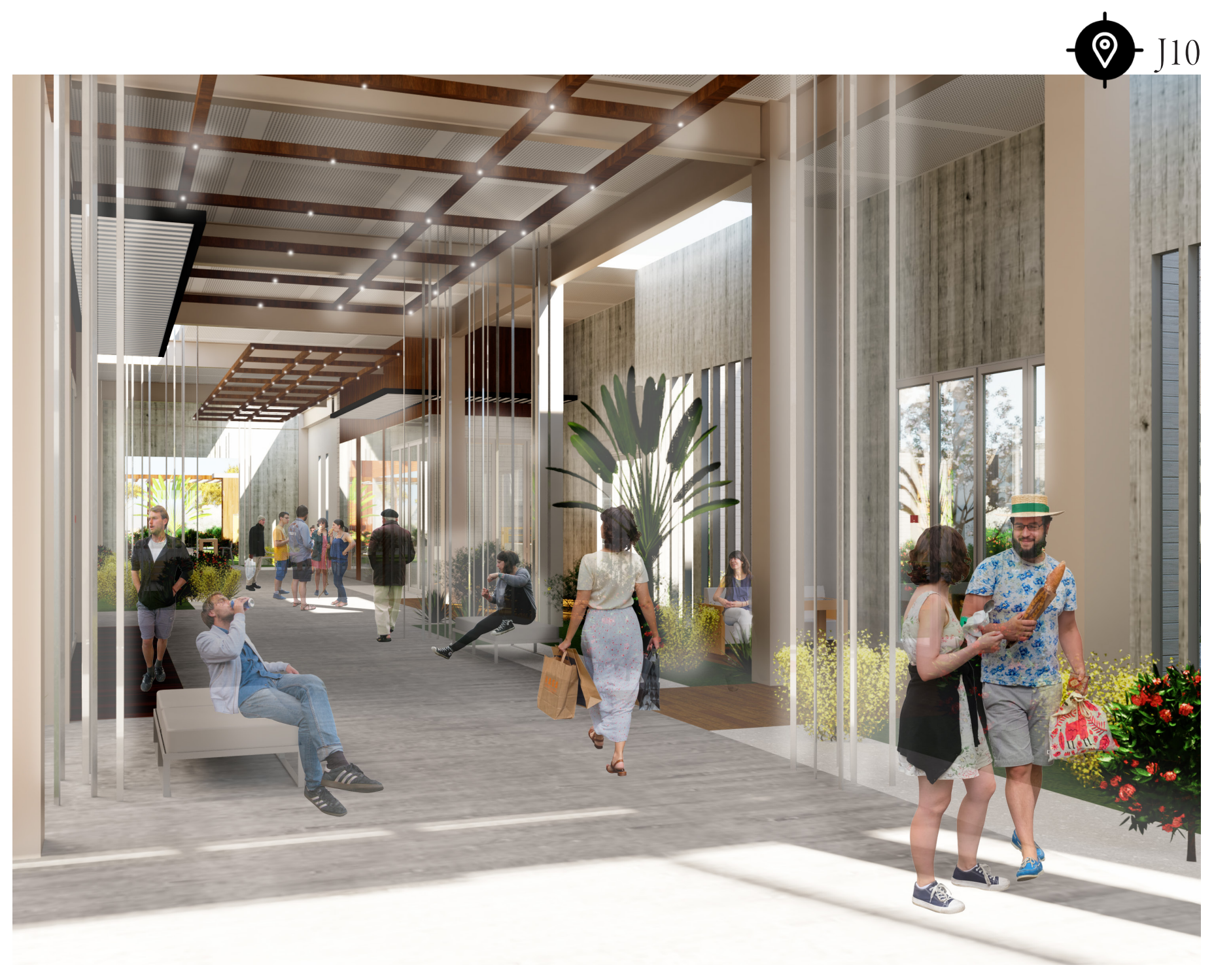

Figure 7.36. Hybrid circulation space. 


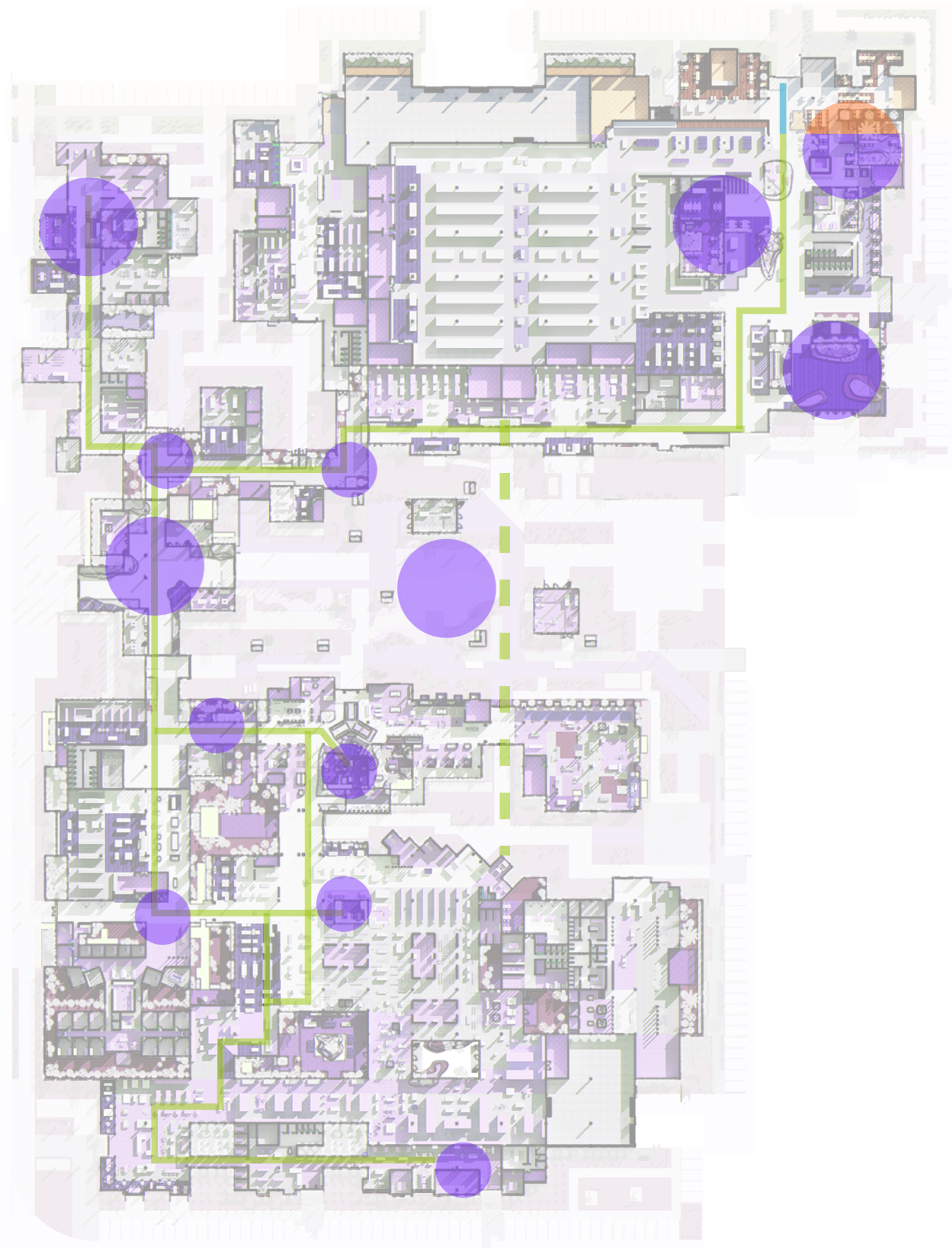

Figure 7.37. Location of social spaces 


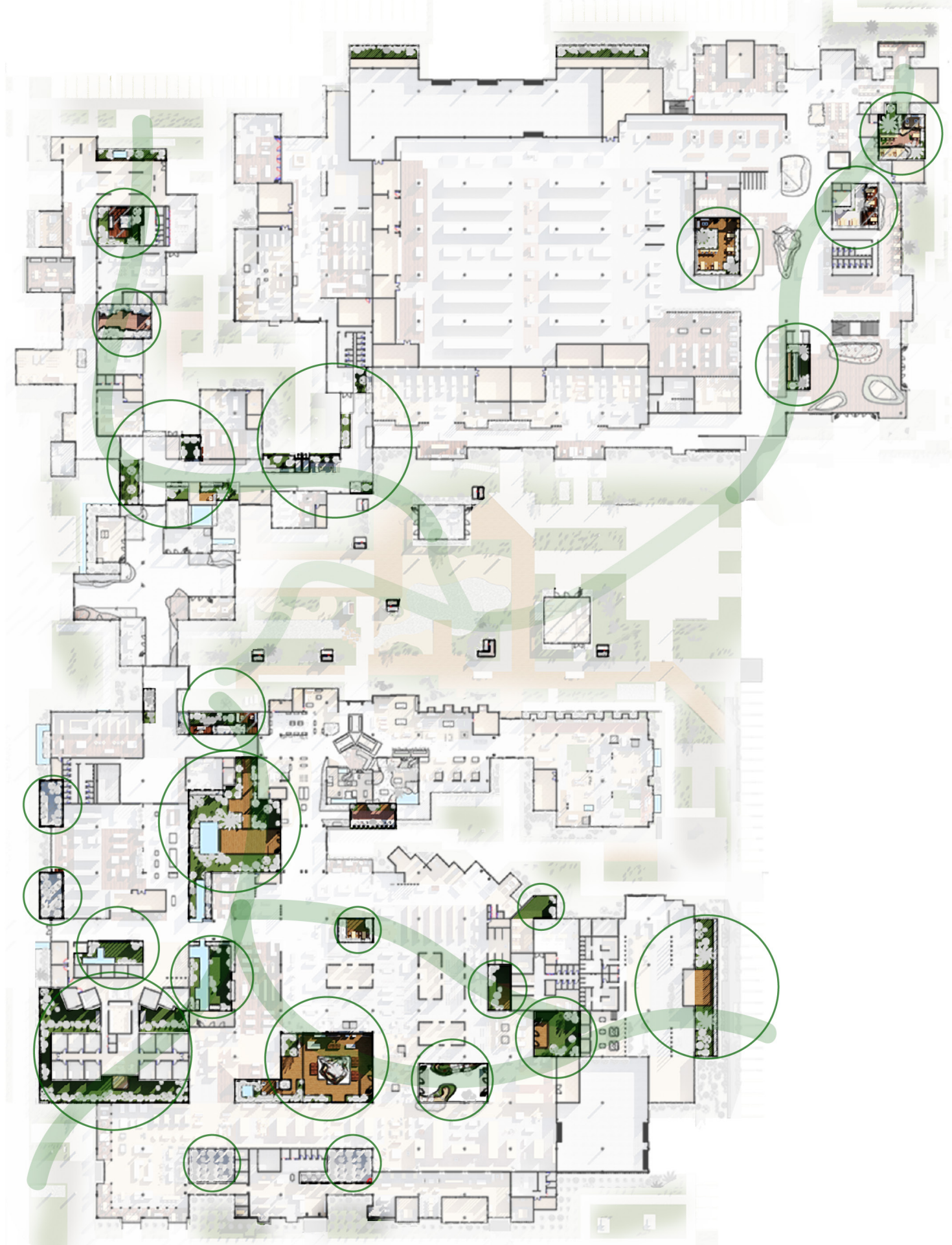

Figure 7.38. Location of green spaces within mall buildings. 

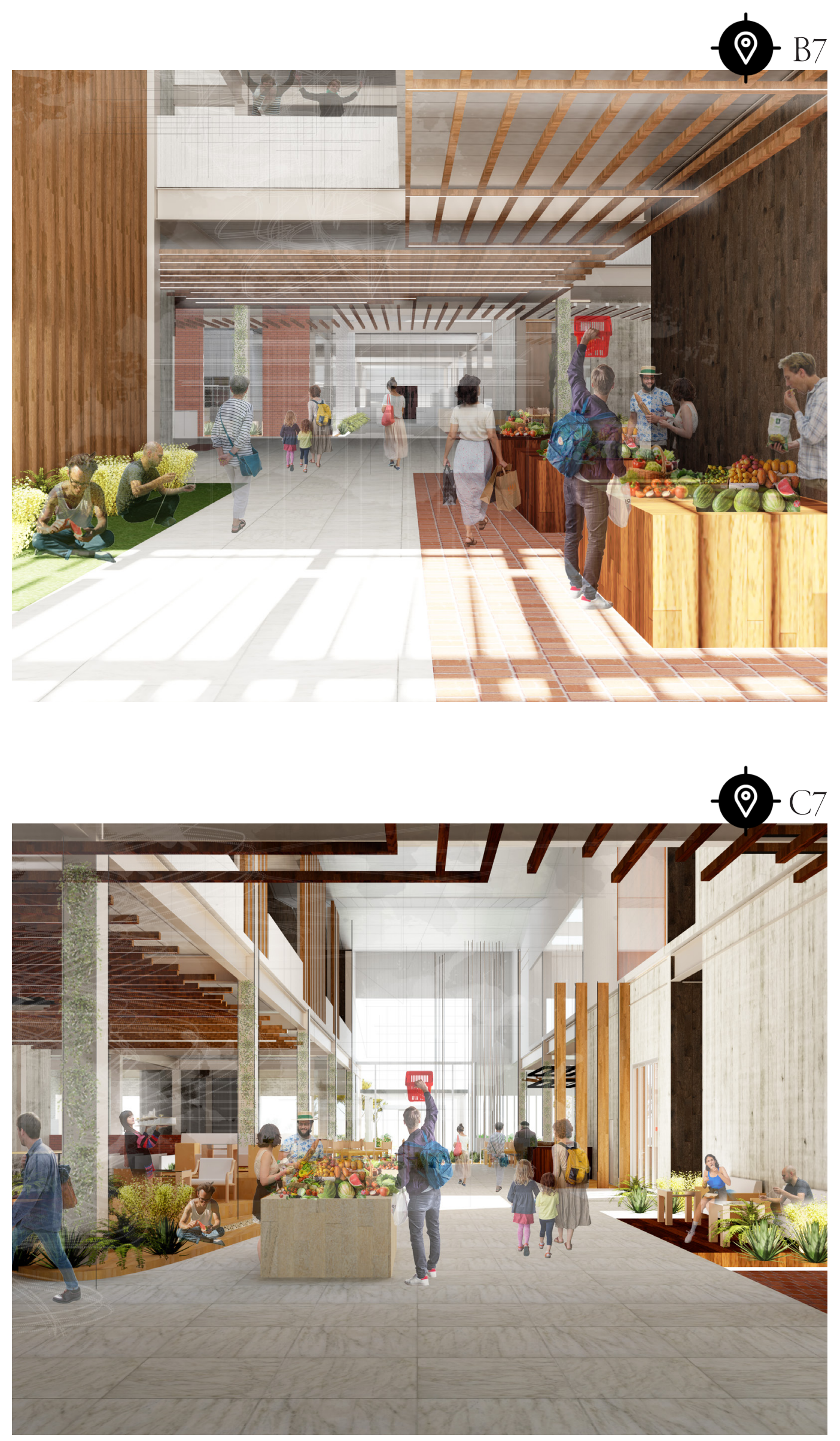
Figure 7.39-7.41. Proposed market spaces

by food court.

Q.

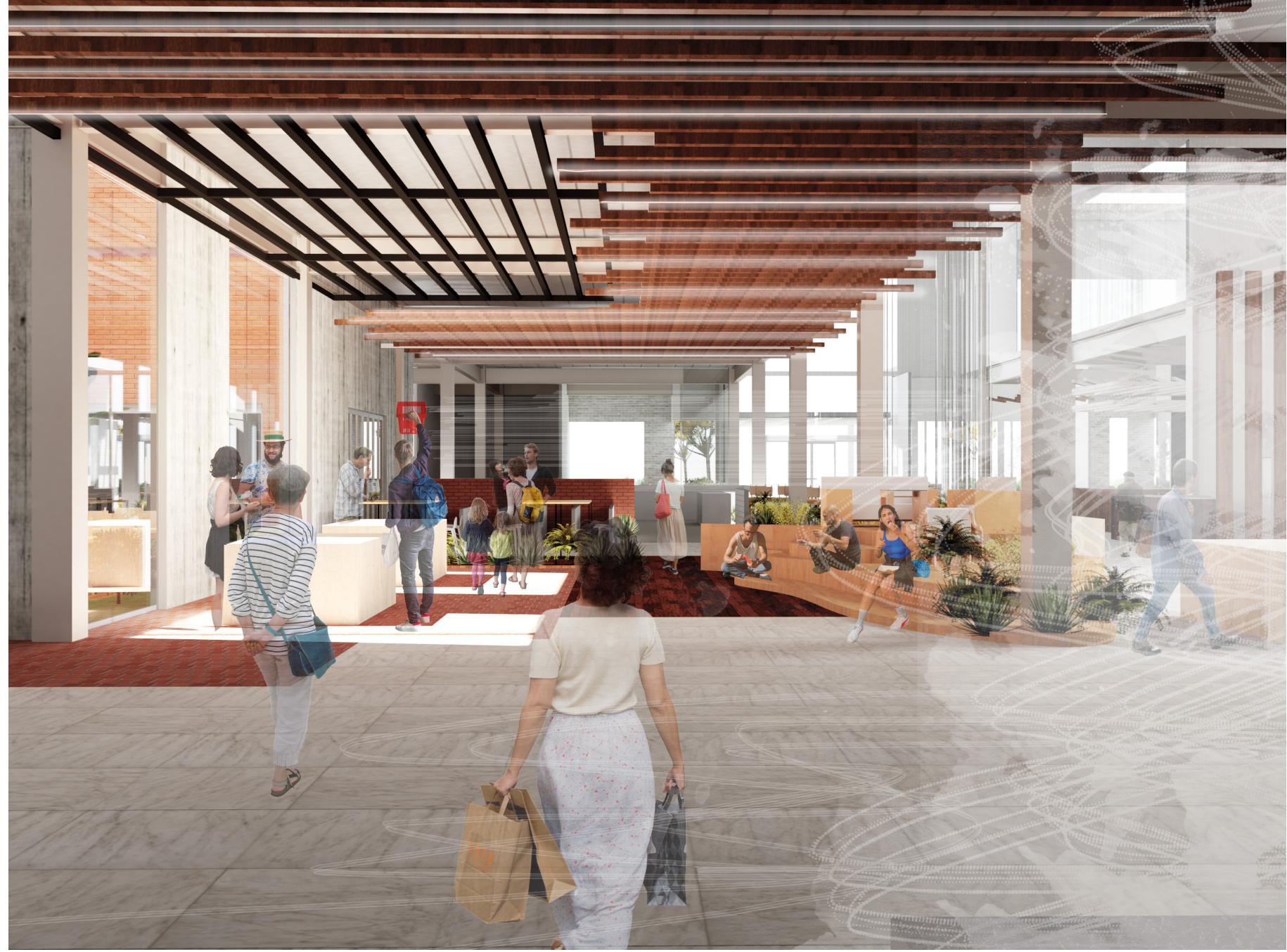

Markets

To resemble the unique ambience in traditional markets; bring a series of spaces and functions

close to human scale as a way to attract traffic and provide a unique shopping experience. 


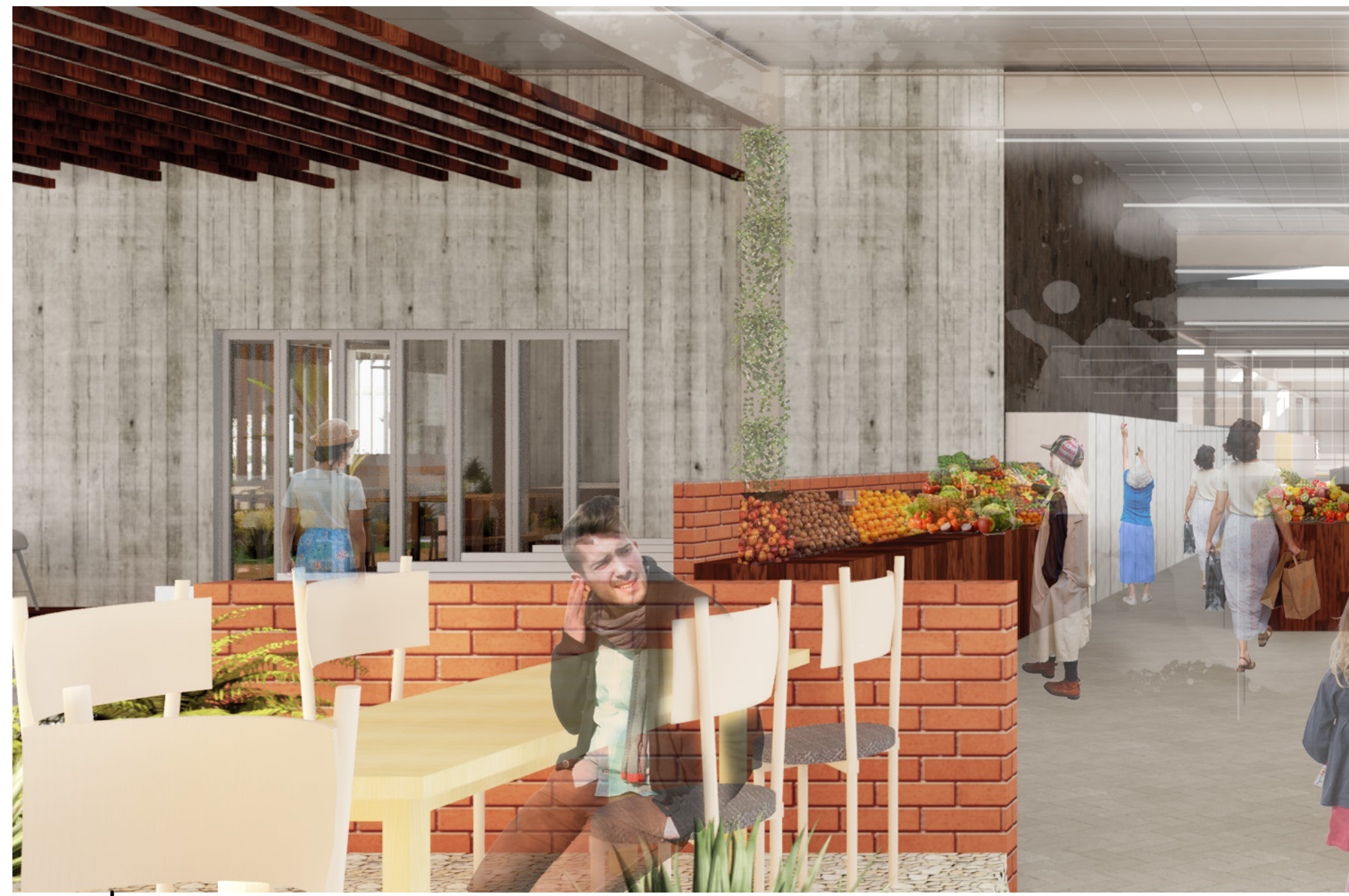

\section{C5}
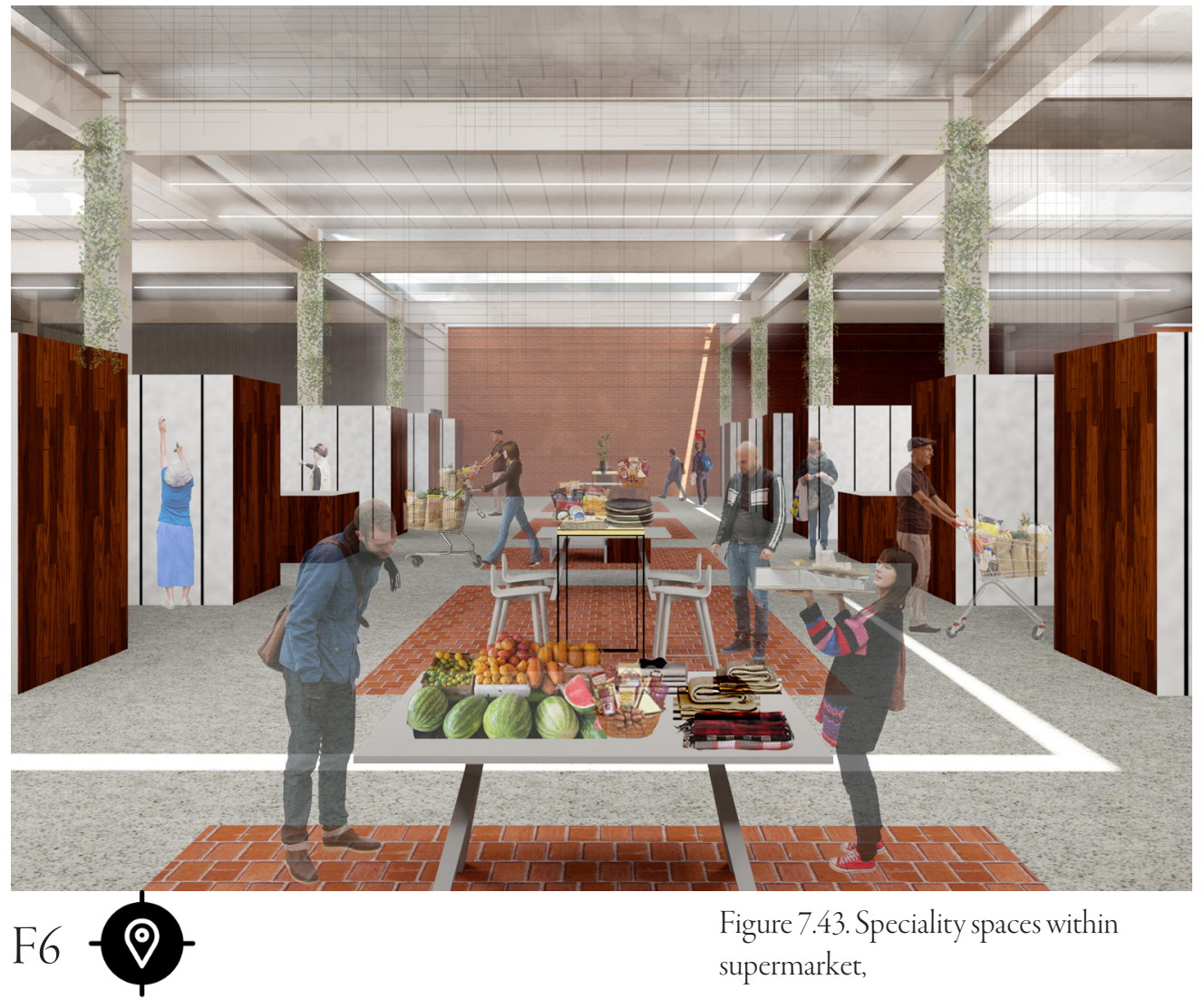

Supermarket

Pop-up spaces and stalls within supermarket, add an exciting and social dimension to grocery shopping.

This Remains mostly unchanged to maintain convenient shopping trips. 


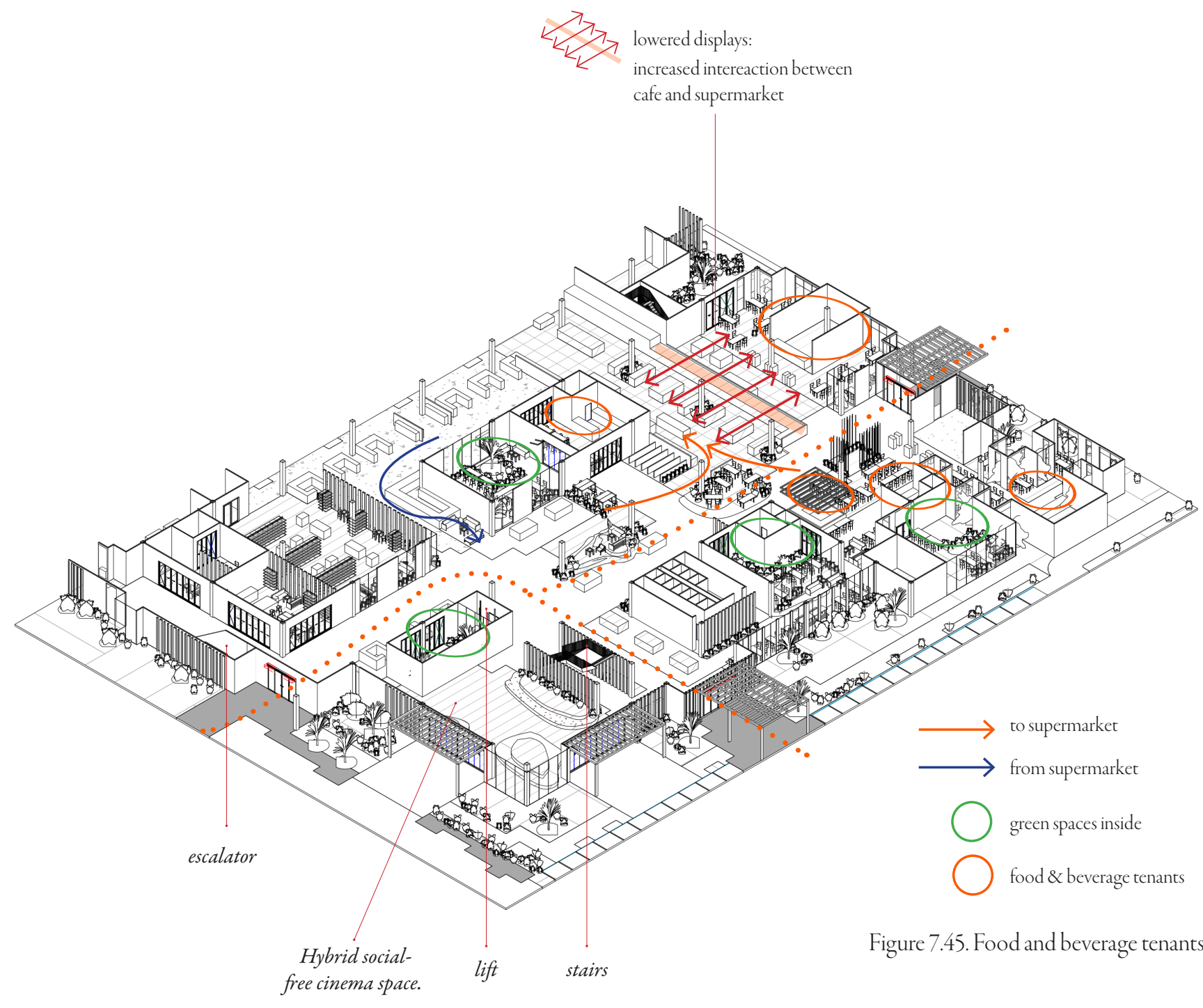




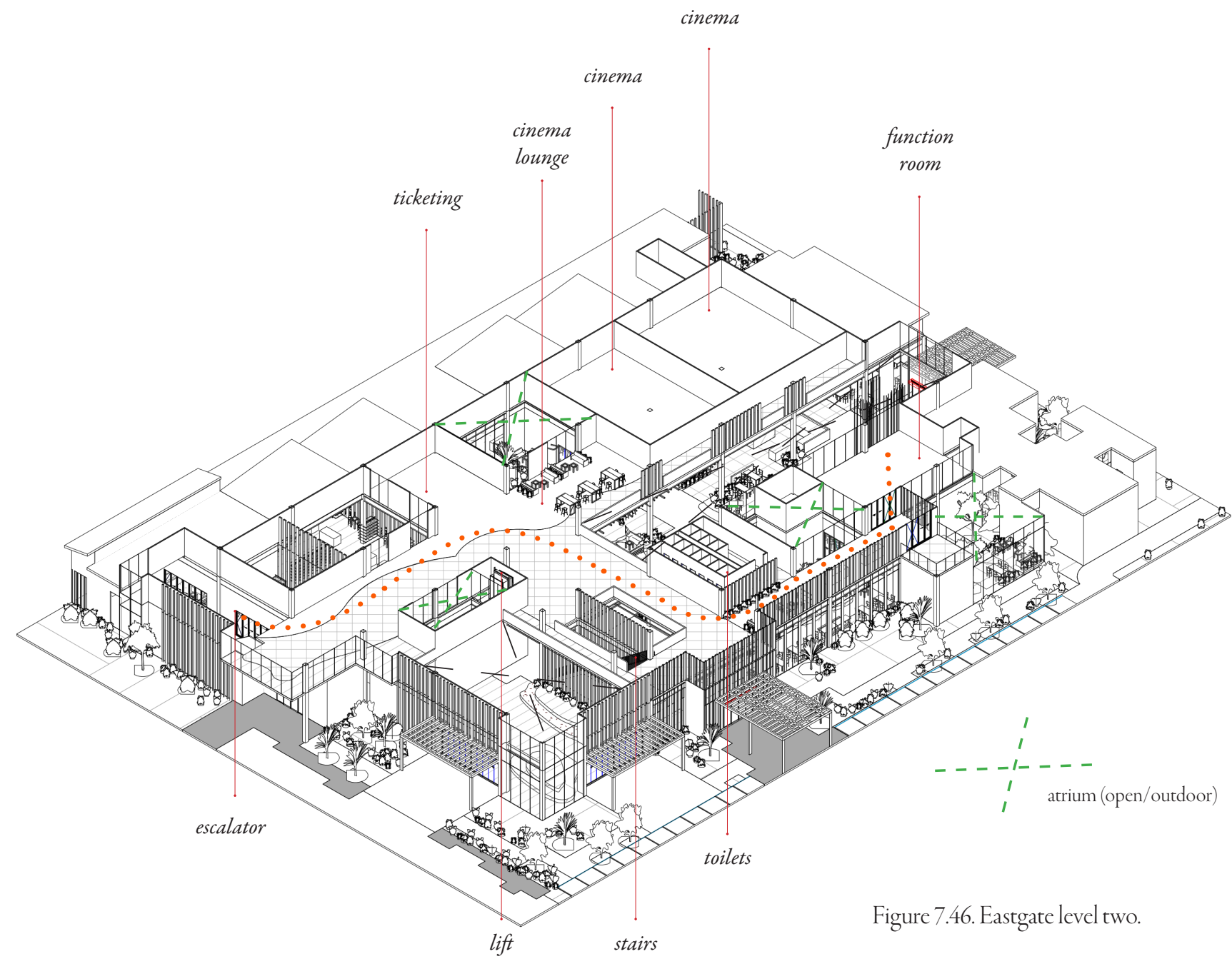




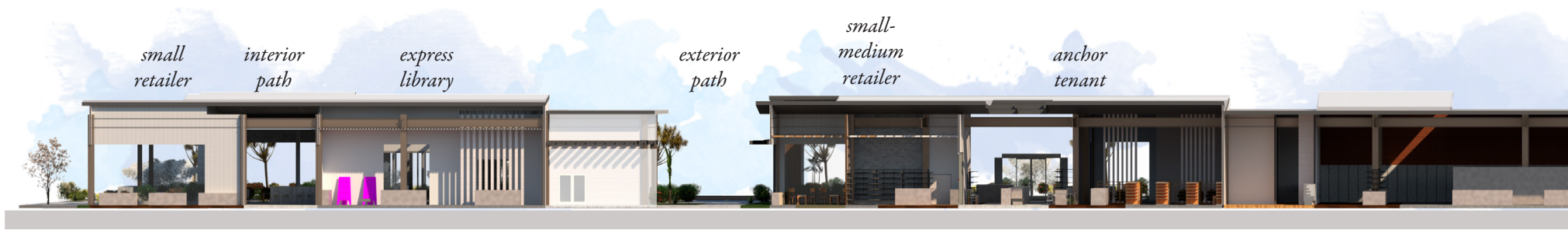

$1: 500$

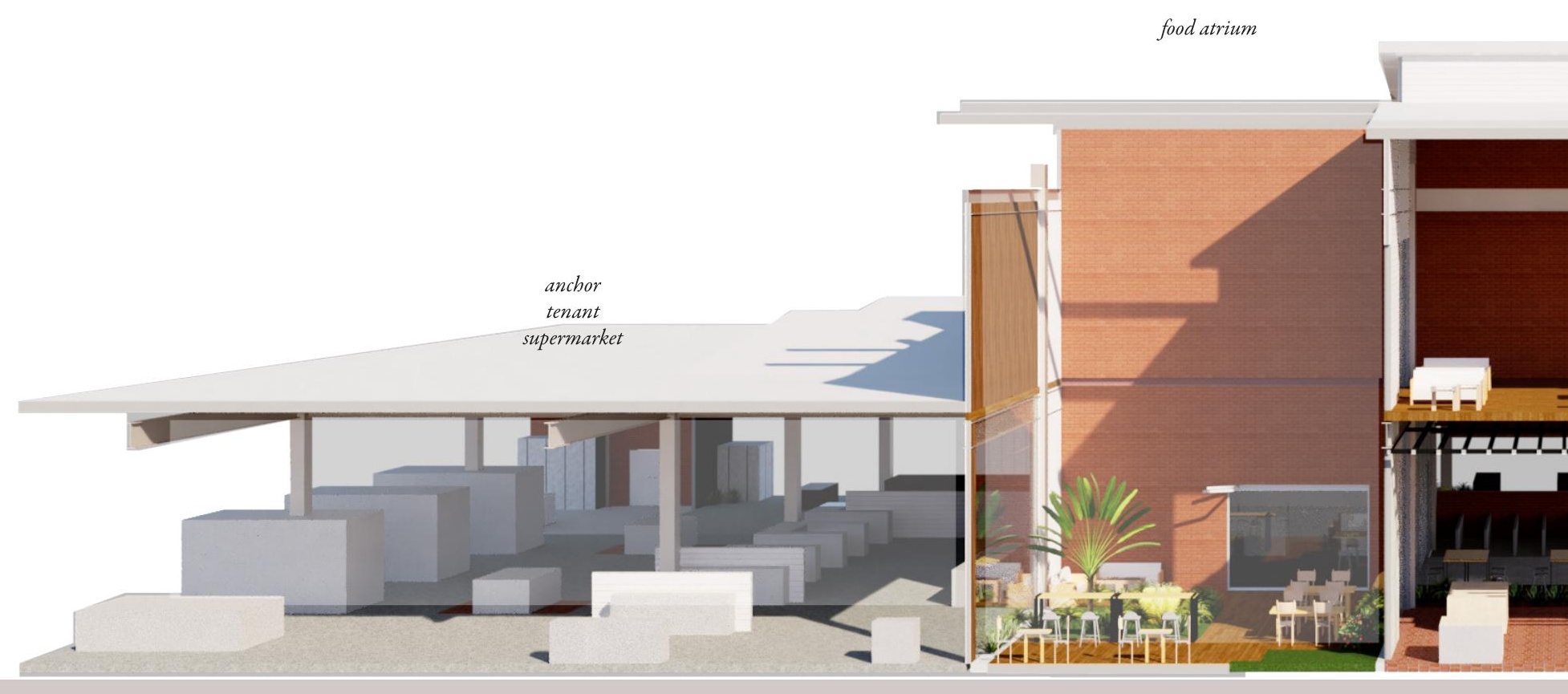

$1: 200$ 


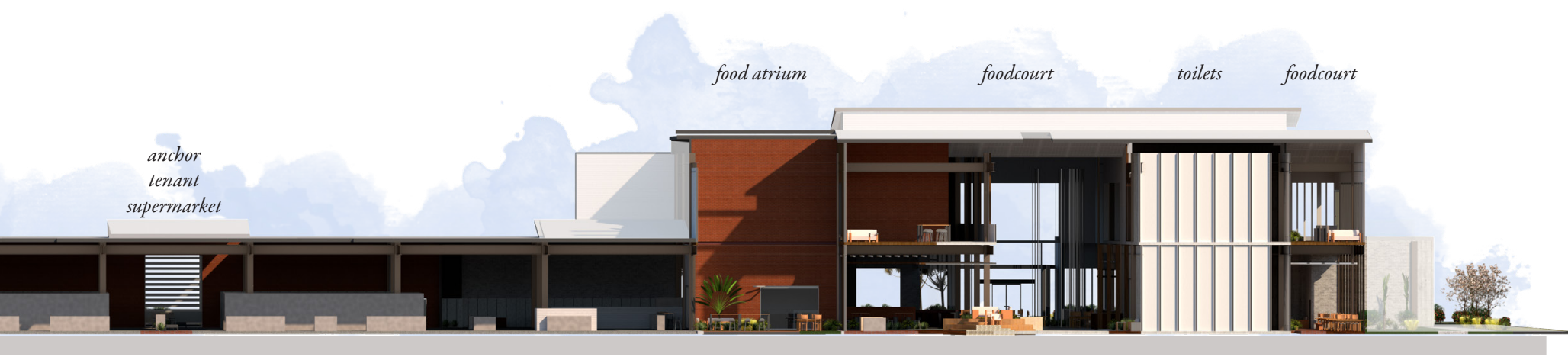

Figure 7.47. Partial section

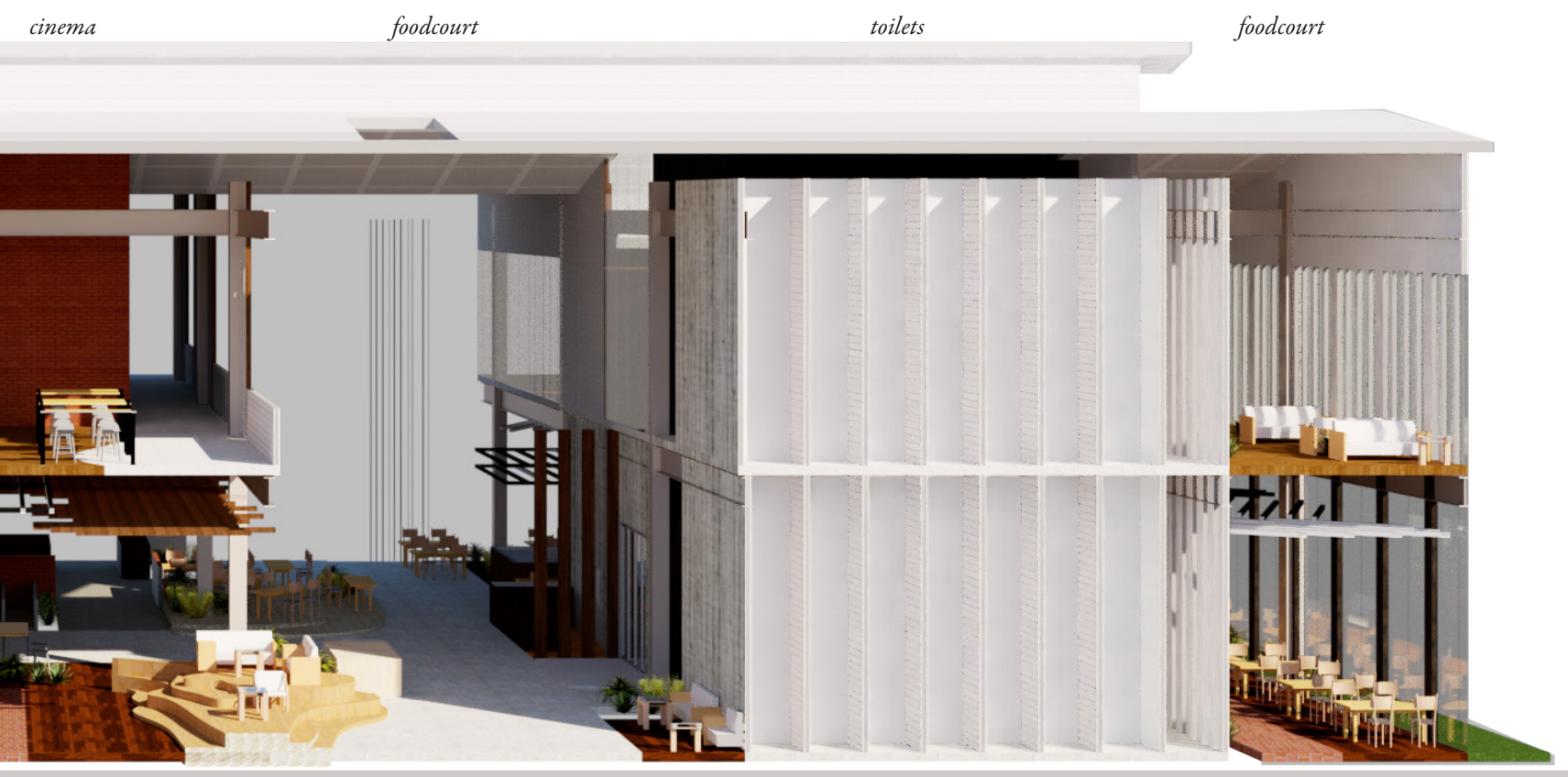

Figure 7.48. Partial section 

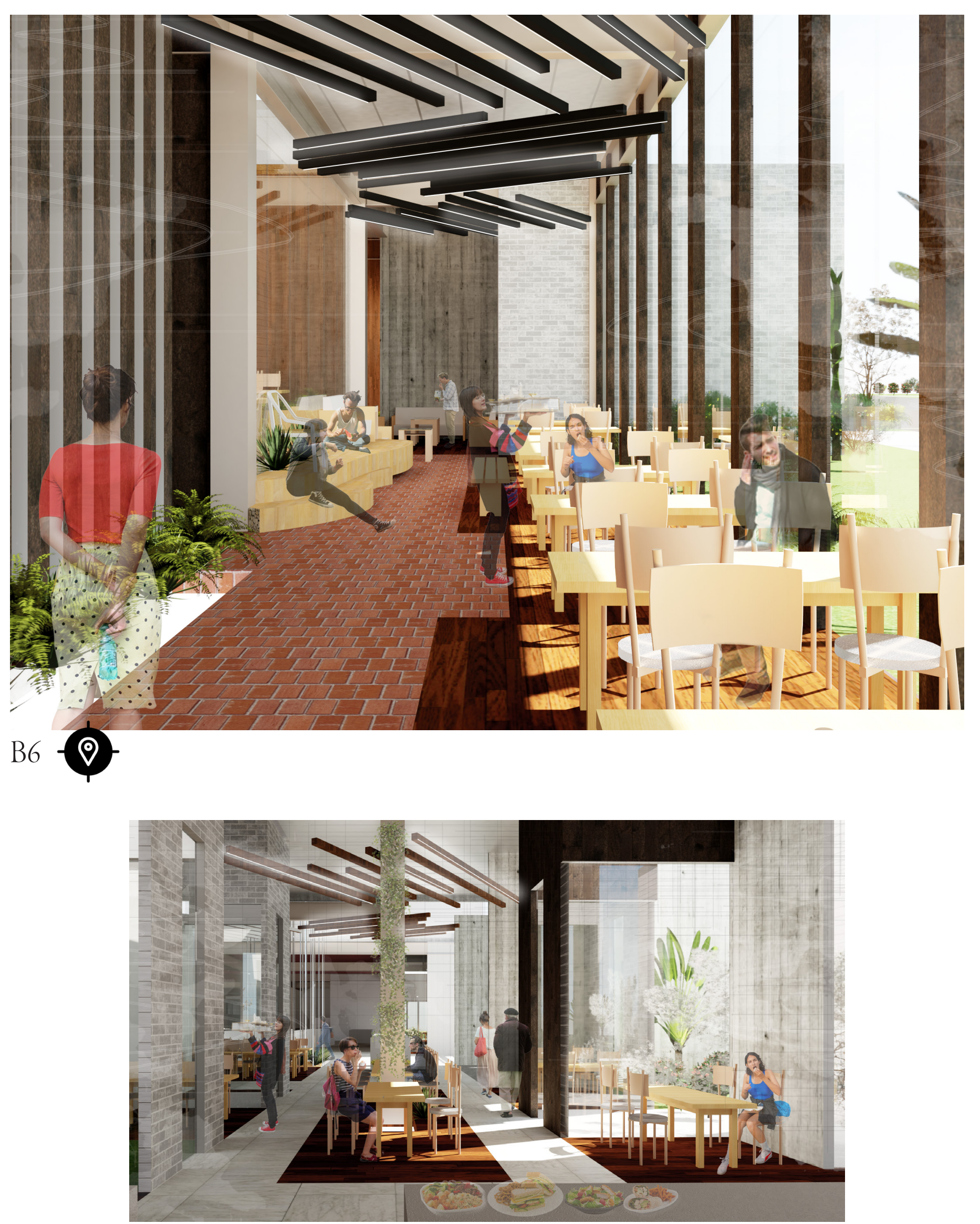

${ }^{B}$.

Figures 7.49-7.51. Food court spaces. 

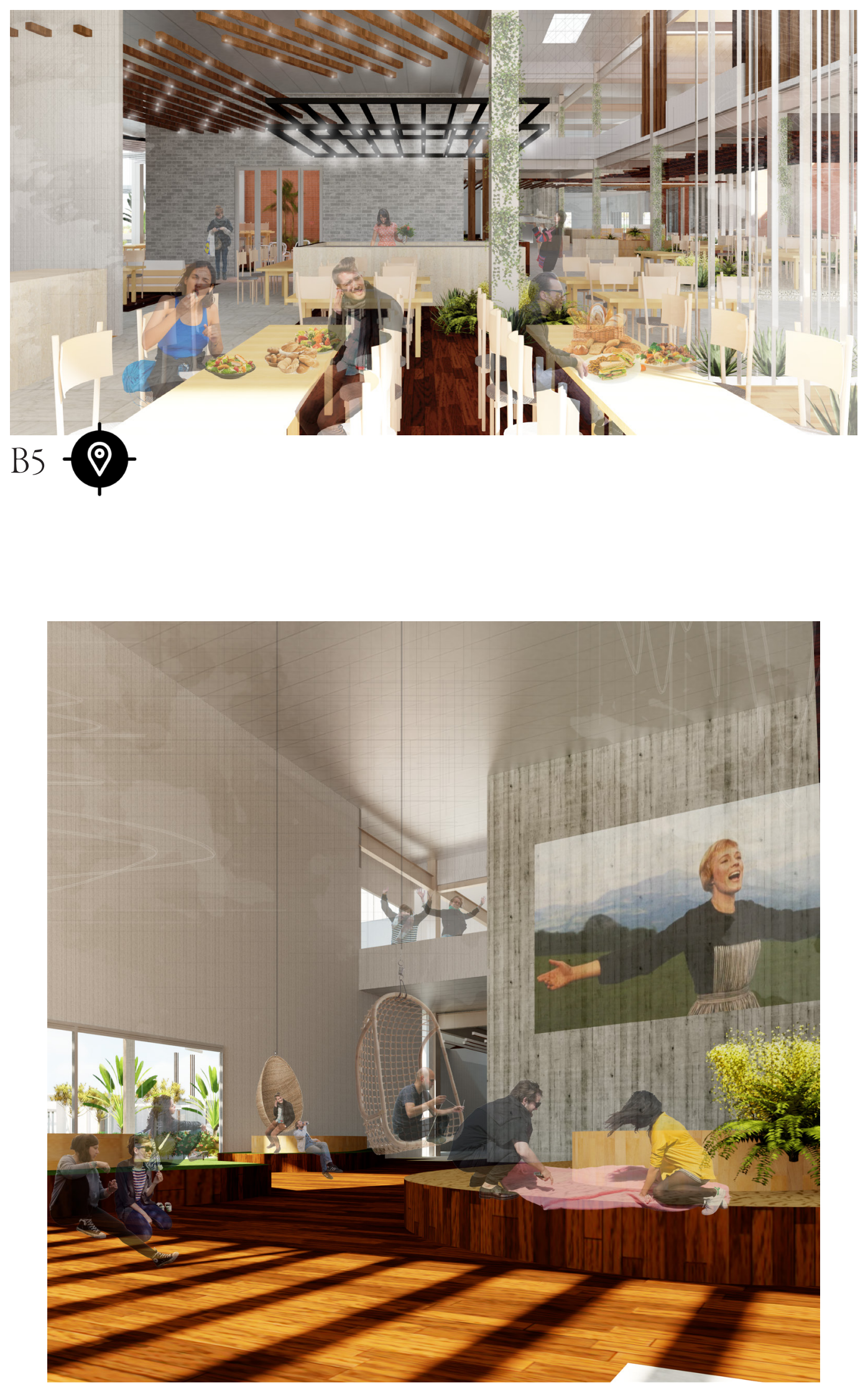

B8 $(2)$

Figure 7.52. Hybrid social-free cinema space. 


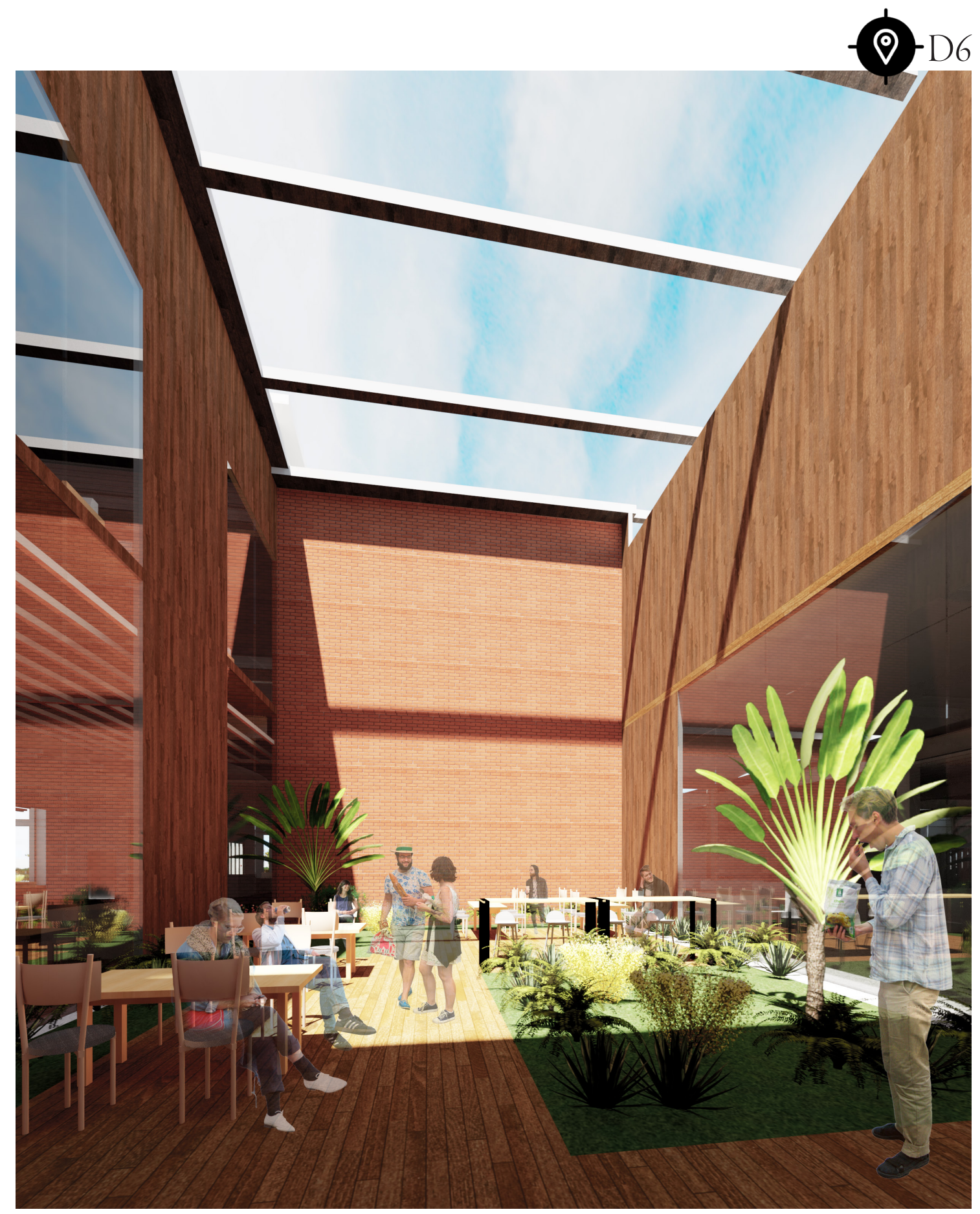

Food Atrium

Reflecting the area's historical significance for exchanging and gathering food and resources, while simultaneously providing spaces for trade and resting. Embedding the theme of verticality from the structures utilised in these food exchanges evident as the exterior doublestorey atriums. These atriums are embedded deep into the building plan as a development of skylights to bring lightness to the vast complex, by bringing daylight to the interior. 


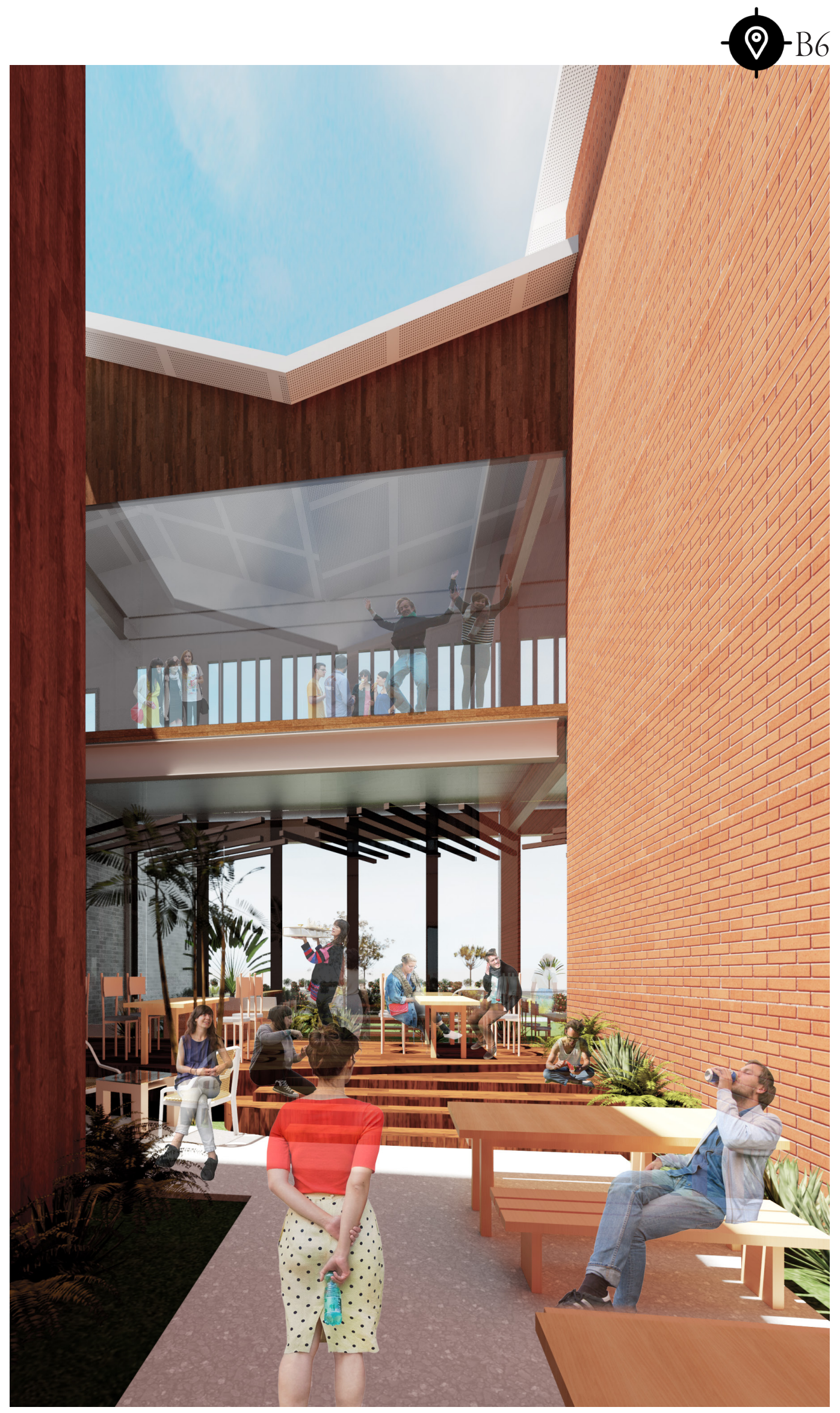

Figures $7.53 \& 7.54$. Outdoor food court atriums. 


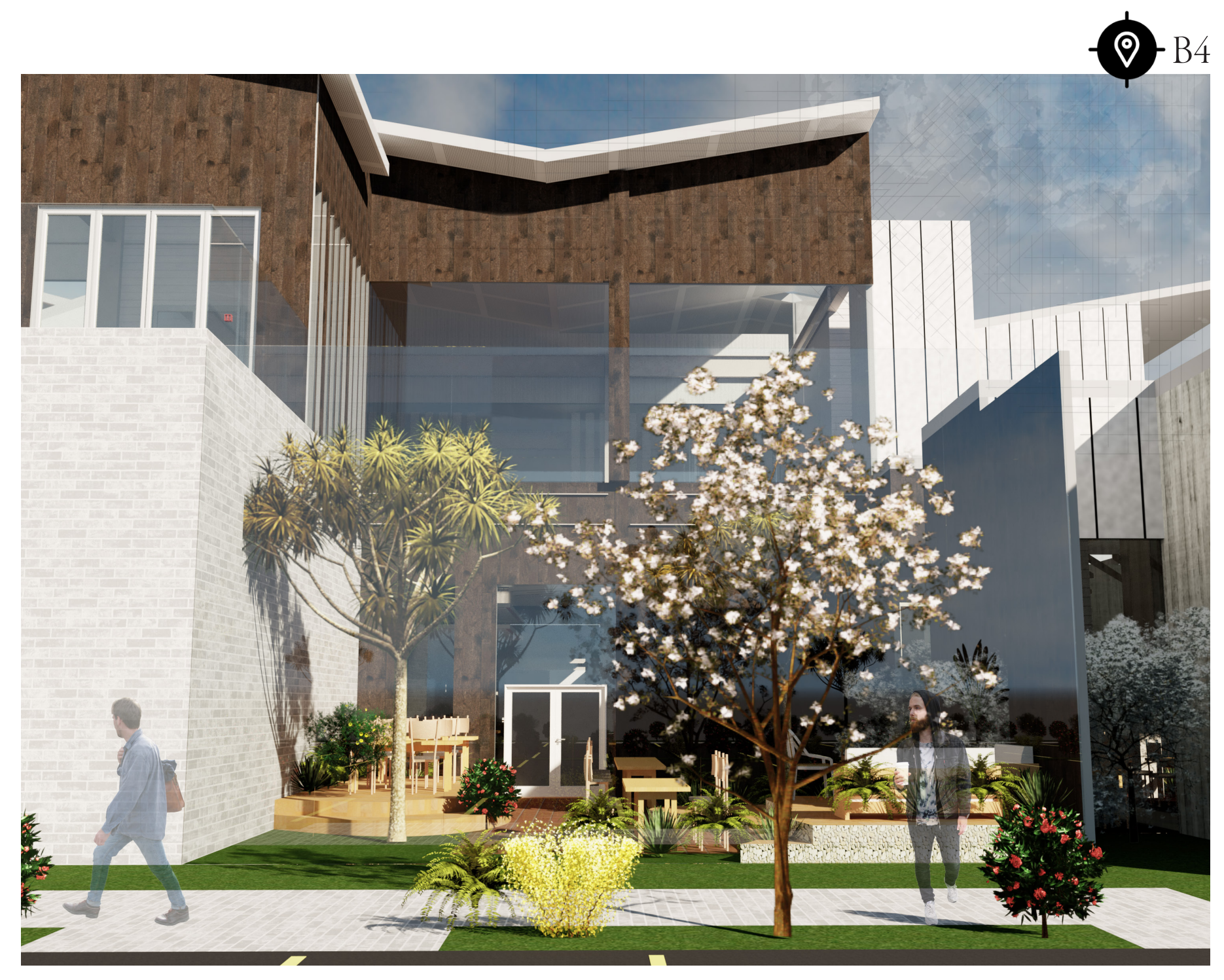

- Offer experiences of air, light and landscape; echoing the sophistication and atmospheric vibrancy of al fresco

- allow light to penetrate deep into the mall, to provide more natural experiences within the shopping mall buildings

- $\quad$ These are implemented to ensure that shoppers do not feel imprisoned and overwhelmed by the monumental scale of Eastgate. A food atrium can be seen from the carpark to equip these spaces with a sense of fading into the surrounding context. 


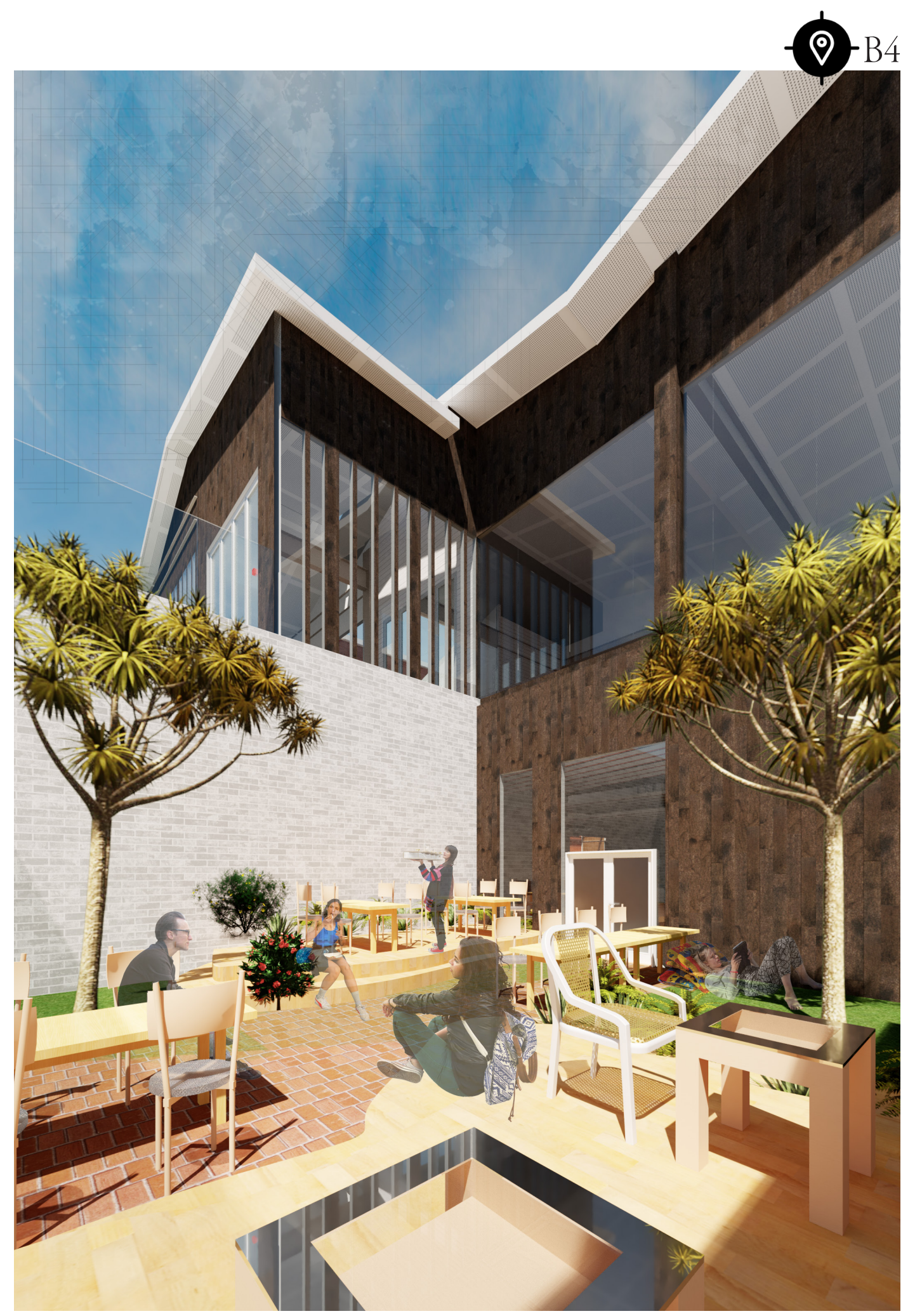

Figures 7.55\&7.56. Outdoor food court atriums. 
anchor tenant-
OUTDOOR displays

(exterior)

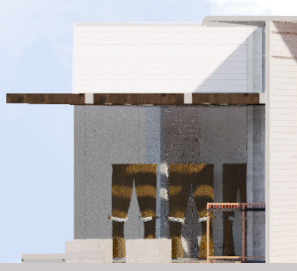

$1: 200$ anchor tenant-i.e.

the warehouse

walk-in-

storage

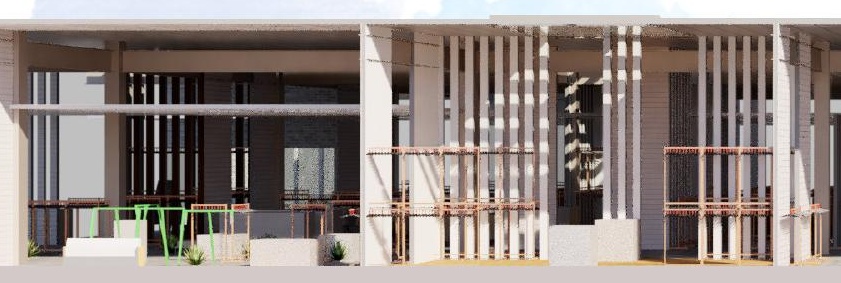

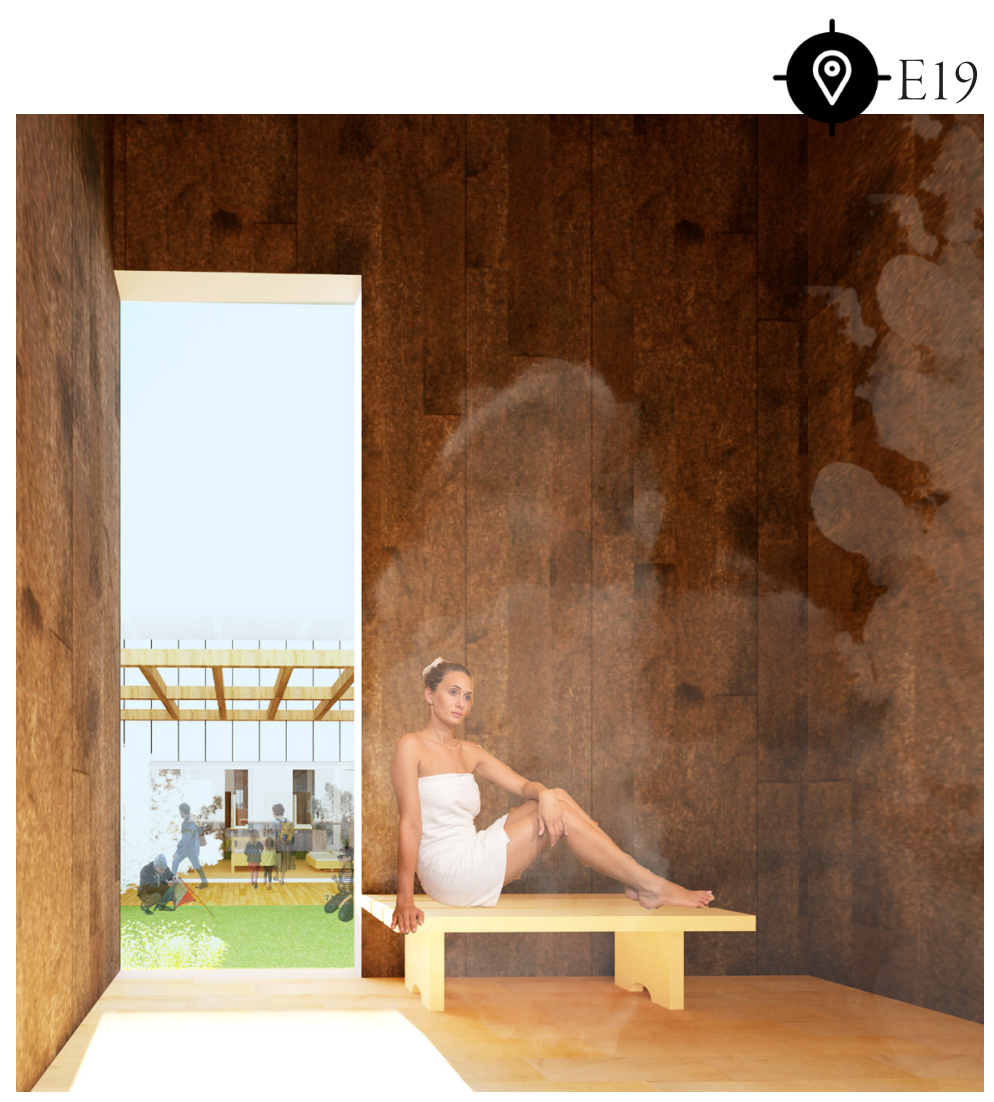




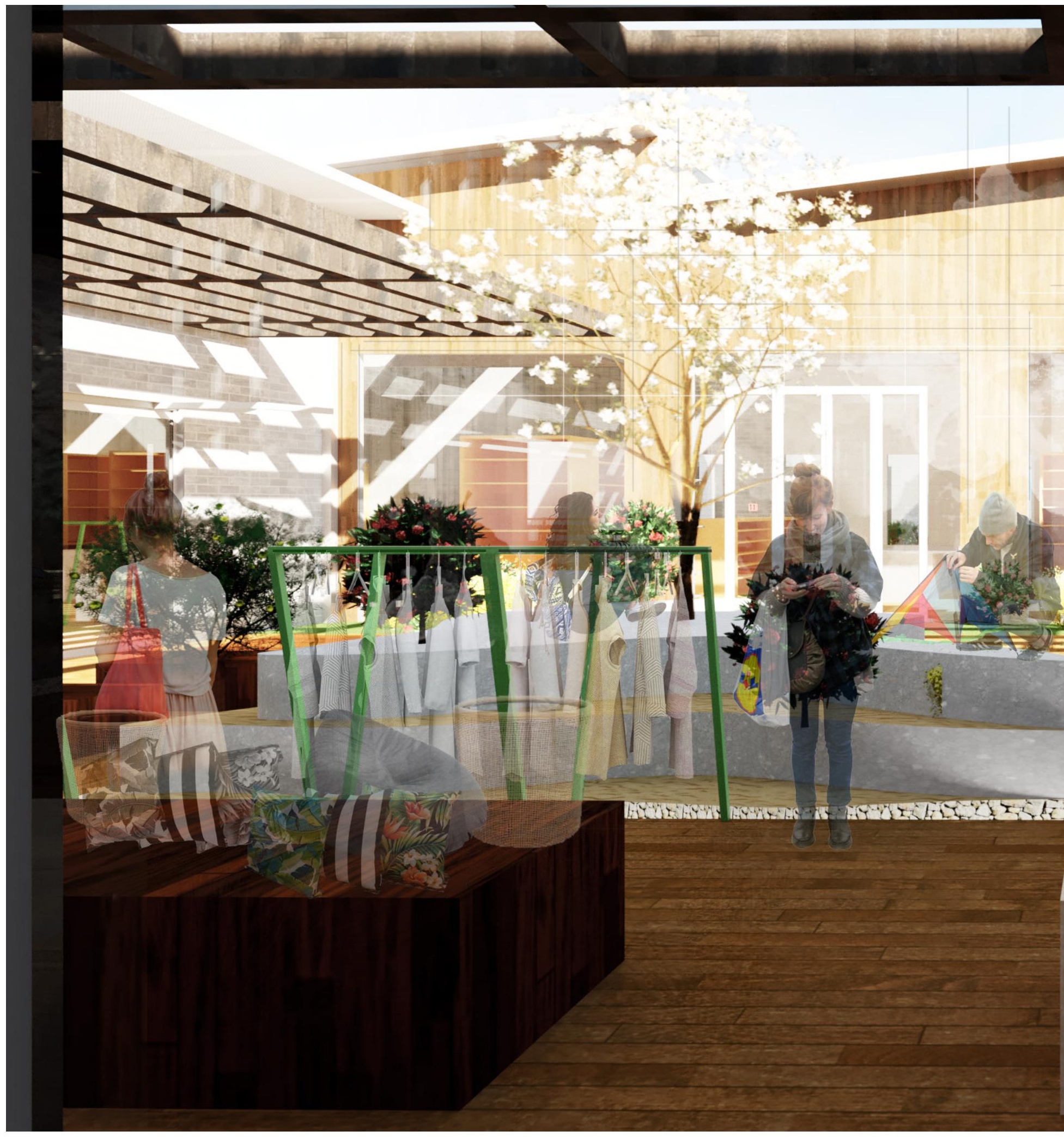

\section{Outdoor Anchor Spaces}

Outdoor spaces are embedded in anchor stores to display products in an external but sheltered environment. This is potentially a way for retailers and their products to test out the integrity of select products (suitable for outdoors) in exterior environments and could increase the legitimacy of retailers/brands leading to more sales. 


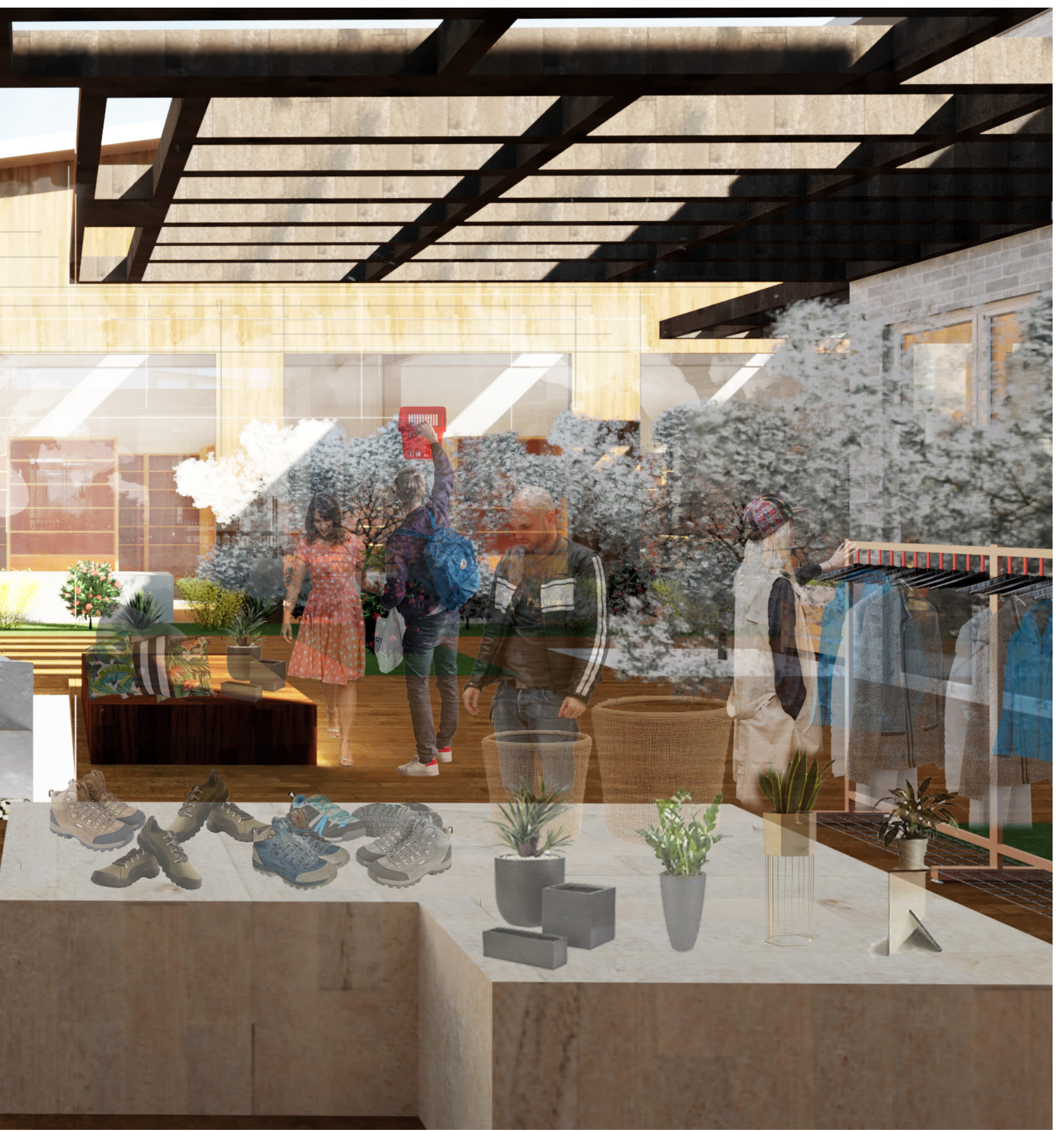

- I20 $\begin{aligned} & \text { Figure 7.60. Outdoor anchor spaces to } \\ & \text { display outdoor products. }\end{aligned}$ 


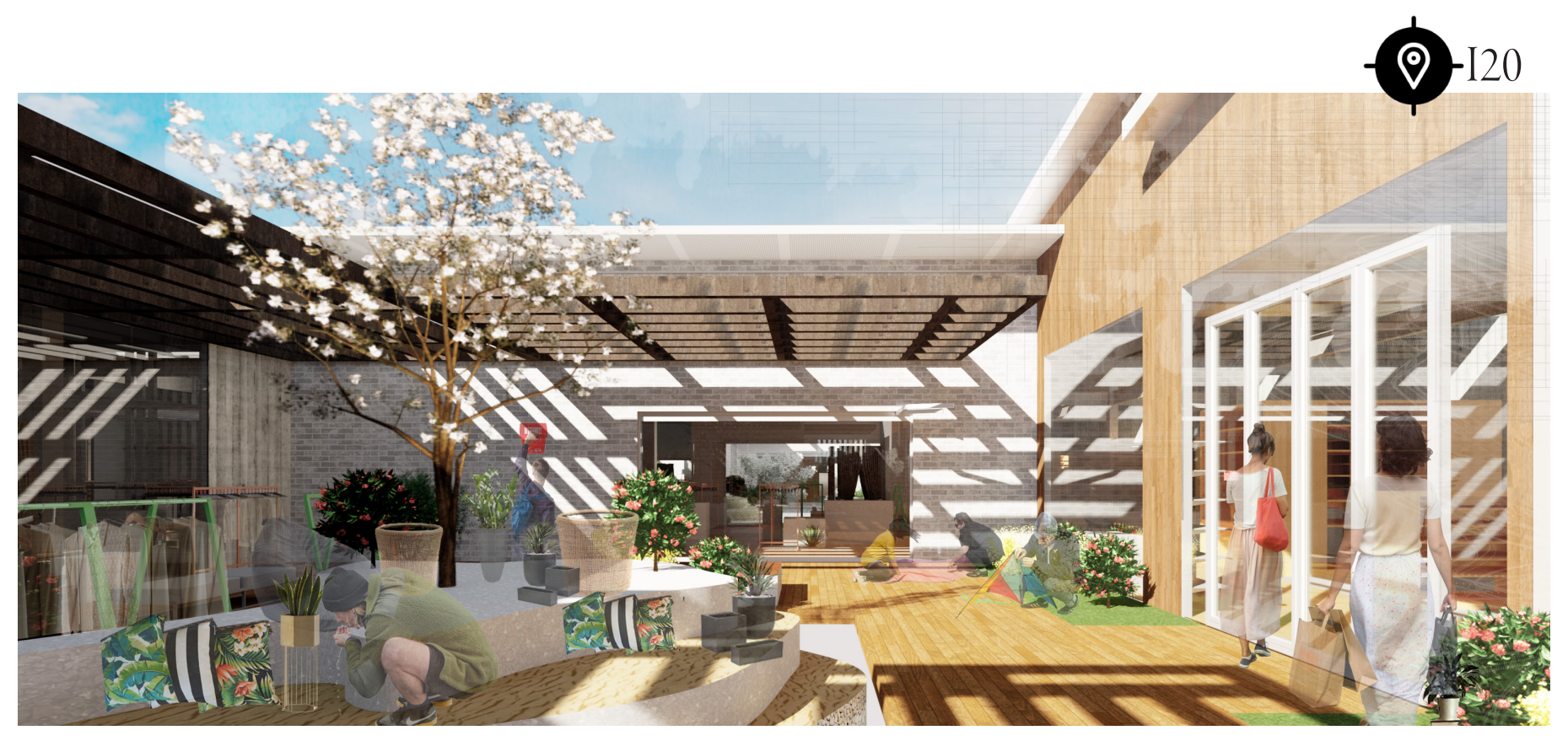

Figure 7.61. Outdoor anchor spaces to display outdoor products.

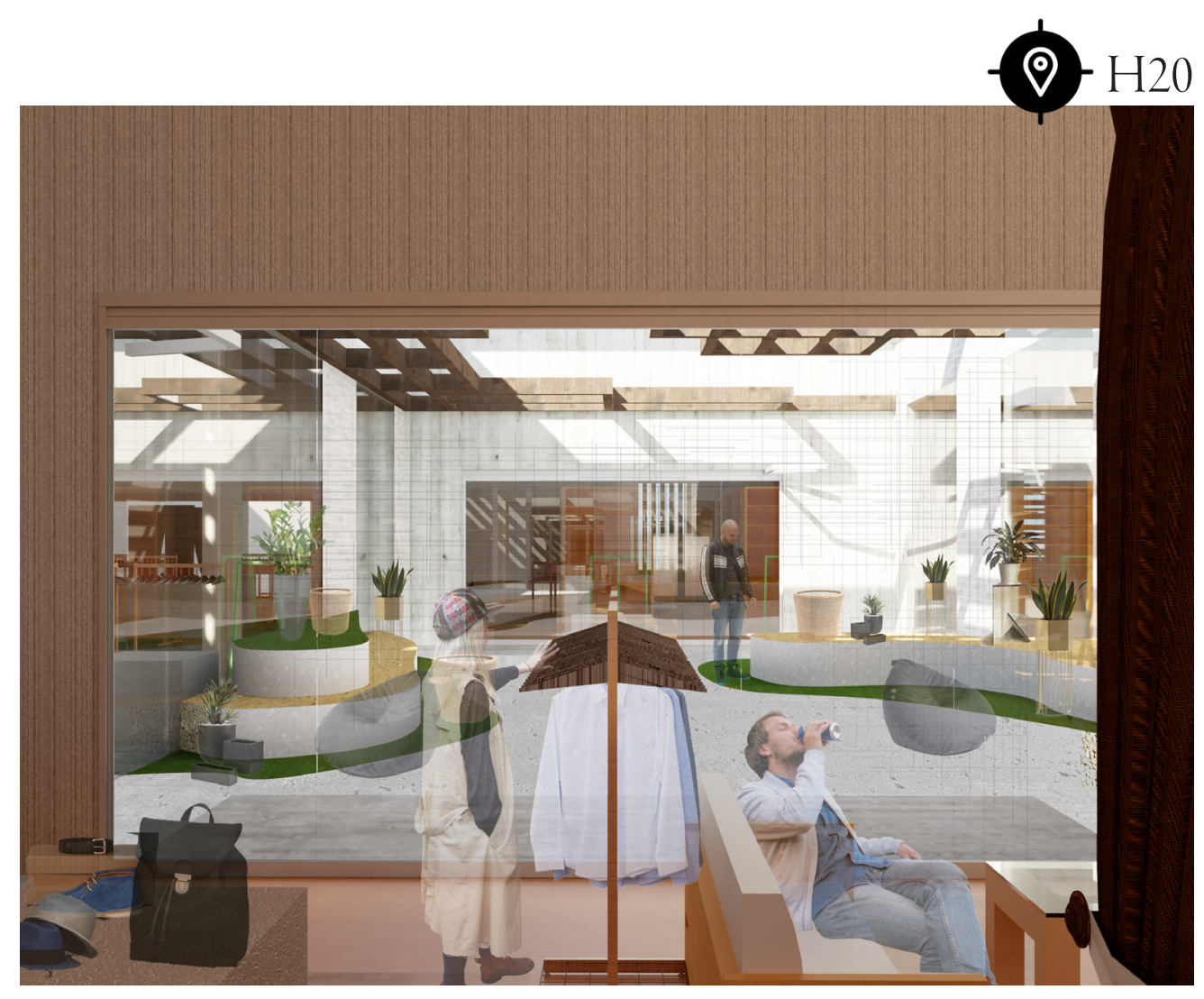

Figure 7.62. Overlooking outdoor anchor spaces from inside. 


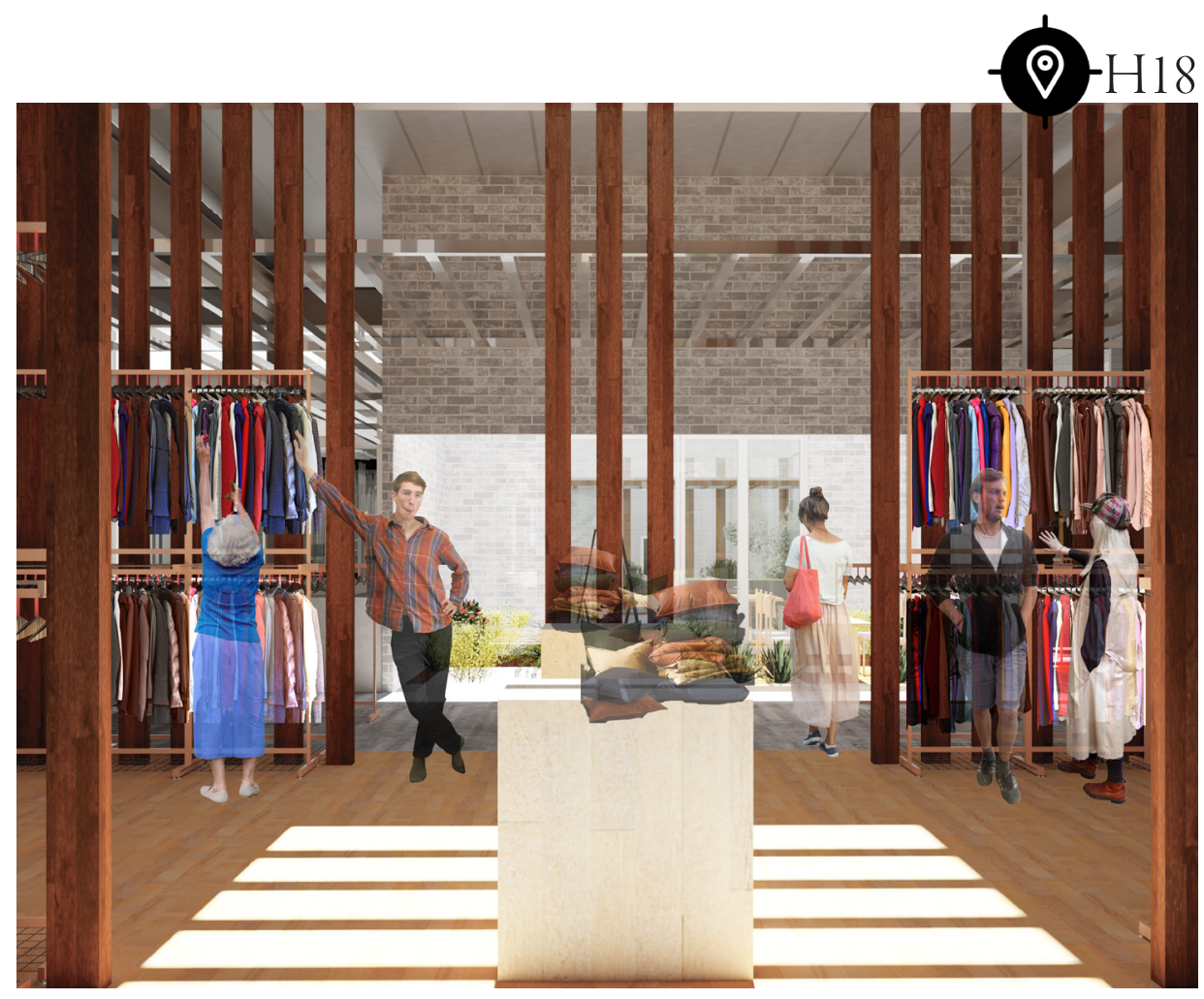

Figure 7.63\&7.64. Walk-in storage

concept.

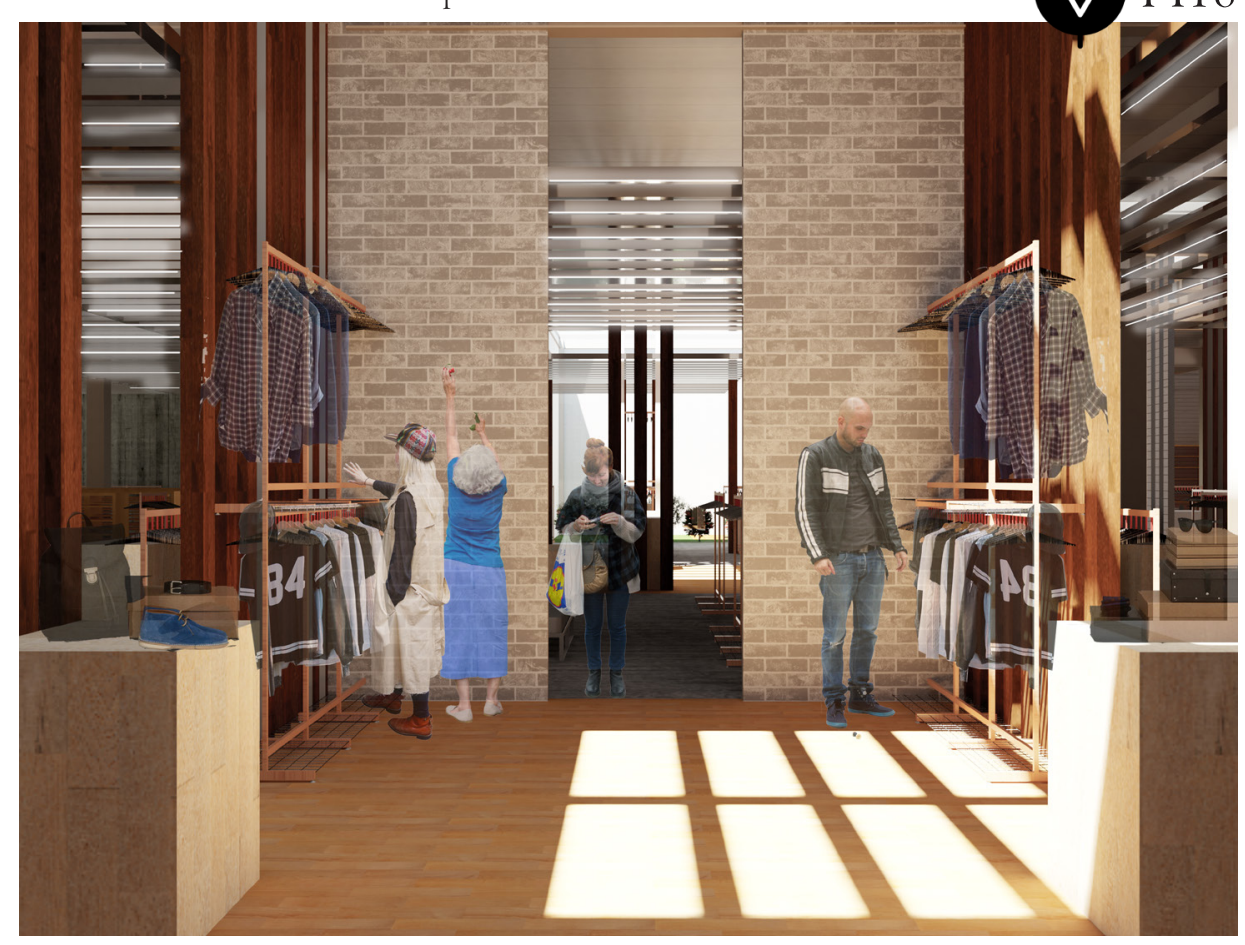

\section{Walk in Storage}

Located within the anchor to break down or blur the notion of storage rooms that can only be exclusively accessed by retail staff. This to break down traditions requiring retail staff to have to man storage spaces and instead make it accessible for people and potentially increase engagement between retail staff and customers. 


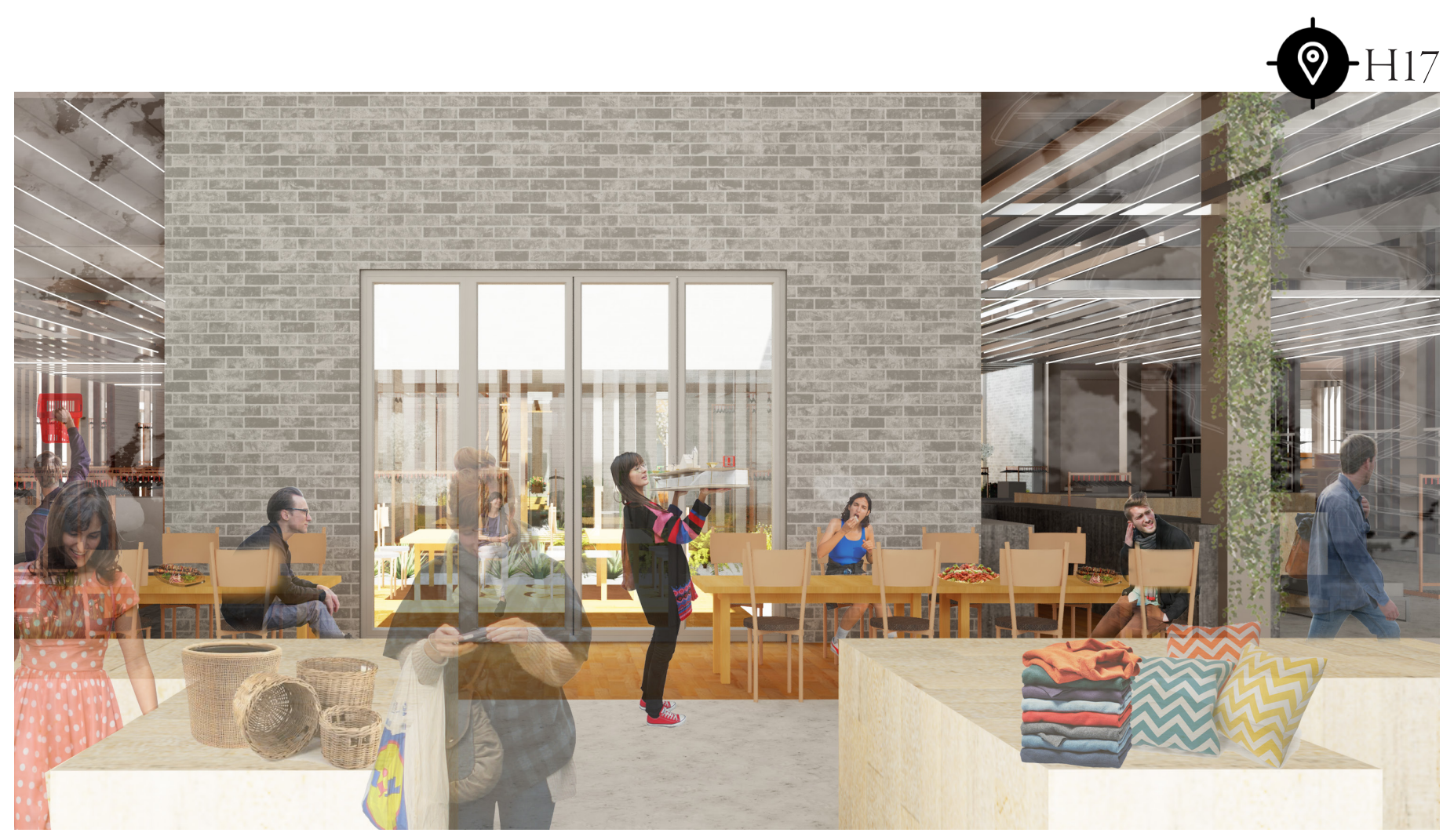

Figure 7.65. Café within anchor tenant.

\section{Hospitality within tenants (of different sizes)}

Examples:

- $\quad$ Café inside anchor retailers

- $\quad$ Bar inside supermarket

Implemented to:

- Intertwine different functions- retail/shopping with lifestyle/relaxation, hospitality with fashion

- Enhance social spaces to interrupt or counteract the intensity people experience when shopping; provide a space to recharge their bodies while engaging with a vast space.

- Café also offers outdoor space to allow light to penetrate deep into the vast space.

- Increase convenience of certain retailers as one-stop places, potentially increasing frequency of visits, sales or purchases.

- Stage shopping activities as performances or spectacles for hospitality customers or visitors; one way to enable potential consumers to contemplate products 


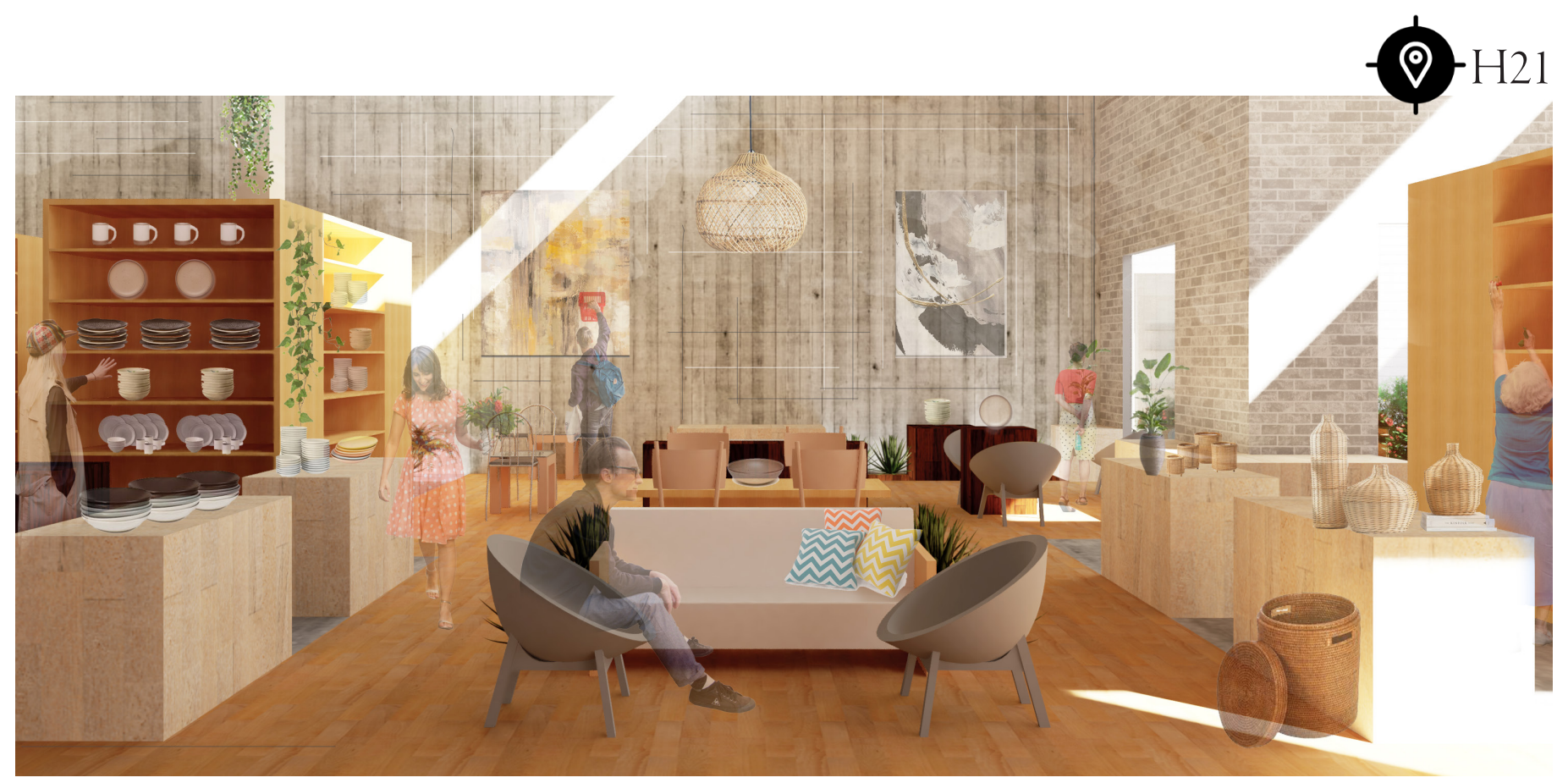

Figure 7.66. Showroom/"customise your own spaces" to see how products fit into desired context (i.e. living/ kitchen).

\section{Showroom within Retailers}

i.e. showroom kitchen within The Warehouse'

- Exhibit products in realistic contexts or environments to depict how products could be consumed or used to provide some hierarchy and logic- i.e. towels in a display kitchen

- $\quad$ Provide a platform to experience and assess products; help bring customers and potential consumers closer to the products leading to purchases

- can potentially promote collaboration between brands and stockists/retailers

- $\quad$ increase legitimacy of brands and retailer; support their identities

This can provide potential spaces for collaboration between different retailers who could pop up within larger retailers. For example Mitre 10 pop-ups within the Warehouse. 
Hairdresser, Salon \& spa within anchor retailer

Linked to anchor retailer, to exploit and attract footfall from anchors

- Small retailers can demonstrate their services to customers in anchor spaces

- Small retailers can display their products in anchor spaces at close proximity to their own spaces

- Breaking down walls in anchors; a way for to the anchors to support viability of small retailers.

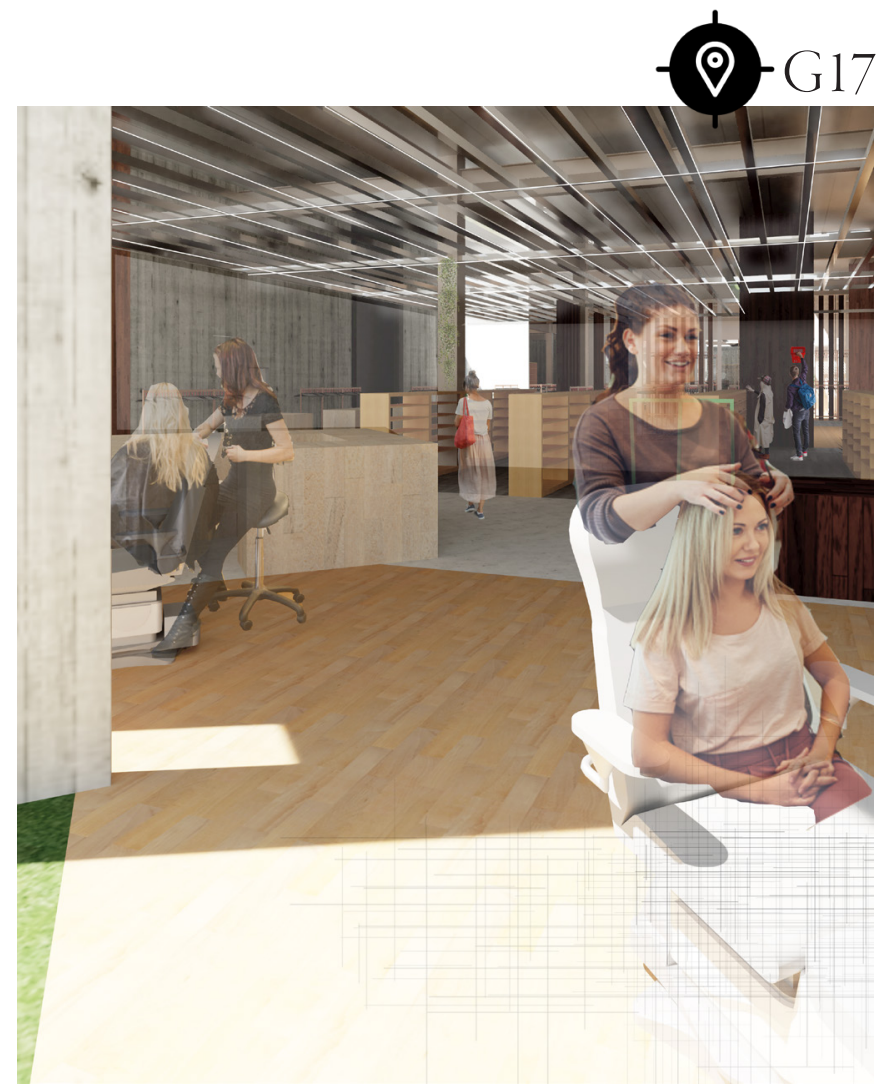

Figure 7.67. Hairdresser within anchor tenant.

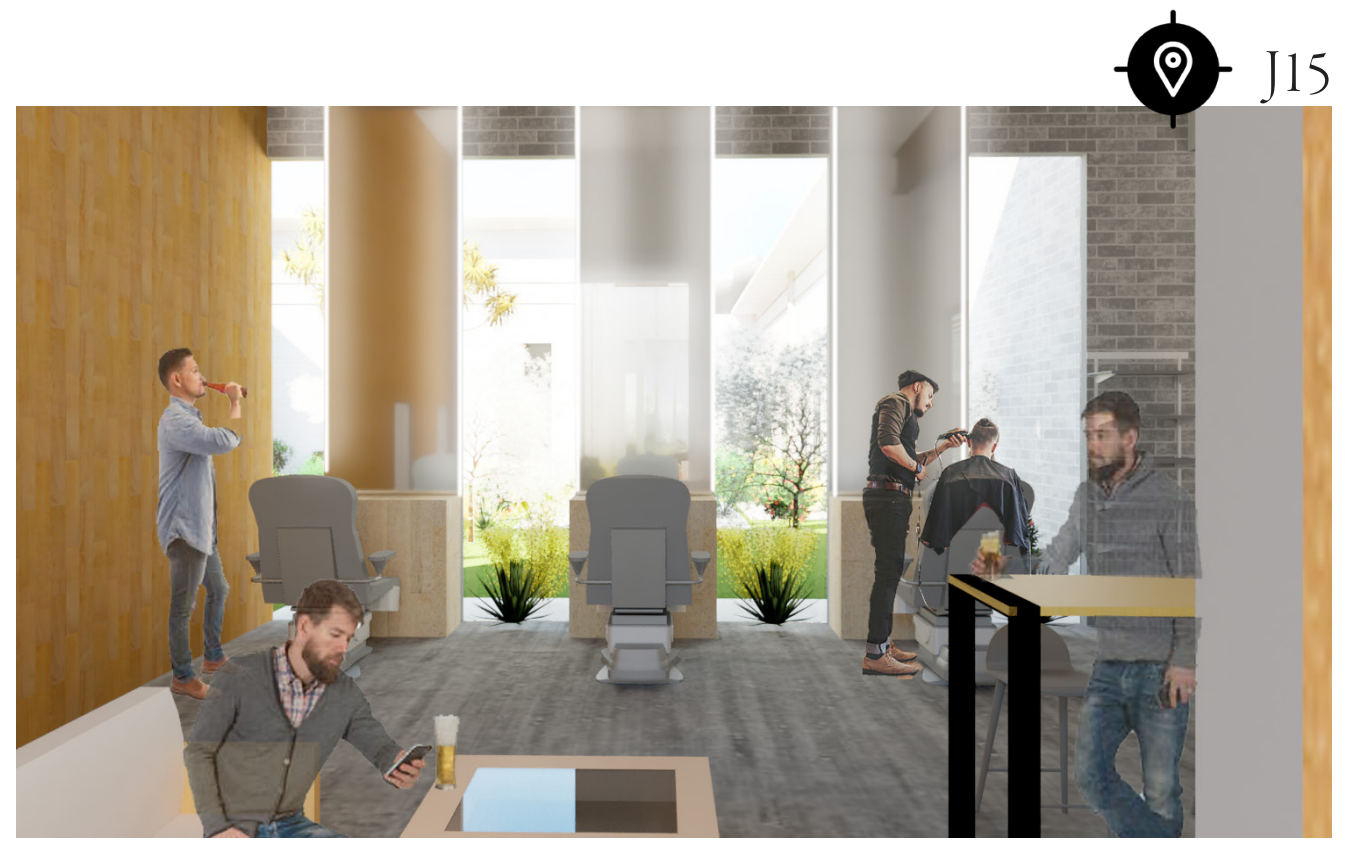

Figure 7.68. Barber-Pub hybrid.

\section{Barber + Pub}

Increase convenience and entertainment while waiting. A way to keep mall spaces dynamic. 


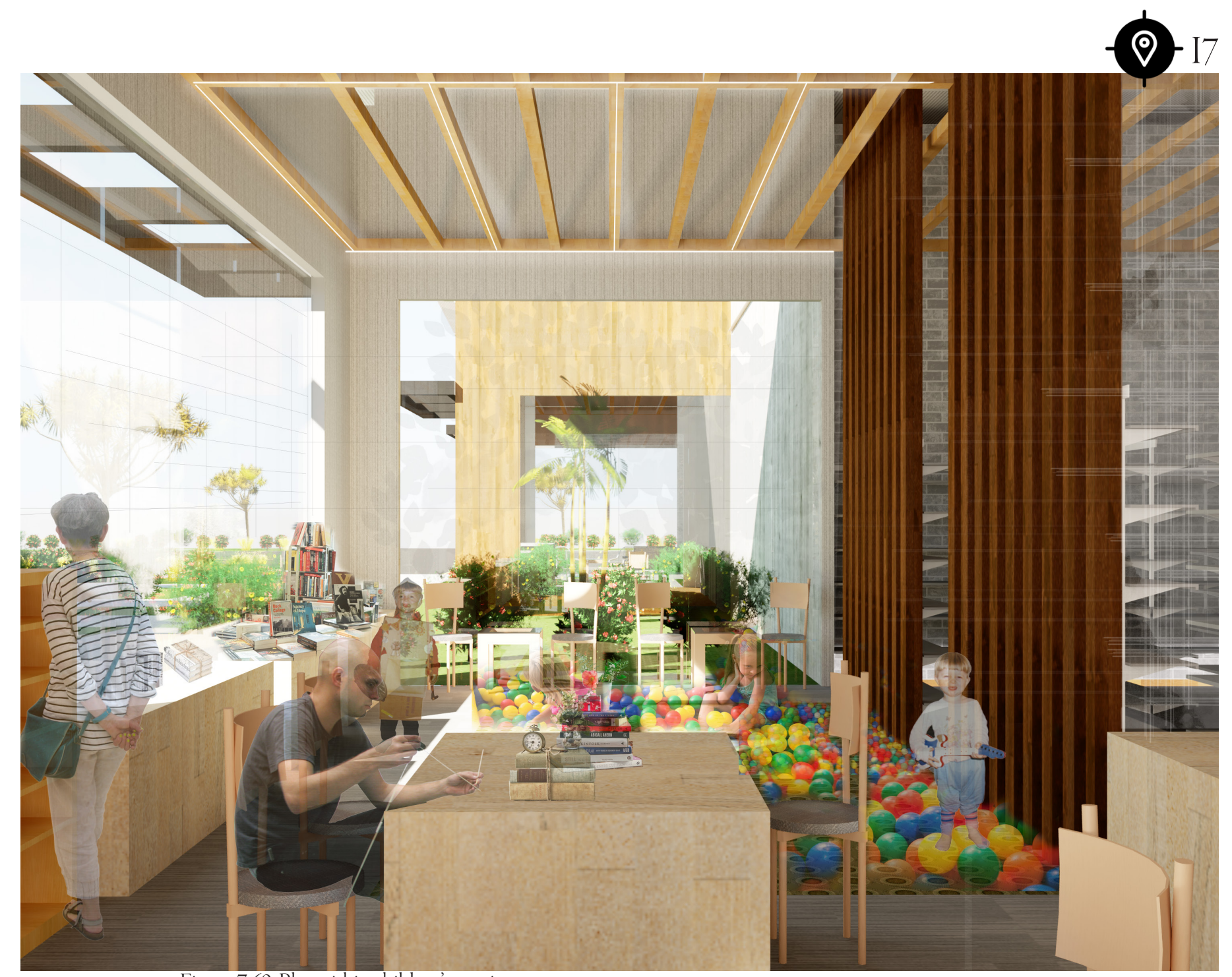

Figure 7.69. Play within children's area in stores.

\section{Play within Retailers}

i.e. inside Whitcoulls

Ball pit to attract children and utilise play as a way to connect people with products. 


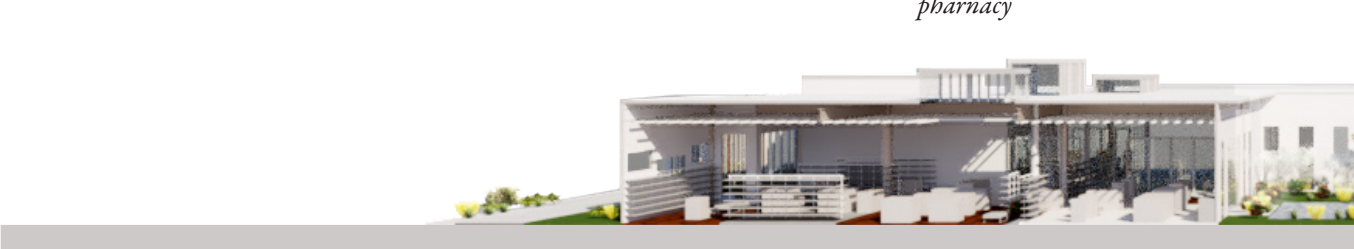

$1: 500$

\section{Pharmacy}

Aims to challenge traditional pharmacy design by eradicating the one-way mode of traditional pharmacy counter services and enhance interaction between pharmacists/retail staff and customers. Large tables are distributed throughout to demonstrate products to customers, enabling these architectural gestures to emphasise listening, interaction and human warmth over products.

Pharmacies are closely placed next to the medical centre due to their compatibility. More importantly, this is to dissociate the mercantile aspect of related medical professions. This would give the medical and wellbeing function of the mall a human side. Consequently, both the medical centre and pharmacies become empathetic places, simple and collective, allowing these facilities to be more accessible and easily seen by patients and people requiring attention and care.

\section{Medical Centre}

Established to strengthen the contribution of the rejuvenated design as a community hub. This is to:

- $\quad$ Provide a clear communal function to Eastgate

- $\quad$ Provide space to learn and discuss the physical aspects of healthy living, mindfulness and living a life of possibility — something Linwood is deprived of, to some extent

- $\quad$ Angled floor plan to provide privacy for patients and clients

- Greenery surrounds each private room (appointments/offices) to create an oasis of tranquillity 
Figure 7.70. Partial section.

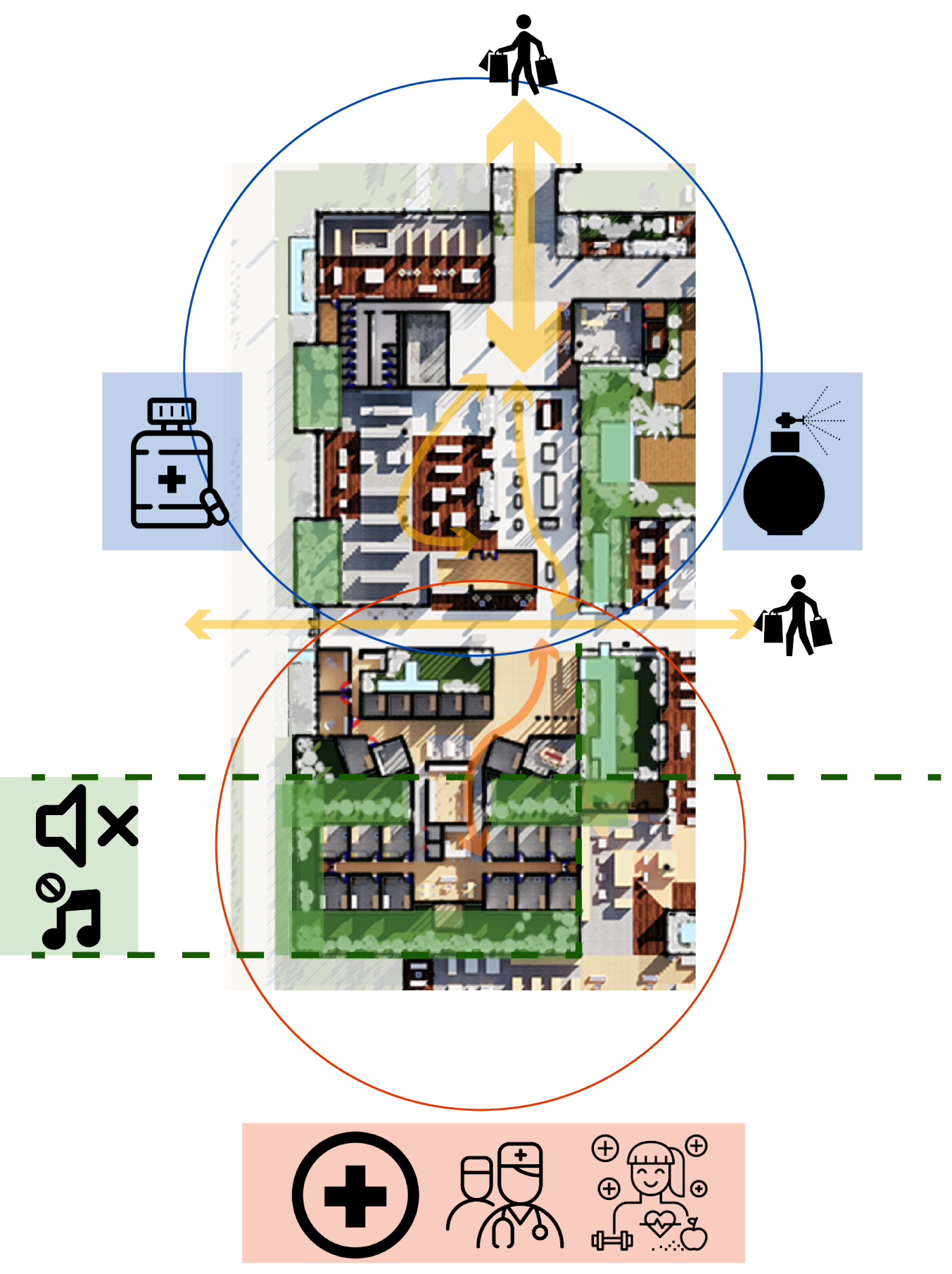

Figure 7.71. Health and medical wing of Eastgate. 


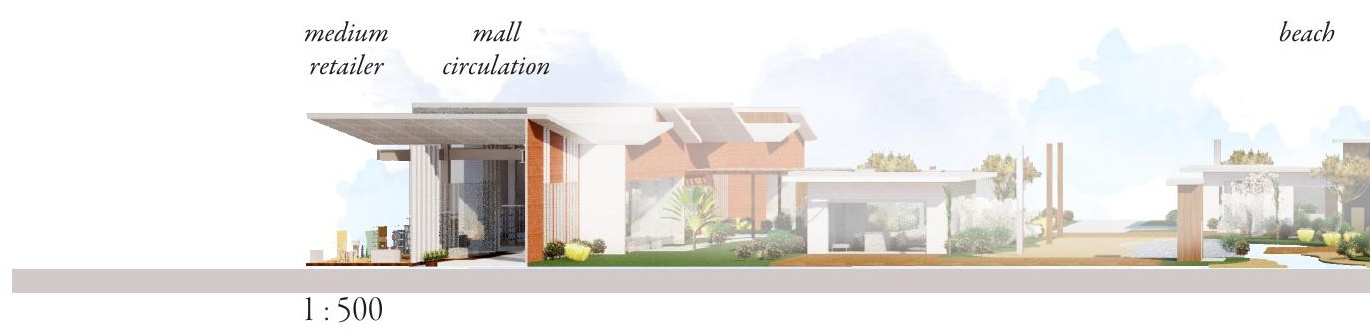

\section{Fashion Hall}

The fashion hall eradicates the idea of zoning through the absence of walls between shops. This is implemented to create an organic feel to enhance customer movement and promote collaboration between fashion retailers. Many walls are absent so retailers and their spaces merge together, to create unity preventing absorption by larger tenants/big-box retailers that would serve as anchors.

This space employs unifying elements to tie different areas together. Significantly, materiality and colour are employed.

- $\quad$ Concrete and timber are heavily used throughout

- $\quad$ Board-formed concrete adds texture and visual interest

- Concrete juxtaposed with timber, to highlight texture and contrast between industrial and natural aesthetics

- $\quad$ Timber utilised to promote human scale and sense of warmth

- Louvered ceilings of timber running throughout the space, varied with the use of reflective metal 


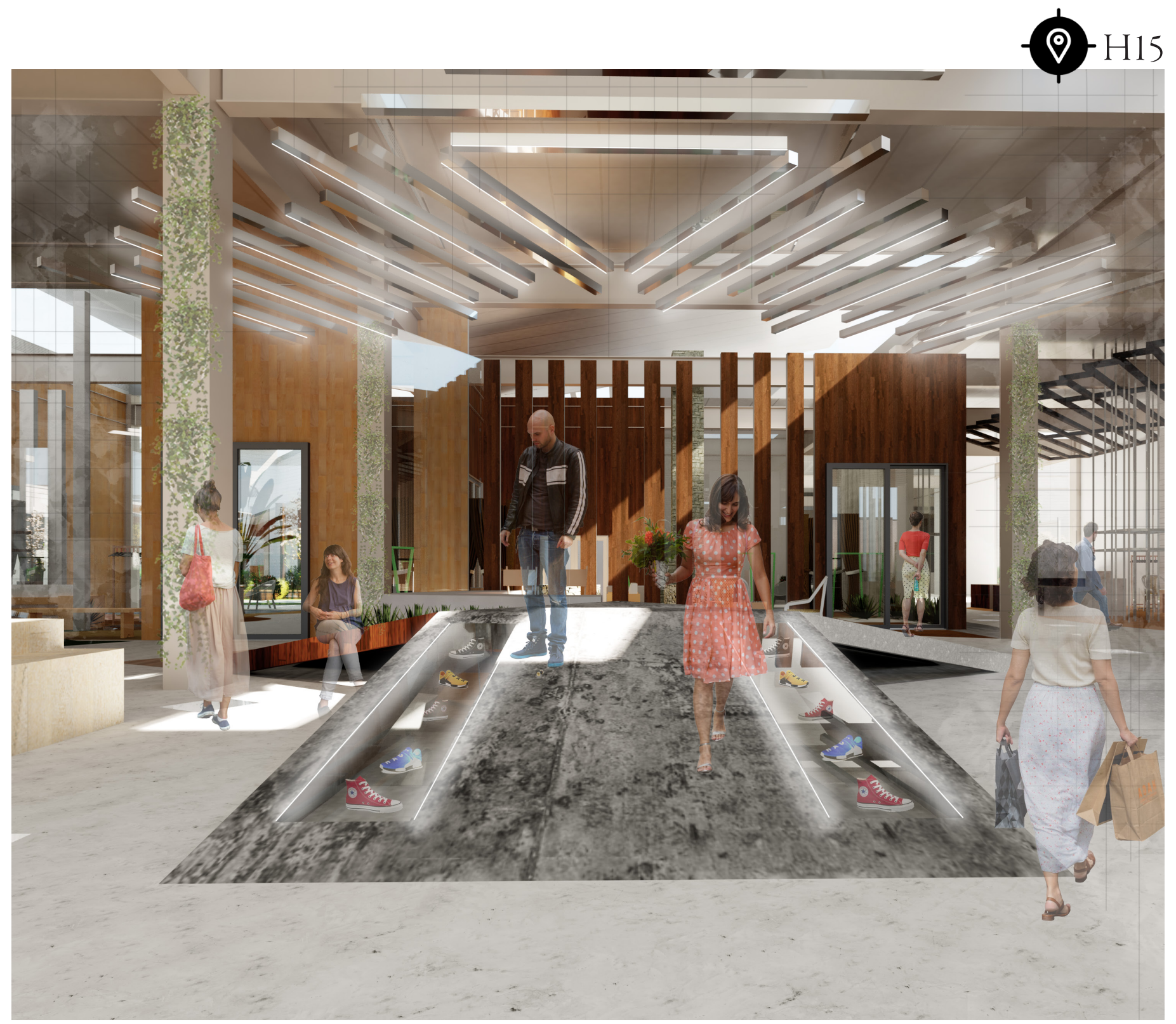

Figure 7.73. Fashion hall shoe ramp. 


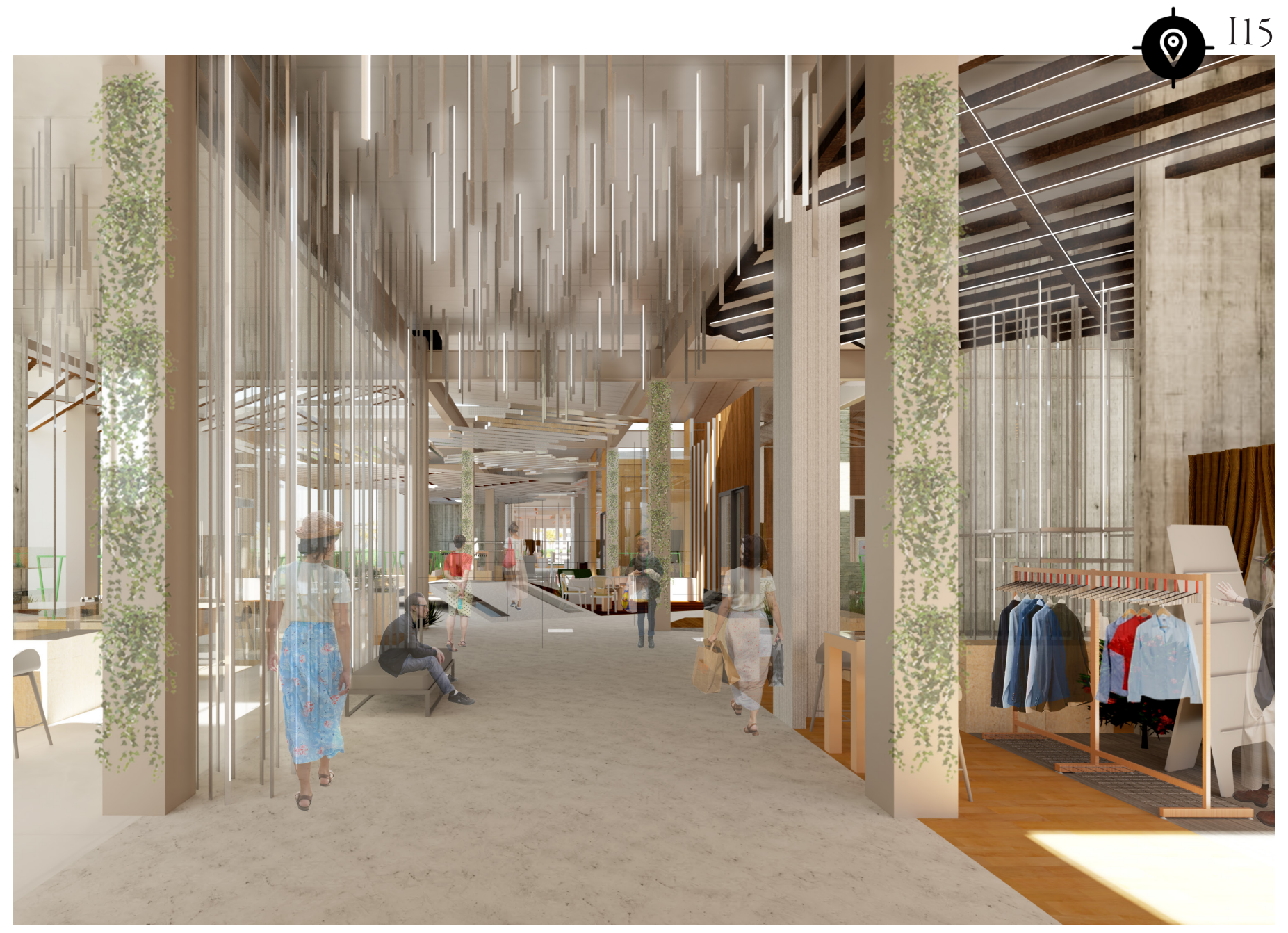

Figure 7.74. Fashion hall main path. 


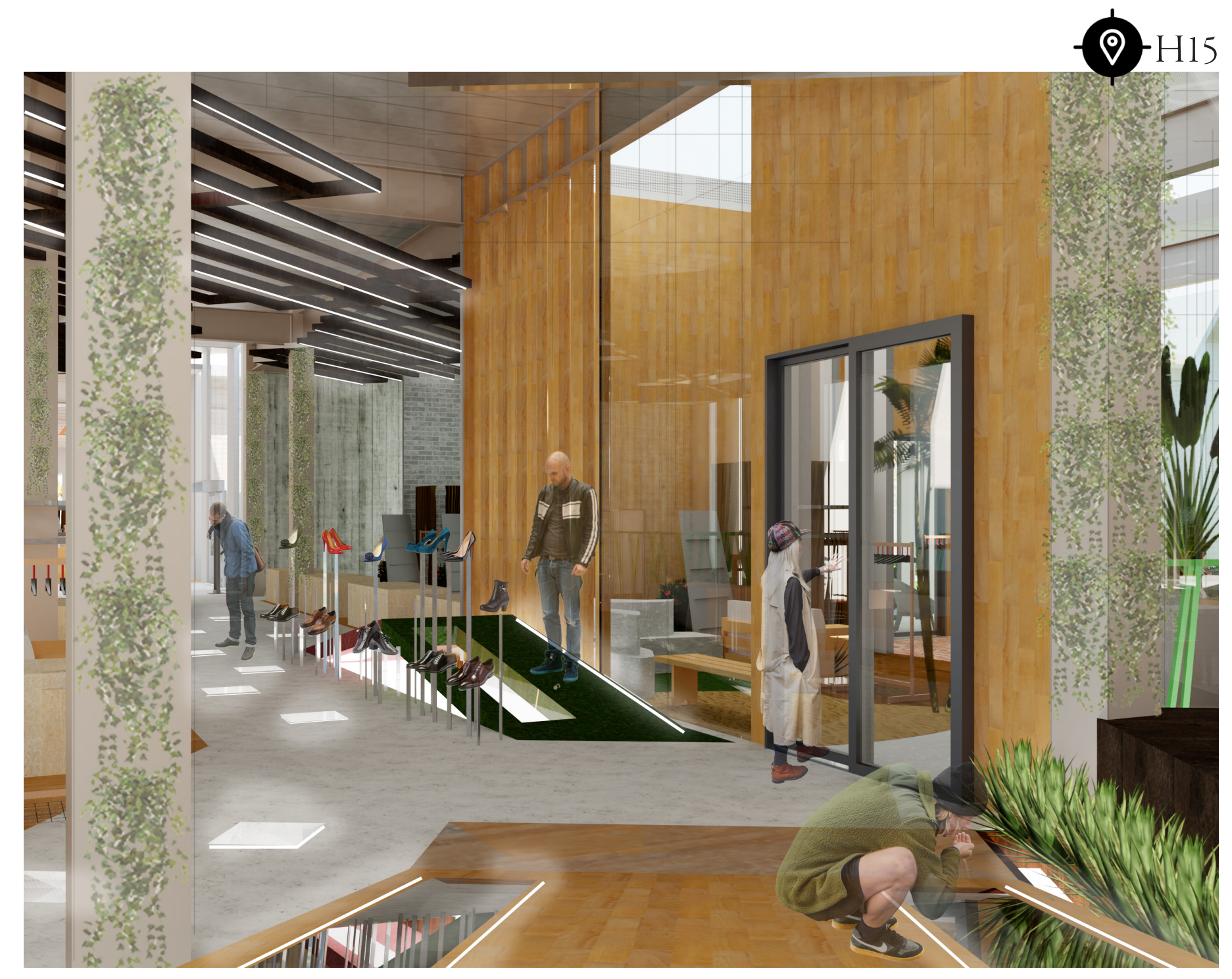

Figure 7.75. More shoe ramps within different materials and surfaces to try shoes in different conditions. 


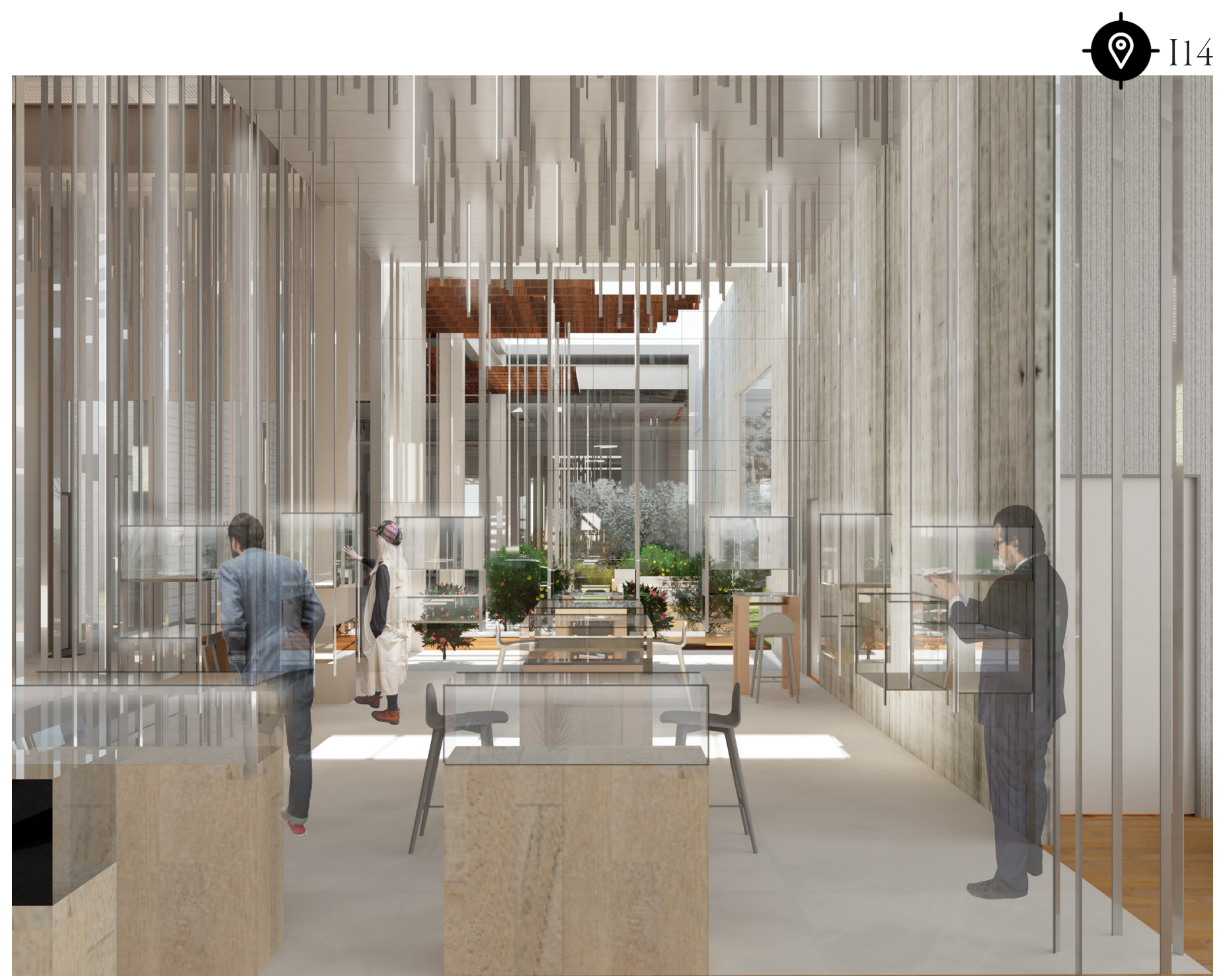

Figure 7.76. Jewellery store overlooking green spaces with shiny surfaces to emphasise luxury experience. 


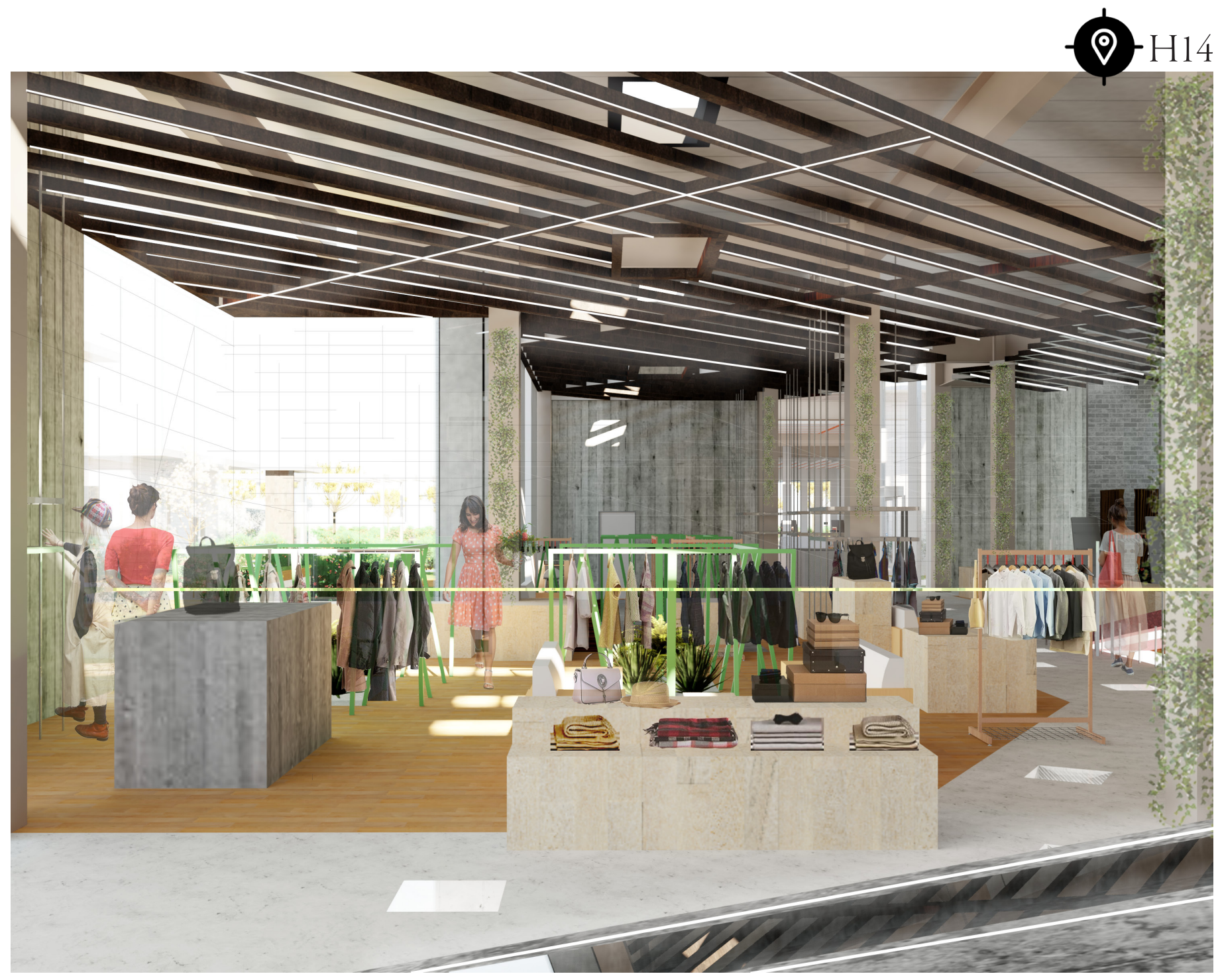

Figure 7.77. Fashion hall spaces. 

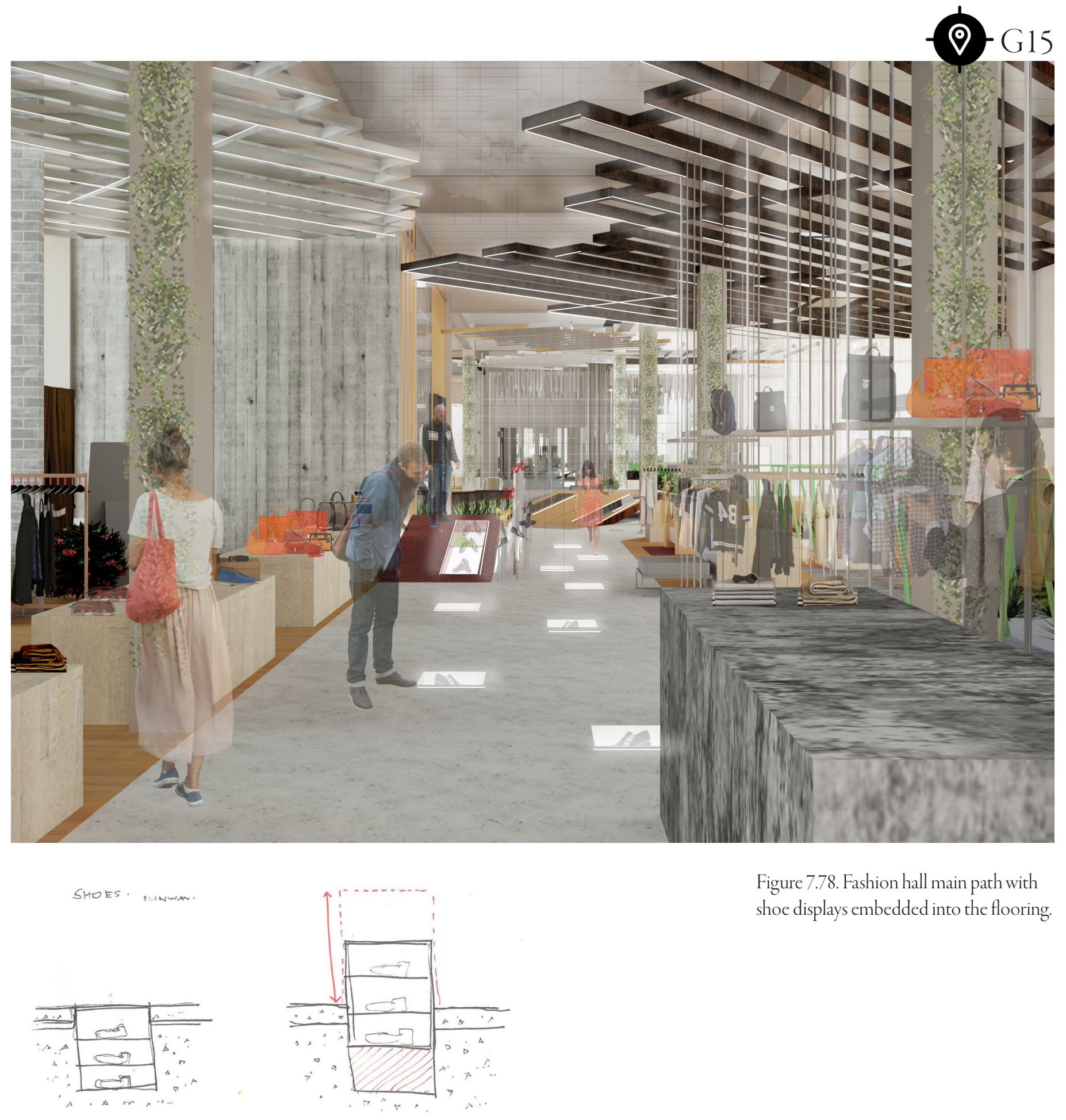

Figure 7.78. Fashion hall main path with shoe displays embedded into the flooring. 


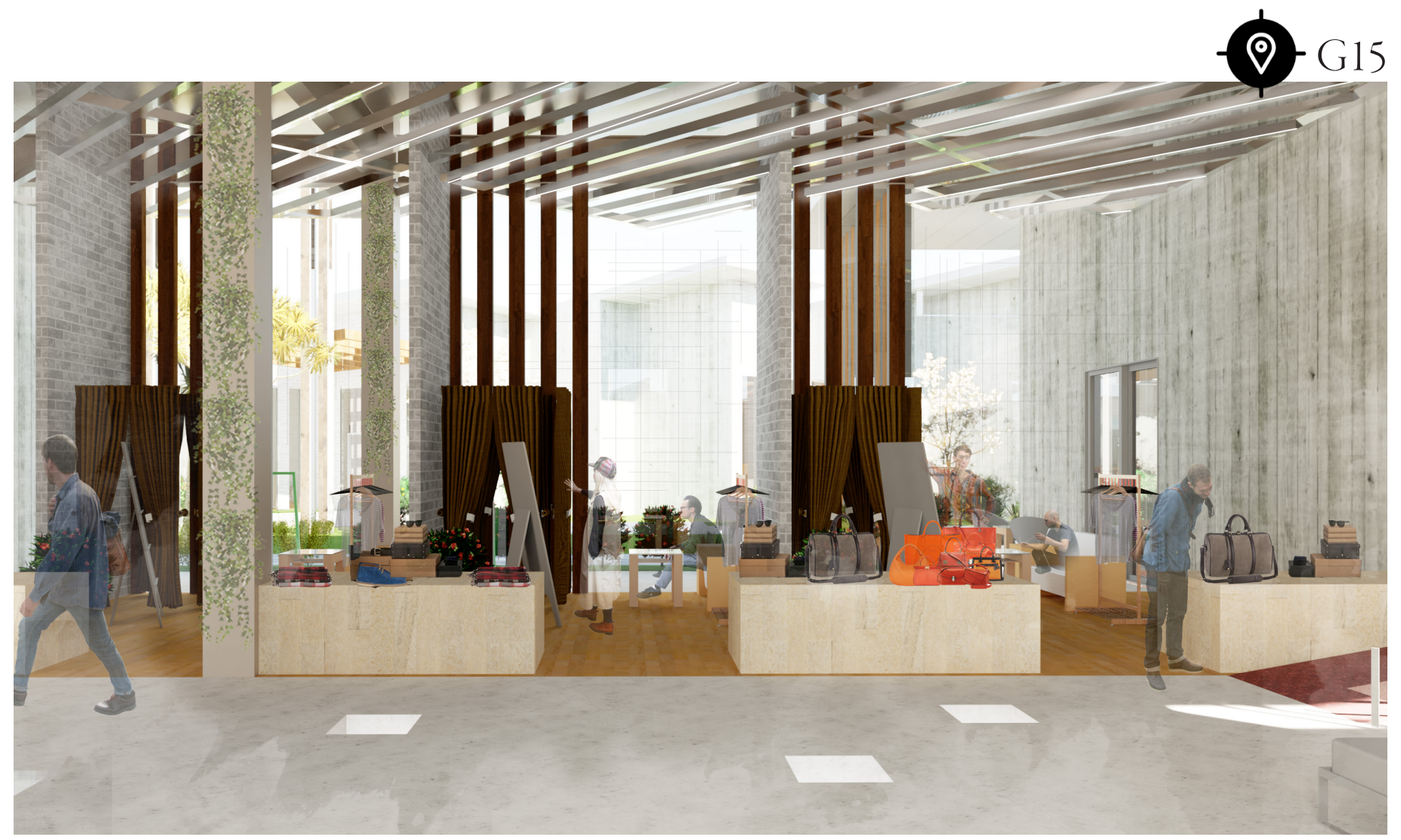

Figure 7.79. Social changing rooms

equipped with couches and small tables. 


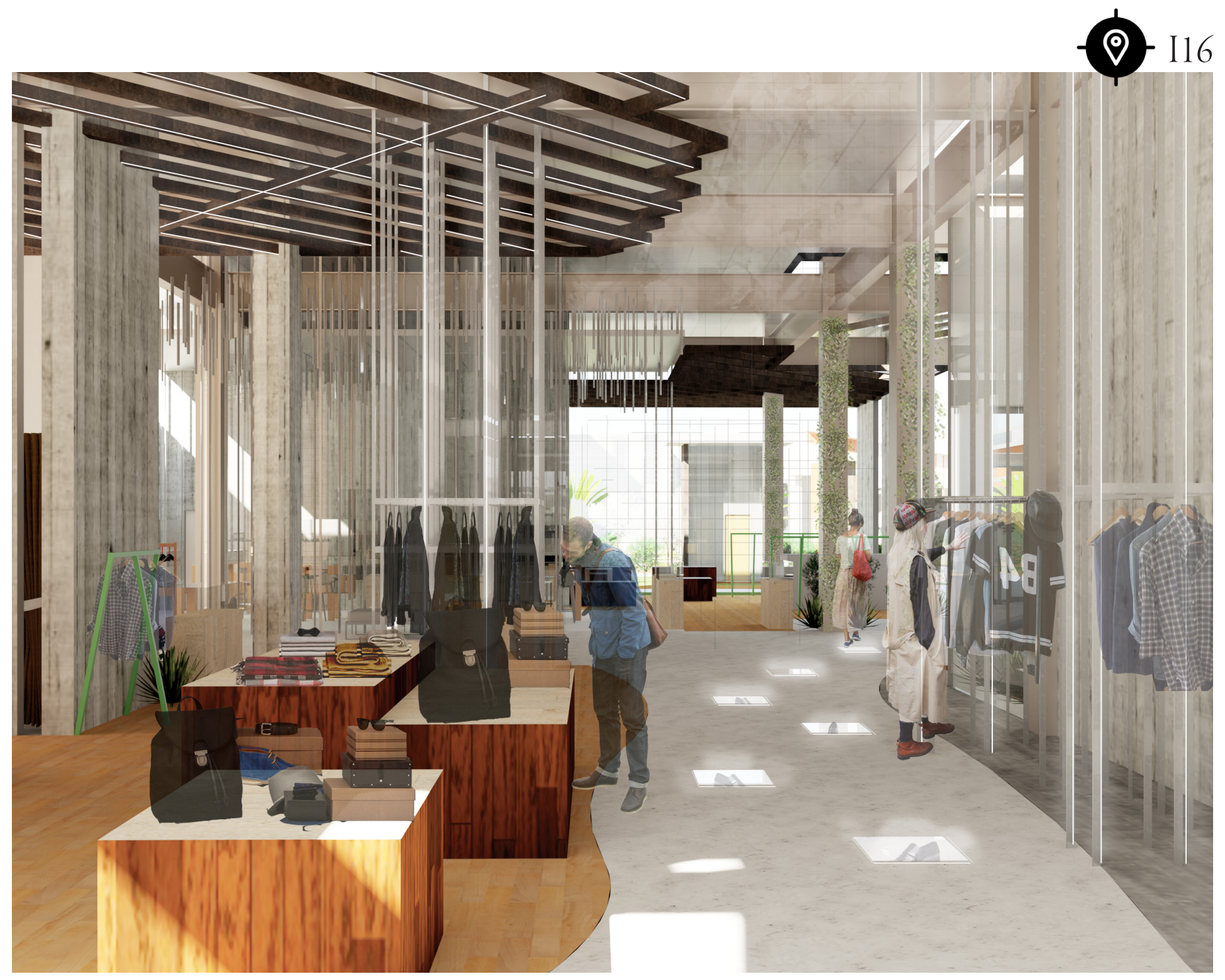

Figure 7.80. Fashion hall main path. Author's illustration. 


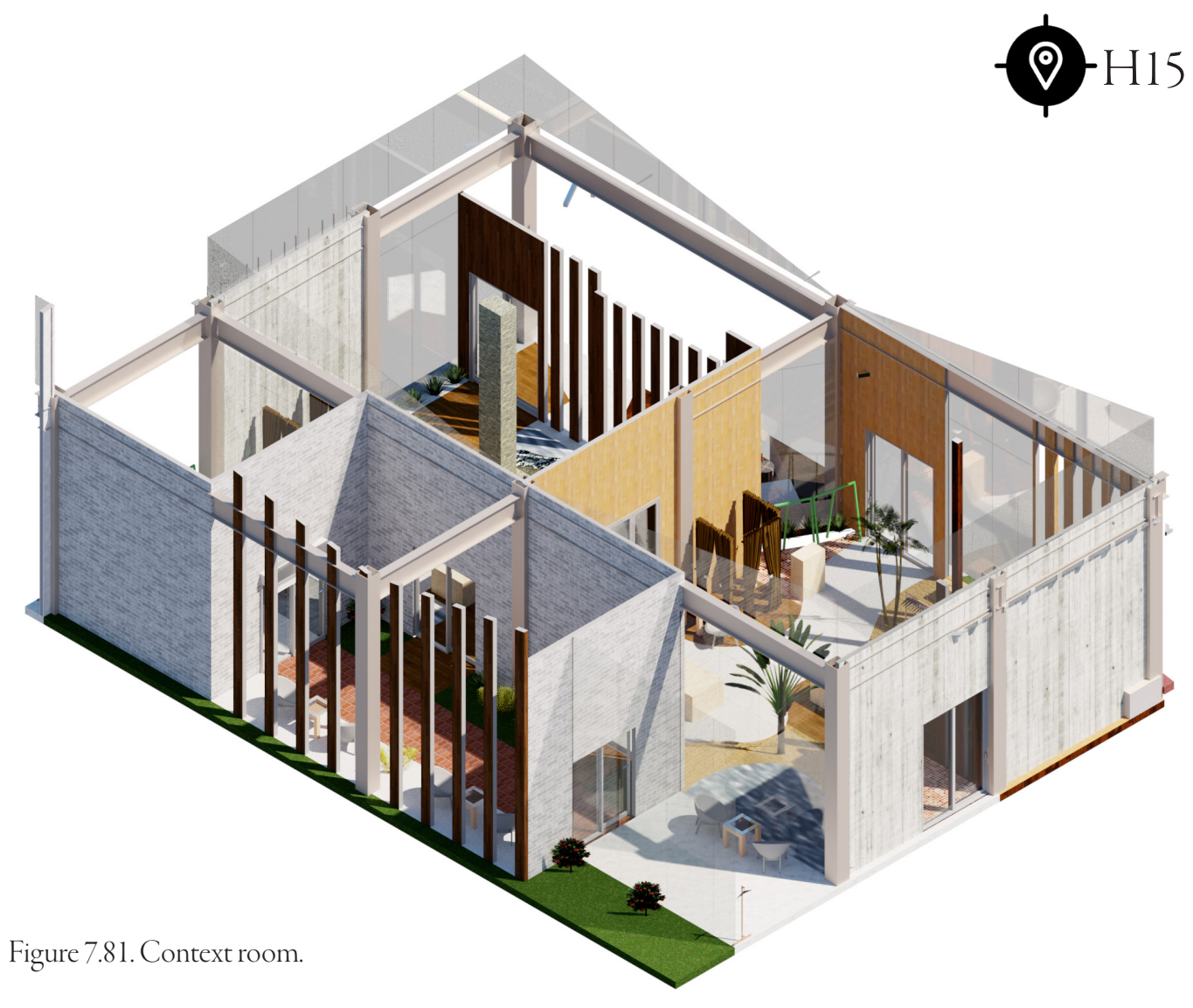

\section{Context Rooms}

These are a development of fitting rooms which play a crucial role in differentiating the mall experience; they cannot be replicated by online services. These rooms reduce formality and eradicate expectations of traditional fitting rooms (still provided throughout). Context rooms transform traditional fitting rooms into social spaces where people can try products together and still interact with each other in the process. These can help in minimising customers dumping products in a corner making maintenance of visual presentations less stressful for retailers.

Contextual fitting rooms provide an opportunity to try products in the context in which they would be used:

- $\quad$ summer clothes are able to be tried in a summer context room despite being in midwinter

- winter context room provide the opposite during the summer months

- $\quad$ live context room to try products in current weather conditions

These are implemented to increase the level of personalisation and also allows retailers to sell out-of-season products; increase attraction for outlet retailers. 
- -115

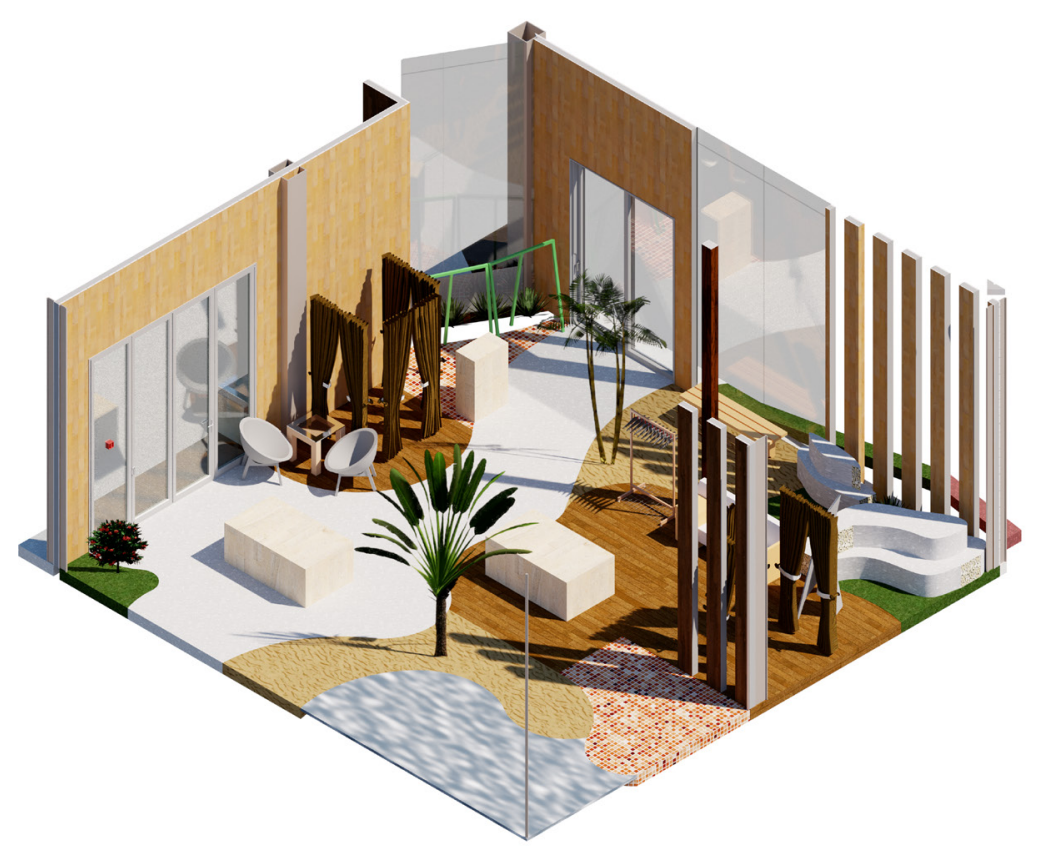

Figure 7.82. Summer context room.

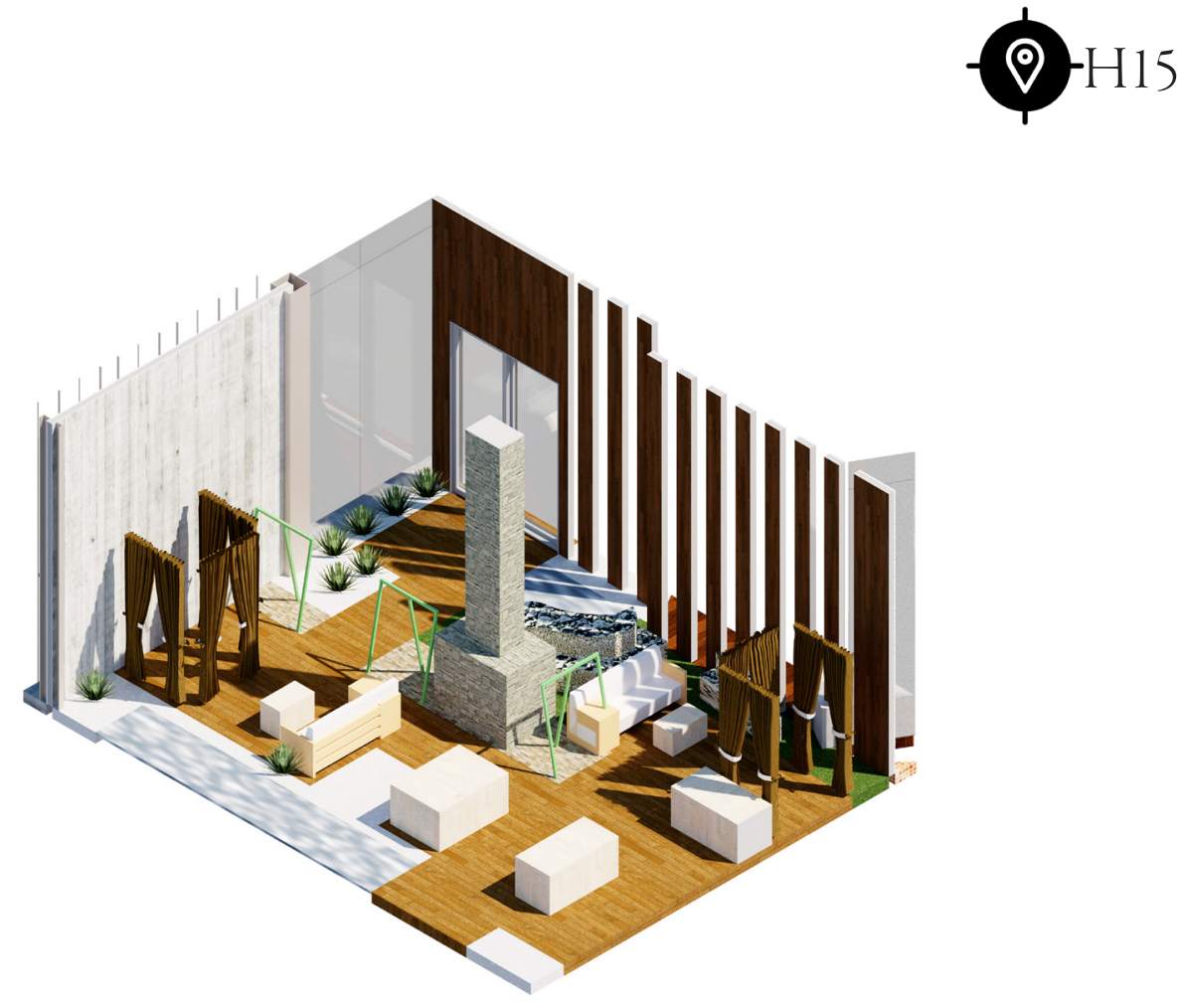

Figure 7.83. Winter context room. 


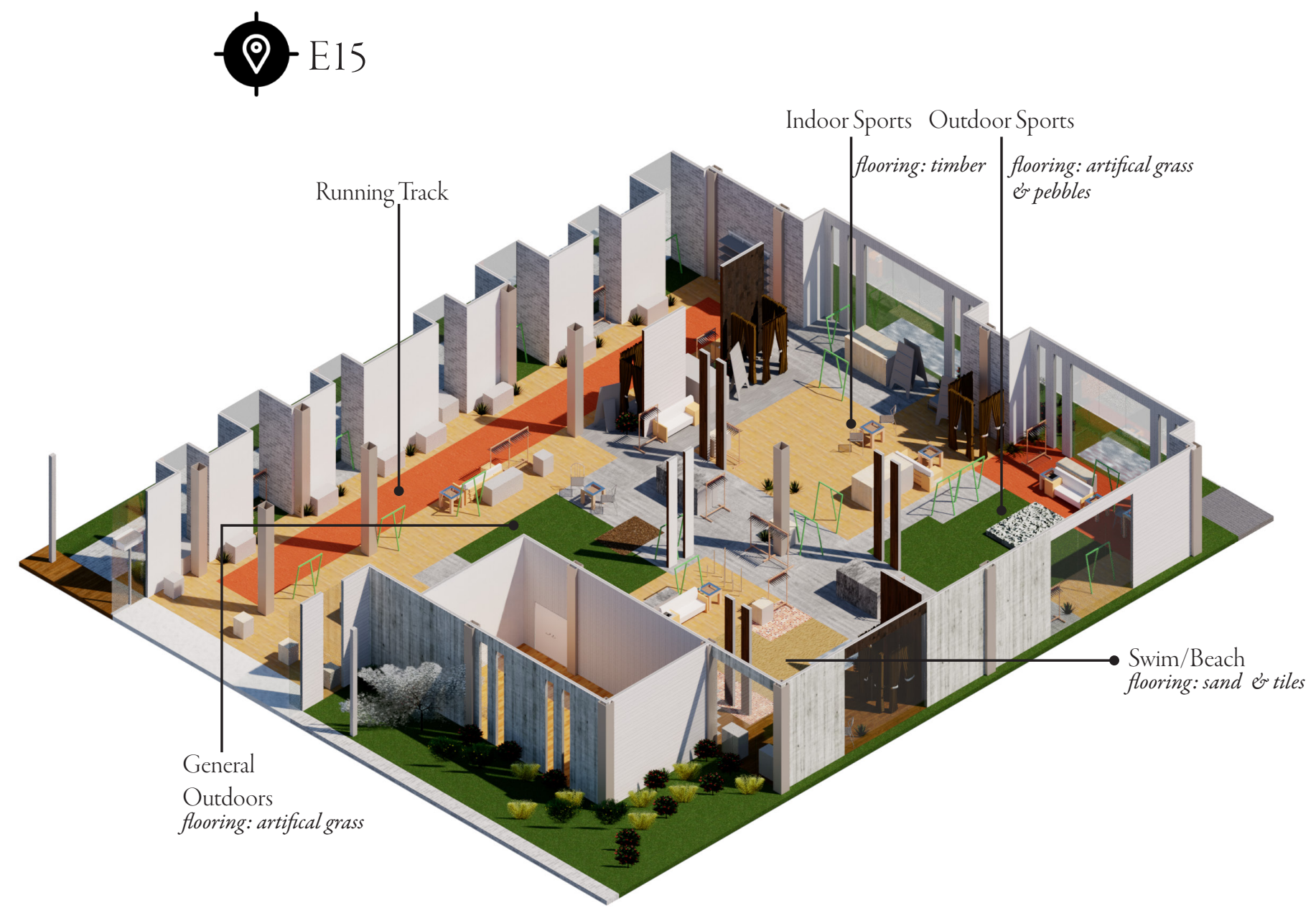

Figure 7.84. Sports retailer

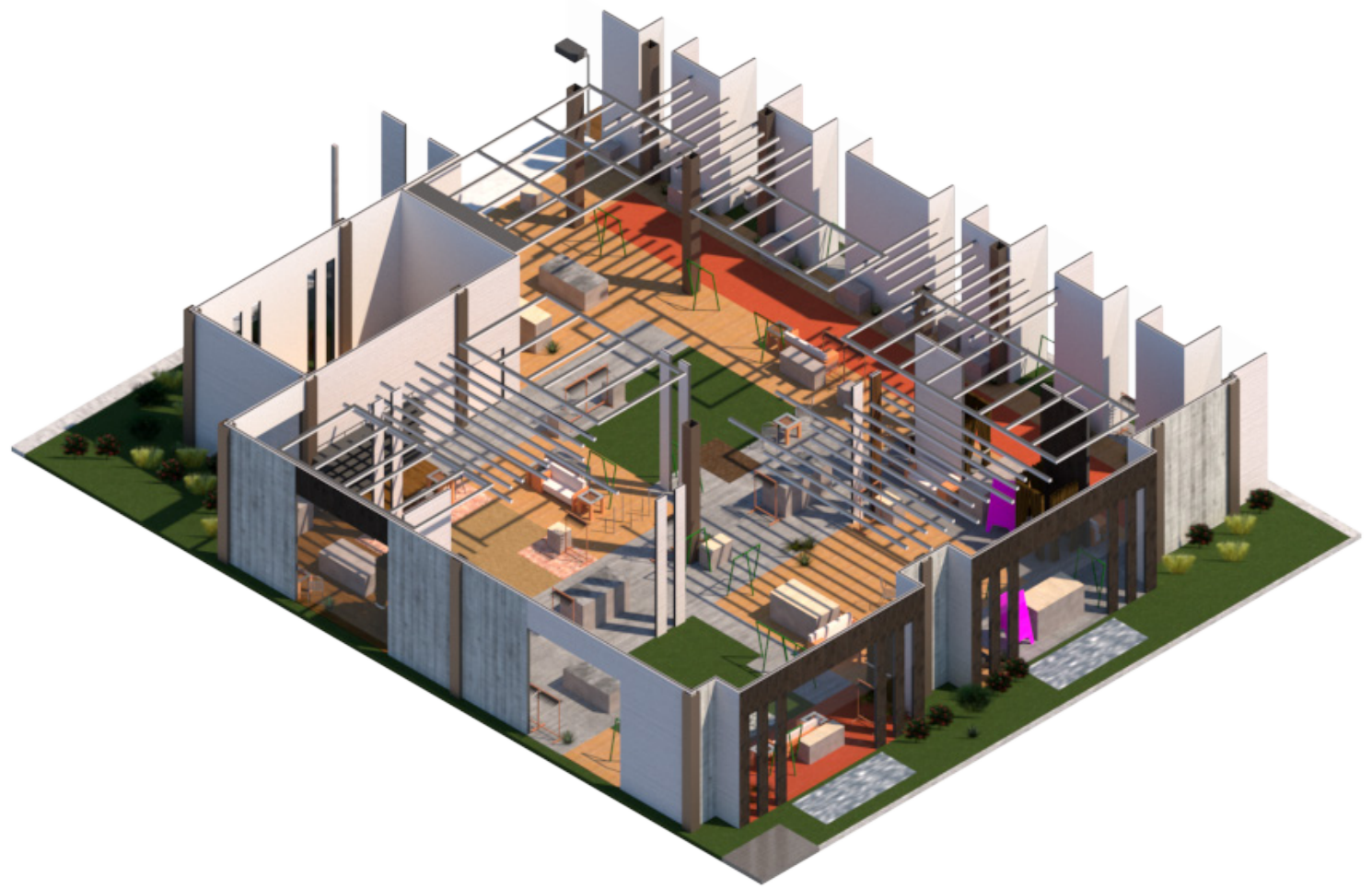

Figure 7.85. Sports retailer. 


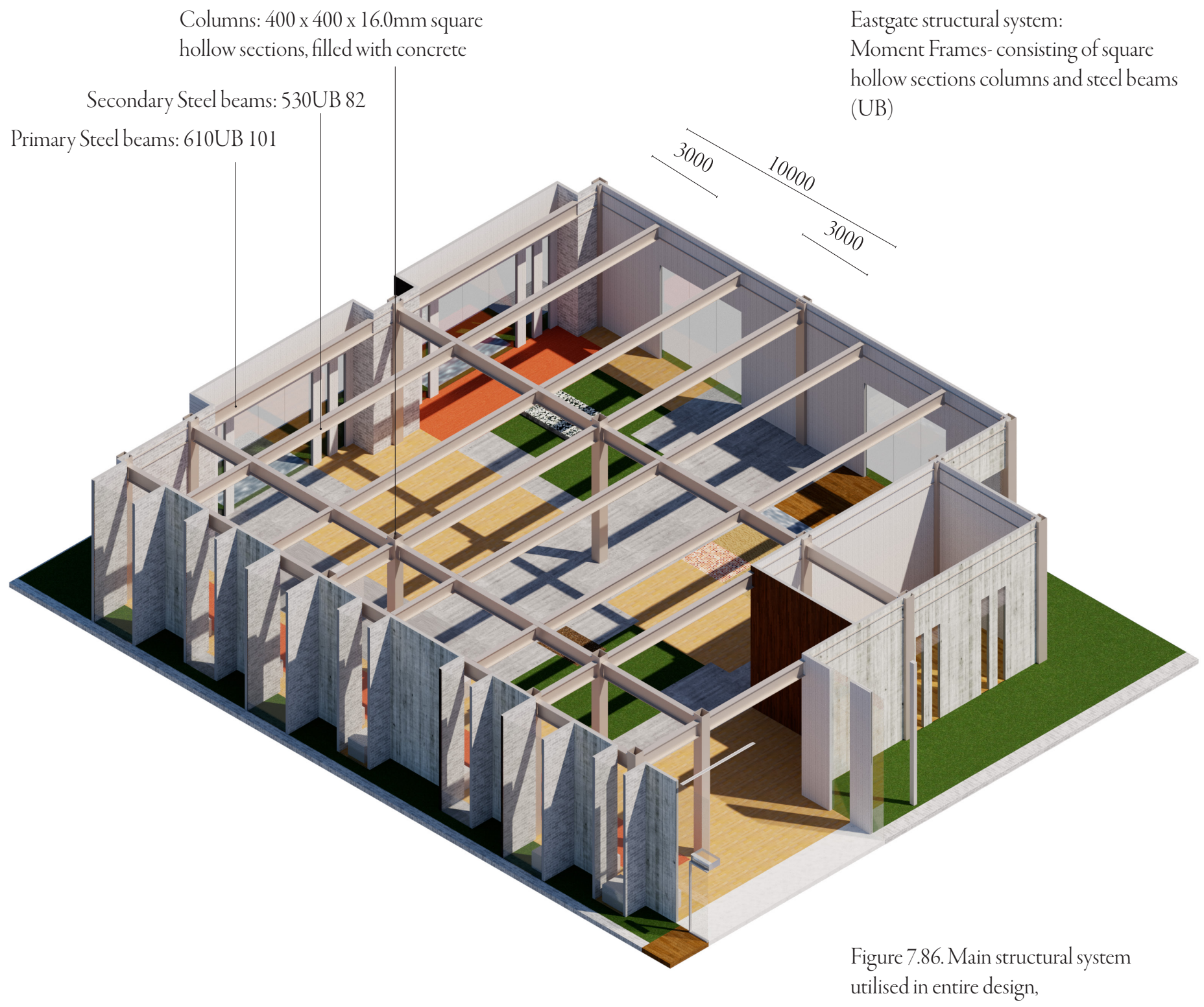

Structure

This design has developed into a complex, fragmented arrangement, constituting a series of separate structures and components. This would be prone to many construction issues including for instance weather-proofing, particularly for the larger structures. A critical analysis of the complications of this form would need to be undertaken for potential further development. 


\section{CONCLUSION \\ $\&$ \\ REFLECTION}


The reconfigured design for Eastgate continues to respect the traditional model for shopping malls. The proposed design continues to strongly rely on anchor tenants, which would drive foot traffic into the mall and contribute to evenly distributing it throughout.

Today, many anchor tenants like big-box retailers and department stores are financially struggling. Once an anchor tenant departs or falls, the entire Eastgate Mall is at risk with other tenants potentially following suit. This may mean that the mall would also struggle to find large retailers to serve as replacement anchor tenants. If no "replacement" anchors can be found, Eastgate's operators may struggle to find several smaller tenants to fill this vacancy, which may prove to be unfeasible.

For further development and "reconfiguration" of the proposed design, to ensure it persists, the design explorations and process should take key challenges. Anchor tenants should be eradicated to explore a shopping landscape without them. By taking this challenge, greater focus would be directed towards creating more unique experiences through architectural design, as means of attracting more people and customers in immersive and entertaining ways. Consequently, experiences become the driver of the mall instead of the anchors, to provide protection and also divert more attention to the smaller and local retailers. These small and local retailers can immerse themselves into these experiences rather than being consumed by large anchor tenants. 


\section{Process}

Through an initial literature review and case studies, this research establishes that the need to differentiate shopping malls needs to be explored through architectural design. The initial research highlights issues in many current shopping malls, including:

- The need to accommodate changing shopping habits and an increasing preference to shop online

- Integration of immersive experiences

- Their overwhelmingly commercial nature that denies retailers and surrounding communities their diversity, and economic and cultural prosperity

- Threats-particularly to small local businesses

It formulates a criteria for design exploration that proposes that the changing needs of shopping have potential to be addressed through the enrichment of architecture that shows and sells experiences. This enrichment would be a way to revive Eastgate Mall and further differentiate its physical retail spaces from those in the online channel. By embodying transience and immediacy strongly present today, the mall's spaces can shift from static and one-dimensional to multi-functional and hybrid, which are flexible and responsive to consumer needs. 


\section{Site}

The current Eastgate Mall site in Linwood provided for a range of links to the site, that were explored and analysed, to enable for the development of ideas. Strengths, weaknesses, threats and opportunities of the mall and its vicinity were analysed to help define the rejuvenated design and identify physical, social and economic factors it would need to deal with.

To embed a stronger and more enduring means of evoking context and culture, the significance of Maori heritage and traditions in the site were explored. These are vital towards gaining awareness of and care for local characteristics and traditions. This would give the rejuvenated design for Eastgate a stronger purpose, identity and place in the community and people.

The awareness of the site's cultural and historic significance enables architecture to direct people through spaces. With communities like Linwood, which are more multi-cultural, these paths are not so clear. However, by drawing on the site's cultural and historical significance, this thesis discovered an urge and feeling to create architecture that celebrates the human experience, that invites exploration, discovery and immersion. 


\section{Initial Design Explorations}

Initial design explorations generated general principles of a design approach to create simple reconfigurations of the current Eastgate Mall and retailers. A set of strategies was developed to guide the experiments in meeting the criteria set earlier. These explorations reconfigure the shopping mall by exploring potential rearrangements of retailers. These form a basis for further design experiments to take place.

The second phase expands on this process and begins exploring experiential architecture through different strategies and directions. Natural elements, in the form of greenery, are introduced to break the efficiency and stability earlier experiments showed and dwelled on. This was executed to strengthen relationships with the site, enhance shoppers' moods and as a small gesture to bringing historic and contextual themes as a means of giving the mall a rejuvenated identity. This is also in response to fulfilling the objective of avoiding the creation of a traditional shopping mall.

These explorations aim to define how stabilisation and efficiency could be designed for in response to programme and form. With the inclusion of natural elements, experiments shift focus onto form. This was to visualise how form interacted with site and most significantly, the shopping experiences people obtain.

This then leads to further exploration and investigation of architectural design from a more micro, intimate scale to celebrate people's shopping experiences. 


\section{Design Rethink/Reflection}

A reflection upon what "persist" means was undertaken due to issues arising from the outcomes of the initial design experiments. Although the design incorporated the fundamentals of successful shopping malls, it did not showcase that it had sufficient experiential and spatial qualities to enable Eastgate to differentiate itself from nearby retail competitors and the booming online shopping format. It seemingly focused on stabilising Eastgate. It should instead look into exploring ideas that would radically challenge the struggling model of shopping malls as well as their impact on surrounding communities.

A defining step of this reflection, included the following critical questions:

- Why have precedents like the bazaar worked? And why do they persist today?

- How has person to person trade persisted and what are the ways the built environment has aided it?

These reflective questions urged a change in direction, to tackle the design process from a different perspective-through the small scale. This led to several critical points including:

- By thinking and working at a smaller scale, perhaps we can contribute to persistence by asking "how do we reinvent the store to enrich customer experiences?"

- Many people do not buy products; they buy the brand. People today want more than a product and the act of consumption. They want experiences which are the extension of brands and retailers.

- Realisation of the importance of physical modelling to better comprehend and develop form- it is later utilised 


\section{Further Iterations \& Development}

Findings obtained through critical reflection are utilised as a guide in this change of direction and further design development. From stabilising the mall space the design process takes a riskier yet more experiential approach and intervention.

This approach demanded that the design intervention be tackled by working in the small scale-exploring and designing small experiential spaces. These spaces along with their experiences are collated together, to create one big comprehensive experience that will define the rejuvenated architectural design for Eastgate Mall. With this approach, it became apparent that there is greater potential for the proposed design to develop dynamic, flexible and more unique spaces. This would help Eastgate Mall to persist.

It also became apparent that these experiential spaces (including green spaces distributed throughout) are useful in the activation of the shopping mall as a social hub. By making spaces experiential, they can become more entertaining, immersive and even educational, to turn retailers and tenants into destinations. This would increase and enhance the level of engagement between people/customers and retailers/products. People's experiences would be given priority over the products, making them not only points of potential sales but more importantly as points of contact. The proposed design and associated ideas and process pursue this approach, to avoid reverting into a traditional enclosed shopping mall that consumes small and local businesses.

Despite a stronger focus on experiences and experiential spaces, this design highlights the need to balance those with convenience. Architectural spaces being designed must ensure that consumer needs for efficiency are not disrupted-i.e. groceries (efficient layouts, close proximity to carpark), supermarket/warehouse storage, delivery docks. Consequently, it can be assured that retailers largely reliant on or requiring convenience and efficiency will still remain viable and functional. 


\section{Developed Design}

This design addresses issues raised in preliminary design process and fully takes account of a new direction and critical points obtained from the preceding reflection. This process included the evaluation of strengths and weaknesses and a search for ways to define persist.

A more complex architectural design integrating experience was generated in this process. Experiences were utilised to define architectural form, to further enrich shopper experiences and enhance Eastgate's link and relationship to the surrounding community. Architectural form is further scrutinised and dissected to continue enhancing the shopping experiences and environments. This design stage allows for the testing of generated principles and criteria in this thesis, along with discussion into how experiences may be integrated to a greater extent for further design exploration.

\section{Final Summary}

Principles developed through extensive investigations forming initial parts of this research were tested through a range of iterative design explorations. These explored the reconfiguration of the shopping mall for persistence at all scales. Questioning how shopping mall spaces may be reconfigured with experience was a key principle that later defined the final proposed architectural design and the associated processes leading to the outcome. 
These explorations propose that experiential spaces have the ability to enhance the act of shopping. This experiential quality enhances the flexibility and diversity of Eastgate's shopping spaces, to increase the level of interaction, immersion and collaboration that would occur within.

With indications that experiential spaces and environments will impact retailers, shoppers and the people, this thesis proposes that:

In response to traditional shopping malls, an experiential shopping mall that emphasises and dedicates spaces for social interactions, customer immersion and tenant collaboration, is a desirable alternative to malls that prioritise products and their points of sales over the people they serve. Experiences will attract and draw people together, and enhance their moodspotentially leading to increased sales. The balance between experience and convenience or efficiency, however, must continue to be maintained to ensure the retailers would remain viable and functional. However, further research and design exploration are needed to test and understand the implications of this desgn intervention in a real-life context. This is to allow Eastgate Mall to follow shifts in cultural tastes and in social and urban patterns, and to adapt to the changing world around it. 


\section{Next Steps}

For further research vital for further design development

\section{Greater functional hybridity}

Further development of experiences and experiential spaces; key experiences to potentially replace anchor tenants/retailers

Integrate the concept of play, educational spaces (considering close proximity of school to mall); maintain convenience and efficiency where needed

Experiences that would draw people from beyond the nearby suburbs and communities

\section{Structural Integration}

Further development of structure, and a stronger relationship between form and structure, and especially structure and experience.

Investigate how structure will affect and shape experiences inside the mall

\section{Different Physical Retail Formats}

Exploring even further beyond physical and traditional stores; further breaking down anchor tenants and large format retailers critically

Integrating a variety of physical retail formats-i.e. pop-ups, media-based stores, shop-sharing Exploring architectural links to omnichannel shopping through digital tools-virtual reality, augmented reality?

\section{Landscaping}

Further integration of biophilic design principles

Evaluation of landscaping ecologies and their appropriateness for shopping environments.

\section{Flexibility}

Investigate ability for spaces and structure to be changeable, adaptable and adjustable 



\section{REFERENCES}

Alexander, B., \& Bain, J. K. (2016). Small Store Design and Marketing Effects: Experiential Developments in SME Fashion Pop-Up Store Strategies. In C. Mcintyre, T. C. Melewar, \& C. Dennis (Eds.), Multi-Channel Marketing, Branding and Retail Design (pp. 163-192). Emerald Group Publishing Limited. https://doi.org/10.1108/978-1-78635-456-320161004

Alexander, B., \& Blazquez Cano, M. (2020). Store of the future: Towards a (re)invention and (re)imagination of physical store space in an omnichannel context. Journal of Retailing and Consumer Services, 55, 101913. https://doi.org/10.1016/j.jretconser.2019.101913

Alexander, B., Kent, A., \& Kent, A. (2016, December 1). Retail environments. Retail Design; Routledge. https://doi.org/10.4324/9781315605920-10

Allard, T., Babin, B. J., \& Chebat, J.-C. (2009). When income matters: Customers evaluation of shopping malls hedonic and utilitarian orientations. Journal of Retailing and Consumer Services, 16(1), 40-49. https://doi.org/10.1016/j.jretconser.2008.08.004

Arnold, S. J., \& Narang Luthra, M. (2000). Market entry effects of large format retailers:a stakeholder analysis. International Journal of Retail \& Distribution Management, 28(4/5), 139-154. https://doi.org/10.1108/09590550010319896

Azadarmaki, M. (2014). The Synchronic Continuity of the Traditional Bazaar Traditional and Modern Bazaar: Tajrish and Ghaem Shopping Center. Journal of Socio-Cultural Change, $1(1), 85-101$.

Baghaee, S., Aram, F., Daudén, F. L., \& Denzin, P. (2019, July 28). The Modern Retail Center: A Study on the New Role of Retails Centers as a Place for Spending Leisure Time. Preprints; Basel; MDPI AG. http://dx.doi.org/10.20944/preprints201907.0315.v1

BEHF Architects. (n.d.-a). Retail Centre NEUKAUF VILLACH: Unique Shopping Experience. BEHF. Retrieved March 18, 2021, from https://www.behf.at/project/retailcentre-neukauf-villach/

BEHF Architects. (n.d.-b). Shopping Mall EO in Oberwart: Austria’s First Power Centre. BEHF. Retrieved March 19, 2021, from https://www.behf.at/project/shopping-mall-eo/ 
Berezko, O. (2014). Principles of urban structure in social spaces of shopping malls. Środowisko Mieszkaniowe, nr 13. http://yadda.icm.edu.pl/baztech/element/bwmeta1.element.baztech9ef9bc21-456a-4f69-90f2-e8722095378d

Berman, B. (2019). Flatlined: Combatting the death of retail stores. Business Horizons, 62(1), 75-82. https://doi.org/10.1016/j.bushor.2018.08.006

Blázquez, M. (2014). Fashion Shopping in Multichannel Retail: The Role of Technology in Enhancing the Customer Experience. International Journal of Electronic Commerce, 18(4), 97-116. https://doi.org/10.2753/JEC1086-4415180404

Bloch, P. H., Ridgway, N. M., \& Dawson, S. A. (1994). The shopping mall as consumer habitat. Journal of Retailing, 70(1), 23-42. https://doi.org/10.1016/0022-4359(94)90026-4

Blundell, S. (2006, February). Down at the mall. New Zealand Geographic, 077. https:// www.nzgeo.com/stories/down-at-the-mall/

Carter, C., \& Vandell, K. (2005). Store Location in Shopping Centers: Theory and Estimates. Journal of Real Estate Research, 27(3), 237-266. https://doi.org/10.5555/ rees.27.3.735134vm6848265q

Chavan, A., Peralta, C., \& Steins, C. (2007). Planetizen contemporary debates in urban planning. Island Press.

Chhabra, D. (2012). Examining the pros and cons of shopping mall culture as a leisure phenomenon. Leisure/Loisir, 36(1), 85-93. https://doi.org/10.1080/14927713.2012.7018 82

Christiaans, H. (2016, December 1). The future of retail and retail design. Retail Design; Routledge. https://doi.org/10.4324/9781315605920-17

Chung, C. J., Inaba, J., Koolhaas, R., Leong, S. T., \& Harvard University Graduate School of Design. (2001). Harvard Design School guide to shopping. Taschen.

Corroto, C., \& Richardson, L. (2019). We Have Seen It All. At the Mall. Qualitative Inquiry, 25(9-10), 1078-1084. https://doi.org/10.1177/1077800418789451

Costa, F. C. X. D., \& And, G. G. (2016, December 1). Retail formats. Retail Design; Routledge. https://doi.org/10.4324/9781315605920-9

Crawford, M. (2002). Suburban Life and Public Space. In Sprawl and Public Spaces: Redressing the Mall (pp. 21-30). Princeton Architectural Press. 
ash, M., \& Akshaya, L. (2016). A Study on the Impact of Visual Merchandising on Impulse Purchase in Apparel Retail Stores. International Journal of Marketing \& Business Communication; New Delhi, 5(2), n/a.

Dovey, K. (2014). Framing Places: Mediating Power in Built Form. Routledge.

Feinberg, R. A., \& Meoli, J. (1991). A Brief History of the Mall. ACR North American Advances, NA-18. https:///www.acrwebsite.org/volumes/7196/volumes/v18/NA-18

Goodman, R., \& Coiacetto, E. (2012). Shopping Streets or Malls: Changes in Retail Form in Melbourne and Brisbane. Urban Policy and Research, 30(3), 251-273. https://doi.org/10.10 $80 / 08111146.2012 .667771$

Goss, J. (1993). The "Magic of the Mall": An Analysis of Form, Function, and Meaning in the Contemporary Retail Built Environment. Annals of the Association of American Geographers, 83(1), 18-47. https://doi.org/10.1111/j.1467-8306.1993.tb01921.x

Grüner, F. (2011). In the Streets and Bazaars of Harbin: Marketers, Small Traders, and Peddlers in a Changing Multicultural City. Itinerario, 35(3), 37-72. https://doi.org/10.1017/ S016511531200006X

Gwee, M., \& Chang, K. (2014). What Triggers Impulse Purchase Behavior: The Moderating Effects of User Expertise and Product Type. ICIS 2014 Proceedings. https://aisel.aisnet.org/icis2014/proceedings/EBusiness/50

Harris, F., \& O’Brien, L. (2012). Retailing (RLE Retailing and Distribution): Shopping, Society, Space. Taylor \& Francis Group. http://ebookcentral.proquest.com/lib/vuw/detail. action? docID $=1039310$

Harrouk, C. (2020, March 18). OMA to Create a New Retail Experience in Melbourne's Countryside. ArchDaily. https://www.archdaily.com/935834/oma-to-create-a-new-retailexperience-in-melbournes-countryside

Helm, S. V., Kim, S., \& Riper, S. V. (2020). Navigating the 'retail apocalypse': A framework of consumer evaluations of the new retail landscape. https://doi.org/10.1016/J. JRETCONSER.2018.09.015

Herzberg, R., Ridings, E., \& Schoutrop, P. (2020, May 22). Post-pandemic design: Buchan on the future of retail. Architecture Now. /articles/post-pandemic-design-buchan-on-the-futureof-retail/ 
Ibrahim, M. F., \& Galven, T. W. R. (2007). New age retail tenants: A new phenomenon. Journal of Retail \& Leisure Property, 6(3), 239-262. https://doi.org/10.1057/palgrave.rlp.5100065

Insider Trends. (2019). The Future of Retail Space. https://www.insider-trends.com/wpcontent/uploads/2019/02/The-Future-of-Retail-Space-report.pdf

Jackson, P., Rowlands, M., Miller, D., Holbrook, B., \& Rowlands, M. (1998). Shopping, Place and Identity. Routledge. http://ebookcentral.proquest.com/lib/vuw/detail. action? docID $=235367$

Jewell, N. (2001). The fall and rise of the British mall. The Journal of Architecture, 6(4), $317-$ 378. https://doi.org/10.1080/13602360110071450

Jewell, N. (2016). Shopping Malls and Public Space in Modern China. Routledge.

Joye, Y., Willems, K., Brengman, M., \& Wolf, K. (2010). The effects of urban retail greenery on consumer experience: Reviewing the evidence from a restorative perspective. Urban Forestry \& Urban Greening, 9(1), 57-64. https://doi.org/10.1016/j.ufug.2009.10.001

Kärrholm, M., Nylund, K., \& Prieto de la Fuente, P. (2014). Spatial resilience and urban planning: Addressing the interdependence of urban retail areas. Cities, 36, 121-130. https:// doi.org/10.1016/j.cities.2012.10.012

Kitchen Center / Nicolás Lipthay | Kit Corp. (2010, July 22). ArchDaily. https://www. archdaily.com/69737/kitchen-center-nicolas-lipthay-kit-corp

Kreutzer, M. (2017). Retail Without Walls: The Built Impacts of a Post-Spatial Retail Reality. Theses from the Architecture Program. https://digitalcommons.unl.edu/archthesis/175

Laermans, R. (1993). Learning to Consume: Early Department Stores and the Shaping of the Modern Consumer Culture (1860-1914). Theory, Culture \& Society, 10(4), 79-102. https:// doi.org/10.1177/026327693010004005

Lukito, R. S. H., \& Tulipa, D. (2016). Impulse buying behavior on consumer retail fashion in Surabaya-Indonesia. International Journal of Applied Business and Economic Researchh, 14(11), 8071-8086.

Manuelli, S. (2006). Design for shopping: New retail interiors. Laurence King.

McGreevy, M. P. (2017). The Precinct versus the Shopping Centre: Order, Complexity and Endogenous Dynamism in Suburbs and Towns. Urban Policy and Research, 35(4), 424-442. https://doi.org/10.1080/08111146.2017.1328352 
McKinnon, T. (2020, January 21). The Top 5 Shopping Mall Trends To Watch Over the Next Decade. Indigo Digital. https://www.indigo9digital.com/blog/shoppingmalltrends

Miles, S. (2010). Spaces for Consumption. SAGE Publications. http://ebookcentral.proquest. $\mathrm{com} / \mathrm{lib} /$ vuw/detail.action?docID=581681

Mokgabudi, L. R. (2012). The impact of shopping mall developments on consumer behaviour in township areas [Dissertation, University of Pretoria]. https://repository.up.ac.za/ handle/2263/25200

Musil, T. A. (2011). Evaluating development and community benefits of shopping malls: A case study using input/output analysis. Journal of Financial Management of Property and Construction, 16(2), 111-125. https://doi.org/10.1108/13664381111153105

MVSA Architects. (n.d.). Westfield Mall of the Netherlands. MVSA Architects. Retrieved March 18, 2021, from https://mvsa-architects.com/project/westfield-mall-of-thenetherlands/

Nicholls, J. A. F., Li, F., Kranendonk, C. J., \& Roslow, S. (2002). The seven year itch? Mall shoppers across time. Journal of Consumer Marketing, 19(2), 149-165. https://doi. org/10.1108/07363760210420568

On Buy. (2017, August 18). The Pros and Cons of Shopping Centres. On Buy. https://www. onbuy.com/gb/blog/the-pros-and-cons-of-shopping-centres a $49 /$

Ortegón-Cortázar, L., \& Royo-Vela, M. (2019). Effects of the biophilic atmosphere on intention to visit: The affective states' mediating role. Journal of Services Marketing, 33(2), 168-180. https://doi.org/10.1108/JSM-01-2018-0019

Petermans, A., Kent, A., \& Kent, A. (2016, December 1). Retail design: A contextual lens. Retail Design; Routledge. https://doi.org/10.4324/9781315605920-7

Quartier, K. (2016, December 1). Retail design: What's in the name? Retail Design; Routledge. https://doi.org/10.4324/9781315605920-8

Rajagopal. (2009). Growing shopping malls and behaviour of urban shoppers. Journal of Retail \& Leisure Property, 8(2), 99-118. https://doi.org/10.1057/rlp.2009.3

Rao, F. (2019). Resilient forms of shopping centers amid the rise of online retailing: Towards the urban experience. Sustainability (Switzerland), 11(15). Scopus. https://doi.org/10.3390/ su11153999 
Reimers, V., \& Clulow, V. (2004). Retail concentration: A comparison of spatial convenience in shopping strips and shopping centres. Journal of Retailing and Consumer Services, 11(4), 207-221. https://doi.org/10.1016/S0969-6989(03)00038-9

Robertson, J., \& Fennell, J. (2007). The economic effects of regional shopping centres. Journal of Retail \& Leisure Property, 6(2), 149-170. https://doi.org/10.1057/palgrave.rlp.5100057

Rosenbaum, M. S., Otalora, M. L., \& Ramírez, G. C. (2016). The restorative potential of shopping malls. Journal of Retailing and Consumer Services, 31, 157-165. https://doi. org/10.1016/j.jretconser.2016.02.011

Rosenbaum, M. S., Ramirez, G. C., \& Camino, J. R. (2018). A dose of nature and shopping: The restorative potential of biophilic lifestyle center designs. Journal of Retailing and Consumer Services, 40, 66-73. https://doi.org/10.1016/j.jretconser.2017.08.018

Rosenbaum, M. S., Ramírez, G. C., \& Matos, N. (2019). A neuroscientific perspective of consumer responses to retail greenery. The Service Industries Journal, 39(15-16), 1034-1045. https://doi.org/10.1080/02642069.2018.1487406

Rouz, R. K. (2014). From Bazaars to Shopping Centers | Mediterranean Journal of Social Sciences. 5(23). http://www.richtmann.org/journal/index.php/mjss/article/view/4731

Sadafi, N., \& Sharifi, M. (2018). A Study of the Concept of Iranian Traditional Architecture in Bazaars and Shopping Centres. Journal of Construction in Developing Countries; Pinang, 23(2), 151-165. http://dx.doi.org/10.21315/jcdc2018.23.2.9

Searls, D., \& Weinberger, D. (2001). Markets Are Conversations. In The Cluetrain Manifesto: The End of Business as Usual (pp. 155-212). Fazi Editore. https://www.cluetrain.com/book/ markets.html

Taylor, M.J. (Ed.). (2002). Repositioning the Older Shopping Mall. In Sprawl and Public Space: Redressing The Mall (1st ed, pp. 49-50). National Endowment for the Arts; Distributed by Princeton Architectural Press.

Taylor, W. (1952). Lore and History of the South Island Maori. Bascands Ltd. https:// viewer.waireto.victoria.ac.nz/client/viewer/IE862974/rep/REP863130/FL863132?dps_ $\mathrm{dvs}=1615090022294 \sim 178$

Tikao, D. (n.d.). The Public Realm of Central Christchurch Narrative. Otakaro Ltd. https:// www.otakaroltd.co.nz/assets/Uploads/ThePublicRealm.pdf 
von Briel, F. (2018). The future of omnichannel retail: A four-stage Delphi study. Technological Forecasting and Social Change, 132, 217-229. https://doi.org/10.1016/j. techfore.2018.02.004

Voyce, M. (2007). Shopping Malls in India: New Social "Dividing Practices." Economic and Political Weekly, 42(22), 2055-2062. JSTOR.

Wakefield, K. L., \& Baker, J. (1998). Excitement at the mall: Determinants and effects on shopping response. Journal of Retailing, 74(4), 515-539. https://doi.org/10.1016/S00224359(99)80106-7

Wilcox, M., \& O'Callaghan, E. (2001). The strategic response of Dublin's traditional department stores to intensifying competition. Journal of Retailing and Consumer Services, 8(4), 213-225. https://doi.org/10.1016/S0969-6989(00)00027-8

Yu, C., \& Bastin, M. (2017). Hedonic Shopping Value and Impulse Buying Behavior in Transitional Economies: A Symbiosis in the Mainland China Marketplace. 15.

Zhuang,G.,Tsang,A.S.L.,Zhou,N.,Li,F., \&Nicholls,J.A.F.(2006).Impactsofsituationalfactors on buying decisions in shopping malls: An empirical study with multinational data. European Journal of Marketing, 40(1/2), 17-43. https://doi.org/10.1108/03090560610637293

Zielke, S., \& Toporowski, W. (2009). Does Architecture Influence the Price Image and Intention to Shop in a Retail Store? In D. Morschett, T. Rudolph, P. Schnedlitz, H. SchrammKlein, \& B. Swoboda (Eds.), European Retail Research (pp. 83-100). Gabler Verlag. https:// doi.org/10.1007/978-3-8349-8203-2_5 


\section{LIST OF FIGURES}

* All images not listed below are by author

Figure 3.0. Herzberg, R., Ridings, E., \& Schoutrop, P. (2020, May 22). Post-pandemic design: Buchan on the future of retail. Architecture Now. /articles/post-pandemic-design-buchan-on-the-future-ofretail/

Figure 3.1. ExpatFocus. (2017, May 5). Moving To Morocco? Here's How To Navigate The Bazaars.

Expat Focus. https://www.expatfocus.com/morocco/living/moving-to-morocco-here-s-how-tonavigate-the-bazaars- $4172 /$

Figure 3.6. BEHF Architects. (n.d.-b). Shopping Mall EO in Oberwart: Austria's First Power Centre. BEHF. Retrieved March 19, 2021, from https://www.behf.at/project/shopping-mall-eo/

Figure 3.7. BEHF Architects. (n.d.-a). Retail Centre NEUKAUF VILLACH. BEHF. Retrieved April 28, 2021, from https://www.behf.at/project/retail-centre-neukauf-villach/

Figure 3.8. MVSA Architects. (n.d.). Westfield Mall of the Netherlands. MVSA Architects. Retrieved March 18, 2021, from https://mvsa-architects.com/project/westfield-mall-of-the-netherlands/

Figures 4.1, 4.3-4.5. Author's edit. Stats NZ. (2018). Linwood West. Stats NZ Tatauranga Aotearoa. https://www.stats.govt.nz/tools/2018-census-place-summaries/linwood-west

Figures 4.6\&4.7. Author's edit. Christchurch City Council. (2017). Commercial centre factsheets. Christchurch City Council. https://ccc.govt.nz/assets/Documents/Culture-Community/Statsand-facts-on-Christchurch/Community-Ward-Profiles/Commercial-Centre-Factsheets/LinwoodEastgate.pdf

Figures 4.25, 4.30, 4.33. Author's edit. Eastgate Mall. (n.d.). Our shops-Eastgate Mall - Shop Easy Christchurch. Https://Eastgate.Co.Nz/. Retrieved April 28, 2021, from https://eastgate.co.nz/ shops/?map=map

Figure 4.37, 4.38. Canterbury Earthquakes Royal Commission. (2011, October 20). Christchurch area showing waterways, swamps \& vegetation cover in 1856 map. The Canterbury Earthquakes Royal Commission. https://canterbury.royalcommission.govt.nz/documents-by-key/2011-09-2348

Figure 4.39. Eagle Vision Times. (2019, May 19). Curator's Notes: Te Aika Hei Tiki. Eagle Vision Times. https://eaglevisiontimes.com/featured/curators-notes-te-aika-hei-tiki/

Figure 4.42. Stirling, C. (2018, May 5). Supermarket shift concerns locals. METRONEWS. https:// metronews.co.nz/article/supermarket-shift-concerns-locals 
Figure 4.44. Authors edit. South City Shopping Centre. (2020, March 24). Directory. South City Shopping Centre. https://southcity.co.nz/wp-content/uploads/2020/03/South-City-Map.pdf

Figure 4.45. McDonald, L. (2020, March 6). Malls turn to new ideas to fill spaces as big tenants move on and shoppers' habits change. Stuff. https://www.stuff.co.nz/business/119969538/malls-turn-to-newideas-to-fill-spaces-as-big-tenants-move-on-and-shoppers-habits-change

Figure 4.57. Author's edit. AMP Capital Shopping Centres. (n.d.). Centre Map. The Palms. Retrieved April 28, 2021, from https://www.thepalms.co.nz/centre-map

Figure 4.48. Fulton, T. (2015, December 17). Christchurch retail developer Alasdair Cassells plans more Woolston investment. Stuff. https://www.stuff.co.nz/business/75217500/christchurch-retaildeveloper-alasdair-cassells-plans-more-woolston-investment

Figure 4.50. The Tannery. (n.d.). Store Directory \& Parking Information. The Tannery Christchurch. Retrieved April 28, 2021, from https://thetannery.co.nz/contact/parking-information/

Figure 4.51. Rhodes \& Associates. (n.d.). The Crossing, Christchurch | Rhodes + Associates. The Crossing, Christchurch. Retrieved March 25, 2021, from https://www.rhodesqs.co.nz/projects/thecrossing-christchurch/

Figure 4.53. Author's edit. Rhodes \& Associates. (n.d.). The Crossing, Christchurch $\mid$ Rhodes + Associates. The Crossing, Christchurch. Retrieved March 25, 2021, from https://www.rhodesqs.co.nz/ projects/the-crossing-christchurch/

Figure 4.54. MRM. (n.d.). The Hub Hornby Mall | NZ Metal Roofing Manufacturers. MRM. Retrieved March 26, 2021, from https://www.metalroofing.org.nz/feature-articles/hub-hornby-mall

Figure 4.56. Author's edit. The Hub Hornby. (n.d.). The Hub Hornby. The Hub Hornby. Retrieved April 28, 2021, from https://thehubhornby.co.nz/location/

Figure 4.57. Keith Ussher Architecture. (n.d.). Bush Inn Shopping Centre. Bush Inn Shopping Centre. Retrieved March 25, 2021, from https://www.kua.co.nz/Portfolio/Commercial/Bush-Inn-ShoppingCentre/

Figure 4.59. Author's edit. Bush Inn Centre. (n.d.). Bush Inn Centre. Bush Inn Centre. Retrieved April 28, 2021, from https://bushinncentre.co.nz/?da_image $=24$ 
Figure 4.60. Steeman, M. (2019, October 17). Australian property giant Lendlease to sell two big Dress Smart outlets, Dunedin mall. Stuff. https://www.stuff.co.nz/business/116662217/ australian-property-giant-lendlease-puts-two-big-dress-smart-outlets-and-a-dunedin-mallon-the-market

Figure 4.62. Dress Smart. (n.d.). Stores-Dress Smart. Dress Smart Outlet Shopping. Retrieved April 28, 2021, from https://www.dress-smart.co.nz/stores

Figure 4.63. Scentre Group. (n.d.). Westfield Riccarton. Scentre Group. Retrieved March 26, 2021, from https://www.scentregroup.com/our-portfolio/centres/westfield-riccarton

Figure 4.65. Author's edit. Westfield. (n.d.). Westfield Riccarton Centre Map | Map of Stores in Centre. Riccarton. Retrieved April 28, 2021, from https://www.westfield.co.nz/riccarton/ centre-map

Figure 4.66, 4.68. Tinline Property. (n.d.). About Barrington. Tinline Property. Retrieved April 28, 2021, from https://www.tinline.co.nz/our-places/barrington/the-place/ 